\title{
Natural Products Analysis of South Pacific Marine Sponges
}

by

Taitusi Taufa

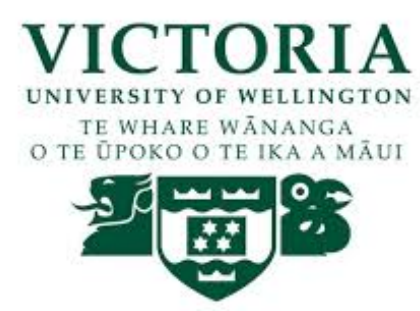

A thesis

submitted to Victoria University of Wellington in fulfilment of the requirements for the degree of Doctor of Philosophy in Chemistry.

Victoria University of Wellington 2018 


\begin{abstract}
This thesis describes the isolation and structure elucidation of 15 new secondary metabolites from Tongan and New Zealand marine sponges. A total of 18 sponge specimens were subjected to an NMR-based screening method, of which four were analysed in detail.

Examination of a two-sponge association, Stelletta crater and Desmacella dendyi from New Zealand, resulted in the isolation of two new 4-methylenesterols, craterols A (94) and B (95). To the best of the author's knowledge, compounds 94 and 95 represent the first secondary metabolites to be reported from either species. Both 94 and 95 possess a double bond between C-5 and C-6, a feature that is unprecedented in this subgroup of marine natural products.
\end{abstract}

An investigation of a Tongan sponge Zyzzya fuliginosa afforded two new pyrroloquinoline alkaloids, 6-bromodamirone B (182) and makaluvamine W (183). Makaluvamine W (183) contains an oxazole moiety, which is uncommon in this group of natural products. Both 182 and 183 lacked activity against the human promyelocytic leukemia cells (HL-60).

Five new compounds were isolated from a Tongan sponge of the genus Leucetta, including two glycerol lipids (238 and 239), three glycerol ethers (244-246) and an imidazole alkaloid (243). Naamidine $\mathrm{K}(\mathbf{2 4 3})$ is a new addition to the naamidine family, while the glycerol metabolites are non-imidazole alkaloid additions to the group of compounds reported from this genus.

A spectroscopic investigation into the Tongan sponge Cacospongia mycofijiensis yielded four new zampanolide analogues (282-285) and a new oxygenated sesquiterpene, isodictyodendrillin A (280). The isolation of the zampanolide analogues gives insight into the structure-activity relationship (SAR) in this family of compounds. Zampanolides B-D (282-284) displayed potent antiproliferative activity towards HL-60 cell lines in the low nanomolar range (3-5 nM), while zampanolide E (285) was significantly less potent with an $\mathrm{IC}_{50}$ value of $306 \mathrm{nM}$. In addition, the re-isolation of dactylolide (281) 
and zampanolide A (278) from this sponge, established a firm conclusion regarding the controversial configuration of dactylolide (281), which possesses the same absolute configuration as (-)-zampanolide A (278) and has a levorotatory optical rotation.<smiles>C=C(CC[C@H](C)[C@H]1CC[C@H]2[C@@H]3CC=C4C(=C)[C@@H](O)CC[C@]4(C)[C@H]3CC[C@@]21C)C(C)C</smiles>

94<smiles>CN1CCc2c[nH]c3c2C1=C(Br)C(=O)C3=O</smiles>

182<smiles>CCCCCCCCCC/C=C\C/C=C\CCCC(C)C1OCC(O)CO1</smiles>

$238 \Delta_{12,13}$

239

$$
\begin{aligned}
& \mathbf{2 4 4} \mathrm{m}=5 \mathrm{n}=7 \\
& \mathbf{2 4 5} \mathrm{m}=7 \mathrm{n}=6 \\
& \mathbf{2 4 6} \mathrm{m}=8 \mathrm{n}=6
\end{aligned}
$$

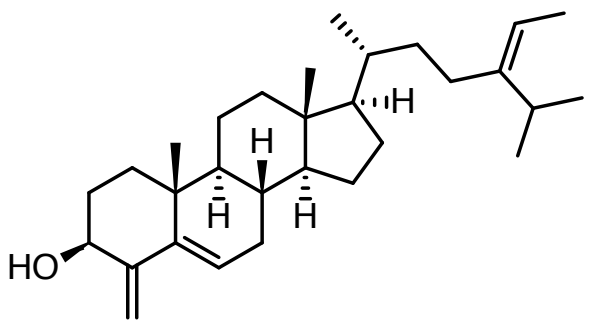

95<smiles>CN1CCc2c[nH]c3c2c1cc1ocnc13</smiles>

183<smiles>COc1ccc(Cc2nc(NC3=NC(=O)N(C)C3=O)n(C)c2Cc2ccc(O)c(O)c2)cc1</smiles>

243

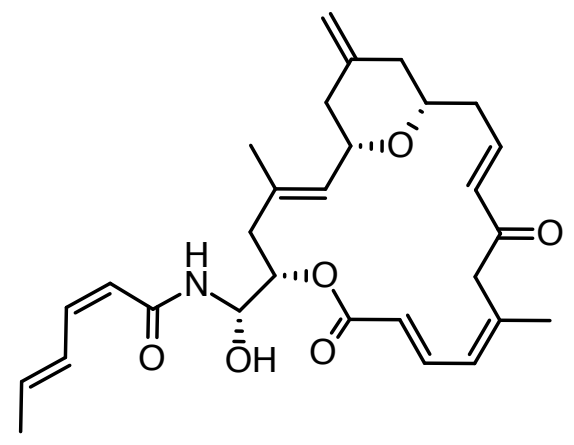

278 
<smiles>CC(C)=CCC/C(C)=C/CCC12CC(=O)OC1O2</smiles>

280

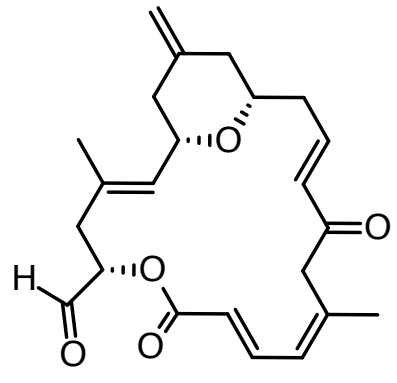

281

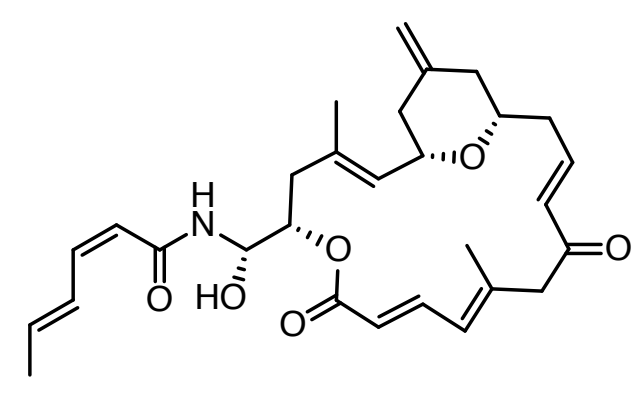

282

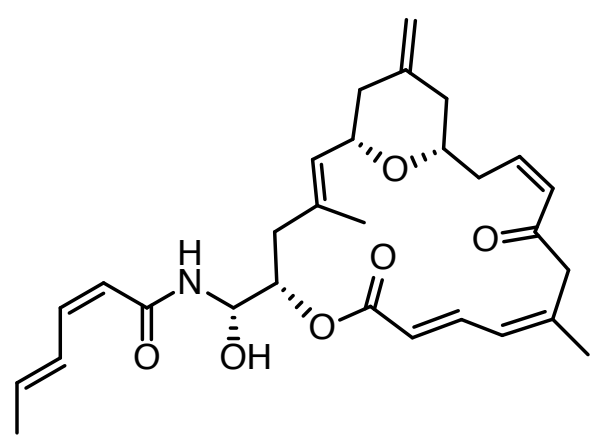

283

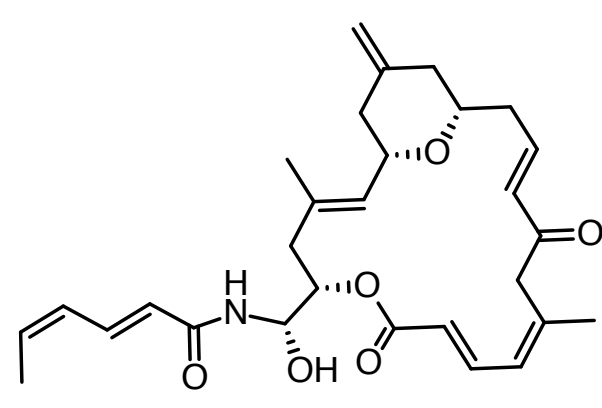

284

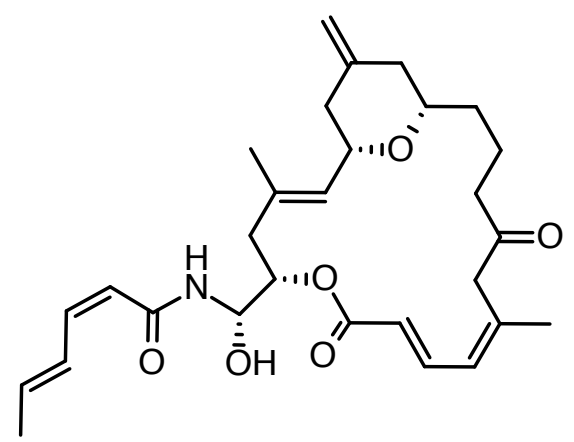

285 


\section{This thesis is dedicated to my parents who have been a great source of inspiration and support.}




\section{Acknowledgments}

A number of people have made valuable contributions to this thesis, for which I am truly grateful for, but first, I would like to give thanks to the Lord, He is good, His love endures forever. Without His blessings, this achievement would not have been possible.

I wish to thank my primary supervisor, Assoc. Prof. Peter Northcote for introducing me to the field of Marine Natural Products. You have been my mentor and guide right from the time I started my toddler steps in this field. It has been a great privilege and honour to work and study under your guidance. I would also like to acknowledge my secondary supervisor, Dr. Rob Keyzers, thank you for the support and encouragement. And most importantly, thank you for proof-reading and fastidious editing of my thesis. Without your able guidance, this thesis would not have been possible and I am eternally grateful for your assistance.

I am grateful to the individuals over the years in the Marine Natural Products and AquaVino research groups. In particular, Dr. Helen Woolner for teaching me tricks-of-thetrade, for listening to me, thank you for tirelessly editing of my thesis. Thank you for putting up with me - you have become a little sister, a good friend and an amazing lab mate. Thanks to Dr. Jonathan Singh for his friendship and meticulous effort in editing my thesis. I would like to thank Dr. Sa Weon Hong, Ethan Wooly, Joe Bracegirdle and Sarah Andreassend for the help and support you offered. A special thanks to Chloe Harland for doing the semi-purification on Cacospongia mycofijiensis, which helped me saved a lot of time and for that I will be eternally grateful.

For the biological aspects of the research I would like to thank Prof. John Miller, Jessica Field, Ben Jones and Rosie Gordon from the School of Biological Sciences for all the assays you have run over the years.

I am grateful to Dr. Matthias Lein for acquiring the DFT data. Of course thanks goes out to the entire technical support staff, we are very lucky as a department to have such great in-house technical expertise. Ian Vorster for all your help with NMR. To Teresa Gen, thank you so much for all the help you have given me over the years.

The Ministry of Fisheries of Tonga is also acknowledged for giving us permission to collect and export samples from Tonga. I thank Sam Tatafu of Deep Blue Cruises, Paul and Karen Stone of Dive Vava'u, and Jeff Laurie of Whale Swim, Fish \& Dive for the assistance in our collections in Tonga. Also, thanks to Dr. Michelle Kelly and Mike Page of NIWA for the underwater photo of Stelletta crater, and for the sponge identification.

The financial support of the New Zealand Commonwealth Scholarship is greatly appreciated.

On a personal note, I would like to thank my parents, Siopau and Temaleti, for their support and prayers over the years. Thanks to all my brothers and sisters for believing in me. To my aunties, Drs 'Anamaui Taufe 'ulungaki and Sepi Taufe 'ulungaki for all their help throughout my academic years. To aunty Vika Taufa for always making her house available for us during our diving collecting trips. My special thanks to my wife, Dr. Salome Taufa, my daughters, 'Iunisi, 'Eseta, Moana, and my sons, Palu and Sitiveni. They have lost a lot of family time with me due to my research abroad, thank you for your vast understanding, moral support, encouragement and prayers. 
Dedication i

Acknowledgments ii

Table of Contents iii

List of Figures $\quad$ ix

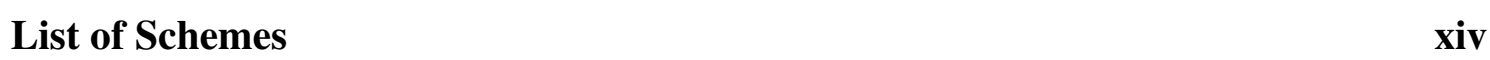

\begin{tabular}{ll}
\hline List of Tables & xv
\end{tabular}

Glossary

\begin{tabular}{lll}
\hline & Introduction & 1
\end{tabular}

1.1 Marine Natural Product as Potential Drug Leads . . . . . . . . . . . . . 1

1.2 Marine Sponges . . . . . . . . . . . . . . . 5

1.3 Tongan Sponges and Chemistry $\ldots \ldots \ldots$. . . . . . . . . . 7

1.4 Isolation Methods for Natural Products at VUW $\ldots \ldots \ldots$

$1.4 .1 \quad$ Cyclic Loading . . . . . . . . . . . . . . . . . 12

1.5 Screening of Marine Organisms $\ldots \ldots \ldots \ldots$. . . . . . . . . 15

1.5 .1 Bioassay-Guided Isolation . . . . . . . . . . . . 15

1.5 .2 Structure-Guided Isolation $\ldots \ldots \ldots$. . . . . . . . . . 16

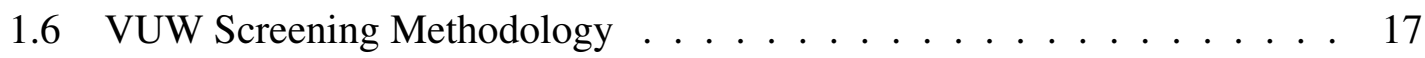

1.6.1 ${ }^{1}$ H NMR Screening . . . . . . . . . . . . . . . . . . . 17

1.6 .2 HSQC Screening . . . . . . . . . . . . . . . . . . 18

1.6 .3 HMBC Screening . . . . . . . . . . . . . . . 18

1.7 Research Objectives $\ldots \ldots \ldots \ldots$. . . . . . . . . . . . . 20 
\begin{tabular}{|ll|}
2 & Spectroscopic Screening of Marine Organisms \\
\hline
\end{tabular}

$2.1 \quad$ Organisms Screened from the Vava'u Group . . . . . . . . . . . . . . . . 21

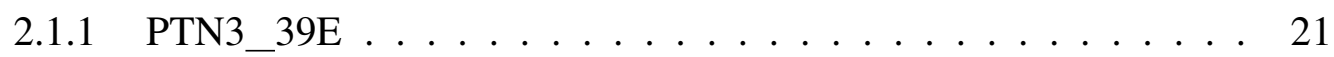

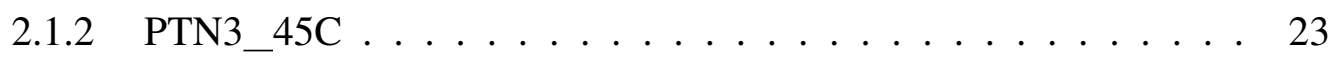

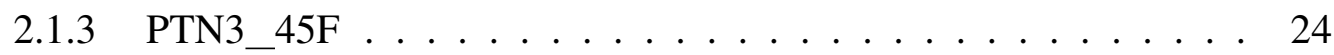

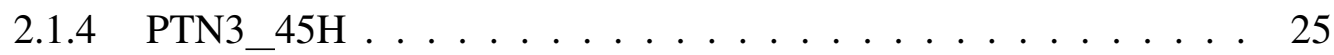

2.1 .5 PTN4_02H . . . . . . . . . . . . . . . 25

2.1 .6 PTN4_10A . . . . . . . . . . . . . . 26

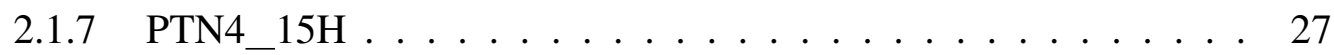

2.2 Organisms Screened from 'Eua Island . . . . . . . . . . . . . . 27

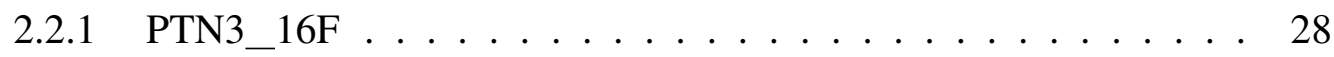

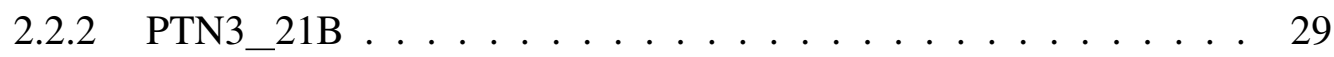

2.2 .3 PTN4_24E $\ldots \ldots \ldots \ldots \ldots$

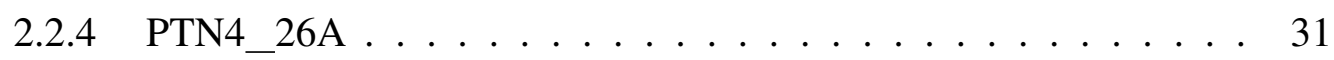

2.2 .5 PTN4_27B . . . . . . . . . . . . . 31

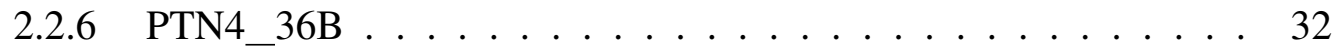

$2.2 .7 \quad$ PTN4_38A and PTN4_42E $\ldots \ldots \ldots \ldots$. . . . . . . . . 34

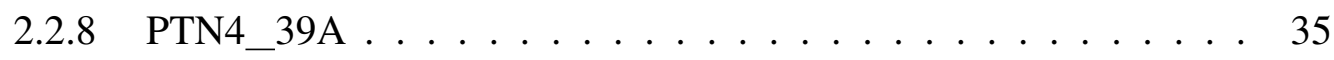

2.3 Organisms Screened from New Zealand . . . . . . . . . . . . . . . 36

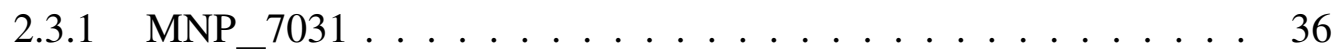

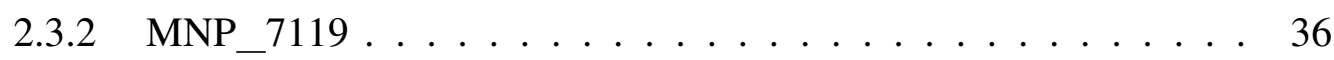

\begin{tabular}{|lll|}
\hline 3 & Two New 4-Methylenesterols from a Two-Sponge Association from New \\
\hline \hline & Zealand & 38 \\
\hline
\end{tabular}

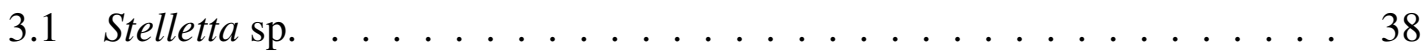

$3.2 \quad$ Stelletta crater $\ldots \ldots \ldots \ldots \ldots \ldots \ldots$

3.3 Isolation . . . . . . . . . . . . . . . . . . 43

3.4 Craterol A . . . . . . . . . . . . . . . . 46 
3.5 Craterol B . . . . . . . . . . . . . . . 52

3.6 Biological Activity $\ldots \ldots \ldots \ldots \ldots \ldots$

3.7 4-Methylenesterols $\ldots \ldots \ldots \ldots \ldots \ldots$

3.8 Concluding Remarks $\ldots \ldots \ldots \ldots \ldots$. . . . . . . . . . . . 62

4 New Pyrroloiminoquinone Analogues from the Tongan Marine Sponge Zyzzya $\begin{array}{ll}\text { fuliginosa } & 63\end{array}$

$4.1 \quad$ Zyzzya fuliginosa $\ldots \ldots \ldots \ldots \ldots \ldots$

4.2 Isolation $\ldots \ldots \ldots \ldots \ldots \ldots$

4.3 6-Bromodamirone B $\ldots \ldots \ldots \ldots$

4.4 Makaluvamine $\mathrm{W} \ldots \ldots \ldots \ldots$

4.5 Biological Activity $\ldots \ldots \ldots \ldots \ldots$. . . . . . . . . . . 84

4.6 The New Pyrroloiminoquinone Alkaloids Biogenesis . . . . . . . . . . . 84

$4.7 \quad$ Related Compounds . . . . . . . . . . . . . . . . . . . . . 88

4.8 Concluding Remarks $\ldots \ldots \ldots \ldots$

5 Chemical Investigation of a Tongan Marine Sponge of the Genus Leucetta 94

$5.1 \quad$ Leucetta $\mathrm{sp} . \ldots \ldots \ldots \ldots$. . . . . . . . . . . . . . . . . . . . 94

5.2 Isolation $\ldots \ldots \ldots \ldots$. . . . . . . . . . . . . . . . . . . . 97

5.2.1 Isolation and Structural Elucidation of the Three Glycerol Ethers . 101

5.3 Glycerol Lipid A $\ldots \ldots \ldots$

5.4 Glycerol Lipid B $\ldots \ldots \ldots$. . . . . . . . . . . . . . 110

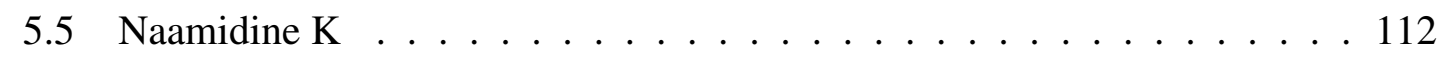

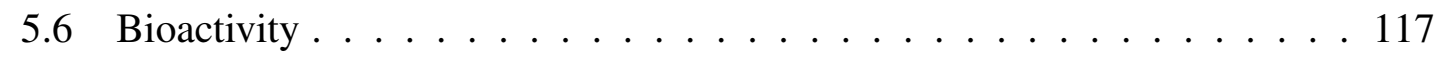

5.7 Concluding Remarks $\ldots \ldots \ldots \ldots \ldots \ldots$ \begin{tabular}{|ll|}
\hline 6 & Zampanolides B-E and Dactylolide from the Tongan Sponge Cacospongia \\
\hline \hline & mycofijiensis
\end{tabular}

$6.1 \quad$ Cacospongia mycofijiensis . . . . . . . . . . . . . . . . . . 119 
6.2 Tongan Marine Sponge Cacospongia mycofijiensis _ . . . . . . . . . 124

6.3 Isolation . . . . . . . . . . . . . . . . . . . . . . 125

6.4 Isodictyodendrillin $\mathrm{A} \ldots \ldots \ldots \ldots$. . . . . . . . . . . . 130

6.5 Dactylolide . . . . . . . . . . . . . . . . . . . 134

$6.5 .1 \quad$ Isolation of $(-)$-Dactylolide . . . . . . . . . . . . . . . . . 134

6.5 .2 The Absolute Configuration of (-)-Dactylolide . . . . . . . . . 134

6.6 Zampanolide B . . . . . . . . . . . . . . . . . . . 139

6.7 Zampanolide C . . . . . . . . . . . . . . . . . . . . . . . 149

6.8 Zampanolide D . . . . . . . . . . . . . . . . . . . 157

6.9 Zampanolide E . . . . . . . . . . . . . . . . . . 162

6.10 Biological Activity $\ldots \ldots \ldots$. . . . . . . . . . . . 167

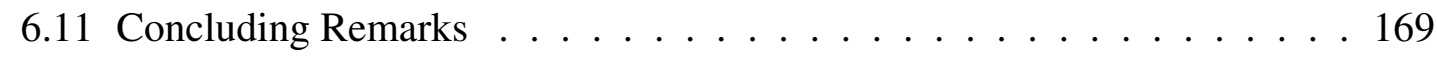

\begin{tabular}{lll}
\hline 7 & Conclusion & 170
\end{tabular}

\begin{tabular}{lll}
\hline & Experimental & 172
\end{tabular}

$8.1 \quad$ General Experimental . . . . . . . . . . . . . . . . . . 172

8.2 Computational Methods . . . . . . . . . . . . . . . . . . . . . . 174

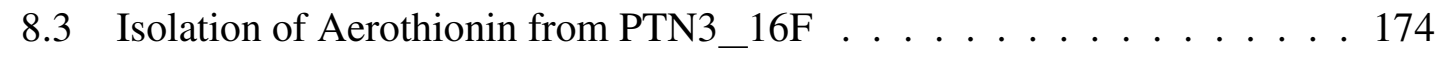

8.4 Isolation of Compounds from Stelletta crater . . . . . . . . . . . . 175

8.5 Isolation of Compounds from Zyzzya fuliginosa $\ldots . . . . .176$

$8.5 .1 \quad$ Screening . . . . . . . . . . . . . . 176

8.5 .2 Bulk Isolation . . . . . . . . . . . . . . . . . 177

$8.6 \quad$ Isolation of Compounds from Leucetta sp. . . . . . . . . . . . . . . . . . 179

$8.6 .1 \quad$ Screening . . . . . . . . . . . . . . . . . 179

8.6 .2 Bulk Isolation . . . . . . . . . . . . . . . . . . . . . . 180

8.6 .3 Oxidation of the Glycerol Ethers . . . . . . . . . . . . . . 185

$8.7 \quad$ Isolation of Compounds from Cacospongia mycofijiensis . . . . . . . . . 186 


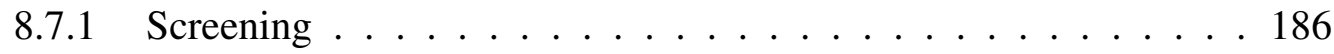

8.7 .2 First Bulk Isolation . . . . . . . . . . . . . . . . . . . . 187

8.7 .3 Second Bulk Isolation $\ldots \ldots$. . . . . . . . . . . . . . . . . . 189

\begin{tabular}{|ll|}
\hline A Current Screening Protocol & 194
\end{tabular}

\begin{tabular}{|l|l|}
\hline NMR Spectra of Known Compounds from Zyzzya fuliginosa & 197
\end{tabular}

\begin{tabular}{|l|l|}
\hline NMR Spectra of Known Compounds from Leucetta sp. & 206
\end{tabular}

\begin{tabular}{|l}
\hline NMR Spectra of Known Compounds from Cacospongia mycofijiensis \\
223
\end{tabular}

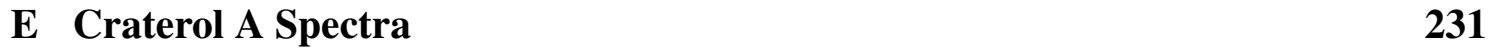

\begin{tabular}{|ll}
\hline F & Craterol B Spectra \\
\hline
\end{tabular}

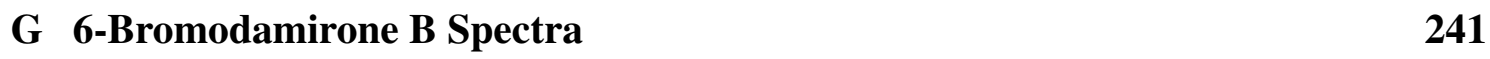

\begin{tabular}{|ll}
\hline H & Makaluvamine W Spectra \\
\hline
\end{tabular}

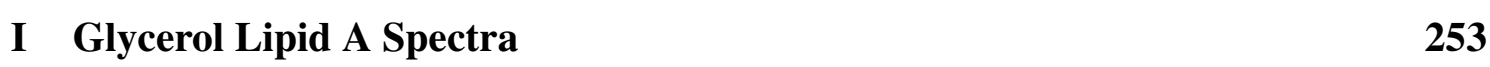

\begin{tabular}{|lr}
\hline J Glycerol Lipid B Spectra & 258 \\
\hline
\end{tabular}

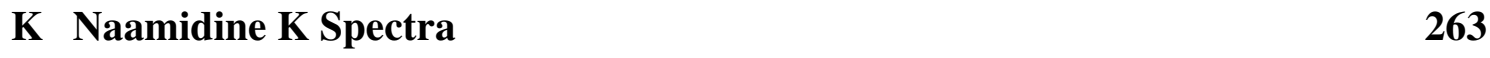

\begin{tabular}{|lr}
\hline L Glycerol Ether A Spectra & 268
\end{tabular}

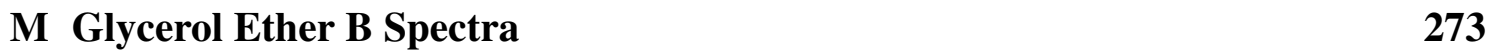

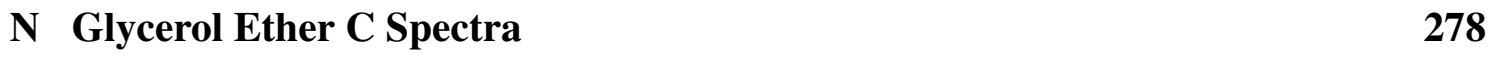

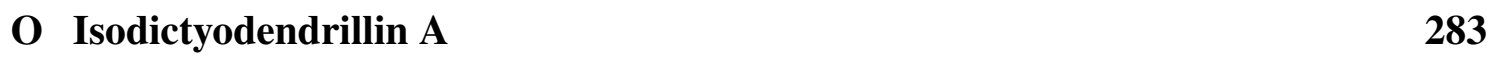

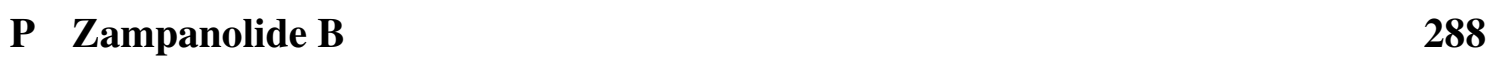


\begin{tabular}{|ll}
\hline R Zampanolide D & 298
\end{tabular}

\begin{tabular}{lll}
\hline S & Zampanolide E & $\mathbf{3 0 3}$
\end{tabular}

\begin{tabular}{lr}
\hline References & 308
\end{tabular} 


\section{List of Figures}

1.1 Map of the Kingdom of Tonga. Image courtesy of the Ministry of Lands, Survey \& Natural Resources, Tonga. . . . . . . . . . . . . . . . . . 8

1.2 Schematic of the mass distribution in a typical marine sponge extract over a reversed-phase medium. . . . . . . . . . . . . 13

1.3 Schematic of the cyclic loading process. . . . . . . . . . . . . . . . 14

1.4 (a) Current digital HSQC mask (contains 160 sponges). (b) Common correlations in the HSQC mask. . . . . . . . . . . . . . . . 19

$1.5 \quad$ (a) An uninteresting sponge screen. (b) An interesting screen. . . . . . . . . 19

2.1 Surface photograph of the sponge PTN3_39E. . . . . . . . . . . . . 22

$2.2{ }^{1} \mathrm{H}$ NMR $\left(600 \mathrm{MHz}, \mathrm{CD}_{3} \mathrm{OD}\right)$ spectrum of the $30 \% \mathrm{Me}_{2} \mathrm{CO} / \mathrm{H}_{2} \mathrm{O}$ fraction

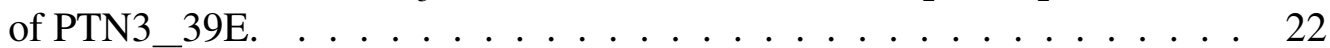

2.3 Surface photograph of the sponge PTN3_45C. . . . . . . . . . 23

$2.4{ }^{1} \mathrm{H}$ NMR $\left(600 \mathrm{MHz}, \mathrm{CDCl}_{3}\right)$ spectrum of the $80 \% \mathrm{Me}_{2} \mathrm{CO} / \mathrm{H}_{2} \mathrm{O}$ fraction

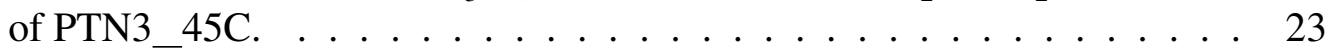

2.5 Surface photograph of the sponge PTN3_45F. . . . . . . . . . . . 24

$2.6{ }^{1} \mathrm{H}$ NMR $\left(600 \mathrm{MHz}, \mathrm{CDCl}_{3}\right)$ spectra comparison between two semipurified aromatic sesquiterpenes from PTN3_45F. . . . . . . . . 25

$2.7 \quad$ Surface photograph of the sponge PTN4_02H. . . . . . . . . . 26

$2.8{ }^{1} \mathrm{H}$ NMR $\left(600 \mathrm{MHz}, \mathrm{CD}_{3} \mathrm{OD}\right)$ spectrum of the $75 \% \mathrm{Me}_{2} \mathrm{CO} / \mathrm{H}_{2} \mathrm{O}$ fraction

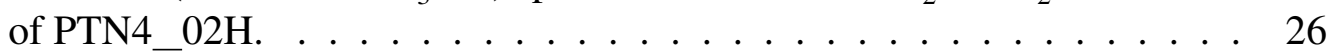

2.9 Surface photograph of the sponge PTN4_15H. . . . . . . . . . . 27

2.10 Surface photograph of the sponge PTN3_16F. . . . . . . . . . 28

$2.11{ }^{1} \mathrm{H}$ NMR $\left(600 \mathrm{MHz}, \mathrm{CD}_{3} \mathrm{OD}\right)$ spectrum of aerothionin. . . . . . . . . . 28

2.12 Surface photograph of the sponge PTN3_21B. . . . . . . . . . 29

2.13 Surface photograph of the sponge PTN4_24E. . . . . . . . . . . . 30

$2.14{ }^{1} \mathrm{H}$ NMR $\left(600 \mathrm{MHz}, \mathrm{CD}_{3} \mathrm{OD}\right)$ spectra comparison between the $30 \%$ and $75 \% \mathrm{Me}_{2} \mathrm{CO} / \mathrm{H}_{2} \mathrm{O}$ fractions of PTN4_24E. . . . . . . . . . 30

2.15 Surface photograph of the sponge PTN4_26A. . . . . . . . . . 31 
$2.17{ }^{1} \mathrm{H}$ NMR $\left(600 \mathrm{MHz}, \mathrm{CD}_{3} \mathrm{OD}\right)$ spectrum of the $75 \% \mathrm{Me}_{2} \mathrm{CO} / \mathrm{H}_{2} \mathrm{O}$ fraction of PTN4_27B.

2.18 Surface photograph of the sponge PTN4_36B.

$2.19{ }^{1} \mathrm{H}$ NMR $\left(600 \mathrm{MHz}, \mathrm{CD}_{3} \mathrm{OD}\right)$ spectrum of the $30 \% \mathrm{Me}_{2} \mathrm{CO} / \mathrm{H}_{2} \mathrm{O}$ fraction

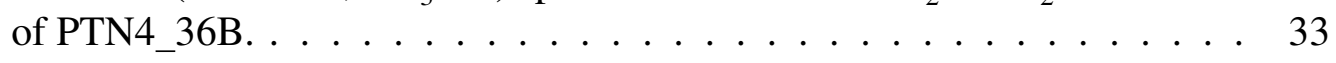

2.20 Surface photograph of the sponges PTN4_38A and PTN4_42E. . . . . . 34

$2.21{ }^{1} \mathrm{H}$ NMR $\left(600 \mathrm{MHz}, \mathrm{CD}_{3} \mathrm{OD}\right)$ spectrum of the $30 \% \mathrm{Me}_{2} \mathrm{CO} / \mathrm{H}_{2} \mathrm{O}$ fraction

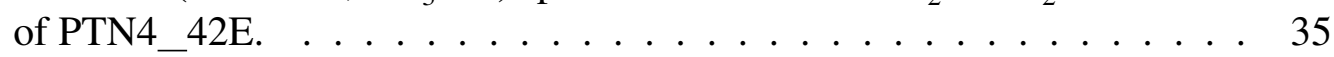

2.22 Surface photograph of the sponge PTN4_39A. . . . . . . . . . 35

$2.23{ }^{1} \mathrm{H}$ NMR $\left(600 \mathrm{MHz}, \mathrm{CD}_{3} \mathrm{OD}\right)$ spectrum of an unknown metabolite from

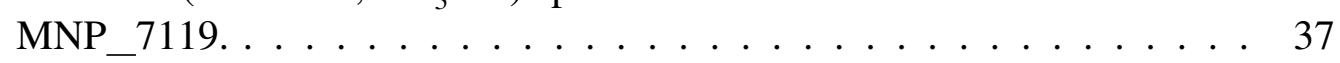

2.24 Key COSY and HMBC correlations establishing the partial structure of a linear peptide-like metabolite from Cliona celata. . . . . . . . . . . 37

3.1 Underwater photograph of Stelletta crater, collected from Three Kings Island, New Zealand. Photograph courtesy of Mike Page, NIWA, Marine Natural Products Project. . . . . . . . . . . . . . . . 44 43

$3.2{ }^{1} \mathrm{H}$ NMR $\left(600 \mathrm{MHz}\right.$, in $\left.\mathrm{CDCl}_{3}\right)$ spectra comparison between the semipurified fraction, craterol A and craterol B. . . . . . . . . . . . 45

3.3 Key COSY, HMBC, 1D TOCSY, HSQC-TOCSY correlations establishing rings $\mathrm{A}$ and $\mathrm{B}$ of craterol $\mathrm{A} . \ldots \ldots \ldots . \ldots 47$

3.4 Key COSY, HMBC, 1D TOCSY, HSQC-TOCSY correlations establishing rings $\mathrm{C}$ and $\mathrm{D}$ of craterol $\mathrm{A} . \ldots \ldots \ldots . \ldots 48$

3.5 Key COSY, HMBC, 1D TOCSY, HSQC-TOCSY correlations establishing rings the side chain moiety of craterol A. . . . . . . . . . . . . 49

$3.6 \quad$ NOESY correlations establishing the configuration of craterol A. . . . . . 50

3.7 Key COSY and HMBC correlations establishing rings A and B of craterol

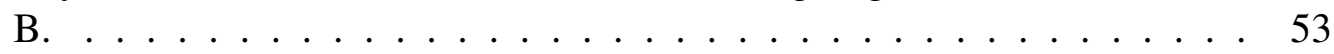

$3.8 \quad$ Key COSY and HMBC correlations establishing the tetracyclic moiety of craterol B. ....................... 54

3.9 Key COSY and HMBC correlations establishing rings the side chain moiety of craterol B. . . . . . . . . . . . 55

3.10 NOESY correlations establishing the configuration of craterol B. . . . . . 56 
4.1 Underwater photograph of Zyzzya fuliginosa, collected from Vava'u, Tonga. Photograph courtesy of Karen Stone. . . . . . . . . . . . . . 68

$4.2{ }^{1} \mathrm{H}$ NMR $\left(600 \mathrm{MHz}, \mathrm{CD}_{3} \mathrm{OD}\right)$ spectra comparison between damirone $\mathrm{B}$, makaluvanone and 6-bromodamirone B. . . . . . . . . . . 72

4.3 Key COSY and HMBC correlations establishing the partial structure of 6-bromodamirone B. . . . . . . . . . . . 74

4.4 Completed planar structure of 6-bromodamirone B. . . . . . . . . . . . . 74

4.5 Key COSY and HMBC correlations establishing the partial structure of makaluvamine $\mathrm{W} . \ldots \ldots \ldots \ldots 78 \ldots \ldots \ldots$

4.6 Key COSY and HMBC correlations establishing the aromatic and the oxazole rings of makaluvamine $\mathrm{W}$.

$4.7 \quad$ Possible planar structures for makaluvamine $\mathrm{W} . \quad \ldots \ldots$. . . . . . . 80

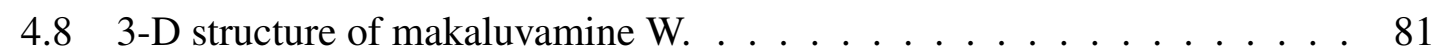

5.1 Underwater photograph of Leucetta sp., collected from Vava'u, Tonga. Photograph courtesy of Karen Stone. . . . . . . . . . . . . . . 97

5.2 Oxidative cleavage of compound glycerol ether A . . . . . . . . . 102

$5.3 \quad$ Key COSY and HMBC correlations establishing the 1,3-dioxane ring of the glycerol lipid A. . . . . . . . . . . . . . 107

5.4 Key COSY and HMBC correlations establishing the C-7 to C-14 segment of the glycerol lipid A. . . . . . . . . . . . . 107

5.5 Key COSY and HMBC correlations establishing the C-15 to C-23 segment of the glycerol lipid A. . . . . . . . . . . . 108

5.6 Key COSY and HMBC correlations establishing the structure of glycerol lipid B. . . . . . . . . . . . . . . 110

5.7 Key COSY and HMBC correlations establishing the 1,4-disubstituted benzene ring of naamidine $\mathrm{K} . \ldots \ldots \ldots 113$

5.8 Key HMBC correlations establishing the 1,2,4-trisubstituted benzene ring of naamidine K. . . . . . . . . . . . . . . . . . 114

5.9 Key HMBC correlations establishing the imidazole moiety of naamidine K. 114

5.10 Key HMBC correlations establishing the hydantoin moiety of naamidine K. 115

5.11 3-D structure of naamidine K. . . . . . . . . . . . . . . 115

6.1 Underwater photograph of Cacospongia mycofijiensis, collected from 'Eua, Tonga. Photograph courtesy of Dan Crossett. . . . . . . . . . . . 125 
6.2 Key COSY and HMBC correlations establishing the connectivities of the terminal isoprene unit, substructure A, of isodictyodendrillin A. . . . . . 131

6.3 Key COSY and HMBC correlations establishing the connectivities of the

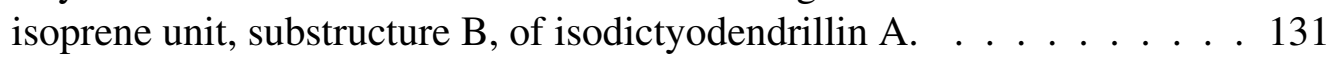

6.4 Key COSY and HMBC correlations establishing the connectivities of the isoprene unit, substructure $\mathrm{C}$, of isodictyodendrillin $\mathrm{A}$. . . . . . . . . 132

6.5 HPLC chromatogram of dactylolide purification. . . . . . . . . . . 135

$6.6 \quad{ }^{1} \mathrm{H}$ NMR $\left(600 \mathrm{MHz}\right.$, in $\left.\mathrm{CDCl}_{3}\right)$ spectra comparison between compounds

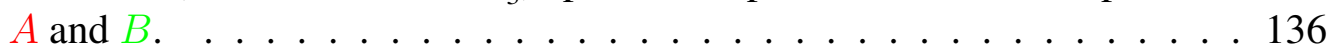

$6.7{ }^{1} \mathrm{H}$ NMR $\left(600 \mathrm{MHz}\right.$, in $\mathrm{CDCl}_{3}$ ) spectra comparison between zampanolide A, zampanolide B and dactylolide. . . . . . . . . . . . . 140

6.8 Key COSY, HMBC and NOESY correlations establishing the C-1 to C-6 segment of zampanolide B. . . . . . . . . . . . . . 141

6.9 Key COSY and HMBC correlations establishing the C-7 to C-12 segment of zampanolide B. . . . . . . . . . . . . . . . . 142

6.10 Key COSY, HMBC and NOESY correlations establishing the tetrahydropyran ring of zampanolide B. . . . . . . . . . . . . . 143

6.11 Key COSY, HMBC and NOESY correlations establishing the marcocyclic moiety of zampanolide B. . . . . . . . . . . . . . . . 144

6.12 Key COSY, HMBC and NOESY correlations establishing the branched unsaturated moiety of zampanolide B. . . . . . . . . . . . . 145

6.13 Completed planar structure of zampanolide B. . . . . . . . . . . . . . 145

6.14 NOESY correlations establishing the relative configuration of zampanolide B. . . . . . . . . . . . . . . . . 147

$6.15{ }^{1} \mathrm{H}$ NMR $\left(600 \mathrm{MHz}\right.$, in $\mathrm{CDCl}_{3}$ ) spectra comparison between zampanolide A, zampanolide B and zampanolide C. . . . . . . . . . . . . 150

6.16 Key COSY, HMBC and NOESY correlations for the C-1 to C-12 region of zampanolide C. . . . . . . . . . . . . . . 152

6.17 Key COSY, HMBC and NOESY correlations establishing the marcocyclic moiety of zampanolide C. . . . . . . . . . . . 153

6.18 Key COSY, HMBC and NOESY correlations establishing the $N$-acyl

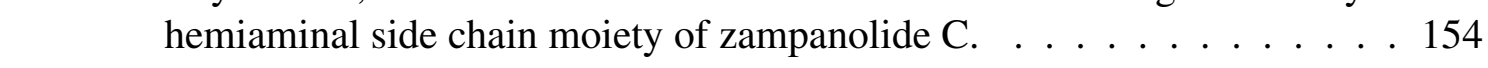

6.19 Completed planar structure of zampanolide C. . . . . . . . . . . . . 155

6.20 NOESY correlations establishing the relative configuration of zampanolide C . . . . . . . . . . . . . . . . . 155 
6.21 Key COSY and HMBC correlations establishing the structure of zampanolide D. . . . . . . . . . . . . . . . 159

6.22 NOESY correlations establishing the relative configuration of zampanolide D. . . . . . . . . . . . . . . . . . . 160

6.23 Key COSY and HMBC correlations establishing the structure of zampanolide E. . . . . . . . . . . . . . . . . . . 164

6.24 NOESY correlations establishing the relative configuration of zampanolide E. . . . . . . . . . . . . . . . . . . . . . . . . . . . . . 


\section{List of Schemes}

3.1 The isolation procedure for compounds from the sponge Stelletta crater, collected from the Three Kings Island, New Zealand. . . . . . . . . . . . 44

4.1 The initial isolation procedure for compounds from the sponge Zyzzya fuliginosa, collected from Vava‘u, Tonga. . . . . . . . . . . . . . . . 69

4.2 The bulk isolation procedure for compounds from the sponge Zyzzya fuliginosa, collected from Vava'u, Tonga. . . . . . . . . . 70

$4.3 \quad$ Postulated biogenesis of 6-bromodamirone B and makaluvamine W. . . . 87

5.1 The bulk isolation procedure for compounds from the sponge Leucetta sp., collected from Vava'u, Tonga. . . . . . . . . . . . . . . . . . . . 99

6.1 The initial isolation procedure for compounds from the sponge Cacospongia mycofijiensis, collected from 'Eua, Tonga. . . . . . . . . . . . . . . . 126

6.2 The first bulk isolation procedure of zampanolides B-E and dactylolide from the sponge Cacospongia mycofijiensis, collected from 'Eua, Tonga. . 128

6.3 The second bulk isolation procedure of zampanolides B-E and dactylolide from the sponge Cacospongia mycofijiensis, collected from 'Eua, Tonga. . . . . . . . . . . . . . . . . . . . . . . 129 


\section{List of Tables}

1.1 Taxonomic classification within the Phylum Porifera to the Order level as presented by World Porifera Database. . . . . . . . . . . . . . 6

3.1 Taxonomic classification of the genus Stelletta from order Tetractinellida as presented by World Porifera Database. . . . . . . . . . . . . . . 39

$3.2{ }^{13} \mathrm{C}(150 \mathrm{MHz})$ and ${ }^{1} \mathrm{H}(600 \mathrm{MHz}) \mathrm{NMR}$ Data for Craterol $\mathrm{A}$ in $\mathrm{CDCl}_{3}$. . 51

$3.3{ }^{13} \mathrm{C}(150 \mathrm{MHz})$ and ${ }^{1} \mathrm{H}(600 \mathrm{MHz}) \mathrm{NMR}$ Data for Craterol B in $\mathrm{CDCl}_{3} . \quad 57$

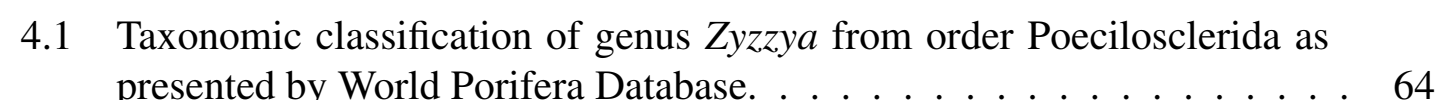

$4.2{ }^{15} \mathrm{~N}(60 \mathrm{MHz}),{ }^{13} \mathrm{C}(150 \mathrm{MHz})$ and ${ }^{1} \mathrm{H}(600 \mathrm{MHz}) \mathrm{NMR}$ Data of 6Bromodamirone $\mathrm{B}$ in $\mathrm{CD}_{3} \mathrm{OD} . \ldots \ldots \ldots 75$

$4.3{ }^{13} \mathrm{C}$ experimental and DFT calculated chemical shifts for makaluvamine $\mathrm{W}$ in $\mathrm{CD}_{3} \mathrm{OD}$ and DMSO- $d_{6} . \ldots \ldots \ldots . \ldots . \ldots 81$

$4.4{ }^{15} \mathrm{~N}(60 \mathrm{MHz}),{ }^{13} \mathrm{C}(150 \mathrm{MHz})$ and ${ }^{1} \mathrm{H}(600 \mathrm{MHz})$ NMR Data of Makaluvamine $\mathrm{W}$ in DMSO- $d_{6} . \ldots \ldots \ldots 8 . \ldots \ldots$

$4.5{ }^{15} \mathrm{~N}(60 \mathrm{MHz}),{ }^{13} \mathrm{C}(150 \mathrm{MHz})$ and ${ }^{1} \mathrm{H}(600 \mathrm{MHz})$ NMR Data of Makaluvamine $\mathrm{W}$ in $\mathrm{CD}_{3} \mathrm{OD} . \ldots \ldots \ldots . \ldots . \ldots . \ldots 3$

5.1 Taxonomic classification of the genus Leucetta from sub-class Calcinea as presented by World Porifera Database. . . . . . . . . . . . . 95

$5.2{ }^{13} \mathrm{C}(150 \mathrm{MHz})$ and ${ }^{1} \mathrm{H}(600 \mathrm{MHz}) \mathrm{NMR}$ Data for Glycerol Ether A in

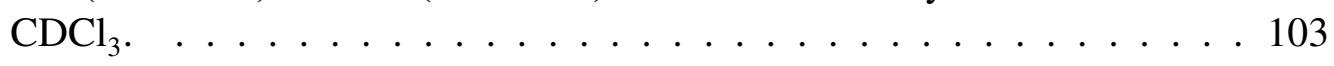

$5.3{ }^{13} \mathrm{C}(150 \mathrm{MHz})$ and ${ }^{1} \mathrm{H}(600 \mathrm{MHz}) \mathrm{NMR}$ Data for Glycerol Ether B in $\mathrm{CDCl}_{3} \ldots \ldots \ldots \ldots \ldots \ldots$

$5.4{ }^{13} \mathrm{C}(150 \mathrm{MHz})$ and ${ }^{1} \mathrm{H}(600 \mathrm{MHz}) \mathrm{NMR}$ Data for Glycerol Ether $\mathrm{C}$ in

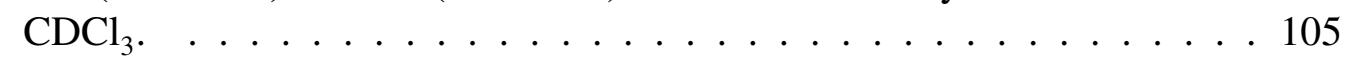

$5.5 \quad{ }^{13} \mathrm{C}(150 \mathrm{MHz})$ and ${ }^{1} \mathrm{H}(600 \mathrm{MHz})$ NMR Data for Glycerol Lipid A in $\mathrm{CDCl}_{3} \ldots \ldots \ldots \ldots \ldots \ldots$

$5.6{ }^{13} \mathrm{C}(150 \mathrm{MHz})$ and ${ }^{1} \mathrm{H}(600 \mathrm{MHz})$ NMR Data for Glycerol Lipid B in

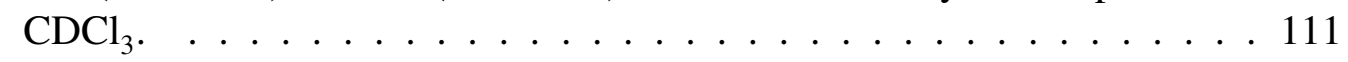

$5.7{ }^{15} \mathrm{~N}(60 \mathrm{MHz}),{ }^{13} \mathrm{C}(150 \mathrm{MHz})$ and ${ }^{1} \mathrm{H}(600 \mathrm{MHz})$ NMR Data for Naamidine $\mathrm{K}$ in $\mathrm{CD}_{3} \mathrm{OD} . \ldots \ldots \ldots . \ldots 116$

$5.8 \quad \mathrm{IC}_{50}$ values of compounds from Leucetta $\mathrm{sp}$. against the HL-60 cell line. . 117 
6.1 Taxonomic classification of the genus Cacospongia from order Dictyoceratida as presented by World Porifera Database. . . . . . . . . . . . . 120

$6.2{ }^{13} \mathrm{C}(150 \mathrm{MHz})$ and ${ }^{1} \mathrm{H}(600 \mathrm{MHz}) \mathrm{NMR}$ Data of Isodictyodendrillin A in

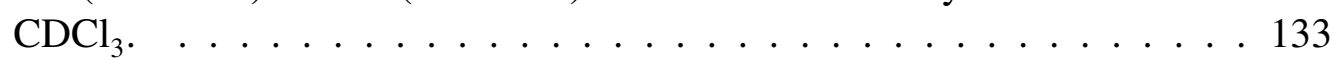

6.3 Comparison of the optical rotations of the isolated dactylolide and zampanolide with their literature values. . . . . . . . . . . . . 138

$6.4{ }^{13} \mathrm{C}(150 \mathrm{MHz})$ and ${ }^{1} \mathrm{H}(600 \mathrm{MHz}) \mathrm{NMR}$ Data for Zampanolide B in $\mathrm{CDCl}_{3} .148$

$6.5 \quad{ }^{13} \mathrm{C}(150 \mathrm{MHz})$ and ${ }^{1} \mathrm{H}(600 \mathrm{MHz}) \mathrm{NMR}$ Data of Zampanolide $\mathrm{C}$ in $\mathrm{CDCl}_{3} .156$

$6.6{ }^{13} \mathrm{C}(150 \mathrm{MHz})$ and ${ }^{1} \mathrm{H}(600 \mathrm{MHz}) \mathrm{NMR}$ Data of Zampanolide D in $\mathrm{CDCl}_{3} .161$

$6.7{ }^{13} \mathrm{C}(150 \mathrm{MHz})$ and ${ }^{1} \mathrm{H}(600 \mathrm{MHz}) \mathrm{NMR}$ Data of Zampanolide E in $\mathrm{CDCl}_{3} .166$

$6.8 \quad \mathrm{IC}_{50}$ values of zampanolides and (-)-dactylolide against the HL-60 cell line. 167 


\section{Glossary}

\begin{tabular}{|c|c|}
\hline$\delta$ & Chemical shift (ppm) \\
\hline${ }^{13} \mathrm{C} \mathbf{N M R}$ & Carbon-13 nuclear magnetic resonance \\
\hline C18 & Octadecyl derivatised silica gel \\
\hline $\mathrm{CDCl}_{3}$ & Deuterated chloroform \\
\hline $\mathrm{CD}_{3} \mathrm{OD}$ & Deuterated methanol \\
\hline $\mathrm{CH}_{2} \mathrm{Cl}_{2}$ & Dichloromethane \\
\hline COSY & Homonuclear correlation spectroscopy \\
\hline Da & Dalton \\
\hline DAD & Diode array detector \\
\hline DMSO- $d_{6}$ & Deuterated DMSO \\
\hline DIOL & 2,3-Dihydroxypropoxypropyl-derivatized silica gel \\
\hline d & doublet \\
\hline $\mathbf{E D}_{50}$ & Concentration that is an effective dose in $50 \%$ of test subjects \\
\hline EtOAc & Ethyl acetate \\
\hline FDA & United States Food and Drug Administration \\
\hline${ }^{1} \mathrm{H} \mathbf{N M R}$ & Proton nuclear magnetic resonance \\
\hline HL-60 & Human promyleocytic leukaemia cell line \\
\hline НМBC & Heteronuclear multiple bond correlation \\
\hline $\mathbf{H}_{2} \mathbf{O}$ & Water \\
\hline HPLC & High pressure (performance) liquid chromatography \\
\hline HP20/HP20SS & PSDVB stationary support \\
\hline HRESIMS & High resolution electro-spray ionisation mass spectrometry \\
\hline HOMO2DJ & Homonuclear $J$-resolved 2D experiment \\
\hline HSQC & Heteronuclear single quantum coherence \\
\hline HTS & High-throughput screening \\
\hline $\mathbf{I C}_{\mathbf{5 0}}$ & Concentration that is inhibitory in $50 \%$ of test subjects \\
\hline IPA & Isopropyl alcohol (2-propanol) \\
\hline$J$ & Scalar coupling constant \\
\hline LH20 & Crosslinked dextran-based size exclusion resin \\
\hline
\end{tabular}




\begin{tabular}{|c|c|}
\hline$m / z$ & Mass to charge ratio \\
\hline m & Multiplet \\
\hline MS & Mass spectrometry \\
\hline$m / z$ & Mass to charge ratio \\
\hline $\mathrm{Me}_{2} \mathrm{CO}$ & Acetone \\
\hline NIWA & National lnstitute for Water and Atmospheric research \\
\hline NOE & Nuclear Overhauser effect \\
\hline NOESY & Nuclear Overhauser enhancement spectroscopy \\
\hline${ }^{15} \mathrm{~N}$ NMR & Nitrogen-15 nuclear magnetic resonance \\
\hline ppm & Parts per million \\
\hline PSDVB & Poly(styrene-divinylbenzene) \\
\hline $\mathbf{q}$ & Quartet \\
\hline quin & Quintet \\
\hline SEM & Scanning electron microscope \\
\hline SCUBA & Self contained underwater breathing apparatus \\
\hline SAR & Structure-activity relationship \\
\hline $\mathbf{t}$ & Triplet \\
\hline TLC & Thin layer chromatography \\
\hline TMS & Trimethylsilyl \\
\hline TOCSY & Total correlation spectroscopy \\
\hline VUW & Victoria University of Wellington \\
\hline
\end{tabular}




\section{Chapter 1}

\section{Introduction}

Chapter 1 gives a brief introduction to the field of marine natural products. The utilisation of NMR spectroscopy as a screening tool for discovering novel secondary metabolites is also discussed.

\subsection{Marine Natural Product as Potential Drug Leads}

The perception of utilising natural products (also known as secondary metabolites) for medicinal purposes precedes recorded human history, probably by thousands of years. 1 Since the commercialisation of the first Nature-derived compound, morphine (1), and the first semi-synthesis drug, aspirin (2), research into natural products as a source for therapeutic remedies has significantly increased in the last century. ${ }^{[2]}$ The focus on this field of research has also turned to new sources in the search for biologically active compounds, especially the marine realm. ${ }^{3}$ With more than $70 \%$ of our planet's surface covered by oceans, the biological diversity of the marine environment is far higher than in tropical rain forests, represented by 34 of 36 phyla of life. ${ }^{\sqrt[45]{5}}$ Accordingly, the marine environment is an exceptional reservoir of bioactive natural products, many of which exhibit structural/chemical features not found in terrestrial natural products. ${ }^{6}$

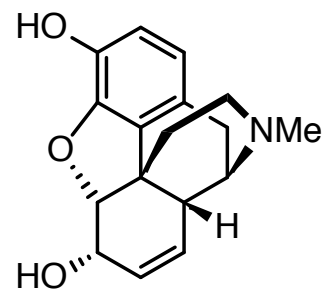

1

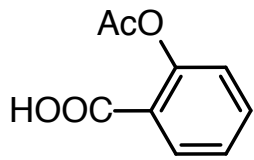

2

Many marine organisms are soft bodied and/or have a sedentary life style, making survival harder due to threats from the surrounding environment. Hence, many marine organisms have evolved the ability to synthesise toxic compounds or obtain them from symbiotic 
microorganisms to defend against predation, keep competitors at bay or to paralyse their prey. For this reason, and because of the diversity of organisms in the marine environment, it is increasingly recognised that a huge number of marine natural products could be developed into drugs. 718

Interest in marine natural products, however, awaited refinements in technologies such as SCUBA (self-contained underwater breathing apparatus), which allowed access to new areas and facilitated extensive sampling of marine life. ${ }^{9}$ The discovery and identification of the two nucleosides spongothymidine (3) and spongouridine (4) in the early 1950s from the Caribbean marine sponge Cryptotethya crypta lay the first stone for marine natural products as promising new chemical entities of potential therapeutic value. ${ }^{10-12}$ Subsequent development of synthetic analogues has provided the clinically used anticancer drug, cytarabine (Ara-C, 5) and the antiviral agent vidarabine (Ara-A, 6).

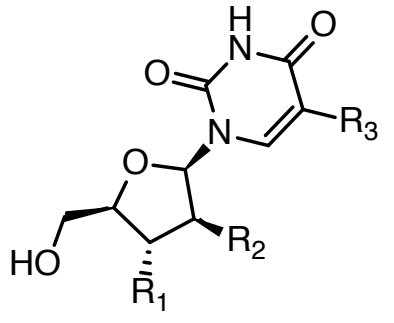

$3 \quad \mathrm{R}_{1}=\mathrm{OH} \quad \mathrm{R}_{2}=\mathrm{OH} \quad \mathrm{R}_{3}=\mathrm{Me}$

$4 \quad \mathrm{R}_{1}=\mathrm{OH} \quad \mathrm{R}_{2}=\mathrm{OH} \quad \mathrm{R}_{3}=\mathrm{H}$

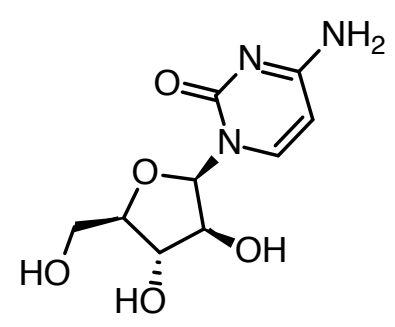

5

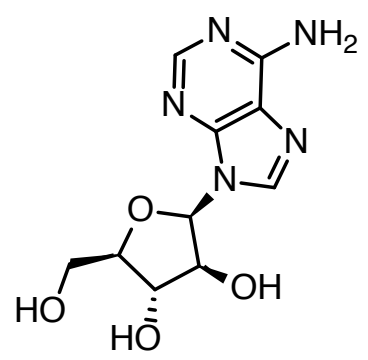

6

However, despite the very successful drug discovery and development programs based on natural products, many of the larger pharmaceutical companies de-emphasised their natural product discovery programs during the 1990s and early 2000s. The advent of automated high-throughput screening (HTS) increased the speed of biological testing and combinatorial chemistry began to be promoted as a better approach to creating drug-like chemical compounds for HTS. ${ }^{[13}$ As a result, many of the pharmaceutical companies disposed of or sold their collections of screening extracts, despite the unproven success of the new technologies. The downsizing or termination of natural product screening programs was made because many of the most promising natural product lead compounds are available in only small amounts, and often have complex structures that are difficult to be synthesised. ${ }^{[14}$ Also, natural product screening programs were considered to be time consuming and expensive. Yet, despite the early promises of both combinatorial synthesis 
and HTS, only one de novo new chemical entity, the antitumour compound sorafenib (7), has been reported from this approach in the public domain for drug use. $\frac{15] 16}{16}$<smiles>CNC(=O)c1cc(Oc2ccc(NC(=O)Nc3ccc(Cl)c(C(F)(F)F)c3)cc2)ccn1</smiles>

The chemical structural diversity of natural products is immense and they have developed to be evolutionarily advantageous as compared with non-natural compounds. As a result, these natural compounds are biochemically specific, have excellent binding efficiency and have the tendency to interact with biological targets, which has resulted in natural products being the most reliable source for new medicinal chemistry and drug discovery. 17

Marine natural products has become an established discipline of natural products chemistry, with over 29,600 new compounds reported from the marine environment. $\frac{18}{18}$ Today there are several marine-derived drugs currently commercially available including Ziconotide (Prialt ${ }^{\circledR}, 8$ ) a synthetic equivalent of a naturally occurring peptide isolated from the venom of the cone snail Conus magus. ${ }^{19-21}$ It was the first conotoxin drug to be approved by the FDA (Food and Drug Adminstration) in 2004 for the management of severe chronic pain associated with cancer, AIDS and neuropathies. 22

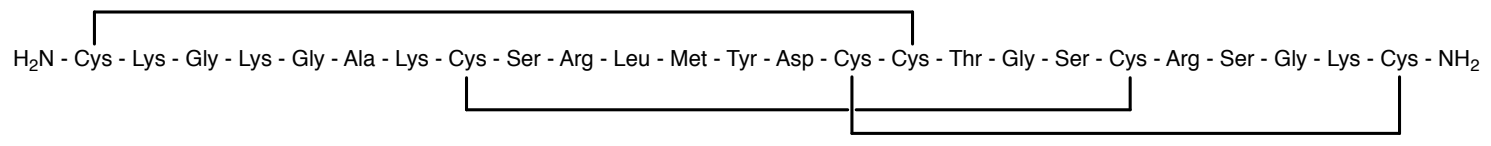

8

Trabectedin (ET-743, Yondelis $\left.{ }^{\circledR}, 9\right)$ was obtained from the Caribbean ascidian Ecteinascidia turbinate, and became the first marine anticancer drug to be approved for the treatment of soft tissue sarcomas and ovarian cancer. ${ }^{[23-25}$ Eribulin mesylate $\left(\right.$ Halaven $\left.{ }^{\circledR}, \mathbf{1 0}\right)$ is a synthetic analogue of halichondrin B (11), which is a marine natural product extracted from the marine sponge Halichondria okadai, used for the treatment of metastatic breast cancer. ${ }^{2627}$ Brentuximab vedotin (Adcetris ${ }^{\mathrm{TM}}, \mathbf{1 2}$ ) is an antibody-drug conjugate and is based on a fully synthetic analogue of dolastatin (13) that was reported in 1972, from the sea hare Dolabella auricularia ${ }^{28}$ Compound 12 was granted accelerated approval by the FDA in 2011 for the treatment of Hodgkin's lymphoma and systemic anaplastic large cell 
lymphoma. ${ }^{29}$ These examples demonstrate the fascinating biomolecules associated with marine organisms as a major source of chemical diversity for starting materials for drug design and discovery.

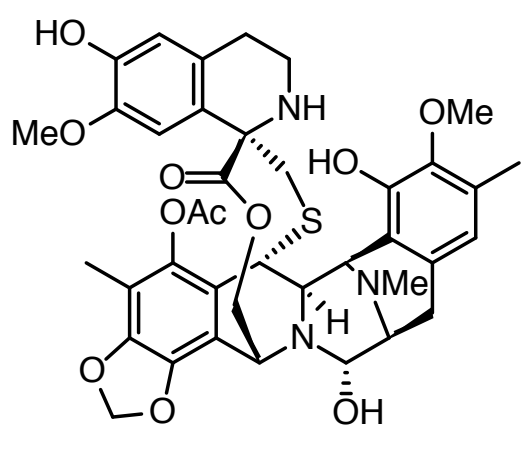

9

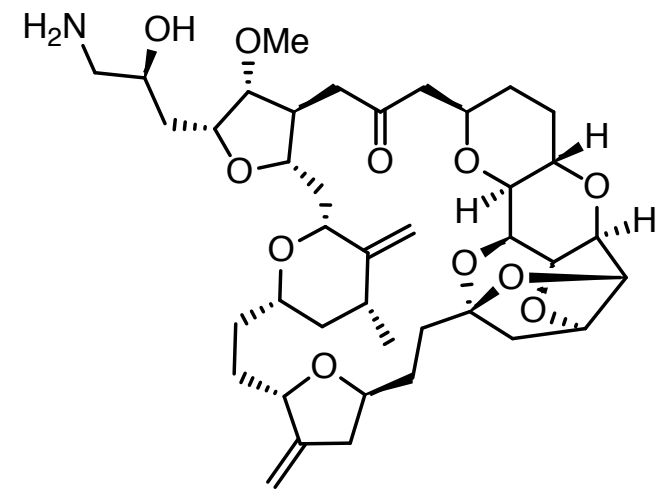

10

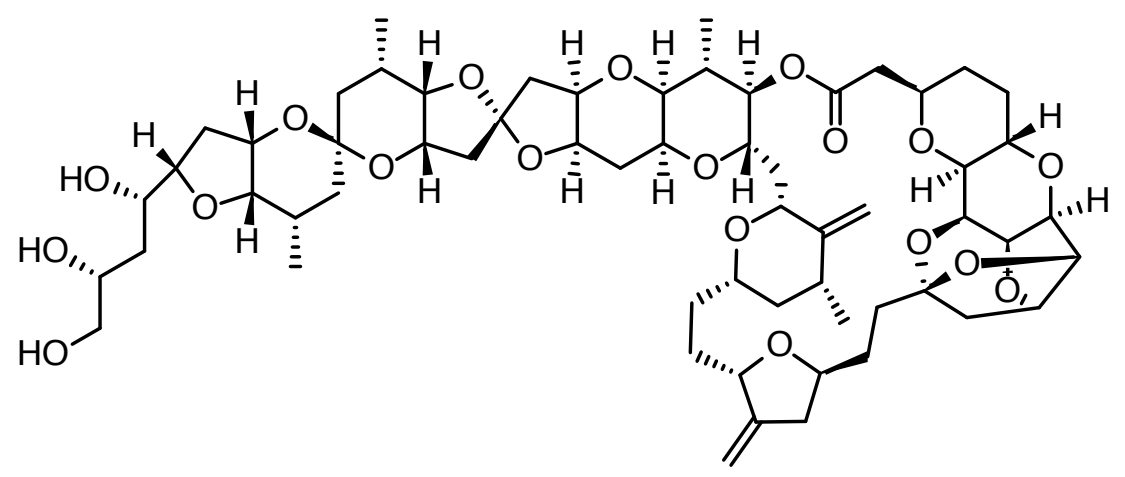

11<smiles>CCCCCN1C(=O)CC(SCCC)C1=O</smiles>

12<smiles>CCC(C)C(NC(=O)C(NC(=O)C(NC(=O)C(C)C(C)C)C(C)C)C(C)C)C(=O)N1CCCC1C(OC)C(C)C(=O)N[C@@H](Cc1ccccc1)c1nccs1</smiles> 


\subsection{Marine Sponges}

Sponges (phylum Porifera) are filter-feeding invertebrates that have survived until the present day almost morphologically unaltered in approximately 500 million years. $\frac{30}{30}$ They are the most primitive of the multicellular organisms and, for that reason, they are considered living fossils. Currently, there are more than 8800 known sponge species and, of these, around $98 \%$ live in marine habitats. 31

Marine sponges come in a rainbow of colours, various shapes and sizes, from flat cushions to elaborate branching or cup-shaped forms, from very small to several metres in height. $\frac{32}{32}$ Many of the differences in size and shape are due to environmental factors, such as hydrodynamics, light, and turbidity. ${ }^{32}$ This means that the shapes of sponges are variable among different species and genera, but also vary to some extent between individuals of the same species. Thus the paucity of complex morphological characters in sponges, combined with high degree of plasticity makes them hard to characterise, which leads to problems with their taxonomy. About the only consistent structures in most sponges are their spicules; microscopic skeletal structures that provide support and sometimes deter predators. Traditionally, comparison of the shapes and sizes of these spicules found in the sponge with data from the literature aid the identification of sponge species. From these characterisations, the Porifera were divided among three distinct classes; Calcarea (spicules of crystalline $\mathrm{CaCO}_{3}$ ), Demospongiae (siliceous spicules and/or collagen fibres), and Hexactinellida (siliceous spicules). ${ }^{30}$ However, recent techniques have also been used as tools in sponge taxonomic classification such as chemotaxonomic trends and molecular phylogenetics, led to the inclusion of two more classes, the Homoscleromorpha ${ }^{32[33}$ and the Porifera incertae sedis. $\frac{31}{}$ Demospongiae is the largest and most diverse class of the Porifera, accounting for more than $80 \%$ of sponge species (see Table 1.1 ).

Sponges are sedentary, soft-bodied and are prone to predation and other biotic factors such as overgrowth by fouling organisms or competition for space. Consequently, sponges have experienced an intense evolutionary pressure to evolve and produce secondary metabolites to serve as a chemical defence, which compensates for their lack of morphological defence structures, such as spines or a protective shell. These metabolites affect numerous 
Table 1.1. Taxonomic classification within the Phylum Porifera to the Order level as presented by World Porifera Database. 31

\begin{tabular}{|c|c|c|c|}
\hline Phylum & Class & Sub-class & Order \\
\hline \multirow{9}{*}{ Porifera } & \multirow[t]{2}{*}{ Calcarea } & Calcaronea & $\begin{array}{l}\text { Baerida } \\
\text { Leucosolenida } \\
\text { Lithonida }\end{array}$ \\
\hline & & Calcinea & $\begin{array}{l}\text { Clathrinida } \\
\text { Murrayonida }\end{array}$ \\
\hline & \multirow[t]{3}{*}{ Demospongiae } & Heteroscleromorpha & $\begin{array}{l}\text { Agelasida } \\
\text { Axinellida } \\
\text { Blemnida } \\
\text { Bubarida } \\
\text { Clionaida } \\
\text { Desmacellida } \\
\text { Haplosclerida } \\
\text { Merliida } \\
\text { Poecilosclerida } \\
\text { Polymastiida } \\
\text { Scopalinida } \\
\text { Sphaerocladina } \\
\text { Spongillida } \\
\text { Suberitida } \\
\text { Tethyida } \\
\text { Tetractinellida } \\
\text { Trachycladida }\end{array}$ \\
\hline & & Keratosa & $\begin{array}{l}\text { Dendroceratida } \\
\text { Dictyoceratida }\end{array}$ \\
\hline & & Verongimorpha & $\begin{array}{l}\text { Chondrillida } \\
\text { Chondrosiida } \\
\text { Verongiida }\end{array}$ \\
\hline & \multirow[b]{2}{*}{ Hexactinellida } & Amphidiscophora & Amphidiscosida \\
\hline & & Hexasterophora & $\begin{array}{l}\text { Lychniscosida } \\
\text { Lyssacinosida } \\
\text { Sceptrulophora }\end{array}$ \\
\hline & Homoscleromorpha & & Homosclerophorida \\
\hline & Porifera incertae sedis & & \\
\hline
\end{tabular}

biological targets that make them biologically active and pharmacologically valuable. In fact, marine sponges are among the richest sources of interesting chemicals produced by marine organisms. $\frac{34}{34}$

Marine sponges have been shown to harbour a large number of micro-organisms, in some cases up to $40 \%$ of the tissue biomass and they can contribute significantly to the host metabolism. ${ }^{35}$ Due to this relationship, there is an uncertainty as to whether the biologically active metabolites isolated from sponges are in fact produced by the sponges or the micro-organisms, in particular when one sponge species contains different classes of metabolites while taxonomically different species contain the same metabolite or when the free-living microbes produce similar/identical compounds. ${ }^{36}$ Nevertheless, 
studies have shown that a number of secondary metabolites isolated from sponges are of microbial origin. $\underline{37 / 38}$

\subsection{Tongan Sponges and Chemistry}

The Kingdom of Tonga is an archipelago in the South Pacific Ocean, consisting of 176 islands, of which 53 are inhabited (Figure 1.1). Tonga is located north-east of New Zealand and east of Fiji. It has a total land area of $688 \mathrm{~km}^{2}$ with Exclusive Economic Zone (EEZ) of 700,000 km², 1000 times more than its land area.

Tropical sponges are known to produce large quantities and vast numbers of structurally diverse and biologically active secondary metabolites compared with those from temperate environments. It has been speculated that since sponges rely mostly on secondary metabolites to deter predators, their chemical defences may be more abundant or more potent in the tropical environments because of greater predation pressure than in environments with lower levels of predation. $\frac{39}{39}$

The first marine natural products research group to investigate Tongan sponges was from the University of California at Santa Cruz, led by Professor Phillip Crews. Their collections were made in the early 1980s from Vava'u and the Ha'apai groups, located in northern Tonga. The first novel compound reported from the Tongan marine environment was nuapapuin A (14), isolated together with the known norsesterterpene muqubilin (15) from the marine sponge Diacarnus $c f$. spinopoculum ${ }^{* 40-42}$ Compound $\mathbf{1 4}$ is considered to be the first norditerpene isolated from a marine sponge. A study of anti-inflammatory extracts of the sponge Hyrtios erecta revealed hyrtial (16), and a further five novel scalarane-type sesterterpenes (17-21). ${ }^{43 / 44}$ Psammaplin A (22) was reported from the marine sponge Psammaplysilla sp. in 1987, and was the first example of a disulfide derived from a marine sponge. ${ }^{45}$ Three novel isomalabaricane triterpenes $(\mathbf{2 3 - 2 5})$ were obtained from the organic extract of a specimen of Japsis sp. collected near Tonga, along with the known triterpene $\mathbf{2 6} .{ }^{46}$

\footnotetext{
*Previously identified as Prianos sp.
} 


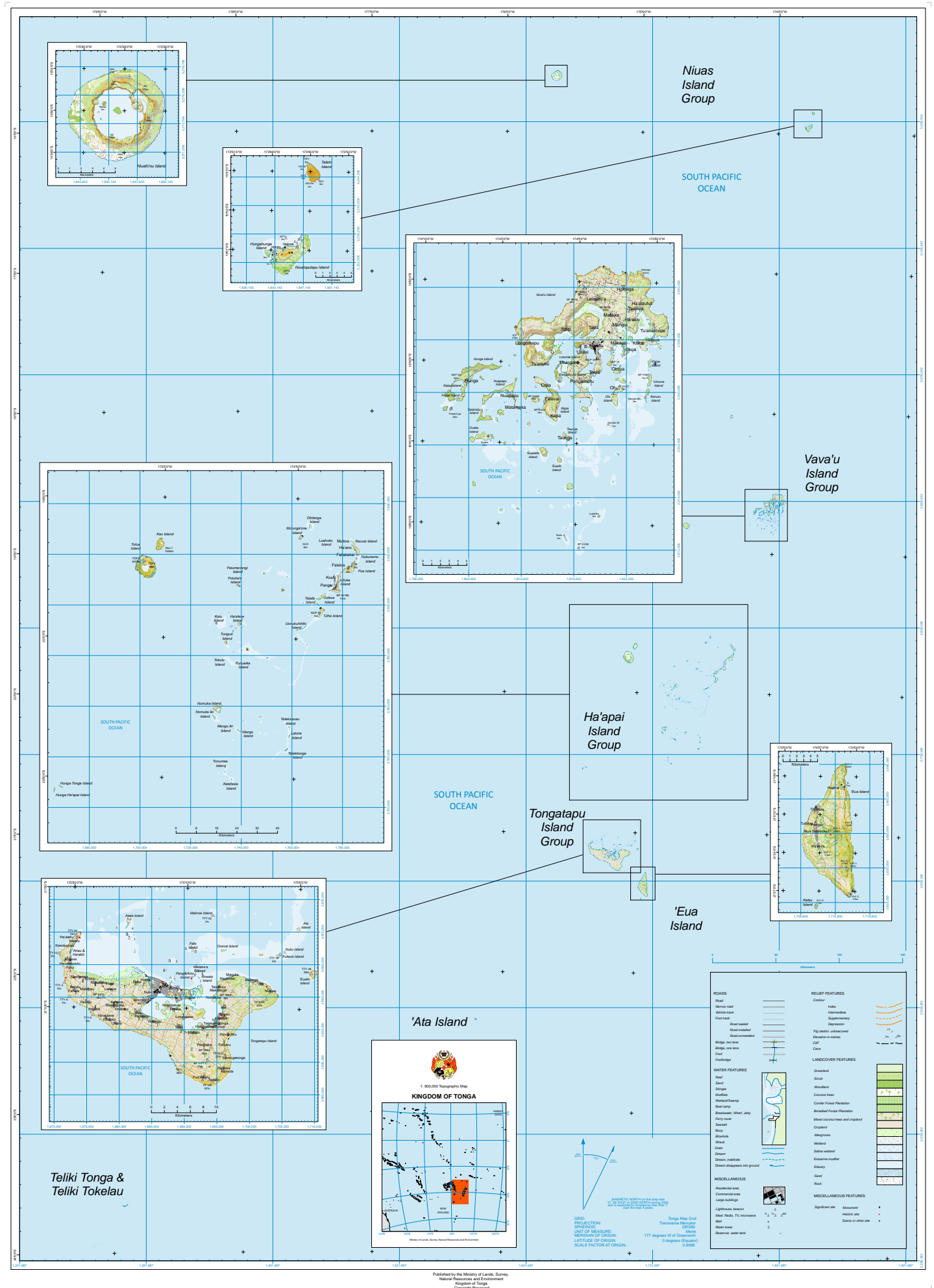

Figure 1.1. Map of the Kingdom of Tonga. Image courtesy of the Ministry of Lands, Survey \& Natural Resources, Tonga. 


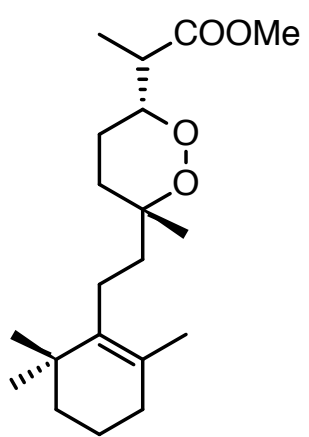

14

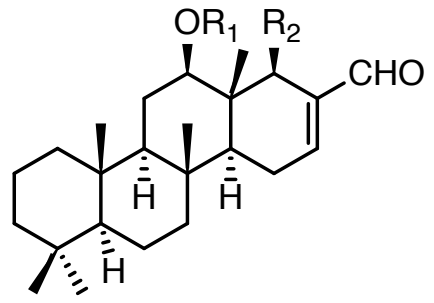

$16 \mathrm{R}_{1}=\mathrm{Ac} \quad \mathrm{R}_{2}=\mathrm{H}$

$17 \quad \mathrm{R}_{1}=\mathrm{H} \quad \mathrm{R}_{2}=\mathrm{CHO}$

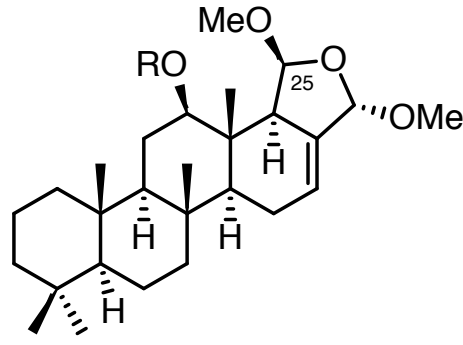

$20 \mathrm{R}=\mathrm{Ac}$

21 25-ерi $\mathrm{R}=\mathrm{H}$

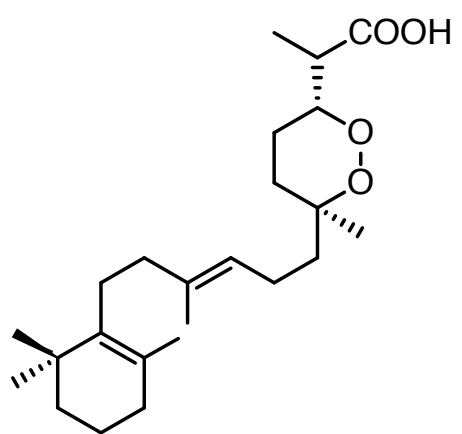

15

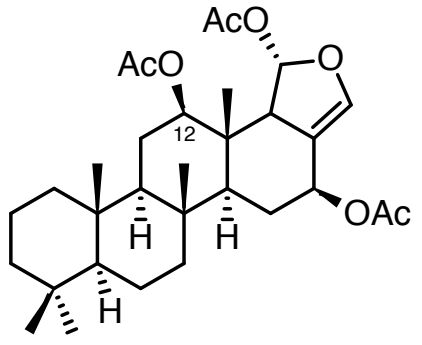

18

19 12-ерi

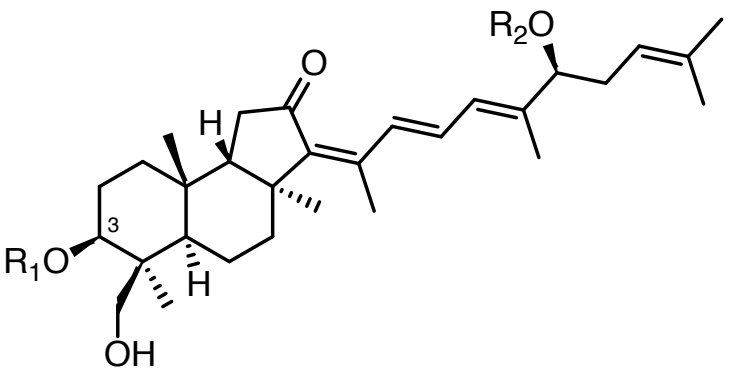

$23 \mathrm{R}_{1}=\mathrm{Ac} \mathrm{R}_{2}=\mathrm{Ac}$

$24 \mathrm{R}_{1}=\mathrm{Ac} \mathrm{R}_{2}=\mathrm{H}$

25 3-epi $\mathrm{R}_{1}=\mathrm{H} \mathrm{R}_{2}=\mathrm{Ac}$

26 3-epi $\mathrm{R}_{1}=A c \mathrm{R}_{2}=A c$ 
Over the past few years the Marine Natural Products Research Group at Victoria University of Wellington (VUW) has shifted their research and attention from New Zealand marine organisms to the tropical waters of the Kingdom of Tonga. This shift was made due to continual recollection of the same marine organisms, repeated isolation of similar or related metabolites from New Zealand's organisms, and the paucity of chemical investigation on Tongan marine fauna. Two collection trips were made to Tonga, the first collection trip was to Tongatapu and 'Eua in late 2008 and the second was to the Vava' $u$ Group in late 2009. These studies have led to the isolation of a variety of interesting biologically active secondary metabolites.

Chemical investigation of a Plakortis sponge specimen by Barber led to the isolation and identification of seven novel metabolites of polyketide origin, lehualides E-K (27-33). ${ }^{47}$ Biological testing showed that $\mathbf{2 8}-\mathbf{3 3}$ displayed micromolar cytotoxicity against the HL-60 cell line. ${ }^{48}$ Luakuliides A-C (34-36) are new labdane diterpenes isolated from two samples of a dictyoceratid sponge. ${ }^{47}$ Four new polyketides $(\mathbf{3 7}-\mathbf{4 0})$ were obtained from a Plakinidae sponge, all of which possess different cyclic peroxide moieties. ${ }^{47}$ Cyclic peroxides 37, 39 and $\mathbf{4 0}$ displayed potent cytoxicity against HL-60 cells. Four fascaplysin derivatives (41-44) were isolated by Woolner from a marine sponge of the

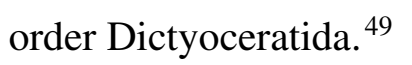

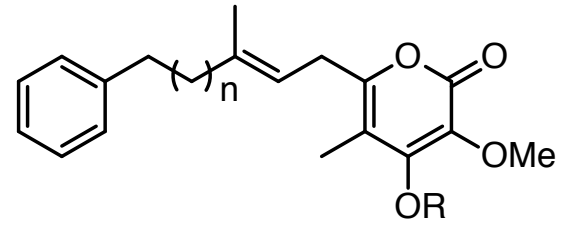

$27 \mathrm{R}=\mathrm{Me} \quad \mathrm{n}=4$

$28 \mathrm{R}=\mathrm{H} \quad \mathrm{n}=4$

$29 \mathrm{R}=\mathrm{H} \quad \mathrm{n}=6$<smiles>[R]CCCCCc1oc(=O)c(OC)c(OC)c1C</smiles>

$30 \mathrm{R}=\mathrm{Ac}$

$31 \mathrm{R}=\mathrm{Me}$

$32 \mathrm{R}=\mathrm{SOMe}$<smiles>COc1c(C)c(CCCCCCCCCCCSSCCCCCCCCCCc2oc(=O)c(OC)c(OC)c2C)oc(=O)c1OC</smiles> 


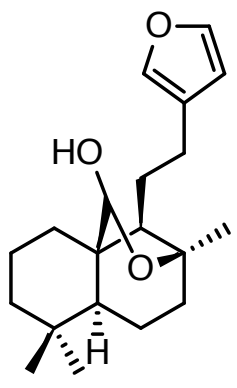

34

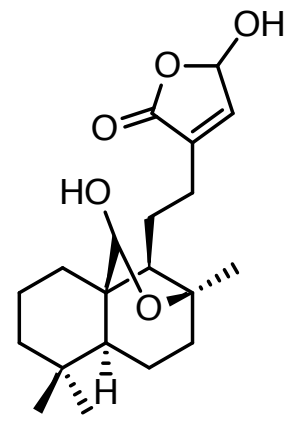

35

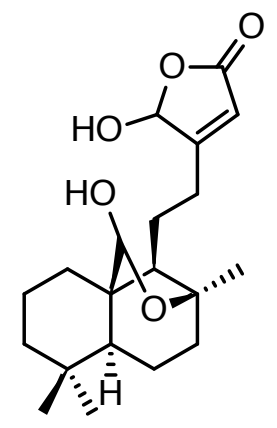

36

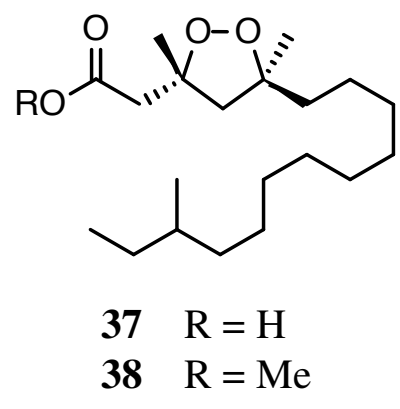

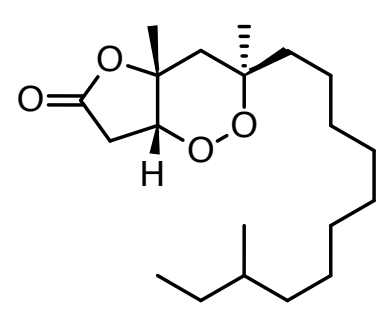

39

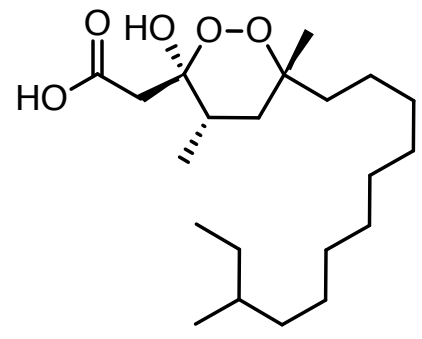

40<smiles></smiles>

41<smiles>[R]c1c2n(c3ccccc13)C(OC)C(OC)c1c-2[nH]c2cc(Br)ccc12</smiles>

$42 \mathrm{R}=\mathrm{CHO}$

$43 \mathrm{R}=\mathrm{CH}_{2} \mathrm{COCH}_{3}$<smiles></smiles>

44 
In continuation of our search for bioactive metabolites from marine organisms, we have investigated several specimens (in some cases of the same species) collected from different geographical areas from Tonga. Interestingly, most of the novel and biologically active compounds isolated from these marine organisms were collected from the island of 'Eua. 'Eua is the most ancient island in the Kingdom and it is geologically unrelated to the rest of the islands and is believed to be 30 million years older. $\underline{50}$ 'Eua therefore has a unique marine environment that could host organisms that produce interesting and novel chemistry. Among the fascinating sponges collected from 'Eua was the marine sponge Cacospongia mycofijiensis, which proved to be a rich source of structurally diverse as well as biologically active metabolites. 151 As a result, a third expedition to 'Eua was made in June 2016 - to collect new marine organisms and also target collected several organisms, especially that of the Indo-Pacific C. mycofijiensis in the search for new biologically active compounds. Investigation of this sponge is discussed in Chapter 6 .

\subsection{Isolation Methods for Natural Products at VUW}

The chemistry and biology of natural products are at the heart of our research interests at VUW. This involves the search for novel or new chemical structures with interesting and useful biological activities, employing certain techniques. These include a chromatographic method, cyclic loading, as well as NMR (Nuclear Magnetic Resonance)-based screening methods, which are both discussed below.

\subsubsection{Cyclic Loading}

For secondary metabolites to be biologically effective, the structure usually has hydrophobic and hydrophilic properties, which enables them not only to be easily transported across cell membranes and other biological barriers, but also allows interaction with their substrate. This requires the overall polarity of many secondary metabolites to be of an intermediate nature. ${ }^{52}$ The crude extracts of sponges contain a wide range of compounds with varying degrees of polarity, ranging from polar amino acids, salts and 
sugars to non-polar fats, lipids and steroids, with small amounts of secondary metabolites in comparison. As a result, fractionation of secondary metabolites at the beginning of the isolation process is a challenging task due to solubility issues.

The wide range of polarity also causes problems with the chromatographic separation of the extract using standard procedures. This all can be best described in terms of a mass window (Figure 1.2), where the intermediate region (lowest relative mass, intermediate polarity) contains few primary metabolites, making the mass window an ideal target for the first stage of fractionation of a crude extract. However, in practice we have found examples where this mass window is shifted to either polar or non-polar fractions.

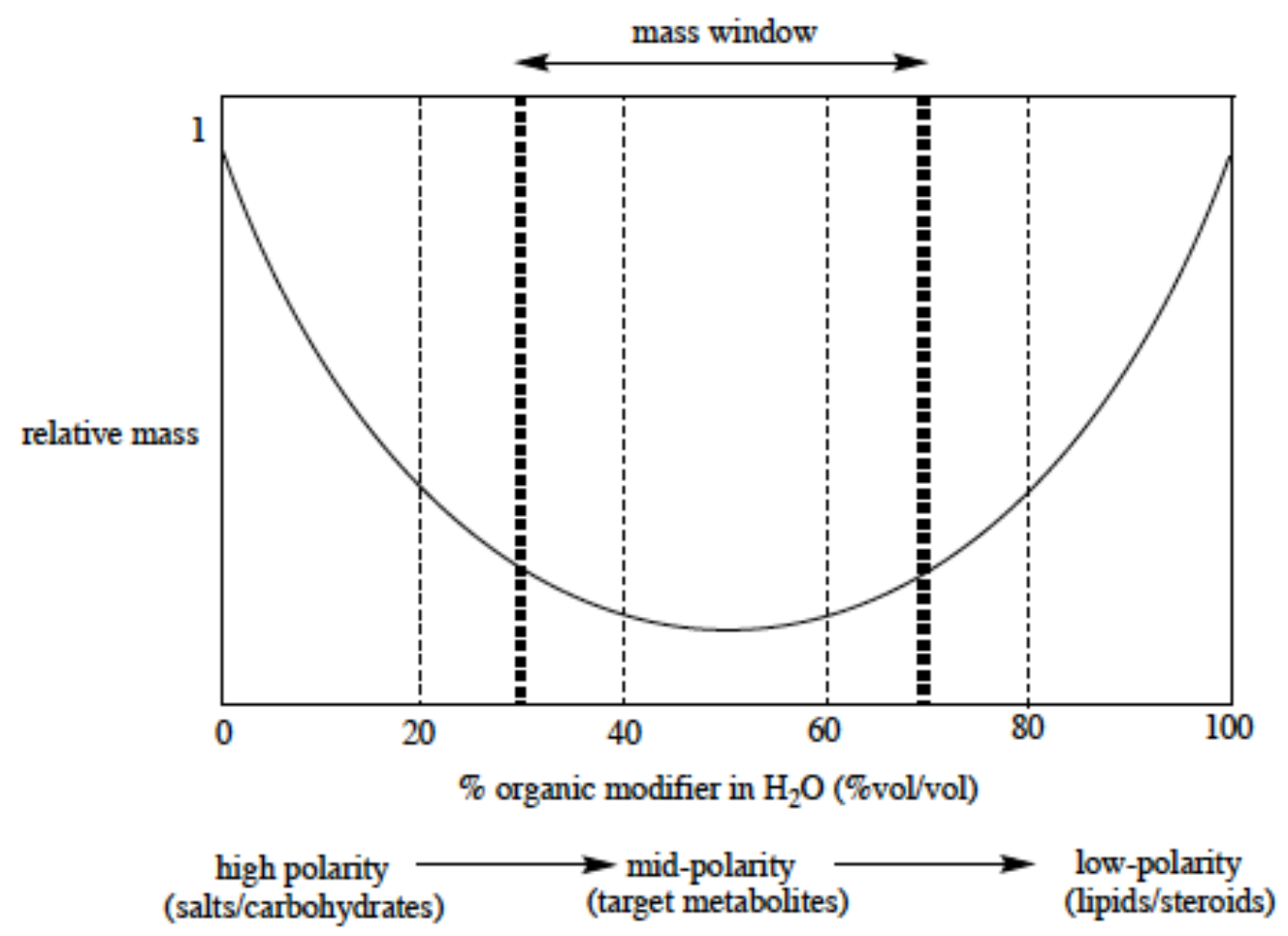

Figure 1.2. Schematic of the mass distribution in a typical marine sponge extract over a reversed-phase medium.

The Marine Natural Products group at VUW has developed a technique known as cyclic loading (Figure 1.3 to deal with this problem. ${ }^{53}$ This reversed-phase chromatographic technique utilises poly(styrene-divinylbenzene) (PSDVB) cross-linked polymeric resin as the stationary phase. PSDVB is chemically inert and stable across a large $\mathrm{pH}$ range. 54 This resin is highly porous, lacks polar sites and can be reused a number of times without decreased performance. The advantage of using a technique such as cyclic loading is that it uses inexpensive and less toxic solvents than the halogenated solvents frequently used 
in other methods such as liquid-liquid partitioning.

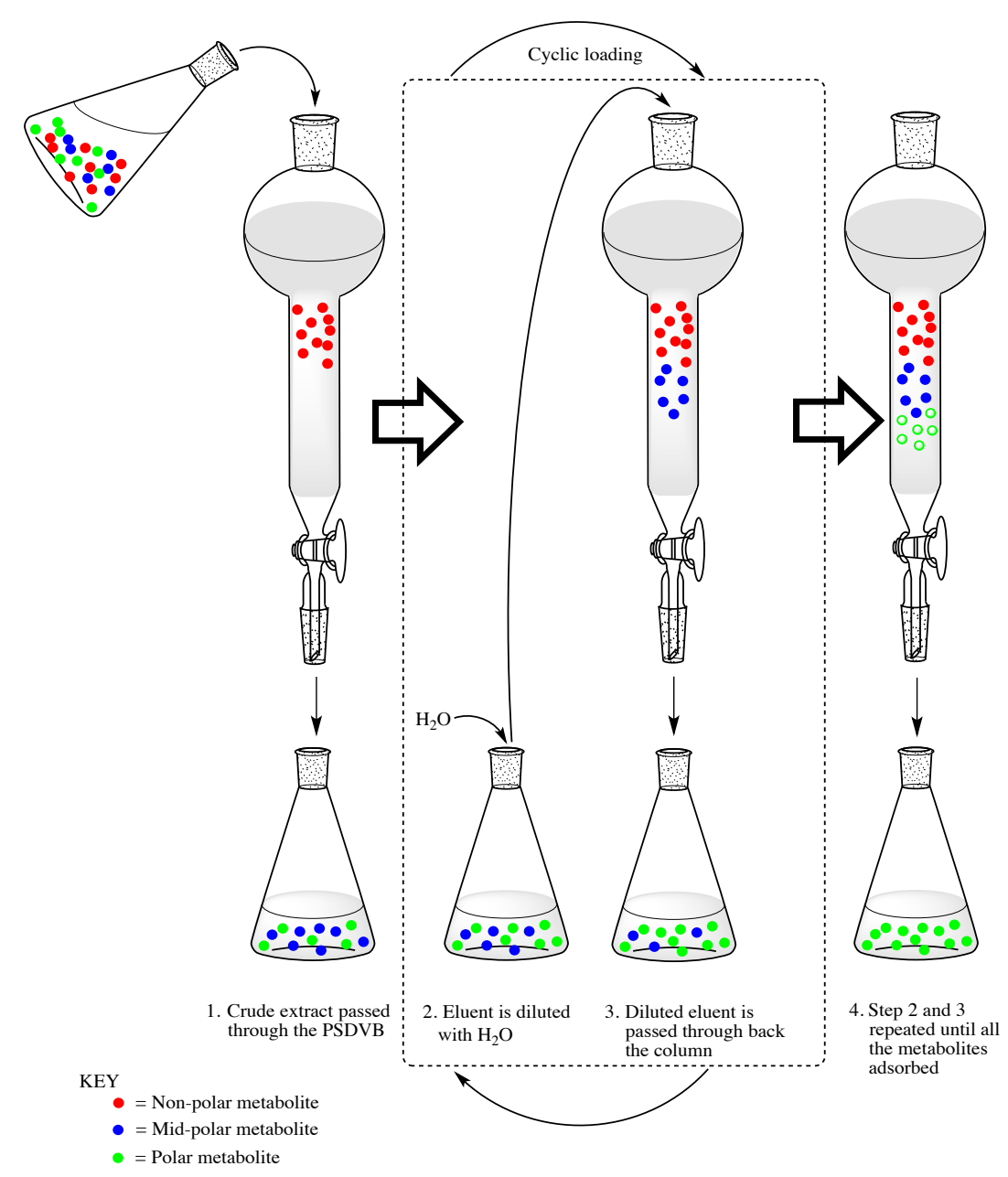

Figure 1.3. Schematic of the cyclic loading process.

Cyclic loading involves passing the extract(s) through the PSDVB column, which allows most of the non-polar compounds in the extracts to adhere to the PSDVB beads. The eluent is then diluted with $\mathrm{H}_{2} \mathrm{O}$ and passed back through the column. Usually addition of $\mathrm{H}_{2} \mathrm{O}$ to a crude extract under normal circumstances would result in the precipitation of the non-polar compounds. This is avoided during cyclic loading, as the most non-polar fats and triglycerides have adsorbed to the PSDVB beads during the first pass. As polarity of the mobile phase increases by each dilution with $\mathrm{H}_{2} \mathrm{O}$, more compounds in the initial extract are adsorbed to the column. The cyclic process is repeated until all the compounds of interest are retained on the column.

The loaded column is then washed with distilled $\mathrm{H}_{2} \mathrm{O}$ to remove any remaining salts. The compounds that are adsorbed on the column are sequentially eluted with a gradient of 
increasing organic solvent $\left(\mathrm{Me}_{2} \mathrm{CO}\right.$ or $\left.\mathrm{MeOH}\right)$ in $\mathrm{H}_{2} \mathrm{O}$ to obtain a number of fractions of decreasing polarity, commonly $30 \% \mathrm{Me}_{2} \mathrm{CO} / \mathrm{H}_{2} \mathrm{O}, 75 \% \mathrm{Me}_{2} \mathrm{CO} / \mathrm{H}_{2} \mathrm{O}$ and $\mathrm{Me}_{2} \mathrm{CO}$. The earliest fraction $\left(30 \% \mathrm{Me}_{2} \mathrm{CO} / \mathrm{H}_{2} \mathrm{O}\right)$ usually contains the most polar compounds such as sugars and proteins. The very non-polar compounds such as steroids and lipids usually come off in the later fraction $\left(\mathrm{Me}_{2} \mathrm{CO}\right)$. Most of the interesting secondary metabolites are eluted in the middle fraction $\left(75 \% \mathrm{Me}_{2} \mathrm{CO} / \mathrm{H}_{2} \mathrm{O}\right)$. The use of the mass window and cyclic loading is a general overview but in practice the intermediate fraction will still have metabolites from the adjacent fractions.

\subsection{Screening of Marine Organisms}

At the core of drug discovery is the identification of biologically active compounds by either employing bioassay-guided or structure-guided techniques. Most natural product research has focused on the first of these two methods, however, natural product researchers have realised the importance of structural novelty in drug discovery.

\subsubsection{Bioassay-Guided Isolation}

Bioassay (biological assay) guided isolation is the most commonly used technique and still the basic procedures for conventional drug discovery. The primary purpose of a bioassay is to characterise a natural product with defined biological activity from biological crude extracts. This method involves screening the crude extracts from the target organism against assays of specific activity and pursuing the activity through chromatographic steps until the active component is isolated. The major advantage of this method is the isolation of a biologically active compound that perhaps exhibits novel activity against the chosen target, however it is not without flaws. This strategy involves targeting a specific cellular target or receptor, or an organism in total, which means that compounds that may have activity in other biological systems will not be identified. It also requires a large number of fractions to be assayed and frequently results in the realisation that the desired compound is not novel after a great deal of time and resources have been 
invested. Therefore, it is exceedingly important to identify known compounds early on, not only for saving time and money, but to allocate resources to more profitable extracts. Additionally, the activity of lower concentration metabolites can be masked by a higher concentration metabolite since an organism can produce numerous biologically active compounds.

\subsubsection{Structure-Guided Isolation}

Over the last two decades several spectroscopic techniques have been significantly developed to detect novel compounds in crude extracts, particularly in the area of hyphenated analytical techniques. These chemical screening strategies combined chromatographic and spectral methods to exploit the advantages of both techniques, such as HPLC coupled to UV photodiode array detection (LC/DAD-UV) and to mass spectrometry (LC/MS or LC/MS/MS). These techniques have their own advantages and drawbacks. MS has a greater sensitivity but does not provide sufficient structural information. Furthermore, these methods depend on the ease of ionisation (MS) and UV absorbance/chromophore intensity (DAD).

NMR is the least sensitive analytical technique, and yet it provides the most useful information toward the structure elucidation of natural products. Advances in the capabilities of NMR such as miniaturised and cryogenic NMR probes have reduced the experimental times and increased sensitivity toward more efficient analyses of natural materials available in microgram quantities. ${ }^{55}$ The advantage of this technique is that it is a universal assay that can be applied to virtually any secondary metabolite. It is also non-destructive, which allows for sample recovery. Finally, it requires no target-specific assay or knowledge of target function, thus minimising false positives that can plague functional assays. NMR can be used to rapidly identify known or undesirable compounds (dereplication) in biological extracts, which is a critical step in any natural products discovery program. NMR screening strategies have been incorporated into drug discovery and design programmes of many research groups, especially at pharmaceutical companies. ${ }^{56}$ This stems from the fact that NMR screening is naturally synergistic with 
combinatorial chemistry, high throughput screening (HTS), genomics, and structurebased drug design such as HPLC-NMR ${ }^{57}$ However, solubility is a major problem due to the larger range of polarities present in the crude extracts. In our laboratory, this problem is overcome by using cyclic loading and targeting the mass window as the primary partition stage after extraction.

\subsection{VUW Screening Methodology}

The VUW marine natural products program uses an NMR-based screening protocol for screening marine sponges, and guiding the isolation procedure, and has been well developed over the years. Typically for screening a New Zealand sponge in our laboratory, about $100 \mathrm{~g}$ of the sponge is required, which is four times the amount needed to screen a sponge (25 g) collected from Tongan waters . This is due to the fact that tropical sponges typically produce more chemical components (smaller amount of sponges are collected as well). The extracts are then cyclic loaded onto a PSDVB column and then sequentially eluted with $30 \%, 75 \% \mathrm{Me}_{2} \mathrm{CO} / \mathrm{H}_{2} \mathrm{O}$ and $\mathrm{Me}_{2} \mathrm{CO}$. From a screening perspective, the biologically active secondary metabolites tend to elute in the intermediate region, the $75 \% \mathrm{Me}_{2} \mathrm{CO} / \mathrm{H}_{2} \mathrm{O}$ fraction.

\subsection{1 ${ }^{1}$ H NMR Screening}

Originally, the screening fractions were analysed by ${ }^{1} \mathrm{H} \mathrm{NMR}$, as this was the fastest way to generate information. The ${ }^{1} \mathrm{H}$ NMR spectra of the semi-purified extracts $\left(75 \% \mathrm{Me}_{2} \mathrm{CO} / \mathrm{H}_{2} \mathrm{O}\right)$ were analysed by differentiating between the common and unusual resonances. The use of this simple screening technique led to the isolation of biologically active compounds such as pelorusides A (45) and B (46), amongst others. ${ }^{5153}$ However, the primary metabolites still present in the screening fractions conceal a large portion of the ${ }^{1} \mathrm{H}$ NMR spectrum, thus limiting the amount of structural information available. As a result, a new screening protocol was developed using 2D-NMR experiments, since 2D-NMR spectroscopy offers more detailed structural information, that can greatly 
enhance dereplication. This provided a great advantage in the detection of novel secondary metabolites.

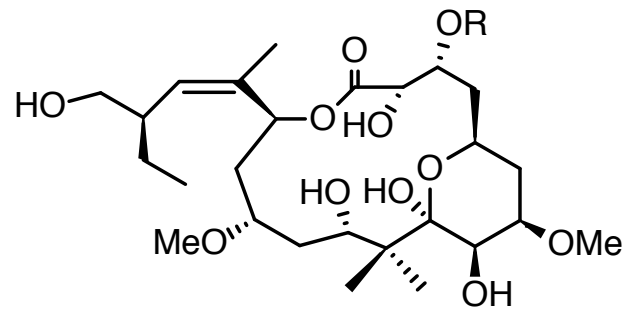

$$
\begin{array}{ll}
45 & \mathrm{R}=\mathrm{Me} \\
46 & \mathrm{R}=\mathrm{OH}
\end{array}
$$

\subsubsection{HSQC Screening}

The quicker COSY (Homonuclear Correlation Spectroscopy) experiment was initially used as a screening tool, but it was too complicated to be transformed to a database so HSQC (Heteronuclear Single Quantum Coherence) experiment was chosen instead. ${ }^{58}$ The HSQC screening protocol was started as paper mask, $\stackrel{59}{ }$ but as more spectra were used to generate the mask sheets, the more it became difficult to manually interpret the spectral data. A computer-based screen was developed in a similar manner by constructing an electronic mask. $\frac{5860}{2}$ The HSQC data of the $75 \% \mathrm{Me}_{2} \mathrm{CO} / \mathrm{H}_{2} \mathrm{O}$ screen fractions were added together to generate a digital mask (Figure 1.4). The HSQC data of new sponge extracts are compared to this mask, where common signals (green peaks) are distinguished from those that are interesting (uncommon signals, red peaks). Thus, uncommon correlations may indicate the presence of novel secondary metabolite(s) (Figure 1.5). This screening method has led to the detection of many structurally unique biologically active compounds from New Zealand sponges and red algae.

\subsubsection{HMBC Screening}

Despite the fact that the HSQC screen has been a successful tool in detecting novel secondary metabolites, it does have some drawbacks. The HSQC experiment does not detect non-protonated carbons such as carbonyl carbons (excluding aldehydes), nonprotonated olefinic and $s p^{3}$-hybridised quaternary carbons. In addition, there is no direct 


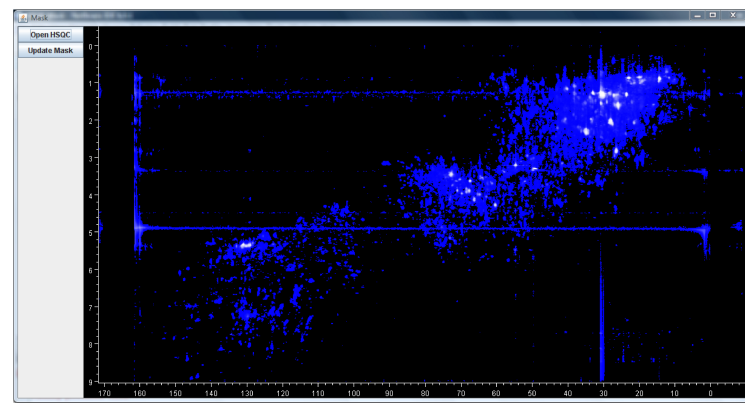

(a)

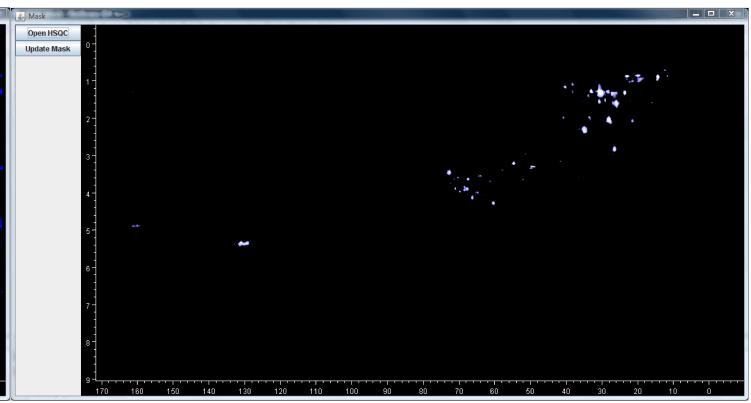

(b)

Figure 1.4. (a) Current digital HSQC mask (contains 160 sponges). (b) Common correlations in the HSQC mask.

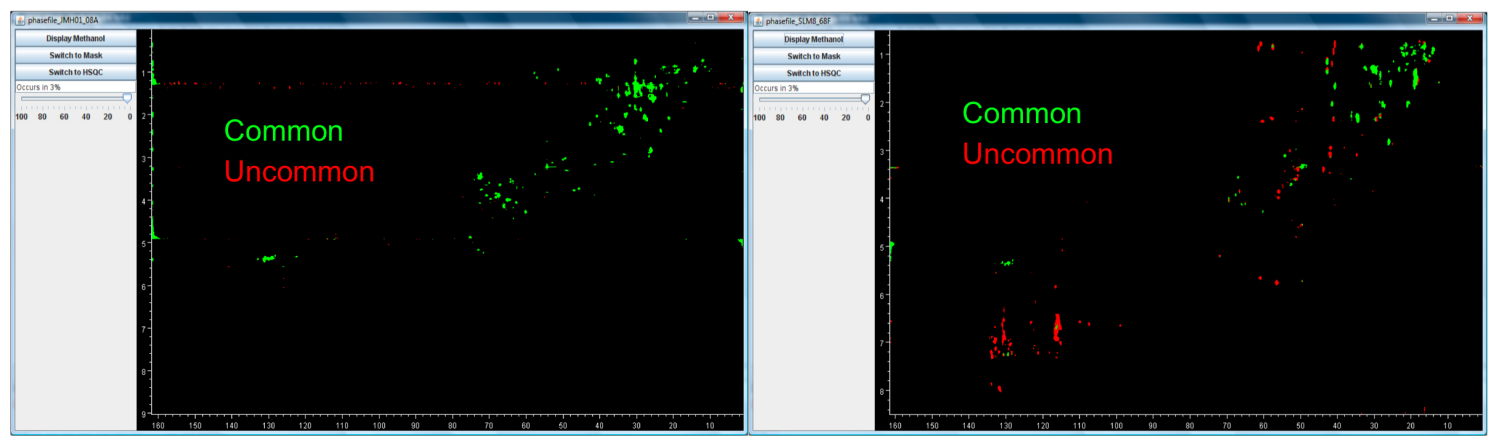

(a)

(b)

Figure 1.5. (a) An uninteresting sponge screen. (b) An interesting screen.

evidence provided that indicates that any of the correlations observed belong to a single molecular entity. Finally, the selection of the ${ }^{1} J_{\mathrm{CH}}$ value dictates which correlations appear most intense. ${ }^{1} J_{\mathrm{CH}}$ values can range between 110 to $320 \mathrm{~Hz}, \stackrel{62}{ }$ and the current HSQC screen has a optimum ${ }^{1} J_{\mathrm{CH}}$ value of $140 \mathrm{~Hz}$, which allows ${ }^{1} J_{\mathrm{CH}}$ values between $110-170$ $\mathrm{Hz}$ to appear with the highest intensity. ${ }^{51}$ Thus protonated functional groups with ${ }^{1} J_{\mathrm{CH}}$ values outside this range appear proportionally weaker or missing unless the optimum value is changed.

An advanced screening protocol has been developed based on the HMBC (Heteronuclear Multiple Bond Correlation) experiment in a similar manner to the HSQC screen. ${ }^{51}$ While the HSQC experiment correlates ${ }^{1} \mathrm{H}$ directly attached to a ${ }^{13} \mathrm{C}$, the $\mathrm{HMBC}$ experiment detects long range coupling between ${ }^{1} \mathrm{H}$ and ${ }^{13} \mathrm{C}$ thus providing more information, particularly in the carbon dimension. The HMBC experiment is able to indirectly detect quaternary carbons coupled to protons, thus providing detailed structural information about the skeleton of a molecule. Even though the HMBC experiment is less sensitive 
than HSQC, the HMBC screen could be an important tool in identification of interesting signals at an early stage of purification. This would help decide if a sponge extract is worthy of further investigation without fully committing to the purification process. Unfortunately, these 2D-NMR screening methods were not working during the course of this study, which led to isolation of compounds already known from the literature.

\subsection{Research Objectives}

The aim of this research was to investigate a selection of Tongan and New Zealand marine sponges in an effort to identify and isolate new secondary metabolites by using an NMR-guided isolation methodology. The structure of the isolated compounds were elucidated principally by NMR spectroscopy and mass spectrometry. Following the identification process, the compounds were subjected for biological activity profiling. 


\section{Chapter 2}

\section{Spectroscopic Screening of Marine Organisms}

During the course of this study, a total of 18 marine sponges were subjected to NMR-based screening. These organisms were collected from Tongan waters on three dive collection trips in 2008, 2009 and 2016, and from the Three Kings Islands, New Zealand, which were collected by NIWA (National Institute of Water and Atmospheric Research) in 2002. Several sponges were selected for further investigation based on their promising spectral signatures in the 2D-NMR spectra, which led to isolation of novel and known compounds, the details of which are described in the following chapters.

\subsection{Organisms Screened from the Vava'u Group}

Vava' $\mathrm{u}$ is a group of more than 50 islands and is situated about $310 \mathrm{~km}$ north of Tongatapu. Like the remainder of the Kingdom, these islands are raised coral limestone, with some volcanic islands. A collection trip was carried out in late November 2009, resulting in the collection of more than 200 samples of marine organisms (mostly sponges) from 12 different sites within the island group.

\subsubsection{PTN3_39E}

PTN3_39E is an undescribed demosponge (see Figure 2.1) collected by hand using SCUBA from Split Rock, Vava'u. The sponge is dark brown on the outside with a rough texture, but tan on the inside. The NMR spectra of the polar PSDVB screening fraction (30\% $\mathrm{Me}_{2} \mathrm{CO} / \mathrm{H}_{2} \mathrm{O}$ of PTN3_39E) was dominated by one compound. The ${ }^{1} \mathrm{H}$ NMR spectrum (see Figure 2.11) showed an aromatic proton at $\delta_{\mathrm{H}} 6.97\left(\mathrm{CH}-2: \delta_{\mathrm{C}} 125.4\right)$ and an olefinic proton at $\delta_{\mathrm{H}} 5.20\left(\mathrm{CH}-6: \delta_{\mathrm{C}}\right.$ 93.2). In addition, a spin system comprising a pair of methylene triplets at $\delta_{\mathrm{H}} 2.89\left(\mathrm{CH}_{2}-3: \delta_{\mathrm{C}} 20.9\right)$ and $\delta_{\mathrm{H}} 3.70\left(\mathrm{CH}_{2}-4: \delta_{\mathrm{C}} 53.2\right)$, as well as a downfield-shifted methyl singlet at $\delta_{\mathrm{H}} 3.15\left(\mathrm{NCH}_{3}-5: \delta_{\mathrm{C}} 38.7\right)$ was also evident. 


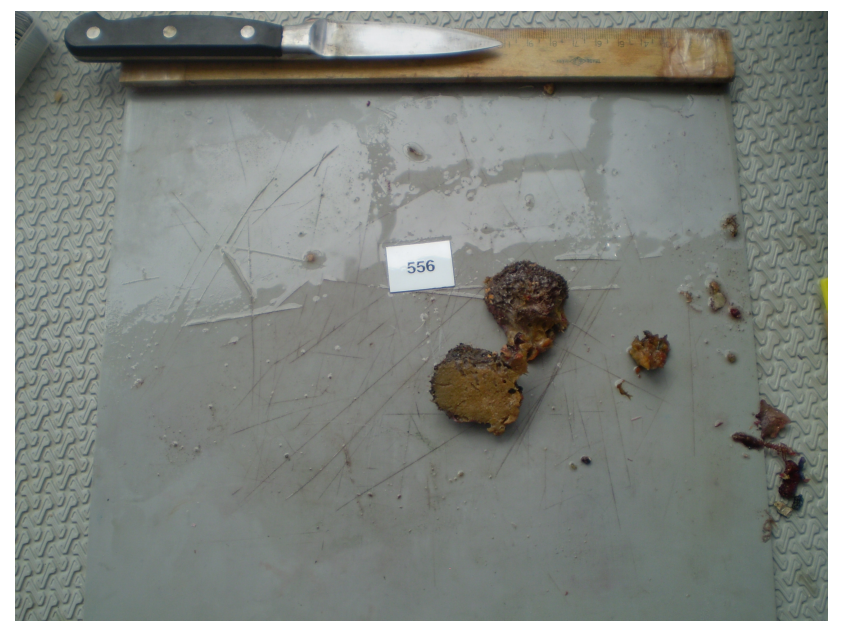

Figure 2.1. Surface photograph of the sponge PTN3_39E.

The fraction was subjected to LC-MS and NMR analysis, leading to the identification of the known compound, damirone B (47). ${ }^{63}$ Further investigation of this sponge was discontinued.

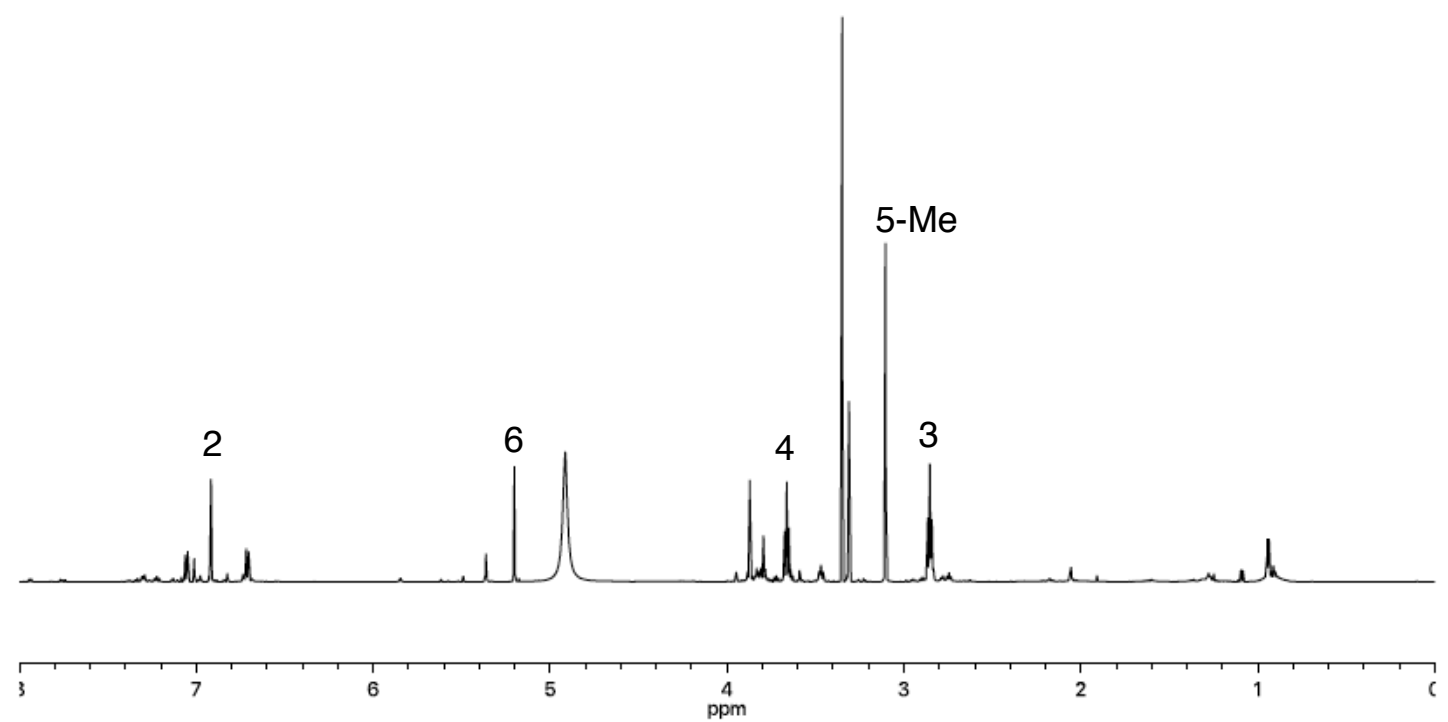

Figure 2.2. ${ }^{1} \mathrm{H} \mathrm{NMR}\left(600 \mathrm{MHz}, \mathrm{CD}_{3} \mathrm{OD}\right)$ spectrum of the $30 \% \mathrm{Me}_{2} \mathrm{CO} / \mathrm{H}_{2} \mathrm{O}$ fraction of PTN3_39E.<smiles>CN1CCc2c[nH]c3c2C1=CC(=O)C3=O</smiles> 


\subsubsection{PTN3_45C}

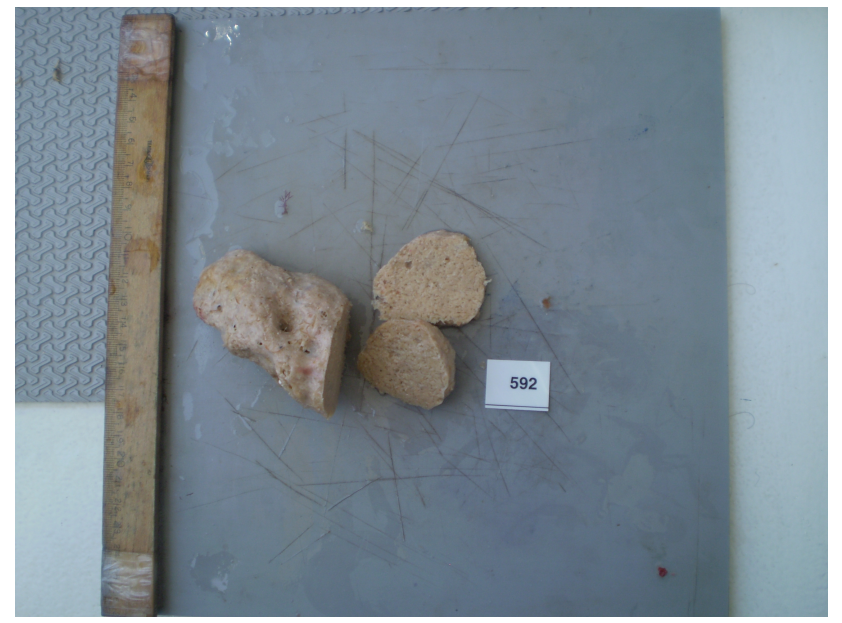

Figure 2.3. Surface photograph of the sponge PTN3_45C.

An unidentified sponge (see Figure 2.3) was collected by hand using SCUBA from an underwater cave from Tu'ungasika Island, Vava'u. Several interesting metabolites dominated the 1D and 2D-NMR spectra of the $30 \%$ and $75 \% \mathrm{Me}_{2} \mathrm{CO} / \mathrm{H}_{2} \mathrm{O}$ fractions. The $75 \% \mathrm{Me}_{2} \mathrm{CO} / \mathrm{H}_{2} \mathrm{O}$ was further partitioned over reversed-phase PSDVB column and eluted with increasing concentrations of $\mathrm{Me}_{2} \mathrm{CO}$ in $\mathrm{H}_{2} \mathrm{O}$. The ${ }^{1} \mathrm{H}$ (see Figure 2.4) and HMBC NMR spectra of the $80 \% \mathrm{Me}_{2} \mathrm{CO} / \mathrm{H}_{2} \mathrm{O}$ fraction showed signs of olefinic methyls and other signs of unsaturation. Further analysis is required but was beyond the scope of this current study.

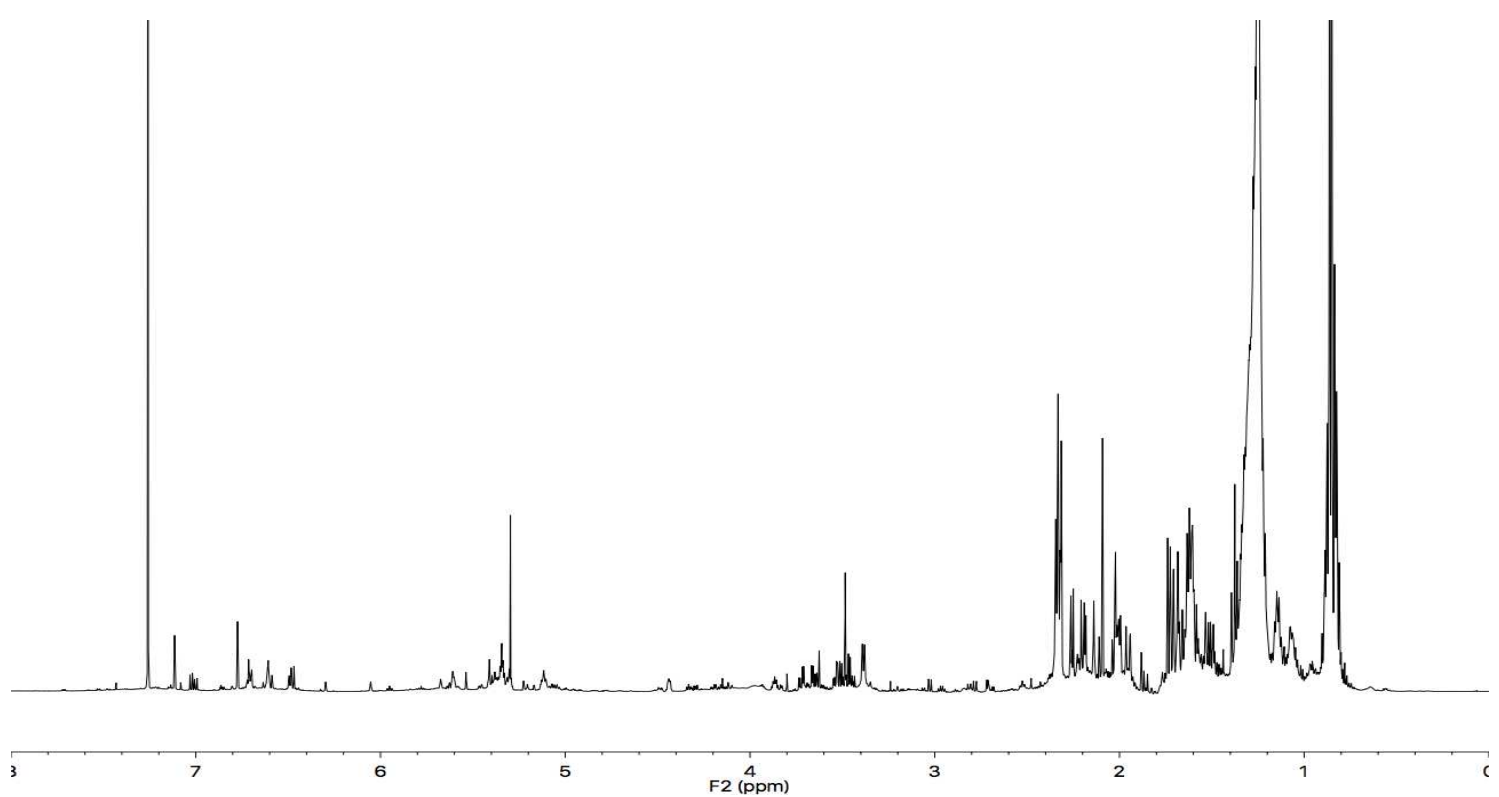

Figure 2.4. ${ }^{1} \mathrm{H} \mathrm{NMR}\left(600 \mathrm{MHz}, \mathrm{CDCl}_{3}\right)$ spectrum of the $80 \% \mathrm{Me}_{2} \mathrm{CO} / \mathrm{H}_{2} \mathrm{O}$ fraction of PTN3 45C. 


\subsubsection{PTN3_45F}

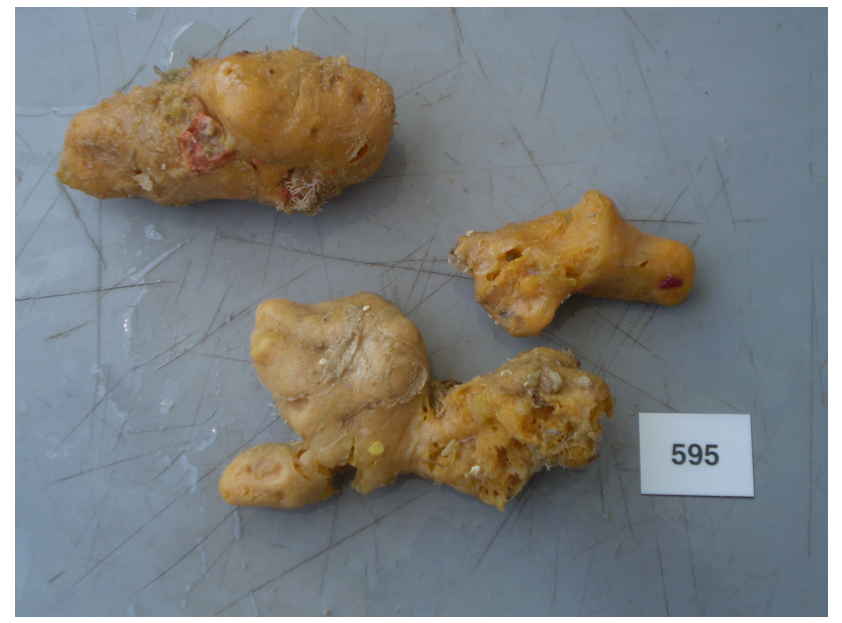

Figure 2.5. Surface photograph of the sponge PTN3_45F.

An unidentified ginger-like sponge (see Figure 2.5) was collected by hand using SCUBA from an underwater cave from Tu'ungasika Island, Vava' $u$. The 1D and 2D-NMR spectra of the $75 \% \mathrm{Me}_{2} \mathrm{CO} / \mathrm{H}_{2} \mathrm{O}$ fraction showed olefinic methyl, olefinic methine and aromatic correlations consistent with a cyclic terpenoid skeleton. The HMBC spectrum obtained for this fraction revealed methyl-based substructures including a gem-dimethyl group, which shared correlations to the same olefinic carbons as well as to each other, implying the presence of a trisubstituted double bond. In addition to these, aromatic proton resonances were observed and deshielded methyl singlets correlated to aromatic carbons suggesting a substituted benzene moiety. An additional step of purification of this fraction led to the identification of two known aromatic sesquiterpenes, $48^{64}$ and $49 .{ }^{65}$ Further purification of these compounds was discontinued.<smiles>C=C(C)C(C)=CC=C(C)C</smiles>

48<smiles>CC(C)=CCC(C)c1ccc(C)cc1O</smiles>

49 

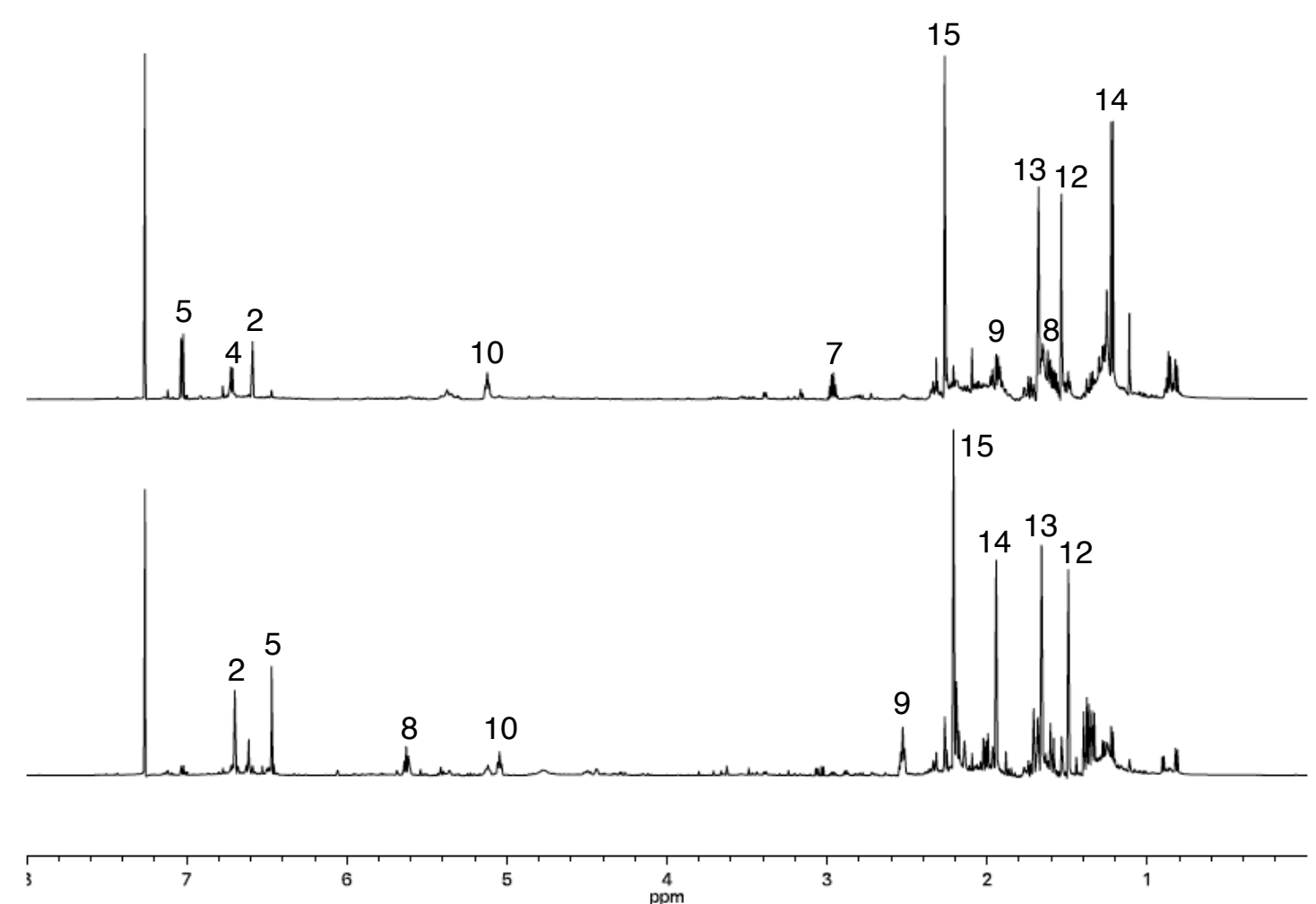

Figure 2.6. ${ }^{1} \mathrm{H} \mathrm{NMR}\left(600 \mathrm{MHz}, \mathrm{CDCl}_{3}\right)$ spectra comparison between semi-purified fractions of compounds 48 (bottom) and 49 (top).

\subsubsection{PTN3_45H}

A bright yellow calcareous sponge was collected from an underwater cave in northernwest Vava'u. Analysis of the ${ }^{1} \mathrm{H}$ NMR spectra of the $75 \% \mathrm{Me}_{2} \mathrm{CO} / \mathrm{H}_{2} \mathrm{O}$ and $\mathrm{Me}_{2} \mathrm{CO}$ fractions drew attention to an unusual combination of signals, including deshielded methylene protons, olefinic protons, aromatic protons, and evidence of steroids and long alkyl chains. The results of the investigation of this sponge are presented in Chapter 5 .

\subsubsection{PTN4_02H}

PTN4_02H is a soft, black coloured sponge collected from Hunga Island, Vava'u (see Figure 2.7). Interesting correlations observed within the $75 \% \mathrm{Me}_{2} \mathrm{CO} / \mathrm{H}_{2} \mathrm{O}$ fraction $\mathrm{NMR}$ spectra were mainly confined to those in the aromatic/heteroaromatic range between $\delta_{\mathrm{H}} 8.00-10.00$ (see Figure 2.8). Further investigation is required but was beyond the scope of this current study. 


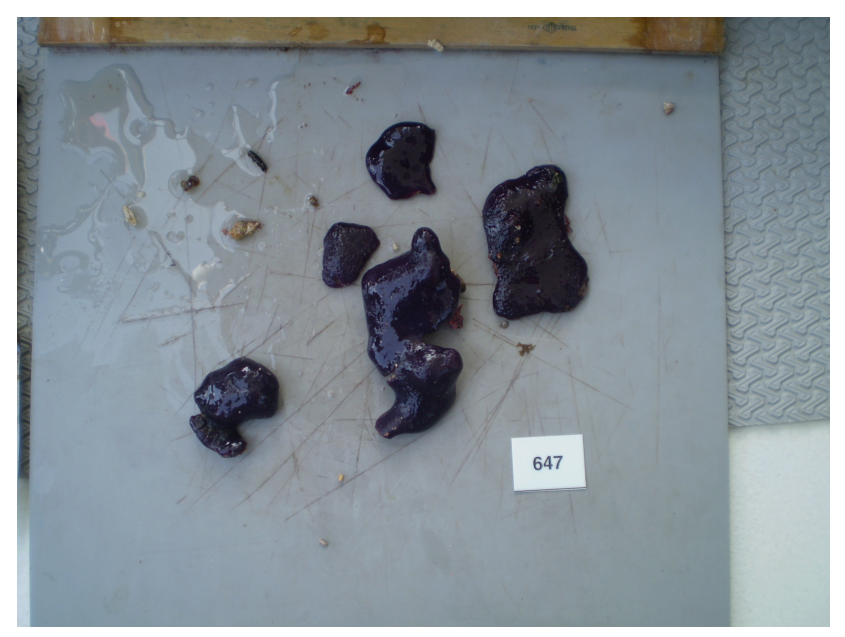

Figure 2.7. Surface photograph of the sponge PTN4_02H.

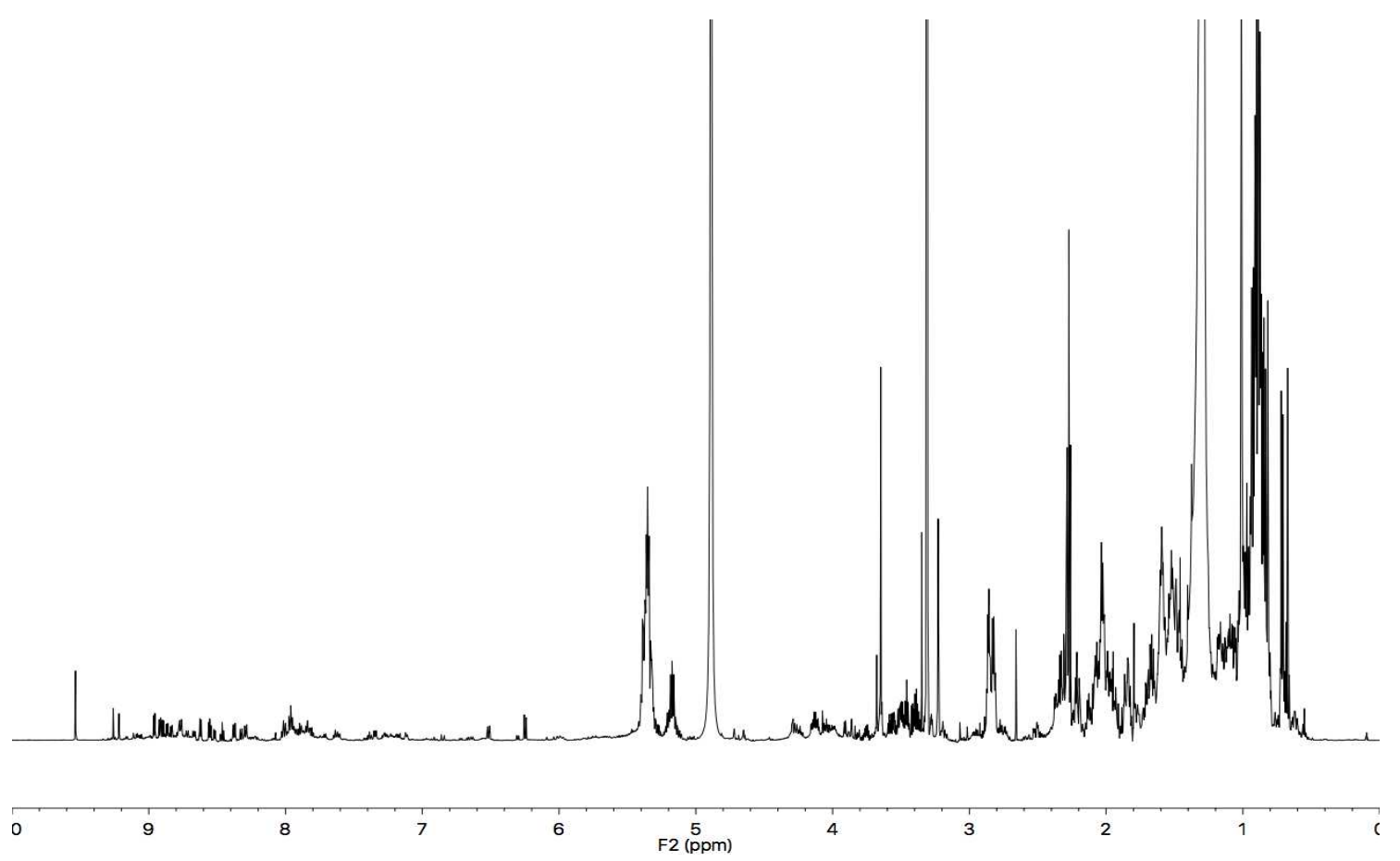

Figure 2.8. ${ }^{1} \mathrm{H} \mathrm{NMR}\left(600 \mathrm{MHz}, \mathrm{CD}_{3} \mathrm{OD}\right)$ spectrum of the $75 \% \mathrm{Me}_{2} \mathrm{CO} / \mathrm{H}_{2} \mathrm{O}$ fraction of PTN4_02H.

\subsubsection{PTN4_10A}

The sponge, PTN4_10A, examined in this study was a massive, soft sponge with a black exterior and interior. The sponge exudes abundant mucus when handled and the methanol extract has a very dark greenish pigment. Evident within the HMBC experiments of the screened fractions were correlations from the protons of deshielded methylenes and olefinic methines to non-protonated olefinic centres. These interesting structural fragments encouraged investigation of the specimen, which are further discussed in Chapter 4. 


\subsubsection{PTN4_15H}

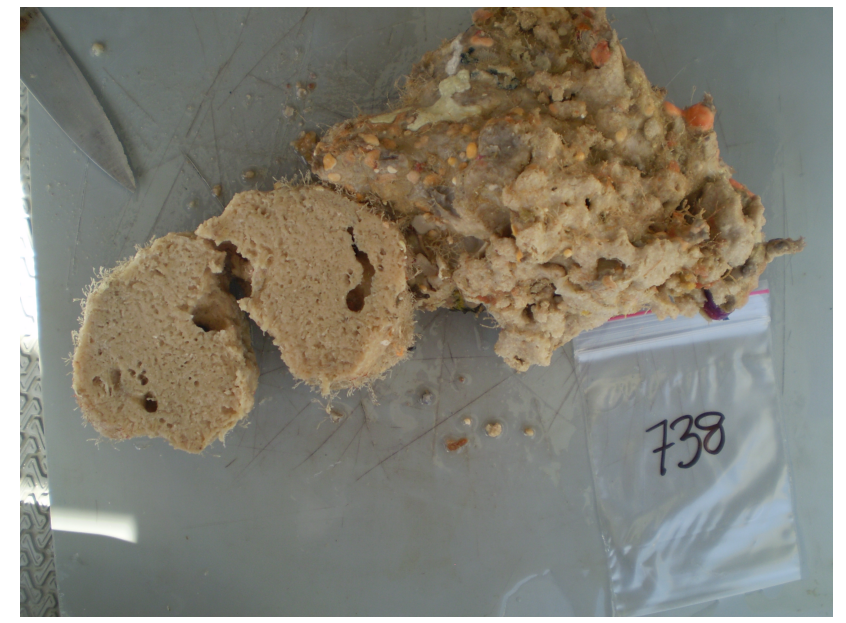

Figure 2.9. Surface photograph of the sponge PTN4_15H.

A massive sponge with a beige coloured exterior and interior (see Figure 2.9) was collected from Sea Fans, Vava'u. The screen NMR spectra of the $75 \% \mathrm{Me}_{2} \mathrm{CO} / \mathrm{H}_{2} \mathrm{O}$ fraction contained resonances largely attributed to oxymethine, oxymethylene, and oxymethyl resonances with a few signals in the aromatic region. Further purification and analysis was discontinued.

\subsection{Organisms Screened from 'Eua Island}

The island of 'Eua is located only $17.5 \mathrm{~km}$ southeast from Tongatapu. Despite its proximity to the main island, 'Eua is geologically unrelated to the rest of the islands. $\underline{50}$ 'Eua is a hilly island but not volcanic. It was formed as a result of a tectonic collision between the Tonga plate and the Pacific plate pushing the island up and leaving the $7 \mathrm{~km}$ Tonga trench on the bottom of the ocean. Two collection trips were made to 'Eua - in late November 2008 and in early June 2016. The combined trips resulted in the collection of more than 170 samples of marine organisms, mostly sponges. 


\subsubsection{PTN3_16F}

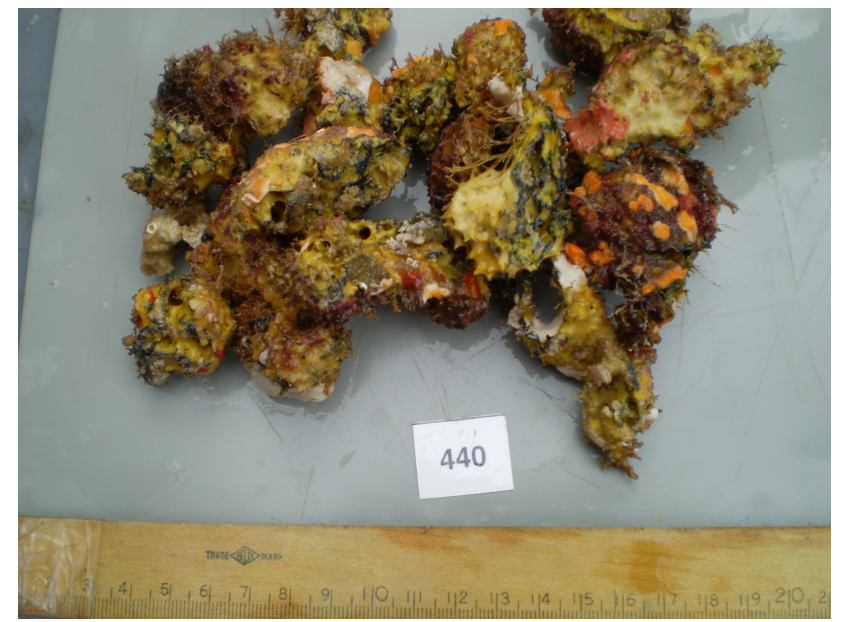

Figure 2.10. Surface photograph of the sponge PTN3_16F.

PTN3_16F (see Figure 2.10) is an unidentified yellowed coloured, rubble-like sponge belonging to the order Verongiida: ${ }^{\text {t }}$ The sponge was collected from the coastline of Houma, 'Eua, November 2008. Marine sponges of the order Verongiida have been noted to be a rich source of bromotyrosine-derived secondary metabolites. $\stackrel{30}{[}$ Initial analysis of the NMR spectra of the $80 \% \mathrm{Me}_{2} \mathrm{CO} / \mathrm{H}_{2} \mathrm{O}$ fraction showed characteristics of a spirocyclooxazoline ring system $\left[\mathrm{CH}-1: \delta_{\mathrm{H}} 4.09, \delta_{\mathrm{C}} 75.4 ; \mathrm{CH}-5: \delta_{\mathrm{H}} 6.43, \delta_{\mathrm{C}} 132.2\right.$; $\left.\mathrm{CH}_{3}-14: \delta_{\mathrm{H}} 3.73, \delta_{\mathrm{C}} 60.4\right]$ and an $\mathrm{AB}$ system $\left[\mathrm{CH}_{2}-7: \delta_{\mathrm{H}} 3.10,3.78 ; \delta_{\mathrm{C}} 40.2\right]-$ a common feature encountered in bromotyrosine-derived compounds from Verongiid sponges. This fraction was further purified on $\mathrm{S} \mathrm{SiO}_{2}$ column followed by reversed-phase C18 HPLC yielded the known compound, aerothionin (50).

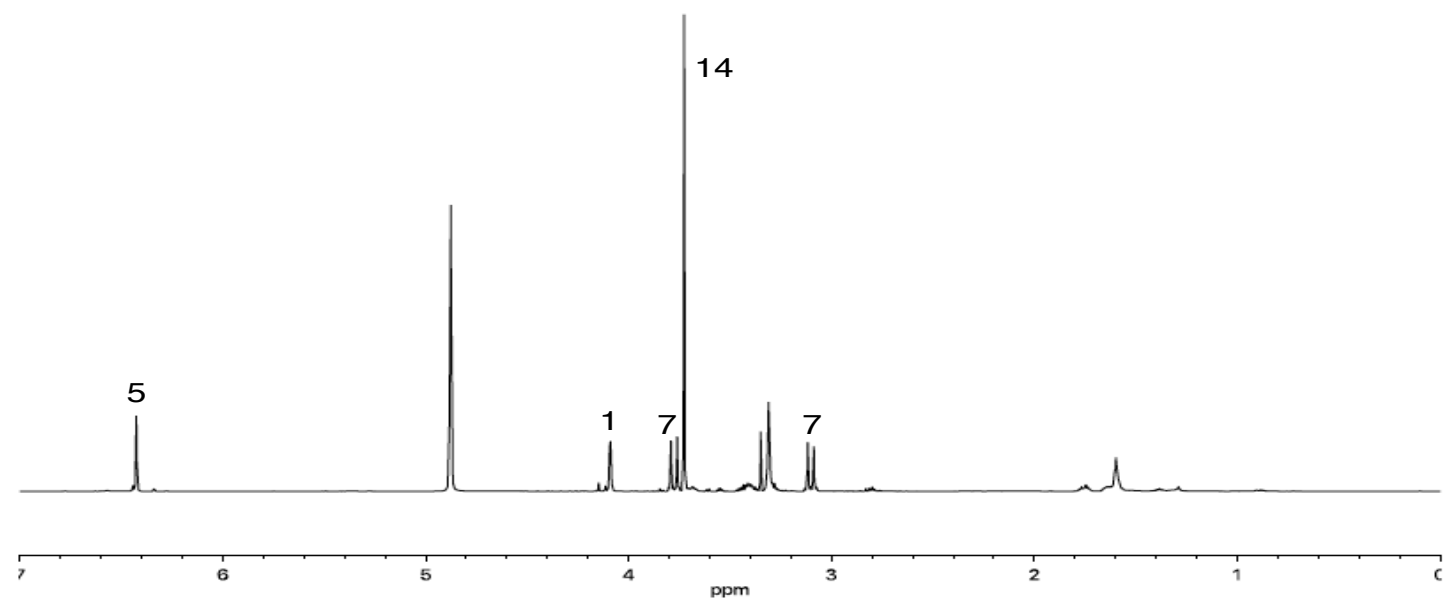

Figure 2.11. ${ }^{1} \mathrm{H} \mathrm{NMR}\left(600 \mathrm{MHz}, \mathrm{CD}_{3} \mathrm{OD}\right)$ spectrum of aerothionin (50).

${ }^{*}$ The sponge was tentatively identified as Verongiid based on its chemical constituents. 
<smiles>COC1=C(Br)C(O)[C@]2(C=C1Br)CC(C(=O)NCCCCNC(=O)C1=NO[C@]3(C=C(Br)C(OC)=C(Br)[C@@H]3O)C1)=NO2</smiles>

\subsubsection{PTN3 21B}

An undescribed massive orange coloured sponge (see Figure 2.12) was collected from an underwater cave on the southwestern of 'Eua, November 2008, and screened in the usual manner. The 1D and 2D-NMR spectra of the $80 \% \mathrm{Me}_{2} \mathrm{CO} / \mathrm{H}_{2} \mathrm{O}$ fraction contained resonances largely attributed to aromatics, oxymethines, oxymethylenes and long alkyl chain regions. This fraction was further purified on a $\mathrm{SiO}_{2}$ column, leading to the identification of a known aromatic sesquiterpene (48). ${ }^{64}$ Further purification and analysis was discontinued.

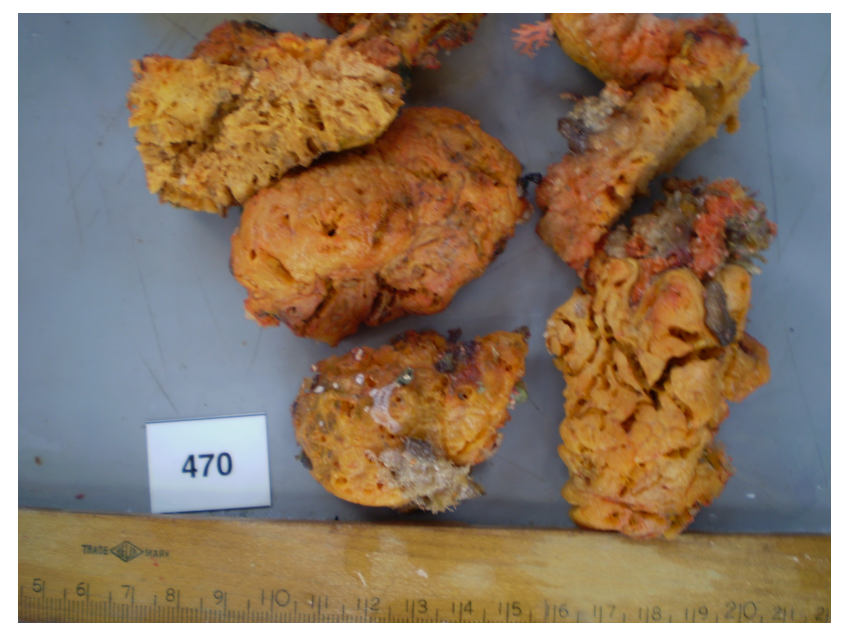

Figure 2.12. Surface photograph of the sponge PTN3_21B.

\subsubsection{PTN4_24E}

PTN4_24E is an unidentified sponge of the genus Fascaplysinopsis (order Dictyoceratida, family Thorectidae) collected from 'Eua, June 2016 (see Figure 2.13). The sponge is massive and has a globular shape with a shiny red-brown appearance. The $30 \%$ and the $75 \% \mathrm{Me}_{2} \mathrm{CO} / \mathrm{H}_{2} \mathrm{O}$ fractions were dominated by one major compound. The ${ }^{1} \mathrm{H}$ NMR spectra (see Figure 2.14) of these fractions were mainly confined to those in the 


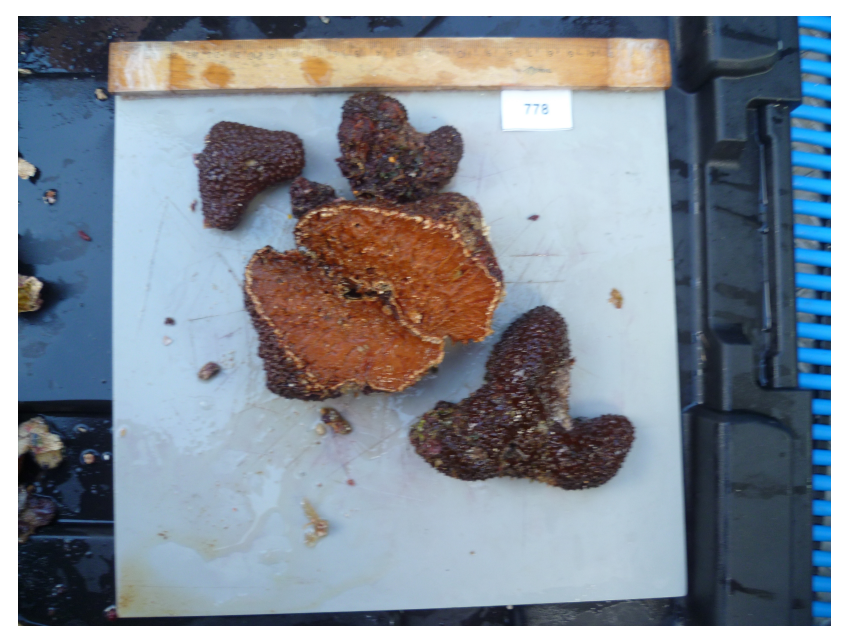

Figure 2.13. Surface photograph of the sponge PTN4_24E.

aromatic/heteroaromatic range between $\delta_{\mathrm{H}} 7.50-9.50$, with little elsewhere. Detailed analysis of the 1D and 2D-NMR spectra of these fractions revealed the major compound as homofascaplysin A (51). ${ }^{67}$ This compound has previously been isolated within this laboratory. ${ }^{68}$ Further investigation was discontinued.
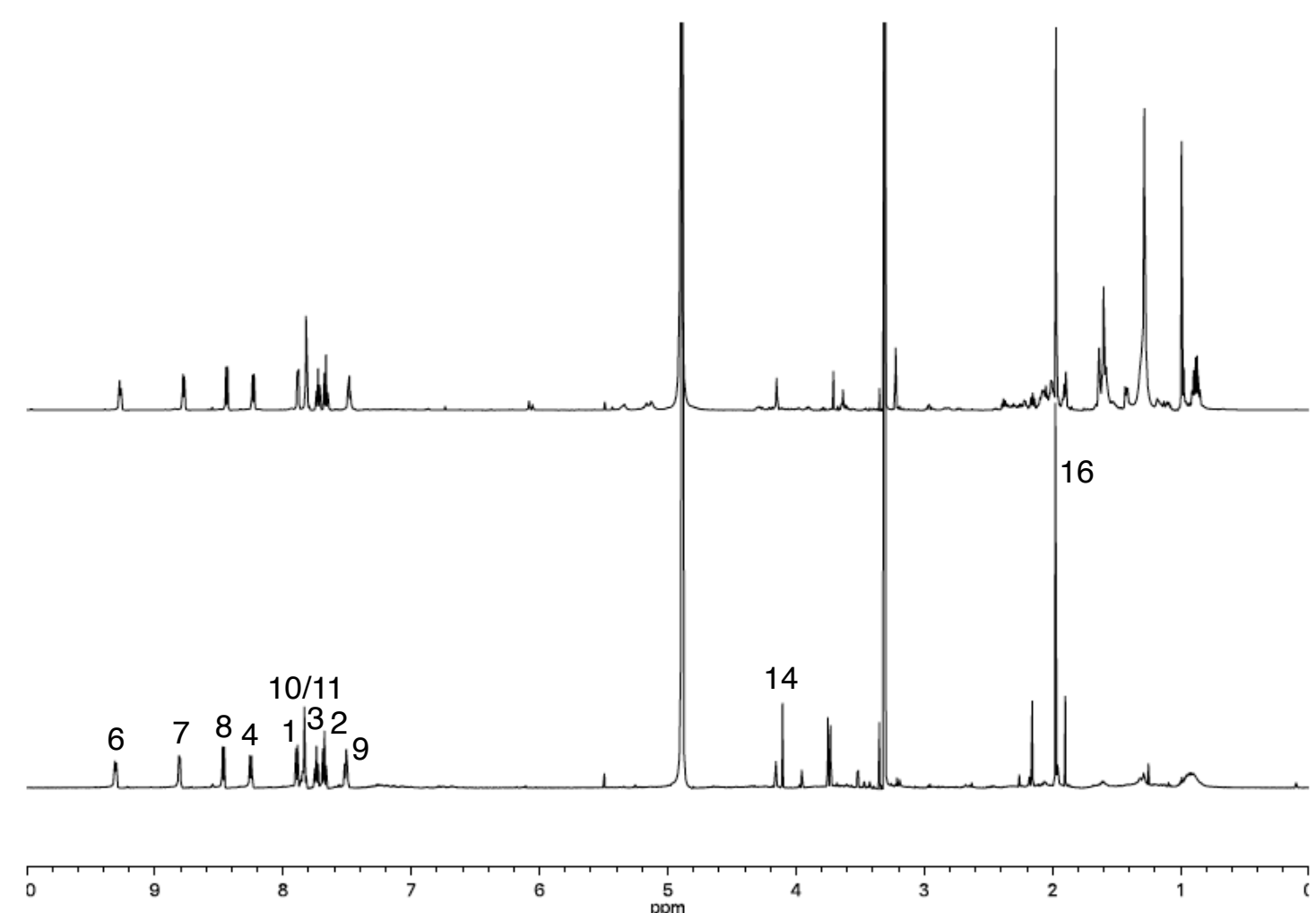

Figure 2.14. ${ }^{1} \mathrm{H}$ NMR $\left(600 \mathrm{MHz}, \mathrm{CD}_{3} \mathrm{OD}\right)$ spectra comparison between the $30 \%$ (bottom) and $75 \% \mathrm{Me}_{2} \mathrm{CO} / \mathrm{H}_{2} \mathrm{O}$ (top) fractions of PTN4_24E. 


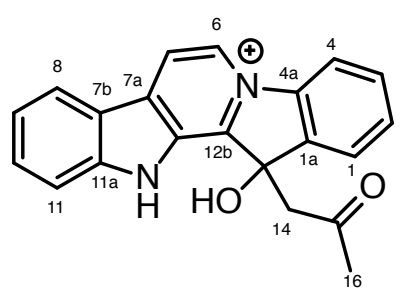

51

\subsubsection{PTN4 26A}

A tan coloured sponge collected from an underwater cave in northern tip of 'Eua, June 2016. The sponge was identified as Cacospongia mycofijiensis and were previously collected from 'Eua and the Vava'u group in 2008 and 2009, respectively. Investigation of the specimen from the two collections by Singh yielded several biologically active compounds including zampanolide. The re-isolation of zampanolide resulted in the discovery of its stabilising activity and initiated several studies towards its mode of action, which prompted interest in re-investigation of this specimen for novel biologically active compounds. The re-collection of $C$. mycofijiensis in 2016 and the results are presented in Chapter 6 .

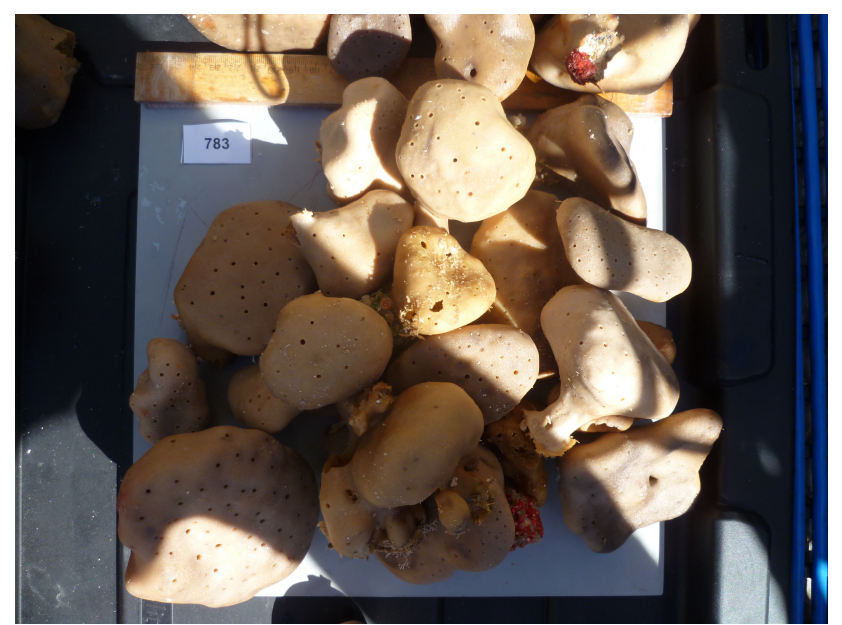

Figure 2.15. Surface photograph of the sponge PTN4_26A.

\subsubsection{PTN4_27B}

PTN4_27B is an unidentified grey Dictyoceratid sponge collected from an underwater cave at the northern tip of 'Eua, June 2016. The screen NMR spectra of the $75 \%$ $\mathrm{Me}_{2} \mathrm{CO} / \mathrm{H}_{2} \mathrm{O}$ contained resonances attributed mainly to aromatics, oxymethyls and 
oxymethines. Further investigation is required but was beyond the scope of this current study.

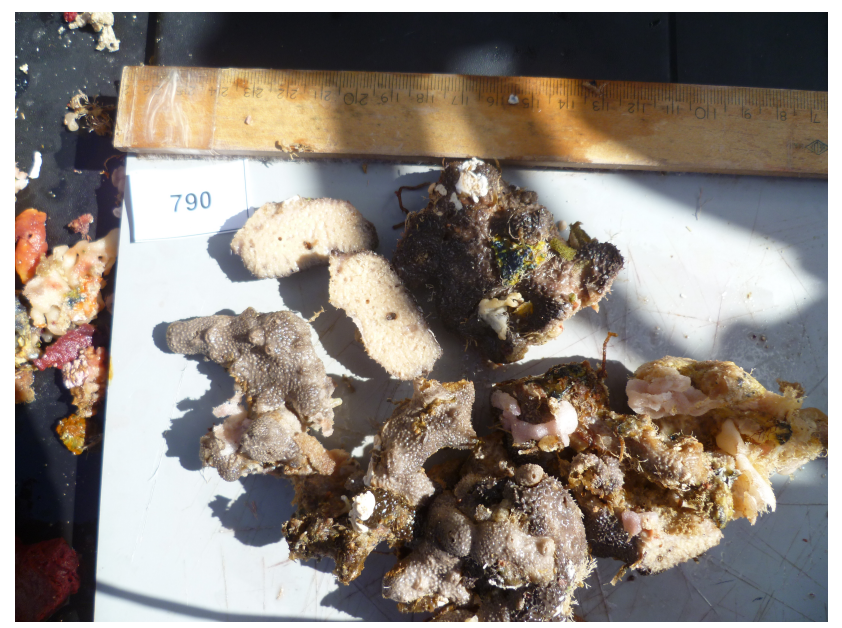

Figure 2.16. Surface photograph of the sponge PTN4_27B.

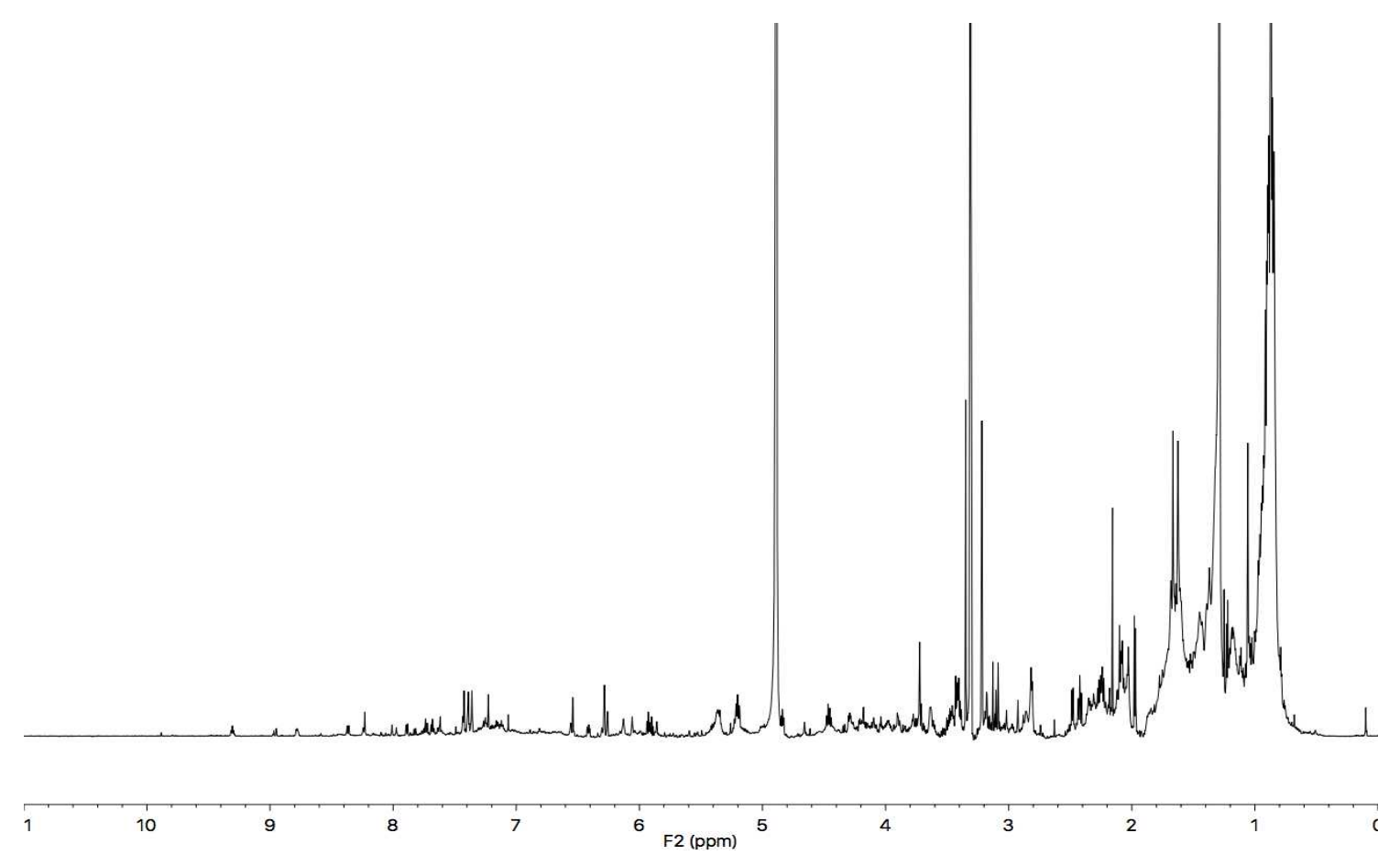

Figure 2.17. ${ }^{1} \mathrm{H}$ NMR $\left(600 \mathrm{MHz}, \mathrm{CD}_{3} \mathrm{OD}\right)$ spectrum of the $75 \% \mathrm{Me}_{2} \mathrm{CO} / \mathrm{H}_{2} \mathrm{O}$ fraction of PTN4_27B.

\subsubsection{PTN4_36B}

A dark brown sponge collected from an underwater cave in southwestern 'Eua, June 2016. The ${ }^{1} \mathrm{H}$ NMR spectrum (see Figure 2.19) of the $30 \% \mathrm{Me}_{2} \mathrm{CO} / \mathrm{H}_{2} \mathrm{O}$ fraction revealed one major compound. The coupling constants of three aromatic protons at $\delta_{\mathrm{H}} 7.15(\mathrm{CH}-5: \mathrm{dd}, J=8.5,1.8 \mathrm{~Hz}), \delta_{\mathrm{H}} 7.49(\mathrm{CH}-7: \mathrm{d}, J=1.8 \mathrm{~Hz})$ and $\delta_{\mathrm{H}} 7.55$ 
(CH-4: d, $J=8.5 \mathrm{~Hz}$ ), were characteristic of a 1,2,4-trisubstituted benzene ring. The remainder of the molecule consisted of an aromatic proton at $\delta_{\mathrm{H}} 7.19\left(\mathrm{CH}-1: \delta_{\mathrm{C}} 126.1\right)$, a deshielded methyl at $\delta_{\mathrm{H}} 3.30\left(\mathrm{CH}_{3}-11: \delta_{\mathrm{C}} 52.7\right.$, integrating for nine equivalent protons), a deshielded methylene at $\delta_{\mathrm{H}} 3.42\left(\mathrm{CH}_{2}-9: \delta_{\mathrm{C}} 24.4\right)$ and a deshielded methine at $\delta_{\mathrm{H}} 3.86$ $\left(\mathrm{CH}-10: \delta_{\mathrm{C}} 80.5\right)$. Further inspection of the 1D and 2D-NMR spectra, as well as HRESIMS analysis of this fraction indicated the presence of the known compound, 6bromohypaphorine (52). ${ }^{69}$ Further investigation of this sponge was discontinued.

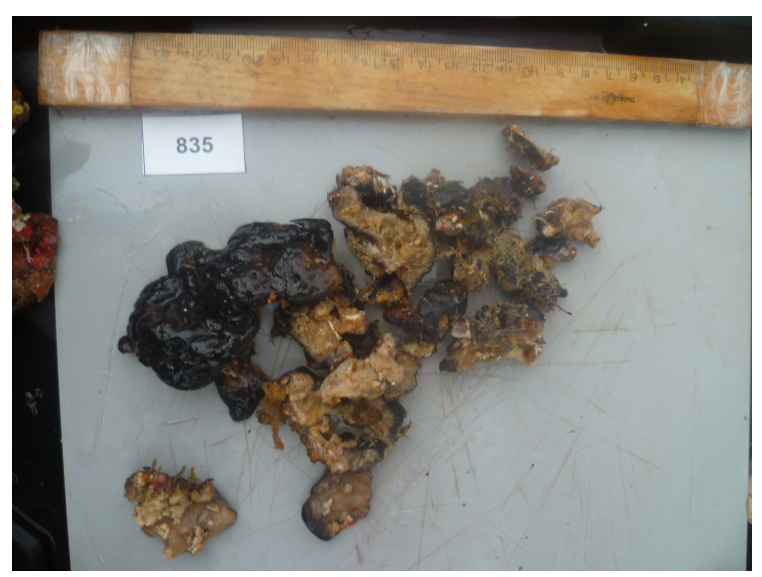

Figure 2.18. Surface photograph of the sponge PTN4_36B.

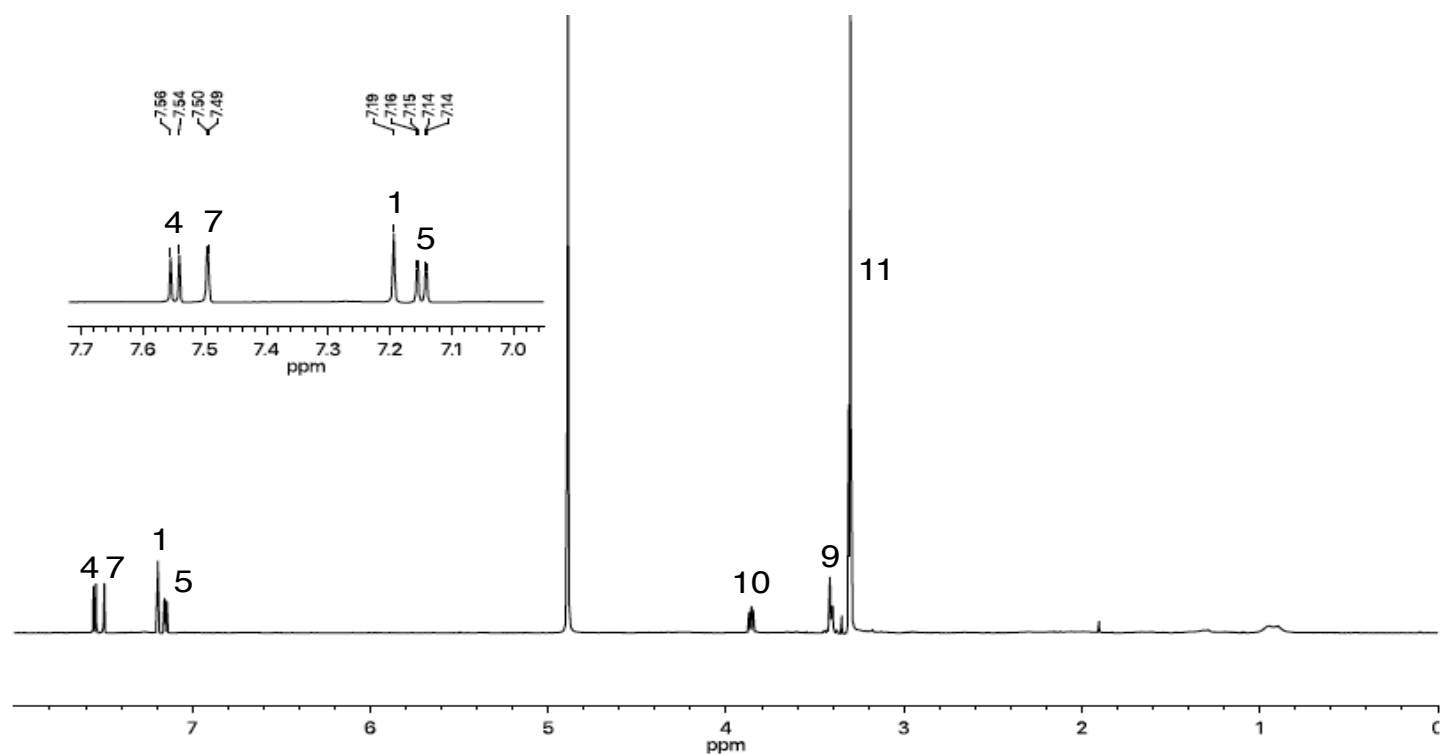

Figure 2.19. ${ }^{1} \mathrm{H}$ NMR (600 MHz, $\left.\mathrm{CD}_{3} \mathrm{OD}\right)$ spectrum of the $30 \% \mathrm{Me}_{2} \mathrm{CO} / \mathrm{H}_{2} \mathrm{O}$ fraction of PTN4_36B. 


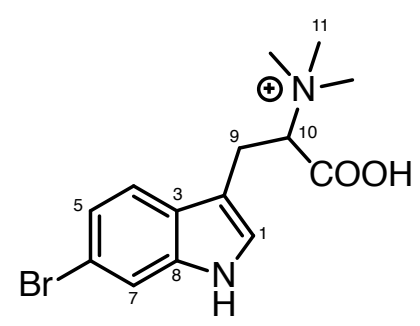

52

\subsubsection{PTN4_38A and PTN4_42E}
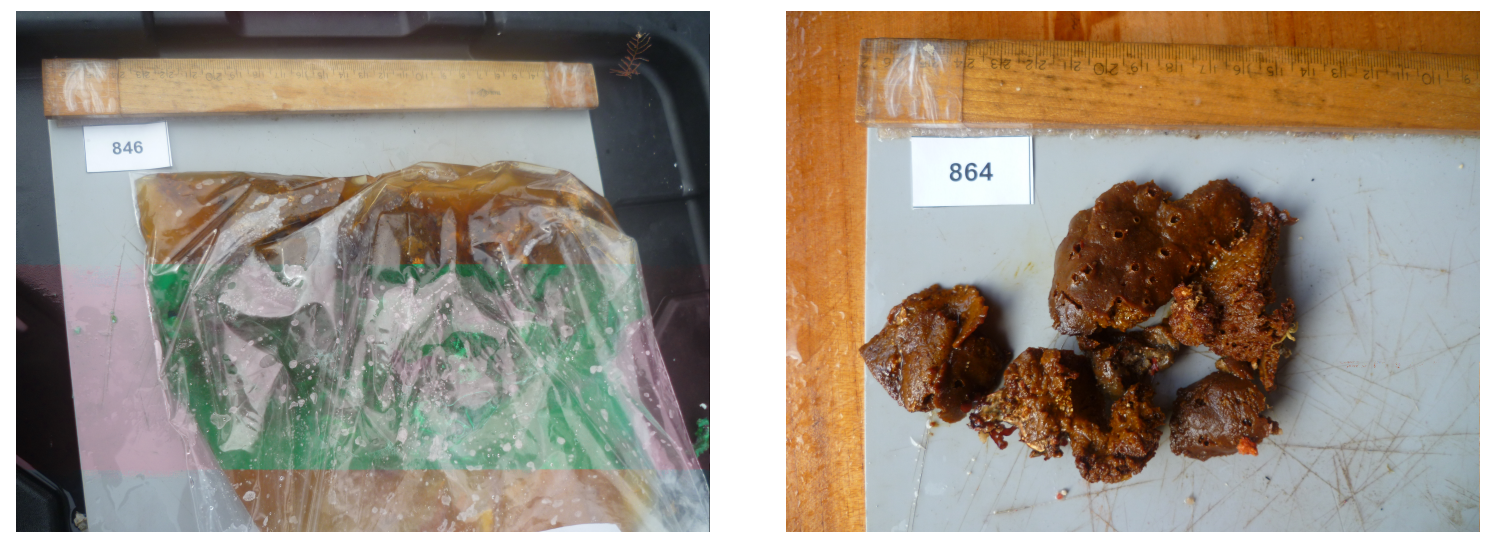

Figure 2.20. Surface photograph of the sponges PTN4_38A (left) and PTN4_42E (right).

The two sponges, PTN4_38A and PTN4_42E were collected from two different locations along the southern coast of 'Eua, June 2016, and were screened independently. The sponge is friable and soft with smooth rounded oscules. The PTN4_38A specimen disintegrated upon collection making the surface photo identification of the sponge difficult. However, the ${ }^{1} \mathrm{H}$ NMR spectra of the screened fractions from the two sponges were similar, therefore indicating the two sponges to be of the same species. The screen ${ }^{1} \mathrm{H}$ NMR spectrum (see Figure 2.21) of the $30 \% \mathrm{Me}_{2} \mathrm{CO} / \mathrm{H}_{2} \mathrm{O}$ for this sponge predominately contained resonances attributable to one compound. Detailed analysis of the 1D and 2D-NMR data with the supporting data from the HRESIMS identified the major compound as halenaquinol sulfate $(\mathbf{5 3}) .{ }^{70}$ The structural elucidation of this compound was difficult due to the proton-deficiency of the fused pentacycle, particularly the connections between the trisubstituted furan and the adjacent $\alpha, \beta$-unsaturated ketone. Further analysis of this sponge was discontinued, however the $75 \% \mathrm{Me}_{2} \mathrm{CO} / \mathrm{H}_{2} \mathrm{O}$ fraction is worthy of further investigation. 


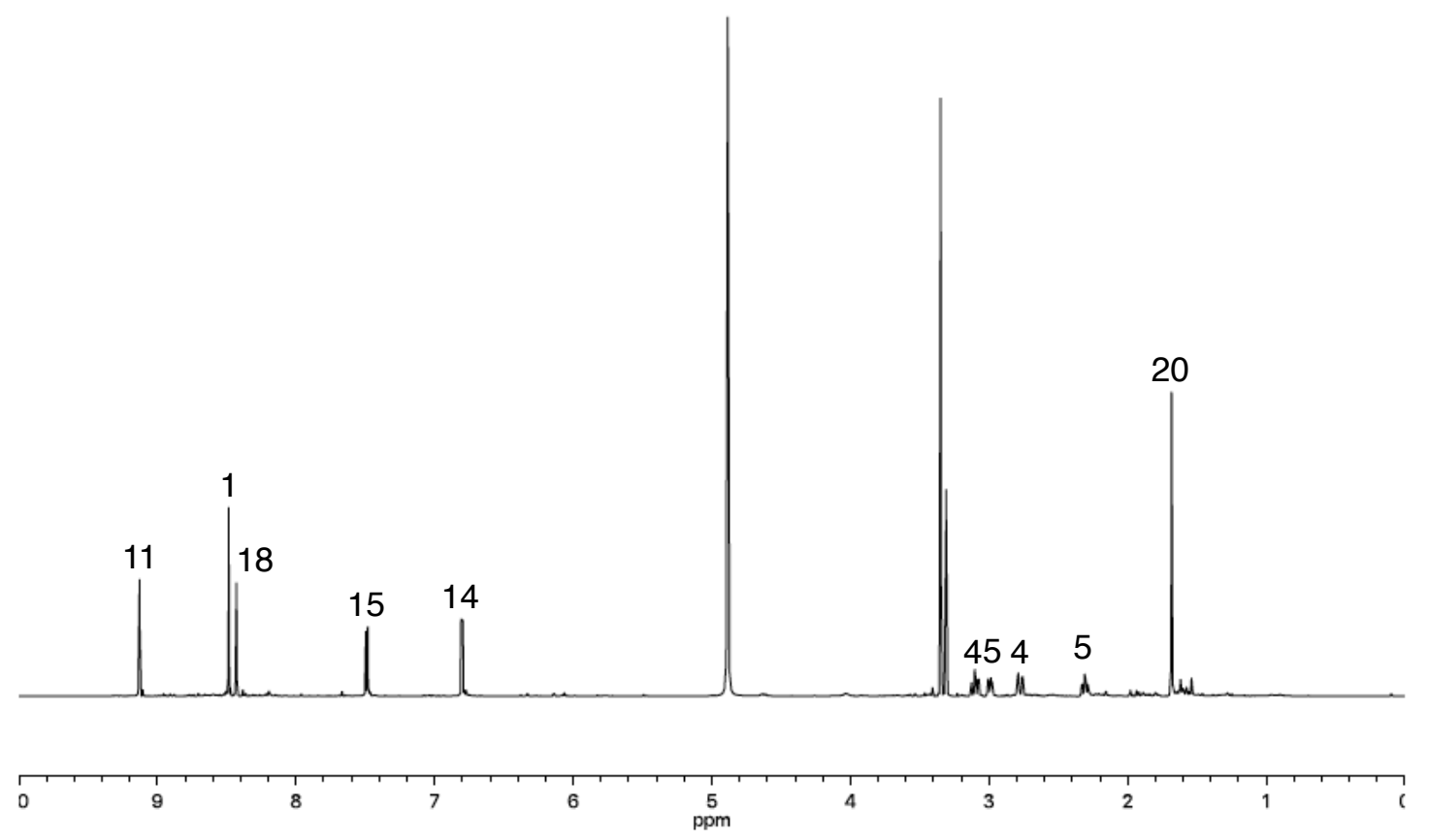

Figure 2.21. ${ }^{1} \mathrm{H} \mathrm{NMR}\left(600 \mathrm{MHz}, \mathrm{CD}_{3} \mathrm{OD}\right)$ spectrum of the $30 \% \mathrm{Me}_{2} \mathrm{CO} / \mathrm{H}_{2} \mathrm{O}$ fraction of PTN4_42E.

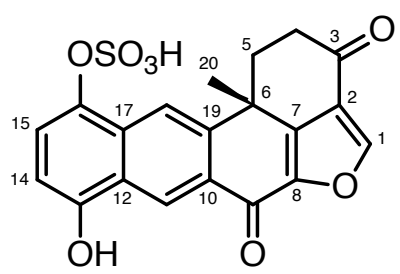

53

\subsubsection{PTN4_39A}

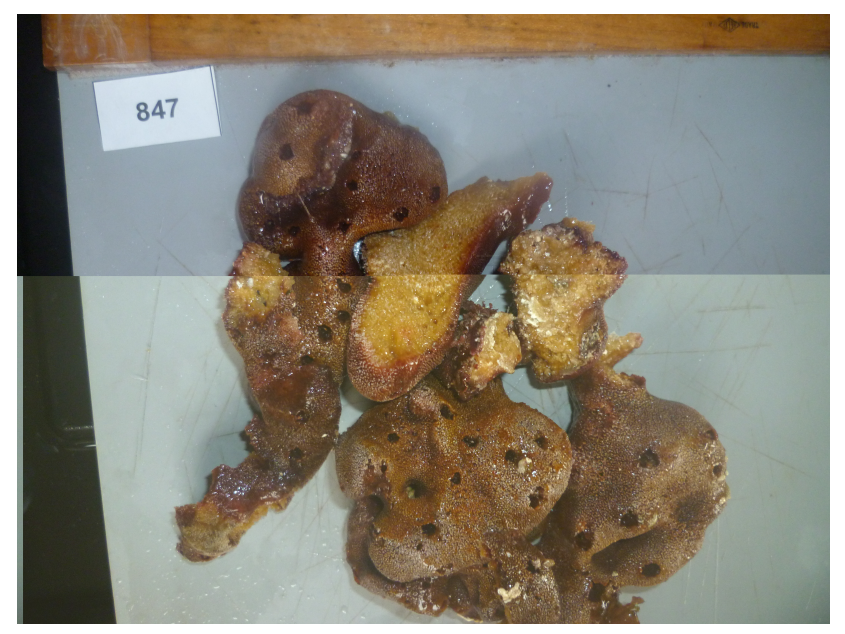

Figure 2.22. Surface photograph of the sponge PTN4_39A.

The brown slimy sponge, PTN4_39A, is an undescribed sponge collected from southern 'Eua, June 2016. The sponge has a soft and smooth texture with rounded oscules. 
The NMR spectra of the screen fractions showed very little in the way of interesting resonances. Further analysis was discontinued.

\subsection{Organisms Screened from New Zealand}

Two sponges examined in this study were collected by NIWA from the Three Kings Islands, New Zealand in 2002. The Three Kings Islands are a group of 13 uninhabited islands, located $55 \mathrm{~km}$ northwest of Cape Reinga, North Island.

\subsubsection{MNP_7031}

A massive orange sponge collected from the Three Kings Islands, North Island, New Zealand. The $1 \mathrm{D}$ and 2D-NMR spectra of the $\mathrm{Me}_{2} \mathrm{CO}$ fraction showed signs of methyl singlets, consistent with steroidal metabolites, in addition to other signs of unsaturation. The isolation and structural elucidation of these compounds is dealt with in Chapter 3 .

\subsubsection{MNP_7119}

MNP_7119 was identified as Cliona celata, a red excavating sponge. The 1D and 2D-NMR spectra of the $30 \% \mathrm{Me}_{2} \mathrm{CO} / \mathrm{H}_{2} \mathrm{O}$ fraction showed interesting resonances attributed to aromatics and also evidence of an amide. This fraction was further purified on a normal phase (DIOL) column followed by reversed-phase C18 HPLC to yield a pure compound. The NMR spectra for this compound showed correlations consistent with an $\alpha, \beta$-unsaturated amide (see Figure 2.23). Unfortunately, the remainder of the molecule remained unclear, after an intense search of the MarinLit database produced no results featuring the partial substructure (see Figure 2.24). In addition, no suitable chemical formula was identified from the analysis of the HRESIMS spectra, preventing the identification of the isolated metabolite..$^{*}$ The possibility of this compound as being

*A possible dimer structure was also proposed, however its molecular formula was not detected on the HRESIMS spectra. 
novel is high, unfortunately it was set aside for further analyse at a later stage.

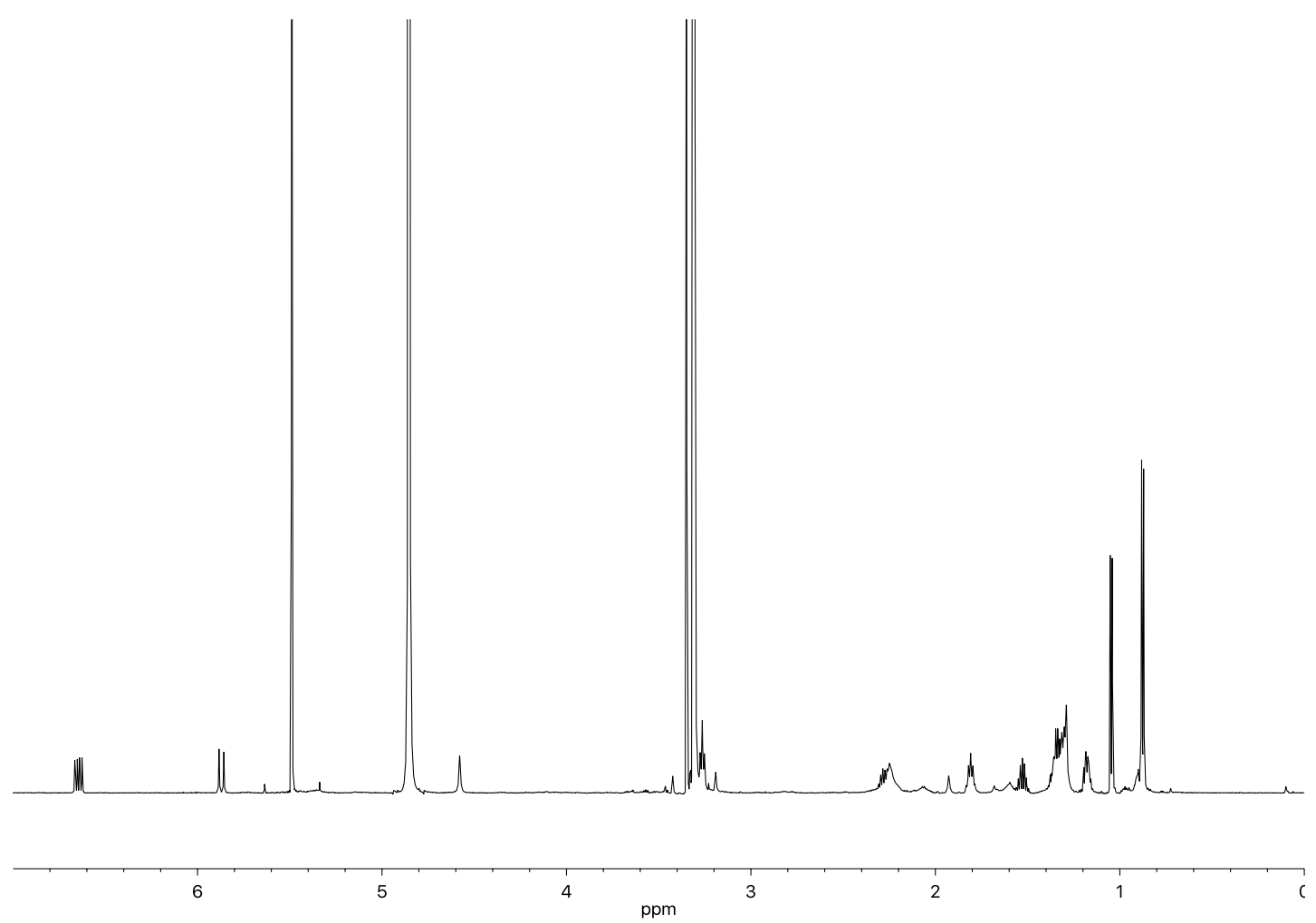

Figure 2.23. ${ }^{1} \mathrm{H}$ NMR $\left(600 \mathrm{MHz}, \mathrm{CD}_{3} \mathrm{OD}\right)$ spectrum of an unknown metabolite from $\mathrm{MNP} \_7119\left(\delta_{\mathrm{H}} 5.30=\mathrm{CH}_{2} \mathrm{Cl}_{2}, \delta_{\mathrm{H}} 4.87=\mathrm{H}_{2} \mathrm{O}\right)$.

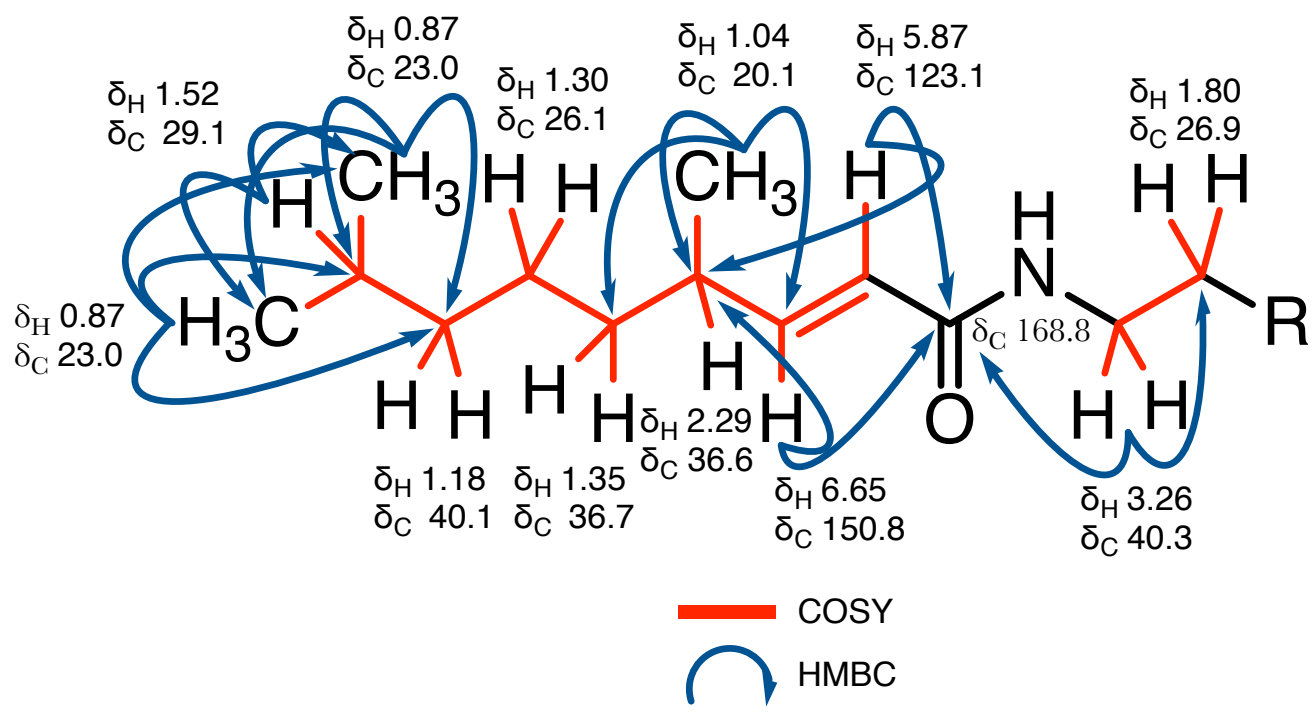

Figure 2.24. Key COSY and HMBC correlations establishing the partial structure of a linear peptide-like metabolite from Cliona celata. 


\section{Chapter 3}

\section{Two New 4-Methylenesterols from a Two-Sponge Association from New Zealand}

Chapter 3 describes the NMR-guided isolation and structure elucidation of two new 4-methylenesterols from a two-sponge association, Stelletta crater and Desmacella dendyi, collected in New Zealand. The sterols are new additions to the 4-methylenesterol family and to the best of the author's knowledge, represent the first secondary metabolites to be reported from either species.

\subsection{Stelletta sp.}

The genus Stelletta is one of 17 currently accepted genera within the family Ancorinidae of the order Tetractinellida (see Table 3.1). Chemical investigations of sponges in this genus have resulted in the isolation of alkaloids, ${ }^{71+73}$ peptides, ${ }^{7475}$ fatty acids, ${ }^{76}$

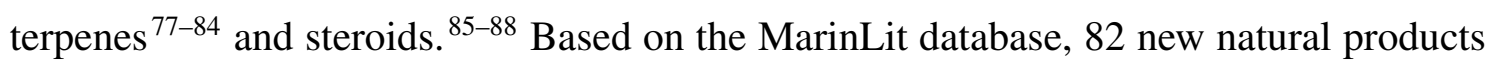
have been isolated from this genus. ${ }^{18}$ While it is beyond the scope of this thesis to account for all of these compounds, this review will be limited to a discussion of isoprene-derived compounds (terpenoids and steroids).

Stellettin A (54) was first reported from a Fijian collection of the sponge Jaspis stellifera ${ }^{77}$ and the Somalian sponge Stelletta sp. ${ }^{78}$ Later, it was obtained together with its $E$ isomer, stelletin B (55), from the sponge S. tenuis collected off Hainan Island, China. ${ }^{79}$ Stellettin A (54) revealed significant cytotoxicity against the murine leukemia P388 cell line with an $\mathrm{IC}_{50}$ value of $2.1 \mathrm{nM} \cdot \frac{79}{70}$ Reported in 1996, bioassay-guided examination of a Stelletta sp. from northern Australia led to the isolation of stellettins C-F (56-59). ${ }^{80}$ Globostellatic acids A-D (60-63) were reported from the Japanese sponge S. globostellata, and were found to exhibit cytotoxicity against the P388 murine leukemia cell with $\mathrm{IC}_{50}$ values of 0.1-0.46 $\mu \mathrm{g} / \mathrm{mL} . \sqrt[89]{ }$ In 2000, 29-hydroxystelliferin D (64), 3-epi-29-hydroxystelliferin A 
Table 3.1. Taxonomic classification of the genus Stelletta from order Tetractinellida as presented by World Porifera Database. 31

\begin{tabular}{|c|c|c|c|}
\hline Order & Sub-Order & Family & Genus \\
\hline Tetractinellida & Astrophorina & Ancorinidae & $\begin{array}{l}\text { Ancorina } \\
\text { Asteropus } \\
\text { Chelotropella } \\
\text { Cryptosyringa } \\
\text { Dercitus } \\
\text { Disyringa } \\
\text { Ecionemia } \\
\text { Geostelletta } \\
\text { Holoxea } \\
\text { Jaspis } \\
\text { Psammastra } \\
\text { Rhabdastrella } \\
\text { Stelletta } \\
\text { Stellettinopsis } \\
\text { Stryphnus } \\
\text { Tethyopsis } \\
\text { Tribrachium }\end{array}$ \\
\hline
\end{tabular}

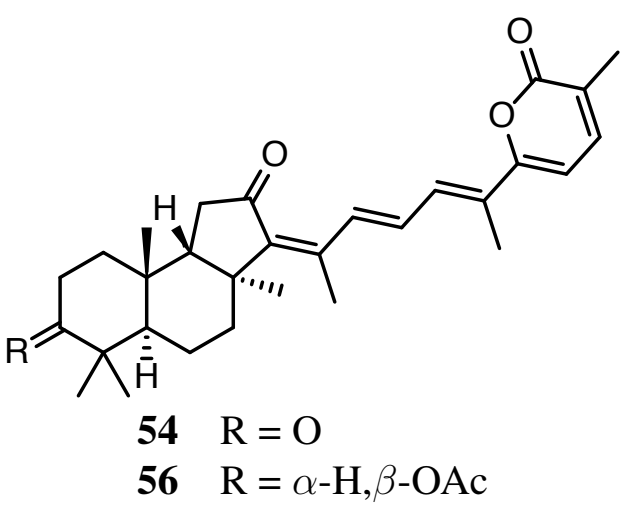

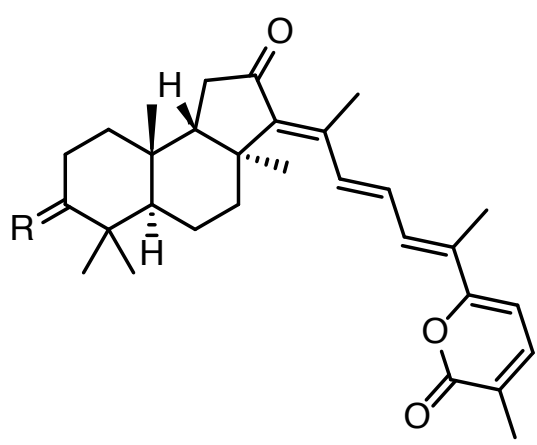

$55 \mathrm{R}=\mathrm{O}$

$57 \quad \mathrm{R}=\alpha-\mathrm{H}, \beta-\mathrm{OAc}$

(65) and 3-epi-29-hydroxystelliferin E (66) were extracted from S. globostellata, and were shown to induce unusual morphological changes in rat fibroblasts. ${ }^{81}$ Two isomalabaricane terpenoids (67 and 68) were isolated from the sponge Stelletta sp. collected from the South China Sea. ${ }^{82}$ Compounds 67 and 68 displayed significant antitumor activity, with respective $\mathrm{ED}_{50}$ values of 0.5 and $1.0 \mu \mathrm{g} / \mathrm{mL}$ against the $\mathrm{P} 388$ tumor cell line. ${ }^{[82}$ From the sponge S. tenuis collected in the South China Sea came stellettins L (69) and M (70). ${ }^{88}$ Stellettin N (71) was reported in 2013 from a Chinese Stelletta sp. ${ }^{83}$ Two years later, stellettins N-P (72-74) were reported from a Chinese specimen of S. tenuis. ${ }^{84}$ Compounds 72: 73 and $\mathbf{7 4}$ demonstrated significant cytotoxicity against AGS (human gastric cancer) cells with $\mathrm{IC}_{50}$ values of $4.52,9.61$ and $7.44 \mu \mathrm{M}$, respectively. $\frac{84}{6}$

\footnotetext{
${ }^{*}$ Compound 72 was also given the name stellettin $\mathrm{N}$.
} 


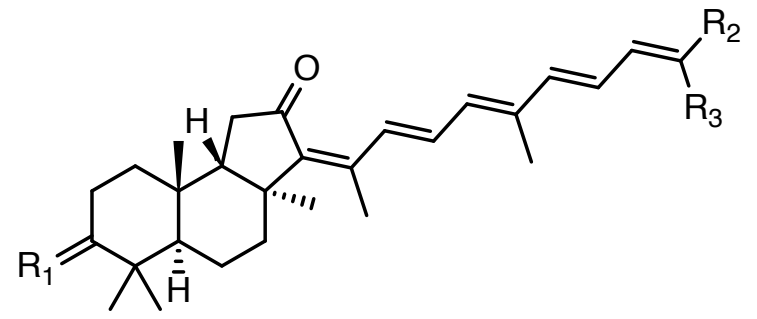

$\begin{array}{llll}\mathbf{5 8} & \mathrm{R}_{1}=\mathrm{O} & \mathrm{R}_{2}=\mathrm{COOH} & \mathrm{R}_{3}=\mathrm{Me} \\ \mathbf{7 0} & \mathrm{R}_{1}=\alpha-\mathrm{H}, \beta-\mathrm{OH} & \mathrm{R}_{2}=\mathrm{COOH} & \mathrm{R}_{3}=\mathrm{Me} \\ \mathbf{6 7} & \mathrm{R}_{1}=\mathrm{O} & \mathrm{R}_{2}=\mathrm{Me} & \mathrm{R}_{3}=\mathrm{COOMe} \\ \mathbf{6 8} & \mathrm{R}_{1}=\alpha-\mathrm{H}, \beta-\mathrm{OAc} & \mathrm{R}_{2}=\mathrm{Me} & \mathrm{R}_{3}=\mathrm{COOMe}\end{array}$

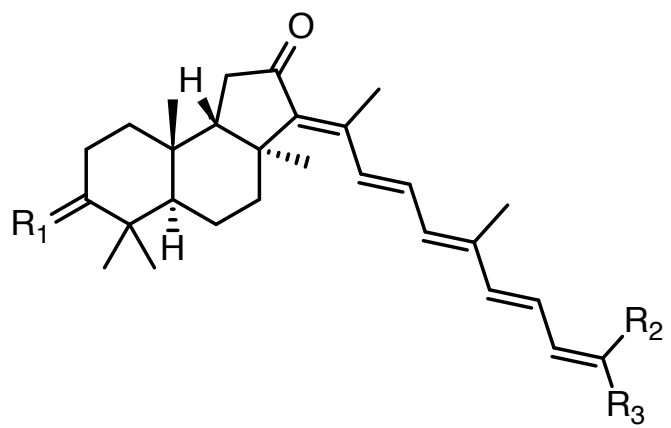

$$
\begin{array}{llll}
\mathbf{5 9} & \mathrm{R}_{1}=\mathrm{O} & \mathrm{R}_{2}=\mathrm{COOH} & \mathrm{R}_{3}=\mathrm{Me} \\
\mathbf{6 9} & \mathrm{R}_{1}=\alpha-\mathrm{H}, \beta-\mathrm{OH} & \mathrm{R}_{2}=\mathrm{Me} & \mathrm{R}_{3}=\mathrm{COOH} \\
\mathbf{7 1} & \mathrm{R}_{1}=\alpha-\mathrm{H}, \beta-\mathrm{OH} & \mathrm{R}_{2}=\mathrm{Me} & \mathrm{R}_{3}=\mathrm{COOH}
\end{array}
$$

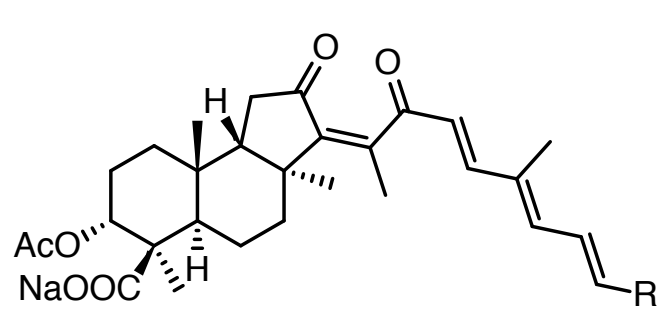

$60 \mathrm{R}=\mathrm{iPr}-\mathrm{OH}$<smiles>[R]C=CC(OC)C(C)=CC=CC(C)=C1C(=O)C[C@@H]2[C@]1(C)CC[C@@H]1[C@]2(C)CC[C@H](C(N)=O)[C@]1(C)C(N)=O</smiles>

$$
61 \mathrm{R}=\mathrm{iPr}-\mathrm{OH}
$$

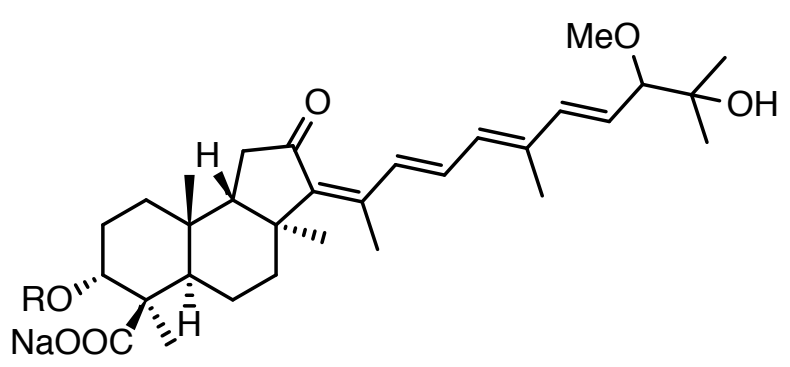

$62 \mathrm{R}=\mathrm{OAc}$

$63 \mathrm{R}=\mathrm{H}$

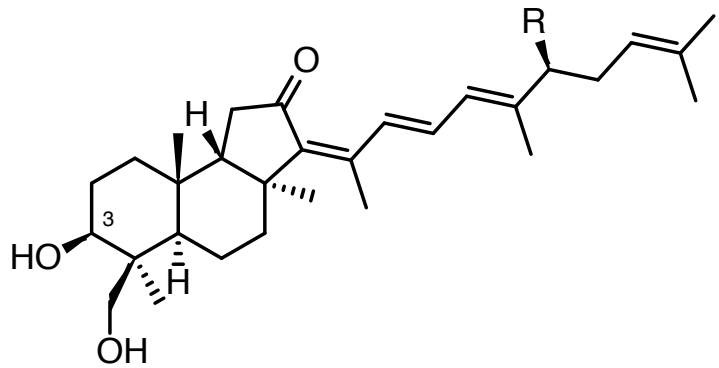

$64 \mathrm{R}=\mathrm{H}$

65 3-ерi $\mathrm{R}=\mathrm{OAc}$

66 3-ерi $\mathrm{R}=\mathrm{OH}$ 


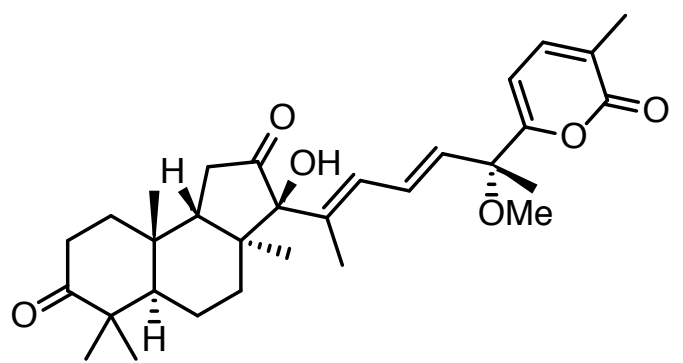

72

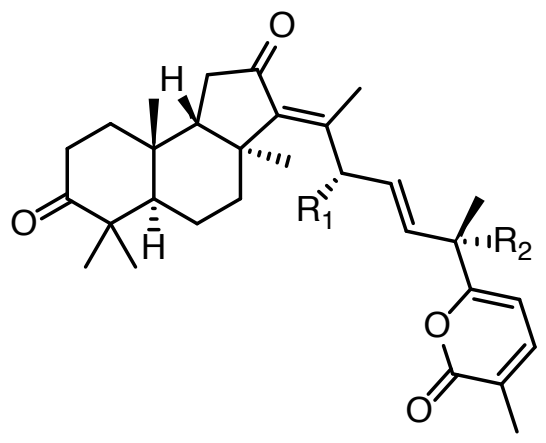

$73 \quad \mathrm{R}_{1}=\mathrm{OH} \quad \mathrm{R}_{2}=\mathrm{OMe}$

$74 \quad \mathrm{R}_{1}=\mathrm{OMe} \quad \mathrm{R}_{2}=\mathrm{OH}$

Sheikh and Djerassi reported eight steroids (75-82) from a Californian collection of the sponge $S$. clarella ${ }^{90}$ Six steroids were obtained (83-88) from a deep-water sponge Stelletta sp. collected from the Coral Sea. $\frac{85}{5}$ Stellettasterol (89), a 9,11-seco-steroid identified from a Japanese specimen Stelletta sp., displayed antifungal activity against Mortieralla ramannianus. ${ }^{86}$ From the sponge $S$. hiwasaensis came orostanal (90), a novel abeo-sterol, which was found to induce apoptosis in HL-60 cells. ${ }^{87}$ Compound 90 was the first example of a 6/5/6/5 fused ring sterol isolated from the marine environment. Three oxygenated sterols (91-93) were reported in 2007 from the sponge $S$. tenuis ${ }^{*}$ collected from the South China Sea. $\frac{88}{}$

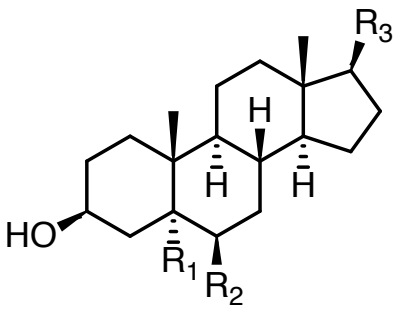

$75 \quad \mathrm{R}_{1}=\mathrm{H}$

$76 \mathrm{R}_{1}=\mathrm{H}$

$77 \quad \mathrm{R}_{1}=\mathrm{H}$

$88 \quad \mathrm{R}_{1}=\mathrm{H}$

$93 \mathrm{R}_{1}=\mathrm{OH}$
$\mathrm{R}_{3}=\mathrm{A}$

$\mathrm{R}_{3}=\mathrm{B}$

$\mathrm{R}_{3}=\mathrm{C}$

$\mathrm{R}_{3}=\mathrm{E}$

$R_{3}=G$

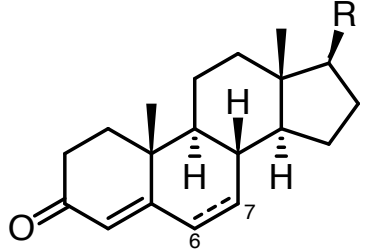

$78 \mathrm{R}=\mathrm{D}$

$79 \mathrm{R}=\mathrm{A} \Delta_{22,23}$

$80 \mathrm{R}=\mathrm{B} \Delta_{22,23}$

$81 \mathrm{R}=\mathrm{A}$

$82 R=B$

$83 \mathrm{R}=\mathrm{E}$

$84 \mathrm{R}=\mathrm{E} \Delta_{6,7}$

*The same Chinese specimen from which they originally isolated stellettins L and M 


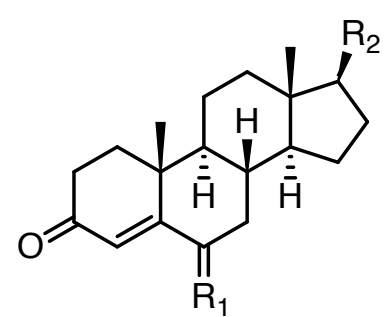

$\begin{array}{lll}\mathbf{8 5} & \mathrm{R}_{1}=\mathrm{O} & \mathrm{R}_{2}=\mathrm{E} \\ \mathbf{8 6} & \mathrm{R}_{1}=\alpha-\mathrm{H}, \beta-\mathrm{OH} & \mathrm{R}_{2}=\mathrm{E}\end{array}$

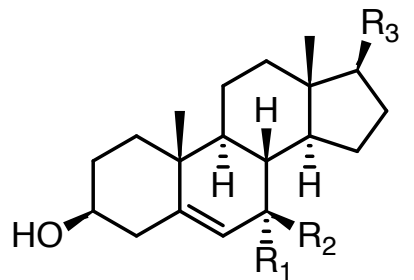

$87 \quad \mathrm{R}_{1}=\mathrm{H} \quad \mathrm{R}_{2}=\mathrm{H} \quad \mathrm{R}_{3}=\mathrm{E}$

$91 \mathrm{R}_{1}=\mathrm{H} \quad \mathrm{R}_{2}=\mathrm{OH} \quad \mathrm{R}_{3}=\mathrm{G}$

$92 \quad \mathrm{R}_{1}=\mathrm{OH} \quad \mathrm{R}_{2}=\mathrm{H} \quad \mathrm{R}_{3}=\mathrm{G}$

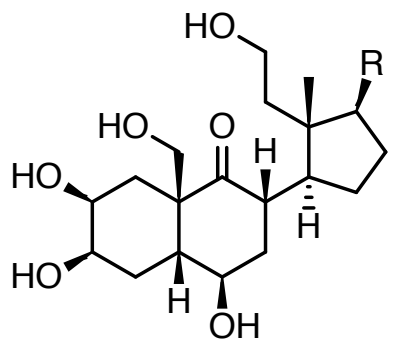

$89 \quad \mathrm{R}=\mathrm{F}$

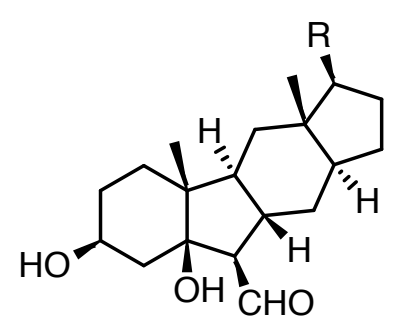

$90 \mathrm{R}=\mathrm{G}$

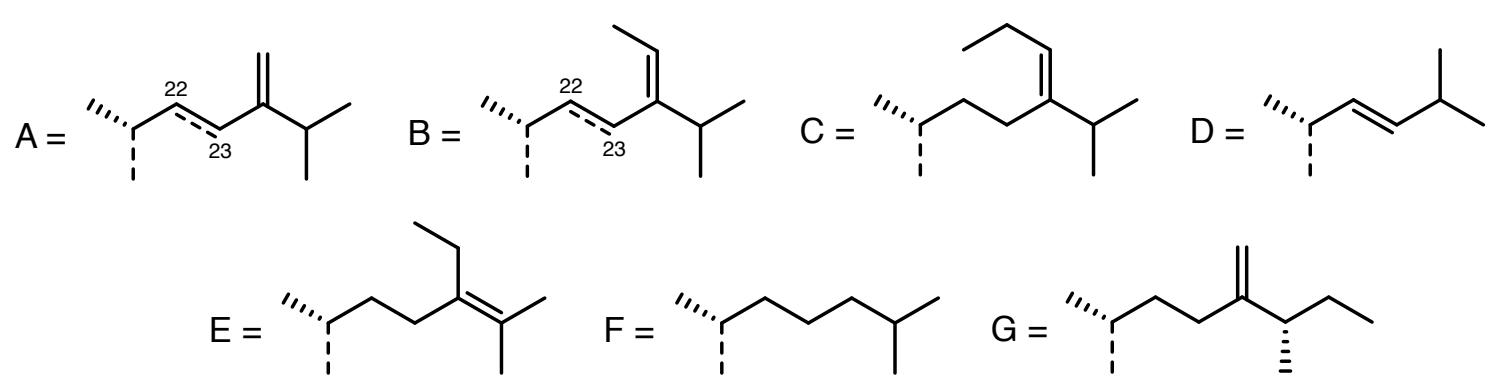




\subsection{Stelletta crater}

Stelletta crater is a bright orange sponge (see Figure 3.1) and is endemic to New Zealand. ${ }^{91}$ The orange dermis is due to the encrusting commensal sponge Desmacella dendyi, however, internally it is white. 91 They are usually found on shaded deep reef slopes that are free of sediment and in caves along the northeastern coastline of the North Island, from North Cape and Spirits Bay to Cook Strait. ${ }^{92|93|}$ The sponge is usually massive with shallow bowl or tall thick cup-like shapes with oscules at the base. They occur individually or as a connected mass up to $30 \mathrm{~cm}$ in diameter, and stand up to $25 \mathrm{~cm}$ in height. ${ }^{91}$ The surface of the sponge has a rough and incompressible texture, with projecting spicules that gives it a whiskery appearance and prickly feel. To the best of the author's knowledge, no secondary metabolites have been reported from these species, S. crater and D. dendyi ${ }^{*}$

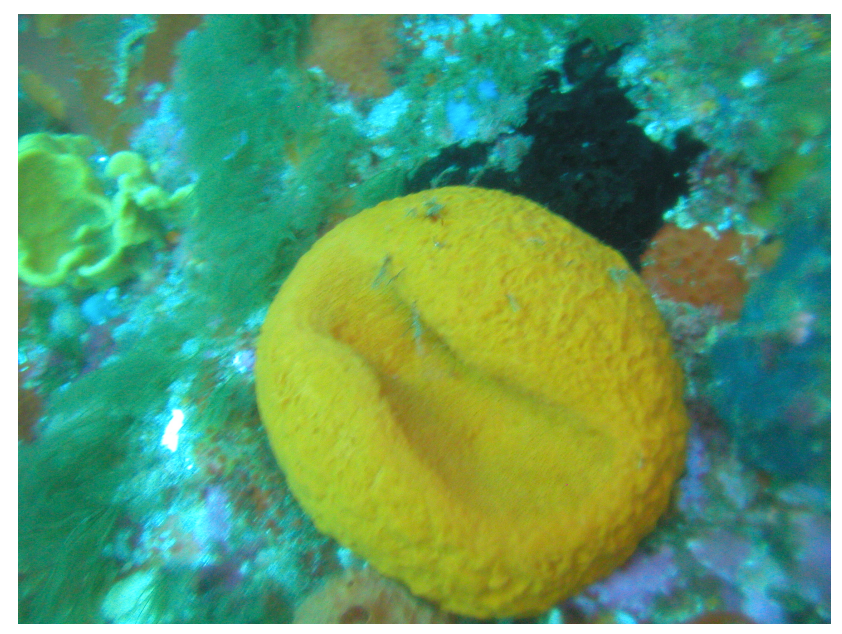

Figure 3.1. Underwater photograph of Stelletta crater, collected from Three Kings Island, New Zealand. Photograph courtesy of Mike Page, NIWA, Marine Natural Products Project.

\subsection{Isolation}

The New Zealand marine sponge Stelletta crater (MNP_7031) was collected by NIWA from the Three Kings Island in 2002. A screen extraction of the sponge was performed (see Scheme 3.1). The methanolic extracts were cyclic loaded onto a reversed-phase

\footnotetext{
* No secondary metabolites have been reported from the sponge of the genus Desmacella.
} 
PSDVB column, and eluted with increasing concentrations of $\mathrm{Me}_{2} \mathrm{CO}$ in $\mathrm{H}_{2} \mathrm{O}$. The $\mathrm{Me}_{2} \mathrm{CO}$ fraction showed interesting features in the NMR spectra, and was further purified on a normal phase $\left(\mathrm{SiO}_{2}\right)$ column eluted with increasing amounts of EtOAc in $\mathrm{CH}_{2} \mathrm{Cl}_{2}$. All the fractions from the $\mathrm{SiO}_{2}$ gel column were combined based on thin layer chromatography (TLC) that clearly displayed relatively good separation. Fractions eluted with $1 \% \mathrm{CH}_{2} \mathrm{Cl}_{2}$ in EtOAc showed distinct purple chars when visualised by sequentially dipping in $5 \%$ methanolic $\mathrm{H}_{2} \mathrm{SO}_{4}$ and $0.1 \%$ vanillin in $\mathrm{EtOH}$, followed by heating. With continued application of heat, the purple chars turned dark brown, which is a characteristic of steroid metabolites. ${ }^{[9495}$ The ${ }^{1} \mathrm{H}$ NMR analysis of this fraction confirmed the presence of a steroid-like compound. However, a comprehensive examination of the 2D-NMR spectra revealed the presence of two structurally related metabolites, not as one pure compound as the TLC and the ${ }^{1} \mathrm{H}$ NMR spectrum suggested (see figure 3.2). Final purification of this fraction was completed by reversed-phase C18 HPLC, resulting in the isolation of two structurally related sterols, named here as craterols A (94) and B (95). *

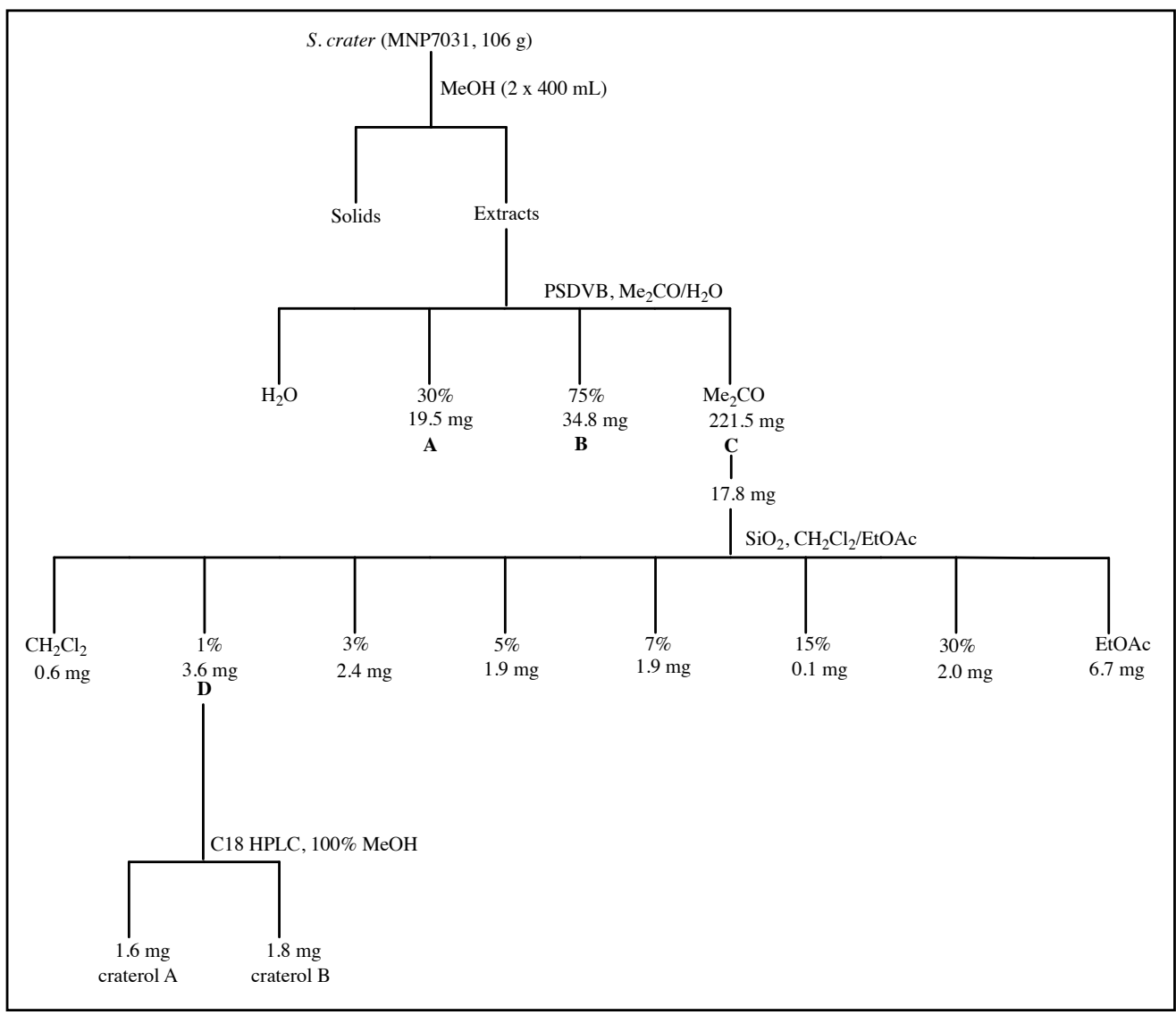

Scheme 3.1. The isolation procedure for compounds from the sponge Stelletta crater, collected from the Three Kings Island, New Zealand.

${ }^{*}$ Subsequent work by Dr. Keyzers confirmed $S$. crater as the source of these compounds. 


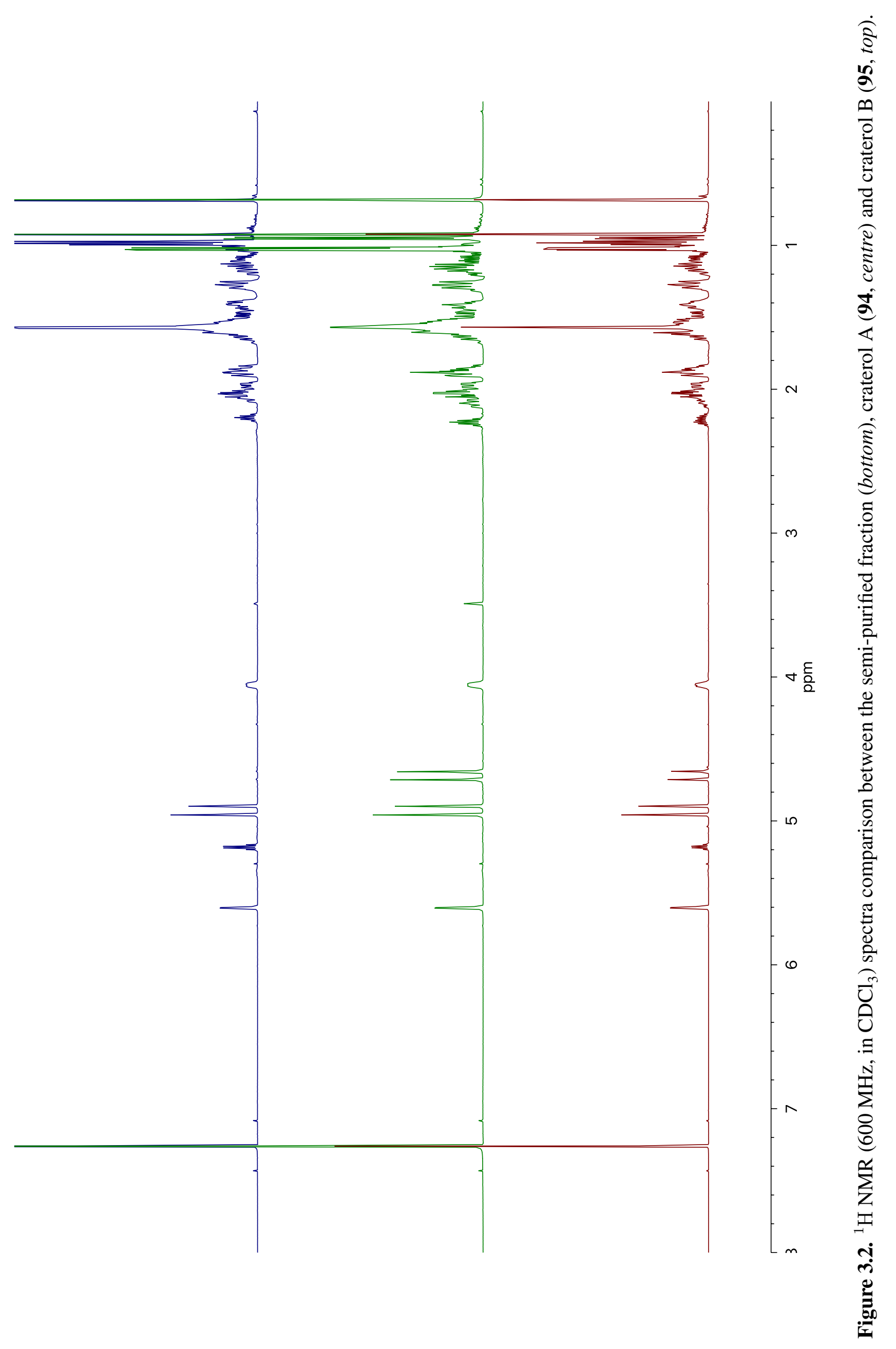




\subsection{Craterol A}

Craterol A (94) was obtained as a white amorphous solid. The HRESIMS spectrum of compound 94 exhibited a protonated ion peak at $m / z 433.3432[\mathrm{M}+\mathrm{Na}]^{+}$ ( $\Delta=-2.08 \mathrm{ppm}$ ), which established a molecular formula of $\mathrm{C}_{29} \mathrm{H}_{46} \mathrm{O}$, implying seven degrees of unsaturation. The ${ }^{13} \mathrm{C}$ NMR spectrum contained 29 signals while the multiplicity-edited HSQC spectrum accounted for 45 of the 46 protons indicating the presence of an exchangeable proton. Since there was only one heteroatom in the molecular formula, it suggested the presence of a hydroxyl functionality. Identifiable features in the NMR spectra included five methyls $\left(\delta_{\mathrm{C}} 22.2 ; 22.0 ; 20.3 ; 18.9 ; 12.0\right)$, nine methylenes $\left(\delta_{\mathrm{C}} 39.9 ; 36.6 ; 34.8 ; 32.2 ; 32.0 ; 31.1 ; 28.4 ; 24.4 ; 21.4\right)$, two methylidenes $\left(\delta_{\mathrm{C}} 106.1 ; 105.5\right)$, six methines $\left(\delta_{\mathrm{C}} 56.8 ; 56.2 ; 49.8 ; 35.9 ; 34.0 ; 31.7\right)$, one oxymethine $\left(\delta_{\mathrm{C}} 73.1\right)$ and one olefinic methine $\left(\delta_{\mathrm{C}} 122.1\right)$. Of the remaining five non-protonated carbons, three were assigned as olefinic carbons $\left(\delta_{\mathrm{C}} 157.0 ; 153.1 ; 145.5\right)$ and two $s p^{3}$ quaternary carbons $\left(\delta_{\mathrm{C}} 42.6 ; 38.0\right)$. With no further evidence of double bonds, a tetracyclic structure was required to account for the remaining four degrees of unsaturation.

Severe resonance overlap in most of the NMR spectra, especially for the majority of the methylene proton resonances, made the structural elucidation of craterol A (94) a challenging task. However the use of HSQC-TOCSY and 1D TOCSY experiments were instrumental in the unambiguous identification of the spin systems in the molecule, as they dispersed any overlapping proton signals in the carbon and proton dimensions, respectively. Examination of correlations in the COSY, 1D TOCSY and HSQC-TOSCY experiments from the well-resolved oxymethine $\mathrm{CH}-3\left(\delta_{\mathrm{H}} 4.06 ; \delta_{\mathrm{C}} 73.1\right)$ and the olefinic methine $\mathrm{CH}-6\left(\delta_{\mathrm{H}} 5.60 ; \delta_{\mathrm{C}} 122.1\right)$ allowed the construction of two separate substructures. COSY correlations between $\mathrm{H}-3$ and methylene $\mathrm{CH}_{2}-2\left(\delta_{\mathrm{H}} 1.54,1.97 ; \delta_{\mathrm{C}} 32.0\right)$, and between $\mathrm{H}_{2}-2$ and methylene $\mathrm{CH}_{2}-1\left(\delta_{\mathrm{H}} 1.28,1.89 ; \delta_{\mathrm{C}} 36.6\right)$ established the connection from C-1 to C-3. This linkage was supported by the correlations between the proton resonances of $\mathrm{H}-3$ and $\mathrm{H}_{2}-1$ in the 1D TOCSY experiment, in addition to the series of HSQC-TOCSY experiments where $\mathrm{H}_{2}-1$ showed TOCSY correlations to the proton 
resonances of C-2 and C-3, thereby reinforcing this proposition. In the HSQC-TOCSY experiment, a correlation observed from $\mathrm{H}-3$ to the methylidene carbon $\mathrm{CH}_{2}-29\left(\delta_{\mathrm{H}} 4.90\right.$, $\left.4.96 ; \delta_{\mathrm{C}} 105.7\right)$ together with an HMBC correlation to a non-protonated carbon $\mathrm{C}-4$ $\left(\delta_{\mathrm{C}} 153.1\right)$ placed a double bond adjacent to the substructure. COSY correlations between H-3 and $\mathrm{H}_{2}-29$ confirmed the placement of the methylidene group, thus establishing the first fragment. Similarly, a series of sequential COSY correlations were also observed from the olefinic methine $\mathrm{H}-6$ to an allylic methylene $\mathrm{CH}_{2}-7\left(\delta_{\mathrm{H}} 1.62,2.03 ; \delta_{\mathrm{C}} 32.2\right)$, from $\mathrm{H}_{2}-7$ to a methine $\mathrm{CH}-8\left(\delta_{\mathrm{H}} 1.48 ; \delta_{\mathrm{C}} 31.7\right)$, and from $\mathrm{H}-8$ to a methine $\mathrm{CH}-9\left(\delta_{\mathrm{H}} 1.01\right.$; $\delta_{\mathrm{C}} 49.8$ ) establishing the connection between C-6 to C-9. Selective excitation of H-6 in a 1D TOCSY experiment confirmed the connection between these protonated centres. The connection between C-4 to C-6 was established through HMBC correlations from $\mathrm{H}_{2}-29$ and H-6 to the non-protonated olefinic carbon C-5 $\left(\delta_{\mathrm{C}} 145.5\right)$ and C-4 respectively, establishing a 1,3-diene unit. This connection was further confirmed by the strong HMBC correlations from the methyl singlet $\mathrm{CH}_{3}-19\left(\delta_{\mathrm{H}} 0.92 ; \delta_{\mathrm{C}} 20.3\right)$ to four different carbons including C-1, C-5, C-9 and the $s p^{3}$ quaternary carbon C-10 ( $\left.\delta_{\mathrm{C}} 38.0\right)$, and completed rings $\mathrm{A}$ and $\mathrm{B}$ (see Figure 3.3 .
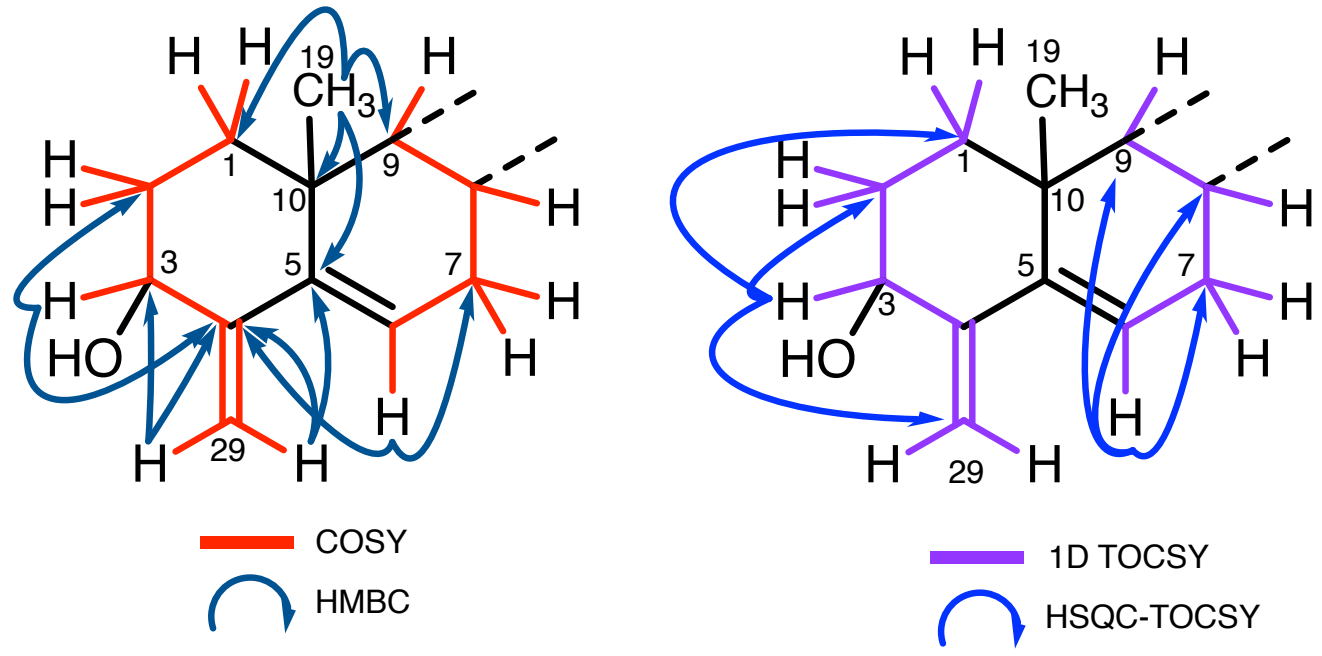

Figure 3.3. Key COSY, HMBC, $1 \mathrm{D}$ TOCSY and HSQC-TOCSY correlations establishing rings $\mathrm{A}$ and $\mathrm{B}$ of craterol A (94).

The second substructure was extended from the first substructure by a series of COSY correlations between $\mathrm{H}-9$ and two contiguous methylenes $\mathrm{CH}_{2}-11\left(\delta_{\mathrm{H}} 1.43,1.52 ; \delta_{\mathrm{C}} 21.4\right)$ and $\mathrm{CH}_{2}-12\left(\delta_{\mathrm{H}} 1.18,2.02 ; \delta_{\mathrm{C}} 39.9\right)$. This linkage was supported by HSQC-TOCSY correlations from $\mathrm{H}-9$ to the proton resonances of $\mathrm{C}-11$ and $\mathrm{C}-12$ as observed sequentially 
with increasing spin-lock mixing times (30 to $150 \mathrm{~ms}$ ). On the other side, the fragment was extended from $\mathrm{CH}-8$ through a series of sequential COSY correlations which consisted of a chain of a methine $\mathrm{CH}-14\left(\delta_{\mathrm{H}} 1.03 ; \delta_{\mathrm{C}} 56.8\right)$, two contiguous methylenes $\left[\mathrm{CH}_{2}-15\left(\delta_{\mathrm{H}} 1.07,1.59 ; \delta_{\mathrm{C}} 24.4\right), \mathrm{CH}_{2}-16\left(\delta_{\mathrm{H}} 1.29,1.86 ; \delta_{\mathrm{C}} 28.4\right)\right]$ and a methine $\mathrm{CH}-17$ $\left(\delta_{\mathrm{H}} 1.14 ; \delta_{\mathrm{C}} 56.2\right)$. Again, this connectivity was confirmed through observed correlations from $\mathrm{H}-8$ to $\mathrm{H}-14, \mathrm{H}_{2}-15, \mathrm{H}_{2}-16$ and $\mathrm{H}-17$ in the HSQC-TOCSY experiment over mixing times of $30 \mathrm{~ms}$ to $150 \mathrm{~ms}$. The methyl singlet $\mathrm{CH}_{3}-18\left(\delta_{\mathrm{H}} 0.68 ; \delta_{\mathrm{C}} 12.0\right)$ showed strong HMBC correlations to C-12, C-14, C-17, and the $s p^{3}$ quaternary carbon C-13 $\left(\delta_{\mathrm{C}} 42.6\right)$. These observed correlations allowed the placement of $\mathrm{CH}_{3}-18$ and established the C/D ring fusion and the tetracyclic moiety (see Figure 3.4).
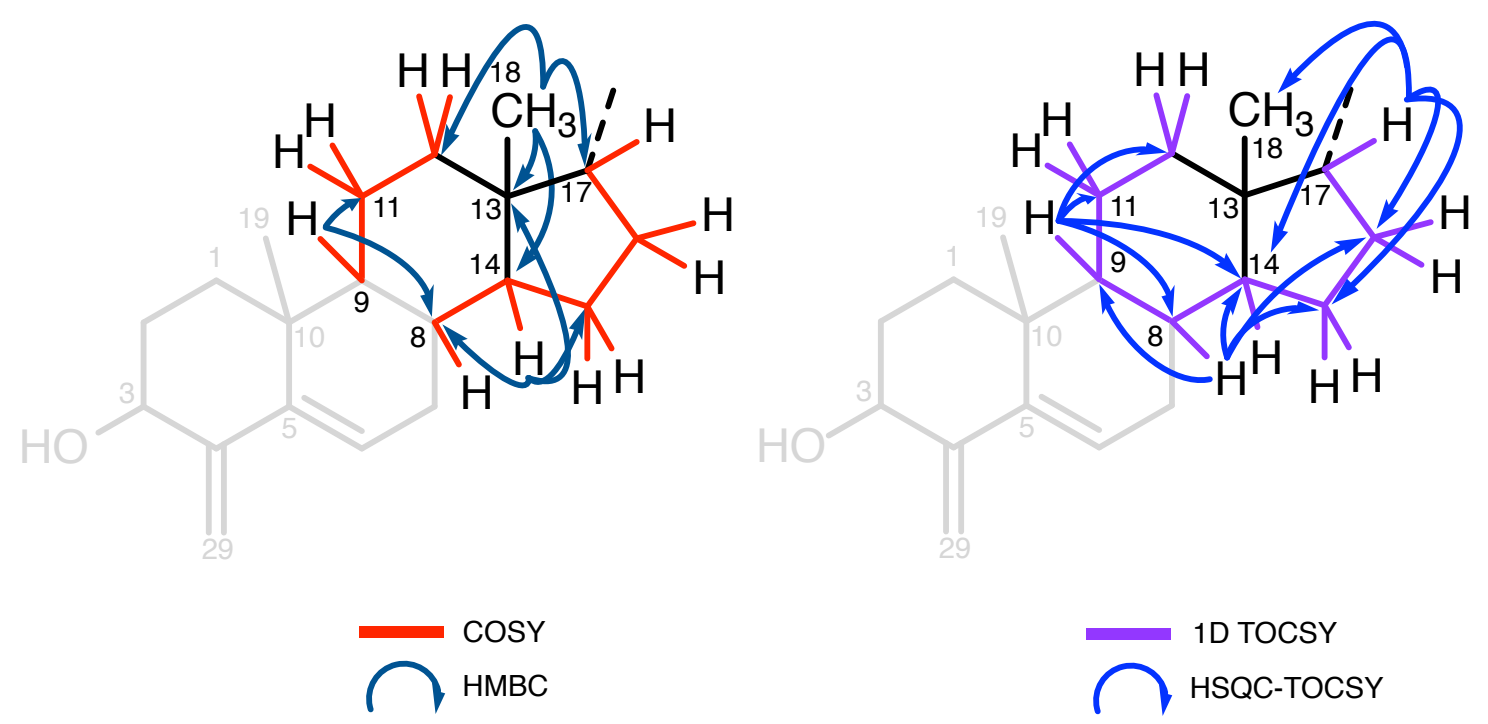

Figure 3.4. Key COSY, HMBC, 1D TOCSY and HSQC-TOCSY correlations establishing rings $\mathrm{C}$ and $\mathrm{D}$ of craterol $\mathrm{A}(\mathbf{9 4})$.

The final substructure was constructed through HMBC correlations from the methyl doublet $\mathrm{CH}_{3}-21\left(\delta_{\mathrm{H}} 0.95 ; \delta_{\mathrm{C}} 18.9\right)$ to the methylene $\mathrm{CH}_{2}-22\left(\delta_{\mathrm{H}} 1.15,1.54 ; \delta_{\mathrm{C}} 34.8\right)$, methine $\mathrm{CH}-20\left(\delta_{\mathrm{H}} 1.41 ; \delta_{\mathrm{C}} 35.9\right)$ and $\mathrm{CH}-17$, establishing the connection of the side at C-17. COSY, 1D TOCSY and HSQC-TOCSY correlations observed between the proton resonances of $\mathrm{H}-20, \mathrm{H}_{3}-21$ and $\mathrm{H}-17$ confirmed this assignment. The methylene protons of $\mathrm{H}_{2}-22$ and the allylic methylene $\mathrm{CH}_{2}-23\left(\delta_{\mathrm{H}} 1.88,2.09 ; \delta_{\mathrm{C}} 31.1\right)$ showed COSY correlations to each other and HMBC correlations to C-23 and C-22 respectively, extending the fragment. The two methyl doublets $\mathrm{CH}_{3}-26\left(\delta_{\mathrm{H}} 1.02 ; \delta_{\mathrm{C}} 22.2\right)$ and $\mathrm{CH}_{3}-27$ $\left(\delta_{\mathrm{H}} 1.03 ; \delta_{\mathrm{C}} 22.0\right)$ showed strong HMBC correlations to an allylic methine $\mathrm{CH}-25$ $\left(\delta_{\mathrm{H}} 2.22 ; \delta_{\mathrm{C}} 34.0\right)$ and also to each other, establishing a terminal isopropyl unit. HMBC 
correlations from the methylidene $\mathrm{CH}_{2}-28\left(\delta_{\mathrm{H}} 4.41,4.66 ; \delta_{\mathrm{C}} 106.1\right)$ to the non-protonated olefinic carbon C-24 ( $\left.\delta_{\mathrm{C}} 157.0\right), \mathrm{C}-23$ and C-25 connected the two fragments together. With all carbons and degrees of unsaturation accounted for, this provided the completed planar structure of craterol A as shown in Figure 3.5 .
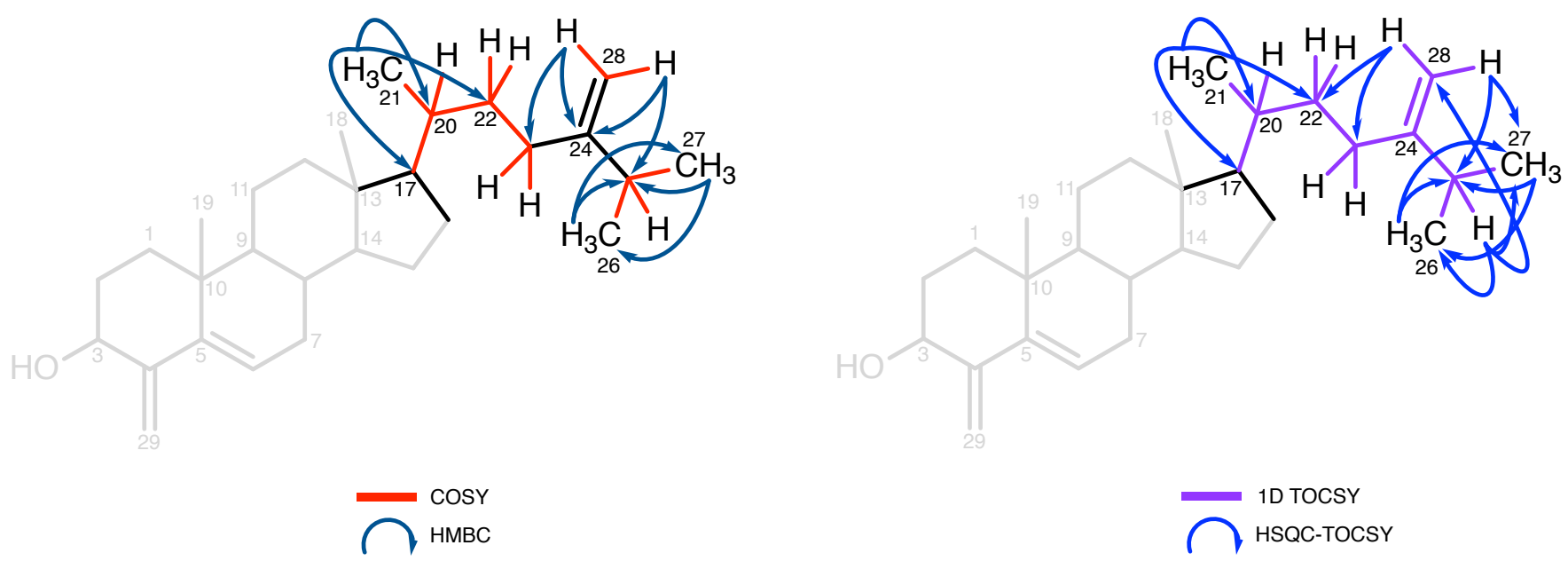

Figure 3.5. Key COSY, HMBC, 1D TOCSY and HSQC-TOCSY correlations establishing rings the side chain moiety of craterol A (94).

The relative configuration of craterol A (94) was established mainly from the NOE correlations from a 2D NOESY experiment (see Figure 3.6). There are eight stereogenic centres to consider; $\mathrm{CH}-3, \mathrm{CH}-8, \mathrm{CH}-9, \mathrm{C}-10, \mathrm{C}-13, \mathrm{CH}-14, \mathrm{CH}-17$ and $\mathrm{CH}-20$. A strong NOE correlation between the methyl proton resonances of $\mathrm{H}_{3}-19$ and $\mathrm{H}-8$ was observed in the NOESY spectrum. The proton resonance of H-8 also shared a 1,3-diaxial NOESY correlation to the other tertiary angular methyl $\mathrm{H}_{3}-18$, suggesting that $\mathrm{H}-8$ is also on the same face as the two methyls $\mathrm{CH}_{3}-18$ and $\mathrm{CH}_{3}-19$. As a result, both methyls $\mathrm{CH}_{3}-18$ and $\mathrm{CH}_{3}-19$ and the methine $\mathrm{CH}-8$ were assigned on the $\beta$ side of the molecule based on the observed NOE correlations between these proton resonances. The proton resonance of $\mathrm{H}-8$ showed no NOE correlation to the methine proton resonance of $\mathrm{H}-9$, consistent with the standard steroid trans $\mathrm{A} / \mathrm{B} / \mathrm{C}$ ring fusions. This assignment was supported by the strong 1,3 diaxial NOE correlation between $\mathrm{H}-9$ and the $\mathrm{H}-1 \alpha$. Subsequently, a 1,3-diaxial correlation between $\mathrm{H}-1 \alpha$ and the oxymethine proton resonance of $\mathrm{H}-3$ was observed in the NOESY experiment. Consequently the hydroxyl group attached to C-3 was assigned as $\beta$ (equatorial) and H-3 as $\alpha$ (axial). Further analysis of the NOESY spectrum showed an additional NOE correlation from $\mathrm{H}_{3}-18$ to the proton resonance of $\mathrm{H}-20$, allowing the placement of the side-chain of craterol $\mathrm{A}$ on the $\beta$ face of the molecule. This was 
consistent with majority of the steroids as they normally possess a trans $\mathrm{C} / \mathrm{D}$ ring fusion. This assignment was further supported by a strong NOE correlation between $\mathrm{H}-14$ and $\mathrm{H}-17$ (anti-periplanar relationship to $\mathrm{H}-20$ ), indicating these protons to be on the $\alpha$ side of the molecule. Assuming standard steroidal configuration, the molecule can therefore be assigned as $3 S, 8 S, 9 S, 10 R, 13 R, 14 S, 17 R, 20 R$.

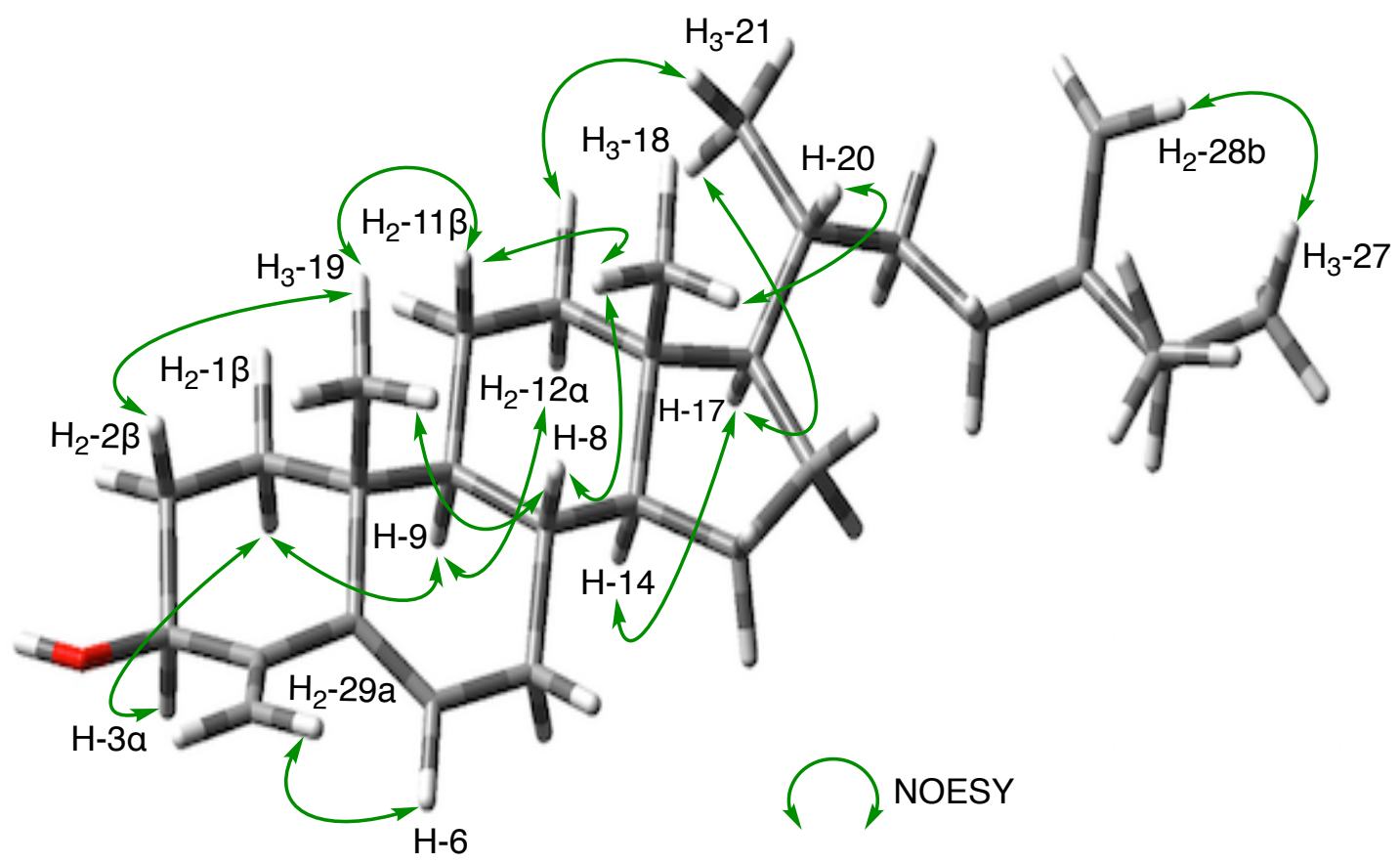

Figure 3.6. NOESY correlations establishing the configuration of craterol A (94). 


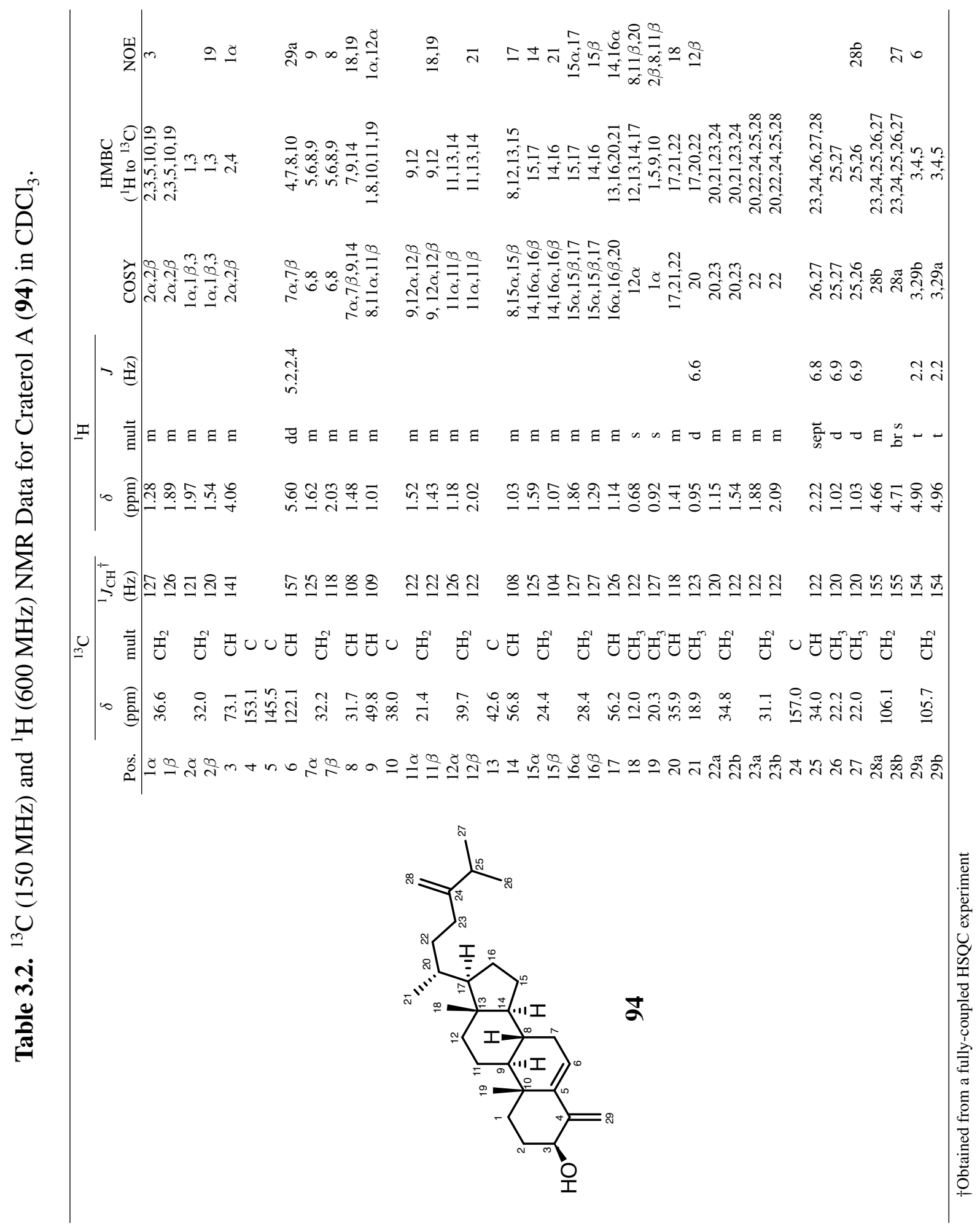




\subsection{Craterol B}

Craterol B (95) was isolated as a white amorphous solid. Positive ion HRESIMS analysis of a monoprotonated ion $[\mathrm{M}+\mathrm{H}]^{+}$at $\mathrm{m} / z, 425.3762$ indicated a molecular formula of $\mathrm{C}_{30} \mathrm{H}_{48} \mathrm{O}(\Delta=-3.76 \mathrm{ppm})$, differing from craterol $\mathrm{A}(\mathbf{9 5})$ by addition of $\mathrm{CH}_{2}$, requiring seven degrees of unsaturation. Initial analysis of the ${ }^{13} \mathrm{C} N M R$ spectrum revealed the presence of 30 distinct carbons, and the multiplicity-edited HSQC spectrum accounted for 47 of the 48 protons indicating the presence of one exchangeable proton. The ${ }^{13} \mathrm{C}$ and HSQC spectra revealed six methyls $\left(\delta_{\mathrm{C}} 22.4 ; 22.3 ; 20.3 ; 18.9 ; 13.3,12.0\right)$, nine methylenes $\left(\delta_{\mathrm{C}} 39.9 ; 36.6 ; 35.4 ; 32.2 ; 32.0 ; 28.4 ; 25.8 ; 24.4 ; 21.4\right)$, one methylidene $\left(\delta_{\mathrm{C}} 105.7\right)$, six methines $\left(\delta_{\mathrm{C}} 56.8 ; 55.9 ; 49.8 ; 36.6 ; 34.9 ; 31.7\right)$, one oxymethine $\left(\delta_{\mathrm{C}} 73.1\right)$ and two olefinic methines $\left(\delta_{\mathrm{C}} 122.1 ; 115.7\right)$. Of the remaining five non-protonated carbons, three were assigned as olefinic carbons $\left(\delta_{\mathrm{C}} 153.1 ; 147.1 ; 145.5\right)$ and two $s p^{3}$ quaternary carbons $\left(\delta_{\mathrm{C}} 42.5 ; 38.0\right)$. With the evidence of three double bonds, the remainder of the structure must contain an additional four rings to satisfy the remaining degrees of unsaturation.

Given the high degree of similarity of NMR data between the two isolated compounds, assignment of most resonances of compound 95 was established through direct comparison against compound 94. The structure was elucidated in the same fashion as craterol A, beginning with the well-resolved oxymethine $\mathrm{CH}-3\left(\delta_{\mathrm{H}} 4.06 ; \delta_{\mathrm{C}} 73.1\right)$ and the olefinic methine CH-6 $\left(\delta_{\mathrm{H}} 5.60 ; \delta_{\mathrm{C}} 122.1\right)$. A series of sequential COSY correlations starting from H-3 to two consecutive methylenes $\mathrm{CH}_{2}-2\left(\delta_{\mathrm{H}} 1.54,1.97 ; \delta_{\mathrm{C}} 32.0\right)$ and $\mathrm{CH}_{2}-1\left(\delta_{\mathrm{H}} 1.28\right.$, $\left.1.89 ; \delta_{\mathrm{C}} 36.7\right)$, all of which were supported through HMBC, HSQC-TOCSY and 1D TOCSY correlation data. The methylidene group [C-4 $\left(\delta_{\mathrm{C}} 153.1\right), \mathrm{CH}_{2}-30\left(\delta_{\mathrm{H}} 4.90\right.$, $\left.\left.4.96 ; \delta_{\mathrm{C}} 105.7\right)\right]$ was then placed between C-3 and the non-protonated olefinic carbon C-5 $\left(\delta_{\mathrm{C}} 154.5\right)$ through HMBC correlations from $\mathrm{H}_{2}-30$ to $\mathrm{C}-3, \mathrm{C}-4$ and $\mathrm{C}-5$, extending the first spin system. The second spin system began with the vicinal COSY correlations between the olefinic methine proton resonance $\mathrm{CH}-6\left(\delta_{\mathrm{H}} 5.60 ; \delta_{\mathrm{C}} 122.1\right)$ and the allylic methylene $\mathrm{CH}_{2}-7\left(\delta_{\mathrm{H}} 1.63,2.03 ; \delta_{\mathrm{C}} 32.2\right)$. HMBC correlations from $\mathrm{H}-6$ to C-4 and C-5 connected the two spin systems and established the 1,3-diene unit. Sequential COSY 
correlations from $\mathrm{H}_{2}-7$ to two contiguous methines $\mathrm{CH}-8\left(\delta_{\mathrm{H}} 1.48 ; \delta_{\mathrm{C}} 31.7\right)$ and $\mathrm{CH}-9$ $\left(\delta_{\mathrm{H}} 1.01 ; \delta_{\mathrm{C}} 49.8\right)$, extended the carbon framework. Strong HMBC correlations from the methyl singlet $\mathrm{H}_{3}-19\left(\delta_{\mathrm{H}} 0.93 ; \delta_{\mathrm{C}} 20.3\right)$ to $\mathrm{C}-1, \mathrm{C}-5, \mathrm{C}-9$ and the $s p^{3}$ quaternary carbon C-10 $\left(\delta_{\mathrm{C}} 38.0\right)$ confirmed the connection between the two spin systems and established the first substructure (see Figure 3.7).

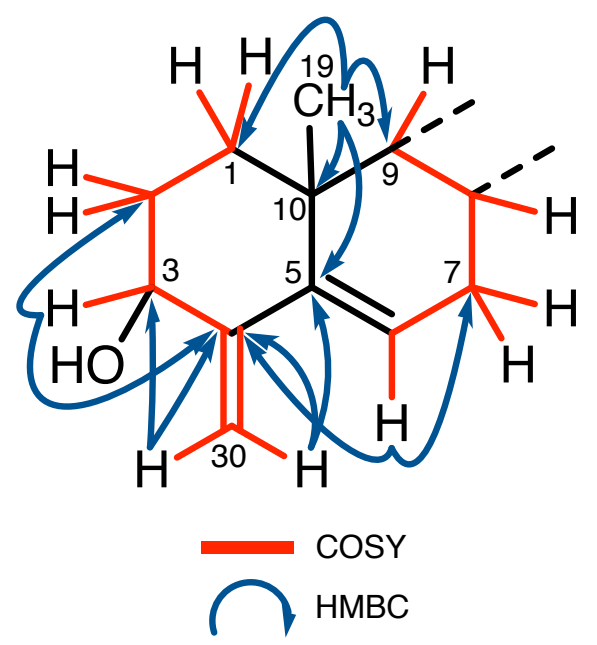

Figure 3.7. Key COSY and HMBC correlations establishing rings A and B of craterol B (95).

Further analysis of the COSY spectrum showed a series of COSY correlations from H-9 to two contiguous methylenes $\mathrm{CH}_{2}-11\left(\delta_{\mathrm{H}} 1.43,1.52 ; \delta_{\mathrm{C}} 21.4\right)$ and $\mathrm{CH}_{2}-12\left(\delta_{\mathrm{H}} 1.17\right.$, $\left.2.02 ; \delta_{\mathrm{C}} 39.7\right)$, thereby extending the carbon framework of the first substructure. This connectivity was supported by HSQC-TOCSY and HMBC correlations between these proton and carbon resonances. Vicinal COSY correlations between H-8 and methine CH-14 $\left(\delta_{\mathrm{H}} 1.02 ; \delta_{\mathrm{C}} 56.8\right)$, followed by two contiguous methylenes $\left[\mathrm{CH}_{2}-15\left(\delta_{\mathrm{H}} 1.07\right.\right.$, $\left.\left.1.59 ; \delta_{\mathrm{C}} 24.4\right), \mathrm{CH}_{2}-16\left(\delta_{\mathrm{H}} 1.28,1.87 ; \delta_{\mathrm{C}} 28.4\right)\right]$ and a methine $\mathrm{CH}-17\left(\delta_{\mathrm{H}} 1.14 ; \delta_{\mathrm{C}} 56.2\right)$, extended the spin system from ring $\mathrm{C}$ to $\mathrm{D}$. Again, this linkage was supported by HMBC and HSQC-TOCSY correlation data. The connection between rings C and D was corroborated by the strong $\mathrm{HMBC}$ correlations from the methyl singlet $\mathrm{CH}_{3}-18\left(\delta_{\mathrm{H}} 0.68\right.$; $\left.\delta_{\mathrm{C}} 12.0\right)$ to the protonated centres $\mathrm{C}-12, \mathrm{C}-14, \mathrm{C}-17$ and the $s p^{3}$ quaternary carbon $\mathrm{C}-13$ $\left(\delta_{\mathrm{C}} 42.6\right)$, thus establishing the tetracyclic moiety (see Figure 3.8 ).

A methyl doublet $\mathrm{CH}_{3}-21\left(\delta_{\mathrm{H}} 0.99 ; \delta_{\mathrm{C}} 18.9\right)$ showed strong HMBC correlations to a methine $\mathrm{CH}-20\left(\delta_{\mathrm{H}} 1.40 ; \delta_{\mathrm{C}} 36.6\right)$, methylenes $\mathrm{CH}_{2}-22\left(\delta_{\mathrm{H}} 1.15,1.54 ; \delta_{\mathrm{C}} 34.8\right)$ and C-17, establishing the connection of the side chain to the steroidal carbon skeleton of 


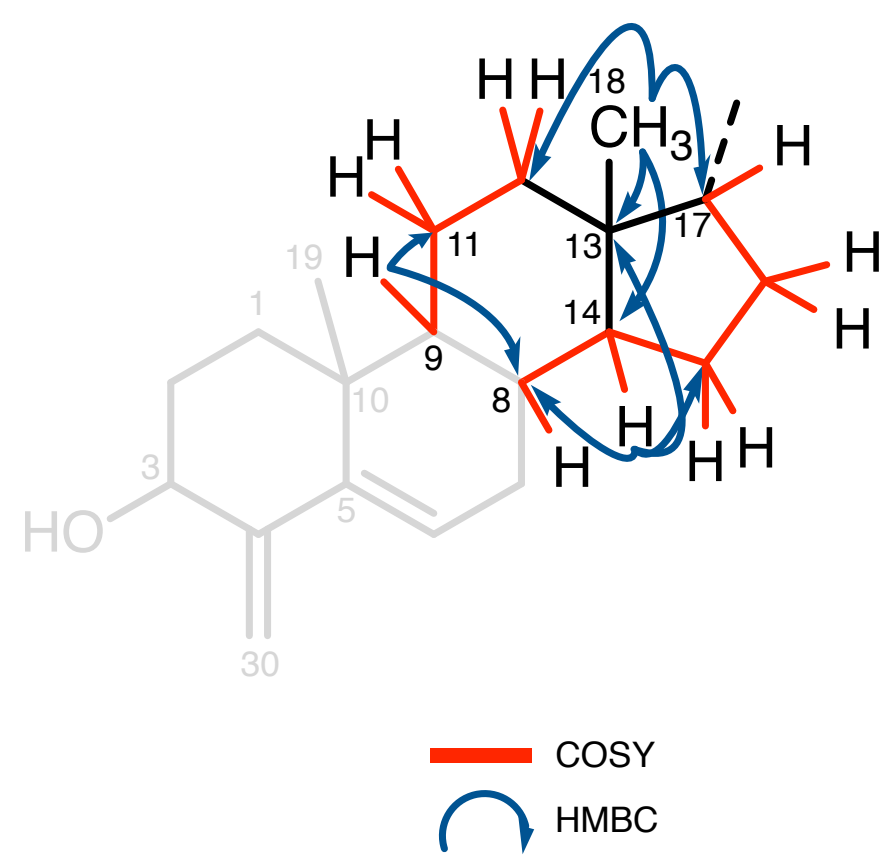

Figure 3.8. Key COSY and HMBC correlations establishing the tetracyclic moiety of craterol B (95).

craterol B (95). This connection was confirmed by HSQC-TOSCY, COSY and 1D TOCSY correlations between these proton resonances. The substructure was extended by the vicinal COSY correlations between $\mathrm{H}_{2}-22$ and the allylic methylene protons $\mathrm{CH}_{2}-23$ $\left(\delta_{\mathrm{H}} 1.15,1.54 ; \delta_{\mathrm{C}} 34.8\right)$. The methylene protons $\mathrm{H}_{2}-23$ displayed HMBC correlations to $\mathrm{C}-22$, the non-protonated olefinic carbon C-24 $\left(\delta_{\mathrm{C}} 147.1\right)$ and the olefinic methine CH-28 $\left(\delta_{\mathrm{H}} 5.18 ; \delta_{\mathrm{C}} 115.7\right)$, placing a double bond along the side chain moiety. The methyl doublet $\mathrm{CH}_{3}-29\left(\delta_{\mathrm{H}} 1.57 ; \delta_{\mathrm{C}} 13.3\right)$ showed strong HMBC correlations to only two carbons, C-24 and C-28, all of which was supported by HSQC-TOSCY and COSY correlations between their respective proton resonances, thus supporting the adjacent branched double bond. The geometry of $\Delta_{24,28}$ was assigned as $Z$ on the basis of the observed NOESY correlation between $\mathrm{H}_{3}-29$ and $\mathrm{H}_{3}-27$. HMBC and HSQC-TOCSY correlations from the proton resonance of $\mathrm{H}-28$ to those of $\mathrm{CH}_{2}-23, \mathrm{CH}-25\left(\delta_{\mathrm{H}} 2.19\right.$; $\left.\delta_{\mathrm{C}} 34.9\right), \mathrm{CH}_{3}-26\left(\delta_{\mathrm{H}} 0.98 ; \delta_{\mathrm{C}} 22.3\right)$ and $\mathrm{CH}_{3}-27\left(\delta_{\mathrm{H}} 0.98 ; \delta_{\mathrm{C}} 22.4\right)$ established the connection of the double bond to C-23 and also extended the substructure. The two methyl doublets $\mathrm{CH}_{3}-26$ and $\mathrm{CH}_{3}-27$ displayed strong HMBC correlations to C-25 and also to each other, forming the terminal isopropyl unit and established the completed planar structure of craterol B (95) (see Figure 3.9). 


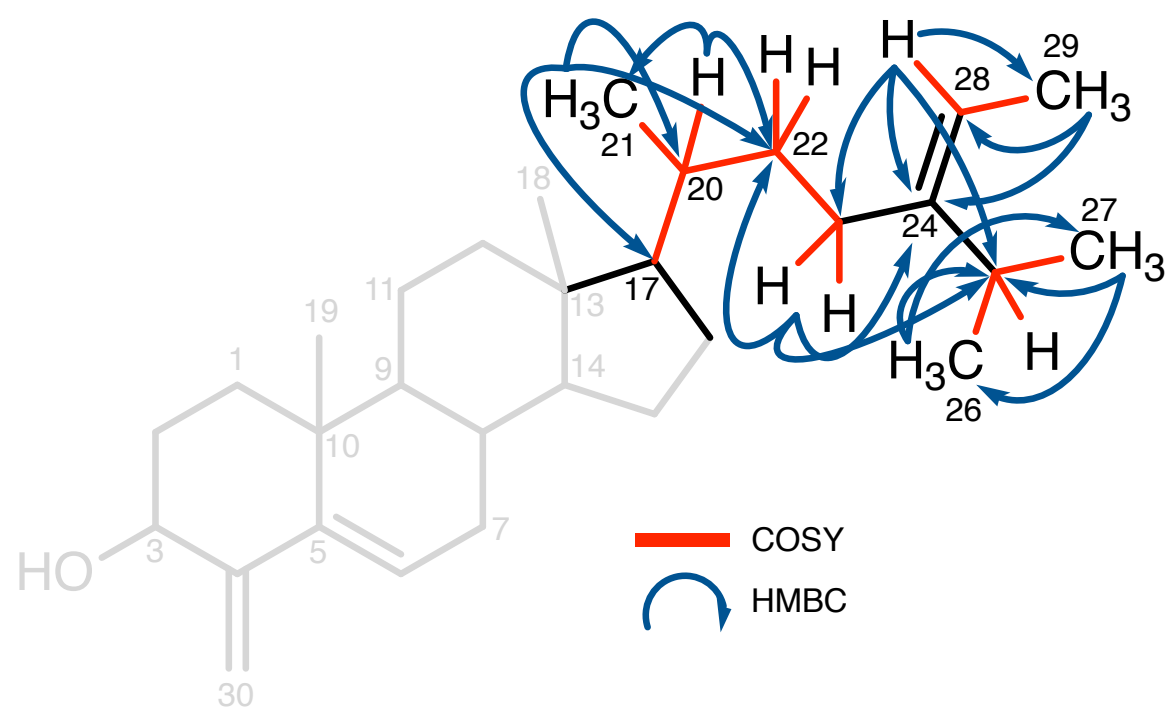

Figure 3.9. Key COSY and HMBC correlations establishing rings the side chain moiety of craterol B (95).

The relative configuration of craterol B (95) was assigned on the basis of NOE correlations observed in a 2D NOESY experiment (see Figure 3.10). The 2D NOESY spectrum displayed 1,3-diaxial NOESY correlations between the methine proton resonance H-8 and both methyls $\mathrm{H}_{3}-18$ and $\mathrm{H}_{3}-19$, suggesting $\mathrm{H}-8$ is also on the same face as the two methyls C-18 and C-19, thus possessing a $\beta$-orientation. A NOESY correlation between $\mathrm{H}-8$ and the methine proton resonance of $\mathrm{H}-9$ was not observed in the NOESY experiment, implying the standard steroid trans $\mathrm{A} / \mathrm{B} / \mathrm{C}$ ring fusions. A strong 1,3-diaxial NOESY correlation between H-9 and H-1 $\alpha$ supported this assignment. Subsequently, 1,3-diaxial correlation between $\mathrm{H}-1 \alpha$ and the proton resonance of $\mathrm{H}-3$ was observed in the NOESY experiment, therefore assigning the 3-OH as $\beta$ and $\mathrm{H}-3$ as $\alpha$. Further examination of the 2D NOESY spectrum showed an additional NOE correlation from the $\mathrm{H}_{3}-18$ to the methine proton $\mathrm{H}-20$, allowing the placement of the side-chain on the $\beta$ face of the molecule. This was consistent with the majority of the steroids reported in the literature as they normally possess a trans $\mathrm{C} / \mathrm{D}$ ring fusion. This assignment was supported by the strong NOE correlation between the proton resonances of $\mathrm{H}-14$ and $\mathrm{H}-17$, revealing the $\alpha$-orientation of these protons. Assuming normal steroid configuration, these observations allow the configuration of craterol B (95) to be assigned as $3 S, 8 S, 9 S, 10 R, 13 R, 14 S, 17 R$, $20 R$. 


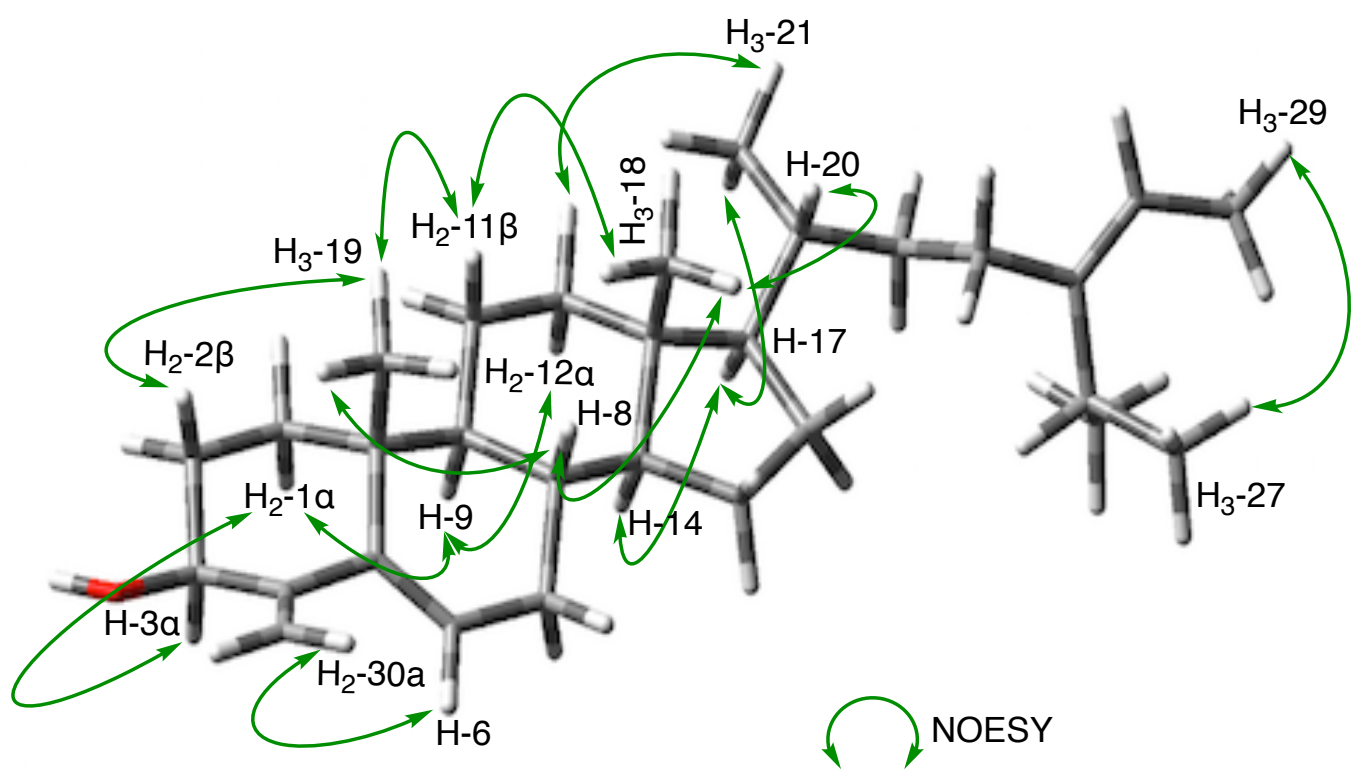

Figure 3.10. NOESY correlations establishing the configuration of craterol B (95). 


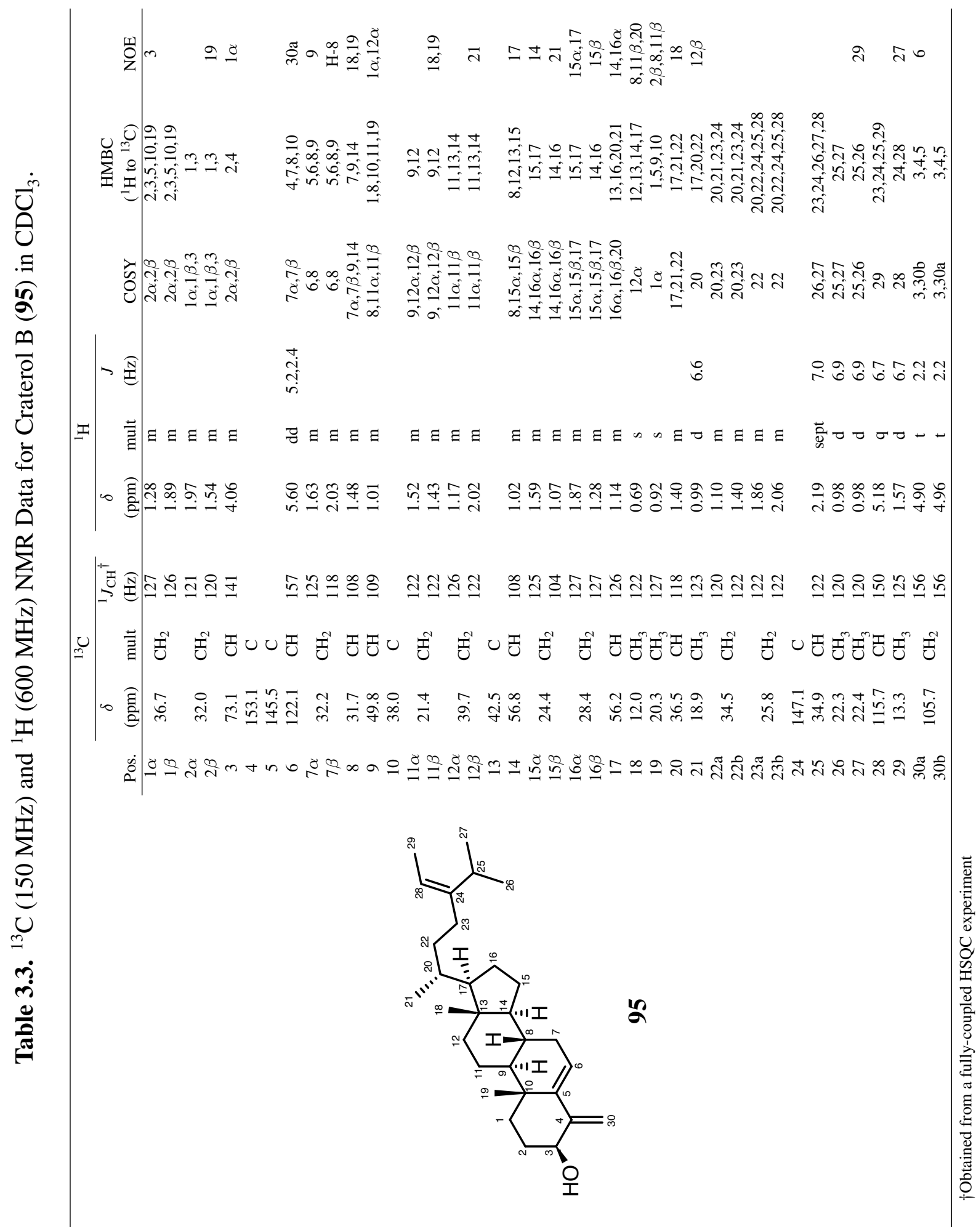




\subsection{Biological Activity}

The potential antiproliferative activity of craterols A (94) and B (95) was evaluated in vitro against the human promyelocytic leukaemia cell line HL-60 at the School of Biological Sciences, VUW. Unfortunately both compounds showed poor solubility in DMSO and while they appeared to dissolve in $1 \%$ triton-X, both compounds displayed no activity.

\subsection{4-Methylenesterols}

The 4-methylenesterols are unusual steroids that possess a methylidene group at position C-4. They are relatively rare, with fewer than 50 of such compounds having been reported to date, mostly from the marine sponge genus Theonella. $\underline{-109}$ These sterols display a variety of biological activities, including cytotoxic activity, ${ }_{99}$ and pharmacological evaluation has shown them to be potent agonists of human pregnane-X-receptor (PXR) and antagonists of human farnesoid-X-receptor (FXR). $102+106$

In 1981, the first of the 4-methylenesterols, theonellasterol (96) and conicasterol (97), were reported from two marine sponges, Theonella conica and Theonella swinhoei collected from the Red Sea. ${ }^{96}$ A recent article by Zampella and co-workers showed theonellasterol to be a highly selective FXR antagonist that protects against cholestatic liver injury. $\frac{110}{1 n}$ I992, two new 3-keto-4-methylenesterols, theonellasterone (98) and conicasterone (99) were obtained from Okinawan collections of T. swinhoei, along with theonellasterol and conicasterol. ${ }^{97}$ In 1995, nine oxygenated 4-methylenesterols (100-108) were isolated from the sponge T. swinhoei, collected from Hachijo Island

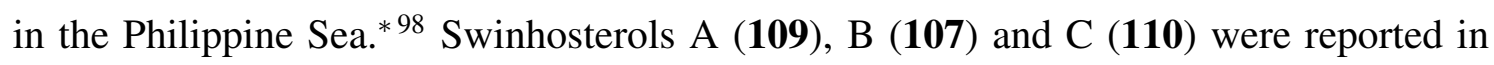
1997 from an Okinawan collection of T. swinhoei. ${ }^{111}$ Swinhosterol B was reported in this article as a new compound, however it was isolated three years earlier by Sugo et al. ${ }^{98}$ These compounds contained a unique 8,14-seco carbon framework, which is uncommon in natural products chemistry.

\footnotetext{
${ }^{*}$ Compound 105 contained an undetermined fatty acid.
} 
Qureshi and Faulkner reported $7 \alpha$-hydroxytheonellasterol (111) from the Philippine sponge T. swinhoei in 2000, together with the known compounds theonellasterol and bistheonellide A. ${ }^{99}$ In 2009, dehydroconicasterol (112) was obtained from an Indonesian collection of $T$. swinhoei. $\frac{100}{1}$ The $9 \alpha$-hydroxy-15-oxoconicasterol (113) and the $8 \beta$ hydroxy-B-norconicasta-6 $\alpha$-aldehyde (114) were reported in 2010 from an ethanolic extract of the sponge T. swinhoei collected from the South China Sea. ${ }^{101}$ A year later, the unprecedented bis-secosterol, malaitasterol A (115), was isolated from a Solomon Islands collection of T. swinhoei. ${ }^{102}$ In 2011 , re-examination of the hydrophilic fraction of this sponge by the same research group lead to the isolation of theonellasterols B-H (116-122) and conicasterols B-D (123-125). $\frac{103}{10}$ Consequently, the same research group successively published three articles in 2012, describing conicasterols E-K (126-132) and theonellasterols I-J (133-134) from the same collections. 104 Theonellasterol K (135), acetyltheonellasterol (136) and acetyldehydroconicasterol (137), along with known theonellasterol and theonellasterone, were isolated from a Taiwan sponge T. swinhoei. ${ }^{107}$ Compound 135 exhibited significant cytotoxicity against several cancer cell lines. 107

Most recently, preconicasterol (138), 24-dehydroconicasterol D (139) and 25-dehydrotheonellasterol (140) were obtained from T. swinhoei and T. conica specimens collected from the Solomon Islands and Kagoshima, Japan, respectively. ${ }^{108}$ Chemical analysis of the hydrophilic extract of $T$. swinhoei obtained from the South China Sea led to the isolation of swinhoeisterols A (141) and B (142), which feature an unprecedented 6/6/5/7 fused ring system. 109 The absolute configurations of both compounds (141 and 142) were established by single-crystal X-ray diffraction and were shown to exhibit cytotoxicity against $\mathrm{A} 549\left(\mathrm{IC}_{50}=8.6 \mu \mathrm{M}\right.$ and $14.6 \mu \mathrm{M}$, respectively $)$ and $\mathrm{MG}-63\left(\mathrm{IC}_{50}=10.3 \mu \mathrm{M}\right.$ and $20.0 \mu \mathrm{M}$, respectively) cells. $\frac{109}{}$ Interestingly, 4-methylenesterols are not confined to the marine environment and have been isolated from Coprinus micaceus, an edible terrestrial fungus, yielding micaceol (143). 112 


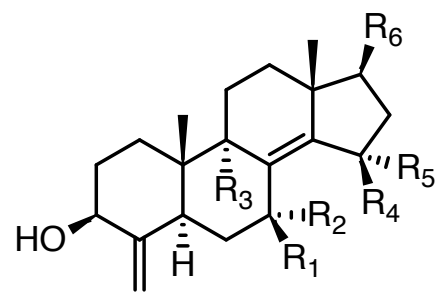

\begin{tabular}{|c|c|c|c|c|c|c|}
\hline 96 & $\mathrm{R}_{1}=\mathrm{H}$ & $\mathrm{R}_{2}=\mathrm{H}$ & $\mathrm{R}_{3}=\mathrm{H}$ & $\mathrm{R}_{4}=\mathrm{H}$ & $\mathrm{R}_{5}=\mathrm{H}$ & $\mathrm{R}_{6}=\mathrm{A}$ \\
\hline 97 & $\mathrm{R}_{1}=\mathrm{H}$ & $\mathrm{R}_{2}=\mathrm{H}$ & $\mathrm{R}_{3}=\mathrm{H}$ & $\mathrm{R}_{4}=\mathrm{H}$ & $\mathrm{R}_{5}=\mathrm{H}$ & $\mathrm{R}_{6}=\mathrm{B}$ \\
\hline 100 & $\mathrm{R}_{1}=\mathrm{H}$ & $\mathrm{R}_{2}=\mathrm{OH}$ & $\mathrm{R}_{3}=\mathrm{H}$ & $\mathrm{R}_{4}=\mathrm{H}$ & $\mathrm{R}_{5}=\mathrm{H}$ & $\mathrm{R}_{6}=\mathrm{B}$ \\
\hline 101 & $\mathrm{R}_{1}=\mathrm{H}$ & $\mathrm{R}_{2}=\mathrm{OMe}$ & $\mathrm{R}_{3}=\mathrm{H}$ & $\mathrm{R}_{4}=\mathrm{H}$ & $\mathrm{R}_{5}=\mathrm{H}$ & $\mathrm{R}_{6}=\mathrm{B}$ \\
\hline 102 & $\mathrm{R}_{1}=\mathrm{H}$ & $\mathrm{R}_{2}=\mathrm{OH}$ & $\mathrm{R}_{3}=\mathrm{H}$ & $\mathrm{R}_{4}=\mathrm{H}$ & $\mathrm{R}_{5}=\mathrm{OMe}$ & $\mathrm{R}_{6}=\mathrm{B}$ \\
\hline 103 & $\mathrm{R}_{1}=\mathrm{H}$ & $\mathrm{R}_{2}=\mathrm{OH}$ & $\mathrm{R}_{3}=\mathrm{H}$ & $\mathrm{R}_{4}=\mathrm{OMe}$ & $\mathrm{R}_{5}=\mathrm{H}$ & $\mathrm{R}_{6}=\mathrm{B}$ \\
\hline 104 & $\mathrm{R}_{1}=\mathrm{H}$ & $\mathrm{R}_{2}=\mathrm{OH}$ & $\mathrm{R}_{3}=\mathrm{H}$ & $\mathrm{R}_{4}=\mathrm{H}$ & $\mathrm{R}_{5}=\mathrm{OH}$ & $\mathrm{R}_{6}=\mathrm{B}$ \\
\hline 105 & $\mathrm{R}_{1}=\mathrm{H}$ & $\mathrm{R}_{2}=\mathrm{OH}$ & $\mathrm{R}_{3}=\mathrm{H}$ & $\mathrm{R}_{4}=\mathrm{H}$ & $\mathrm{R}_{5}=\mathrm{OCOR}$ & $\mathrm{R}_{6}=\mathrm{B}$ \\
\hline 106 & $\mathrm{R}_{1}=\mathrm{H}$ & $\mathrm{R}_{2}=\mathrm{H}$ & $\mathrm{R}_{3}=\mathrm{H}$ & $\mathrm{R}_{4}=\mathrm{H}$ & $\mathrm{R}_{5}=\mathrm{OH}$ & $\mathrm{R}_{6}=\mathrm{B}$ \\
\hline 110 & $\mathrm{R}_{1}=\mathrm{H}$ & $\mathrm{R}_{2}=\mathrm{OMe}$ & $\mathrm{R}_{3}=\mathrm{H}$ & $\mathrm{R}_{4}=\mathrm{H}$ & $\mathrm{R}_{5}=\mathrm{H}$ & $\mathrm{R}_{6}=\mathrm{A}$ \\
\hline 111 & $\mathrm{R}_{1}=\mathrm{H}$ & $\mathrm{R}_{2}=\mathrm{OH}$ & $\mathrm{R}_{3}=\mathrm{H}$ & $\mathrm{R}_{4}=\mathrm{H}$ & $\mathrm{R}_{5}=\mathrm{H}$ & $\mathrm{R}_{6}=\mathrm{A}$ \\
\hline 112 & $\mathrm{R}_{1}=\mathrm{H}$ & $\mathrm{R}_{2}=\mathrm{H}$ & $\mathrm{R}_{3}=\mathrm{H}$ & $\mathrm{R}_{4}=\mathrm{H}$ & $\mathrm{R}_{5}=\mathrm{H}$ & $\mathrm{R}_{6}=\mathrm{C}$ \\
\hline 113 & $\mathrm{R}_{1}=\mathrm{H}$ & $\mathrm{R}_{2}=\mathrm{H}$ & $\mathrm{R}_{3}=\mathrm{OH}$ & $\mathrm{R}_{4}=\mathrm{O}$ & $\mathrm{R}_{5}=\mathrm{O}$ & $\mathrm{R}_{6}=\mathrm{A}$ \\
\hline 118 & $\mathrm{R}_{1}=\mathrm{H}$ & $\mathrm{R}_{2}=\mathrm{H}$ & $\mathrm{R}_{3}=\mathrm{OMe}$ & $\mathrm{R}_{4}=\mathrm{H}$ & $\mathrm{R}_{5}=\mathrm{H}$ & $\mathrm{R}_{6}=\mathrm{A}$ \\
\hline 119 & $\mathrm{R}_{1}=\mathrm{H}$ & $\mathrm{R}_{2}=\mathrm{H}$ & $\mathrm{R}_{3}=\mathrm{OH}$ & $\mathrm{R}_{4}=\mathrm{H}$ & $\mathrm{R}_{5}=\mathrm{H}$ & $\mathrm{R}_{6}=\mathrm{A}$ \\
\hline 120 & $\mathrm{R}_{1}=\mathrm{H}$ & $\mathrm{R}_{2}=\mathrm{OH}$ & $\mathrm{R}_{3}=\mathrm{H}$ & $\mathrm{R}_{4}=\mathrm{OH}$ & $\mathrm{R}_{5}=\mathrm{H}$ & $\mathrm{R}_{6}=\mathrm{A}$ \\
\hline 124 & $\mathrm{R}_{1}=\mathrm{H}$ & $\mathrm{R}_{2}=\mathrm{H}$ & $\mathrm{R}_{3}=\mathrm{OMe}$ & $\mathrm{R}_{4}=\mathrm{OH}$ & $\mathrm{R}_{5}=\mathrm{H}$ & $\mathrm{R}_{6}=\mathrm{B}$ \\
\hline 125 & $\mathrm{R}_{1}=\mathrm{H}$ & $\mathrm{R}_{2}=\mathrm{H}$ & $\mathrm{R}_{3}=\mathrm{OH}$ & $\mathrm{R}_{4}=\mathrm{OH}$ & $\mathrm{R}_{5}=\mathrm{H}$ & $\mathrm{R}_{6}=\mathrm{B}$ \\
\hline 126 & $\mathrm{R}_{1}=\mathrm{H}$ & $\mathrm{R}_{2}=\mathrm{OH}$ & $\mathrm{R}_{3}=\mathrm{H}$ & $\mathrm{R}_{4}=\mathrm{OH}$ & $\mathrm{R}_{5}=\mathrm{H}$ & $\mathrm{R}_{6}=\mathrm{B}$ \\
\hline 128 & $\mathrm{R}_{1}=\mathrm{O}$ & $\mathrm{R}_{2}=\mathrm{O}$ & $\mathrm{R}_{3}=\mathrm{H}$ & $\mathrm{R}_{4}=\mathrm{H}$ & $\mathrm{R}_{5}=\mathrm{OH}$ & $\mathrm{R}_{6}=\mathrm{B}$ \\
\hline 131 & $\mathrm{R}_{1}=\mathrm{H}$ & $\mathrm{R}_{2}=\mathrm{OH}$ & $\mathrm{R}_{3}=\mathrm{H}$ & $\mathrm{R}_{4}=\mathrm{O}$ & $\mathrm{R}_{5}=\mathrm{O}$ & $\mathrm{R}_{6}=\mathrm{B}$ \\
\hline 138 & $\mathrm{R}_{1}=\mathrm{H}$ & $\mathrm{R}_{2}=\mathrm{H}$ & $\mathrm{R}_{3}=\mathrm{H}$ & $\mathrm{R}_{4}=\mathrm{H}$ & $\mathrm{R}_{5}=\mathrm{H}$ & $\mathrm{R}_{6}=\mathrm{E}$ \\
\hline 139 & $\mathrm{R}_{1}=\mathrm{H}$ & $\mathrm{R}_{2}=\mathrm{H}$ & $\mathrm{R}_{3}=\mathrm{OH}$ & $\mathrm{R}_{4}=\mathrm{OH}$ & $\mathrm{R}_{5}=\mathrm{H}$ & $\mathrm{R}_{6}=\mathrm{C}$ \\
\hline 140 & $\mathrm{R}_{1}=\mathrm{H}$ & $\mathrm{R}_{2}=\mathrm{H}$ & $\mathrm{R}_{3}=\mathrm{H}$ & $\mathrm{R}_{4}=\mathrm{H}$ & $\mathrm{R}_{5}=\mathrm{H}$ & $\mathrm{R}_{6}=\mathrm{F}$ \\
\hline
\end{tabular}

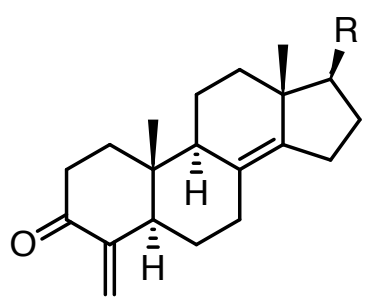

$98 \mathrm{R}=\mathrm{A}$

$99 \mathrm{R}=\mathrm{B}$

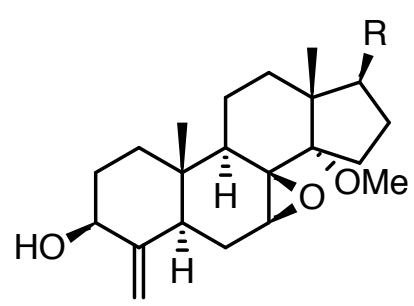

$108 \mathrm{R}=\mathrm{B}$

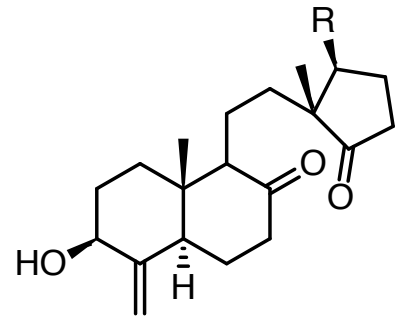

$109 \mathrm{R}=\mathrm{A}$

$107 \mathrm{R}=\mathrm{B}$ 


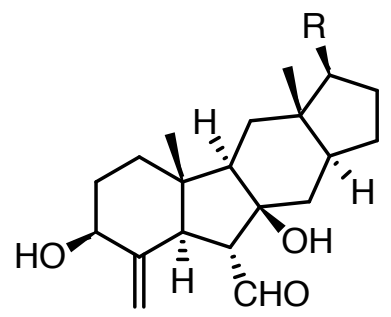

$114 \mathrm{R}=\mathrm{B}$

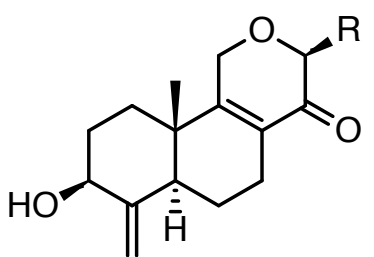

$115 \mathrm{R}=\mathrm{D}$

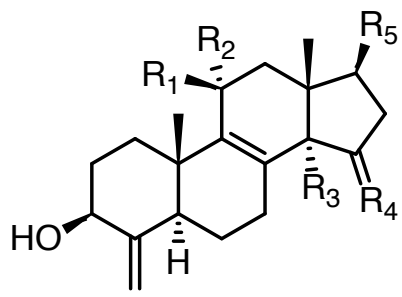

$\begin{array}{llllll}117 & \mathrm{R}_{1}=\mathrm{H} & \mathrm{R}_{2}=\mathrm{H} & \mathrm{R}_{3}=\mathrm{H} & \mathrm{R}_{4}=\mathrm{O} & \mathrm{R}_{5}=\mathrm{A} \\ \mathbf{1 2 1} & \mathrm{R}_{1}=\mathrm{OH} & \mathrm{R}_{2}=\mathrm{H} & \mathrm{R}_{3}=\mathrm{OH} & \mathrm{R}_{4}=\alpha-\mathrm{OH}, \beta-\mathrm{H} & \mathrm{R}_{5}=\mathrm{A} \\ \mathbf{1 2 2} & \mathrm{R}_{1}=\mathrm{H} & \mathrm{R}_{2}=\mathrm{OH} & \mathrm{R}_{3}=\mathrm{OH} & \mathrm{R}_{4}=\alpha-\mathrm{OH}, \beta-\mathrm{H} & \mathrm{R}_{5}=\mathrm{A} \\ \mathbf{1 3 0} & \mathrm{R}_{1}=\mathrm{OH} & \mathrm{R}_{2}=\mathrm{H} & \mathrm{R}_{3}=\mathrm{OH} & \mathrm{R}_{4}=\alpha-\mathrm{OH}, \beta-\mathrm{H} & \mathrm{R}_{5}=\mathrm{B}\end{array}$

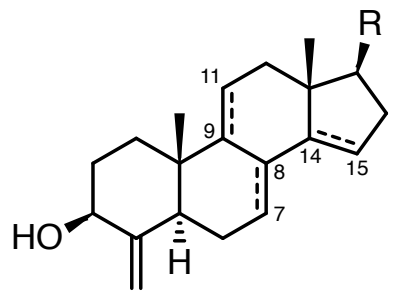

$116 \mathrm{R}=\mathrm{A} \Delta_{7,8} \Delta_{9,11} \Delta_{14,15}$

$123 \quad \mathrm{R}=\mathrm{B} \Delta_{7,8} \Delta_{9,11} \Delta_{14,15}$

$132 \mathrm{R}=\mathrm{B} \Delta_{7,8} \Delta_{14,15}$

$134 \mathrm{R}=\mathrm{A} \Delta_{7,8} \Delta_{14,15}$

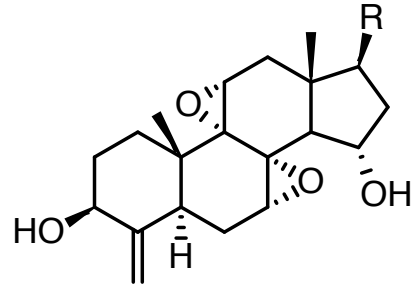

$127 \mathrm{R}=\mathrm{B}$

$133 \mathrm{R}=\mathrm{A}$

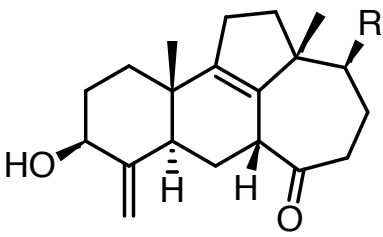

$141 \mathrm{R}=\mathrm{B}$

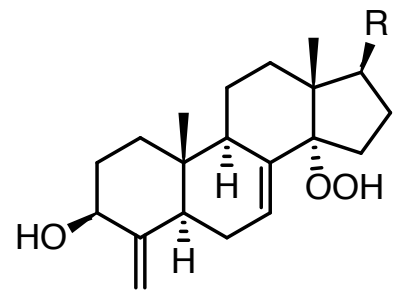

$129 \mathrm{R}=\mathrm{B}$

$135 \mathrm{R}=\mathrm{A}$

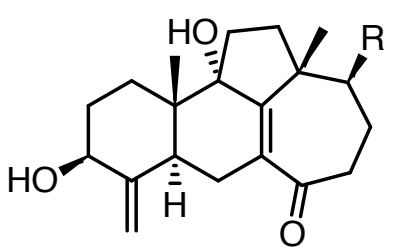

$142 \mathrm{R}=\mathrm{B}$<smiles>[R]C1CCC2=C3CC[C@H]4C(=C)[C@@H](OC(C)=O)CC[C@]4(C)[C@H]3CC[C@]21C</smiles>

$136 \mathrm{R}=\mathrm{A}$

$137 \mathrm{R}=\mathrm{C}$

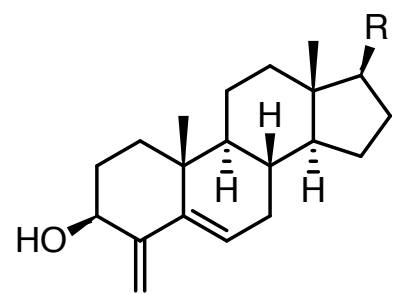

$143 R=G$ 


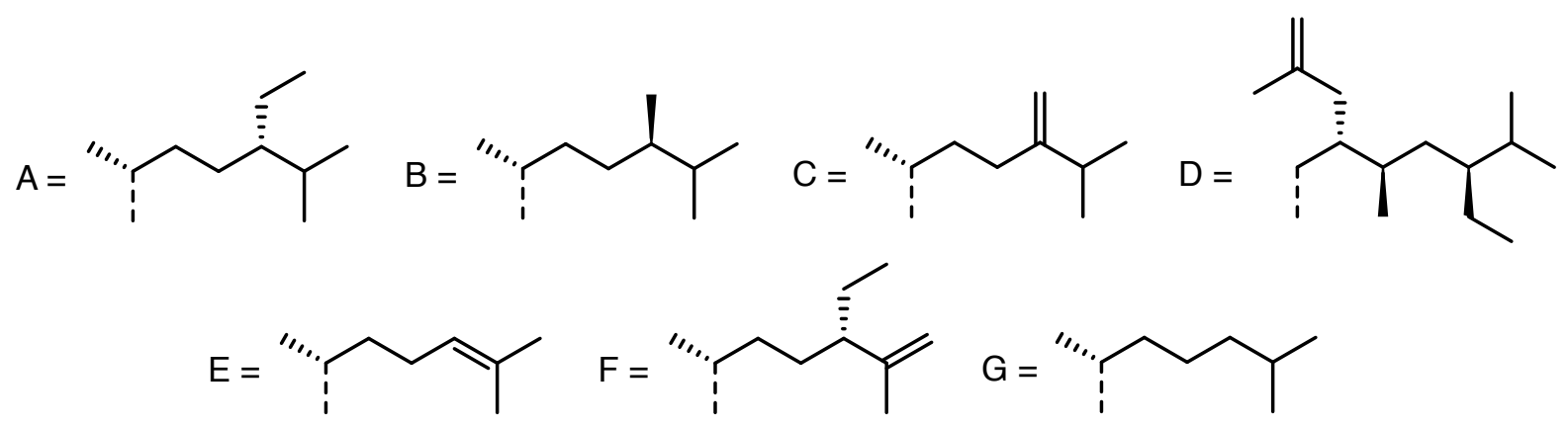

\subsection{Concluding Remarks}

A spectroscopic-guided investigation of a two-sponge association, Stelletta crater and Desmacella dendyi, collected from the Three Kings Island in New Zealand has resulted in the isolation of two new compounds, craterols A (94) and B (95). To the best of the author's knowledge, compounds 94 and 95 represent the first secondary metabolites to be reported from these species. Craterols A (94) and B (95) are 4-methylenesterols and the first in this group of marine natural product to possess a double bond between C-5 and C-6.

These unusual steroids are primarily isolated from the sponge of the genus Theonella (mainly from Theonella swinhoei). As a result, the 4-methylenesterols have been proposed as ideal taxonomic markers for sponges of the genus Theonella. ${ }^{101}$ However, the isolation of 94 and 95 from the Stelletta and Desmacella two-sponge association is a reminder of the complication of using chemotaxonomic makers for sponge classification due to their lack of consistency. 


\section{Chapter 4}

\section{New Pyrroloiminoquinone Analogues from the Tongan}

\section{Marine Sponge Zyzzya fuliginosa}

Chapter 4 describes the NMR-guided isolation and structure elucidation of two new pyrroloiminoquinone alkaloids from the Tongan marine sponge Zyzzya fuliginosa. 6-Bromodamirone $B$ and makaluvamine $W$ are new additions to the damirone and the makaluvamine family respectively, which give some insight into the biogenesis of these compounds. Makaluvamine W contains an oxazole moiety, which is uncommon in this group of natural products.

\subsection{Zyzzya fuliginosa}

Zyzzya fuliginosa is a Poecilosclerid sponge (see Table 4.1) and is widely distributed in the tropical Indo-West Pacific. ${ }^{31}$ The live sponge is dark-green to black underwater and is commonly found excavating into calcareous or sedimentary substrates. Z. fuliginosa is usually massive with an irregular bulbous surface and prominent fistules in the gamma stage. ${ }^{32}$ The sponge is generally fragile and produces copious amounts of dark green pigment. Z. fuliginosa has proved to be a prolific source of biologically active metabolites, particularly the pyrroloiminoquinone alkaloids. ${ }^{113}$ This group of natural products possesses a dihydropyrrolo[4,3,2-de]quinoline core that can be found in discorhabdins, 114

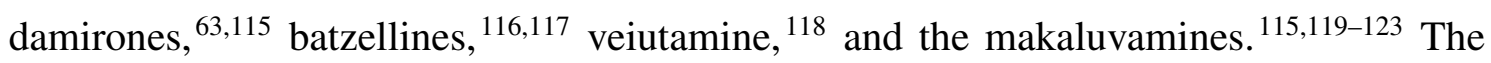
pyrroloiminoquinone alkaloids are known for their potent bioactivity toward various types of tumor cell lines, $\frac{114|118-122| 124}{\text { inhibition of topoisomerase I and II, } 119|120| 122] 124}$ antifungal ${ }^{119,122}$ and antimicrobial activities. 125

The first reported chemical investigations into this species were conducted by Faulkner and Stierle on a Palauan sponge Z. fuliginosa ${ }^{\text {t }}$ which resulted in the isolation of

*Previously identified as Damiria sp. 
Table 4.1. Taxonomic classification of genus Zyzzya from order Poecilosclerida as presented by World Porifera Database. 31

\begin{tabular}{|c|c|c|}
\hline Order & Family & Genus \\
\hline \multirow{3}{*}{ Poecilosclerida } & Acarnidae & $\begin{array}{l}\text { Acanthorhabdus } \\
\text { Acarnus } \\
\text { Acheliderma } \\
\text { Cornulacantha } \\
\text { Cornulella } \\
\text { Cornulum } \\
\text { Damiria } \\
\text { Dolichacantha } \\
\text { Iophon } \\
\text { Megaciella } \\
\text { Paracornulum } \\
\text { Tedaniphorbas } \\
\text { Wigginsia } \\
\text { Zyzzya }\end{array}$ \\
\hline & Latrunculiidae & $\begin{array}{l}\text { Bomba } \\
\text { Cyclacanthia } \\
\text { Latrunclava } \\
\text { Latrunculia } \\
\text { Sceptrella } \\
\text { Strongylodesma } \\
\text { Tsitsikamma } \\
\end{array}$ \\
\hline & Podospongiidae & $\begin{array}{l}\text { Dicarnus } \\
\text { Diplopodospongia } \\
\text { Negombata } \\
\text { Neopodospongia } \\
\text { Podospongia } \\
\text { Sceptrintus } \\
\text { Sigmosceptrella }\end{array}$ \\
\hline
\end{tabular}

damirones A (144) and B (47). ${ }^{63[15]}$ In 1993, seven new cytotoxic pigments, makaluvamines A-F (145-150) and makaluvanone (151), along with the known compounds

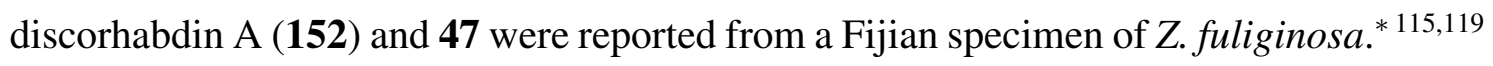
Shortly thereafter, makaluvamine G (153) was isolated from an Indonesian collection of Z. fuliginosa $\underbrace{\lceil[115] 122}$ Investigation of a Micronesian specimen of Z. fuliginosa afforded makaluvamines H-M (154-159) and damirone C (160). ${ }^{115}$ Interestingly, a study by Utkina et al. demonstrated that 154 and 147 could be transformed into 144 and $\mathbf{4 7}$, respectively, by alkaline hydrolysis. .126

Makaluvamine N (161), which possesses a bromine at position C-6 was extracted

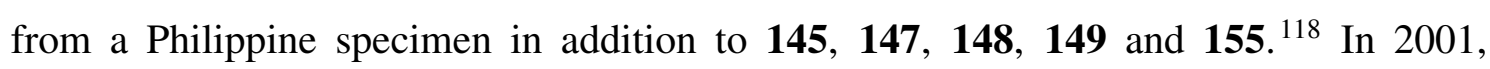
makaluvamine P (162) was reported from a Vanuatu collection of this species, which

*Previously identified as Zyzzya massalis.

${ }^{\dagger}$ Previously identified as Histodermella sp. 
co-occurred with $\mathbf{1 5 3}, \mathbf{1 5 6}, 157$ and $\mathbf{1 5 8} .121$ The related structure makaluvamine V (163) was first reported in a U.S. patent describing the secondary metabolite and structurally related compounds sourced from a Fijian sponge Z. fuliginosa. ${ }^{[27.128}$ The makaluvamines represent a series of seventeen metabolites, all of which were isolated from $Z$. fuliginosa, except makaluvamine $\mathrm{O}$ (164), which was originally isolated from a Jamaican sponge Smenospongia aurea $\stackrel{123}{123}$ Compound 164 is a $N$-1-desmethyl analogue of makaluvanone and represents the first report of a pyrroloquinoline metabolite from the sponge family Thorectidae (see Table 6.1). The authors acknowledge the chemotaxonomic significance of this discovery and the gross morphology of Zyzzya, Smenospongia and Strongylodesma species collected off the coast of Jamaica and for this reason they suggested the possibility that different sponge species were unintentionally mixed together during the field collection. 123

In 1996, makaluvic acids A (165) and B (166) were isolated from the Micronesian

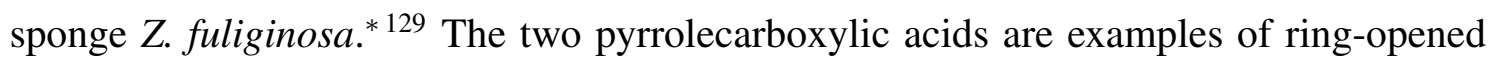
dihydropyrrolo[4,3,2-de]quinolones, in which compound 165 exhibited no cytotoxicity against murine leukemia P388 cells, suggesting that the iminoquinone moiety might be responsible for the previously reported biological activities. ${ }^{122}$ Veiutamine (167) was obtained from a Fijian collection of Z. fuliginosa in 1997 and was the first pyrroloiminoquinone alkaloid bearing a characteristic C-6 p-hydroxy benzyl group. ${ }^{118}$ Investigation of the cytotoxic extracts of the sponge Z. fuliginosa, Latrunculia purpurea and an unidentified sponge Zyzzya sp., afforded discorhabdin Q (168). ${ }^{114}$ Batzelline D (169) and isobatzelline E (170), together with the known compounds batzelline, isobatzelline C, and makaluvamine D, were isolated from an Indo-West Pacific Z. fuliginosa sponge in 2002. 116 6-Dechlorobatzelline C (171) was reported in a 1995 patent, but was first shown as a natural product in 2005 from an Australian specimen of Z. fuliginosa. ${ }^{127 \mid 128}$

Chemical investigations by Utkina and co-workers of Australian collections of Z. fuliginosa yielded zyzzyanone A (172), the first example of a pyrrolo[3,2-f]indole-4,8(1H,7H)dione alkaloid to be isolated from a marine sponge. $\frac{130}{10}$ continued investigation on the same sponge provided three related new dipyrroloquinones zyzzyanones B-D

\footnotetext{
${ }^{*}$ Misspelled in the original manuscript as Z. fuliginosus.
} 
<smiles>[R]C1=C2C3CCN([R8])C=C3CCN([R8])C2C(=O)C1=O</smiles>

47

$144 \quad \mathrm{R}_{1}=\mathrm{Me} \quad \mathrm{R}_{2}=\mathrm{H} \quad \mathrm{R}_{3}=\mathrm{Me}$

$151 \quad \mathrm{R}_{1}=\mathrm{H} \quad \mathrm{R}_{2}=\mathrm{Br} \quad \mathrm{R}_{3}=\mathrm{Me}$

$160 \quad \mathrm{R}_{1}=\mathrm{H}$

$\mathrm{R}_{2}=\mathrm{H}$

$164 \mathrm{R}_{1}=\mathrm{H}$

$\mathrm{R}_{2}=\mathrm{Br}$

$\mathrm{R}_{3}=\mathrm{H}$

$169 \mathrm{R}_{1}=\mathrm{H}$

$171 \mathrm{R}_{1}=\mathrm{H}$

$\mathrm{R}_{2}=\mathrm{Cl} \quad \mathrm{R}_{3}=\mathrm{H}$

$\mathrm{R}_{2}=\mathrm{H} \quad \mathrm{R}_{3}=\mathrm{Me}$<smiles>[R]C1=C(N)C(=O)C2C3C(=CN([R8])CC13)C=CN2[R]</smiles>

(173-175). ${ }^{131}$ Zyzzyanones A (172) and B (173) are relatives of makaluvamines G (153) and L (158), respectively, through intramolecular cyclization at the benzylic position with a concomitant hydrolysis of the imino bond. $\frac{131}{1}$ Compounds 153 and 158 were transformed to $\mathbf{1 7 2}$ and $\mathbf{1 7 3}$ respectively, in the presence of $\mathrm{NH}_{3}$, supporting this proposition, but also suggesting the possibility of forming zyzzyanones during storage or isolation. 131 A new purine 3,7-dimethylguanine (176) was extracted from a Philippines sponge Z. fuliginosa, along with 145, 147 and $157 . \frac{132}{11}$ A series of unusual imidazolone and imidazolidinone metabolites (177-181) were isolated from a New Caledonian sponge,

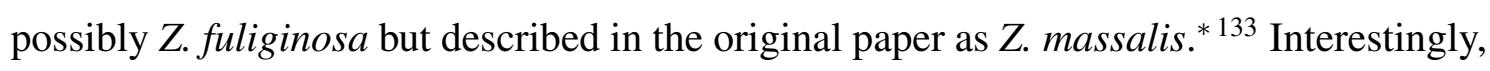
compounds 177, 178 and 179 undergo a temperature-dependent interconversion. For example, compound 178 would transform into 179 and then to 177 when heated in $\mathrm{MeOH} / \mathrm{H}_{2} \mathrm{O}$, whereas cooling of compound 177 would regenerate 178 and $\mathbf{1 7 9}$. The authors of this article stated that this is the first thermochromic system of marine origin.

${ }^{*}$ Zyzzya massalis (Dendy, 1922) has since been taxonomically revised to Zyzzya fuliginosa. 31 


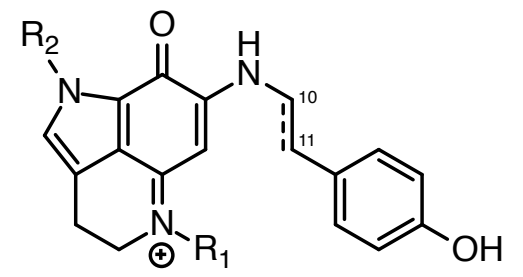

$148 \quad \mathrm{R}_{1}=\mathrm{H} \quad \mathrm{R}_{2}=\mathrm{H}$

$149 \quad \mathrm{R}_{1}=\mathrm{H} \quad \mathrm{R}_{2}=\operatorname{Me} \Delta_{10,11}$

$153 \quad \mathrm{R}_{1}=\mathrm{Me} \quad \mathrm{R}_{2}=\operatorname{Me} \Delta_{10,11}$

$156 \mathrm{R}_{1}=\mathrm{Me} \quad \mathrm{R}_{2}=\mathrm{H}$

$157 \quad \mathrm{R}_{1}=\mathrm{H} \quad \mathrm{R}_{2}=\mathrm{Me}$

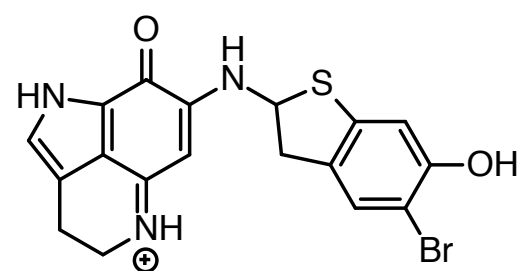

150

$158 \quad \mathrm{R}_{1}=\mathrm{Me} \quad \mathrm{R}_{2}=\mathrm{H} \Delta_{10,11}$

$159 \quad \mathrm{R}_{1}=\mathrm{H} \quad \mathrm{R}_{2}=\mathrm{H} \Delta_{10,11}$

$162 \mathrm{R}_{1}=\mathrm{Me} \quad \mathrm{R}_{2}=\mathrm{Me}$

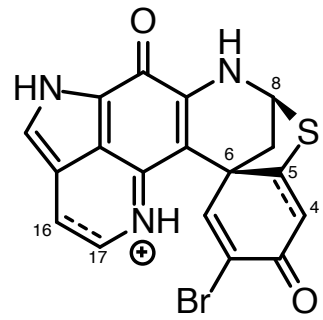

$152(+)-(5 R, 6 S, 8 S)$

$168(-)-(6 R, 8 R) \Delta_{4,5} \Delta_{16,17}$<smiles>NC1=C(Cc2ccc(O)cc2)C2=NCCC3=CNC(C1=O)C32</smiles>

167

172

173<smiles></smiles>

163

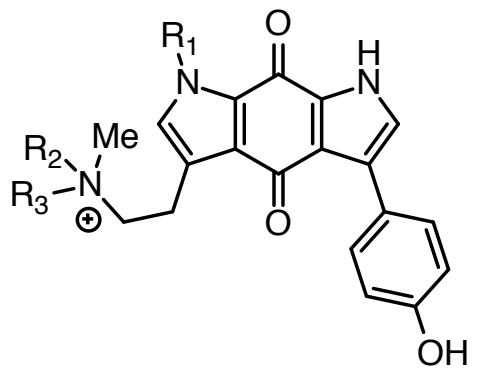

$165 \mathrm{R}_{1}=\mathrm{Me} \quad \mathrm{R}_{2}=\mathrm{H}$

$166 \mathrm{R}_{1}=\mathrm{H} \quad \mathrm{R}_{2}=\mathrm{Me}$<smiles>Cn1cnc2c1c(=O)nc(N)n2C</smiles>

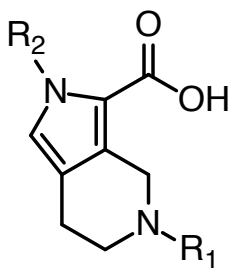

$\mathrm{R}_{1}=\mathrm{Me} \quad \mathrm{R}_{2}=\mathrm{H} \quad \mathrm{R}_{3}=\mathrm{H}$

$\mathrm{R}_{1}=\mathrm{H} \quad \mathrm{R}_{2}=\mathrm{H} \quad \mathrm{R}_{3}=\mathrm{H}$

$174 \mathrm{R}_{1}=\mathrm{Me} \quad \mathrm{R}_{2}=\mathrm{CHO} \quad \mathrm{R}_{3}=2 \mathrm{e}^{-}$

$175 \mathrm{R}_{1}=\mathrm{H} \quad \mathrm{R}_{2}=\mathrm{CHO} \quad \mathrm{R}_{3}=2 \mathrm{e}^{-}$

176

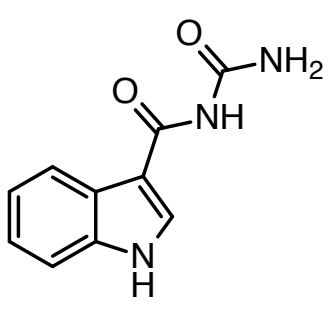

$177 \mathrm{R}=\mathrm{H}$

$178 \mathrm{R}=\mathrm{Me}$<smiles></smiles>

$179 \quad \mathrm{X}=\mathrm{O}$

$180 \quad X=S$ 


\subsection{Isolation}

The Tongan marine sponge Zyzzya fuliginosa (PTN4_10A) was collected using SCUBA from Fakafotulā, Vava'u, Tonga in late November 2009. The massive and soft sponge with partially burrowing bases as well as emergent fistules, was black in life (both exterior and interior) and produced a deep greenish-black mucus on collection.

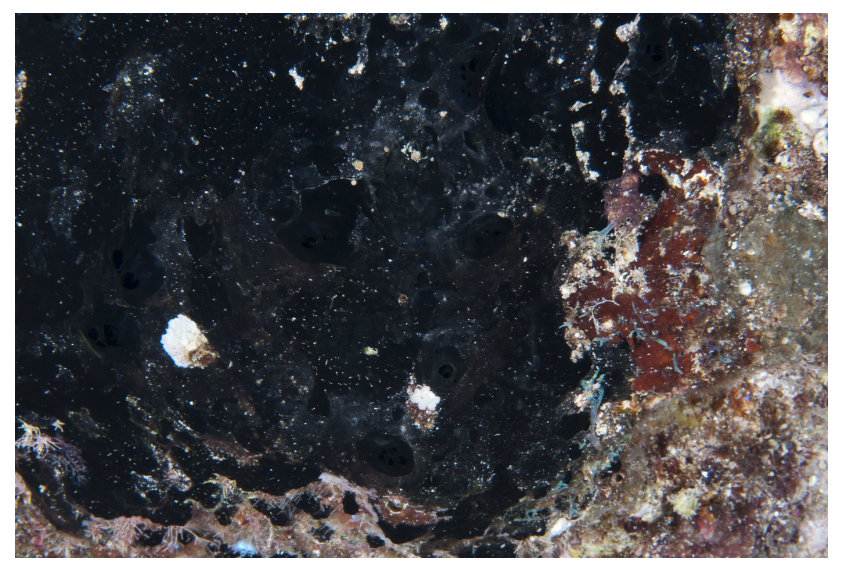

Figure 4.1. Underwater photograph of Zyzzya fuliginosa, collected from Vava 'u, Tonga. Photograph courtesy of Karen Stone.

The sponge was extracted twice in $\mathrm{MeOH}$ and the extracts were cyclic loaded onto a reversed-phase PSDVB column. The column was batch-eluted with increasing amounts of $\mathrm{Me}_{2} \mathrm{CO}$ in $\mathrm{H}_{2} \mathrm{O}$. Examination of the screen fractions by NMR showed that several interesting signals were confined to the $20 \%, 40 \%$ and $60 \% \mathrm{Me}_{2} \mathrm{CO} / \mathrm{H}_{2} \mathrm{O}$ fractions, containing three major structurally-related compounds, damirone B (47), makaluvamine K (157) and makaluvamine E (149), respectively. These fractions were further purified on either DIOL or LH20, with final purification by reversed-phase C18 HPLC, to yield known compounds makaluvamines A (145), E (149), F (150), K (157), makaluvanone (151) and damirone B (47) along with a new pyrroloiminoquinone alkaloid, 6-bromodamirone B (182) (see Scheme 4.1).

A large-scale extraction of $1042.7 \mathrm{~g}$ of Z. fuliginosa was carried out. The methanolic extracts were cyclic loaded ${ }^{*}$ onto a reversed-phase PSDVB column. The column was eluted with increasing concentrations of $\mathrm{Me}_{2} \mathrm{CO}$ in $\mathrm{H}_{2} \mathrm{O}$. Interestingly, the NMR spectra of the $40 \% \mathrm{Me}_{2} \mathrm{CO} / \mathrm{H}_{2} \mathrm{O}$ and the $60 \% \mathrm{Me}_{2} \mathrm{CO} / \mathrm{H}_{2} \mathrm{O}$ fractions, indicated the presence of an additional, structurally related compound that was not detected in the initial

\footnotetext{
${ }^{*}$ Cyclic loading process was carried out by employing an automated pumping system.
} 
screen. These fractions were further partitioned on a PSDVB column followed by final purification using C18 HPLC, which led to the isolation of a new compound, named here as makaluvamine $\mathrm{W}(\mathbf{1 8 3})$, together with additional known compounds makaluvic acid A (165) and tsitsikammamine B (184). 134

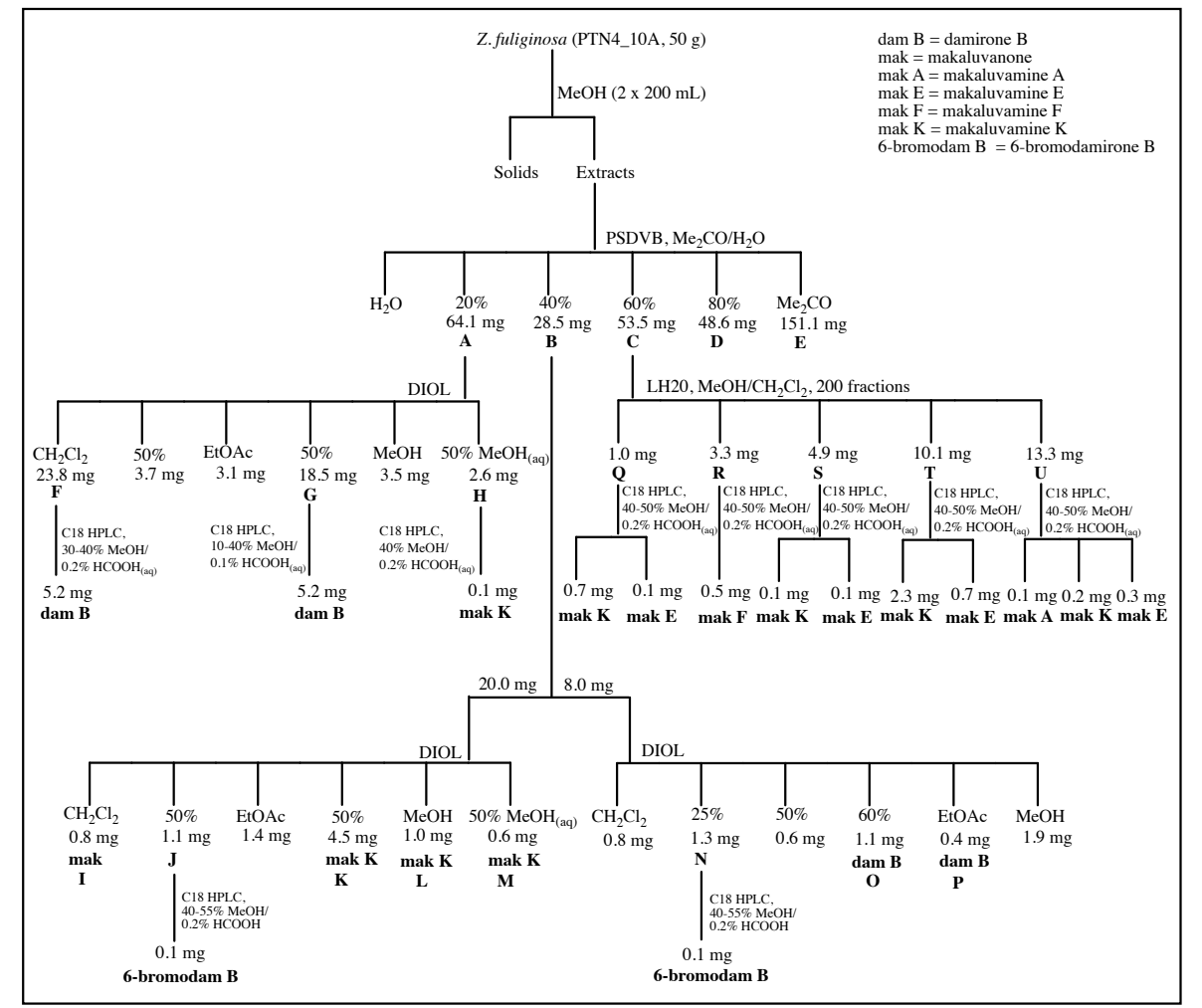

Scheme 4.1. The initial isolation procedure for compounds from the sponge Zyzzya fuliginosa, collected from Vava'u, Tonga.

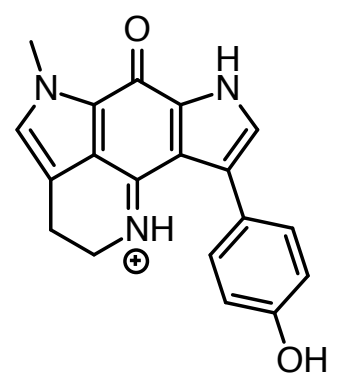

184

As previously mentioned, the makaluvamines represent a series of 17 metabolites, where 16 were named as makaluvamines A to P followed by makaluvamine V. Surprisingly, so far there has been no report of makaluvamines Q-U, which may have inadvertently been skipped and not used in the nomenclature of the makaluvamine family. However the new pyrroloquinoline alkaloid obtained from the Tongan Z. fuliginosa examined in this study, is named here as makaluvamine $\mathrm{W}(\mathbf{1 8 3})$ instead of makaluvamines Q 


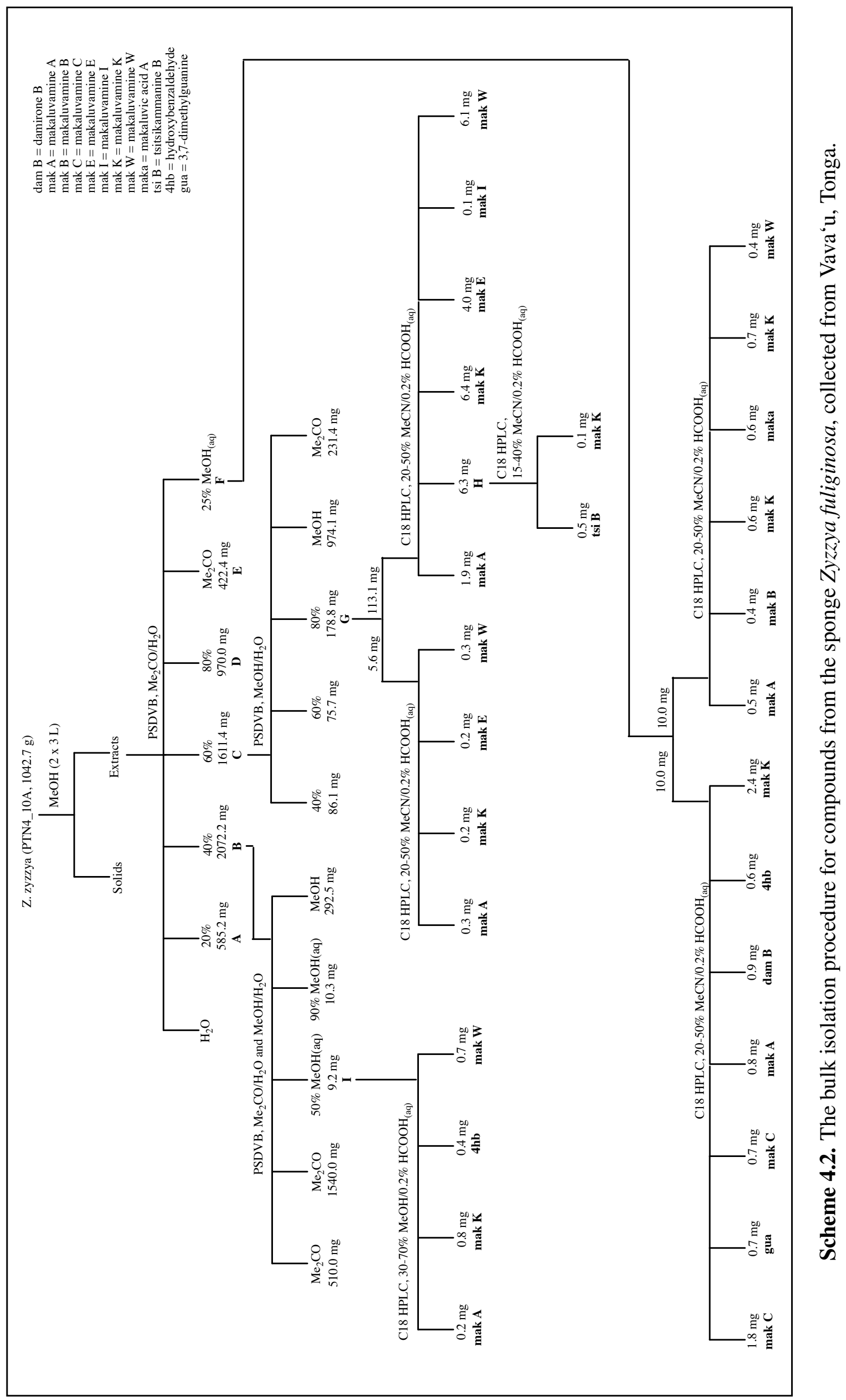




\subsection{6-Bromodamirone B}

6-Bromodamirone B (182) was isolated as a dark purple solid. Positive ion HRESIMS analysis of a monoprotonated ion $[\mathrm{M}+\mathrm{H}]^{+}$at $m / z 280.9918$ indicated a molecular formula of $\mathrm{C}_{11} \mathrm{H}_{9} \mathrm{BrN}_{2} \mathrm{O}_{2}(\Delta=-0.71 \mathrm{ppm})$ and eight degrees of unsaturation. The presence of bromine was evident by a $[\mathrm{M}+2+\mathrm{H}]^{+}$doublet peak in a 1:1 ratio. The ${ }^{13} \mathrm{C} N \mathrm{NMR}$ spectrum revealed 11 resonances and a multiplicity edited HSQC experiment confirmed that all hydrogens but one were attached to carbon. The remaining proton, identified as exchangeable, and was not observed in the ${ }^{1} \mathrm{H}$ NMR spectrum in $\mathrm{CD}_{3} \mathrm{OD}$. The ${ }^{13} \mathrm{C}$ and HSQC spectra revealed one methyl $\left(\delta_{\mathrm{C}} 43.5\right)$, two methylenes $\left(\delta_{\mathrm{C}} 56.9 ; 20.5\right)$ and one olefinic methine $\left(\delta_{\mathrm{C}}\right.$ 125.7). The remaining seven non-protonated centres were assigned as two $\alpha, \beta$-unsaturated carbonyls $\left(\delta_{\mathrm{C}} 176.5 ; \delta_{\mathrm{C}} 168.8\right)$ and five olefinic carbons $\left(\delta_{\mathrm{C}} 154.3\right.$; $126.8 ; 125.7 ; 120.2 ; 112.9)$. With eight of the 11 carbons $s p^{2}$-hybridised, including the two carbonyls, this suggested that the molecule has three rings.

The structural elucidation of 6-bromodamirone B (182) proved to be a challenge due to the highly proton-deficient features of the molecule. Compound $\mathbf{1 8 2}$ falls under the so-called "Crews rule", which suggests that when the ratio of the number of protons to the sum of the heavy atoms (such as $\mathrm{C}, \mathrm{N}, \mathrm{O}, \mathrm{S}$, etc.) in a molecule is $<2, \frac{135.136}{12}$ the structure elucidation of that molecule becomes correspondingly more difficult, and in some cases impossible, to elucidate using conventional suites of NMR experiments such as ${ }^{1} \mathrm{H},{ }^{13} \mathrm{C}$, COSY, multiplicity-edited HSQC, and especially the long-range HMBC experiment. Fortunately, the published literature NMR data for these pyrroloiminoquinone alkaloids are extensive, which made the structural elucidation of 182 practicable by comparison to the published data for makaluvanone, $\frac{119}{10}$ makaluvamines $\frac{115 \mid 119}{123}$ and the damirones, $\underline{63[115}$ The proposed molecular formula of 182 is identical to 151 and its ${ }^{1} \mathrm{H}$ NMR spectrum was similar to that of the isolated makaluvanone (151) and damirone B (47) (see Figure 4.2). In contrast, the pyrrole $N$ methyl $\left(\delta_{\mathrm{H}} 3.91 ; \delta_{\mathrm{C}} 36.2\right)$ of $\mathbf{1 5 1}$ was absent while the iminoquinone $\mathrm{N}-5$ was substituted with a methyl $\left(\delta_{\mathrm{H}} 3.75 ; \delta_{\mathrm{C}} 43.5\right)$. Additionally, the notable absence of the diagnostic olefinic proton $\mathrm{CH}-6\left(\delta_{\mathrm{H}} 5.30 ; \delta_{\mathrm{C}} 93.1\right)$ of damirone B (47), fully supports bromination 


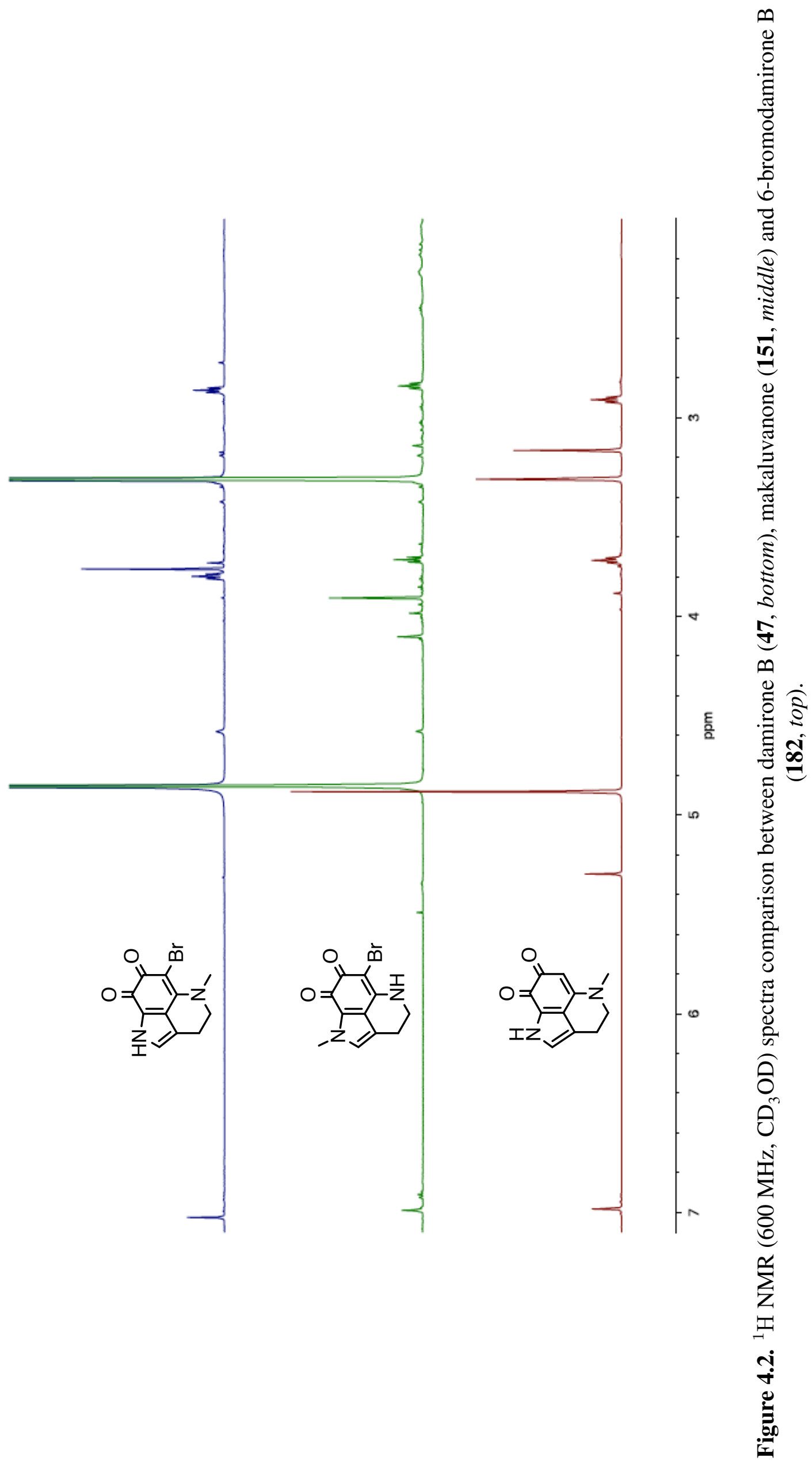


at position 6 of the damirone ring. 6-Bromodamirone B (182) is therefore assigned as a new isomer of makaluvanone (151), with the NMR data presented in Table 4.2 .

The structural elucidation of 6-bromodamirone B (182) began with a series of HMBC correlations from the olefinic methine singlet proton $\mathrm{CH}-2\left(\delta_{\mathrm{H}} 7.02 ; \delta_{\mathrm{C}} 125.7\right)$ to three olefinic non-protonated carbons; C-2a $\left(\delta_{\mathrm{C}} 120.2\right), \mathrm{C}-8 \mathrm{a}\left(\delta_{\mathrm{C}} 126.8\right)$ and $\mathrm{C}-8 \mathrm{~b}\left(\delta_{\mathrm{C}} 125.7\right)$. The olefinic methine $\mathrm{CH}-2$ has an unusually large ${ }^{1} J_{\mathrm{CH}}$ coupling constant $(194 \mathrm{~Hz})$ as compared to the standard olefinic methines $(150-170 \mathrm{~Hz})$, suggesting the attachment of a heteroatom, likely nitrogen. The molecular formula obtained for $\mathbf{1 8 2}$ supported the presence of two nitrogens and the observation of a correlation from $\mathrm{H}-2$ to $\mathrm{NH}-1$ $\left(\delta_{\mathrm{N}}-224.1\right)$ in a ${ }^{1} \mathrm{H}-{ }^{15} \mathrm{~N}$ CIGAR experiment established a pyrrole moiety - a common feature in damirones and makaluvamines. A weak COSY correlation between $\mathrm{H}-2$ and the methylene triplet $\mathrm{CH}_{2}-3\left(\delta_{\mathrm{H}} 2.85 ; \delta_{\mathrm{C}} 20.5\right)$ indicated a long-range coupling between these protons. Analysis of the HMBC spectrum showed correlations from $\mathrm{H}_{2}-3$ to $\mathrm{C}-2, \mathrm{C}-2 \mathrm{a}$ and $\mathrm{C}-8 \mathrm{~b}$, establishing the connection between the pyrrole moiety and $\mathrm{CH}_{2}-3$. Methylene $\mathrm{H}_{2}-3$ showed a vicinal COSY correlation to another methylene triplet resonance at $\delta_{\mathrm{H}} 3.79$ $\left(\mathrm{CH}_{2}-4 ; \delta_{\mathrm{C}} 56.9\right)$, which was supported through diagnostic HMBC correlation data, establishing the connectivity between the two respective carbons. Subsequently, $\mathrm{H}_{2}-4$ showed four HMBC correlations to C-2a, C-3, a non-protonated olefinic carbon C-5a ( $\delta_{\mathrm{C}}$ 154.3) and a methyl singlet $\mathrm{CH}_{3}-5\left(\delta_{\mathrm{H}} 3.75 ; \delta_{\mathrm{C}} 43.5\right)$, establishing the connection between the pyrrole moiety and the spin system. Both $\mathrm{CH}_{2}-4\left({ }^{1} J_{\mathrm{CH}}=142 \mathrm{~Hz}\right)$ and $\mathrm{CH}_{3}-5$ $\left({ }^{1} J_{\mathrm{CH}}=139 \mathrm{~Hz}\right)$ had moderately large ${ }^{1} J_{\mathrm{CH}}$ coupling constants, as compared to typical $s p^{3}$ protonated carbons $(120-130 \mathrm{~Hz})$, again suggesting the attachment of a heteroatom. The remaining nitrogen required by the molecular formula was confirmed at this position through the observed correlation from $\mathrm{H}_{3}-5$ to $\mathrm{N}-5\left(\delta_{\mathrm{N}}-279.5\right)$ in the ${ }^{1} \mathrm{H}-{ }^{15} \mathrm{~N}$ CIGAR experiment. 


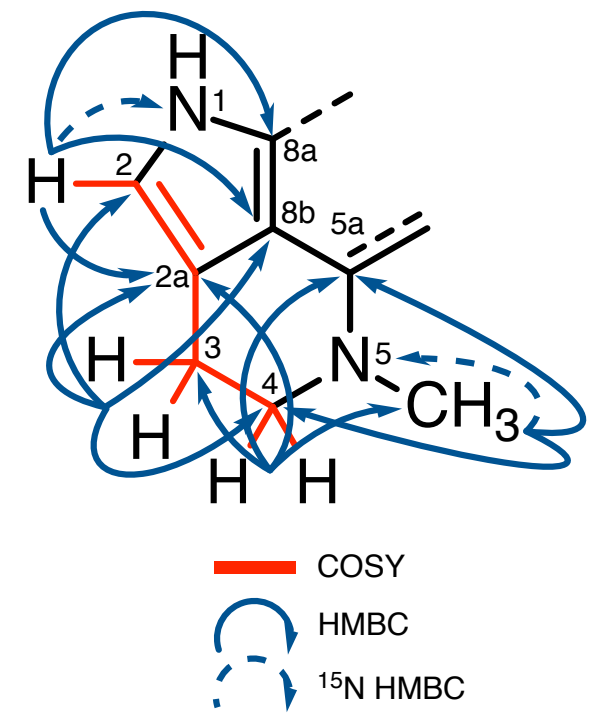

Figure 4.3. Key COSY and HMBC correlations establishing the partial structure of 6-bromodamirone B (182).

With eight of the 11 carbons and all nine protons accounted for, a fragment containing three carbons, two oxygens and one bromine, remained to be assigned. Since all the protons were accounted for, and long-range HMBC correlations were not observed to the remaining quaternary carbons, their chemical shifts were experimentally close enough to those of makaluvanone, ${ }^{119}$ makaluvamine $\mathrm{O}^{123}$ and the damirones, ${ }^{63[115}$ suggesting the retention of a 1,2-diketone moiety. Also supporting this assignment was the fact that four of the eight degrees of unsaturation were yet to be assigned. The olefinic carbon C-6 was the site of bromination, judging from its upfield shift at $\delta_{\mathrm{C}} 87.9$, while the 1,2-diketone carbons were assigned as $\delta_{\mathrm{C}} 168.8(\mathrm{C}-7)$ and $\delta_{\mathrm{C}} 176.5(\mathrm{C}-8)$. Therefore, the structure of 6-bromodamirone B is proposed to be $\mathbf{1 8 2}$ (see Figure 4.4).

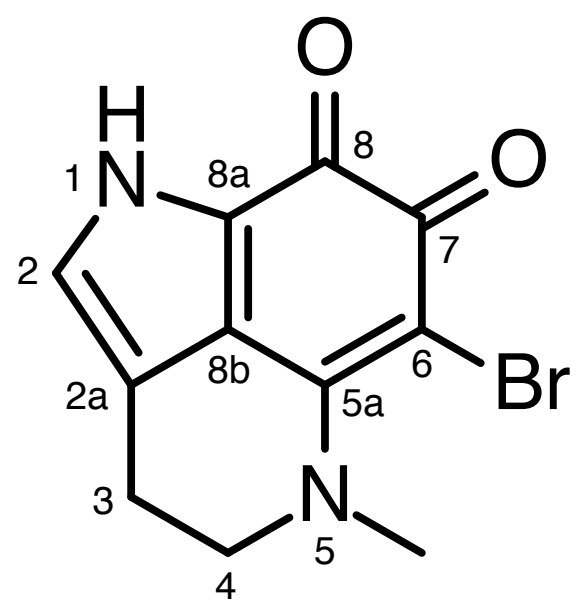

Figure 4.4. Completed planar structure of 6-bromodamirone B (182). 


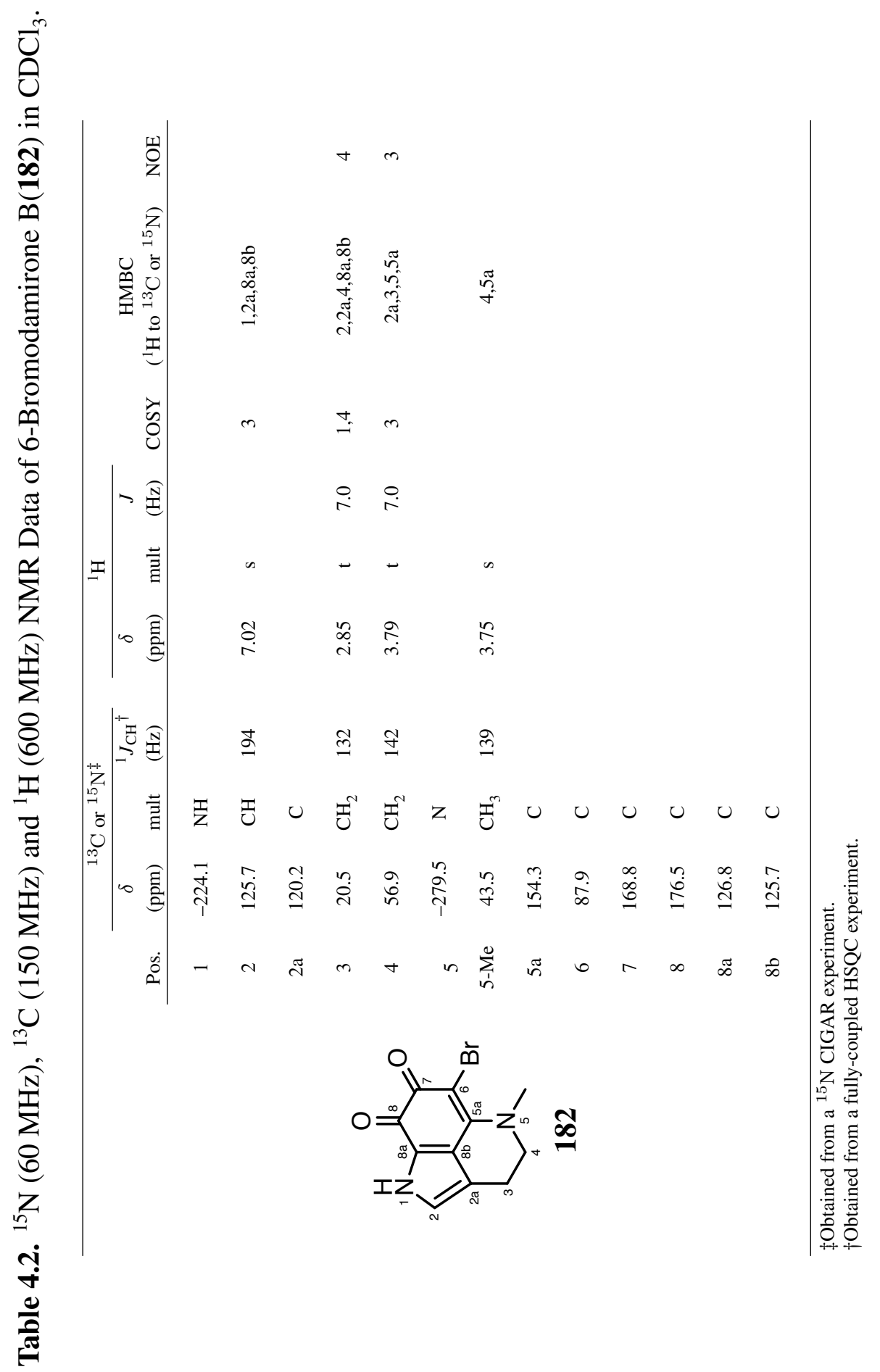




\subsection{Makaluvamine W}

Makaluvamine W (183) was isolated as a brown-purple solid. The observation of a protonated ion by positive ion mode HRESIMS indicated a molecular formula of $\mathrm{C}_{12} \mathrm{H}_{11} \mathrm{~N}_{3} \mathrm{O}$ for $183\left(214.0977[\mathrm{M}+\mathrm{H}]^{+}, \Delta=0.93 \mathrm{ppm}\right)$, for which nine degrees of unsaturation were required. Initial analysis of the ${ }^{13} \mathrm{C}$ NMR spectrum revealed the presence of 12 distinct carbons, and the ${ }^{1} \mathrm{H}$ NMR spectrum accounted for all of the 11 protons. A multiplicity-edited HSQC experiment confirmed the attachment of 10 protons to carbon, indicating the presence of one exchangeable proton. Detailed analysis of the

${ }^{13} \mathrm{C}$ and multiplicity-edited HSQC spectra revealed six protonated carbons including one methyl $\left(\delta_{\mathrm{C}} 38.1\right)$, two methylenes $\left(\delta_{\mathrm{C}} 52.0 ; 22.6\right)$ and three olefinic methines $\left(\delta_{\mathrm{C}} 149.1\right.$; $115.1 ; 82.4)$. The remaining six carbons $\left(\delta_{\mathrm{C}} 149.4 ; 142.0 ; 123.6 ; 118.0 ; 115.8 ; 110.4\right)$ were all assigned as non-protonated olefinic carbons.

Further inspection of the 1D and 2D-NMR experimental data (see Table 4.4) of 183 strongly indicated the presence of a dihydropyrrolo[4,3,2-de]quinoline moiety, including the two methylene triplets $\left[\mathrm{CH}_{2}-3\left(\delta_{\mathrm{H}} 2.97 ; \delta_{\mathrm{C}} 22.6\right), \mathrm{CH}_{2}-4\left(\delta_{\mathrm{H}} 3.25 ; \delta_{\mathrm{C}} 52.0\right)\right]$, the pyrrolic proton at $\delta_{\mathrm{H}} 6.84\left(\mathrm{CH}-2 ; \delta_{\mathrm{C}} 115.1\right)$ and the olefinic proton resonance at $\delta_{\mathrm{H}} 6.46\left(\mathrm{CH}-6 ; \delta_{\mathrm{C}} 82.4\right)$. Simultaneously, it also revealed the presence of an unusual $s p^{2}$-hybridised methine $\mathrm{CH}-10\left(\delta_{\mathrm{H}} 8.36 ; \delta_{\mathrm{C}} 149.1\right)$ with a very large coupling constant $\left({ }^{1} J_{\mathrm{CH}}=235 \mathrm{~Hz}\right)$, suggesting the structure of $\mathbf{1 8 3}$ to be distinct from the common makaluvamines. A subsequent search of the MarinLit database identified citharoxazole (185), an unprecedented pyrroloiminoquinone featuring a benzoxazole moiety that was isolated from the Mediterranean sponge Latrunculia citharistae. $\stackrel{137}{13}$ The large observed ${ }^{1} J_{\mathrm{CH}}$ of $235 \mathrm{~Hz}$ for $\mathrm{CH}-10$ in makaluvamine $\mathrm{W} /$ was exactly the same as the reported value for citharoxazole $\mathrm{CH}-1^{\prime}\left({ }^{1} J_{\mathrm{CH}}=235 \mathrm{~Hz}\right),{ }^{137}$ suggesting the presence of an oxazole moiety. However, the reported NMR spectroscopic data for the oxazole portion of citharoxazole $(\mathbf{1 8 5})^{\dagger}$ did not match that of makaluvamine $\mathrm{W}^{\mathrm{f}}$ suggesting changes to the constitutional structure.

\footnotetext{
*The makaluvamine numbering system is adopted for makaluvamine $\mathrm{W}$, and should not be confused with the system used for citharoxazole.

${ }^{\dagger}$ The NMR for citharoxazole was reported in $\mathrm{CD}_{3} \mathrm{OD}$.

${ }^{\ddagger}$ The NMR data for makaluvamine $\mathrm{W}$ were recorded in $\mathrm{CD}_{3} \mathrm{OD}$ and DMSO- $d_{6}$.
} 


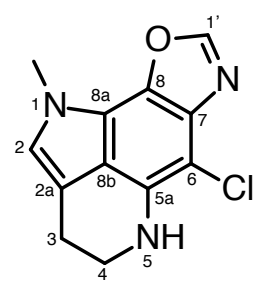

185

The structure of $\mathbf{1 8 3}$ was elucidated in a similar fashion to 6-bromodamirone B (182), beginning at the olefinic methine $\mathrm{CH}-2\left(\delta_{\mathrm{H}} 6.84 ; \delta_{\mathrm{C}} 115.1\right)$, the proton resonance of which displayed a series of HMBC correlations to three olefinic non-protonated carbons; C-2a $\left(\delta_{\mathrm{C}} 110.4\right), \mathrm{C}-8 \mathrm{a}\left(\delta_{\mathrm{C}} 123.6\right)$ and $\mathrm{C}-8 \mathrm{~b}\left(\delta_{\mathrm{C}} 115.8\right)$, leading to the construction of the pyrrole ring. The exchangeable proton $\mathrm{NH}-1\left(\delta_{\mathrm{H}} 11.4\right)$ on the pyrrole ring was observed when the ${ }^{1} \mathrm{H}$ NMR spectrum was acquired in DMSO- $d_{6}$. NH-1 showed a COSY correlation to H-2 and HMBC correlations to four olefinic carbons; $\mathrm{CH}-2, \mathrm{C}-2 \mathrm{a}, \mathrm{C}-8 \mathrm{a}$ and $\mathrm{C}-8 \mathrm{~b}$ of the pyrrole moiety. The unusually large coupling constant $\left(\mathrm{CH}-2 ;{ }^{1} J_{\mathrm{CH}}=184 \mathrm{~Hz}\right)$ obtained from fully-coupled, multiplicity-edited HSQC spectrum, together with the observed correlations from $\mathrm{H}-2$ to $\mathrm{NH}-1\left(\delta_{\mathrm{N}}-248.1\right)$ in a ${ }^{1} \mathrm{H}-{ }^{15} \mathrm{~N}$ CIGAR experiment, established the pyrrole ring. This substructure is the same constitutional section as the other known makaluvamine-type compounds described previously but with significant changes in chemical shifts. $\frac{63[114-116] 118-123}{-13}$ Generally the ${ }^{1} \mathrm{H}$ and ${ }^{13} \mathrm{C}$ chemical shifts for $\mathrm{CH}-2$ in the makaluvamines and damirones range from $\delta_{\mathrm{H}} 7.00$ to $\delta_{\mathrm{H}} 8.15$ and $\delta_{\mathrm{C}} 125$ to $\delta_{\mathrm{C}} 132$, respectively, while $\mathrm{C}-2 \mathrm{a}$ resonates between $\delta_{\mathrm{C}} 117$ to $\delta_{\mathrm{C}} 125$, suggesting changes to the conventional structural features associated with makaluvamine and damirone skeletons for 183 .

Analysis of the COSY spectrum revealed a long-range correlation between H-2 and the methylene triplet protons $\mathrm{H}_{2}-3\left(\delta_{\mathrm{H}} 2.97 ; \delta_{\mathrm{C}} 22.6\right)$, which subsequently showed a vicinal COSY correlation to another methylene triplet at $\delta_{\mathrm{H}} 3.25\left(\mathrm{CH}_{2}-4 ; \delta_{\mathrm{C}} 52.0\right)$, revealing the only spin system in the molecule. HMBC correlations from $\mathrm{H}_{2}-3$ to $\mathrm{CH}-2, \mathrm{C}-2 \mathrm{a}, \mathrm{C}-8 \mathrm{~b}$ and $\mathrm{CH}_{2}-4$ established the connection between the pyrrole moiety and the spin system. Observation of $\mathrm{HMBC}$ correlations from $\mathrm{H}_{2}-4$ to four different carbons; $\mathrm{C}-2 \mathrm{a}, \mathrm{CH}_{2}-3$, methyl $\mathrm{CH}_{3}-5\left(\delta_{\mathrm{H}} 2.91 ; \delta_{\mathrm{C}} 38.1\right)$ and a non-protonated olefinic carbon C-5a $\left(\delta_{\mathrm{C}} 142.0\right)$ extended the fragment further. The downfield shift of methyl $\mathrm{CH}_{3}-5$ and methylene $\mathrm{CH}_{2}-4$ 


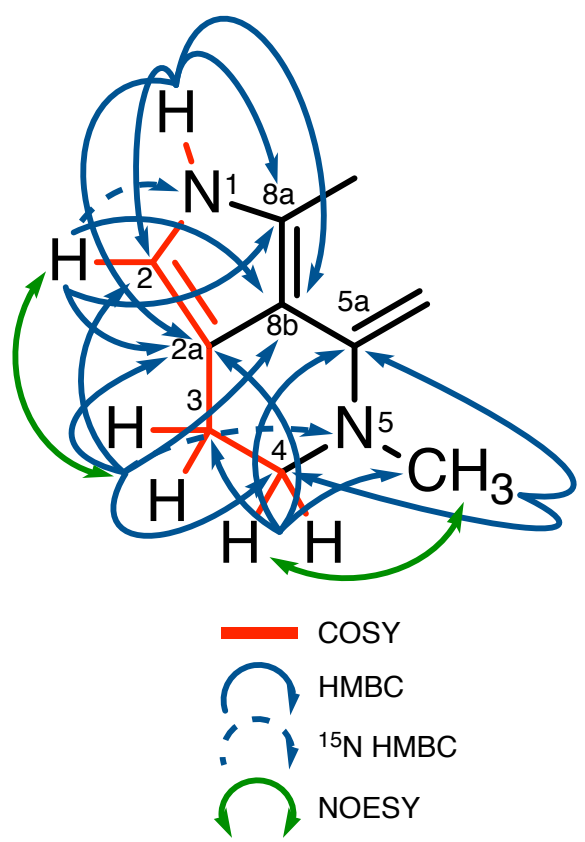

Figure 4.5. Key COSY and HMBC correlations establishing the partial structure of makaluvamine W (183).

suggested their attachment to nitrogen. This was supported by their slightly larger ${ }^{1} J_{\mathrm{CH}}$ coupling constants $\left[\mathrm{CH}_{2}-4\left({ }^{1} J_{\mathrm{CH}}=137 \mathrm{~Hz}\right)\right.$ and $\left.\mathrm{CH}_{3}-5\left({ }^{1} J_{\mathrm{CH}}=135 \mathrm{~Hz}\right)\right]$ observed in the fully-coupled, multiplicity-edited HSQC spectrum, compared to typical protonated $s p^{3}$ carbons $(120-130 \mathrm{~Hz})$. The attachment of nitrogen was further established through a correlation observed in the ${ }^{1} \mathrm{H}-{ }^{15} \mathrm{~N}$ CIGAR experiment, from $\mathrm{H}_{2}-3$ to $\mathrm{N}-5\left(\delta_{\mathrm{N}}-321.2\right)$, and thereby completing the substructure (see Figure 4.5).

In contrast to 6-bromodamirone B (182), the structural elucidation of this part of the molecule was made possible due to the presence of carbon $\mathrm{CH}-6\left(\delta_{\mathrm{H}} 6.46 ; \delta_{\mathrm{C}} 82.4\right)$ and the extra olefinic methine $\mathrm{CH}-10\left(\delta_{\mathrm{H}} 8.36 ; \delta_{\mathrm{C}} 149.1\right)$, despite the proton-deficient natures of 183 (under the "Crews rule"). In Figure 4.6, the first substructure was extended further with COSY and $\mathrm{HMBC}$ correlations between $\mathrm{H}_{3}-5$ and $\mathrm{CH}-6$. In the HMBC experiment, H-6 showed correlations to four non-protonated olefinic carbons including C-5a, C-8b, C-7 $\left(\delta_{\mathrm{C}} 149.4\right)$ and C-8 $\left(\delta_{\mathrm{C}} 118.0\right)$, establishing the presence of the $N$-substituted dihydropyrrolo[4,3,2-de]quinoline core. There were significant changes in the chemical shifts associated with this ring, including the apparent absence of the $\alpha, \beta$-ketone frequently found in makaluvamine-type metabolites. $63[114-116[118,-123$ The established dihydropyrrolo[4,3,2-de]quinolone core accounted for seven degrees of unsaturation. The remaining nitrogen and oxygen should necessitate the inclusion of the 
$s p^{2}$-hybridised methine $\mathrm{CH}-10$ and the final two degrees of unsaturation. Therefore, a substructure was proposed that was consistent with the observed oxidation state and large ${ }^{1} J_{\mathrm{CH}}$ value $(235 \mathrm{~Hz})$ of $\mathrm{CH}-10$, an oxazole ring. ${ }^{137 / 138}$ The nitrogen and the oxygen atoms were also required by the molecular formula and further established through the observed correlation from $\mathrm{H}-10$ to a nitrogen resonance at $\delta_{\mathrm{N}}-135.8$ in the ${ }^{1} \mathrm{H}-{ }^{15} \mathrm{~N}$ CIGAR experiment, supporting the presence of an oxazole ring. The HMBC spectrum showed strong correlations from $\mathrm{H}-10$ to $\mathrm{C}-7, \mathrm{C}-8$ and a weak correlation to $\mathrm{CH}-6$ connected the substructure to the remainder of the molecule.

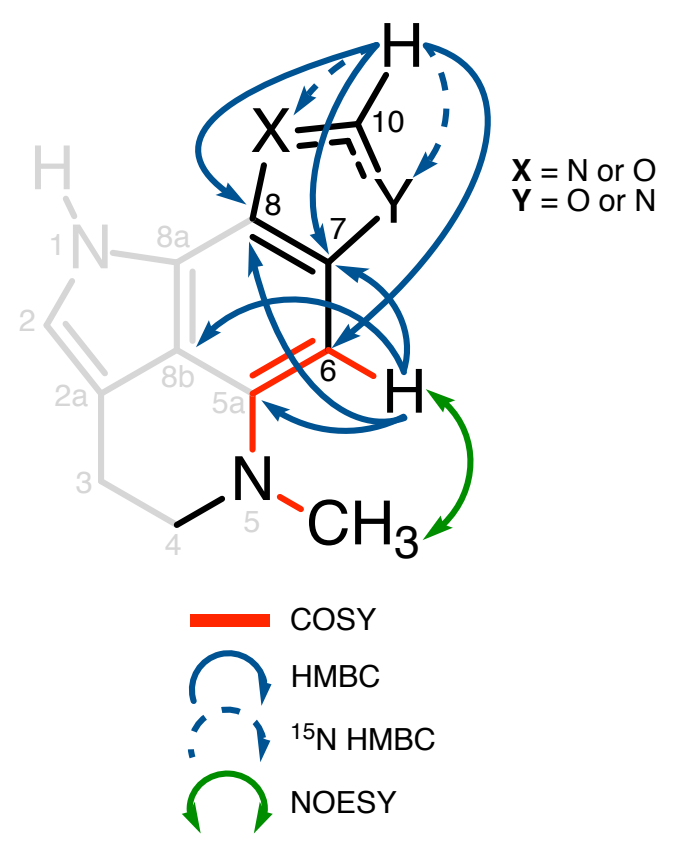

Figure 4.6. Key COSY and HMBC correlations establishing the aromatic and the oxazole rings of makaluvamine $\mathrm{W}(\mathbf{1 8 3})$.

With all carbons and degrees of unsaturation accounted for, two possible structures could be proposed regarding to the placement of the $\mathrm{N}$ and $\mathrm{O}$ atoms (see Figure 4.7). Although H-6 showed HMBC correlations to all the four carbons: C-5a, C-7, C-8 and C-8b, there was no evidence for the order of the two carbon resonances (C-7 and C-8) around the aromatic ring. One of the inherent challenges associated with interpreting HMBC spectra is its inability to differentiate between ${ }^{2} J_{\mathrm{CH}}$ and ${ }^{3} J_{\mathrm{CH}}$. However, certain functional groups have very diagnostic correlation patterns, for example, in aromatic rings the ${ }^{3} J_{\mathrm{CH}}(7-8 \mathrm{~Hz})$ correlations is stronger than ${ }^{2} J_{\mathrm{CH}}(1 \mathrm{~Hz})$ correlations so the ambiguity $\left({ }^{3} J_{\mathrm{CH}} v s^{2} J_{\mathrm{CH}}\right)$ is easily resolved. ${ }^{62}$ Therefore, the placement of the oxazole ring was assigned from the strength of the HMBC correlation intensity from H-6, with weak HMBC correlations from $\mathrm{H}-6$ to $\mathrm{C}-5 \mathrm{a}$ and $\mathrm{C}-7$ and stronger correlations to $\mathrm{C}-8$ and $\mathrm{C}-8 \mathrm{~b}$, thus proposing 
structure $\mathbf{A}$ as the probable structure.

To further validate this proposition, a computational study was carried out, where the two possible structures were fully optimised using hybrid density functional theory (DFT)

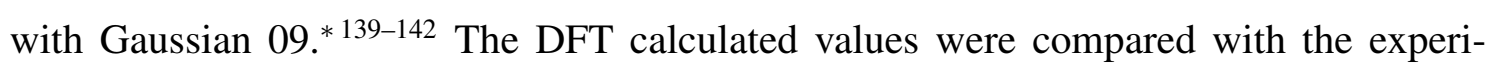
mental chemical shifts of makaluvamine W (183) obtained in $\mathrm{CD}_{3} \mathrm{OD}$ and DMSO- $d_{6}$ (see Table 4.3). The DFT calculated ${ }^{13} \mathrm{C}$ chemical shifts were generally in reasonable agreement with those of the proposed structure A. Structure A has an average error of $7.81 \mathrm{ppm}$ and $6.32 \mathrm{ppm}$, while structure $\mathbf{B}$ has $8.33 \mathrm{ppm}$ and $7.02 \mathrm{ppm}$, in DMSO- $d_{6}$ and $\mathrm{CD}_{3} \mathrm{OD}$, respectively. In addition, calculation values from $\mathrm{DP} 4{ }^{143}$ analysis supported this proposition. Unfortunately the DFT calculated ${ }^{1} \mathrm{H}$ chemical shifts did not provide any conclusive results for both structures. Thus the proposed structure A was assigned as 183, which is opposite to that of the reported citharoxazole (185).

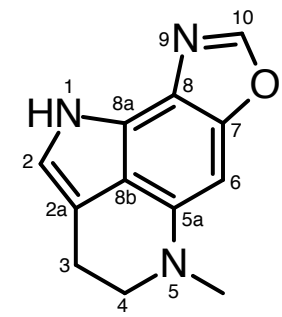

A<smiles>CN1CCc2c[nH]c3c2c1cc1ncoc13</smiles>

B

Figure 4.7. Possible planar structures for makaluvamine W (183).

With the correct arrangement, the structure of makaluvamine W (183) was complete thus establishing only the second example of makaluvamine-type structures containing an oxazole (see Figure 4.8) reported from this family of natural products.

${ }^{*}$ The DFT calculations were performed by Dr. Lein at the School of Chemical and Physical Sciences, VUW. 
Table 4.3. ${ }^{13} \mathrm{C}$ experimental and DFT calculated chemical shifts for makaluvamine $\mathrm{W}$ (183) in $\mathrm{CD}_{3} \mathrm{OD}$ and DMSO- $d_{6}$.

\begin{tabular}{|c|c|c|c|c|c|c|}
\hline \multirow[b]{2}{*}{ Pos. } & \multicolumn{3}{|c|}{ DMSO- $d_{6}$} & \multicolumn{3}{|c|}{$\mathrm{CD}_{3} \mathrm{OD}$} \\
\hline & Exp. (ppm) & $\begin{array}{c}\text { Str. A } \\
\text { DFT calc. (ppm) } \\
\end{array}$ & $\begin{array}{c}\text { Str. B } \\
\text { DFT calc. (ppm) }\end{array}$ & Exp. (ppm) & $\begin{array}{c}\text { Str. A } \\
\text { DFT calc. (ppm) }\end{array}$ & $\begin{array}{c}\text { Str. B } \\
\text { DFT cal. (ppm) }\end{array}$ \\
\hline 2 & 115.1 & 122.9 & 124.4 & 116.0 & 122.9 & 124.4 \\
\hline $2 a$ & 110.4 & 121.8 & 122.3 & 112.4 & 121.8 & 122.2 \\
\hline 3 & 22.6 & 27.6 & 27.7 & 24.0 & 27.6 & 27.6 \\
\hline 4 & 52.0 & 57.3 & 57.3 & 53.9 & 57.2 & 57.6 \\
\hline $5-\mathrm{Me}$ & 38.1 & 40.5 & 40.7 & 38.7 & 40.5 & 40.9 \\
\hline $5 a$ & 142.0 & 152.1 & 151.5 & 143.9 & 152.1 & 151.7 \\
\hline 6 & 82.4 & 88.1 & 95.1 & 83.7 & 88.2 & 95.6 \\
\hline 7 & 149.4 & 160.8 & 148.1 & 151.6 & 160.7 & 148.0 \\
\hline 8 & 118.0 & 126.0 & 138.2 & 119.1 & 126.0 & 138.6 \\
\hline $8 \mathrm{a}$ & 123.6 & 131.8 & 125.8 & 124.9 & 131.8 & 125.9 \\
\hline $8 b$ & 115.8 & 124.7 & 127.1 & 117.8 & 124.6 & 127.2 \\
\hline 10 & 149.1 & 158.6 & 160.2 & 150.2 & 158.6 & 160.7 \\
\hline
\end{tabular}

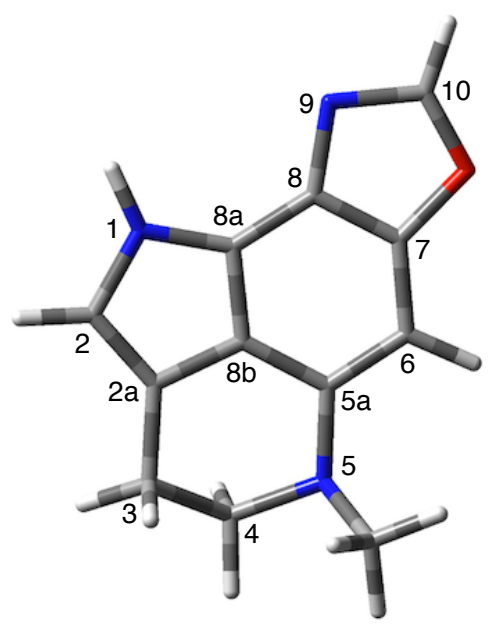

Figure 4.8. 3-D structure of makaluvamine W (183). 


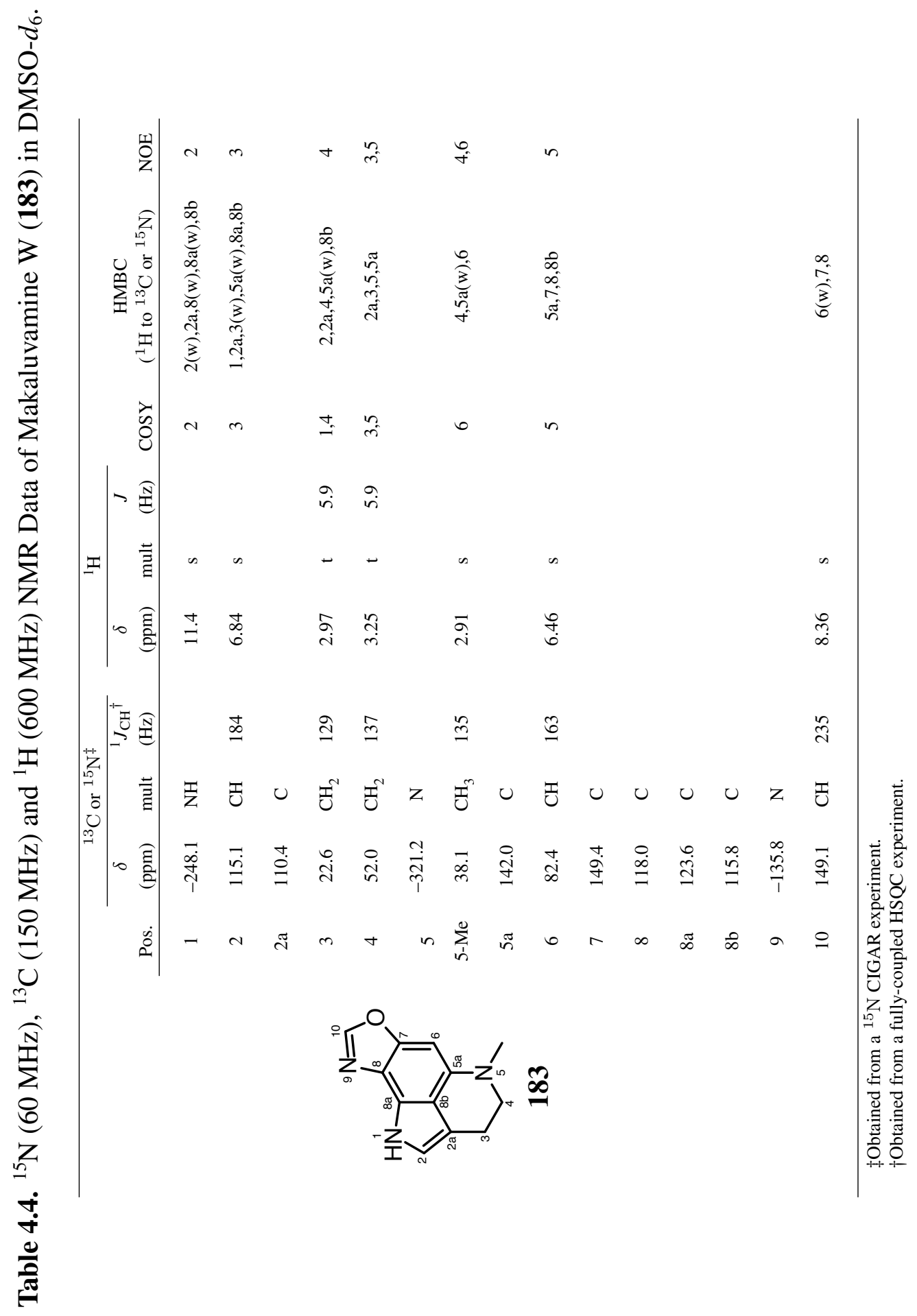




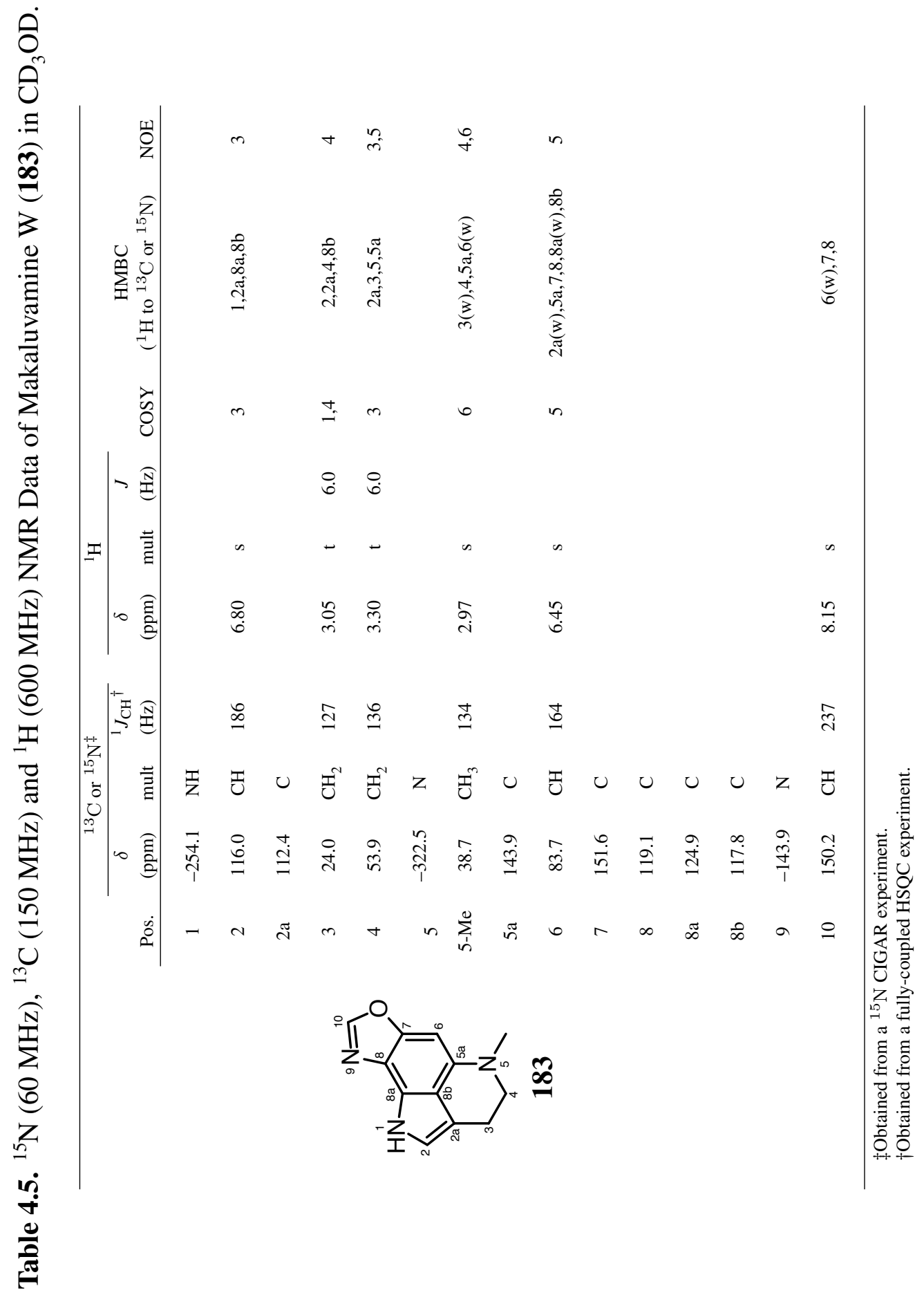




\subsection{Biological Activity}

The new pyrroloiminoquinone analogues and several known compounds were submitted for antiproliferative activity profiling at the School of Biological Sciences, VUW. They were tested in a 48 hour MTT assay against the HL-60 (leukemia) cells. Damirone B (47) and makaluvic acid A (165) showed no inhibitory activities against the HL-60 cell line with $\mathrm{IC}_{50}$ values of $>49 \mu \mathrm{M}$ and $>52 \mu \mathrm{M}$, respectively. This observation was in accordance with the iminoquinone structural requirement necessary for cytotoxicity in the pyrroloiminoquinone alkaloids reported in the literature. ${ }^{122 \mid 129} 6$-Bromodamirone B (182) and makaluvamine W (183) were also ineffective toward the cell lines at the concentrations of $>36 \mu \mathrm{M}$ and $>47 \mu \mathrm{M}$, respectively, which further supported this proposition. In contrast, tsitsikammamine B (184) and makaluvamines C (147), F (150) and $\mathrm{K}(\mathbf{1 5 7})$ exhibited the most antiproliferative potent effect, with $\mathrm{IC}_{50}$ values of 1.59 $\mu \mathrm{M}, 2.57 \mu \mathrm{M}, 3.02 \mu \mathrm{M}$ and $4.50 \mu \mathrm{M}$, respectively, while makaluvamines $\mathrm{A}(\mathbf{1 4 5})$ and $\mathrm{E}$ (149) were found to be the less active with $\mathrm{IC}_{50}$ values of $30.4 \mu \mathrm{M}$ and $20.3 \mu \mathrm{M}$, respectively.

\subsection{The New Pyrroloiminoquinone Alkaloids Biogenesis}

The biosynthesis of pyrroloiminoquinones alkaloids such as the discorhabdins, damirones and makaluvamines have been widely investigated. Due to the structural similarities of these marine alkaloids, Munro and co-workers presented a putative biosynthetic pathway (see Scheme 4.3) that linked these compounds. $\frac{144}{14}$ The postulated biogenetic origin of these metabolites was ascribed to the amino acids tryptophan and phenylalanine (via tryptamine and tyramine) as the biosynthetic precursors. ${ }^{144}$ Appropriate functionalisation and oxidation of typtamine forms the backbone of the pyrroloiminoquinone core. For instance, the incorporation of the tyramine residue in damirones A (144), B (47), and C (160) followed by oxidation could lead to makaluvamines $\mathrm{P}$ (162), J (156), and D (148) respectively, which subsequently undergo cyclisation and elaboration to give the more complex discorhabdins. However, there is some uncertainty associated with 
the hypothetical biosynthetic pathway as to how it proceeds and the origin of these structurally related compounds. The biosynthesis of dischorhabdin B was investigated by Munro and co-workers by incubating slices of antibiotic treated sponge tissue* with $\left(\mathrm{U}_{-}{ }^{14} \mathrm{C}\right)-\mathrm{L}-$ phenylalanine. ${ }^{144}$ The results indicated that the ${ }^{14} \mathrm{C}$ from the (U${ }^{14} \mathrm{C}$ )-L-phenylalanine was incorporated into dischorhabdin B, which implied that Lphenylalanine is also a possible precursor of the pyrroloiminoquinone core skeleton. ${ }^{[144} \mathrm{It}$ also provided convincing evidence that these metabolites are manufactured by the sponge and not by symbiotic micro-organisms. 144

The nature of these metabolites is consistent with the incorporation of decarboxylated amino acids. It is therefore entirely reasonable that the additional feature of makaluvamine $\mathrm{W}$ (183) is derived from a decarboxylated glycine residue. Oxidation and methylation of the pyrroloiminoquinone would give rise to 47 , followed by the attachment of glycine by Schiff's base chemistry. Subsequent decarboxylative elimination would lead to the formation of a phenol with a vicinal imine. Nucleophilic attack of the alcohol upon imine in a [2,3]-sigmatropic shift reaction would lead to the formation of a diene moiety, which further loses a proton to stabilise the developed positive charge on the oxygen atom, consequently forming makaluvamine W (183).

It is proposed that the formation of the oxazole moiety in makaluvamine $\mathrm{W}(\mathbf{1 8 3})$ is derived from an Schiff base reaction between glycine and the carbonyl C-8 of damirone B (47) . $^{\dagger}$ whereas citharoxazole (185) is derived from an Schiff base formation between glycine and the carbonyl C-7 of batzelline C (186) f the presence of the chlorine on C6 in 186 increases the electron density on C-8 through resonance, while decreasing the electron density on C-7 through inductive effect, thereby favouring Schiff base addition on C-7. Similarly, the absence of chlorine on C-6 in 47 increases the electron density on C-7 through resonance from the nitrogen N-5a, thereby favouring Schiff base addition on C-8. As a result, the oxazole moieties in makaluvamine W (183) and citharoxazole (185) have opposite orientations.

In the case of 6-bromodamirone B (182), the pyrroloiminoquinone is considered to be

\footnotetext{
${ }^{*}$ From the marine sponge Latrunculia $\mathrm{sp.}$

${ }^{\dagger}$ Damirone B was isolated as the major compound from the Tongan sponge Z. fuliginosa.

${ }^{\ddagger}$ Citharoxazole was isolated along with the known compound batzelline C.
} 
<smiles>CN1CCc2c[nH]c3c2C1=CC(=O)C3=O</smiles>

47<smiles>Cn1cc2c3c1C(=O)C(=O)C(Cl)=C3NCC2</smiles>

186

a key branching point for the biogenesis of damirones, batzellines, isobatzellines, and simple makaluvamines. $\frac{115[116 \mid 119-123]}{-123}$ Oxidation of the pyrroloiminoquinone would lead to damirone $\mathrm{C}(\mathbf{1 6 0})$, based on the assumption that the methylation would take place before the halogenation process. The methylation of $\mathbf{1 6 0}$ would lead to damirones A (144) or B (47), depending on the nitrogen that is methylated. Methylation of the nitrogen on the iminoquinone N-5 would give rise to 47 while methylation of both the nitrogens would produce 144. On the other hand, bromination of 160 could lead to makaluvamine $O(\mathbf{1 6 4})$, and subsequent methylation would give rise to makaluvanone (151) or 6-bromodamirone B (182), again depending on the nitrogen that was methylated. Methylation of the pyrrolic nitrogen would produce $\mathbf{1 5 1}$ while the methylation of the alternative nitrogen would give rise to 6-bromodamirone $\mathrm{B}$ (182). 


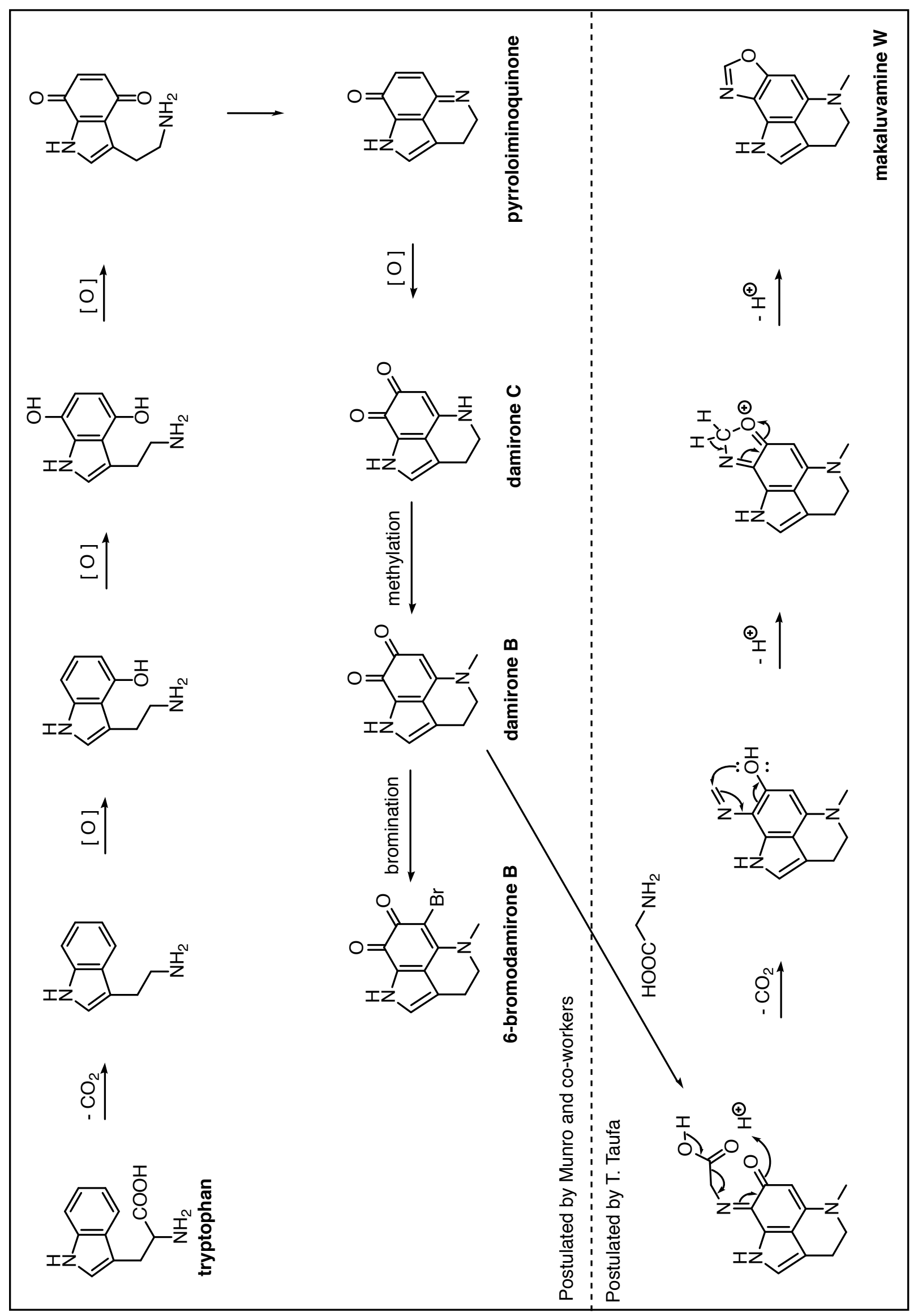

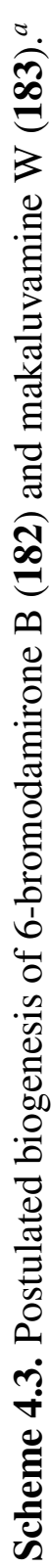




\subsection{Related Compounds}

Over the past 30 years, marine sponges of the families Acarnidae and Latrunculiidae have proved to be a prolific source of pyrroloiminoquinone alkaloids. As previously mentioned, these marine alkaloids usually contain a characteristic dihydropyrrolo[4,3,2de ]quinoline core and represent more than 100 metabolites including discorhabdins, $145-150$

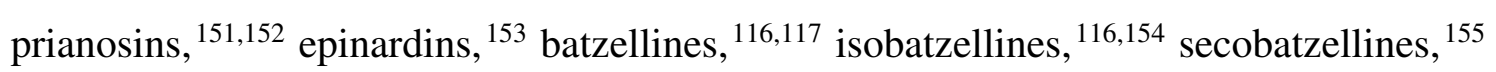

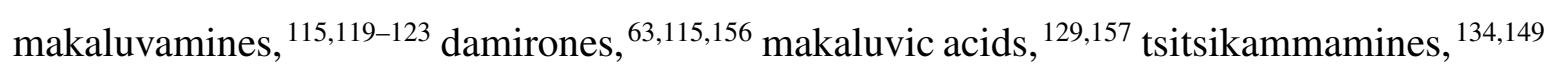
veiutamines ${ }^{118}$ and zyzzyanones. ${ }^{[130 \mid 131}$ Remarkably, almost all of these alkaloids display significant biological properties such as antitumor,

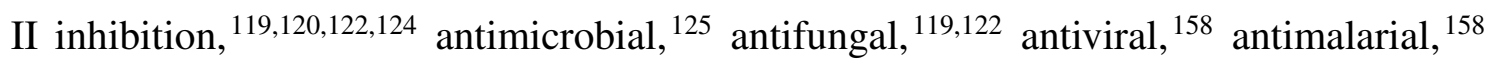
caspase inhibition, ${ }^{159}$ cholinesterase inhibitor ${ }^{160}$ and immunomodulatory activities, 159 thus attracting great interest from both natural product and synthetic chemists alike. Interestingly, these tricyclic pyrroloiminoqui-none-type metabolites are not limited to the marine environment and have also been isolated from terrestrial sources $* 161-166$ As this thesis presents an extensive study of the pyrroloiminoquinone metabolites from the Tongan marine sponge Zyzzya fuliginosa, a review of this class of compounds is deemed necessary. However there were two major reviews conducted by Antunes et al. ${ }^{[13}$ and Hu et al.${ }^{167}$ in 2005 and 2011 respectively, describing the structures, biological activities and synthesis of the pyrroloiminoquinone alkaloids and their analogues. As a result, the review presented here will limit its scope to a comprehensive discussion of the pyrroloiminoquinone-related compounds isolated after the most recent review, together with a thorough discussion of benzoxazole-containing compounds.

In 2012, the new bispyrroloiminoquinone alkaloid, tsitsikammamine $\mathrm{C}$ (187) was isolated from an Australian marine sponge of the genus Zyzzya, together with the known compounds makaluvamines G (153), J (156), K (157), L (158) and damirones A (144) and $\mathrm{B}\left(\mathbf{4 7 )} \cdot \frac{168}{16}\right.$ Compound 187 displayed potent in vitro antimalarial activity with $\mathrm{IC}_{50}$ values of $13 \mathrm{nM}$ and $18 \mathrm{nM}$ against chloroquine-sensitive (3D7) and resistant (Dd2) strains of Plasmodium falciparum, respectively. In 2013, the same group reported four

*Dehydrobufotenine was isolated from the parotid glands of the South American toad Bufo marinus and was the first natural product recognised to contained the pyrrolo[4,3,2-de]quinolone moiety. 161 
thiazine-derived alkaloids, thiaplakortones A-D (188-191) from an Australian marine sponge Plakortis lita using bioassay-guided isolation procedures. ${ }^{169}$ The four compounds were shown to exhibit significant growth inhibition against chloroquine-sensitive (3D7) and resistant (Dd2) P. falciparum $\left(\mathrm{IC}_{50}\right.$ values $\left.<651 \mathrm{nM}\right)$ and only moderate cytotoxicity against human embryonic kidney cell line HEK293 $\left(\mathrm{IC}_{50}\right.$ values $\left.>3.9 \mu \mathrm{M}\right)$. In the same year, the unusual pyrroloiminoquinone scaffold named atkamine (192) ${ }^{\text {* }}$ was reported from the sponge Latrunculia sp $]^{\dagger}$ which was collected from deep cold water of the Aleutian Islands. $\frac{170}{19}$ The structure and absolute configuration of 192 was established by utilising NMR and ECD (electronic circular dichroism) spectroscopies together with chemical degradation and several computational optimisation techniques. Compound 192 employs the same biosynthetic route as the makaluvamines, along with the incorporation of (Z)-15-docosenoic acid Reports of pyrroloiminoquinone alkaloids isolated from the marine environment, in which a fatty acid derivative is incorporated into to its core skeleton, are relatively uncommon. The bioactivity of $\mathbf{1 9 2}$ was not assessed due to the limited quantity of the pure isolated compound and the remoteness of the collection site. In 2017, macrophilone A (193) was the first natural product to be reported from the stinging hydroid Macrorhynchia philippina. ${ }^{171}$ The total synthesis of (193) and several related analogues were also described and were shown to exhibit submicromolar cytotoxicity toward lung adenocarcinoma cells (A549). 171

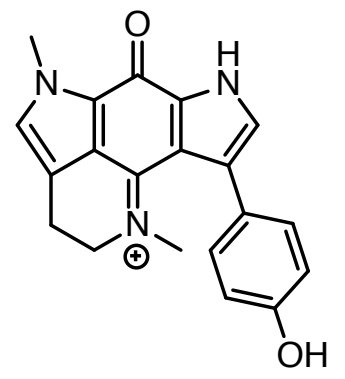

187

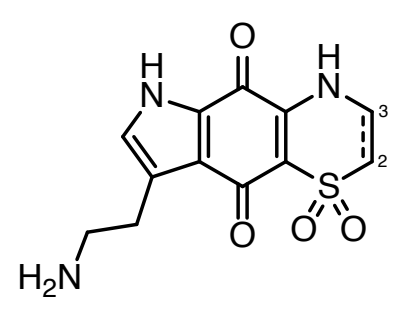

188

$189 \Delta_{2,3}$<smiles>CN[C@@H](Cc1c[nH]c2c1C(=O)C1=C(NC=CS1(=O)=O)C2=O)C(=O)O</smiles>

190

\footnotetext{
*Named after the largest island of the Aleutian Island known as Atka Island.

${ }^{\dagger}$ The same Aleutian collection from which they originally reported dihydrodiscorhabdin B and discorhabdin Y. 158

${ }^{\ddagger}$ A fatty acid commonly found in sponge species in high abundance.
} 
<smiles>CN[C@@H](Cc1c[nH]c2c1C(=O)C1=C(C2=O)S(=O)(=O)C=CN1)C(=O)O</smiles>

191

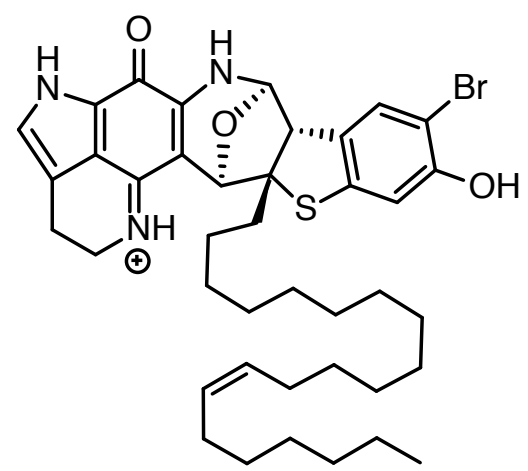

192<smiles>CSC1=C(N)C(=O)c2[nH]cc(CO)c2C1=N</smiles>

193

Benzoxazoles represent a rare category of heterocyclic natural compounds having a variety of pharmacological properties. In 1995, nakijinol A (194) was isolated from an Okinawan sponge of the family Spongiidae. ${ }^{172}$ Compound 194 is considered to be the first sesquiterpenoid with a benzo-fused oxazole ring reported from a natural source. Sixteen years later, a bioassay-guided separation led to the isolation of nakijinol B (195) from the methanolic extract of the marine sponge Dactylospongia elegans. $\frac{173}{13}$ Compound 195 displayed low micromolar cytotoxicity across several human cell lines, including the central nervous system-glioblastoma cells (SF-268), breast-pleural effusion adenocarcinoma cells (MCF-7), lung-large cell carcinoma cells (H460) and colon-rectosigmoid adenocarcinoma cells (HT-29). Chemical investigation of the Indonesian sponge Dactylospongia metachromia afforded 5-epi-nakijinol C (196) and 5-epi-nakijinol D (197). ${ }^{174}$ Both compounds (196 and 197) displayed moderate inhibition of protein kinase. Examination of the New Zealand sponge Dysidea sp. resulted in the isolation of an unnamed benzoxazole sesquiterpenoid (198), along with six new terpenoids. $\frac{175}{17}$ Compound 198 exhibited in vitro cytotoxicity toward the P388 murine leukaemia cell line $\left(\mathrm{IC}_{50}=10.0 \mu \mathrm{M}\right)$ and antimicrobial activity against Bacillus subtilis and Trichophyton mentagrophytes. 175

In 1999, pseudopteroxazole (199) and seco-pseudopteroxazole (200) were obtained from the West Indian gorgonian coral Pseudopterogorgia elisabethae. ${ }^{176}$ Compound 199 was found to have potent inhibitory activity (97\%) against Mycobacterium tuberculosis $\left(\mathrm{H}_{37} \mathrm{Rv}\right)$ at a concentration of $12.5 \mu \mathrm{g} / \mathrm{mL}$, whereas 200 inhibited $66 \%$ of the mycobacterial growth. ${ }^{176}$ Four years later the absolute configuration of $\mathbf{1 9 9}$ was established by total synthesis. ${ }^{177}$ In 2003 , the same research group reported homopseudopteroxazole (201) 
from the same organism, and found to be a strong growth inhibitor of $M$. tuberculosis $\left(\mathrm{H}_{37} \mathrm{Rv}\right) .{ }^{178}$ Further analysis of the same organism by the same research group in 2006 led to the isolation of ileabethoxazole (202), which was shown to inhibit $92 \%$ of the growth of M. tuberculosis $\left(\mathrm{H}_{37} \mathrm{Rv}\right)$ at the concentration range of $64-128 \mu \mathrm{g} / \mathrm{mL} .179$

198 5-epi $\quad \mathrm{R}_{1}=\mathrm{OH} \quad \mathrm{R}_{2}=\mathrm{H} \quad \mathrm{R}_{3}=\mathrm{H}$<smiles>[R5]c1nc2cc([R6])c([R])c(C[C@]3(C)[C@H](C)CC[C@]4(C)C(C)=CCC[C@@H]43)c2o1</smiles>

$$
\mathrm{R}_{1}=\mathrm{OH} \quad \mathrm{R}_{2}=\mathrm{OH} \quad \mathrm{R}_{3}=\mathrm{H}
$$<smiles></smiles>

195<smiles>[R]c1nc2c(C)c3c4c(c2o1)[C@@H](C)CC[C@H]4[C@H](C)C[C@H]3C(C)C</smiles>

$199 \mathrm{R}=\mathrm{H}$

$201 \mathrm{R}=n-\mathrm{C}_{5} \mathrm{H}_{11}$<smiles>CC[C@@H](C)c1c([C@@H](C)CCC=C(C)C)cc(C)c2ncoc12</smiles>

200

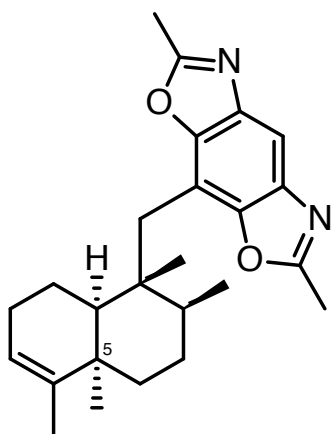

197<smiles>Cc1c2c3c(c(C)c1OC=N2)[C@H](C)CC[C@H]3C</smiles>

202

Caboxamycin (203) was discovered within the cultures of the deep-sea strain Streptomyces sp. NTK 937. 180 Compound 203 displayed antibiotic activity against various Gram-positive bacteria, moderate cytotoxicity against several human tumor cell lines and inhibited the activity of the enzyme phosphodiesterase. ${ }^{180}$ There are several structurally related metabolites to caboxamycin have been identified from terrestrial sources. These include nataxazole (204), ${ }^{181}$ UK-18 (205), ${ }^{182}$ AJ195619 (206) ${ }^{183}$ and the A-33853 (207),, 184 all isolated from terrestrial Streptomyces strains, and were all shown to have similar strong growth inhibitory activity against various human tumor cell lines. 
<smiles>O=C(O)c1cccc2oc(-c3ccccc3O)nc12</smiles>

203

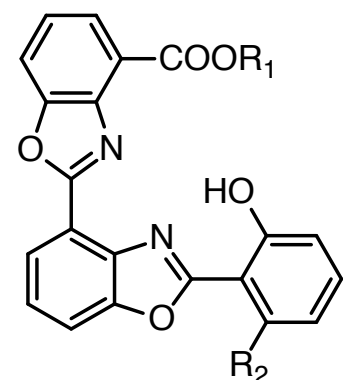

$204 \mathrm{R}_{1}=\mathrm{Me} \quad \mathrm{R}_{2}=\mathrm{Me}$

$205 \mathrm{R}_{1}=\mathrm{Me} \quad \mathrm{R}_{2}=\mathrm{H}$

$206 \quad \mathrm{R}_{1}=\mathrm{H} \quad \mathrm{R}_{2}=\mathrm{Me}$<smiles>O=C(Nc1c(O)cccc1-c1nc2c(C(=O)O)cccc2o1)c1ncccc1O</smiles>

207

In 2011, the aaptamine-type alkaloids nakijinamines $\mathrm{C}$ and $\mathrm{E}$ (208 and 209), were isolated and characterised from the Okinawan sponge of the genus Suberites and were shown to have antifungal activity against Aspergillis niger ${ }^{185}$ Nakijinamines $\mathrm{C}$ and $\mathrm{E}$ were the first natural products to possess a $1 H$-oxazole-[4',5':4,5]benzo[1,2,3-de][1,6]naphthyridine ring system. Most recently, oxazocurcuphenol (210) was obtained from the Caribbean gorgonian Pseudopterogogia rigida and exhibited inhibitory activity against CDC25 phosphatases. 186<smiles>C[N+](C)(C)CC(c1cc2ccc(Br)cc2[nH]1)c1cc2c3[nH]ccc=2[nH]ccc1=c1oc(C[S+]([O-])([O-])[O-])nc1=3</smiles>

208<smiles>Cn1cnc(CC2=Nc3c4c5[nH]ccc(c-4c3c5C(C[N+](C)(C)C)c3cc4ccc(Br)cc4[nH]3)=CC=N2)c1</smiles>

209<smiles>CC(C)=CCC[C@H](C)c1c(O)cc(C)c2ncoc12</smiles>

210 


\subsection{Concluding Remarks}

Sponges of the order Poecilosclerida have proved to be a prolific source of biologically active pyrroloiminoquinone metabolites. On the basis of the chemotaxonomic studies of Z. fuliginosa, a metabolic pattern specific within this species has become evident. Examination of the Tongan sponge $Z$. fuliginosa yielded two new pyrroloiminoquinone analogues (182 and 183), which proved that this species produces an abundance of damirone and makaluvamine-type metabolites. Makaluvamine W (183) represented only the second example of makaluvamine-type structures containing an oxazole reported from this family of natural products. The lack of cytotoxicity of the new pyrroloiminoquinone alkaloids supports the earlier suggestion that the iminoquinone moiety may be responsible for the observed biological activities, since no activity was reported for damirones, makaluvic acids and batzellines which lack this structural feature. 


\section{Chapter 5}

\section{Chemical Investigation of a Tongan Marine Sponge of the}

\section{Genus Leucetta}

Analysis of a Tongan Leucetta sp. sponge yielded five new compounds, including three glycerol ethers, two glycerol lipids and a new imidazole alkaloid. Investigation of this specimen was undertaken following the identification of several interesting NMR correlations in the $1 D$ - and $2 D$-NMR screening spectra.

\subsection{Leucetta sp.}

The genus Leucetta belongs to the family Leucettidae, a member of the order Clathrinida, which in turn belongs to the class Calcarea (commonly called calcareous sponges). $\frac{31 / 32}{.6}$ Calcareous sponges are exclusively marine organisms that possess a calcium carbonate skeleton and are represented by 726 accepted species. ${ }^{32}$ They are found in oceans in all climates and at all depths, from the littoral down to the abyss. Up to the early 1980s, sponges of the class Calcarea had rarely been the subject of chemical investigations and had been overlooked as a source of natural products compared to the Demospongiae, despite their occurrence in all marine habitats. This was due in large part both to their low biomass and their relatively low number of representatives within the phylum Porifera. ${ }^{187}$ Nowadays, chemical studies on calcareous sponges are almost restricted to the sub-class Calcinea (see Table 5.1) and especially to the genera Leucetta and Clathrina. ${ }^{188}$

The MarinLit database ${ }^{\frac{18}{18}}$ provides 65 marine natural products (excluding re-isolated known compounds), which were isolated from the marine sponge genus Leucetta between 1979 and 2017. While it is beyond the scope of this thesis to account for all of these compounds, a selected few will be discussed in this review. Early chemical investigations of the Leucetta sp. sponges led to the isolation of interesting imidazole alkaloids such as naamines (e.g. 211),,$^{1895}$ isonaamines (e.g. 212), $189[190[196$ 
Table 5.1. Taxonomic classification of the genus Leucetta from sub-class Calcinea as presented by World Porifera Database. 31

\begin{tabular}{|c|c|c|c|}
\hline Subclass & Order & Family & Genus \\
\hline \multirow{7}{*}{ Calcinea } & \multirow{7}{*}{ Clathrinida } & Clathrinida & Leucomalthe \\
\hline & & Clathrinidae & $\begin{array}{l}\text { Arthuria } \\
\text { Borojevia } \\
\text { Brattegardia } \\
\text { Clathrina } \\
\text { Ernstia } \\
\text { Guancha } \\
\text { Nicola } \\
\end{array}$ \\
\hline & & Dendyidae & $\begin{array}{l}\text { Dendya } \\
\text { Soleneiscus }\end{array}$ \\
\hline & & Leucaltidae & $\begin{array}{l}\text { Ascandra } \\
\text { Leucaltis } \\
\text { Leucettusa } \\
\text { Leuclathrina }\end{array}$ \\
\hline & & Leucascidae & $\begin{array}{l}\text { Ascaltis } \\
\text { Ascoleucetta } \\
\text { Leucascus }\end{array}$ \\
\hline & & Leucettidae & $\begin{array}{l}\text { Leucetta } \\
\text { Pericharax }\end{array}$ \\
\hline & & Levinellidae & $\begin{array}{l}\text { Burtonulla } \\
\text { Levinella } \\
\text { Sycettaga }\end{array}$ \\
\hline
\end{tabular}

naamidines (e.g. 213) $\frac{189|190| 197-200}{1}$ and isonaamidines (e.g. 214). $\frac{189|190| 193|196| 201}{1}$ These groups of alkaloids are similar in that each possesses a central imidazole ring, to which one or two functionalised benzyl moieties are usually attached at the C-4, C-5, or N-3 positions. Biosynthetically related compounds have also been isolated from this genus, including leucettamines (e.g. 215), 194202 clathridines (e.g. 216), 197201 spirocalcaridines (e.g. 217), $\frac{188}{10}$ kealiinines (e.g. 218) $)^{195}$ and kealiiquinones (e.g. 219). $\frac{191203}{1203}$ These imidazole alkaloids exhibit a diverse array of biological activities such as antimicrobial,, $189[190|193| 196 \mid 198$ anticryptococcal, 192 inhibition of nitric oxide synthase, 203 leukotriene $\mathrm{B}_{4}$ receptor antagonist, $\stackrel{202}{ }$ epidermal growth factor (EGF)-stimulated DNA synthesis inhibition ${ }^{[204}$ and cytotoxic activities. ${ }^{[93 / 195 / 199}$ Imidazole alkaloids dominate the compounds reported from Leucetta sp., however a few non-imidazole alkaloid compounds have also been reported from Leucetta sponges, such as the leucettamols (e.g. 220), 205 rhapsamine (221), 206 leucamide (222) $)^{207}$ and 2E,6Z,9Z-2-methyl-2,6,9icosatrienal (223). $\underline{208}$ 


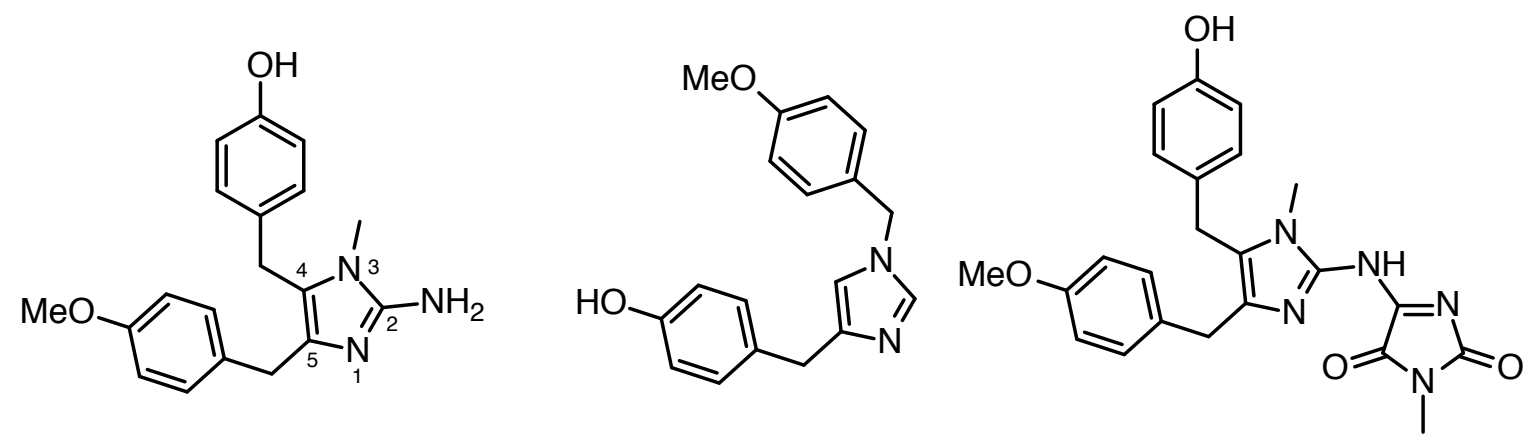

211

212

213

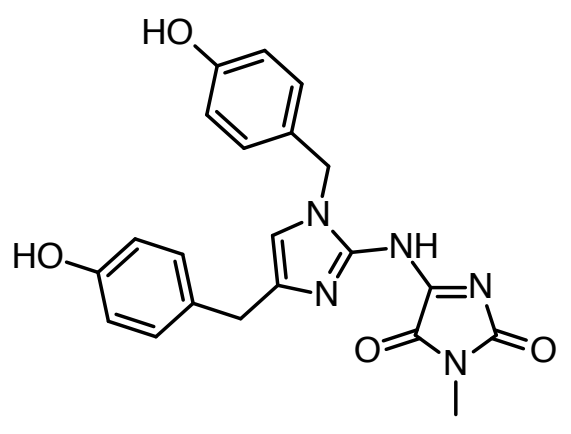

214

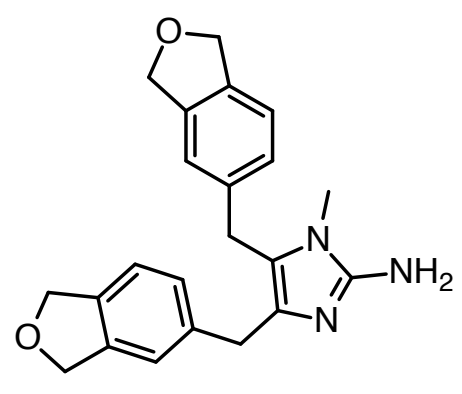

215

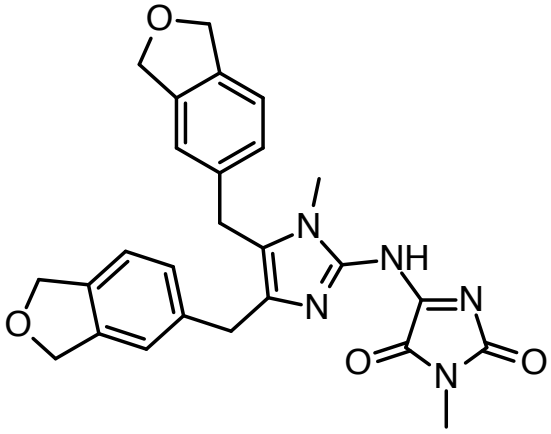

216<smiles>COc1ccc(C2C3(C=CC(=O)C=C3)CC3(O)N(C)C(N)=NC23O)cc1</smiles>

217<smiles>COc1ccc(-c2c3cc(O)c(OC)cc3cc3c2[nH]c(=N)n3C)cc1</smiles>

218<smiles>COC1=C(OC)C(=O)c2c(cc3c(nc(O)n3C)c2-c2ccc(OC)cc2)C1=O</smiles>

219<smiles>C[C@H](N)C(O)C/C=C/C/C=C/C/C=C/C/C=C/C/C=C/C/C=C/CCCCCC[C@H](O)[C@H](C)N</smiles><smiles>NCC(O)CNCC/C=C\C/C=C/C/C=C/C/C=C/C/C=C/C/C=C/CCNCC(O)CN</smiles> 


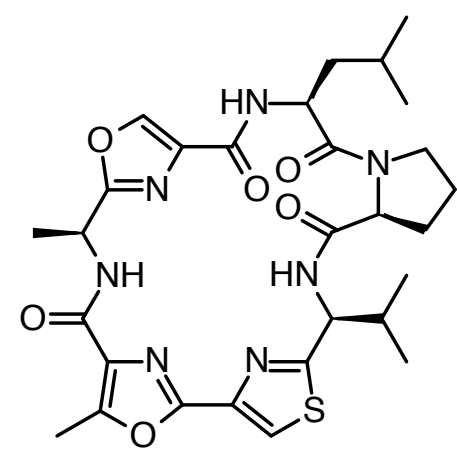

222

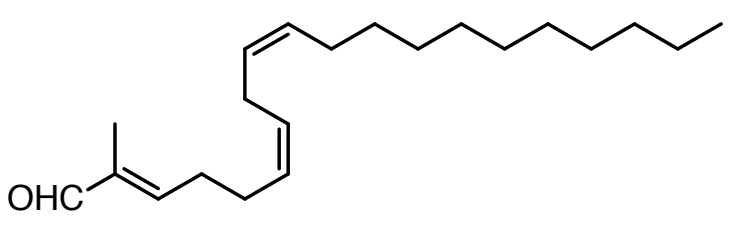

223

\subsection{Isolation}

In this present study, a bright lemon-yellow calcareous sponge $(825 \mathrm{~g})$ of the genus Leucetta (PTN3_45H, Figure 5.1) was collected by hand using SCUBA from an underwater cave from Tu'ungasika Island, Vava' $u$, Tonga in late November 2009. The sponge has a spherical or globular shape with large elevated oscules. They are widely distributed throughout the Indo-Pacific, mostly in shallow waters. ${ }^{188}$ The sponge has a firm, compact and smooth texture but is also friable. A small amount of Leucetta sp. (50 g) was extracted twice in $\mathrm{MeOH}$, and cyclic loaded onto a reversed-phase PSDVB column, which was subsequently eluted with increasing concentrations of $\mathrm{Me}_{2} \mathrm{CO}$ in $\mathrm{H}_{2} \mathrm{O}$.

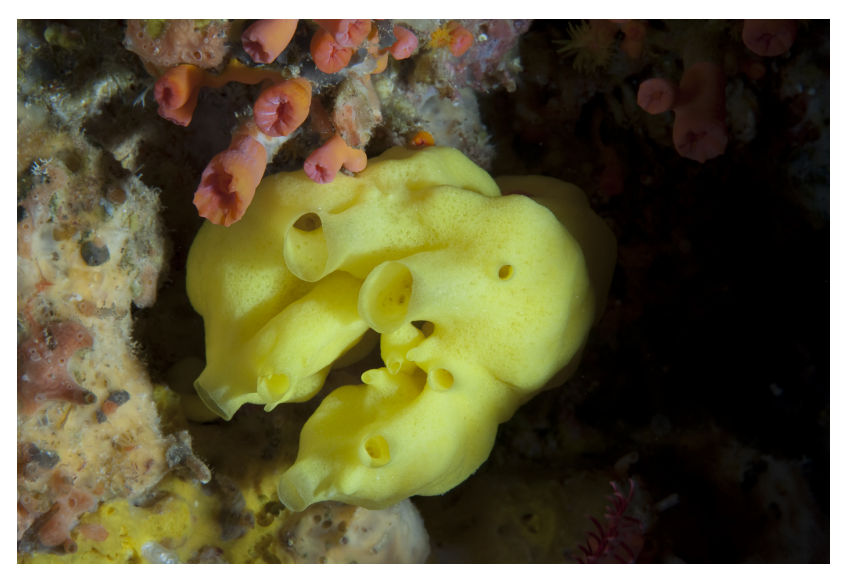

Figure 5.1. Underwater photograph of Leucetta sp., collected from Vava 'u, Tonga. Photograph courtesy of Karen Stone.

The ${ }^{1} \mathrm{H}$ NMR spectrum of the $75 \% \mathrm{Me}_{2} \mathrm{CO} / \mathrm{H}_{2} \mathrm{O}$ fraction showed interesting resonances in the aromatic and $\delta_{\mathrm{H}} 2.00-4.00$ regions. This fraction was further purified using reversedphase (PSDVB) and normal phase $\left(\mathrm{SiO}_{2}\right)$ bench-top chromatography, followed by reversed-phase C18 HPLC to yield two known compounds, cyclolinteinone (224) ${ }^{209}$ and naamidine A (213). $\frac{189}{10}$ A large-scale extraction of the sponge ( $300 \mathrm{~g}$ ) was subsequently 
performed. The $\mathrm{MeOH}$ extracts were cyclic loaded onto a reversed-phase PSDVB column, and subsequently fractionated to give four fractions of increasing concentrations of $\mathrm{Me}_{2} \mathrm{CO}$ in $\mathrm{H}_{2} \mathrm{O}$ (depicted in Scheme 5.1).

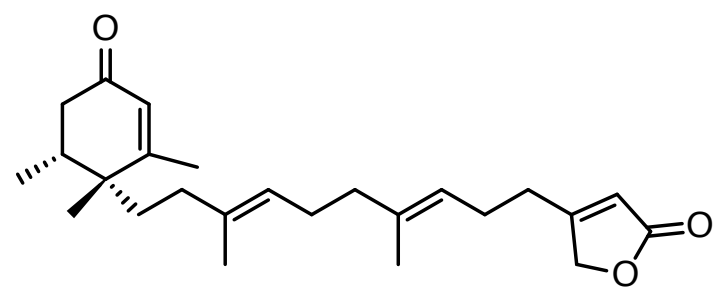

224

NMR analysis of the resulting fractions revealed that the $\mathrm{Me}_{2} \mathrm{CO}$ fraction (fraction D) showed evidence of fused ring systems. Silica flash column chromatography was carried out on this fraction, collecting 96 fractions, which were combined into nine samples based on TLC. Analysis of these fractions using NMR spectroscopy revealed the presence of glycerol lipids in fraction $\mathbf{M}$ and evidence of epidioxy sterols in fraction $\mathbf{N}$. In the ${ }^{1} \mathrm{H}$ NMR spectrum of the sterol-containing fraction (fraction $\mathbf{N}$ ), two doublets at $\delta_{\mathrm{H}} 6.25(1 \mathrm{H}, J=8.6 \mathrm{~Hz})$ and $\delta_{\mathrm{H}} 6.51(1 \mathrm{H}, J=8.6 \mathrm{~Hz})$ were observed, which are characteristic of $5 \alpha, 8 \alpha$-epidioxy sterols. $\frac{210}{2}$ This fraction was purified by a series of reversed-phase C18 HPLC procedures, which led to the isolation of 13 known $5 \alpha, 8 \alpha$-epidioxy sterols (225-237). The glycerol-containing fraction (fraction M) was subsequently purified using a combination of normal phase $\left(\mathrm{SiO}_{2}\right)$ bench-top chromatography and reversed-phase C18 HPLC, which resulted in the isolation of two new glycerol lipids, 238 and 239.

The $80 \% \mathrm{Me}_{2} \mathrm{CO} / \mathrm{H}_{2} \mathrm{O}$ fraction (fraction $\mathbf{C}$ ) was fractionated on a $\mathrm{SiO}_{2}$ column and 105 fractions were collected. These fractions were combined into 14 samples based on TLC and ${ }^{1} \mathrm{H}$ NMR evidence. The least polar fraction (fraction $\mathbf{H}$ ) showed a mixture of compounds by TLC. Further purification of this fraction on C18 HPLC $\left(10 \% \mathrm{H}_{2} \mathrm{O}\right.$ in $\left.\mathrm{MeOH}\right)$ resulted in the isolation of two known compounds, 2E,6Z,9Z2-methyl-2,6,9-icosatrienal (223) $)^{208}$ and 2,4,6-triphenyl-1-hexene (240). ${ }^{211212}$ Fraction I was purified using the same conditions to yield fraction $\mathbf{L}$. The ${ }^{1} \mathrm{H}$ NMR spectrum of this fraction suggested that there was just one compound, but examination of the 2D-NMR data confirmed a mixture of two compounds. Fraction $\mathbf{J}$ contained 


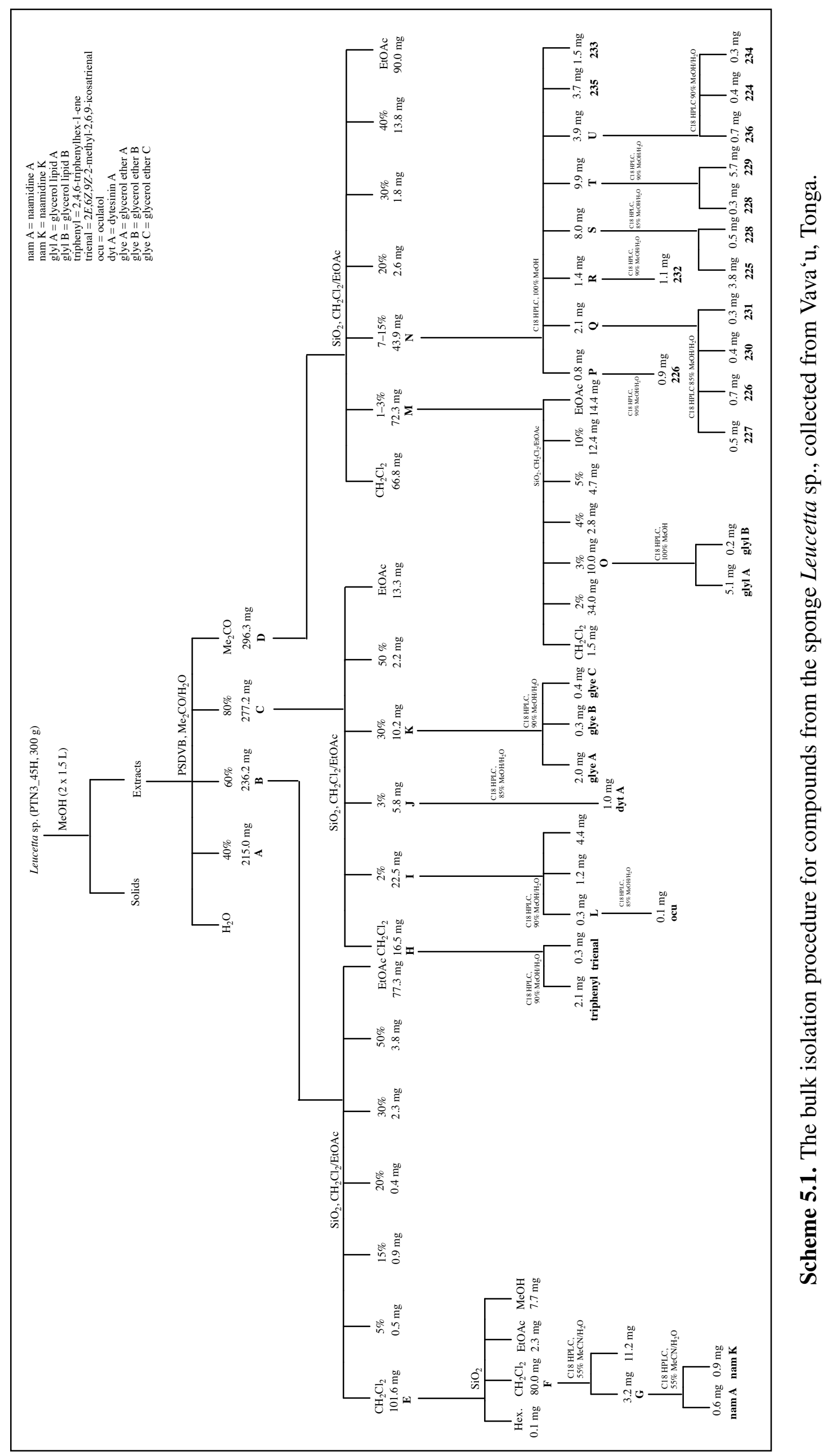




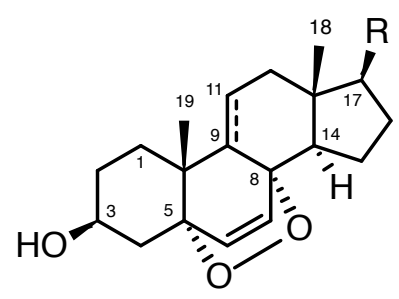

$A=$<smiles>CC(C)CC=CCC(C)C</smiles><smiles>B#CC(C)C=CC(C)C</smiles>

$225 \mathrm{R}=\mathrm{A}$

$226 \mathrm{R}=\mathrm{A}$

$227 \mathrm{R}=\mathrm{A}$

$228 \mathrm{R}=\mathrm{B}$

$229 \mathrm{R}=\mathrm{C}$

230

$231 \mathrm{R}=\mathrm{C} \quad \Delta_{22,23} \Delta_{24,28}$

$232 \quad \mathrm{R}=\mathrm{C} \quad \Delta_{9,11} \Delta_{24,28}$

$233 \quad \mathrm{R}=\mathrm{C} \quad \Delta_{9,11} \Delta_{22,23}$

$234 \mathrm{R}=\mathrm{D}$

$235 \mathrm{R}=\mathrm{D}$

$236 \quad \mathrm{R}=\mathrm{D} \quad \Delta_{22,23}$

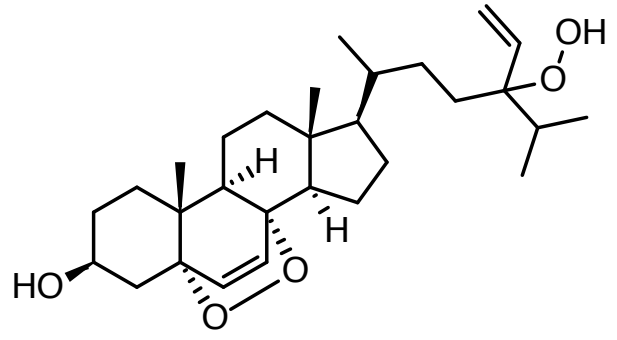

237<smiles>CCCCCCCCCC/C=C\C/C=C\CCCC(C)C1OCC(O)CO1</smiles>

$238 \Delta_{12,13}$

239

similar resonances to fraction $\mathbf{L}$. The unusual chemical shifts of two methylene protons $\left[\delta_{\mathrm{H}} 0.47(1 \mathrm{H}, \mathrm{d}, J=4.2 \mathrm{~Hz})\right.$ and $\left.\delta_{\mathrm{H}} 0.13(1 \mathrm{H}, \mathrm{d}, J=4.2 \mathrm{~Hz})\right]$, together with the unusual coupling constants observed fractions $\mathbf{J}$ and $\mathbf{L}$, were consistent with a cyclopropyl moiety. ${ }^{213}$ Subsequently, fraction $\mathbf{J}$ was subjected to $\mathrm{C} 18$ reversed-phase HPLC to afford the known compound, dytesinin A (241). ${ }^{214}$ The remaining resonances in fraction $\mathbf{J}$ were attributed to oculatolide (242) by comparison to NMR data from the literature. ${ }^{215}$

The $60 \% \mathrm{Me}_{2} \mathrm{CO} / \mathrm{H}_{2} \mathrm{O}$ fraction (fraction $\mathrm{B}$ ) was fractionated onto a $\mathrm{SiO}_{2}$ column, providing 90 fractions, which were combined into 12 samples based on TLC and ${ }^{1} \mathrm{H}$ NMR spectroscopic evidence. The $\mathrm{CH}_{2} \mathrm{Cl}_{2}$ fraction (fraction $\mathbf{E}$ ) showed a mixture of compounds by TLC. Silica flash column chromatography was carried out on this fraction. The $\mathrm{CH}_{2} \mathrm{Cl}_{2}$ fraction (fraction $\mathbf{F}$ ) was then subjected to a series of $\mathrm{C} 18 \mathrm{HPLC}$, which led 
to isolation of naamidine A (213) and a new analogue named here as naamidine K (243).<smiles>C=C(CC(CCc1ccccc1)c1ccccc1)c1ccccc1</smiles>

240

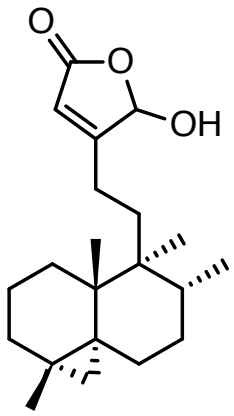

241<smiles>CC1=CCCCC1C</smiles>

242<smiles>COc1ccc(Cc2nc(NC3=NC(=O)N(C)C3=O)n(C)c2Cc2ccc(O)c(O)c2)cc1</smiles>

\subsubsection{Isolation and Structural Elucidation of the Three Glycerol Ethers}

Like fraction $\mathbf{M}$, the ${ }^{1} \mathrm{H}$ NMR spectrum of fraction $\mathbf{K}$ exhibited signals typical of a fatty acid compound with an intense peak at $\delta_{\mathrm{H}} 1.27-1.33$, due to the methylenes in an extended alkyl chain. Fraction $\mathbf{K}$ was subjected to C18 reversed-phase HPLC to afford three new glycerol ethers (244-246). The molecular formulae of the glycerol ethers (244-246) were established based on HRESIMS and NMR spectroscopic analysis. Use of HSQC-TOCSY and ID TOCSY experiments showed the connectivity of the unsaturated long alkyl chain and the glycerol moiety.

Following the structural elucidation of compounds (244-246), successful oxidative cleavage of the alkenes was performed in order to determine the location of the double bond. The oxidation reactions were performed using $\mathrm{RuCl}_{3}$ and $\mathrm{NaIO}_{4}$ in a $\mathrm{CHCl}_{3} / \mathrm{MeCN} / \mathrm{H}_{2} \mathrm{O}$ solution. ${ }^{216}$ For example, in Figure 5.2, the oxidative cleavage of the compound 244 alkene to the carboxylic acids is shown by the MS peak detected at $\mathrm{m} / \mathrm{z}$ 
195.1349, which corresponds to a $\mathrm{C}_{9}$ acid.

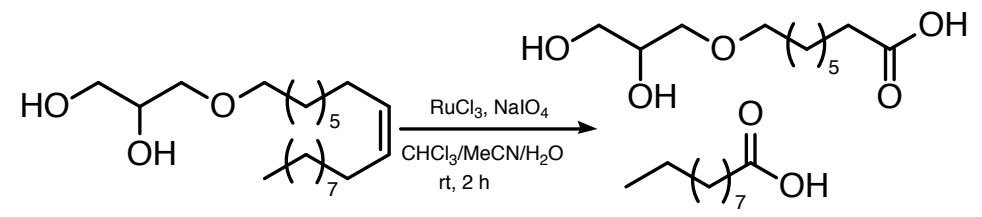

Figure 5.2. Oxidative cleavage of compound 244

The configuration of the double bond in 244-246 was determined by performing homonuclear decoupling experiments, with both sets of protons adjacent to the alkene being decoupled. For each compound, these experiments were able to simplify the alkene protons from multiplets into doublets, from which coupling constants of $8 \mathrm{~Hz}$ were observed, which is consistent with an alkene of $Z$ geometry (see Tables 5.2, 5.3 and 5.4 for NMR data).

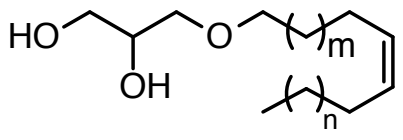

$$
\begin{array}{ll}
244 & m=5 n=7 \\
\mathbf{2 4 5} & \mathrm{m}=7 \mathrm{n}=6 \\
\mathbf{2 4 6} & \mathrm{m}=8 \mathrm{n}=6
\end{array}
$$




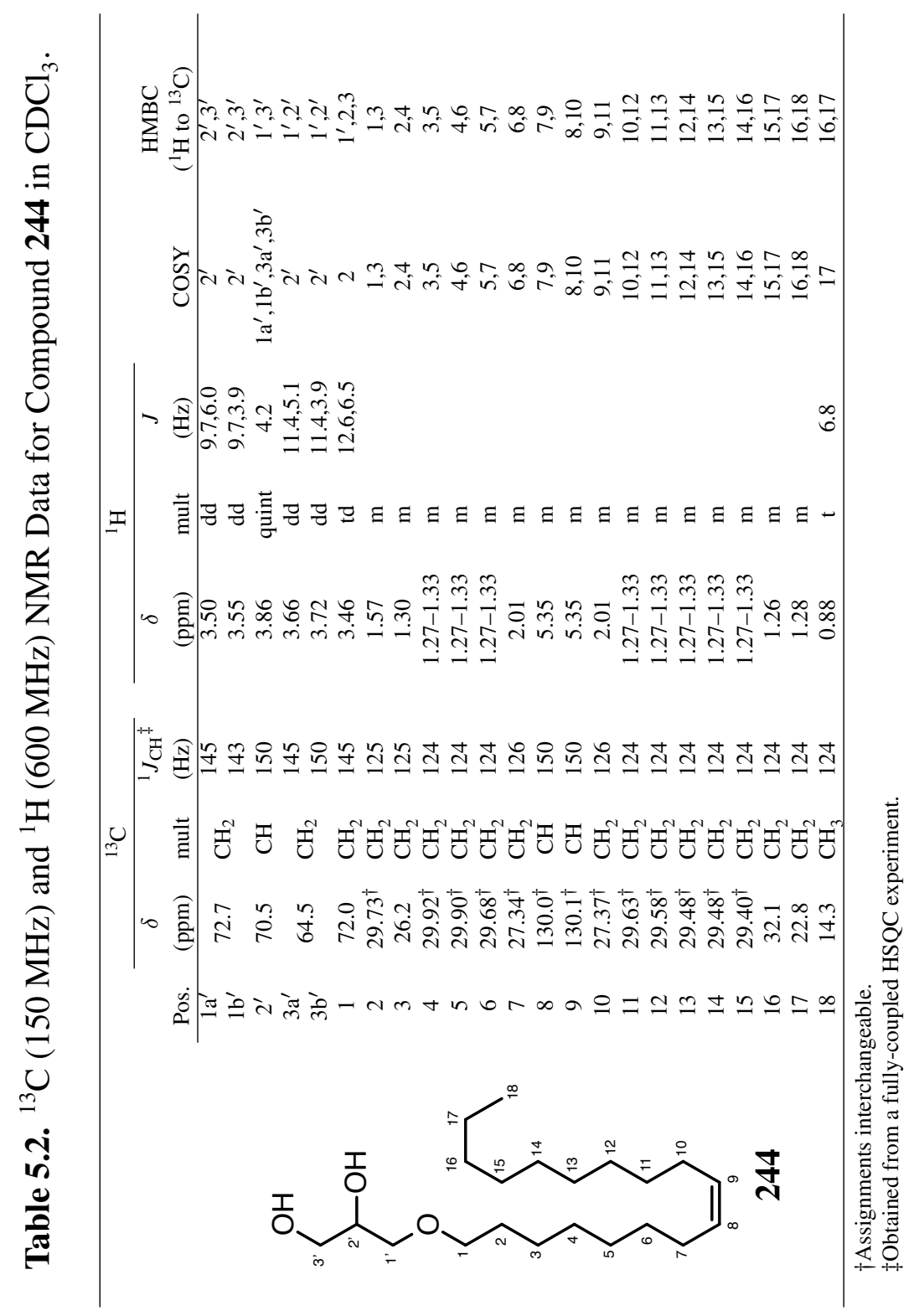




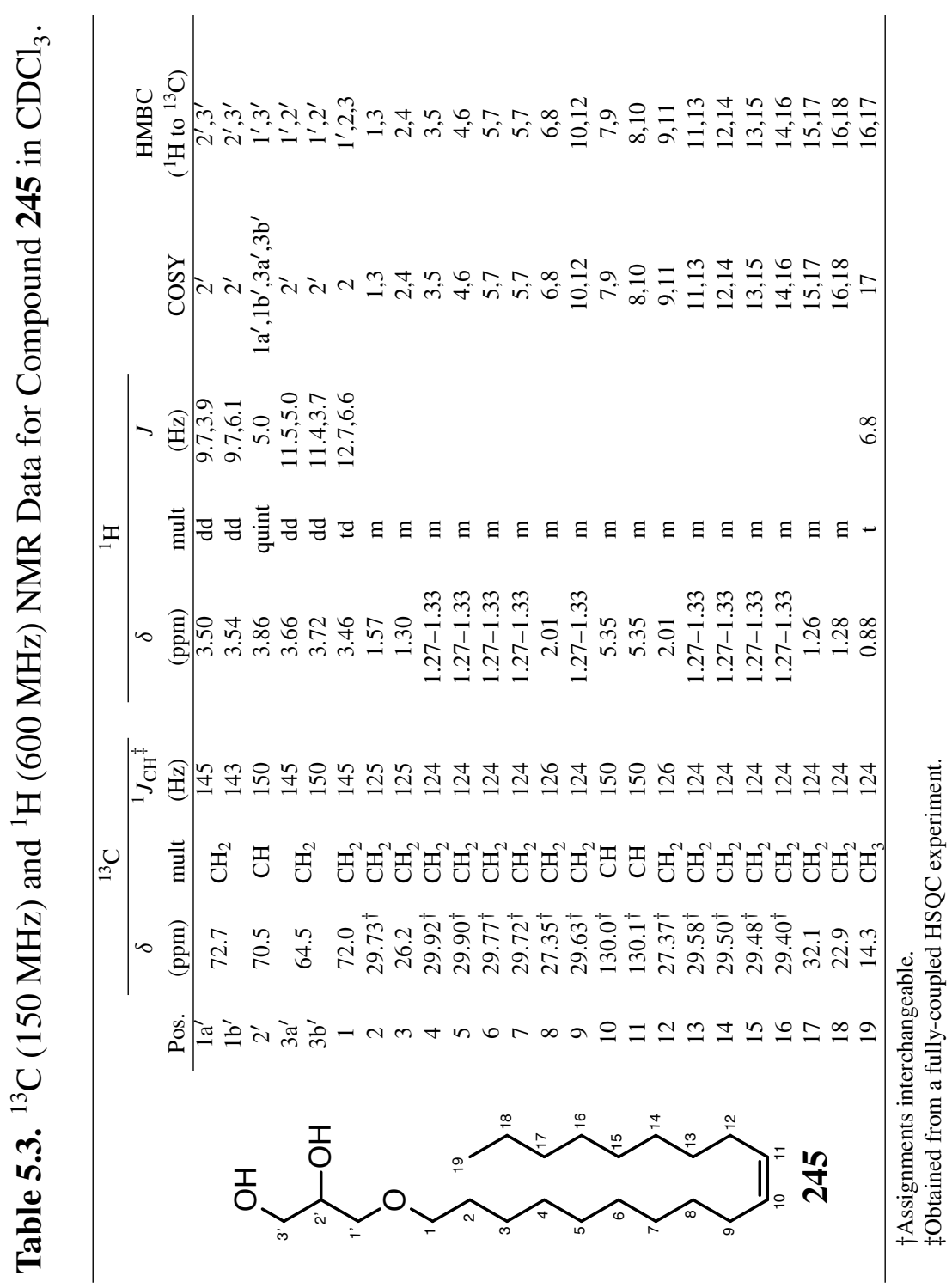




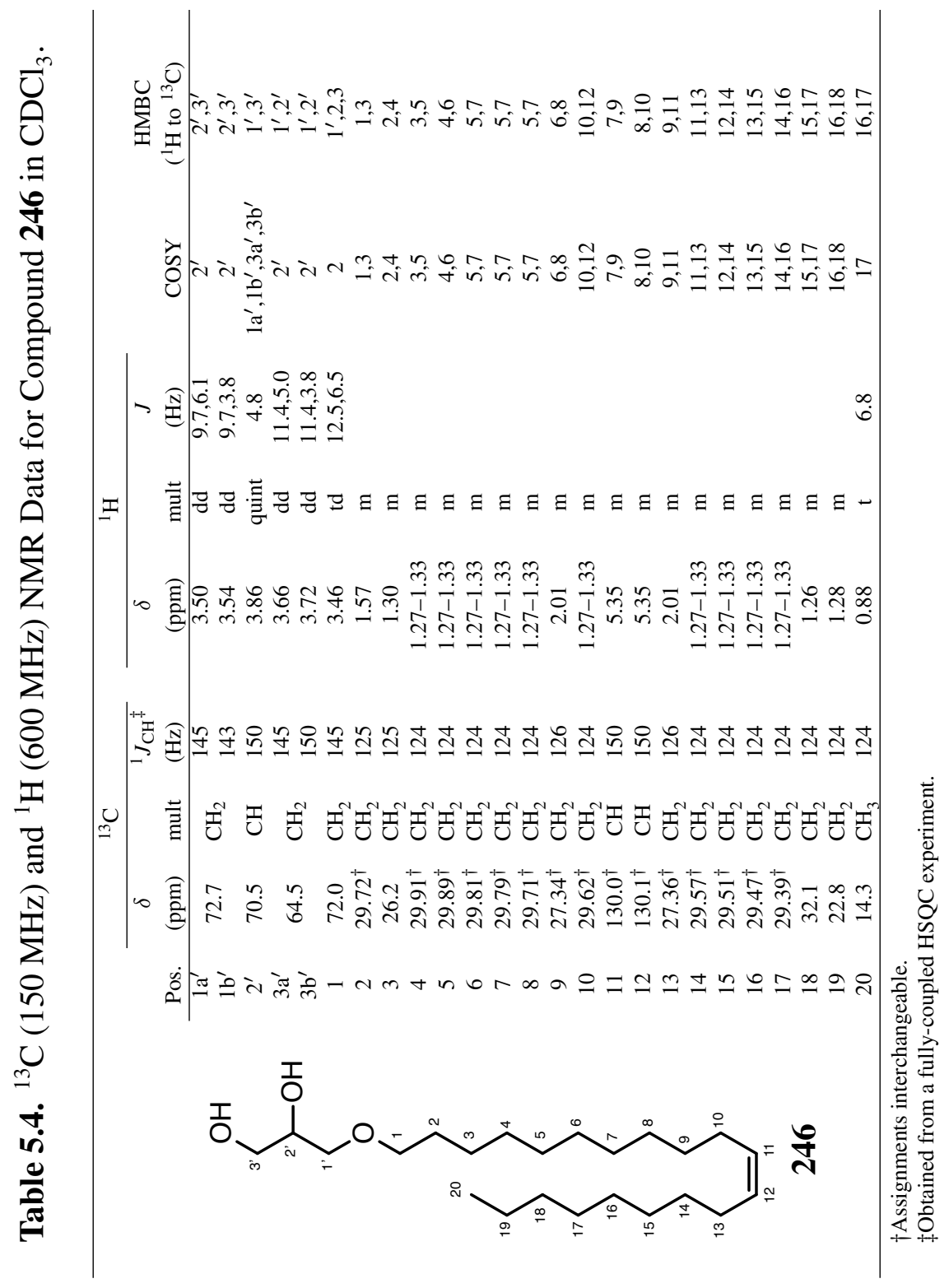




\subsection{Glycerol Lipid A}

Compound 238 was isolated as colourless oil. Positive ion HRESIMS analysis for 238 detected an $[\mathrm{M}+\mathrm{Na}]^{+}$adduct ion at $\mathrm{m} / z 403.3183(\Delta=0.00 \mathrm{ppm})$, indicative of a molecular formula of $\mathrm{C}_{24} \mathrm{H}_{44} \mathrm{O}_{3}$, which required three degrees of unsaturation. In the ${ }^{13} \mathrm{C}$ NMR spectrum, all 24 carbons were observed. The multiplicity-edited HSQC experiment showed that all carbons were protonated and accounted for 43 protons. These carbons consisted of two methyls $\left(\delta_{\mathrm{C}} 14.3 ; 14.0\right), 15$ methylenes $\left(\delta_{\mathrm{C}} 66.8 ; 62.8 ; 32.1 ; 31.1 ; 29.82\right.$; $29.80 ; 29.79 ; 29.72 ; 29.51 ; 29.48 ; 27.6 ; 27.4 ; 27.3 ; 25.8 ; 22.9)$ and seven methines $\left(\delta_{\mathrm{C}} 130.4 ; 130.0 ; 128.4 ; 128.0 ; 108.0 ; 76.4 ; 37.2\right)$. With evidence of four $s p^{2}$-hybridised carbons, the remaining degree of unsaturation must be accounted for by one ring.

A glycerol moiety was identified through a series of sequential COSY correlations between diastereotopic methylene $\mathrm{CH}_{2}-1\left(\delta_{\mathrm{H}} 3.66,4.09 ; \delta_{\mathrm{C}} 66.7\right)$, oxymethine $\mathrm{CH}-2$ $\left(\delta_{\mathrm{H}} 4.17 ; \delta_{\mathrm{C}} 76.4\right)$ and another diastereotopic methylene $\mathrm{CH}_{2}-3\left(\delta_{\mathrm{H}} 3.62,3.72 ; \delta_{\mathrm{C}} 62.8\right)$, establishing the first isolated spin system. This deduction was further confirmed by the HMBC correlations from both $\mathrm{H}_{2}-1$ and $\mathrm{H}_{2}-3$ to C-2. In the $\mathrm{HMBC}$ experiment, $\mathrm{H}_{2}-1$, H-2 and $\mathrm{H}_{2}-3$ showed correlations to an unusual dioxymethine $\mathrm{CH}-4\left(\delta_{\mathrm{H}} 4.81 ; \delta_{\mathrm{C}} 108.0\right)$. Correlations observed in the HMBC spectrum from $\mathrm{H}-4$ to $\mathrm{C}-1$ and $\mathrm{C}-3$ confirmed its attachment to the glycerol moiety. The unusual chemical shifts and the large ${ }^{1} J_{\mathrm{CH}}$ coupling constant $(165 \mathrm{~Hz})$ of $\mathrm{CH}-4$ supported the presence of an acetal moiety, thus establishing the presence of a 1,3-dioxane ring. Additional correlations from $\mathrm{H}-4$ to the methine $\mathrm{CH}-5\left(\delta_{\mathrm{H}} 1.68 ; \delta_{\mathrm{C}} 37.2\right)$, diasterotopic methylene $\mathrm{CH}_{2}-6\left(\delta_{\mathrm{H}} 1.17,1.54\right.$; $\left.\delta_{\mathrm{C}} 31.1\right)$ and methyl $\mathrm{CH}_{3}-24\left(\delta_{\mathrm{H}} 0.92 ; \delta_{\mathrm{C}} 14.0\right)$ in the HMBC spectrum, which was verified by COSY correlations between their respective protons, established the second spin system. This connectivity was supported by the strong HMBC correlations from the methyl doublet $\mathrm{CH}_{3}-24$ to $\mathrm{C}-4, \mathrm{C}-5$ and $\mathrm{C}-6$ (see Figure 5.3). 


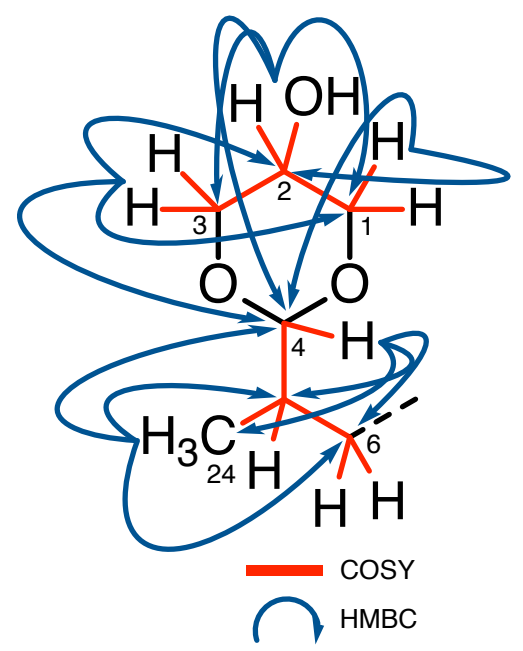

Figure 5.3. Key COSY and HMBC correlations establishing the 1,3-dioxane ring of 238.

The connectivity of the second substructure began with a series of sequential COSY correlations from $\mathrm{H}_{2}-6$ to the two methylenes $\mathrm{CH}_{2}-7\left(\delta_{\mathrm{H}} 1.34,1.46 ; \delta_{\mathrm{C}} 31.1\right)$ and $\mathrm{CH}_{2}-8$ $\left(\delta_{\mathrm{H}} 2.06 ; \delta_{\mathrm{C}} 27.6\right.$ ). Methylene $\mathrm{H}_{2}-8$ showed strong HMBC correlations to C-6 and C-7, confirming this connectivity. Further $\mathrm{HMBC}$ correlations from $\mathrm{H}_{2}-8$ to two olefinic methines $\mathrm{CH}-9\left(\delta_{\mathrm{H}} 5.38 ; \delta_{\mathrm{C}} 130.4\right)$ and $\mathrm{CH}-10\left(\delta_{\mathrm{H}} 5.32 ; \delta_{\mathrm{C}} 128.0\right)$ placed a double bond adjacent to C-8. A series of COSY and HMBC correlations were observed between the two olefinic methines (CH-9 and $\mathrm{CH}-10)$, methylene $\mathrm{CH}_{2}-11\left(\delta_{\mathrm{H}} 2.77 ; \delta_{\mathrm{C}} 25.8\right)$, a second pair of olefinic methines CH-12 $\left(\delta_{\mathrm{H}} 5.38 ; \delta_{\mathrm{C}} 130.0\right)$ and $\mathrm{CH}-13\left(\delta_{\mathrm{H}} 5.32 ; \delta_{\mathrm{C}} 128.4\right)$ and the methylene $\mathrm{CH}_{2}-14\left(\delta_{\mathrm{H}} 2.02 ; \delta_{\mathrm{C}} 27.4\right)$, establishing a 1,4-diene unit. The geometry of the two double bonds, $\Delta_{9,10}$ and $\Delta_{12,13}$, were both determined to be $Z$ on the basis of the observed coupling constants of $J_{9,10}=10.0 \mathrm{~Hz}$ and $J_{12,13}=10.0 \mathrm{~Hz}$ (see Figure 5.4).

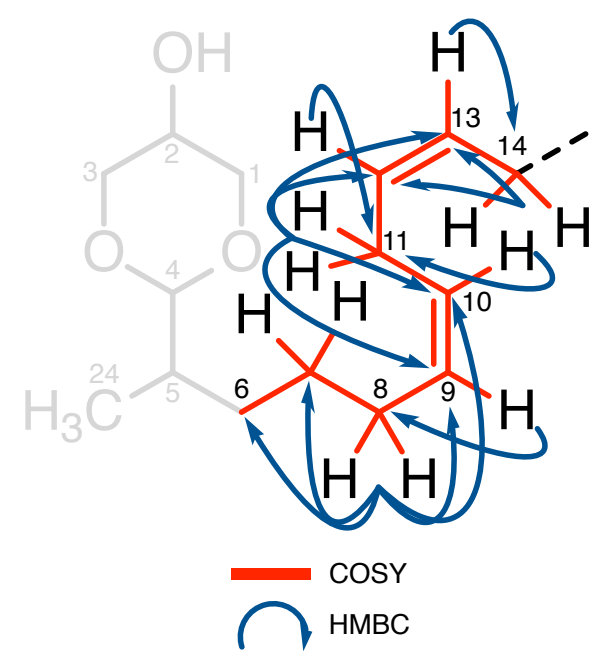

Figure 5.4. Key COSY and HMBC correlations establishing the C-7 to C-14 segment of 238. 
As all three degrees of unsaturation were accounted for, the remaining fragment had to be fully saturated and acyclic, and accounted for $\mathrm{C}_{9} \mathrm{H}_{19}$. The final substructure was typical of a lipid-like compound with an intense peak at $\delta_{\mathrm{H}} 1.22-1.38$ in the ${ }^{1} \mathrm{H}$ NMR spectrum due to the methylenes in an extended alkyl chain, with a triplet at $\delta_{\mathrm{H}} 0.88$ $\left(\mathrm{CH}_{3}-23, \delta_{\mathrm{C}} 14.3\right)$, revealing a terminal methyl group. The structural elucidation began at the methyl terminus which showed strong HMBC correlations to two consecutive methylenes $\mathrm{CH}_{2}-22\left(\delta_{\mathrm{H}} 1.28 ; \delta_{\mathrm{C}} 22.8\right)$ and $\mathrm{CH}_{2}-21\left(\delta_{\mathrm{H}} 1.24 ; \delta_{\mathrm{C}} 32.1\right)$, supported by COSY correlation data. From this point on, the structural elucidation of this substructure became a challenging task, due to the severe overlap of the methylene proton resonances in the range of $\delta_{\mathrm{H}} 1.28-1.38$. At the other end of the substructure, methylene $\mathrm{H}_{2}-14$ showed COSY and HMBC correlations to a methylene $\mathrm{CH}_{2}-15\left(\delta_{\mathrm{H}} 1.28-1.38 ; \delta_{\mathrm{C}} 29.51\right)$, thus leaving five methylenes between $\mathrm{CH}_{2}-15$ and $\mathrm{CH}_{2}-21$, which corresponded to 10 protons. Selective excitation of $\mathrm{H}_{3}-23$ in a 1D TOCSY experiment with increasing mixing times (0-150 ms), confirmed the connection between the protonated centres $\mathrm{CH}_{3}-23$ and $\mathrm{CH}_{2}-14$, providing the completed planar structure of $\mathbf{2 3 8}$ (see Figure 5.5).

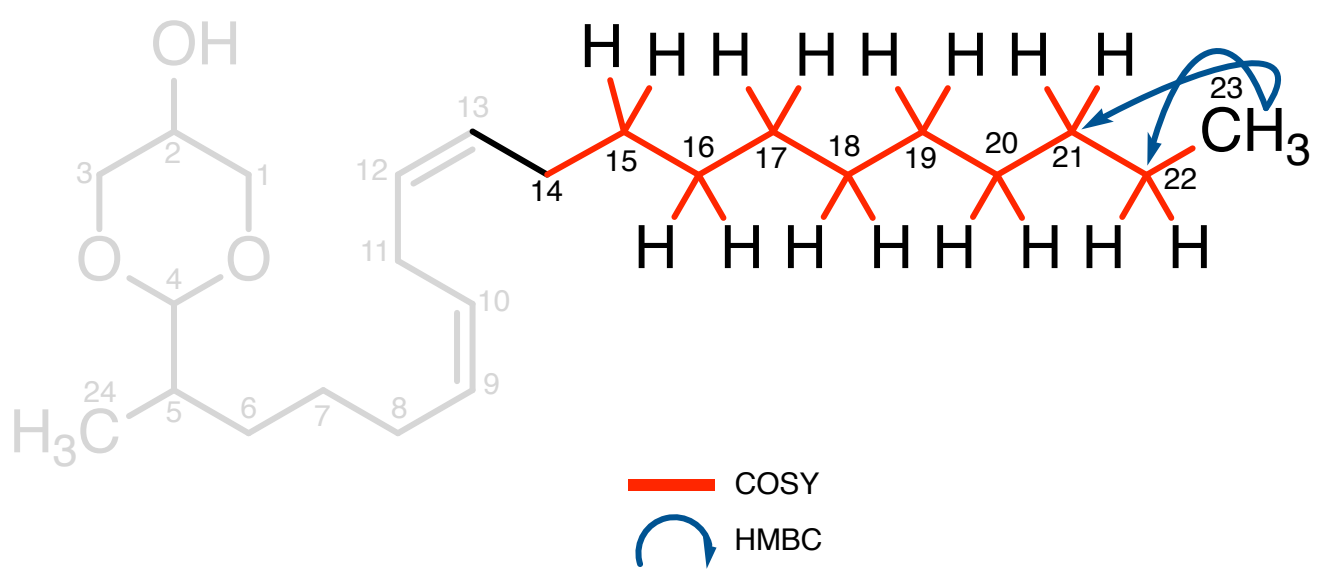

Figure 5.5. Key COSY and HMBC correlations establishing the C-15 to C-23 segment of 238.

Unfortunately, compound $\mathbf{2 3 8}$ degraded before attempts to deduce its relative configuration, or before any biological assays were performed. 


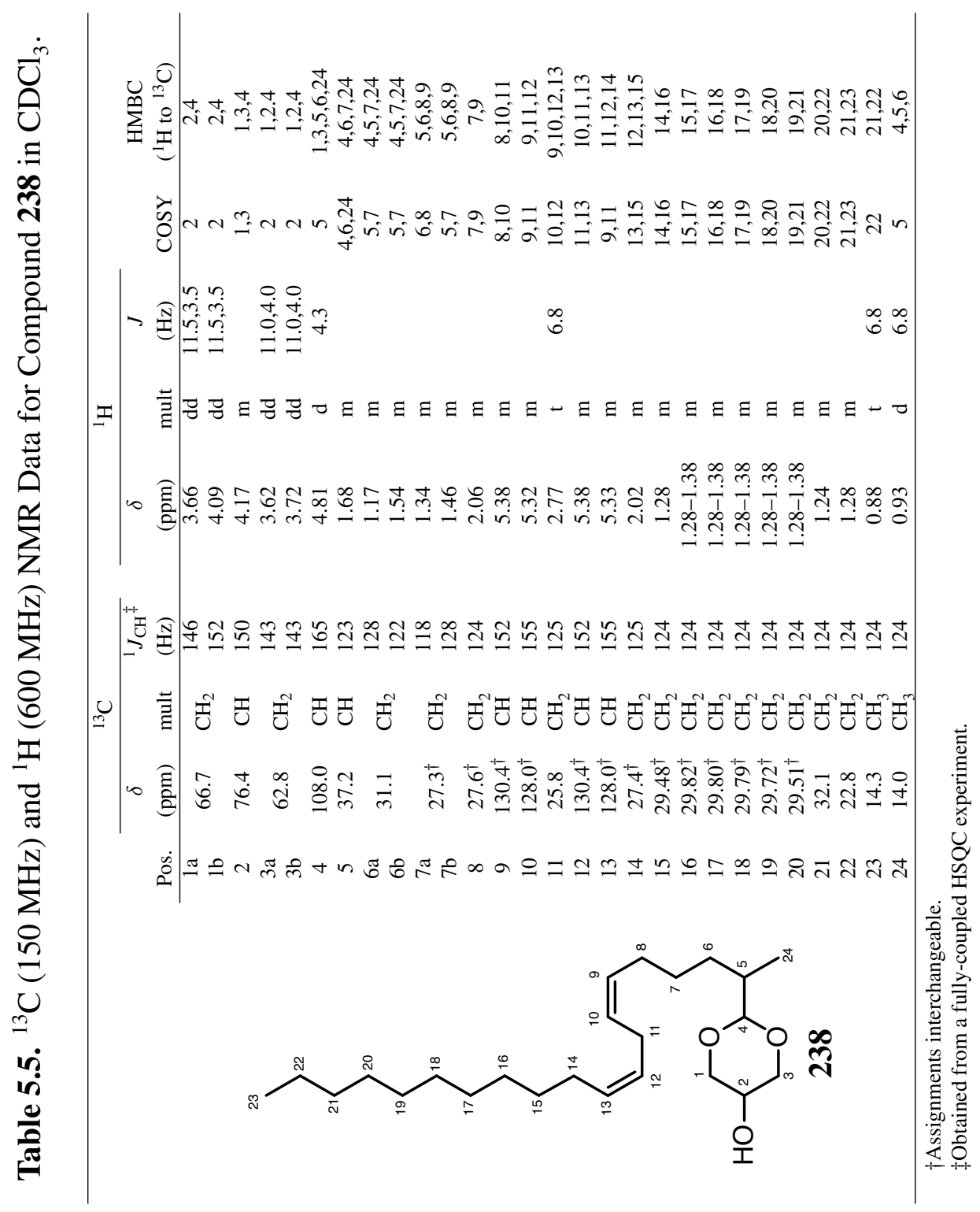




\subsection{Glycerol Lipid B}

Compound 239 was obtained as colourless oil. The molecular formula of 239 was determined to be $\mathrm{C}_{24} \mathrm{H}_{46} \mathrm{O}_{3}$, from the positive HRESIMS ion detected at $m / z \quad 364.3337$ $\left[\mathrm{M}-\mathrm{H}_{2} \mathrm{O}\right]^{+}(\Delta=0.27 \mathrm{ppm})$. The proposed molecular formula differs from that of compound 238 by $2 \mathrm{Da}$ or $\mathrm{H}_{2}$, which could be accounted for by reduction of one of the double bonds. Subsequent detailed analysis of the ${ }^{1} \mathrm{H}$ NMR spectrum revealed the presence of the same 1,3-dioxane ring motif, suggesting modifications were restricted to the lipid moiety. This supported the presence of a monounsaturated lipid chain as well as two degrees of unsaturation as required by the molecular formula, confirming this proposition.

The ${ }^{1} \mathrm{H}$ and ${ }^{13} \mathrm{C}$ NMR data of $\mathbf{2 3 9}$ was typical of a lipid-like compound with an intense peak at $\delta_{\mathrm{H}} 1.22-1.38$, and a triplet at $\delta_{\mathrm{H}} 0.88$ that corresponded to the methyl group. Olefinic protons were observed at $\delta_{\mathrm{H}} 5.34$ and $\delta_{\mathrm{H}} 5.30$, and a methyl doublet at $\delta_{\mathrm{H}} 0.93$ corresponded to a secondary methyl branch. The chemical shifts for a glycerol moiety were observed $\left[\delta_{\mathrm{H}} 4.09(1 \mathrm{H}, \mathrm{dd}, J=11.5,3.5 \mathrm{~Hz}), \delta_{\mathrm{H}} 3.66(1 \mathrm{H}, \mathrm{dd}, J=11.5,6.5 \mathrm{~Hz})\right.$, $\left.\delta_{\mathrm{H}} 3.72(1 \mathrm{H}, \mathrm{dd}, J=11.0,4.0 \mathrm{~Hz}), \delta_{\mathrm{H}} 3.62(1 \mathrm{H}, \mathrm{dd}, J=11.0,4.0 \mathrm{~Hz}), \delta_{\mathrm{H}} 4.17(1 \mathrm{H}, \mathrm{m})\right]$. In addition, an unusual dioxymethine proton was observed at $\delta_{\mathrm{H}} 4.81(1 \mathrm{H}, \mathrm{d}, J=4.3 \mathrm{~Hz}$; $\left.\delta_{\mathrm{C}} 108.0(\mathrm{C}-4)\right)$. Analysis of the ${ }^{1} \mathrm{H}-{ }^{1} \mathrm{H}$ COSY spectrum revealed the connectivity of C-1 to $\mathrm{C}-3$ and $\mathrm{HMBC}$ correlations of $\mathrm{H}-1\left(\delta_{\mathrm{H}} 3.66,4.09\right)$ to $\mathrm{C}-4\left(\delta_{\mathrm{C}} 108.0\right)$ and $\mathrm{H}-4\left(\delta_{\mathrm{H}} 4.81\right)$ to $\mathrm{C}-1\left(\delta_{\mathrm{C}} 66.7\right)$ and $\mathrm{C}-2\left(\delta_{\mathrm{C}} 76.4\right)$ indicated the presence of a 1,3-dioxane ring. The geometry of the $\Delta_{9,10}$ double bond for compound 247 was also assigned as $Z$ based on the coupling constant $(10 \mathrm{~Hz}$ ) (see Figure 5.6). Like 238, compound 239 also degraded before assigning its relative configuration, or any biological assays were carried out.

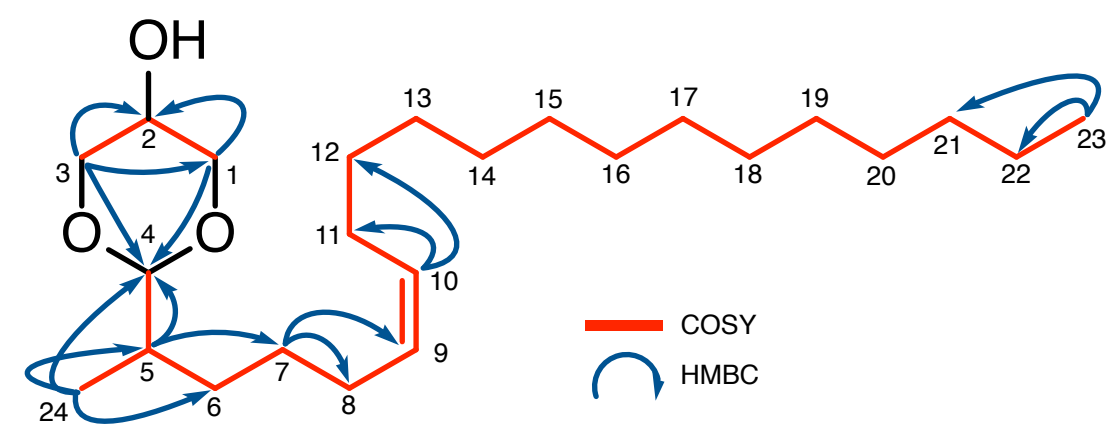

Figure 5.6. Key COSY and HMBC correlations establishing the structure of 239 . 


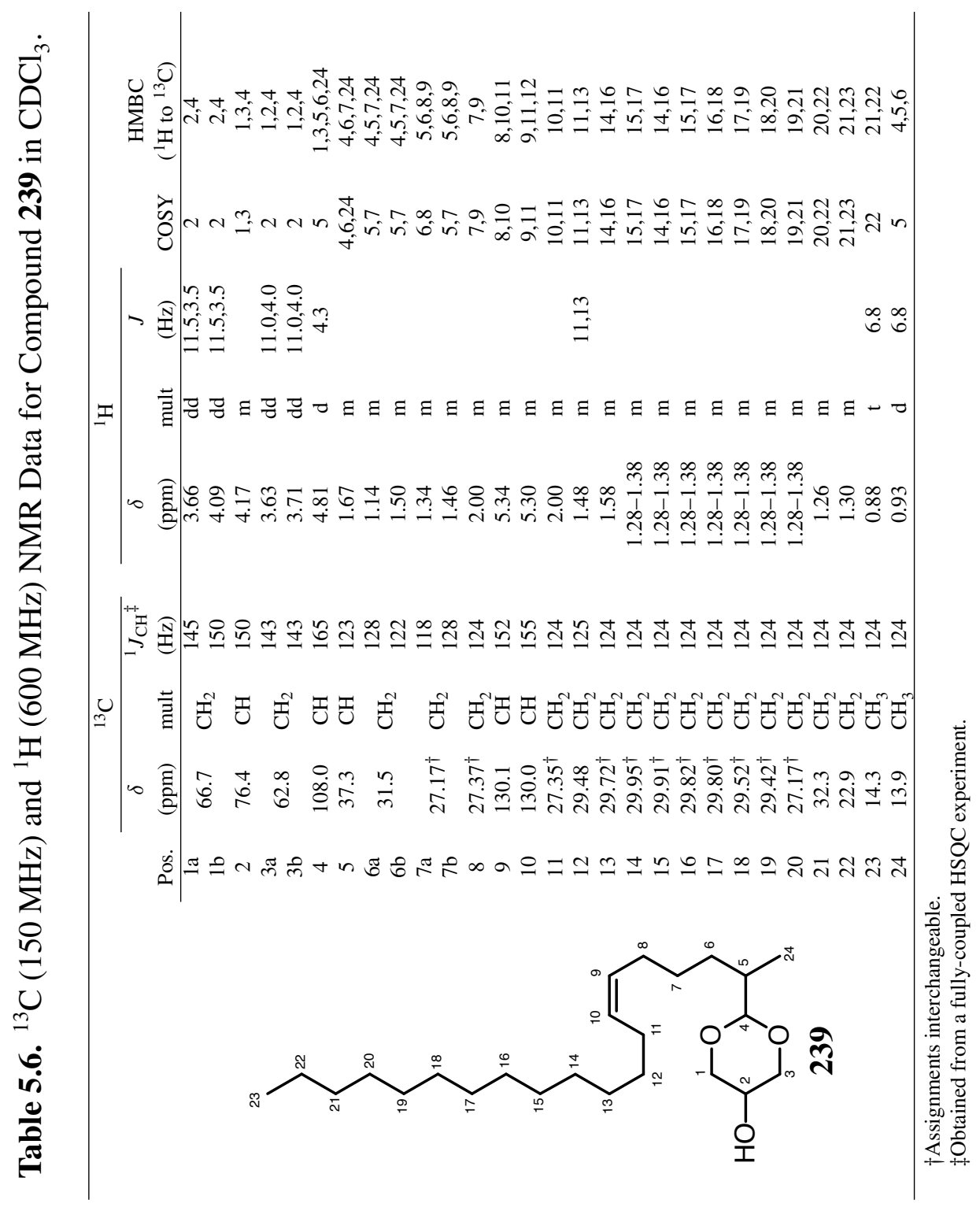




\subsection{Naamidine $K$}

Naamidine K (243) was isolated as a yellow amorphous solid. Positive ion HRESIMS analysis of a protonated ion $[\mathrm{M}+\mathrm{H}]^{+}$at $\mathrm{m} / \mathrm{z}$ 450.1777, which indicated a molecular formula of $\mathrm{C}_{23} \mathrm{H}_{23} \mathrm{~N}_{5} \mathrm{O}_{5}(\Delta=1.11 \mathrm{ppm})$ and 15 degrees of unsaturation. The ${ }^{1} \mathrm{H}$ spectrum of 243 in $\mathrm{CD}_{3} \mathrm{OD}$ accounted for only 20 protons, suggesting the presence of three exchangeable protons. The integration ratios of the signals observed indicated the presence of symmetry in the molecule, assigned to a 1,4-disubstituted benzene ring. The ${ }^{13} \mathrm{C}$ NMR spectrum supported this proposition with evidence for only 21 distinct carbon resonances. The multiplicity-edited HSQC experiment confirmed the attachment of the 20 protons to carbons, confirming the presence of three exchangeable protons. The ${ }^{13} \mathrm{C}$ and multiplicity-edited HSQC spectra revealed 12 protonated carbons including three methyls $\left(\delta_{\mathrm{C}} 24.7 ; 30.2 ; 55.7\right)$, two methylenes $\left(\delta_{\mathrm{C}} 29.1 ; 31.8\right)$ and seven aromatic methines $\left(\delta_{\mathrm{C}} 115.0 ; 115.0 ; 116.2 ; 116.6 ; 120.4 ; 130.5 ; 130.5\right)$. The remaining 11 carbons $\left(\delta_{\mathrm{C}} 165.5 ; 161.7 ; 159.8 ; 153.6 ; 147.3 ; 146.7 ; 145.2 ; 132.2 ; 130.2 ; 129.9 ; 128.2\right)$ were all assigned as non-protonated olefinic carbons.

The proposed molecular formula of naamidine K (243) differs from naamidine A (213) by $16 \mathrm{Da}$, which is consistent with the addition of an oxygen atom. Detailed analysis of the 1D- and 2D-NMR spectra of $\mathbf{2 4 3}$ revealed a high degree of similarity to $\mathbf{2 1 3}$. The most noticeable difference in the NMR spectra of $\mathbf{2 4 3}$ was the loss of symmetry of one of the benzene rings. Three aromatic proton resonances $\left(\delta_{\mathrm{H}} 6.38 ; 6.50 ; 6.65\right)$, each integrating for one proton, were observed suggesting a trisubstituted benzene ring moiety. All the other spectral features of $\mathbf{2 1 3}$ were still present.

The similarity between the NMR data of 243 and 213 allowed the assignment of most resonances through direct comparison against the parent compound. Analysis of the 2D-NMR spectra of $\mathbf{2 4 3}$ allowed the construction of four substructures. COSY correlations between an aromatic doublet methine $\mathrm{H}-17[\mathrm{H}-19]\left(\delta_{\mathrm{H}} 6.81 ; \delta_{\mathrm{C}} 115.0\right)$ to a second aromatic doublet methine $\mathrm{H}-16[\mathrm{H}-20]\left(\delta_{\mathrm{H}} 7.14 ; \delta_{\mathrm{C}} 130.5\right)$ indicated a 1,4disubstituted benzene ring. The placement of these substituents was assigned from the strength of the HMBC correlation intensity from $\mathrm{H}-16[\mathrm{H}-20]$ and $\mathrm{H}-17[\mathrm{H}-19]$. In the 
HMBC spectrum, H-17 showed strong correlations to a non-protonated olefinic carbon C-15 $\left(\delta_{\mathrm{C}} 132.2\right)$ while $\mathrm{H}-16$ correlated strongly to a second non-protonated olefinic carbon C-18 $\left(\delta_{\mathrm{C}}\right.$ 159.8). An HMBC correlation from oxymethyl $\mathrm{CH}_{3}-21\left(\delta_{\mathrm{H}} 3.74 ; \delta_{\mathrm{C}} 55.7\right)$ to $\mathrm{C}-18$, placed $\mathrm{C}-18$ as its attachment point. Further COSY and HMBC correlations from $\mathrm{H}-16[\mathrm{H}-20]$ to a benzylic methylene $\mathrm{CH}_{2}-14\left(\delta_{\mathrm{H}} 3.93 ; \delta_{\mathrm{C}} 31.8\right)$ extended the first substructure (see Figure 5.7).

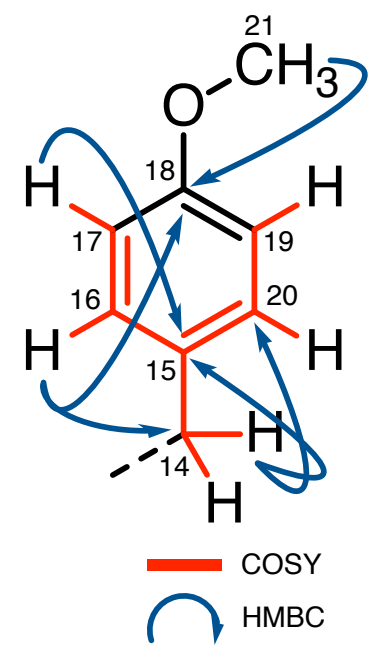

Figure 5.7. Key COSY and HMBC correlations establishing the 1,4-disubstituted benzene ring of naamidine $\mathrm{K}(\mathbf{2 4 3})$.

COSY correlations between aromatic methines $\mathrm{CH}-9\left(\delta_{\mathrm{H}} 6.50 ; \delta_{\mathrm{C}} 116.2\right)$ and $\mathrm{CH}-13$ $\left(\delta_{\mathrm{H}} 6.38 ; \delta_{\mathrm{C}} 120.4\right)$, the latter of which also correlated to an aromatic doublet methine at $\delta_{\mathrm{H}} 6.65\left(\mathrm{C}-12 ; \delta_{\mathrm{C}} 116.6\right)$ established a trisubstituted benzene ring. The coupling constant of $2.1 \mathrm{~Hz}$ measured between $\mathrm{H}-9$ and $\mathrm{H}-13$ was consistent with a metacoupling while the measured coupling constant of $8.1 \mathrm{~Hz}$ between $\mathrm{H}-12$ and $\mathrm{H}-13$ places them ortho to one another. In the HMBC spectrum, strong correlations from H-9 to an oxygenated non-protonated aromatic carbon $\left(\delta_{\mathrm{C}} 145.2\right)$, and from $\mathrm{H}-12$ to a nonprotonated aromatic carbon C-8 $\left(\delta_{\mathrm{C}} 129.9\right)$ and a second oxygenated non-protonated aromatic carbon C-10 $\left(\delta_{\mathrm{C}} 146.7\right)$, completed the 1,2,4-trisubstituted benzene ring. COSY and HMBC correlations from $\mathrm{H}-9$ and $\mathrm{H}-13$ to a benzylic methylene $\mathrm{CH}_{2}-7\left(\delta_{\mathrm{H}} 3.89\right.$; $\delta_{\mathrm{C}} 29.1$ ) extended the second substructure (see Figure 5.8).

The two methylene singlets $\mathrm{H}_{2}-7$ and $\mathrm{H}_{2}-14$ showed HMBC correlations to two nonprotonated olefinic carbons $\mathrm{C}-4\left(\delta_{\mathrm{C}} 128.2\right)$ and $\mathrm{C}-5\left(\delta_{\mathrm{C}} 130.2\right)$, connecting the two benzene rings to the third substructure. The HMBC correlations observed from a methyl 


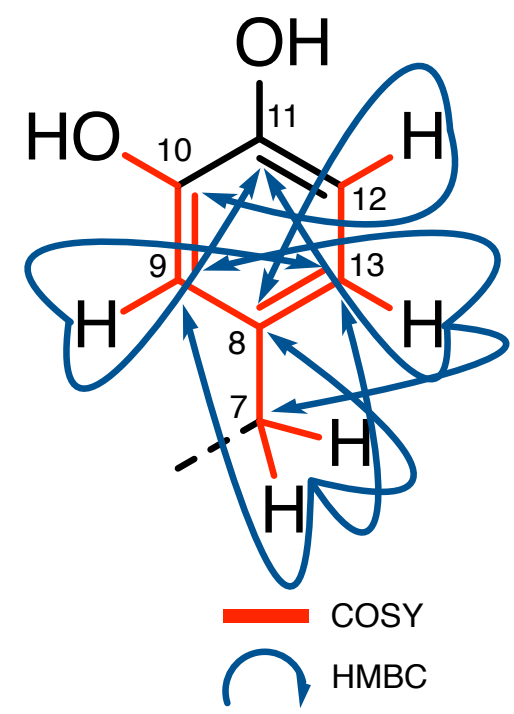

Figure 5.8. Key HMBC correlations establishing the 1,2,4-trisubstituted benzene ring of naamidine $\mathrm{K}$ (243).

singlet $\mathrm{CH}_{3}-22\left(\delta_{\mathrm{H}} 3.49 ; \delta_{\mathrm{C}} 30.2\right)$ to $\mathrm{C}-4$ and a non-protonated olefinic carbon $\mathrm{C}-2$ $\left(\delta_{\mathrm{C}}\right.$ 147.3) suggested the presence of an imidazole moiety - a common feature in naamidines. $189|190| 197-199$ This proposition was supported by the observed correlations from $\mathrm{H}_{2}-7$ and $\mathrm{H}_{3}-22$ to $\mathrm{N}-3\left(\delta_{\mathrm{N}}-224.6\right)$, and $\mathrm{H}_{2}-14$ to $\mathrm{N}-1\left(\delta_{\mathrm{N}}-179.5\right)$ in a ${ }^{1} \mathrm{H}-{ }^{15} \mathrm{~N}$ CIGAR experiment (see Figure 5.9.

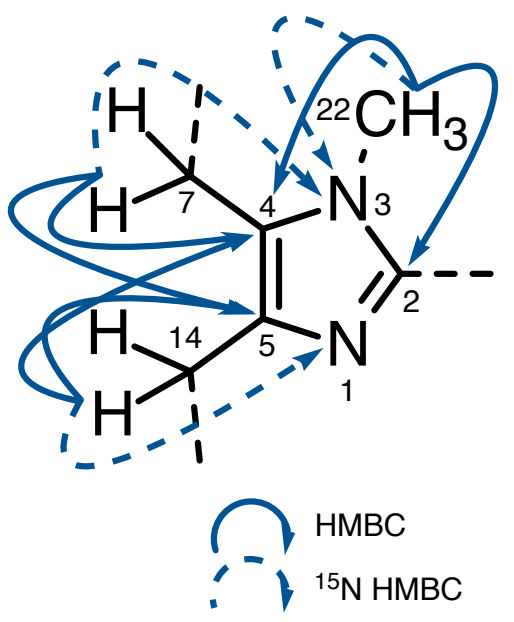

Figure 5.9. Key HMBC correlations establishing the imidazole moiety of naamidine $\mathrm{K}$ (243).

A slightly downfield-shifted methyl singlet $\mathrm{CH}_{3}-28\left(\delta_{\mathrm{H}} 3.06 ; \delta_{\mathrm{C}} 24.7\right)$ with a moderately large ${ }^{1} J_{\mathrm{CH}}$ coupling constant $(138 \mathrm{~Hz})$ showed HMBC correlations to two amide carbonyls [C-25 $\left.\left(\delta_{\mathrm{C}} 161.7\right), \mathrm{C}-27\left(\delta_{\mathrm{C}} 165.5\right)\right]$ and $\mathrm{N}-26\left(\delta_{\mathrm{N}}-240.9\right)$ suggesting the presence of an imide moiety. The molecular formula, the remaining two nitrogens (NH-6 and $\mathrm{N}-24)$ and one quaternary carbon $\left(\delta_{\mathrm{C}}\right.$ 153.6), together with the imide moiety, were 
suggestive of a hydantoin derivative (see Figure 5.10 - a moiety commonly found in naamidines. $\frac{189[190 \mid 197-200}{2}$ This proposed moiety was supported by the fact that 11 degrees of unsaturation were accounted for, leaving four degrees of unsaturation to be assigned. Therefore, the structure of naamidine K (243) was established as shown in Figure 5.11.

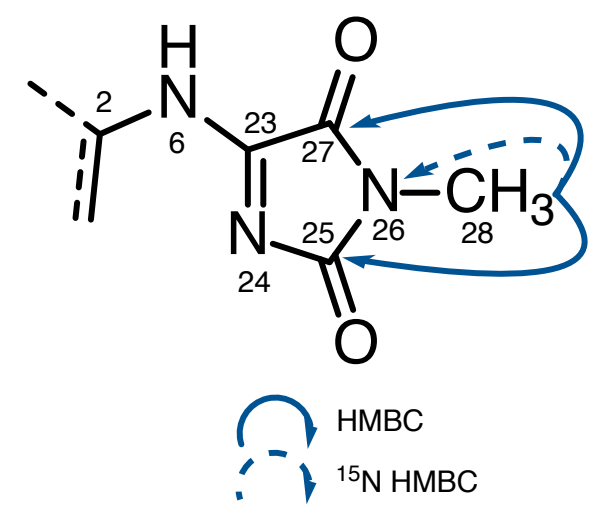

Figure 5.10. Key HMBC correlations establishing the hydantoin moiety of naamidine K (243).

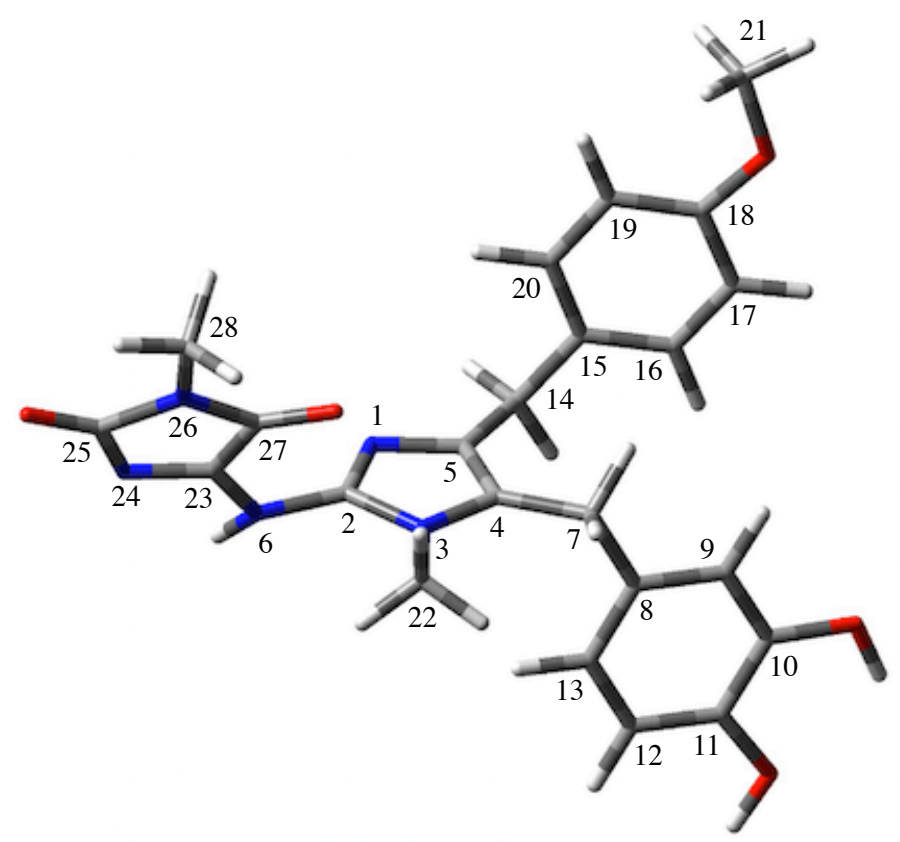

Figure 5.11. 3-D structure of naamidine K (243) 


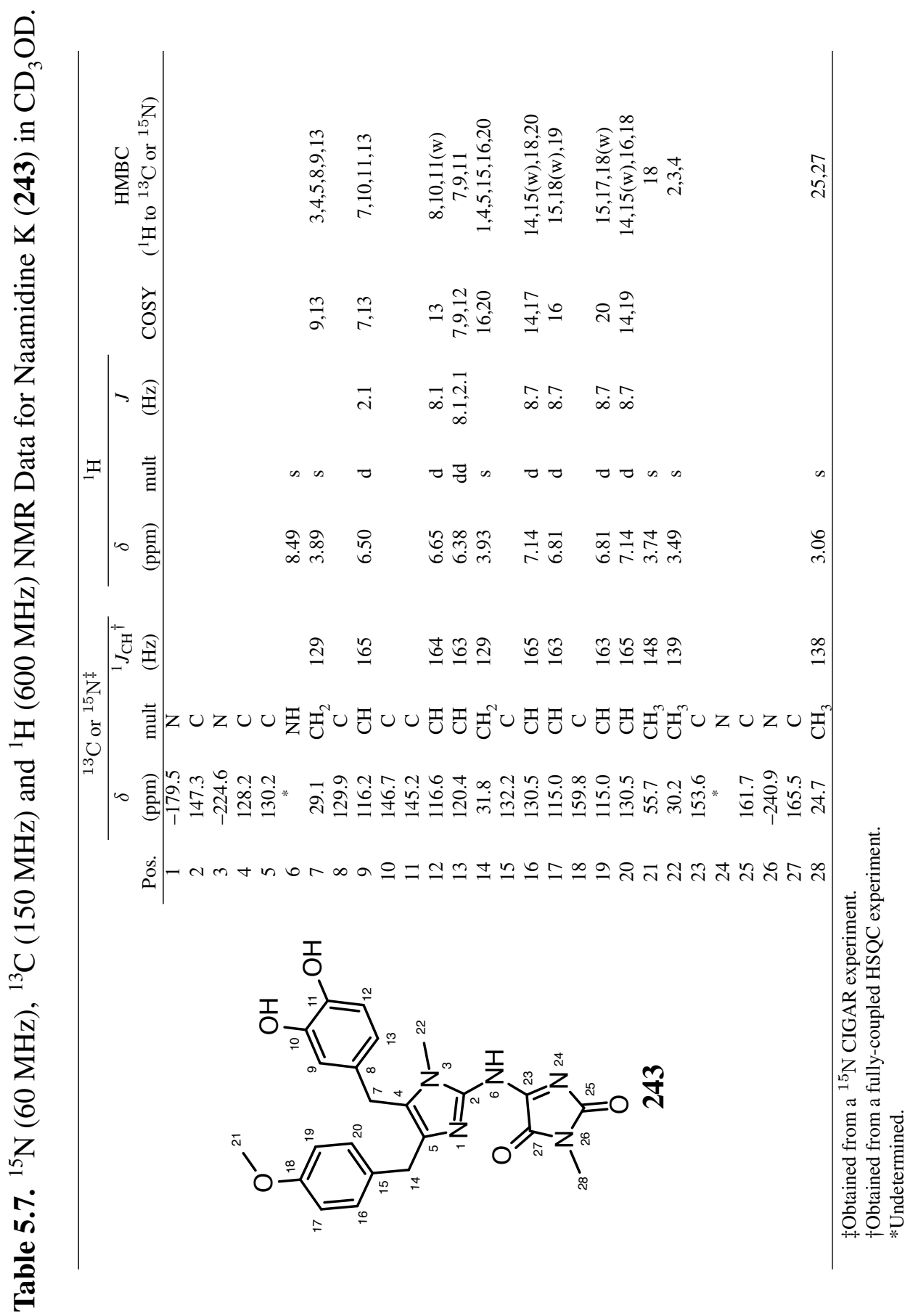




\subsection{Bioactivity}

The majority of the compounds isolated from Leucetta sp. were evaluated for antiproliferative activity against the human leukaemia HL-60 cell line at the School of Biological Sciences, VUW. Many of these compounds showed moderate inhibitory activities, with $\mathrm{IC}_{50}$ values in the low micromolar range. Naamidine A (213) was among the most potent antiproliferative activity of these compounds, with an $\mathrm{IC}_{50}$ value of $6.1 \mu \mathrm{M}$, while naamidine K (243) was ineffective toward the cell lines at the concentrations of $>22 \mu \mathrm{M}$.

Table 5.8. $\mathrm{IC}_{50}$ values of compounds from Leucetta sp. against the HL-60 cell line.

\begin{tabular}{|c|c|}
\hline Compound & $\mathbf{I C}_{\mathbf{5 0}}(\mu \mathrm{M})$ \\
\hline Naamidine A (213) & 6.1 \\
\hline 2E,6Z,9Z-2-Methyl-2,6,9-icosatrienal (223) & $>33.0 \mu \mathrm{M}$ \\
\hline Cyclolinteione (224) & 11.9 \\
\hline $5 \alpha, 8 \alpha$-Epidioxycholesta-6-en-3 $\beta$-ol (225) & 15.7 \\
\hline $5 \alpha, 8 \alpha$-Epidioxy-24-cholesta-6,22-dien-3 $\beta$-ol (226) & 0.6 \\
\hline $5 \alpha, 8 \alpha$-Epidioxycholesta-6,9(11),22-trien-3 $\beta$-ol (227) & 7.3 \\
\hline $5 \alpha, 8 \alpha$-Epidioxy-24-norcholesta-6,22-dien-3 $\beta$-ol (228) & 9.0 \\
\hline $5 \alpha, 8 \alpha$-Epidioxy-24-methylcholesta-6,24(28)-dien-3 $\beta$-ol (229) & 20.5 \\
\hline $5 \alpha, 8 \alpha$-Epidioxy-24-methylcholesta-6,22-dien-3 $\beta$-ol (230) & 20.2 \\
\hline $5 \alpha, 8 \alpha$-Epidioxy-cholesta-6,22,24(28)-trien-3 $\beta$-ol (231) & 11.2 \\
\hline $5 \alpha, 8 \alpha$-Epidioxy-24-methylcholesta-6,9(11),24(28)-trien-3 $\beta$-ol (232) & 19.5 \\
\hline $5 \alpha, 8 \alpha$-Epidioxy-24-methylcholesta-6,9(11),22-trien-3 $\beta$-ol (233) & 11.0 \\
\hline $5 \alpha, 8 \alpha$-Epidioxy-24-ethylcholesta-6-en-3 $\beta$-ol (234) & 18.2 \\
\hline $5 \alpha, 8 \alpha$-Epidioxy-24-ethylcholesta-6,24(28)-dien-3 $\beta$-ol (235) & 2.0 \\
\hline $5 \alpha, 8 \alpha$-Epidioxy-24-ethylcholesta-6,22-dien-3 $\beta$-ol (236) & 7.6 \\
\hline $5 \alpha, 8 \alpha$-Epidioxy-24-hydroperoxycholesta-6,28(29)-dien-3 $\beta$-ol (237) & 14.5 \\
\hline 2,4,6-Triphenyl-1-hexene $(\mathbf{2 4 0})$ & $>32.0 \mu \mathrm{M}$ \\
\hline Naamidine K (243) & $>22.0 \mu \mathrm{M}$ \\
\hline
\end{tabular}




\subsection{Concluding Remarks}

Imidazole alkaloids are frequently encountered in marine sponges of the genus Leucetta. The isolation of two glycerol lipids (238-239) and three glycerol ethers (244-246) in this study has added to the few non-imidazole alkaloid compounds reported from this genus. Unfortunately, compounds 238 and 239 degraded, while for compounds 244-246 insufficient isolated materials were obtained for any biological testing.

Naamidine K (243) is a 10-hydroxy analogue of naamidine A (213), and a new addition to the naamidine family. Compound $\mathbf{2 4 3}$ was found to be at least four times less active than 213, suggesting that the 10-hydroxy group might be responsible for the four-fold reduction in antiproliferative potency. 


\section{Chapter 6}

\section{Zampanolides B-E and Dactylolide from the Tongan Sponge Cacospongia mycofijiensis}

A spectroscopic investigation into metabolites of the Tongan sponge Cacospongia mycofijiensis resulted in the isolation of four new zampanolide analogues and a new oxygenated sesquiterpene. In addition, the re-isolation of dactylolide established a firm conclusion regarding its controversial configuration.

\subsection{Cacospongia mycofijiensis}

The marine sponge Cacospongia mycofijiensis ${ }^{217}$ belongs to the family Thorectidae, a member of the order Dictyoceratida (see Table 6.1). It is found throughout the Indo-Pacific with a variable morphology from mushroom to tubular-like shapes depending on the geographical location and the surrounding environment. ${ }^{218}$ In recent years, $C$. mycofijiensis has emerged as a prolific source of structurally diverse and biologically active secondary metabolites, and is comparable to that of Theonella swinhoei. ${ }^{219}$ There are distinct chemotypes that can be frequently obtained from C. mycofijiensis, which include producers of simple terpenoids accompanied by polyketides biosynthesised by either polyketide synthases (PKS) or mixed polyketide nonribosomal peptide synthetases (PKS-NRPS). 220

The first reported investigations of this species were carried out by the Crews research group on a Fijian C. mycofijiensis* and an associated nudibranch Chromodoris lochi, which led to the isolation of two known compounds latrunculin A (248) and dendrolasin (249), a simple furanosesquiterpene. ${ }^{217}$ Compound 248 is a 16-membered macrolide with an attached 2-thiazolidinone originally reported from the Red Sea sponge Negombata magnifica $\amalg^{\mp 2211}$ Latrunculin A (248) is an ichthyotoxic compound and was later

\footnotetext{
*Previously identified as Spongia mycofijiensis.

${ }^{\dagger}$ Previously identified as Latrunculia magnifica.
} 
Table 6.1. Taxonomic classification of the genus Cacospongia from order Dictyoceratida as presented by World Porifera Database. ${ }^{31}$

\begin{tabular}{|c|c|c|c|}
\hline$\overline{\text { Order }}$ & Family & Sub-family & Genus \\
\hline \multirow{18}{*}{ Dictyoceratida } & \multirow{18}{*}{ Thorectidae } & \multirow{18}{*}{ Thorectinae } & Aplysinopsis \\
\hline & & & Cacospongia \\
\hline & & & Collospongia \\
\hline & & & Dactylospongia \\
\hline & & & Fascaplysinopsis \\
\hline & & & Fasciospongia \\
\hline & & & Fenestraspongia \\
\hline & & & Hyrtios \\
\hline & & & Luffariella \\
\hline & & & Narrabeena \\
\hline & & & Petrosaspongia \\
\hline & & & Scalarispongia \\
\hline & & & Semitaspongia \\
\hline & & & Smenospongia \\
\hline & & & Taonura \\
\hline & & & Thorecta \\
\hline & & & Thorectandra \\
\hline & & & Thorectaxia \\
\hline
\end{tabular}

found to be an actin polymerization inhibitor, and consequently compound $\mathbf{2 4 8}$ is the most widely used tool for inhibition of actin polymerization in cell biological studies. .222[223 $^{.2}$ From two separate specimens of $C$. mycofijiensis collected from Fijian waters, seven new latrunculin congeners were obtained; latrunculols A-C (250-252), 18-epi-latrunculol A (253), and latrunculones A and B (254-255). ${ }^{224}$ These structural analogue studies improved the understanding of the latrunculin family chemotypes and their cytotoxic properties. Compounds 250, 251, 253 and 255 showed significant cytotoxicities against both murine and human cancer cell lines.

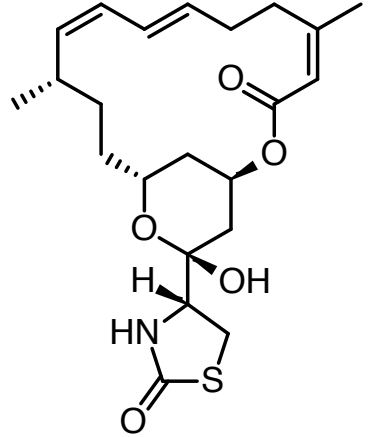

248<smiles>CC(C)=CCC/C(C)=C/CCc1ccoc1</smiles>

249<smiles>C/C=C(/C)CC[C@@H](O)[C@@H](O)/C=C\[C@@H](C)CC[C@@H]1C[C@H](OC(=O)/C=C(/C)CO)C[C@@](O)([C@H]2CSC(=O)N2)O1</smiles>

$250 \mathrm{R}=\mathrm{H} \quad 6 S, 18 R$

$251 \mathrm{R}=\mathrm{Me} 6 S, 18 R$

$252 \mathrm{R}=\mathrm{H} \quad 6 R, 18 R$

$253 \mathrm{R}=\mathrm{H} \quad 6 S, 18 S$ 


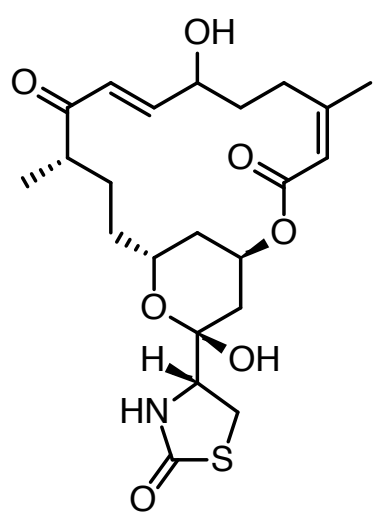

254<smiles>C/C=C(/C)CCC(=O)C/C=C\[C@@H](C)CC[C@@H]1C[C@H](OC(=O)/C=C(/C)CCC(=O)O)CC([C@H]2CSC(=O)N2)O1</smiles>

255

Mycothiazole (256) is an unusual heterocyclic polyketide obtained from a specimen of C.mycofijiensis collected from Vanuatu. 225 A re-investigation of another Vanuatu specimen led to the isolation of a new derivative, mycothiazole-4,19-diol (257), together with the revision of the original structure of 256 ( $E$ configuration at $\Delta_{14,15}$ was revised to $Z){ }^{226}$ Both compounds were cytotoxic towards lung cancer cells and also proved to be valuable prototypes of a mitochondrial complex I inhibitor. From the same Vanuatu collection where they originally reported mycothiazole (256), Crews and co-workers also identified two cytotoxic macrolides; fijianolides A (258) and B (259). $\stackrel{[27}{\cdot}$ These isomers were isolated almost contemporaneously and reported as isolaulimalide (258) and laulimalide (259), respectively from an Indonesian marine sponge Hyatella sp. by Scheuer and colleagues from the University of Hawaii ${ }^{* 228}$ Fijianolide B (259) is a potent inhibitor of cellular proliferation with $\mathrm{IC}_{50}$ values in the low nanomolar range and has shown to interact with tubulin at a similar but distinct binding site relative to that of paclitaxel. $\stackrel{229 \mid 230}{ }$ In addition to fijianolides A (258) and B (259), six new fijianolides D-I (260-265) were extracted from another collection from the coast of Vanuatu, each with modifications to the $\mathrm{C}-20$ side chain of the macrolide ring. ${ }^{231}$ Fijianolides D-I (260-265) displayed a wide range of in vitro activities against several cell lines but were less potent than fijianolide B (259).

A chemical investigation of a Fijian specimen that was stored in $\mathrm{MeOH}$ at $4{ }^{\circ} \mathrm{C}$ for 19 years led to the isolation of a novel heterocyclic compound, CTP-431 (266). Extensive NMR and X-ray crystallography analysis established an unusual thiopyrone structure that has no precedent in natural products chemistry. CTP-431 (266) displayed

\footnotetext{
${ }^{*}$ The trivial names isolaulimalide and laulimalide are used more extensively in the scientific literature.
} 


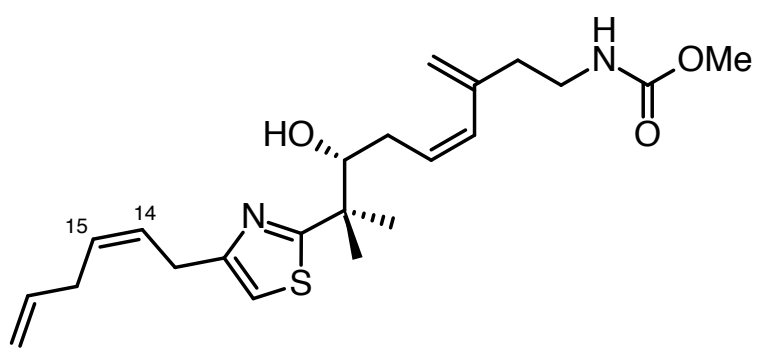

256
(1)

257

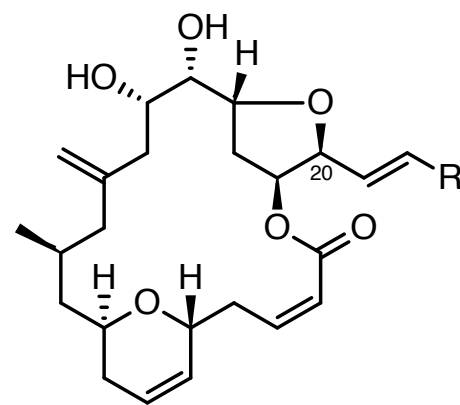

$258 \mathrm{R}=\mathrm{A}$

$260 \mathrm{R}=\mathrm{B}$

$262 \mathrm{R}=\mathrm{C}$

$264 \mathrm{R}=\mathrm{D}$

$265 \mathrm{R}=\mathrm{E}$

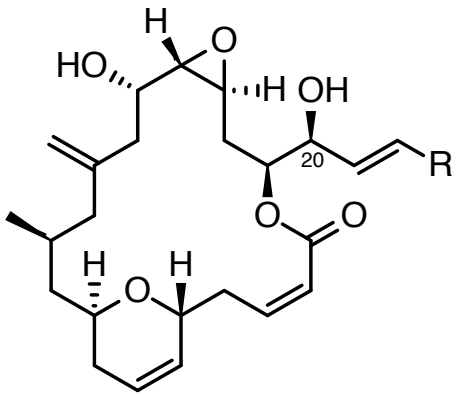

$259 \mathrm{R}=\mathrm{A}$

$261 \mathrm{R}=\mathrm{B}$

$263 \mathrm{R}=\mathrm{C}$<smiles>CC1=CCO[C@H](C)C1</smiles><smiles>[B]C1(C)CC(C)=CC(=O)O1</smiles><smiles>[2H][C@@H]1CC(C)=C[C@@H](OO[C@H]2C=C(C)CC(C)(C)O2)O1</smiles>

no signs of microfilament disrupting effects despite its biogenic relationship to latrunculin A (248). Analysis of individual specimens from Papua New Guinea produced three novel sesquiterpenes; aignopsanoic acid A (267), methyl aignopsanoate A (268), and isoaignopsanoic acid A (269). $\stackrel{233}{ }$ The crude extract of an additional Papua New Guinea sample was used to validate a new hyphenated technique compound library that resulted in the isolation of four new compounds; aignopsanoic acid B (270), aignopsane ketal (271), apo-latrunculin T (272) and 20-methoxyfijianolide A (273). 234

A spectroscopic analysis of a Tongan collection by Singh in this laboratory resulted in the isolation of two new latrunculin congeners; named latrunculin $X$ (274) and

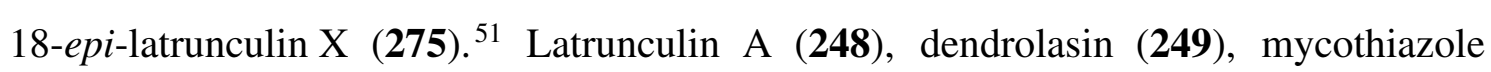
(256), isolaulimalide (258), laulimalide (259), 6,7-epoxylatrunculin A (276), neolaulimalide (277) and zampanolide (278) were also isolated. ${ }^{51}$ 
<smiles>COC(=O)Nc1csc2c(c1=O)[C@H](/C=C/CC/C(C)=C\C(=O)O)[C@@H]1[C@@H](C)CC[C@H]1C2</smiles><smiles>CCCC(=O)C=C1CC[C@]2(C)C(C)CCC[C@]2(C)C1=O</smiles>

$267 \mathrm{R}=\mathrm{H}$

$268 \mathrm{R}=\mathrm{Me}$

266

$269 \mathrm{R}=\mathrm{H} \Delta_{8,11}=E$

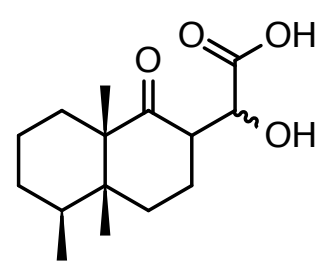

270<smiles>COC(CC1CC[C@]2(C)[C@@H](C)CCC[C@]2(C)C1=O)OC</smiles>

271<smiles>C/C(=C/C(=O)O)CC/C=C/C=C\[C@H](C)CC[C@@H](O)CCCC(=O)C1CSC(=O)N1</smiles>

272

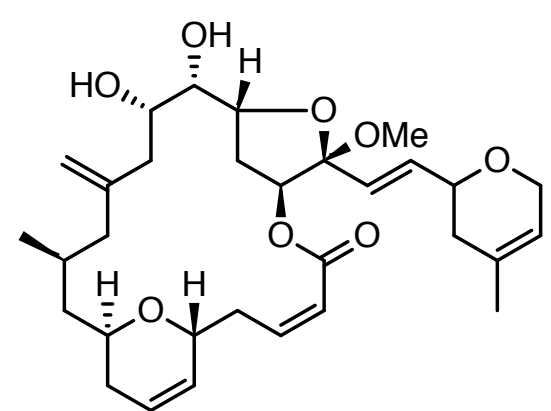

273

274

275 18-epi

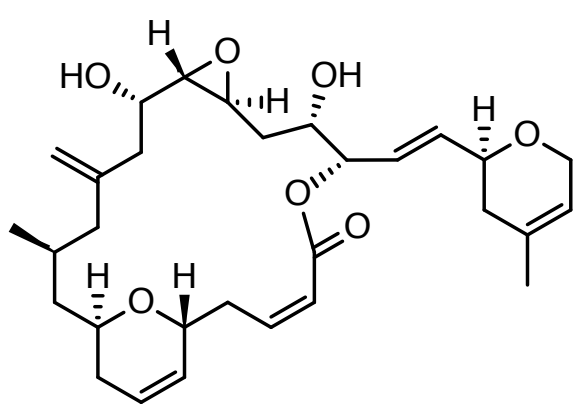

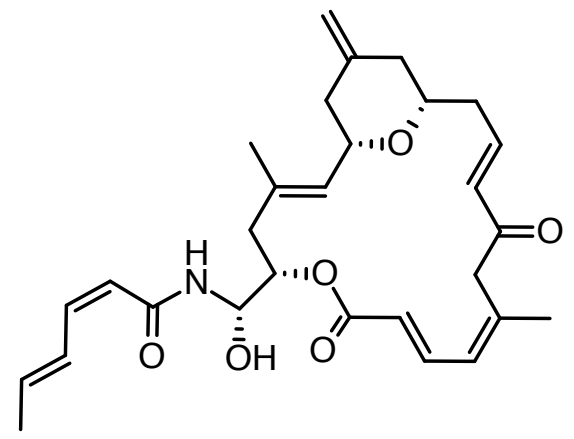




\subsection{Tongan Marine Sponge Cacospongia mycofijiensis}

In this laboratory, collections of $C$. mycofijiensis were obtained from two different geographical locations in the Kingdom of Tonga. The first collection was made from the island of 'Eua in late 2008. As mentioned earlier, Singh, as part of his $\mathrm{PhD}$ research, subjected the sponge to an NMR-based screen that generated a number of known bioactive and structurally diverse compounds, including latrunculin A (248), dendrolasin (249), mycothiazole (256), laulimalide (259), isolaulimalide (258), 6,7epoxylatrunculin A (276), neolaulimalide (277) and zampanolide (278). 51 Compound 278 was originally reported from the Japanese marine sponge Fasciospongia rimosa, and although it exhibited potent cytotoxicity against several cell lines ( $\left.\mathrm{IC}_{50} 2-10 \mathrm{nM}\right)$, there was no information available regarding the mode of action. ${ }^{235}$ The re-isolation of 278 allowed further investigation on its mode of action, which showed it to be a novel and potent microtubule-stabilising compound. ${ }^{236}$ Zampanolide (278) is cytotoxic in nanomolar concentrations, and arrests cells in the $G_{2} / M$ phase of the cell cycle by irreversibly covalently binding to the luminal site on the $\beta$-tubulin, and therefore disrupting the function of the microtubule. ${ }^{237}$ This places zampanolide (278) in an important group of anti-cancer compounds that includes the clinically valuable paclitaxel.

The significance of this discovery initiated a second expedition to Tonga in late 2009. However, the only available boat that could be used for 'Eua did not meet the New Zealand maritime safety requirements and also lacked proper diving equipment. As a result, the collections were made from the Vava'u Group of islands in the northern part of Tonga. During the course of our investigations on bioactive metabolites from these marine organisms, we were intrigued by the geographic variability in the chemistry between the Vava'u and 'Eua organisms. Compared to Vava'u, organisms collected from 'Eua have been shown to produce a greater quantity of secondary metabolites and also have a high probability of discovering novel compounds. ${ }^{47 / 4951}$ This observation was especially pronounced for C. mycofijiensis, as 'Eua specimens had detectable quantities of zampanolide (278) and laulimalide (259), whereas Vava'u specimens were significantly less abundant. Another collection-dive trip was therefore required and a trip to Tonga in 
mid-2016 was organised with a specific target for 'Eua as the collection site. Funding was therefore secured and this time, a boat, which met the New Zealand maritime safety requirements, was available for hire and a third expedition took place in 'Eua in mid 2016. This resulted in the collection of more than $3 \mathrm{~kg}$ of $C$. mycofijiensis.

\subsection{Isolation}

An extraction of C. mycofijiensis (PTN4_26A, see Figure 6.1), collected from an underwater cave, 'Eua, was performed (see Scheme 6.1). The methanolic extracts were chromatographically separated over PSDVB resin, and the resulting $80 \% \mathrm{Me}_{2} \mathrm{CO} / \mathrm{H}_{2} \mathrm{O}$ fraction was purified over a normal-phase $\mathrm{SiO}_{2}$ column, generating 160 fractions. Fractions were combined based on TLC that showed comparatively good separation, which were also confirmed by NMR analysis. These compounds eluted from the $\mathrm{SiO}_{2}$ column in the following order; dendrolasin (249), mycothiazole (256), latrunculin A (248), zampanolide (278), laulimalide (259), neolaulimalide (277) and isolaulimalide (259). The first three compounds were the major components of the extract. The $100 \% \mathrm{CH}_{2} \mathrm{Cl}_{2}$ fraction from the $\mathrm{SiO}_{2}$ column was further purified on a $\mathrm{SiO}_{2}$ column, yielded two oxygenated sesquiterpenes: dictyodendrillin A (279) and its new isomer isodictyodendrillin A (280).

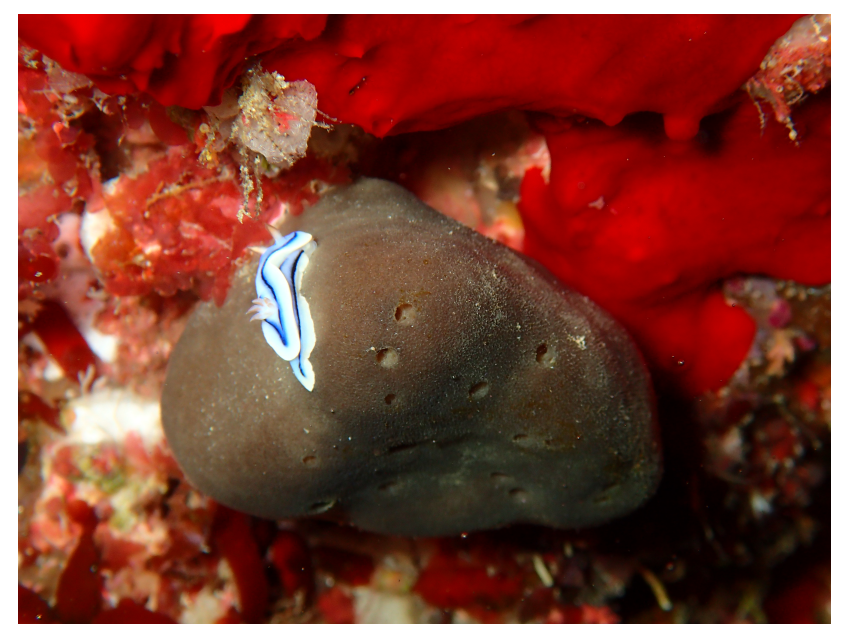

Figure 6.1. Underwater photograph of Cacospongia mycofijiensis, collected from 'Eua, Tonga. Photograph courtesy of Dan Crossett. 


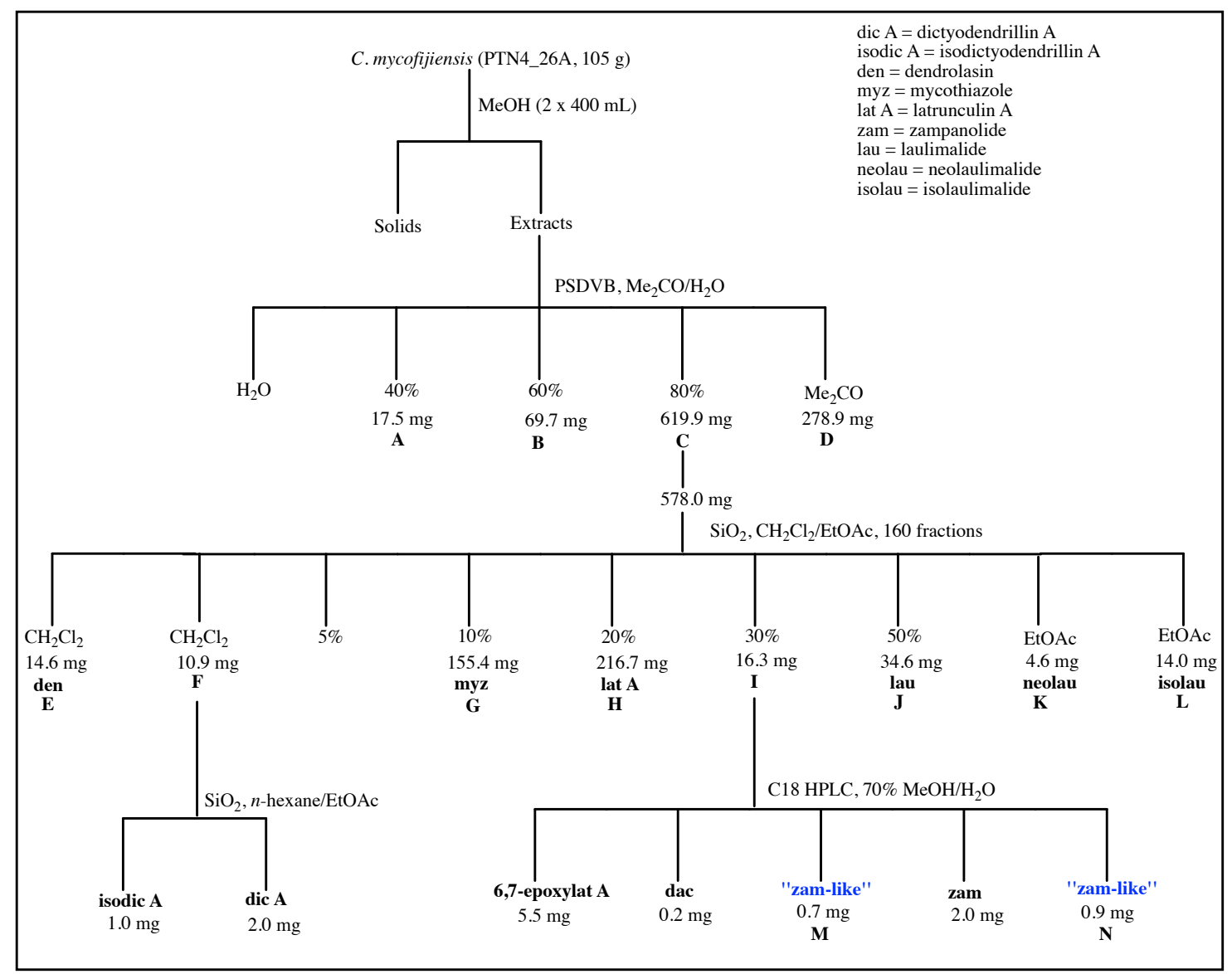

Scheme 6.1. The initial isolation procedure for compounds from the sponge Cacospongia mycofijiensis, collected from 'Eua, Tonga.

Examination of the zampanolide-containing fraction by NMR showed interesting signals, several from minor compounds that appeared to be closely related to zampanolide (278). A proton signal at $\delta_{\mathrm{H}} 9.66$ was observed in the ${ }^{1} \mathrm{H}$ NMR spectrum and appeared to be an aldehyde with a carbon at $\delta_{\mathrm{C}}$ 199.7. ${ }^{*}$ Analysis of the 2D-NMR spectra showed HMBC correlations from this aldehyde proton to a deshielded oxymethine $\left(\delta_{\mathrm{C}} 5.31 ; \delta_{\mathrm{C}} 77.5\right)$ that which is consistent with dactylolide (281), the only known natural product structurally related to zampanolide (278). ${ }^{238}$ This provided an indication that the presence of $\mathbf{2 8 1}$ in the sponge was highly likely and was consistent with Northcote's suspicion that the sponge from the first 'Eua collection contained both 278 and 281. ${ }^{239}$ A final stage of purification was carried out by using $\mathrm{C} 18$ reversed-phase HPLC, which led to the isolation of known compounds 6,7-epoxylatrunculin A (276), zampanolide (278) and dactylolide (281).

* Obtained from multiplicity edited HSQC experiment. 


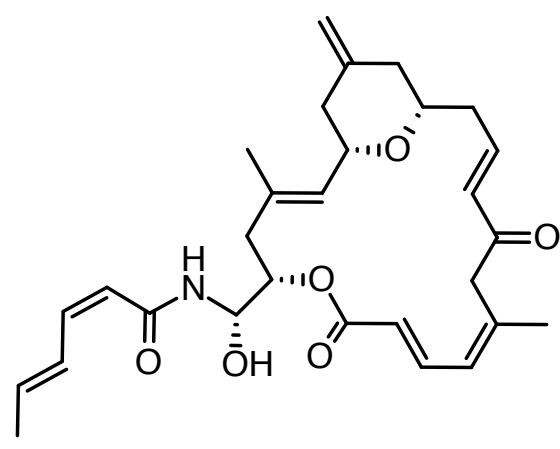

278

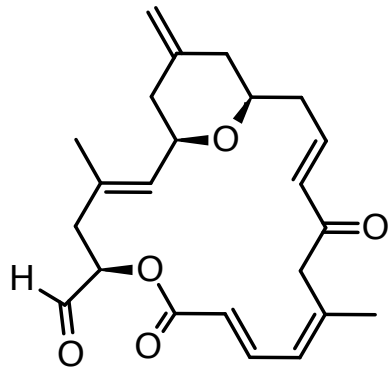

281

In addition, several fractions obtained in very small quantities from the final HPLC purification showed NMR correlations that indicated that the structures in question could be new variants related to zampanolide (278) or dactylolide (281). However, due to the small sample sizes and impurities, the structural elucidation of these compounds proved to be a challenge. As a result, two large-scale isolation procedures targeting zampanolide (278), dactylolide (281) and these related compounds were performed. The two largescale extractions and the semi-purification of the crude extracts were carried out by Harlandf as part of her research project at VUW (see Schemes 6.2 and 6.3). In both cases, C. mycofijiensis (PTN4_26A, $527 \mathrm{~g}$ and $503 \mathrm{~g}$ ) collected from 'Eua, Tonga was extracted with $\mathrm{MeOH}$ and the extracts were cyclic loaded onto reversed-phase PSDVB beads. The column was eluted with increasing concentrations of $\mathrm{Me}_{2} \mathrm{CO}$ in $\mathrm{H}_{2} \mathrm{O}$. The $60 \%$ and the $80 \% \mathrm{Me}_{2} \mathrm{CO} / \mathrm{H}_{2} \mathrm{O}$ fractions were then purified on a $\mathrm{SiO}_{2}$ column and monitored via ${ }^{1} \mathrm{H}$ NMR spectroscopy for signs of zampanolide (278), dactylolide (281) and the related compounds. The "zampanolide-positive" samples were then further purified repeatedly over C18 HPLC to produce four new minor zampanolide analogues named here as zampanolides B-E (282-285), along with zampanolide (278) $\left.\right|^{\dagger}$ and dactylolide (281).

*An MChem student from the University of York.

${ }^{\dagger}$ The original zampanolide will be referred to as zampanolide A. 


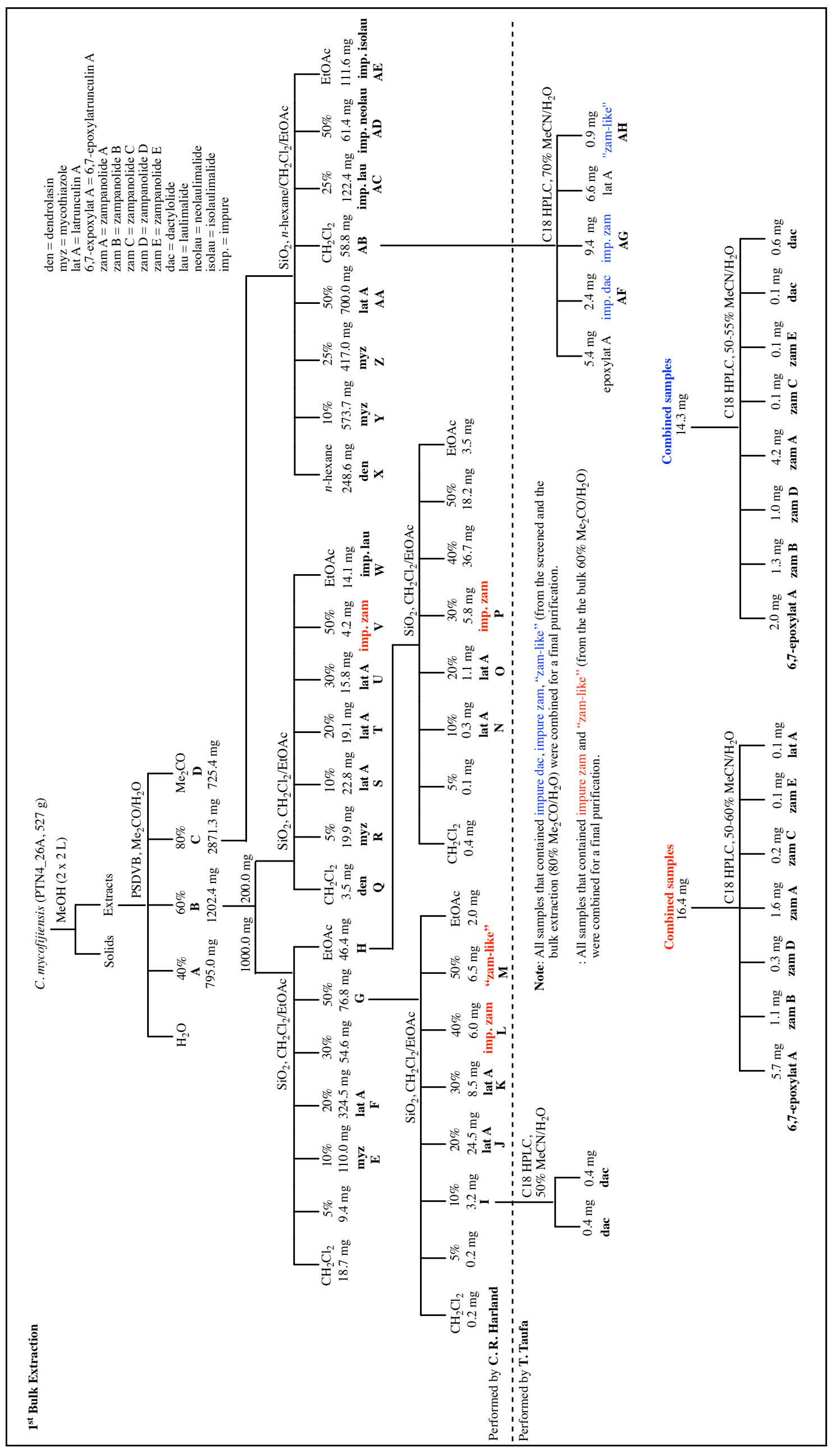

胥

음

웡

.

8

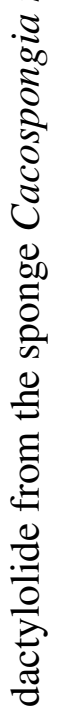




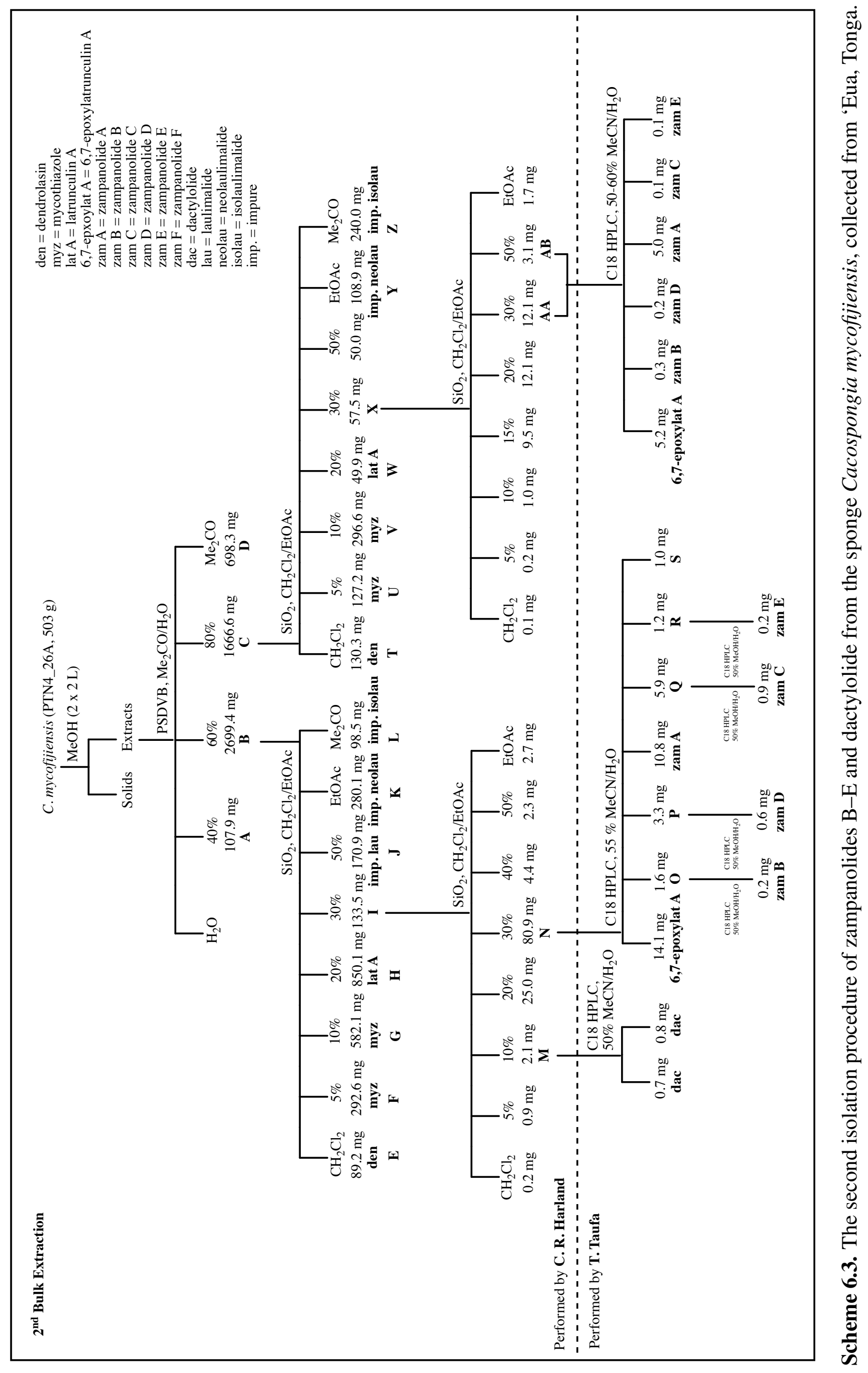




\subsection{Isodictyodendrillin A}

Isodictyodendrillin A (280) was isolated as a colourless oil. Analysis of $\mathbf{2 8 0}$ by positive ion-mode HRESIMS revealed an $[\mathrm{M}+\mathrm{Na}]^{+}$adduct ion peak at $m / z 273.1466$ ( $\Delta=1.83 \mathrm{ppm}$ ), indicative of the molecular formula $\mathrm{C}_{15} \mathrm{H}_{22} \mathrm{O}_{3}$, requiring five degrees of unsaturation. The ${ }^{13} \mathrm{C}$ NMR spectrum displayed all 15 expected resonances, and analysis of the multiplicity edited HSQC experiment in conjunction with the ${ }^{1} \mathrm{H}$ NMR spectrum established that all hydrogens were attached to carbon, suggesting the three proposed oxygens were non-protonated. Identifiable features in the ${ }^{13} \mathrm{C}$ NMR spectrum included three olefinic methyls $\left(\delta_{\mathrm{C}} 25.8 ; 17.9 ; 16.2\right)$, five methylenes $\left(\delta_{\mathrm{C}} 39.7 ; 36.2 ; 29.8\right.$; $26.6 ; 23.2)$, two olefinic methines $\left(\delta_{\mathrm{C}} 124.1 ; 122.2\right)$ and an acetal methine $\left(\delta_{\mathrm{C}} 83.1\right)$. The remaining four non-protonated centres were assigned as: one lactone carbonyl $\left(\delta_{\mathrm{C}}\right.$ 173.6), two olefinic carbons $\left(\delta_{\mathrm{C}} 137.4 ; 131.9\right)$ and one $s p^{3}$-hybridised quaternary carbon $\left(\delta_{\mathrm{C}} 62.4\right)$. The ${ }^{1} \mathrm{H}$ NMR spectrum for $\mathbf{2 8 0}$ revealed singlet resonances for three olefinic methyls associated with two trisubstituted double bonds, while the carbon resonance at $\delta_{\mathrm{C}} 173.6$ was typical of a lactone carbonyl centre. Hence three out of the five degrees of unsaturation were accounted for, proposing that the molecule contained two rings.

Analysis of the 2D-NMR spectra of $\mathbf{2 8 0}$ led to the construction of three substructures. COSY and HMBC correlations observed between two of the methyl singlets $\mathrm{CH}_{3}-12$ $\left(\delta_{\mathrm{H}} 1.68 ; \delta_{\mathrm{C}} 25.8\right)$ and $\mathrm{CH}_{3}-13\left(\delta_{\mathrm{H}} 1.60 ; \delta_{\mathrm{C}} 17.9\right)$ to the same two carbons, quaternary olefinic carbon C-11 $\left(\delta_{\mathrm{C}} 131.9\right)$ and olefinic methine carbon $\mathrm{CH}-10\left(\delta_{\mathrm{H}} 5.06 ; \delta_{\mathrm{C}} 124.1\right)$ as well to each other implied the presence of geminal methyls as part of a trisubstituted double bond. Strong COSY coupling was observed between $\mathrm{H}-10$ and methylene $\mathrm{CH}_{2}-9$ $\left(\delta_{\mathrm{H}} 2.07 ; \delta_{\mathrm{C}} 26.6\right)$ and was corroborated by HMBC correlations as shown in Figure 6.2 , unveiling the substructure $\mathrm{A}$ as an isoprene unit.

Connectivity of the second substructure (Figure 6.3) began with COSY correlations between $\mathrm{H}-9$ and $\mathrm{CH}_{2}-8\left(\delta_{\mathrm{H}} 2.00 ; \delta_{\mathrm{C}} 39.7\right)$, establishing the connectivity between the two respective carbons. HMBC correlations from the protons of the olefinic methyl group $\mathrm{CH}_{3}-14\left(\delta_{\mathrm{H}} 1.61 ; \delta_{\mathrm{C}} 16.2\right)$ to $\mathrm{C}-8$, attachment point $\mathrm{C}-7\left(\delta_{\mathrm{C}} 137.4\right)$ and olefinic 


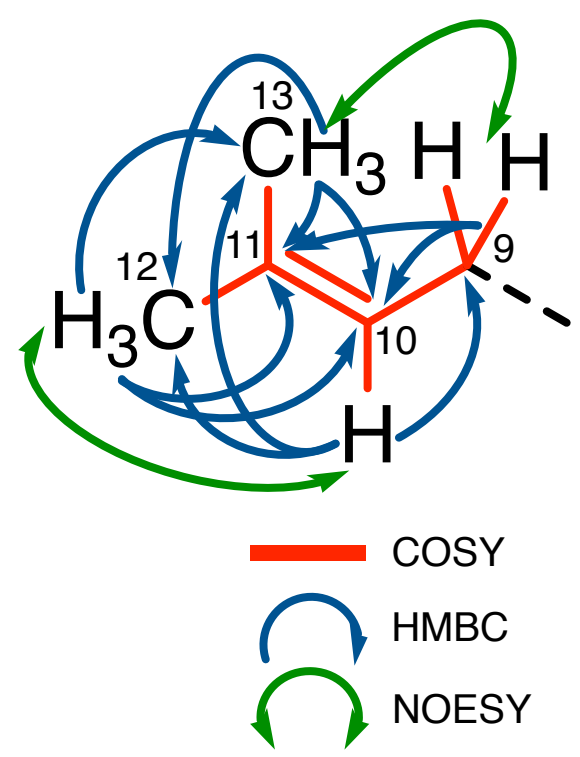

Figure 6.2. Key COSY and HMBC correlations establishing the connectivities of the terminal isoprene unit, substructure A, of isodictyodendrillin A (280).

methine $\mathrm{CH}-6\left(\delta_{\mathrm{H}} 5.07 ; \delta_{\mathrm{C}} 122.2\right)$, all of which were evident through diagnostic COSY correlation data, suggested the presence of another trisubstituted double bond. COSY and HMBC correlations from H-6 to a methylene $\mathrm{CH}_{2}-5\left(\delta_{\mathrm{H}} 2.14 ; \delta_{\mathrm{C}} 23.2\right)$, established substructure B. The methyl groups on the trisubstituted double bond show characteristic NMR chemical shifts for an $E$ alkene: $\delta_{\mathrm{H}}<1.6$ and $\delta_{\mathrm{C}}<20$ for the $E$, compared to $\delta_{\mathrm{H}}>1.6$ and $\delta_{\mathrm{C}}>20$ for $Z{ }^{240 \mid 241}$ Thus, the methyl group revealed the double bond $\Delta_{6,7}$ to have an $E$ geometry which was confirmed by a NOESY correlation between $\mathrm{H}_{2}-5$ and $\mathrm{H}_{3}-14$.

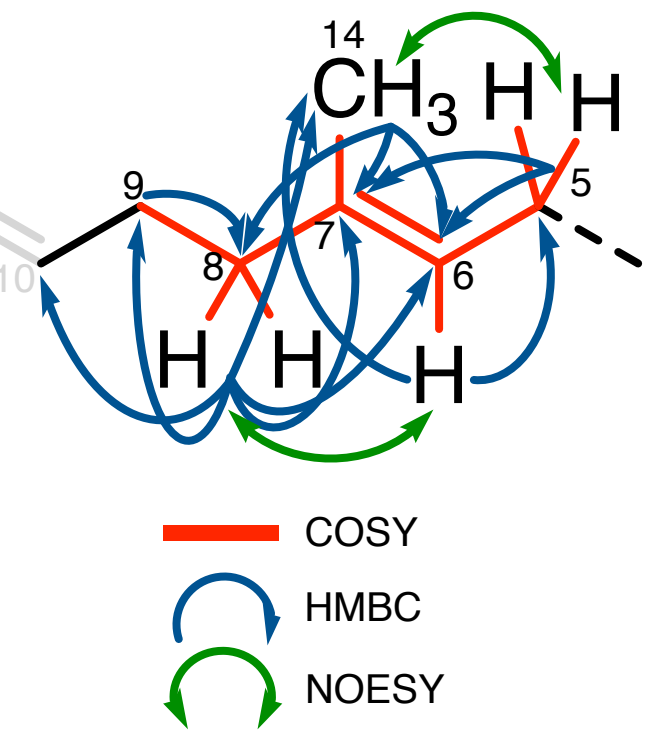

Figure 6.3. Key COSY and HMBC correlations establishing the connectivities of the isoprene unit, substructure B, of isodictyodendrillin A (280). 
Identification of the final substructure by the COSY experiment began with the diastereotopic methylene $\mathrm{CH}_{2}-4\left(\delta_{\mathrm{H}} 1.86,1.96 ; \delta_{\mathrm{C}} 29.8\right)$, the protons of which shared COSY correlations with $\mathrm{H}_{2}-5$, established the connectivity between the two respective carbons. With 11 of the 15 carbons and 19 of the 22 protons accounted for, a fragment containing four carbons, three oxygens and three hydrogens, remained to be assigned $\left(\mathrm{C}_{4} \mathrm{H}_{3} \mathrm{O}_{3}\right)$. The chemical shift of $\mathrm{C}-1\left(\delta_{\mathrm{C}}\right.$ 173.6) was typical of an $\alpha, \beta$-butenolide lactone, 242 however there were no unassigned $s p^{2}$-hybridised carbons. The presence of a quaternary $s p^{3}$-hybridised carbon $\left(\delta_{\mathrm{C}} 62.4\right)$ and an acetal methine $\mathrm{CH}-15\left(\delta_{\mathrm{H}} 5.41 ; \delta_{\mathrm{C}} 83.1\right)$ was consistent with that of a $\beta, \gamma$-epoxy- $\gamma$-butyrolactone ring. ${ }^{243-246}$ Also supporting this assumption was the fact that two of the degrees of unsaturation were already accounted for, leaving three degrees of unsaturation. The $\beta, \gamma$-epoxy- $\gamma$-butyrolactone moiety was then identified with COSY and HMBC correlations beginning with HMBC correlations from $\mathrm{H}_{2}-4$ to a second diastereotopic methylene $\mathrm{CH}_{2}-2\left(\delta_{\mathrm{H}} 2.70,2.82 ; \delta_{\mathrm{C}} 36.2\right), \mathrm{CH}-15$ and the attachment point, C-3. Observation of a weak COSY correlation between $\mathrm{H}_{2}-2 \mathrm{~b}$ and $\mathrm{H}-15$ indicated a long-range $\mathrm{W}$-coupling between these protons. In conjunction with the HMBC correlations from $\mathrm{H}-15$ to $\mathrm{C}-1$ and $\mathrm{C}-3$, the unusually large ${ }^{1} J_{\mathrm{CH}}$ coupling constant measured for $\mathrm{CH}-15(226 \mathrm{~Hz})$ corroborated this assignment. ${ }^{247 / 248}$ Therefore the acyclic moiety in $\mathbf{2 8 0}$ is connected to the $\beta$-carbon instead of the $\alpha$-carbon as shown in Figure 6.4. Unfortunately, attempts to deduce the relative configuration of the two sterogenic centres (C-3 and CH-15) using NOESY data were unsuccessful.

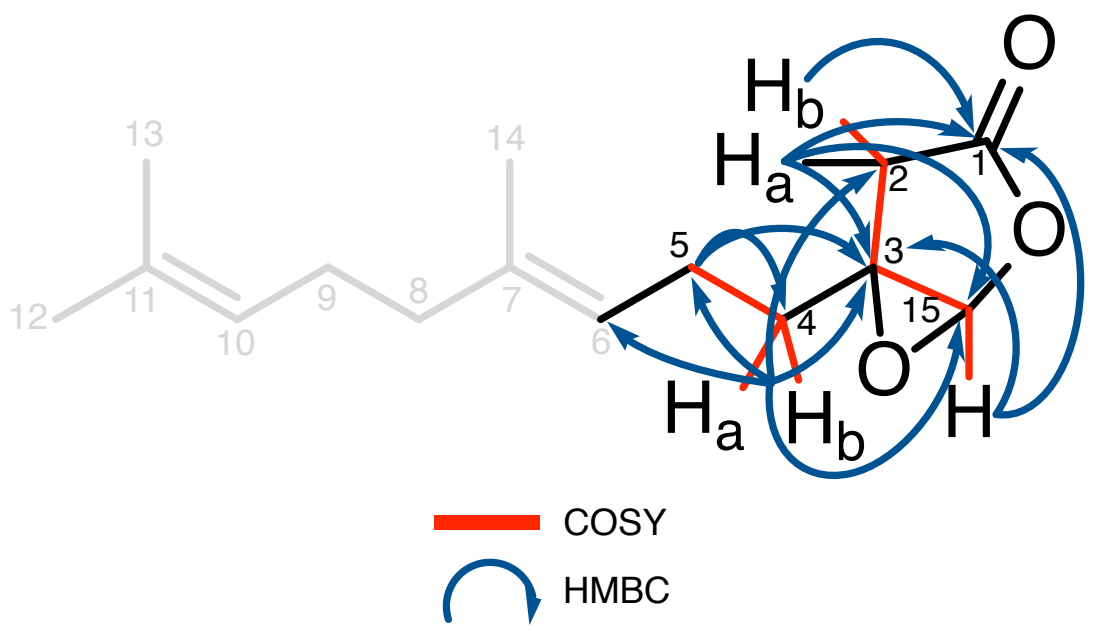

Figure 6.4. Key COSY and HMBC correlations establishing the connectivities of the isoprene unit, substructure $\mathrm{C}$, of isodictyodendrillin $\mathrm{A}$ (280). 
IsodictyodendrillinA (280) is a new isomer of dictyodendrillin A (279), with the only difference being that the acyclic moiety is connected to the $\beta$-carbon instead of the $\alpha$-carbon of the $\beta, \gamma$-epoxybutenolide ring, as seen in many cases. ${ }^{243-246}$ The ${ }^{1} \mathrm{H}$ and ${ }^{13} \mathrm{C}$ NMR data of the acyclic moiety were similar to that of dendrolasin (249) and not surprisingly isodictyodendrillin A (280) could be an oxidation product of $\mathbf{2 4 9}$, as has been shown by the autooxidation studies on the marine furanosesterterpene variabilin by Blunt and Munro. 249

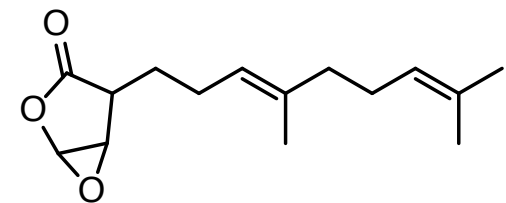

279

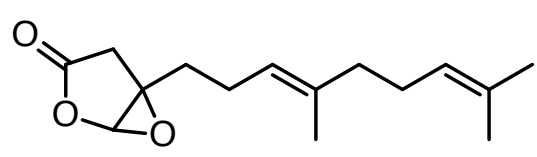

280

Table 6.2. ${ }^{13} \mathrm{C}(150 \mathrm{MHz})$ and ${ }^{1} \mathrm{H}(600 \mathrm{MHz})$ NMR Data of Isodictyodendrillin A (280) in $\mathrm{CDCl}_{3}$.

\begin{tabular}{|c|c|c|c|c|c|c|c|c|c|c|}
\hline & \multirow[b]{2}{*}{ Pos. } & \multicolumn{3}{|c|}{${ }^{13} \mathrm{C}$} & \multicolumn{3}{|c|}{${ }^{1} \mathrm{H}$} & \multirow[b]{2}{*}{ COSY } & \multirow[b]{2}{*}{$\begin{array}{c}\mathrm{HMBC} \\
\left({ }^{1} \mathrm{H} \text { to }{ }^{13} \mathrm{C}\right)\end{array}$} & \multirow[b]{2}{*}{$\mathrm{NOE}^{\ddagger}$} \\
\hline & & $\begin{array}{c}\delta \\
(\mathrm{ppm})\end{array}$ & mult & $\begin{array}{l}{ }^{1} J_{\mathrm{CH}}{ }^{\dagger} \\
(\mathrm{Hz})\end{array}$ & $\begin{array}{c}\delta \\
\text { (ppm) }\end{array}$ & mult & $\begin{array}{c}J \\
(\mathrm{~Hz})\end{array}$ & & & \\
\hline & 1 & 173.6 & $\mathrm{C}$ & & & & & & & \\
\hline & $2 \mathrm{a}$ & 36.2 & $\mathrm{CH}_{2}$ & 130 & 2.70 & d & 19.1 & & 1 & \\
\hline & $2 b$ & & & 130 & 2.82 & $\mathrm{dd}$ & $19.2,1.0$ & 15 & $1,3,15$ & \\
\hline & 3 & 62.4 & C & & & & & & & \\
\hline & $\begin{array}{l}4 \mathrm{a} \\
4 \mathrm{~b}\end{array}$ & 29.8 & $\mathrm{CH}_{2}$ & $\begin{array}{l}128 \\
128\end{array}$ & $\begin{array}{l}1.86 \\
1.96\end{array}$ & $\begin{array}{l}\mathrm{m} \\
\mathrm{m}\end{array}$ & & $\begin{array}{l}5 \\
5\end{array}$ & $\begin{array}{c}2,3,5,6,15 \\
3,5,6,15\end{array}$ & $\begin{array}{l}6 \\
6\end{array}$ \\
\hline & 5 & 23.2 & $\mathrm{CH}_{2}$ & 126 & 2.14 & $q$ & 7.3 & 4,6 & $3,4,6,7$ & 14 \\
\hline & 6 & 122.2 & $\mathrm{CH}$ & 151 & 5.07 & $\mathrm{~m}$ & & 2,4 & $4,5,14$ & 4,8 \\
\hline & 7 & 137.4 & $\mathrm{C}$ & & & & & & & \\
\hline & 8 & 39.7 & $\mathrm{CH}_{2}$ & 120 & 2.00 & $\mathrm{t}$ & 7.8 & 9 & $6,7,9,10,14$ & 6,10 \\
\hline & 9 & 26.6 & $\mathrm{CH}_{2}$ & 122 & 2.07 & $\mathrm{q}$ & 7.5 & 8,10 & $8,10,11$ & 13,14 \\
\hline & 10 & 124.1 & $\mathrm{CH}$ & 151 & 5.06 & $\mathrm{~m}$ & & $9,12,13$ & $8,9,12,13$ & 12,8 \\
\hline & 11 & 131.9 & $\mathrm{C}$ & & & & & & & \\
\hline 280 & 12 & 25.8 & $\mathrm{CH}_{3}$ & 129 & 1.68 & $\mathrm{~s}$ & & $9,10,13$ & $10,11,13$ & 10 \\
\hline & 13 & 17.9 & $\mathrm{CH}_{3}$ & 125 & 1.60 & $\mathrm{~s}$ & & $9,19,12$ & $10,11,12$ & 9 \\
\hline & 14 & 16.2 & $\mathrm{CH}_{3}$ & 125 & 1.61 & $\mathrm{~s}$ & & 5,6 & $10,11,12$ & 5,9 \\
\hline & 15 & 83.1 & $\mathrm{CH}$ & 226 & 5.41 & d & 1.0 & $2 b$ & 1,3 & \\
\hline
\end{tabular}

$\ddagger$ Selected resonances.

†Obtained from a fully-coupled HSQC experiment. 


\subsection{Dactylolide}

\subsubsection{Isolation of (-)-Dactylolide}

Dactylolide (281) and zampanolide A (278) were obtained from the Tongan C. mycofijiensis as minor metabolites. Dactylolide is a 20-membered macrolide originally reported from the sponge Dactylospongia sp. collected from Vanuatu, alongside latrunculin A (248), isolaulimalide (258) and mycothiazole (256). ${ }^{238}$ Compound 281 has not been reported from a natural source since its original publication in 2001. The original paper describing dactylolide reported a dextrorotary optical rotation for the natural product. ${ }^{238}$ However, the final purification of $\mathbf{2 8 1}$ over C18 HPLC during the course of this present study resulted in the isolation of two distinct HPLC peaks (samples $A$ and $B$ ) with similar chromophores and retention times of 42.2 and 51.7 minutes, respectively (see Figure 6.5. A detailed evaluation of their NMR spectra confirmed that both samples were identical and complemented the reported NMR data for the natural dactylolide (281) (see Figure 6.6). In an attempt to determine the relationship between these two samples, each was re-injected onto a C18 HPLC column with the same conditions used to isolate them originally $\left(\mathrm{C} 18,4.6 \times 250 \mathrm{~mm}, 50 \% \mathrm{MeCN} / \mathrm{H}_{2} \mathrm{O}, 1.0 \mathrm{~mL} / \mathrm{min}\right)$. Interestingly, in each case, when one sample was injected and observed, the other peak also appeared at the appropriate retention time with a comparable chromophore and in a similar ratio. Therefore each sample contained two compounds that exist in some form of equilibrium between two major forms, which interconvert back to the equilibrium mixture when stored in solution. Therefore an unresolved spectrum that represents the average conformation between the two compounds is observed in the NMR spectra.

\subsubsection{The Absolute Configuration of (-)-Dactylolide}

The planar structure of dactylolide (281) is very similar to zampanolide A (278), with the only difference being that the unusual $N$-acyl hemiaminal side chain in $\mathbf{2 7 8}$ is replaced by an aldehyde group. Both $\mathbf{2 7 8}$ and $\mathbf{2 8 1}$ have been shown to compete with paclitaxel for binding to microtubules and hence they represent a new class of microtubule-stabilizing 


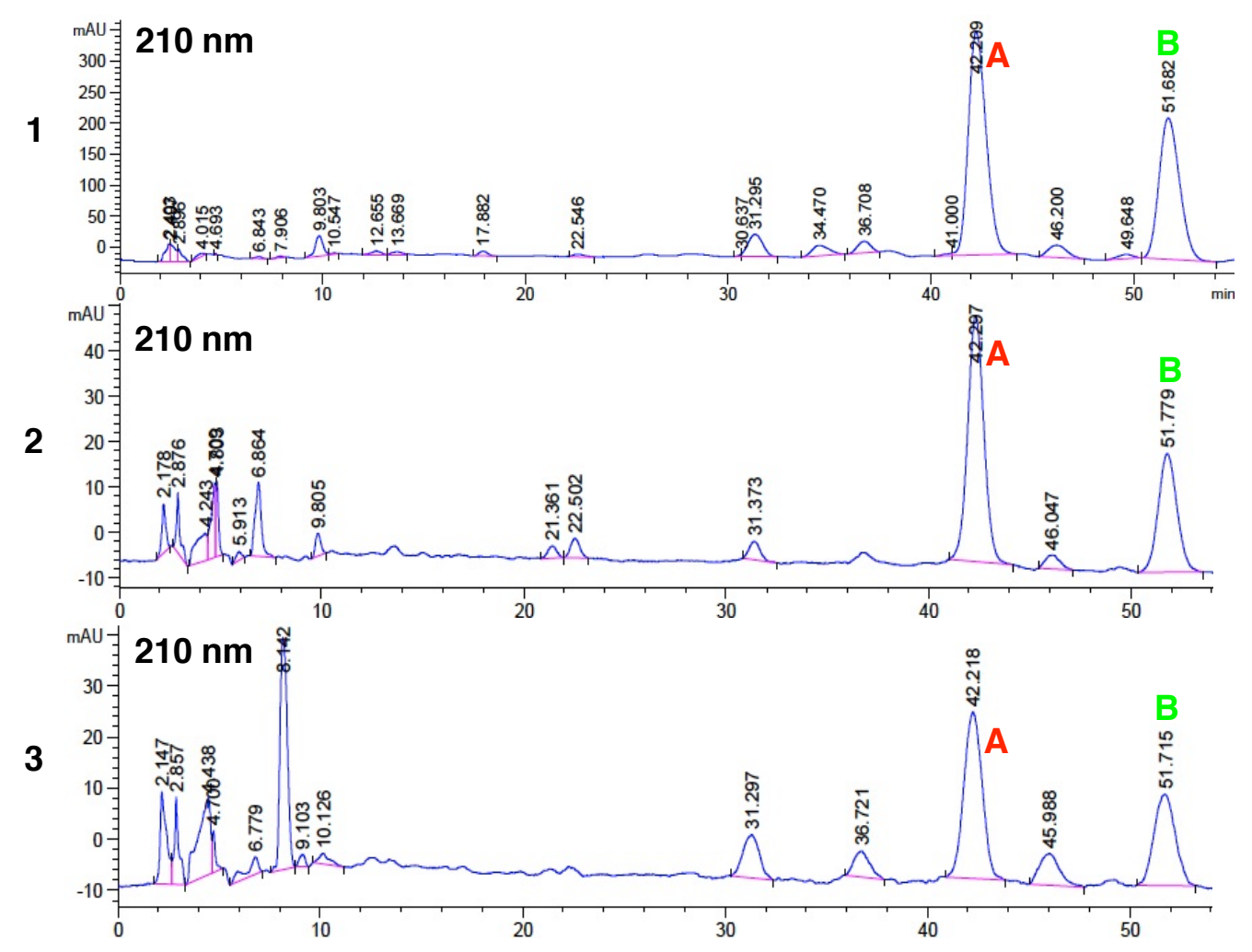

Figure 6.5. 1. HPLC chromatogram of dactylolide purification. 2. HPLC chromatogram of re-injection of sample $A$. 3. HPLC chromatogram of re-injection of sample $B$.

agent (MSA). ${ }^{237}$ Consequently, both compounds have attracted interest from a number of synthetic research groups around the world, and several independent total syntheses of zampanolide A (278), dactylolide (281) and the related macrolactone core have been achieved. 250

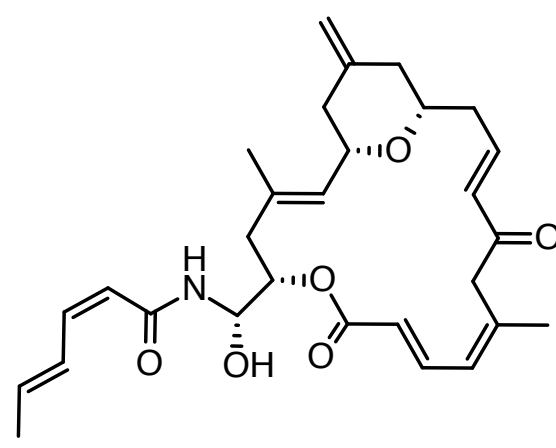

278

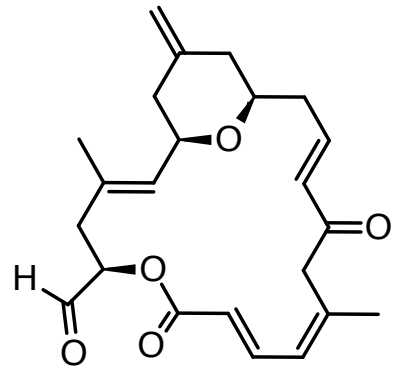

281

The absolute configuration of naturally occurring (-)-zampanolide A (278) was assigned by Smith and co-workers on the basis of the total synthesis of the unnatural antipode (+)-zampanolide..$^{251252}$ The case of dactylolide (281) is more complex, the core macrocyclic structure was suggested to have the opposite configuration to (-)-zampanolide A (278) based on optical rotation data of the isolated and the synthetic samples. ${ }^{238}$ However 


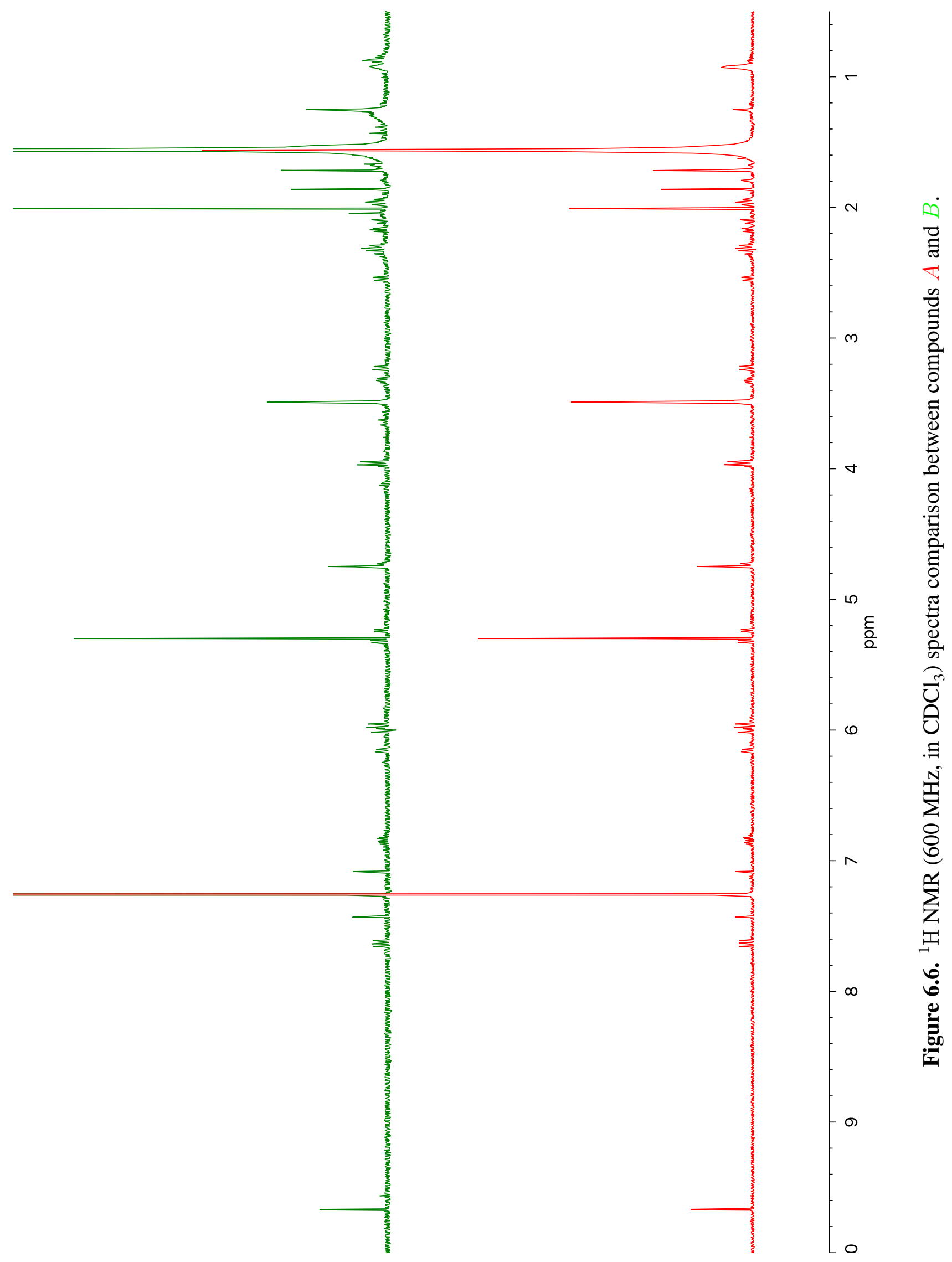


based on biogenetic grounds, it is plausible for both metabolites to be synthesised by the same biosynthetic pathways, even though they were isolated from different sponges. The inversion of the entire configuration of a stereochemically complicated biological molecule during biosynthesis will be unusual as Nature usually makes one enantiomeric form. In contrast to (-)-zampanolide A (278), dactylolide displayed moderate cytotoxicity in the low micromolar range and interestingly, "unnatural" (-)-dactylolide (281) has shown greater potency than the "natural" (+)-dactylolide (281). ${ }^{253}$ Thus it seemed likely that the absolute configuration of the macrocyclic core of $\mathbf{2 8 1}$ is the same as that of $(-)-278$ in spite of its low reported positive (+) optical rotation. This stereochemical relationship was established by Smith and co-workers by thermolysis of the synthetic (+)-zampanolide $\mathrm{A}(\mathbf{2 7 8})$ in $\mathrm{C}_{6} \mathrm{H}_{6}$ to produce (+)-dactylolide $(\mathbf{2 8 1}) \cdot{ }^{[252}$ Consequently they suggested that dactylolide could be a degradation product of, or a macrocyclic precursor for (-)-zampanolide A (278). This raised the possibility that dactylolide might be an artefact produced from decomposition of (-)-278 during the isolation process. A study conducted by Uenishi and co-workers detected no trace of dactylolide when the sponge or (-)-zampanolide A (278) was subjected to the extraction conditions reported by Riccio and co-workers. ${ }^{254}$ Hence dactylolide was thought not to be the decomposition product of (-)-278 but a naturally occurring entity. This also led to the assumption of distinctive biosynthetic pathways for (-)-zampanolide A (278) and (+)-dactylolide (281) and with the incongruence in optical rotations between natural and synthetic antipode dactylolide, therefore, precluding a firm conclusion regarding its absolute configuration.

To shed some light into the perplexity on the absolute configuration of natural dactylolide, an effort was made to isolate dactylolide (281) and zampanolide A (278) from the same natural source and measure their optical rotations. Herein we present the first reported isolation of $\mathbf{2 7 8}$ and $\mathbf{2 8 1}$ from the sponge $C$. mycofijiensis. The optical rotation measurements were carried out for both metabolites using $\mathrm{MeOH}$ and $\mathrm{CH}_{2} \mathrm{Cl}_{2}$ as solvents, since the reported optical rotation for 281 was performed in $\mathrm{MeOH}$ and $\mathrm{CH}_{2} \mathrm{Cl}_{2}$ for 278..$^{235 \mid 238}$ Besides, achiral solvents are known to make an unexpectedly large contribution to the experimentally measured optical rotation of chiral compounds. ${ }^{255}$ As expected, the sign of the optical rotation for dactylolide and zampanolide A were negative (-) in both solvents (see Table 6.3). The optical rotation of the isolated dactylolide was in 
excellent agreement with that reported in literature but with the opposite sign. Therefore, the macrocyclic core of (-)-zampanolide A (278) and (-)-dactylolide (281) has the same absolute configuration.

Table 6.3. Comparison of the optical rotations of the isolated dactylolide and zampanolide with their literature values.

\begin{tabular}{|c|c|c|}
\hline \multirow[b]{2}{*}{ Compound } & \multicolumn{2}{|c|}{ Optical Rotation } \\
\hline & $\mathrm{CH}_{2} \mathrm{Cl}_{2}$ & МeOH \\
\hline Isolated zampanolide A (278) & {$[\alpha]_{\mathrm{D}}^{26}-113.4(c 0.11)$} & {$[\alpha]_{\mathrm{D}}^{26}-154.6(c 0.11)$} \\
\hline Reported zampanolide A (278) & {$[\alpha]_{\mathrm{D}}-101.0(c 0.12)$} & \\
\hline Isolated dactylolide (281) & {$[\alpha]_{\mathrm{D}}^{26}-80.0(c 0.025)$} & {$[\alpha]_{\mathrm{D}}^{26}-40.0(c 0.025)$} \\
\hline Reported dactylolide (281) & & {$[\alpha]_{\mathrm{D}}+30.0(c 0.11)$} \\
\hline
\end{tabular}

The original reported optical rotation for dactylolide (281) may be due to contamination of the natural sample by a highly absorbing species with a positive optical rotatory effect on plane polarised light. ${ }^{250}$ For such a highly conjugated compound, Sanchez and Keck stated that the significant deviations in optical rotations might be due to the enolisation via loss of a proton at C- $6, \mathrm{C}-10$, or even the C-5 methyl group. ${ }^{256}$ Additionally, the tendency of the aldehyde of $\mathbf{2 8 1}$ to generate a stable hemiacetal with $\mathrm{MeOH}$ may contribute to the variation in optical rotations of both (-)-281 and (+)-281. 257

This result is also complicated by the vibrant and ever changing arena in marine sponge taxonomy. Several of the common secondary metabolites isolated from C. mycofijiensis, have also been produced by closely related sponges, together with minor novel compounds. In conjunction with the isolation of zampanolide A (278), (-)-dactylolide (281) and the new zampanolides (282-285) from C. mycofijiensis, it should be noted that the sponges belonging to the genera Dactylospongia, Fasciospongia, Hyattella and Petrosaspongia are believed to have been misidentified (see Table 6.1). 2241258 


\subsection{Zampanolide B}

Zampanolide B (282) was obtained as a white amorphous solid. Positive ion HRESIMS analysis for 282 showed an $[\mathrm{M}+\mathrm{Na}]^{+}$adduct at $m / z 518.2514(\Delta=0.19 \mathrm{ppm})$, suitable for a molecular formula of $\mathrm{C}_{29} \mathrm{H}_{37} \mathrm{NO}_{6}$, identical to zampanolide (278). In the ${ }^{13} \mathrm{C} \mathrm{NMR}$ spectrum, all the 29 carbons required by the molecular formula were observed. The multiplicity-edited HSQC experiment showed 23 protonated carbons accounting for 35 protons consisting of three methyls $\left(\delta_{\mathrm{C}} 18.8 ; 17.3 ; 16.2\right)$, five methylenes $\left(\delta_{\mathrm{C}} 53.6 ; 42.2\right.$; $41.1 ; 40.7 ; 40.3)$, one methylidene $\left(\delta_{\mathrm{C}} 108.9\right)$, ten olefinic methines $\left(\delta_{\mathrm{C}} 146.2 ; 143.6\right.$; $141.3 ; 140.2 ; 132.7 ; 131.6 ; 128.3 ; 128.2 ; 120.2 ; 117.1)$ and four oxymethines $\left(\delta_{\mathrm{C}} 77.7\right.$; $76.9 ; 76.0 ; 71.7)$. The remaining six carbons were assigned as non-protonated centres as no corresponding HSQC correlations were observed, which included an $\alpha, \beta$-unsaturated ketone $\left(\delta_{\mathrm{C}} 198.0\right)$, two ester/amide carbonyls $\left(\delta_{\mathrm{C}} 167.7 ; 167.9\right)$ and three $s p^{2}$-hybridised carbons $\left(\delta_{\mathrm{C}} 130.7 ; 143.7 ; 143.7\right)$. The two remaining protons $\left(\mathrm{OH} \delta_{\mathrm{H}} 3.79 ; \mathrm{NH} \delta_{\mathrm{H}} 6.57\right)$ were observed in the ${ }^{1} \mathrm{H}$ NMR experiment and were assigned as exchangeable based on the lack of HSQC correlation. Since ten out of 12 degrees of unsaturation required by the molecular formula $\mathrm{C}_{29} \mathrm{H}_{37} \mathrm{O}_{6}$ were thus accounted for, compound 282 was inferred to contain two rings.

Inspection of the 1D- and 2D-NMR spectra of zampanolide B (282) revealed a high degree of similarity to the parent compound zampanolide A (278) and (-)-dactylolide (281) (see Figure 6.7). In the ${ }^{1} \mathrm{H}$ NMR spectrum, the resonances attributed to the $N$-acyl hemiaminal side chain in $278\left(\mathrm{H}-22 \delta_{\mathrm{H}} 5.44 ; \mathrm{H}-23 \delta_{\mathrm{H}} 6.46 ; \mathrm{H}-24 \delta_{\mathrm{H}} 7.41 ; \mathrm{H}-25 \delta_{\mathrm{H}} 6.05\right)$ are still present in $282\left(\mathrm{H}-22 \delta_{\mathrm{H}} 5.43 ; \mathrm{H}-23 \delta_{\mathrm{H}} 6.44 ; \mathrm{H}-24 \delta_{\mathrm{H}} 7.41 ; \mathrm{H}-25 \delta_{\mathrm{H}} 6.04\right)$. As the proposed molecular formula was equivalent to $\mathbf{2 7 8}$, together with a comprehensive analysis of the NMR data (in particular absence of the aldehyde functionality at $\delta_{\mathrm{H}} 9.67$ ), immediately eliminated dactylolide or any related compounds to dactylolide as the structure. However, the major difference was the change in chemical shifts of the methylene $\mathrm{CH}_{2}-6\left(\delta_{\mathrm{H}} 3.03\right.$, $\left.4.13 ; \delta_{\mathrm{C}} 45.3\right)$ and the methyl singlet $\mathrm{CH}_{3}-21\left(\delta_{\mathrm{H}} 1.80 ; \delta_{\mathrm{C}} 23.7\right)$ in 278 . In their place, a new methylene carbon resonance at $\delta_{\mathrm{C}} 53.6\left(\delta_{\mathrm{H}} 3.33,3.48\right)$ and a methyl singlet at $\delta_{\mathrm{C}} 17.3$ $\left(\delta_{\mathrm{H}} 1.89\right)$ were present, suggesting changes in the configuration of the double bond $\Delta_{4,5}$. 


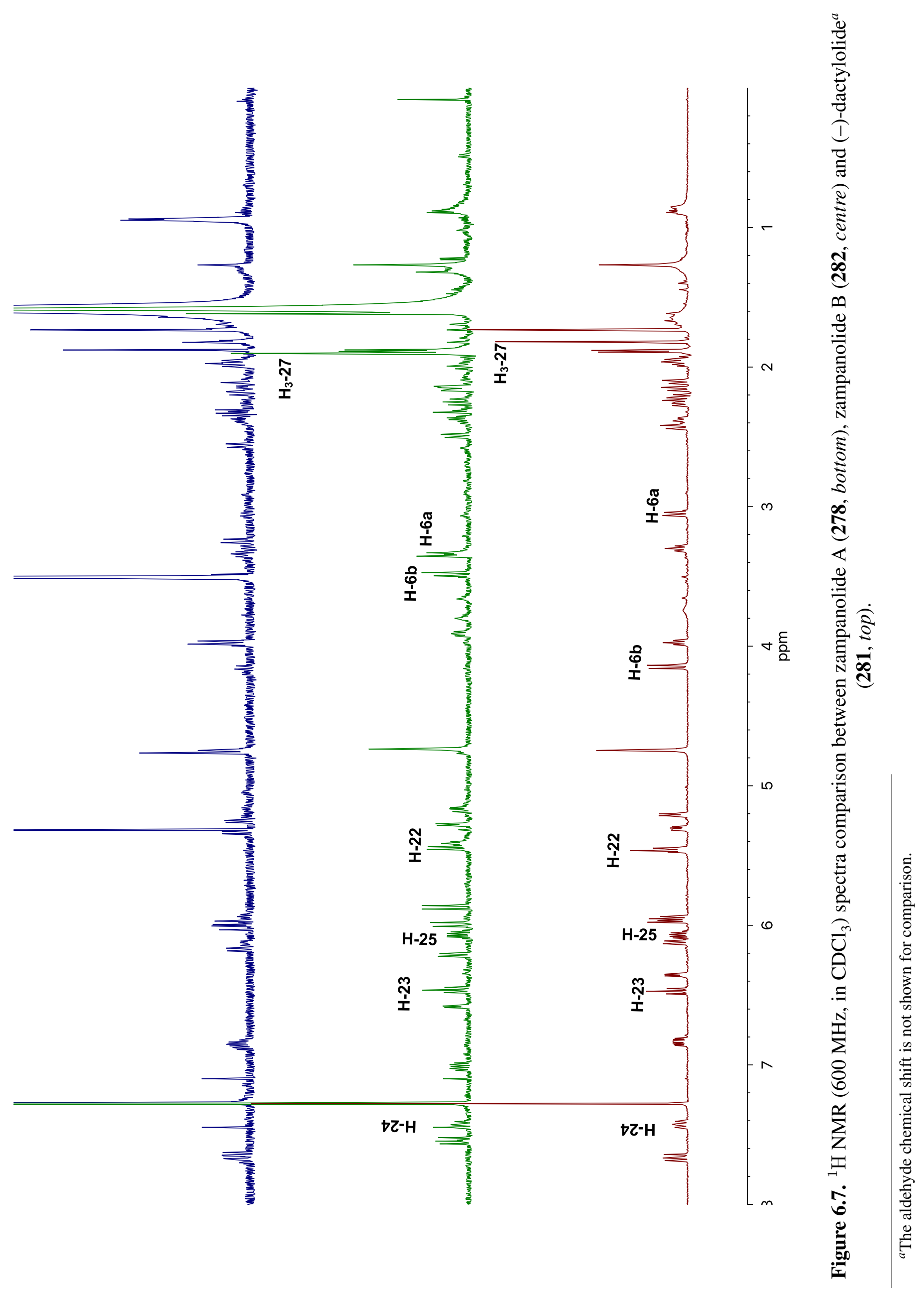


Zampanolide B (282) is therefore assigned as a new geometric isomer of zampanolide A (278), with the NMR data presented in Table 6.4

Given the high degree of similarity of NMR data between zampanolides A (278) and B (282), assignment of most resonances was performed through direct comparison against the parent compound. Initial analysis of the correlations from various proton resonances in both the COSY and HMBC spectra allowed the construction of several substructures. In particular, an $\alpha-\beta$ unsaturated carbonyl was identified based on the characteristic HMBC correlations of $\mathrm{CH}-2\left(\delta_{\mathrm{H}} 5.86 ; \delta_{\mathrm{C}} 120.0\right)$ and $\mathrm{CH}-3\left(\delta_{\mathrm{H}} 7.53 ; \delta_{\mathrm{C}} 141.3\right)$ to $\mathrm{C}-1\left(\delta_{\mathrm{C}} 167.6\right)$. Analysis of the ${ }^{1} \mathrm{H}-{ }^{1} \mathrm{H}$ coupling of these two olefinic methines led to the construction of a 1,3-diene unit through COSY and HMBC correlations with $\mathrm{CH}-4\left(\delta_{\mathrm{H}} 6.20 ; \delta_{\mathrm{C}} 128.2\right)$ and C-5 $\left(\delta_{\mathrm{C}} 143.7\right)$. A methyl singlet $\mathrm{CH}_{3}-27\left(\delta_{\mathrm{H}} 1.89 ; \delta_{\mathrm{C}} 17.3\right)$ was then attached to the system by way of COSY and HMBC correlations to C-4, C-5 and a deshielded methylene $\mathrm{CH}_{2}-6\left(\delta_{\mathrm{H}} 3.33,3.48 ; \delta_{\mathrm{C}} 53.6\right)$. The geometry of the double bond between $\mathrm{C}-2$ and $\mathrm{C}-3$ was determined to be $E$ on the basis of the observed coupling constants $\left(J_{2,3}=15.4 \mathrm{~Hz}\right)$ and NOESY correlation between $\mathrm{H}-3$ and $\mathrm{H}_{3}-27$. However, the configuration of the double bond between C-4 and C-5 was determined to be opposite to that of zampanolide A (278). The observed NOESY enhancements between $\mathrm{H}-2-\mathrm{H}-4$ and between $\mathrm{H}-3-\mathrm{H}_{3}-27$ identified $\Delta_{4,5}$ as $E$. This assignment was also supported by the carbon chemical shift of the methyl group C-27 ( $\delta_{\mathrm{C}}<20$ for $E$ and $\delta_{\mathrm{C}}>20$ for $Z$ geometry ${ }^{240[241}$ ) (see Figure 6.8).

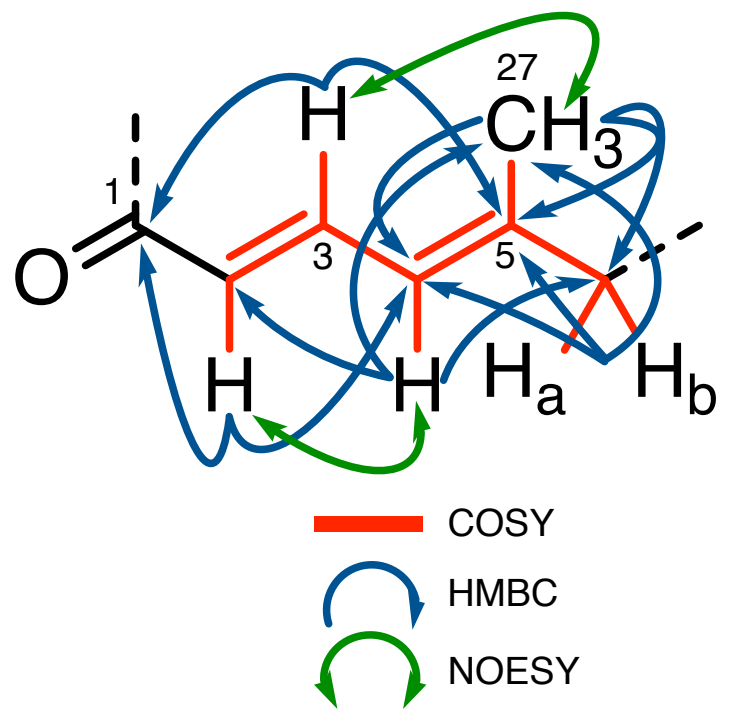

Figure 6.8. Key COSY, HMBC and NOESY correlations establishing the C-1 to C-6 segment of zampanolide B (282). 
Further analysis of the HMBC spectrum showed extra correlations from $\mathrm{H}_{2}-6$ to a carbonyl carbon resonance at $\delta_{\mathrm{C}}$ 197.8. An olefinic methine $\mathrm{CH}-9\left(\delta_{\mathrm{H}} 7.00 ; \delta_{\mathrm{C}} 146.0\right)$ showed a strong HMBC correlation to $\mathrm{C}-7$ and a COSY correlation to another olefinic methine $\mathrm{CH}-8\left(\delta_{\mathrm{H}} 5.98 ; \delta_{\mathrm{C}}\right.$ 132.6). The deshielding effect on the ketone carbon C-7 was consistent with the presence of a conjugated double bond $\left(\Delta_{8,9}\right)$. The geometry of the resulting olefin was assigned as $E$ on the basis of the observed ${ }^{1} \mathrm{H}-{ }^{1} \mathrm{H}$ coupling constant between $\mathrm{H}-8$ and H-9 $\left(J_{8,9}=16.2 \mathrm{~Hz}\right)$. A series of sequential COSY correlations were also observed from $\mathrm{H}-9$ to a slightly deshielded methylene $\mathrm{CH}_{2}-10\left(\delta_{\mathrm{H}} 2.29,2.35\right.$; $\left.\delta_{\mathrm{C}} 40.2\right)$, from $\mathrm{H}_{2}-10$ to a strongly deshielded oxymethine $\mathrm{CH}-11\left(\delta_{\mathrm{H}} 3.32 \delta_{\mathrm{C}} 77.6\right)$, and from $\mathrm{H}-11$ to a slightly deshielded allylic methylene $\mathrm{CH}_{2}-12\left(\delta_{\mathrm{H}} 1.97,2.13 ; \delta_{\mathrm{C}} 40.9\right)$. Correlations observed in the HMBC spectrum from the adjacent methylene $\mathrm{H}_{2}-10$ to C-9 and C-11 confirmed its placement between the two methines. Although HMBC correlations from $\mathrm{H}-11$ to $\mathrm{C}-10$ and C-12 were not observed, their placement was based on their COSY correlations and direct comparison of the chemical shifts of zampanolide A (278), extending the partial structure as shown in Figure 6.9 .

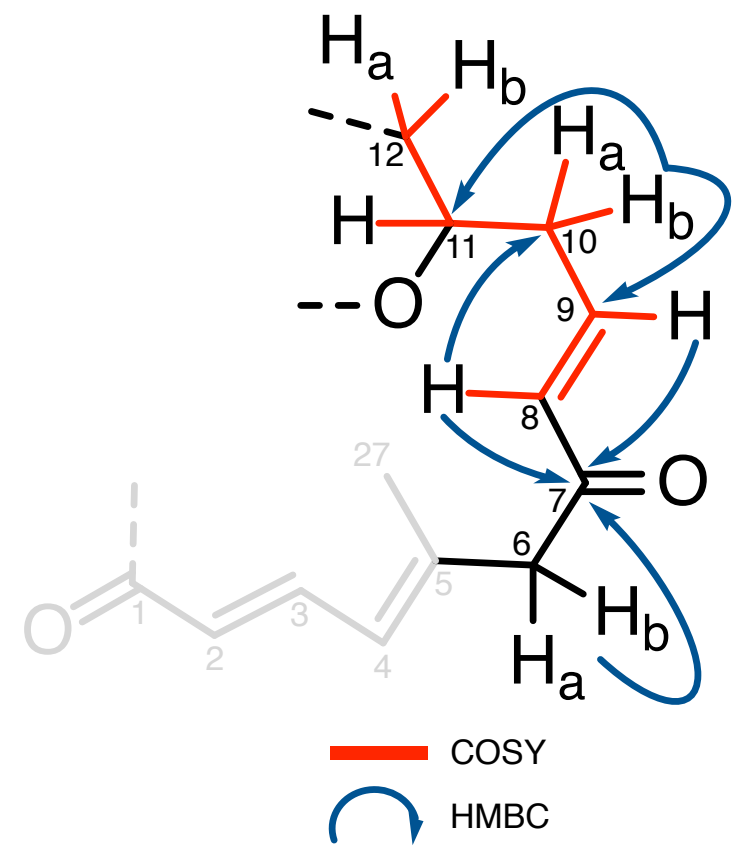

Figure 6.9. Key COSY and HMBC correlations establishing the C-7 to C-12 segment of zampanolide B (282).

Further HMBC correlations from $\mathrm{H}_{2}-12$ to a non-protonated carbon C-13 $\left(\delta_{\mathrm{C}}\right.$ 143.6) and a methylidene $\mathrm{CH}_{2}-28\left(\delta_{\mathrm{H}} 4.72 ; \delta_{\mathrm{C}} 108.9\right)$ placed a double bond adjacent to the substructure. COSY correlations between $\mathrm{H}_{2}-12$ and $\mathrm{H}_{2}-28$ confirmed the placement 
of the methylidene group. The resonance $\mathrm{H}_{2}-28$ showed further coupling to another slightly deshielded allylic methylene $\mathrm{CH}_{2}-14\left(\delta_{\mathrm{H}} 1.89,2.14 ; \delta_{\mathrm{C}} 40.6\right)$ and strong HMBC correlations to C-12, C-13 and C-14. Observation of a COSY correlation between $\mathrm{H}_{2}-14$ and the proton of the oxymethine $\mathrm{CH}-15\left(\delta_{\mathrm{H}} 3.89 ; \delta_{\mathrm{C}} 76.7\right)$ extended the carbon framework. A strong NOESY correlation was observed between H-11 and H-15, thus suggesting that the oxymethines at C-11 and C-15 were linked through an oxygen to form a tetrahydropyran ring (see Figure 6.10).

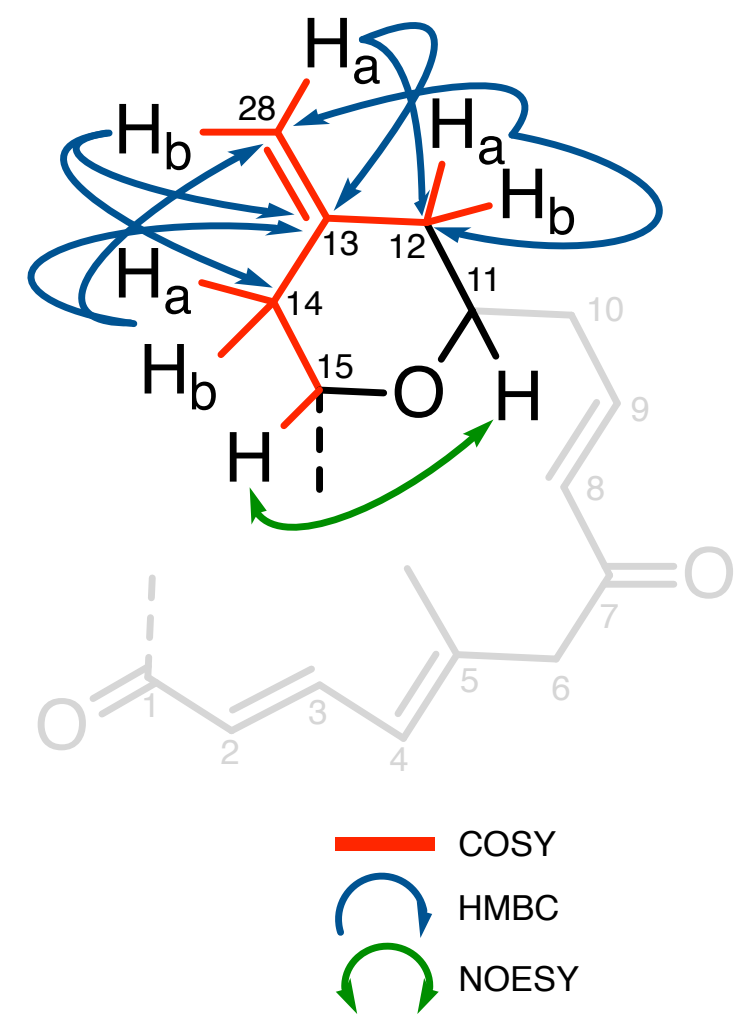

Figure 6.10. Key COSY, HMBC and NOESY correlations establishing the tetrahydropyran ring of zampanolide B (282).

The protons of the upfield olefinic methyl singlet $\mathrm{CH}_{3}-29\left(\delta_{\mathrm{H}} 1.60 ; \delta_{\mathrm{C}} 16.2\right)$ showed strong HMBC correlations to the olefinic carbon C-17 $\left(\delta_{\mathrm{C}} 130.7\right)$, olefinic methine $\mathrm{CH}-16$ $\left(\delta_{\mathrm{H}} 5.26 ; \delta_{\mathrm{C}} 131.6\right)$ and methylene carbon $\mathrm{CH}_{2}-18\left(\delta_{\mathrm{H}} 2.23,2.47 ; \delta_{\mathrm{C}} 42.2\right)$ suggesting the presence of a trisubstituted double bond (see Figure 6.11). COSY correlations between the proton resonances of $\mathrm{H}-15, \mathrm{H}-16$ and $\mathrm{H}_{2}-18$ supported this assignment, establishing the connection of the isolated trisubstituted double bond to the tetrahydropyran ring. The geometry of $\Delta_{16,17}$ was established as $E$, based on the observed NOESY correlations between $\mathrm{H}-16$ and $\mathrm{H}_{2}-18$. This assignment was also supported by the carbon chemical of the methyl C-29 at $\delta_{\mathrm{C}} 16.2\left(\delta_{\mathrm{C}}<20\right.$ for $E$ and $\delta_{\mathrm{C}}>20$ for $Z$ geometry). ${ }^{240241}$ HMBC 
and COSY correlations revealed the connectivity of $\mathrm{H}_{2}-18$ to a deshielded oxymethine $\mathrm{CH}-19\left(\delta_{\mathrm{H}} 5.15 \delta_{\mathrm{C}} 71.7\right)$ and an HMBC correlation from H-19 to the lactone carbonyl $\mathrm{C}-1$ completed the macrocyclic ring. In the COSY experiment, the resonance of $\mathrm{H}-19$ also showed a correlation to another deshielded oxymethine proton $\mathrm{CH}-20\left(\delta_{\mathrm{H}} 5.39 \delta_{\mathrm{C}} 75.9\right)$, while $\mathrm{H}-20$ displayed correlations to two exchangeable protons; $20-\mathrm{OH}\left(\delta_{\mathrm{H}} 3.79\right)$ and $\mathrm{NH}\left(\delta_{\mathrm{H}} 6.57\right)$. Finally, an HMBC correlation from $\mathrm{NH}$ to a non-protonated carbon C-21 $\left(\delta_{\mathrm{C}} 167.9\right)$ extended the branched side chain from the macrocyclic moiety (see Figure 6.11.

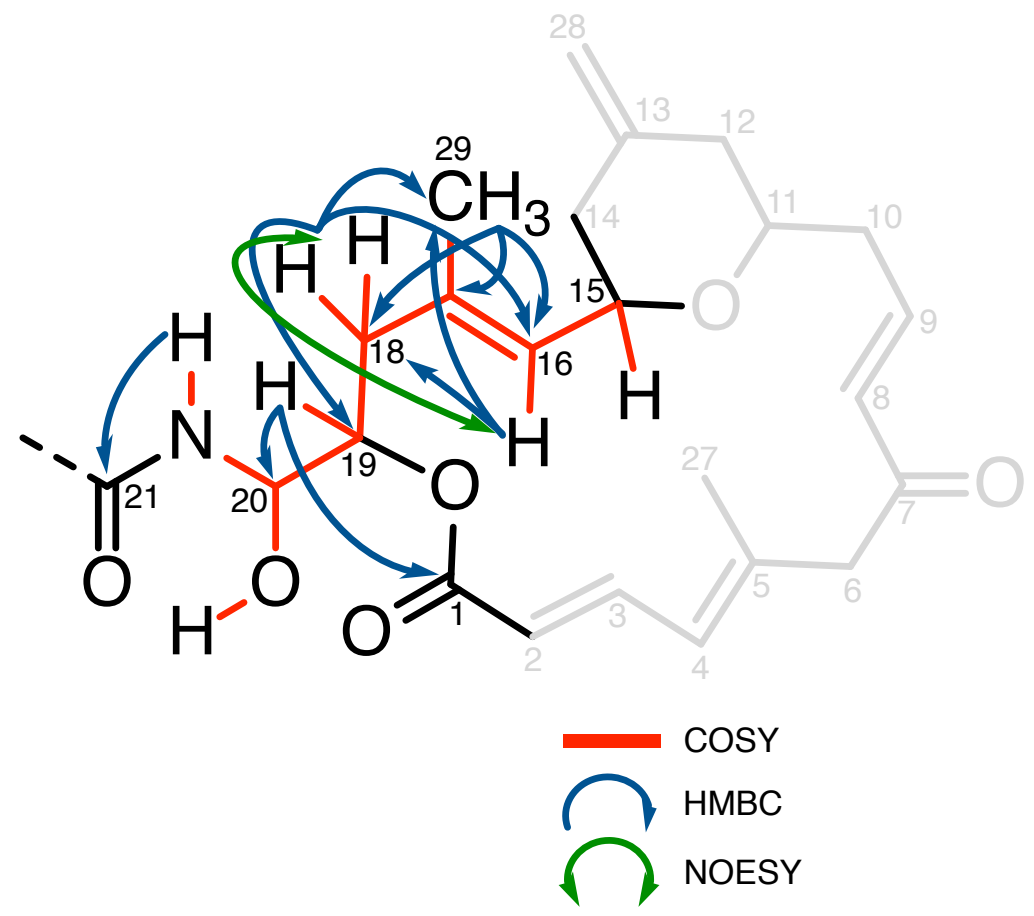

Figure 6.11. Key COSY, HMBC and NOESY correlations establishing the macrocyclic moiety of zampanolide B (282).

The structural elucidation of the last spin system began at the methyl terminus. Analysis of ${ }^{1} \mathrm{H}-{ }^{1} \mathrm{H}$ coupling led to the construction of a 1,3 diene containing substructure (see Figure 6.12). A series of sequential COSY correlations starting from the methyl doublet $\mathrm{CH}_{3}-26\left(\delta_{\mathrm{H}} 1.87 ; \delta_{\mathrm{C}} 18.8\right)$ to four consecutive olefinic methines $\mathrm{CH}-25\left(\delta_{\mathrm{H}} 6.04\right.$; $\left.\delta_{\mathrm{C}} 140.2\right), \mathrm{CH}-24\left(\delta_{\mathrm{H}} 7.41 ; \delta_{\mathrm{C}} 128.3\right), \mathrm{CH}-23\left(\delta_{\mathrm{H}} 6.44 ; \delta_{\mathrm{C}} 143.6\right), \mathrm{CH}-22\left(\delta_{\mathrm{H}} 5.43 ;\right.$ $\delta_{\mathrm{C}}$ 111.7), all of which were supported through diagnostic HMBC correlation data, thus extended the substructure. Observation of a correlation in the HMBC spectrum between H-22 and C-21 completed the unsaturated amide moiety. The geometry of $\Delta_{22,23}$ was established as $Z$, based on a coupling constant of $11.5 \mathrm{~Hz}$ between $\mathrm{H}-22$ and $\mathrm{H}-23$. This assignment was supported by NOESY correlations between H-22, H-23 and H-25. 
Observed NOESY correlations between H-23 to H-25 assigned the geometry of $\Delta_{24,25}$ as $E$, and through a coupling constant of $15.0 \mathrm{~Hz}$ between $\mathrm{H}-24$ and $\mathrm{H}-25$. With all carbons and degrees of unsaturation accounted for, this provided the completed planar structure of zampanolide B (282) as shown in Figure 6.13.
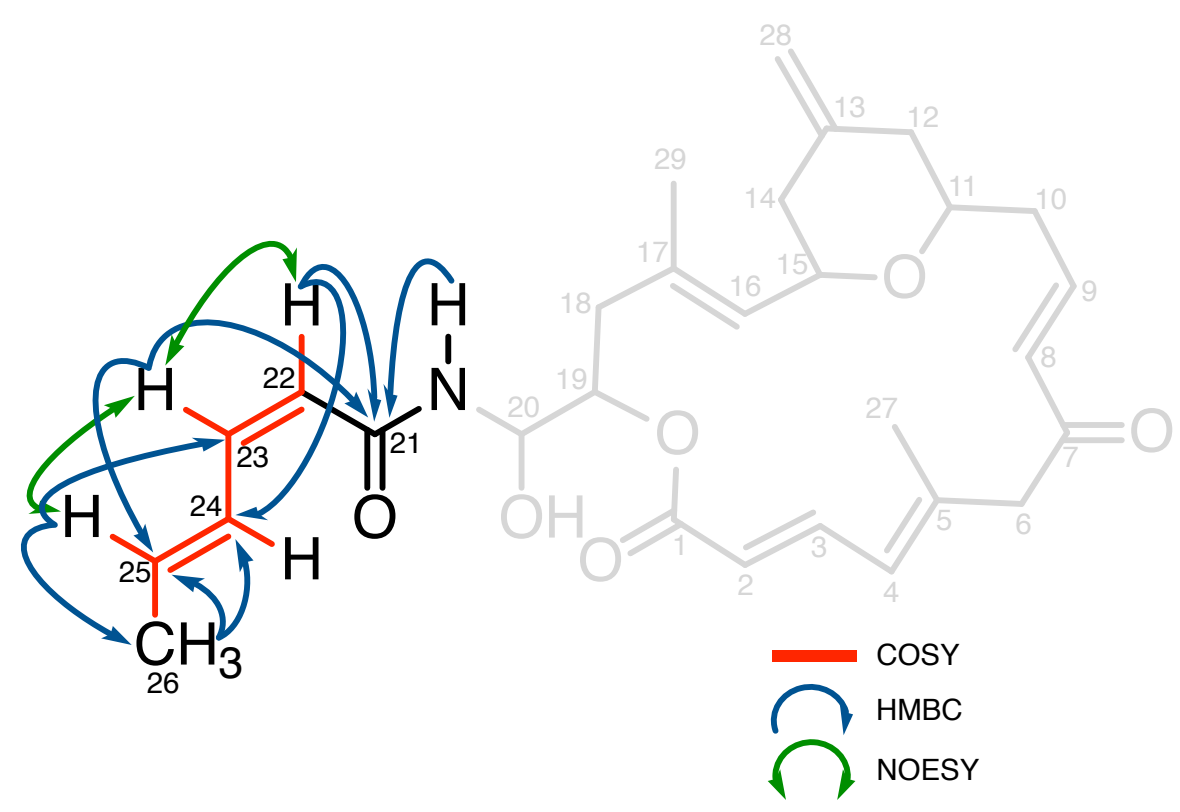

Figure 6.12. Key COSY, HMBC and NOESY correlations establishing the branched unsaturated moiety of zampanolide B (282).

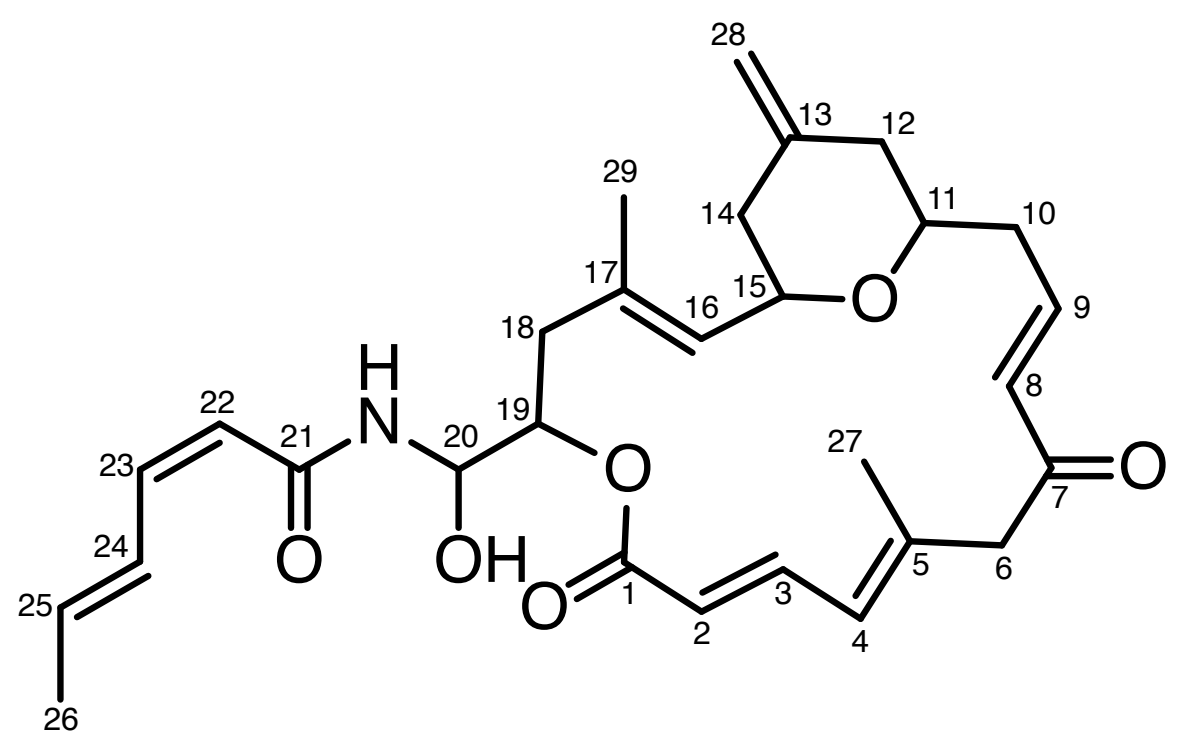

Figure 6.13. Completed planar structure of zampanolide B (282). 
With the connectivity of zampanolide B (282) established, the sterochemical environment of the compound was investigated using ${ }^{1} \mathrm{H}-{ }^{1} \mathrm{H}$ coupling constants and NOESY correlation data (see Figure 6.14 and Table 6.4). There are four stereogenic centres to consider; $\mathrm{CH}-11, \mathrm{CH}-15, \mathrm{CH}-19$ and $\mathrm{CH}-20$. Selective excitation of methine proton $\mathrm{H}-11$ showed NOE enhancements to H-9, H-12b and H-15, the latter of which indicated the 1,3 cis arrangement between $\mathrm{H}-11$ and $\mathrm{H}-15$. The axial orientation of $\mathrm{H}-11$ and $\mathrm{H}-15$ in the tetrahydropyran ring was supported by the large coupling constants $\left(J_{11,12 \mathrm{a}}=9.4 \mathrm{~Hz}\right.$ and $J_{14 \mathrm{a}, 15}=10.7 \mathrm{~Hz}$ ). The NOESY experiment showed correlations between $\mathrm{H}-15$ and $\mathrm{H}_{3}-29$ and $\mathrm{H}_{3}-29$ to $\mathrm{H}-19$, proposing that the double bond $\Delta_{16,17}$ is tilted in a preferred conformation so that the methyl group $\mathrm{CH}_{3}-29$ is on the same face as $\mathrm{H}-15$ and $\mathrm{H}-19$. This conformational preference was corroborated by the relatively large coupling constants observed between $\mathrm{H}-15$ and $\mathrm{H}-16(J=7.5 \mathrm{~Hz})$, therefore the relative configuration of $\mathrm{CH}-19$ can be determined in relation to that of $\mathrm{CH}-15$. Although a NOESY correlation between H-19 and H-20 was observed, the free rotation around the acyl hemiaminal side chain prevented the conclusive assignment on the relative configuration for $\mathrm{CH}-20$. The near identical chemical shifts, ${ }^{1} \mathrm{H}-{ }^{1} \mathrm{H}$ coupling constants and NOESY data suggest the retention of the relative configuration of zampanolide A (278) in zampanolide B (282). However, the sign of the measured optical rotation for the isolated sample of $282\left([\alpha]_{\mathrm{D}}^{24}+27.7\left(c 0.11, \mathrm{CH}_{2} \mathrm{Cl}_{2}\right)\right)$ was opposite to the reported value of zampanolide A $(\mathbf{2 7 8})\left([\alpha]_{\mathrm{D}}-101.0\left(c 0.12, \mathrm{CH}_{2} \mathrm{Cl}_{2}\right)\right)$. Taking into consideration the stereochemical features of zampanolide A (278) for which its absolute configuration has been verified by total synthesis, $\underline{251252}$ assignment of the absolute configuration for the new zampanolide structures reported in this study are implied as drawn. For this reason, the absolute configuration of zampanolide B (282) is proposed to be $11 S, 15 S, 19 S, 20 S$, based on the assumption that the stereogenic centres for this compound are the same as in zampanolide A (278). 


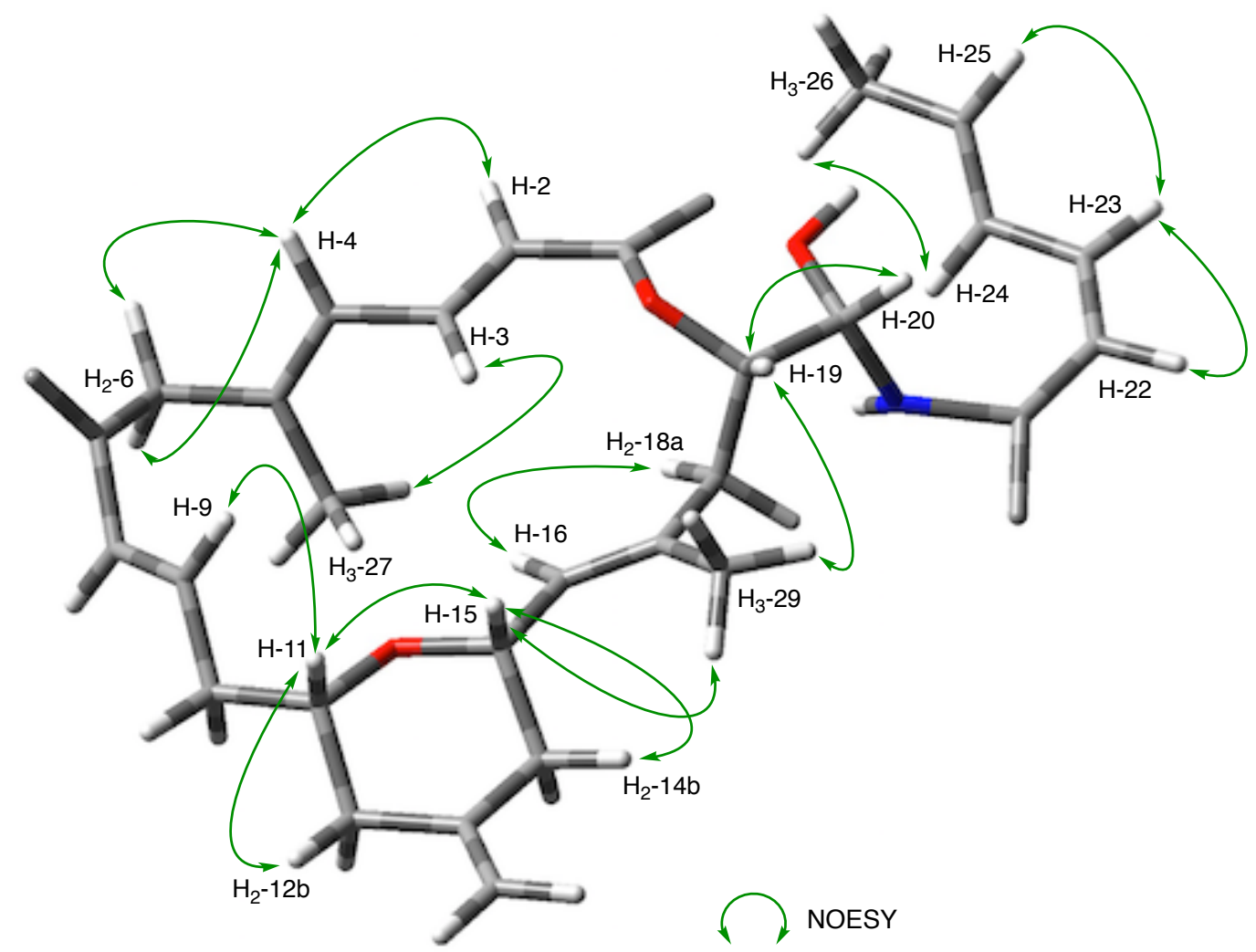

Figure 6.14. NOESY correlations establishing the relative configuration of zampanolide B (282). 


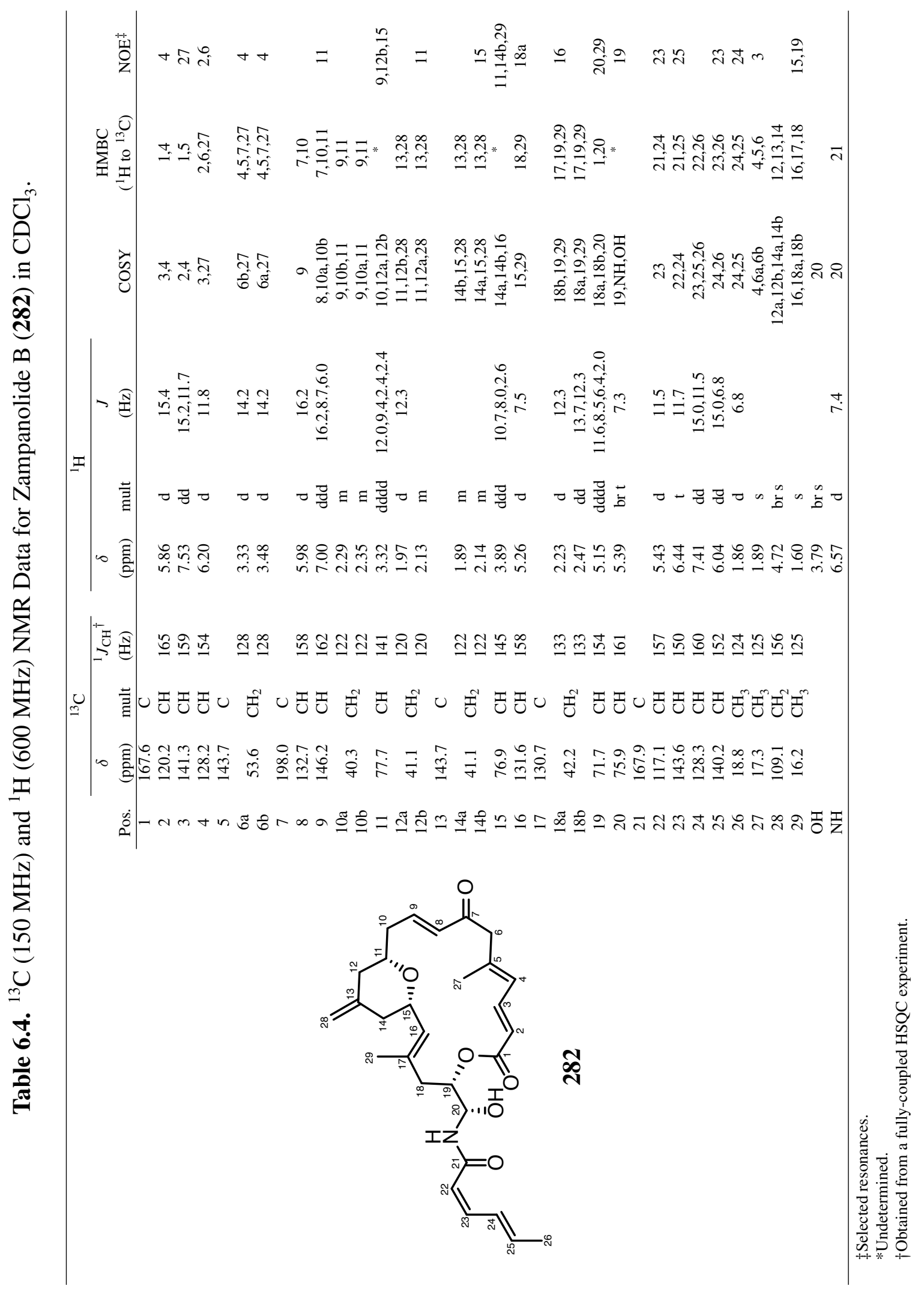




\subsection{Zampanolide C}

Zampanolide C (283) was obtained as white amorphous solid. HRESIMS analysis of 283 exhibited a $[\mathrm{M}+\mathrm{Na}]^{+}$ion at $\mathrm{m} / z 518.2513(\Delta=0.00 \mathrm{ppm})$, consistent with the molecular formula $\mathrm{C}_{29} \mathrm{H}_{37} \mathrm{NO}_{6}$ and 12 degrees of unsaturation. As the proposed molecular formula was identical to zampanolides A and B (278 and 282), subsequent detailed analysis of the ${ }^{1} \mathrm{H}$ NMR spectrum (see Figure 6.15) revealed the presence of the same $N$-acyl hemiaminal side chain, again suggesting modifications were restricted to the macrocylic lactone. Initial analysis of the ${ }^{1} \mathrm{H}$ NMR spectrum of zampanolide C (283) showed close similarities to that of zampanolide B (282), particularly in the $\delta_{\mathrm{H}} 3.00-4.00$ and $\delta_{\mathrm{H}} 5.00-6.60$ regions, suggesting the double bond $\Delta_{4,5}$ geometry remained as $E$ as in $\mathbf{2 8 2}$. Despite these similarities, a detailed inspection of the 1Dand 2D-NMR data revealed the configuration of the double bond as $Z$ (same as in 278). The downfield-shifted olefinic methine proton $\mathrm{H}-8\left(\delta_{\mathrm{H}} 6.26 ; \delta_{\mathrm{C}} 128.5\right)$ and the upfield-shifted chemical shift of its vicinal olefinic methine H-9 $\left(\delta_{\mathrm{H}} 6.04 ; \delta_{\mathrm{C}} 144.6\right)$, implied a change in the geometry of the double bond between C-8 and C-9 (from $E$ to $Z$ ). The small coupling constant $\left(J_{8,9}=11.7 \mathrm{~Hz}\right.$ compared to $J_{8,9}=16.2 \mathrm{~Hz}$ in 278) between the two vicinal olefinic methines supported this assignment as the only alteration throughout the constitutional structure. The structure of zampanolide C (283) is therefore assigned as a new isomer of zampanolide A (278) (NMR data detailed in Table 6.5).

Again the ${ }^{13} \mathrm{C}$ NMR spectrum of $\mathbf{2 8 3}$ contained 29 distinct resonances and the ${ }^{1} \mathrm{H}$ NMR spectrum accounted for all the 37 protons. A multiplicity-edited HSQC experiment confirmed the attachment of 35 of these protons to carbon, indicating the presence of two exchangeable protons. Interpretation of the ${ }^{13} \mathrm{C}$ and HSQC NMR spectra revealed three methyls $\left(\delta_{\mathrm{C}} 26.2 ; 18.8,16.3\right)$, five methylenes $\left(\delta_{\mathrm{C}} 47.5 ; 41.2 ; 40.6 ; 40.2 ; 35.9\right)$, one methylidene $\left(\delta_{\mathrm{C}} 108.9\right)$, ten olefinic methines $\left(\delta_{\mathrm{C}} 144.6 ; 143.6 ; 140.9 ; 140.1 ; 130.3\right.$; $128.5 ; 128.3 ; 126.5 ; 119.7 ; 117.2)$, four oxymethines $\left(\delta_{\mathrm{C}} 77.3 ; 76.3 ; 75.4 ; 71.3\right)$ and six non-protonated centres $\left(\delta_{\mathrm{C}} 198.7 ; 167.8,167.7 ; 144.5 ; 143.7 ; 132.7\right)$. From these data, 10 of the 12 unsaturations were assigned to olefins and carbonyls, again suggesting that the molecule has two rings (one lactone and one ether ring). 


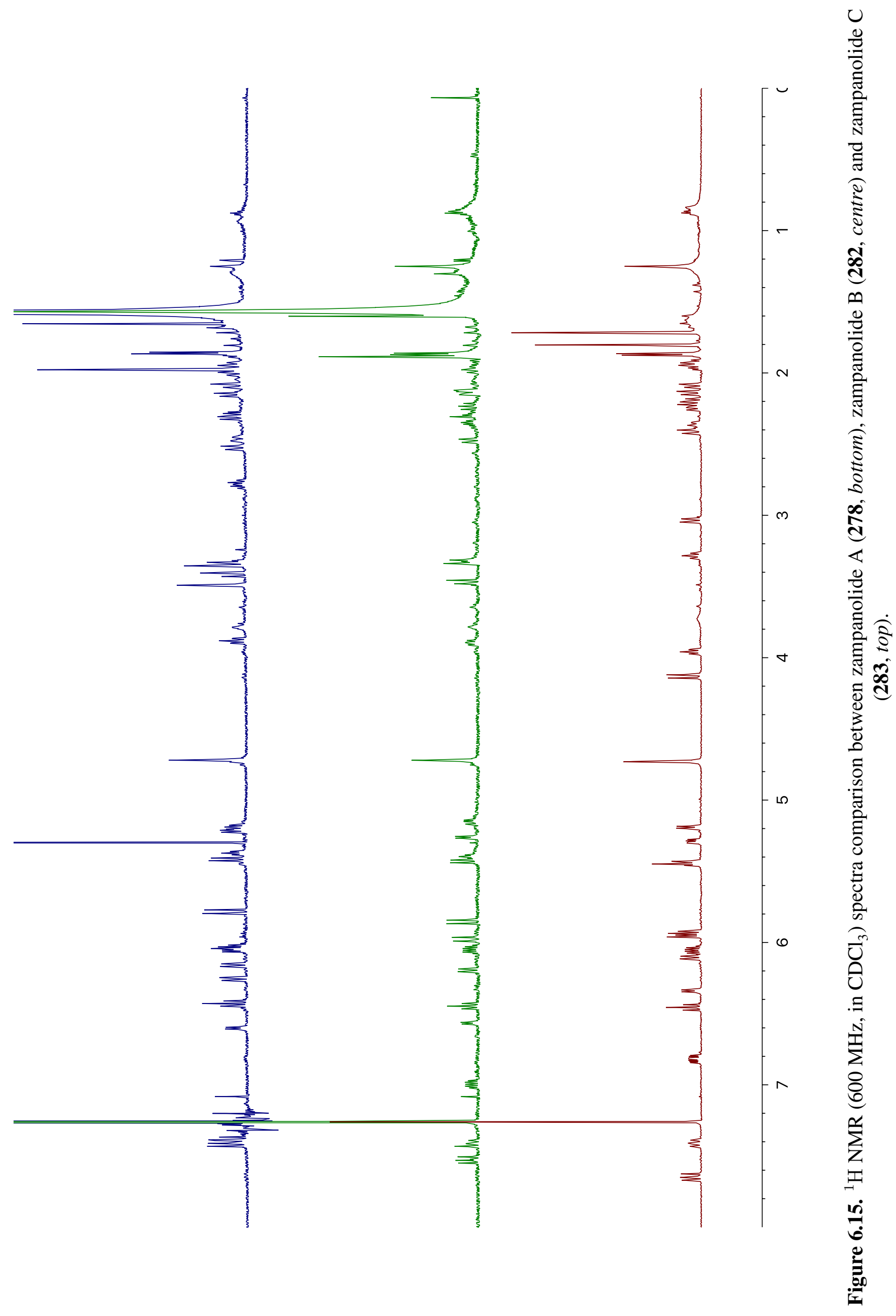


The structure was elucidated in the same fashion as zampanolide B (282), beginning at the lactone moiety of the macrocyclic ring. A series of sequential COSY correlations were observed between three olefinic methine protons $\left[\mathrm{H}-2\left(\delta_{\mathrm{H}} 5.78 ; \delta_{\mathrm{C}} 119.7\right), \mathrm{H}-3\left(\delta_{\mathrm{H}} 7.39\right.\right.$; $\left.\left.\delta_{\mathrm{C}} 140.9\right), \mathrm{H}-4\left(\delta_{\mathrm{H}} 6.16 ; \delta_{\mathrm{C}} 126.5\right)\right]$ establishing the 1,3 diene unit. The connection of the diene to the lactone carbonyl C-1 $\left(\delta_{\mathrm{C}} 167.8\right)$ was then identified with HMBC correlations from $\mathrm{H}-2$ and H-3. A tertiary methyl $\mathrm{CH}_{3}-27\left(\delta_{\mathrm{H}} 1.97 ; \delta_{\mathrm{C}} 26.2\right)$ was attached to C-5 $\left(\delta_{\mathrm{C}} 143.7\right)$ with $\mathrm{HMBC}$ correlations to $\mathrm{C}-4, \mathrm{C}-5$ and methylene $\mathrm{CH}_{2}-6\left(\delta_{\mathrm{H}} 3.34,3.42\right.$; $\delta_{\mathrm{C}}$ 47.5). The coupling constant of $15.1 \mathrm{~Hz}$ between $\mathrm{H}-2$ and $\mathrm{H}-3$ defined $\Delta_{2,3}$ as $E$, supported by the observation of a NOESY enchancement from H-2 to H-4. The geometry of the second double bond $\Delta_{4,5}$ was determined to be $Z$ on the basis of the observed NOESY correlation between $\mathrm{H}_{3}-27$ and $\mathrm{H}-4$. The methyl of a trisubstituted double bond with $Z$ configuration is more deshielded than one on an $E$ configured alkene, confirming this assignment. ${ }^{240[241}$ Correlations from $\mathrm{H}_{2}-6$ to a ketone carbonyl C-7 $\left(\delta_{\mathrm{C}} 198.7\right)$ in the HMBC experiment extended the substructure to the second spin system. HMBC correlations from two olefinic methines $\mathrm{CH}-8\left(\delta_{\mathrm{H}} 6.26 ; \delta_{\mathrm{C}} 128.5\right)$ and $\mathrm{CH}-9\left(\delta_{\mathrm{H}} 6.04\right.$; $\delta_{\mathrm{C}}$ 144.6) to $\mathrm{C}-7$ allowed the connection of the polarised double bond to the ketone. Interestingly, the geometry of the double bond $\Delta_{8,9}$ was determined to be $Z$ on the basis of the observed coupling constant between H-8 and H-9 $\left(J_{8,9}=11.7 \mathrm{~Hz}\right)$, opposite to that of zampanolides A (278) and B (282). This proposal was established from selective irradiation of $\mathrm{H}-8$ in a $1 \mathrm{D}$ NOESY experiment and subsequent enhancement of $\mathrm{H}_{2}-6$. The vicinal couplings between H-8 and H-9 initiated the second spin system through another series of COSY correlations that indicated the connection of $\mathrm{H}-9$ to a methylene $\mathrm{CH}_{2}-10$ $\left(\delta_{\mathrm{H}} 2.46,2.78 ; \delta_{\mathrm{C}} 35.9\right)$, to an oxymethine $\mathrm{CH}-11\left(\delta_{\mathrm{H}} 3.33 ; \delta_{\mathrm{C}} 77.3\right)$ and to a methylene $\mathrm{CH}_{2}-12\left(\delta_{\mathrm{H}} 1.99,2.15 ; \delta_{\mathrm{C}} 40.2\right)$. The assignment of this substructure was supported by the correlations between these resonances in the HMBC experiment (see Figure 6.16. 


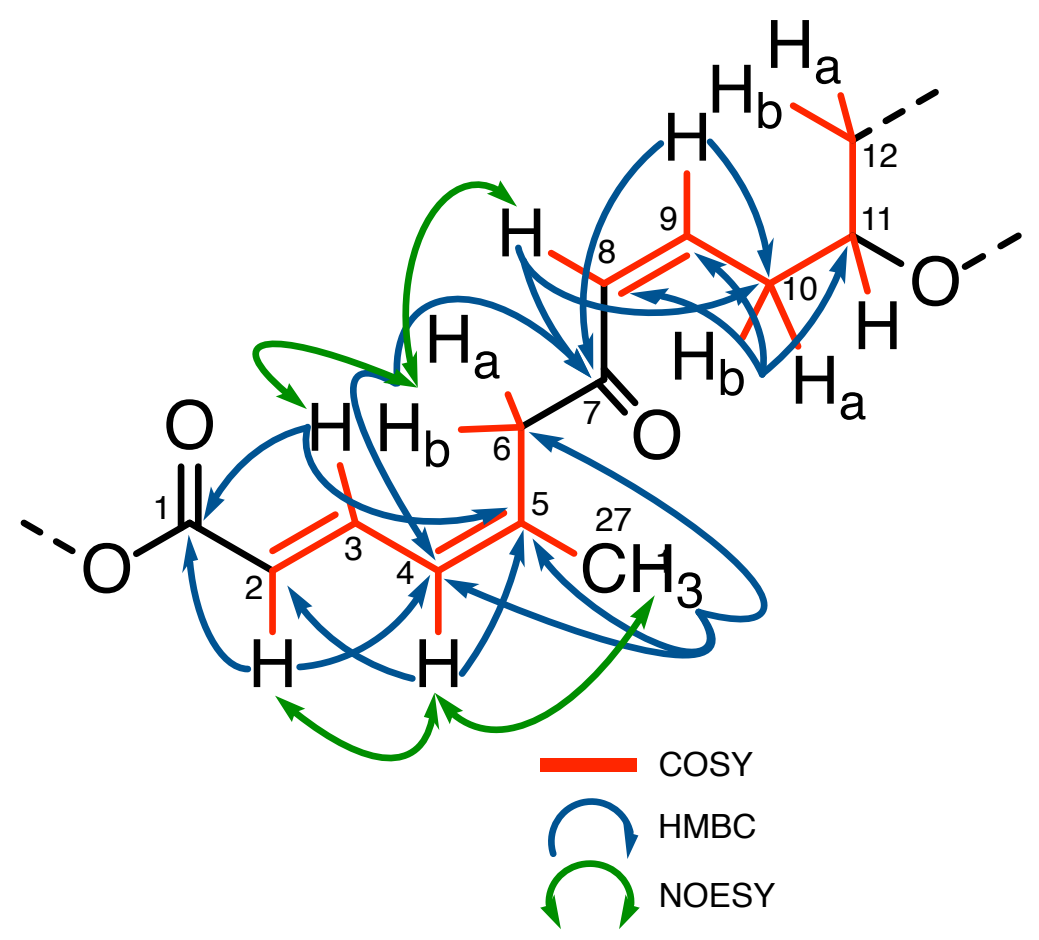

Figure 6.16. Key COSY, HMBC and NOESY correlations for the C-1 to C-12 region of zampanolide C (283).

The methylidene group [C-13 $\left.\left(\delta_{\mathrm{C}} 144.5\right), \mathrm{CH}_{2}-28\left(\delta_{\mathrm{H}} 4.71 ; \delta_{\mathrm{C}} 108.9\right)\right]$ was then placed between $\mathrm{CH}_{2}-12$ and $\mathrm{CH}_{2}-14\left(\delta_{\mathrm{H}} 1.95,2.09 ; \delta_{\mathrm{C}} 40.6\right)$ by the way of COSY and HMBC correlations to C-12, C-13 and C-14, and extended the carbon framework to the next spin system. The vicinal COSY correlations between methylene protons $\mathrm{H}_{2}-14$ and oxymethine $\mathrm{H}-15$ and the observed NOESY enhancement from $\mathrm{H}-15$ to $\mathrm{H}-11$ established the tetrahydropyran ring moiety. Further COSY correlations from $\mathrm{H}-15$ to an olefinic methine $\mathrm{CH}-16\left(\delta_{\mathrm{H}} 5.21 ; \delta_{\mathrm{C}} 130.0\right)$ and $\mathrm{HMBC}$ correlations from a methyl singlet $\mathrm{CH}_{3}-29$ $\left(\delta_{\mathrm{H}} 1.65 ; \delta_{\mathrm{C}} 16.3\right)$ to $\mathrm{C}-16, \mathrm{C}-17\left(\delta_{\mathrm{C}} 132.7\right)$ and $\mathrm{CH}_{2}-18\left(\delta_{\mathrm{H}} 2.30,2.52 ; \delta_{\mathrm{C}} 41.2\right)$ placed the trisubstituted double bond adjacent to the tetrahydropyran ring. Sequential COSY correlations from the methylene protons $\mathrm{H}_{2}-18$ to oxymethine proton $\mathrm{H}-19\left(\delta_{\mathrm{H}} 5.19\right.$; $\left.\delta_{\mathrm{C}} 71.3\right)$, and from $\mathrm{H}-19$ to $\mathrm{H}-20\left(\delta_{\mathrm{H}} 5.37 ; \delta_{\mathrm{C}} 76.3\right)$ positioned two contiguous methines next to the amide moiety (see Figure 6.17). The geometry of the olefin was assigned as $E$ on the basis of the observed NOESY correlations between $\mathrm{H}-16$ and $\mathrm{H}_{2}-18 \mathrm{a}$ and as previously mentioned, the methyl of an $E$ trisubstituted double bond is more shielded than that of $Z .^{240 \mid 241}$ 


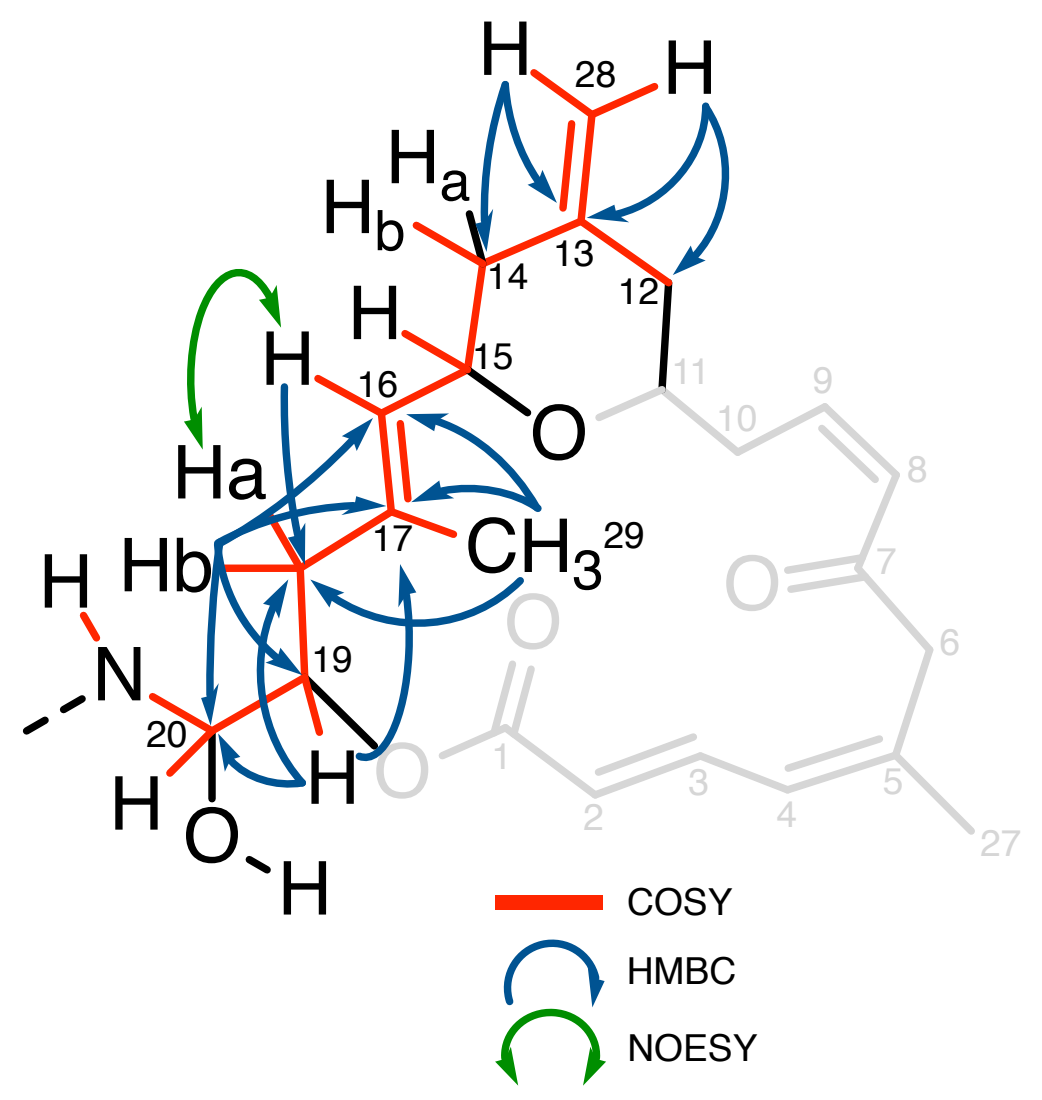

Figure 6.17. Key COSY, HMBC and NOESY correlations establishing the macrocyclic moiety of zampanolide C (283).

The final spin system was constructed from the methyl terminus $\mathrm{CH}_{3}-26\left(\delta_{\mathrm{H}} 1.86\right.$; $\delta_{\mathrm{C}}$ 18.8), and again by a series of sequential COSY correlations from the methyl protons and four contiguous olefinic methines $\left[\mathrm{H}-25\left(\delta_{\mathrm{H}} 6.03 ; \delta_{\mathrm{C}} 140.1\right), \mathrm{H}-24\left(\delta_{\mathrm{H}} 7.41 ; \delta_{\mathrm{C}} 128.3\right)\right.$, H-23 $\left.\left(\delta_{\mathrm{H}} 6.43 ; \delta_{\mathrm{C}} 143.6\right), \mathrm{H}-22\left(\delta_{\mathrm{H}} 5.42 ; \delta_{\mathrm{C}} 117.2\right)\right]$. This order was further was supported by HMBC correlations between these proton and carbon resonances (see Figure 6.18), thereby completing the structure shown in Figure 6.19. The geometry of $\Delta_{22,23}$ was determined to be $Z$ on the basis of the observed coupling constant $\left(J_{22,23}=11.1 \mathrm{~Hz}\right)$ and NOESY enhancements between H-23 and H-25, while the geometry of $\Delta_{24,25}$ was assigned as $E$ on the basis of the observed ${ }^{1} \mathrm{H}-{ }^{1} \mathrm{H}$ coupling constant between $\mathrm{H}-24$ and $\mathrm{H}-25$ of $15.0 \mathrm{~Hz}$ and the observed NOESY enhancement of H-23 to H-25 (see Figure 6.18 .

The relative configuration of zampanolide $\mathrm{C}(\mathbf{2 8 3})$ was established from vicinal ${ }^{1} \mathrm{H}-{ }^{1} \mathrm{H}$ homonuclear coupling constants and NOE correlations from a NOESY experiment (see Figure 6.20). Selective irradiation of H-11 and H-15 during 1D NOESY experiments gave reciprocal enhancement of these resonances, confirming that $\mathrm{H}-11$ and 

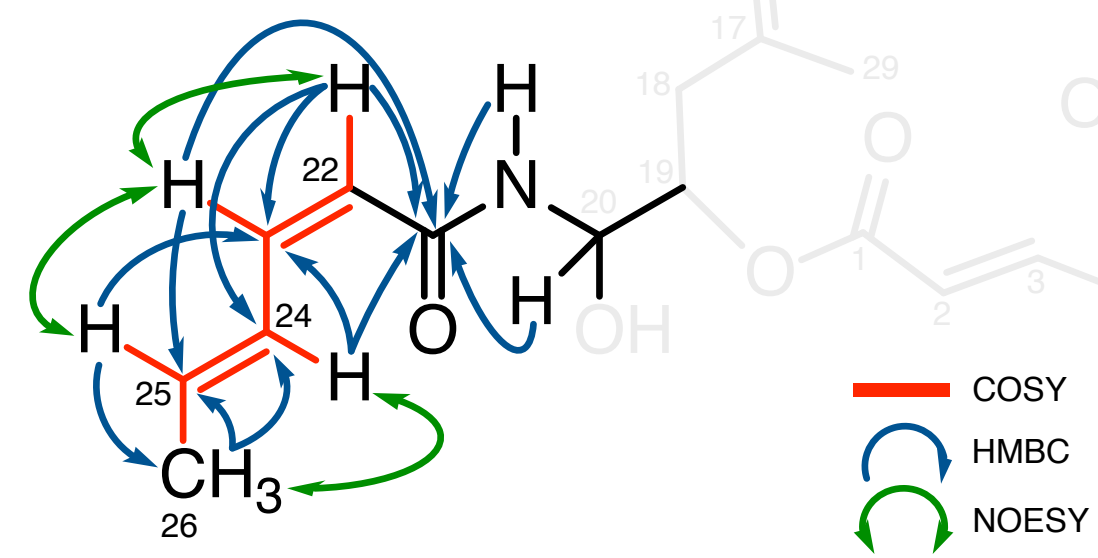

Figure 6.18. Key COSY, HMBC and NOESY correlations establishing $N$-acyl hemiaminal side chain moiety of zampanolide C (283).

H-15 were both axially oriented. The reciprocal 1,3-diaxial orientation between H-11 and $\mathrm{H}-15$ in the tetrahydropyran ring was supported by the large coupling constants $\left(J_{11,12 \mathrm{a}}=12.4 \mathrm{~Hz}\right.$ and $\left.J_{14 \mathrm{a}, 15}=11.8 \mathrm{~Hz}\right)$. The resonance of $\mathrm{H}-15$ also shared a NOESY correlation to $\mathrm{H}_{3}-29$, implying that C-29 is on the same face as H-15 and H-11. NOESY correlations were observed between $\mathrm{H}_{3}-29$ and $\mathrm{H}-20$, suggesting that $\mathrm{H}-20$ is also on the same face as methyl C-29. This assignment was further supported by the large coupling constant between $\mathrm{H}-19$ and $\mathrm{H}_{2}-18 \mathrm{a}\left(J_{18 \mathrm{a}, 19}=9.8 \mathrm{~Hz}\right)$. The relative configuration of $\mathrm{CH}-20$ could not be determined in relation to $\mathrm{CH}-19$, even though a NOESY correlation between H-19 and H-20 was observed, due to the free rotation around the acyl hemiaminal side chain. The measured optical rotation of zampanolide $\mathrm{C}(\mathbf{2 8 3})$ in $\mathrm{CH}_{2} \mathrm{Cl}_{2}$ was -266.7. This is comparable to the literature value of $[\alpha]_{\mathrm{D}}=-101.0$ for $278 .{ }^{235}$ Therefore, the absolute configuration of the four stereogenic centres in zampanolide $\mathrm{C}(\mathbf{2 8 3})$ is proposed to be $11 S, 15 S, 19 S, 20 S$, in keeping with zampanolide A (278). ${ }^{2511252}$ 


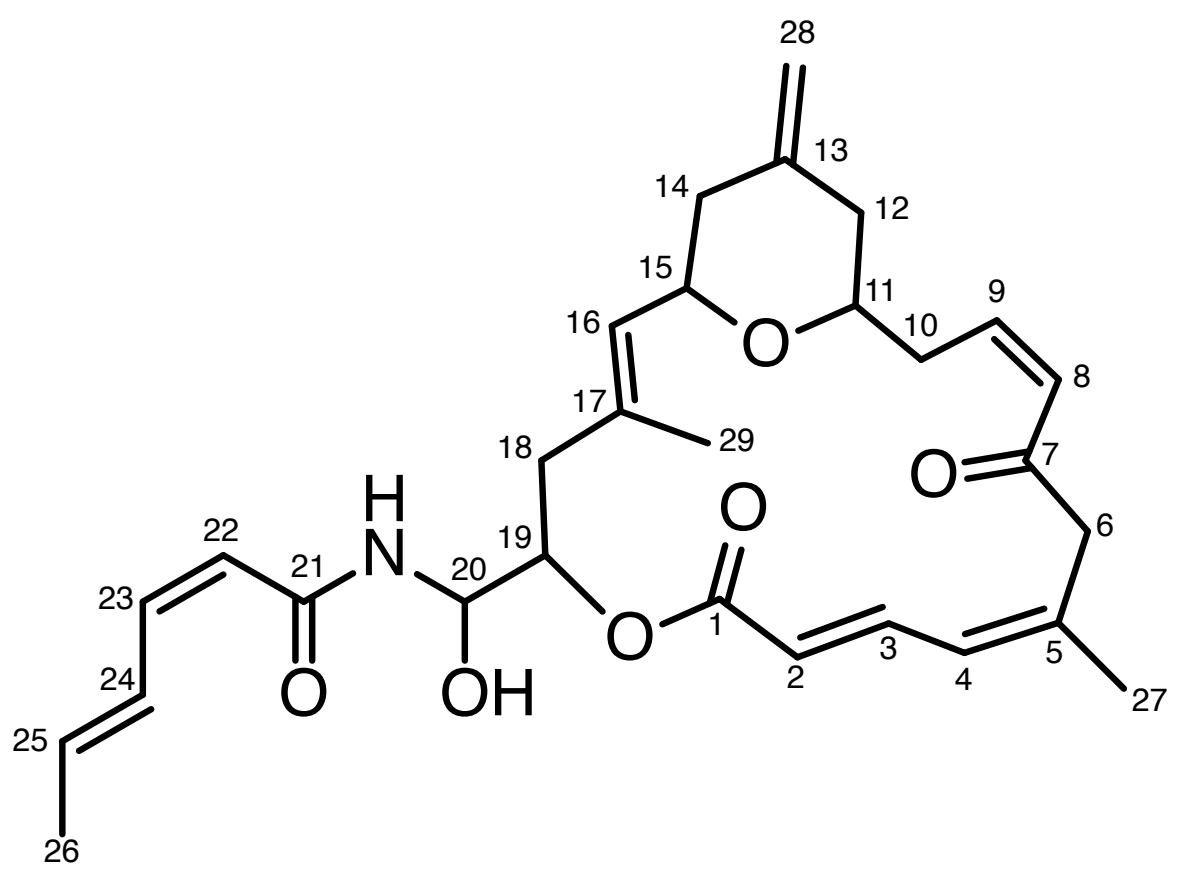

Figure 6.19. Completed planar structure of zampanolide C (283).

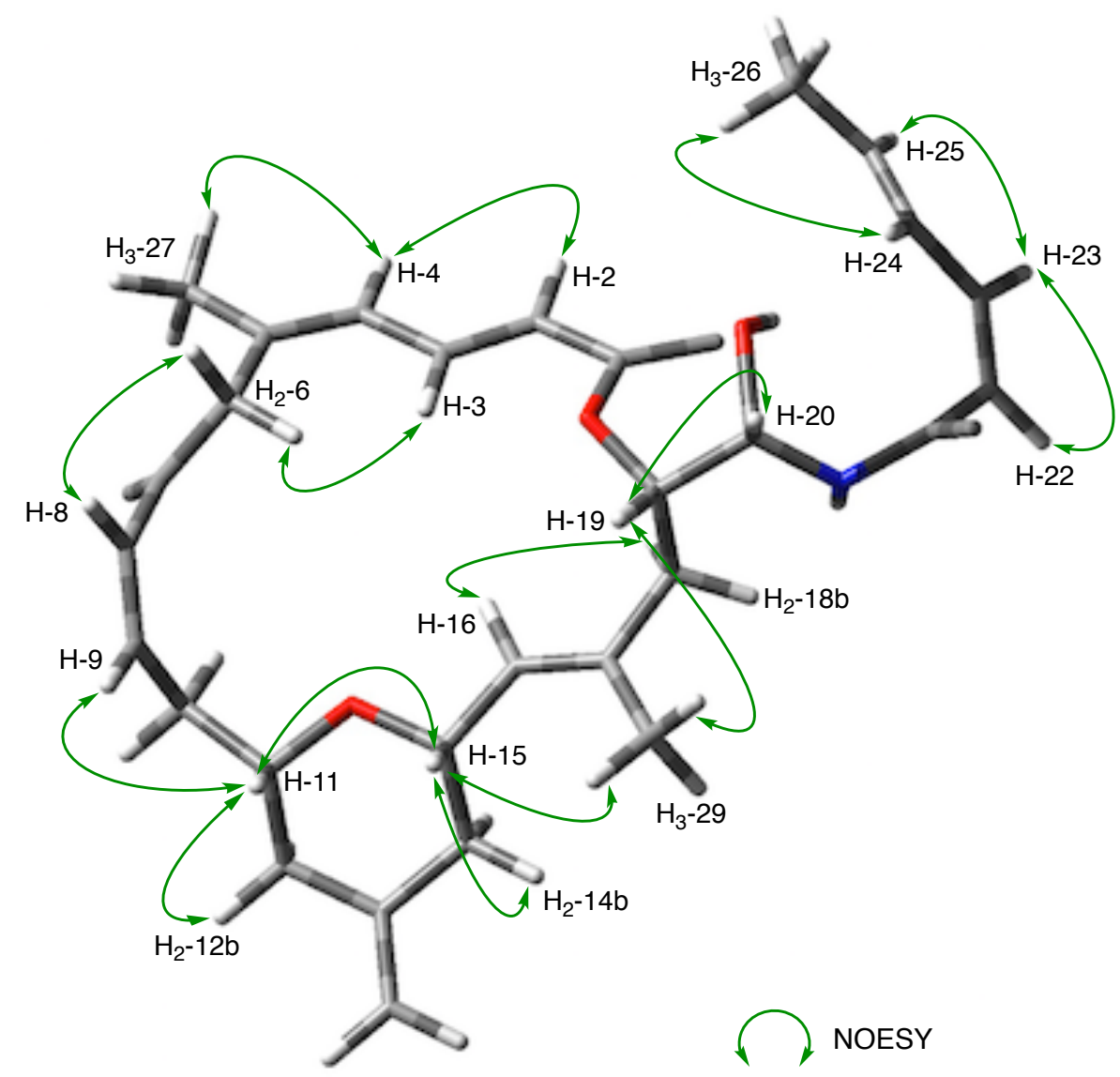

Figure 6.20. NOESY correlations establishing the relative configuration of zampanolide $\mathrm{C}(\mathbf{2 8 3})$. 


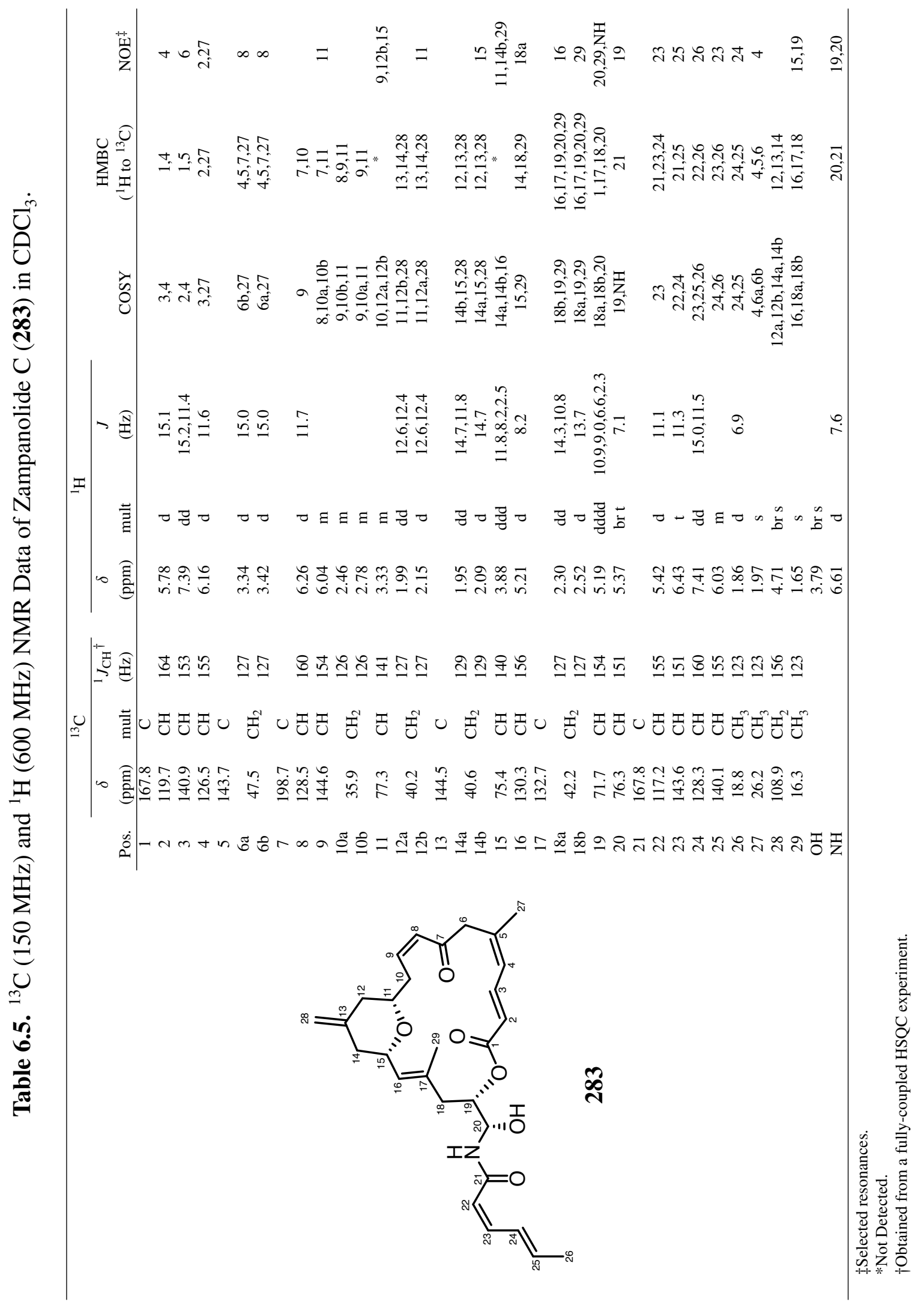




\subsection{Zampanolide D}

Zampanolide D (284) was isolated as an amorphous white solid. Like the previous two compounds (282 and 283) it was shown by HRESIMS analysis to have a monoisotopic mass from the adduct ion at $m / z 518.2509\left([\mathrm{M}+\mathrm{Na}]^{+}, \Delta=-0.77 \mathrm{ppm}\right)$, corresponding to a molecular formula of $\mathrm{C}_{29} \mathrm{H}_{37} \mathrm{NO}_{6}$. The ${ }^{1} \mathrm{H}$ NMR spectrum of zampanolide D (284) was found to be very similar to that of zampanolide A (278), differing only in the chemical shifts corresponding to the $N$-acyl hemiaminal side chain rather than that of the macrocylic moiety. This implied that the geometry of one of the double bonds of the hexadienoyl moiety had changed. Once again it was proposed that 284 was a geometric isomer of zampanolide A (278), based upon its identical 12 degrees of unsaturation. Comparison of the NMR data of both zampanolide A (278) and D (284) allowed most carbons and hydrogens of $\mathbf{2 8 4}$ be assigned to the zampanolide skeleton by direct comparison of chemical shifts. All 29 carbons and 37 protons were observed in the respective ${ }^{13} \mathrm{C}$ and ${ }^{1} \mathrm{H}$ NMR spectra (see Table 6.6), consistent with the proposed molecular formula. The multiplicity-edited HSQC spectrum showed 23 protonated carbons, belonging to three methyls $\left(\delta_{\mathrm{C}} 23.8 ; 18.8 ; 16.8\right)$, six methylenes $\left(\delta_{\mathrm{C}} 109.2 ; 45.3\right.$; $41.9 ; 41.0 ; 40.7 ; 40.3)$ and 14 methines $\left(\delta_{\mathrm{C}} 146.4 ; 142.9 ; 140.4 ; 139.6 ; 131.5 ; 130.2\right.$; $129.6 ; 125.4 ; 120.3 ; 120.2)$. Of the remaining six non-protonated carbons, three were assigned as carbonyls $\left(\delta_{\mathrm{C}} 198.0 ; 167.1 ; 167.0\right)$ and three olefinic carbons $\left(\delta_{\mathrm{C}} 144.0 ; 143.7\right.$ 132.2). With 17 of the 29 carbons being $s p^{2}$-hybridised, including the three carbonyls, the molecule must have two rings.

The planar structure of $\mathbf{2 8 4}$ was elucidated in the same fashion as the previously described compounds. Unfortunately, during the structural analysis of this compound, the cryogenic probe of the $600 \mathrm{MHz}$ NMR spectrometer was out of service. The dramatically decreased sensitivity, due to the absence of the cryogenic probe, made the observation of the longrange HMBC correlations a challenge. However, the highly proton-rich features of the compound and its close similarities to the other zampanolides made the structural elucidation of $\mathbf{2 8 4}$ practicable. Therefore the structural elucidation of this compound was mostly reliant on homonuclear NMR correlation techniques (COSY and NOESY) and 
the proton-carbon heteronuclear shift correlation technique (HSQC). The ${ }^{1} \mathrm{H}-{ }^{1} \mathrm{H}$ COSY spectrum of $\mathbf{2 8 4}$ clearly showed the proton connectivities for three spin systems: H-2 to $\mathrm{H}_{2}-6, \mathrm{H}-8$ to $\mathrm{H}-20$ and $\mathrm{H}-22$ to $\mathrm{H}_{3}-26$. These assignments were confirmed by correlations similar to those obtained with zampanolide A (278). Cross peaks in the COSY spectrum revealed the connectivity of three olefinic methines $\left[\mathrm{H}-2\left(\delta_{\mathrm{H}} 5.94 ; \delta_{\mathrm{C}} 120.2\right), \mathrm{H}-3\right.$ $\left.\left(\delta_{\mathrm{H}} 7.64 ; \delta_{\mathrm{C}} 140.4\right), \mathrm{H}-4\left(\delta_{\mathrm{H}} 6.11 ; \delta_{\mathrm{C}} 125.4\right)\right]$. A series of HMBC correlations from $\mathrm{CH}_{3}-27\left(\delta_{\mathrm{H}} 1.81 ; \delta_{\mathrm{C}} 23.8\right)$ to $\mathrm{C}-4, \mathrm{C}-5\left(\delta_{\mathrm{C}} 143.7\right)$ and $\mathrm{CH}_{2}-6\left(\delta_{\mathrm{H}} 3.05,4.11 ; \delta_{\mathrm{C}} 45.3\right)$, together with the observed correlation from $\mathrm{H}-3$ to $\mathrm{C}-1$ confirmed the connection of the ester carbonyl to the disubstituted double bond. The geometry of $\Delta_{2,3}$ was deduced to be $E$ from a $15.0 \mathrm{~Hz}\left(J_{2,3}\right)$ coupling constant, whereas that of $\Delta_{4,5}$ was found to be $Z$ from observation of a NOESY correlation between $\mathrm{H}-2$ and $\mathrm{H}-4$. The isolated methylene $\mathrm{H}_{2}-6$ showed HMBC connectivities with C-5, C-27 and the carbonyl at $\delta_{\mathrm{C}} 198.0$ (C-7), thus placing it between the carbonyl C-7 and the C-5. Identification of the second spin system by the COSY experiment began with the vicinal correlations between two olefinic methines H-8 $\left(\delta_{\mathrm{H}} 5.95 ; \delta_{\mathrm{C}} 131.5\right)$ and $\mathrm{H}-9\left(\delta_{\mathrm{H}} 6.82 ; \delta_{\mathrm{C}} 146.5\right)$. The spin system extended to $\mathrm{H}_{2}-10\left(\delta_{\mathrm{H}} 2.25,2.37 ; \delta_{\mathrm{C}} 40.3\right)$ followed by an oxymethine $\mathrm{H}-11\left(\delta_{\mathrm{H}} 3.29 ; \delta_{\mathrm{C}} 76.6\right)$ and a methylene $\mathrm{H}_{2}-12\left(\delta_{\mathrm{H}} 1.93,2.14 ; \delta_{\mathrm{C}} 41.0\right)$. It was, however, difficult to obtain unambiguous evidence for the connection between the two spin systems due to the small quantities of the compound obtained, together with the absence of the NMR cryogenic probe. Nevertheless the similarity between the chemical shifts of zampanolides A (278) and D (284) allowed the placement of the second spin system next to the carbonyl C-7. The geometry of the double bond $\Delta_{8,9}$ was easily assigned as $E$ by analysis of the coupling constant of the olefinic protons $\left(J_{8,9}=15.8 \mathrm{~Hz}\right)$ (see Figure6.21).

The HMBC correlations from the methylidene $\mathrm{CH}_{2}-28\left(\delta_{\mathrm{H}} 4.73 ; \delta_{\mathrm{C}} 109.2\right)$ to $\mathrm{C}-12, \mathrm{C}-13$ $\left(\delta_{\mathrm{C}} 144.0\right)$ and $\mathrm{CH}_{2}-14\left(\delta_{\mathrm{H}} 1.95,2.09 ; \delta_{\mathrm{C}} 40.7\right)$ placed the methylidene group between C-12 and C-14 and extended the carbon skeleton. The spin system continued to display a series of correlations in the COSY spectrum between the methylene protons $\mathrm{H}_{2}-14$ and $\mathrm{H}-15\left(\delta_{\mathrm{H}} 3.96 ; \delta_{\mathrm{C}} 76.0\right)$ then between $\mathrm{H}-15$ and $\mathrm{H}-16\left(\delta_{\mathrm{H}} 5.20 ; \delta_{\mathrm{C}} 130.2\right)$. A series of COSY correlations were observed between the methylene protons $\mathrm{H}_{2}-18\left(\delta_{\mathrm{H}} 2.19\right.$, $\left.2.42 ; \delta_{\mathrm{C}} 41.9\right)$ followed by two oxymethines $\mathrm{H}-19\left(\delta_{\mathrm{H}} 5.29 ; \delta_{\mathrm{C}} 71.5\right)$ and $\mathrm{H}-20\left(\delta_{\mathrm{H}} 5.47\right.$; $\delta_{\mathrm{C}}$ 75.8). The connection between these two fragments was substantiated by HMBC 


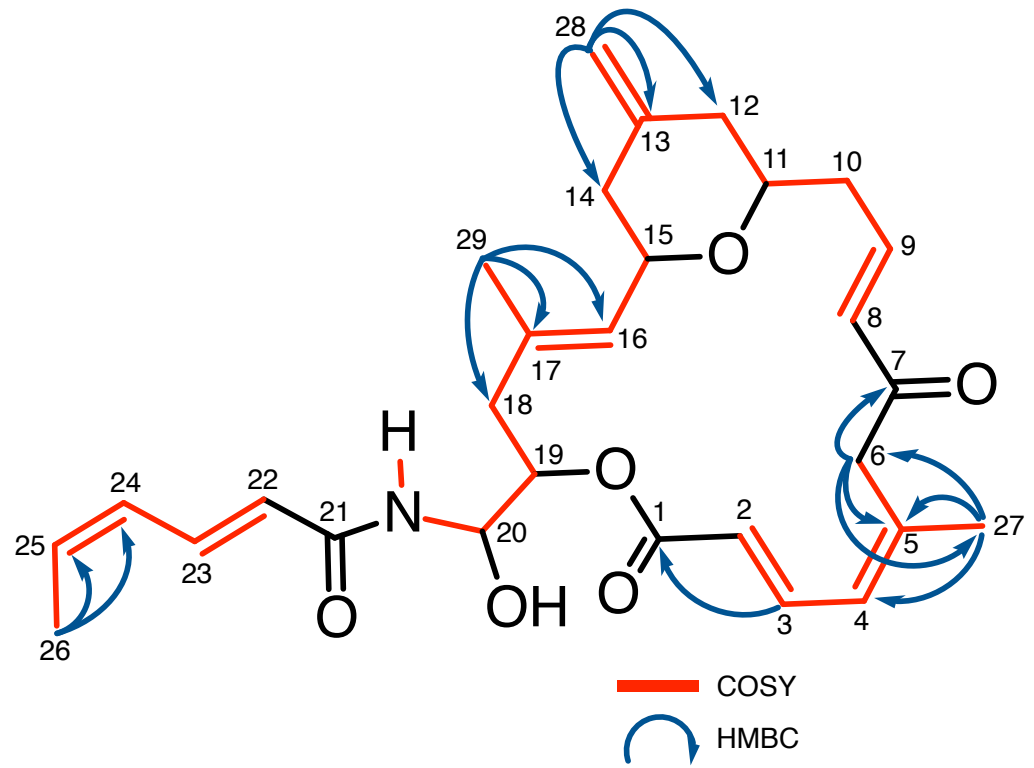

Figure 6.21. Key COSY and HMBC correlations establishing the structure of zampanolide D (284).

correlations from the methyl protons $\mathrm{H}_{3}-29\left(\delta_{\mathrm{H}} 1.72 ; \delta_{\mathrm{C}} 16.8\right)$ to $\mathrm{C}-16, \mathrm{C}-17\left(\delta_{\mathrm{C}} 132.2\right)$ and C-18, thus completing the macrocyclic moiety. The $E$-geometry of the trisubstituted double bond $\Delta_{16,17}$ was determined based on the ${ }^{13} \mathrm{C}$ chemical shift of the olefinic methyl $\left(\delta_{\mathrm{C}}<20\right.$ for $E$ and $\delta_{\mathrm{C}}>20$ for $Z$ geometry $240 \mid 241$ ) (see Figure 6.21).

The last spin system was again constructed starting from the methyl doublet $\mathrm{CH}_{3}-26$ $\left(\delta_{\mathrm{H}} 1.85 ; 18.8\right)$ followed by a chain of olefinic methines $\left[\mathrm{H}-22\left(\delta_{\mathrm{H}} 5.73 ; \delta_{\mathrm{C}} 120.3\right), \mathrm{H}-23\right.$ $\left.\left(\delta_{\mathrm{H}} 7.21 ; \delta_{\mathrm{C}} 142.9\right), \mathrm{H}-24\left(\delta_{\mathrm{H}} 6.15 ; \delta_{\mathrm{C}} 129.6\right), \mathrm{H}-25\left(\delta_{\mathrm{H}} 6.14 ; \delta_{\mathrm{C}} 139.6\right)\right]$, identified through COSY correlations between their respective protons. Again, correlations from the olefinic methines $(\mathrm{H}-2$ and $\mathrm{H}-3)$ to the amide carbonyl C-21 $\left(\delta_{\mathrm{C}} 167.1\right)$ were not observed in the HMBC spectrum. However, with the zampanolide backbone accounting for the majority of the determined molecular formula $\left(\mathrm{C}_{29} \mathrm{H}_{37} \mathrm{NO}_{6}\right)$ of 284 , the remaining degree of unsaturation indicated the presence of a secondary amide (-CONH-) that connected to the macrocycle. The NMR spectra showed significant changes in resonance for the olefinic methines of the $N$-acyl hemiaminal side chain moiety, suggesting a change in the geometry of the double bonds. Analysis of the ${ }^{1} \mathrm{H}$ NMR spectrum revealed coupling constants $\left(J_{22,23}=15.2 \mathrm{~Hz} ; J_{24,25}=11.5 \mathrm{~Hz}\right)$, thus assigning the geometry of the disubstituted double bonds $\Delta_{22,23}$ and $\Delta_{24,25}$ to be $E$ and $Z$ respectively, opposite to that of zampanolides A (278), B (282) and C (283) (see Figure 6.21). 
The relative configuration of zampanolide D (284) was assigned on the basis of NOE enhancements observed in a series of 1D-NOESY experiments and comparison with other zampanolides (see Figure 6.22). Once again the four stereogenic centres (C-11, C-15, C-19, C-20) displayed a series of shared NOESY correlations. Selective excitation of oxymethine $\mathrm{H}-11$ showed NOE enhancement to $\mathrm{H}-15$, while selective irradiation of $\mathrm{H}-15$ revealed NOE enhancements to the methyl protons $\mathrm{H}_{3}-29$. Subsequently NOE enhancements between the methyl protons $\mathrm{H}_{3}-29$ and the hemiaminal methine $\mathrm{H}-20$ suggested the conservation of the relative configuration at these centres. The optical rotation of zampanolide $\mathrm{D}(\mathbf{2 8 4})\left([\alpha]_{\mathrm{D}}^{26}-114.3\left(c 0.04, \mathrm{CH}_{2} \mathrm{Cl}_{2}\right)\right)$ was in excellent agreement in sign and magnitude with that reported in literature for zampanolide A (278) $\left([\alpha]_{\mathrm{D}}-101.0\left(c 0.12, \mathrm{CH}_{2} \mathrm{Cl}_{2}\right)\right)$, suggesting the same absolute configuration. Thus the absolute configuration of zampanolide D (284) is proposed to be $11 S, 15 S, 19 S, 20 S$, based on the biogenic assumption that the chiral centres for this compound are the same as $\mathbf{2 7 8}$. The complete structure of zampanolide D (284) is therefore assigned as $\mathbf{2 8 4}$, with NMR data presented in Table 6.6 (see Figure 6.22).

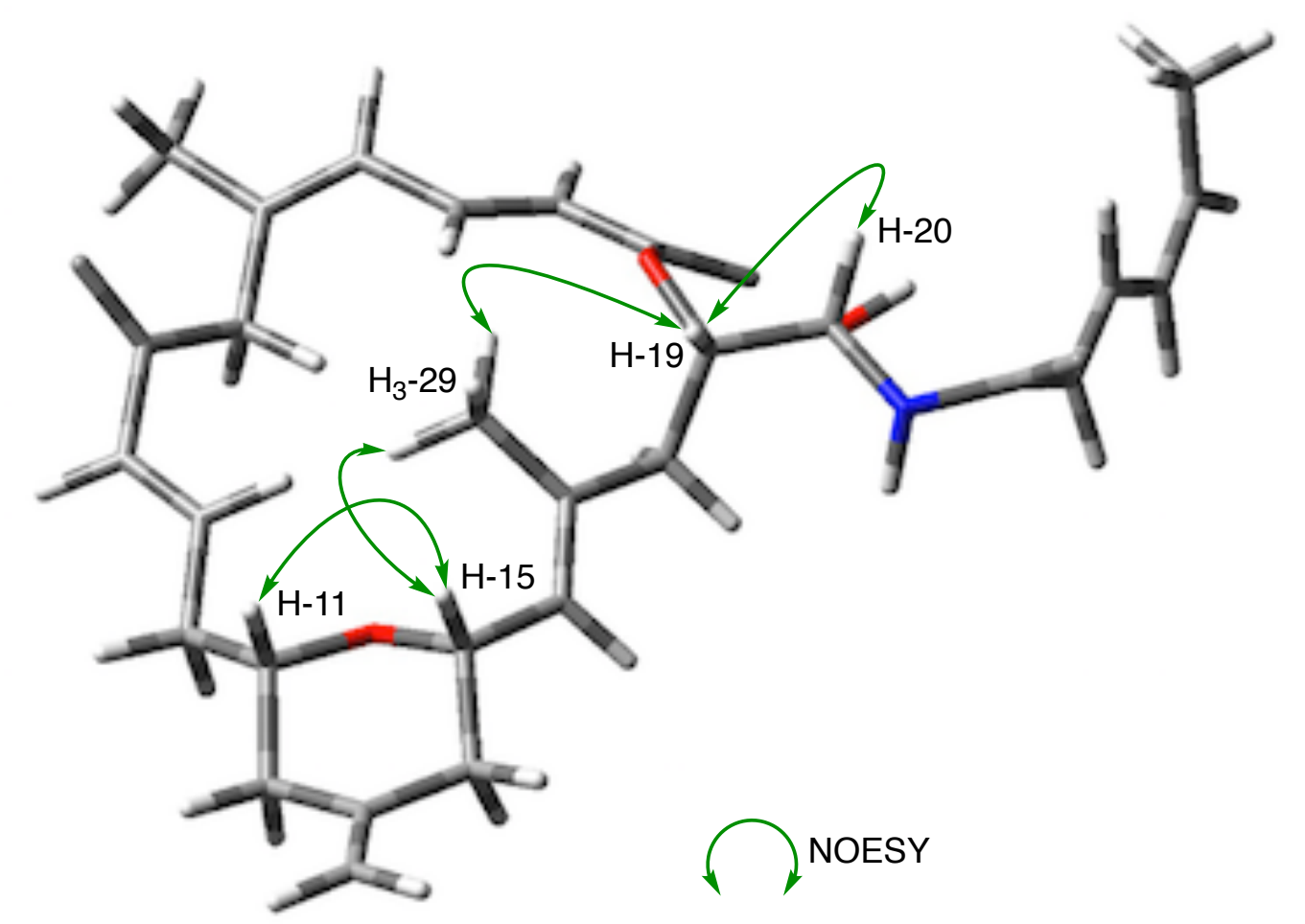

Figure 6.22. NOESY correlations establishing the relative configuration of zampanolide D (284). 


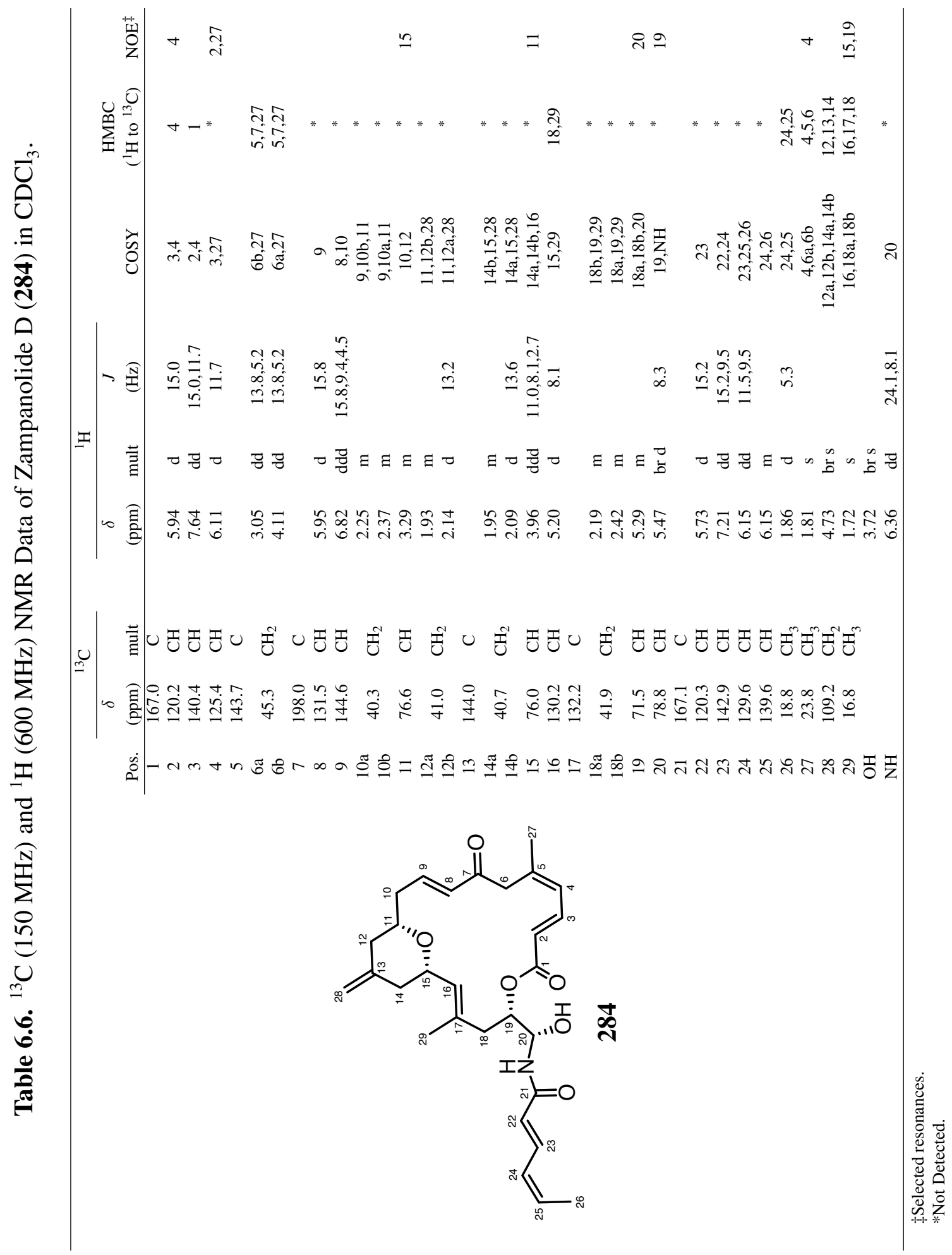




\subsection{Zampanolide E}

Zampanolide E (285) was isolated as white amorphous solid. The positive ion HRESIMS analysis of 285 presented an adduct ion $[\mathrm{M}+\mathrm{Na}]^{+}$at $m / z 520.2674(\Delta=0.77 \mathrm{ppm})$, representing a molecular formula of $\mathrm{C}_{29} \mathrm{H}_{39} \mathrm{NO}_{6}$. The proposed molecular formula differs from that of zampanolides A-D, by $2 \mathrm{Da}$ or $\mathrm{H}_{2}$ which could be accounted for by reduction of one of the double bonds. In the ${ }^{1} \mathrm{H}$ NMR spectrum, the characteristic resonances of the $\alpha, \beta$-unsaturated ketone presented in zampanolide A (278) showed significant changes. A subsequent detailed analysis of the NMR data revealed the absence of the resonances attributed to the olefinic methines H-8 and H-9, along with the downfield-shift of the adjacent carbonyl C-7 (from $\delta_{\mathrm{C}} 198.1$ in $\mathbf{2 7 8}$ to $\delta_{\mathrm{C}} 208.7$ in $\mathbf{2 8 5}$ ). This supported the presence of a saturated ketone as well as eleven degrees of unsaturation as required by the molecular formula, confirming this proposition. The ${ }^{13} \mathrm{C}$ NMR spectrum of $\mathbf{2 8 5}$ showed 29 resolved resonances (see Table 6.7) and the multiplicity edited HSQC experiment confirmed that all hydrogens but two were attached to carbon, confirming the presence of two exchangeable protons. The ${ }^{13} \mathrm{C}$ and the HSQC NMR data showed three olefinic methyls $\left(\delta_{\mathrm{C}} 24.8 ; 18.8 ; 16.3\right)$, seven methylenes $\left(\delta_{\mathrm{C}} 47.2 ; 42.4 ; 41.6 ; 41.1 ; 40.8 ; 35.7\right.$; 22.3), one methylidene $\left(\delta_{\mathrm{C}} 108.7\right)$, eight olefinic methines $\left(\delta_{\mathrm{C}} 143.7 ; 140.4 ; 140.2 ; 130.4\right.$; $128.3 ; 126.7 ; 120.4 ; 117.0)$ and four oxymethines $\left(\delta_{\mathrm{C}} 79.1 ; 76.1 ; 75.8 ; 71.2\right)$. Six further carbons were identified as non-protonated centres as no corresponding HSQC correlations were observed including three carbonyls $\left(\delta_{\mathrm{C}} 208.7 ; 167.8 ; 167.3\right)$ and three olefinic centres $\left(\delta_{\mathrm{C}} 144.5 ; 142.8 ; 131.8\right)$.

Structural elucidation of zampanolide E (285) also encountered the same problem as for 284. As the cryogenic probe was unavailable and a lack of sample mass was available, the elucidation of this structure once again relied heavily on homonuclear NMR correlation techniques (COSY and NOESY) and by comparing NMR data to the other zampanolides. Again, the ${ }^{1} \mathrm{H}-{ }^{1} \mathrm{H}$ COSY spectrum of $\mathbf{2 8 4}$ clearly showed the proton connectivities for three spin systems: $\mathrm{H}-2$ to $\mathrm{H}_{3}-27, \mathrm{H}_{2}-8$ to $\mathrm{H}-20$ and $\mathrm{H}-22$ to $\mathrm{H}_{3}-26$. The first spin system comprised of three olefinic methines $\left[\mathrm{H}-2\left(\delta_{\mathrm{H}} 5.90 ; \delta_{\mathrm{C}} 120.4\right), \mathrm{H}-3\left(\delta_{\mathrm{H}} 7.52 ; \delta_{\mathrm{C}} 140.4\right)\right.$, $\left.\mathrm{H}-4\left(\delta_{\mathrm{H}} 6.16 ; \delta_{\mathrm{C}} 126.7\right)\right]$ was assembled into a 1,3 -diene moiety from the cross peaks in 
the COSY spectrum. HMBC correlations from $\mathrm{H}-1$ to the lactone carbonyl C-1 $\left(\delta_{\mathrm{C}} 167.3\right)$ together with the correlations from the olefinic methyl $\mathrm{H}_{3}-27\left(\delta_{\mathrm{H}} 1.87 ; \delta_{\mathrm{C}} 24.8\right)$ to $\mathrm{C}-4$, C-5 $\left(\delta_{\mathrm{C}} 142.8\right)$ and $\mathrm{CH}_{2}-6\left(\delta_{\mathrm{H}} 3.26,3.43 ; \delta_{\mathrm{C}} 47.2\right)$ completed the first substructure. The geometry of the double bond $\Delta_{2,3}$ was assigned as $E$ basis on the coupling constant $\left(J_{2,3}=15.3 \mathrm{~Hz}\right)$. The methyl of a trisubstituted double bond with $E$ geometry is more shielded than that of one on $Z,{ }^{240[241}$ hence the geometry of the olefin $\Delta_{4,5}$ was deduced as $E$. The second spin system was constructed from another series of COSY correlations, which indicated the connection of three contiguous methylenes $\left[\mathrm{H}_{2}-8\left(\delta_{\mathrm{H}} 2.44 ; \delta_{\mathrm{C}} 42.4\right)\right.$, $\left.\mathrm{H}_{2}-9\left(\delta_{\mathrm{H}} 1.72 ; \delta_{\mathrm{C}} 22.3\right), \mathrm{H}_{2}-10\left(\delta_{\mathrm{H}} 1.44 ; \delta_{\mathrm{C}} 35.7\right)\right]$ to an oxymethine $\mathrm{CH}-11\left(\delta_{\mathrm{H}} 3.21 ;\right.$ $\left.\delta_{\mathrm{C}} 79.1\right)$ and to a methylene $\mathrm{CH}_{2}-12\left(\delta_{\mathrm{H}} 1.93,2.07 ; \delta_{\mathrm{C}} 41.1\right)$. The significant change to the chemical shift of the carbonyl carbon C-7 $\left(\delta_{\mathrm{C}} 208.7\right)$ implied for the reduction of the highly polarized double bond $\Delta_{8,9}$, which is a common feature in other zampanolides described previously. The presence of two new methylenes $\left(\mathrm{CH}_{2}-8\right.$ and $\left.\mathrm{CH}_{2}-9\right)$, which were evident by the molecular formula, together with the downfield-shifted adjacent ketone C-7, supported the presence of a saturated ketone. An HMBC correlation from $\mathrm{H}_{2}-6$ to the ketone carbonyl C-7 established the connection of the first spin system to C-7. However, it was difficult to obtain unambiguous evidence for the connection between the two spin systems, nevertheless the reduction of the double bond $\Delta_{8,9}$ placed the two methylenes next to the carbonyl C-7 as the only change to the constitutional structure (see Figure 6.23).

The spin system showed a further series of correlations $\left[\mathrm{H}_{2}-14\left(\delta_{\mathrm{H}} 1.94,2.08 ; \delta_{\mathrm{C}} 40.8\right)\right.$, $\left.\mathrm{H}-15\left(\delta_{\mathrm{H}} 3.92 ; \delta_{\mathrm{C}} 75.8\right), \mathrm{H}-16\left(\delta_{\mathrm{H}} 5.25 ; \delta_{\mathrm{C}} 130.4\right)\right]$ from the cross peaks in the COSY spectrum and were supported by HMBC correlations from the methylidene $\mathrm{CH}_{2}-28$ $\left(\delta_{\mathrm{H}} 4.70 ; \delta_{\mathrm{C}} 108.7\right)$ to $\mathrm{C}-12, \mathrm{C}-13\left(\delta_{\mathrm{C}} 144.5\right)$ and $\mathrm{C}-14$, establishing the methylidene group between $\mathrm{C}-12$ and $\mathrm{C}-14$. This substructure was extended further again by sequential COSY correlations $\left[\mathrm{H}_{2}-18\left(\delta_{\mathrm{H}} 2.29,2.51 ; \delta_{\mathrm{C}} 41.6\right), \mathrm{H}-19\left(\delta_{\mathrm{H}} 5.24 ; \delta_{\mathrm{C}} 71.2\right), \mathrm{H}-20\right.$ $\left.\left(\delta_{\mathrm{H}} 5.41 ; \delta_{\mathrm{C}} 76.1\right)\right]$ and the association between these substructures was further established by $\mathrm{HMBC}$ correlations from the methyl protons $\mathrm{H}_{3}-29\left(\delta_{\mathrm{H}} 1.68 ; \delta_{\mathrm{C}} 16.3\right)$ to $\mathrm{C}-16, \mathrm{C}-17$ $\left(\delta_{\mathrm{C}} 131.8\right)$ and $\mathrm{C}-18$, thus completing the macrocyclic moiety. The E-geometry of the trisubstituted double bond $\Delta_{16,17}$ was again determined based on the ${ }^{13} \mathrm{C}$ chemical shift of the olefinic methyl $\left(\delta_{\mathrm{C}}<20\right.$ for $E$ and $\delta_{\mathrm{C}}>20$ for $Z$ geometry). ${ }^{240 \mid 241}$ The final spin system 


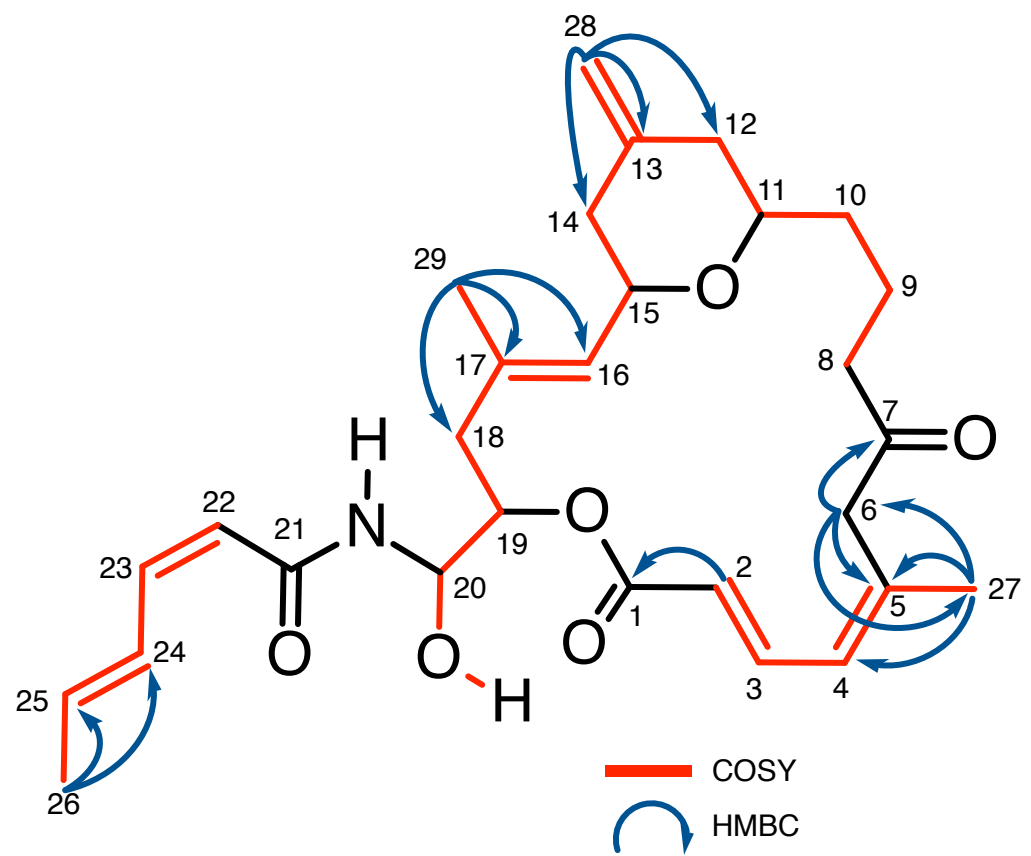

Figure 6.23. Key COSY and HMBC correlations establishing the structure of zampanolide E (285).

consisted of a methyl doublet $\mathrm{CH}_{3}-26\left(\delta_{\mathrm{H}} 1.86 ; 18.8\right)$ followed by four contiguous olefinic methines [H-22 $\left(\delta_{\mathrm{H}} 5.42 ; \delta_{\mathrm{C}} 117.0\right), \mathrm{H}-23\left(\delta_{\mathrm{H}} 6.44 ; \delta_{\mathrm{C}} 143.7\right), \mathrm{H}-24\left(\delta_{\mathrm{H}} 7.41 ; \delta_{\mathrm{C}} 128.3\right)$, H-25 $\left.\left(\delta_{\mathrm{H}} 6.05 ; \delta_{\mathrm{C}} 140.2\right)\right]$, and was identified through COSY correlations between their respective protons. $\mathrm{HMBC}$ correlations from $\mathrm{H}-20$ and $\mathrm{H}-22$ to the amide carbonyl $\mathrm{C}-21$ $\left(\delta_{\mathrm{C}} 167.8\right)$ confirmed the connection between the $N$-acyl hemiaminal side chain and the macrocyclic moiety, thus completing the structure of zampanolide E (285). Analysis of the ${ }^{1} \mathrm{H}$ NMR spectrum revealed coupling constants $\left[J_{22,23}=11.3 \mathrm{~Hz} ; J_{24,25}=15.3 \mathrm{~Hz}\right]$, thus assigning the geometry of the disubstituted double bonds $\Delta_{22,23}$ and $\Delta_{24,25}$ to be $Z$ and $E$ respectively, identical to that of zampanolides A, B and C (see Figure 6.23).

The relative configuration of zampanolide E (285) was assigned on the basis of NOE enhancements observed in a series of 1D-NOESY experiments and comparison with other zampanolides. Once again the four stereogenic centres (C-11, C-15, C-19, C-20) displayed a series of sequential NOESY correlations. Selective excitation of oxymethine $\mathrm{H}-11$ showed NOE enhacement to $\mathrm{H}-15$, while selective irradiation of $\mathrm{H}-15$ revealed NOE enhancements to the methyl protons $\mathrm{H}_{3}-29$. Subsequently NOE enhancements between the methyl protons $\mathrm{H}_{3}-29$ and the hemiaminal methine $\mathrm{H}-20$, suggested the conservation of the relative configuration at these centres. Consequently the absolute configuration of zampanolide D (284) is proposed to be $11 S, 15 S, 19 S, 20 S$, based on the assumption that 
the chiral centres for this compound are the same as zampanolide A (see Figure 6.24).

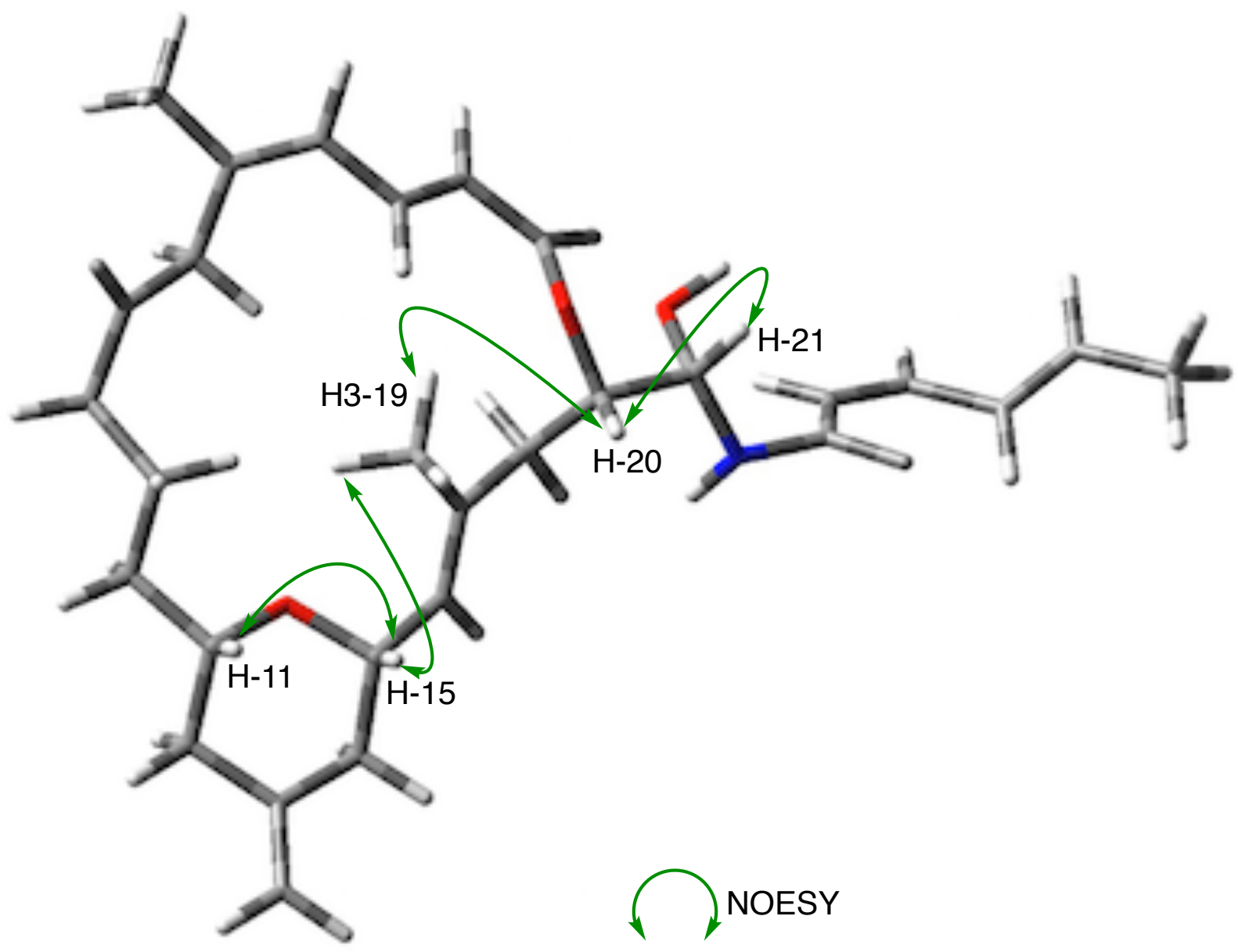

Figure 6.24. NOESY correlations establishing the relative configuration of zampanolide E (285). 


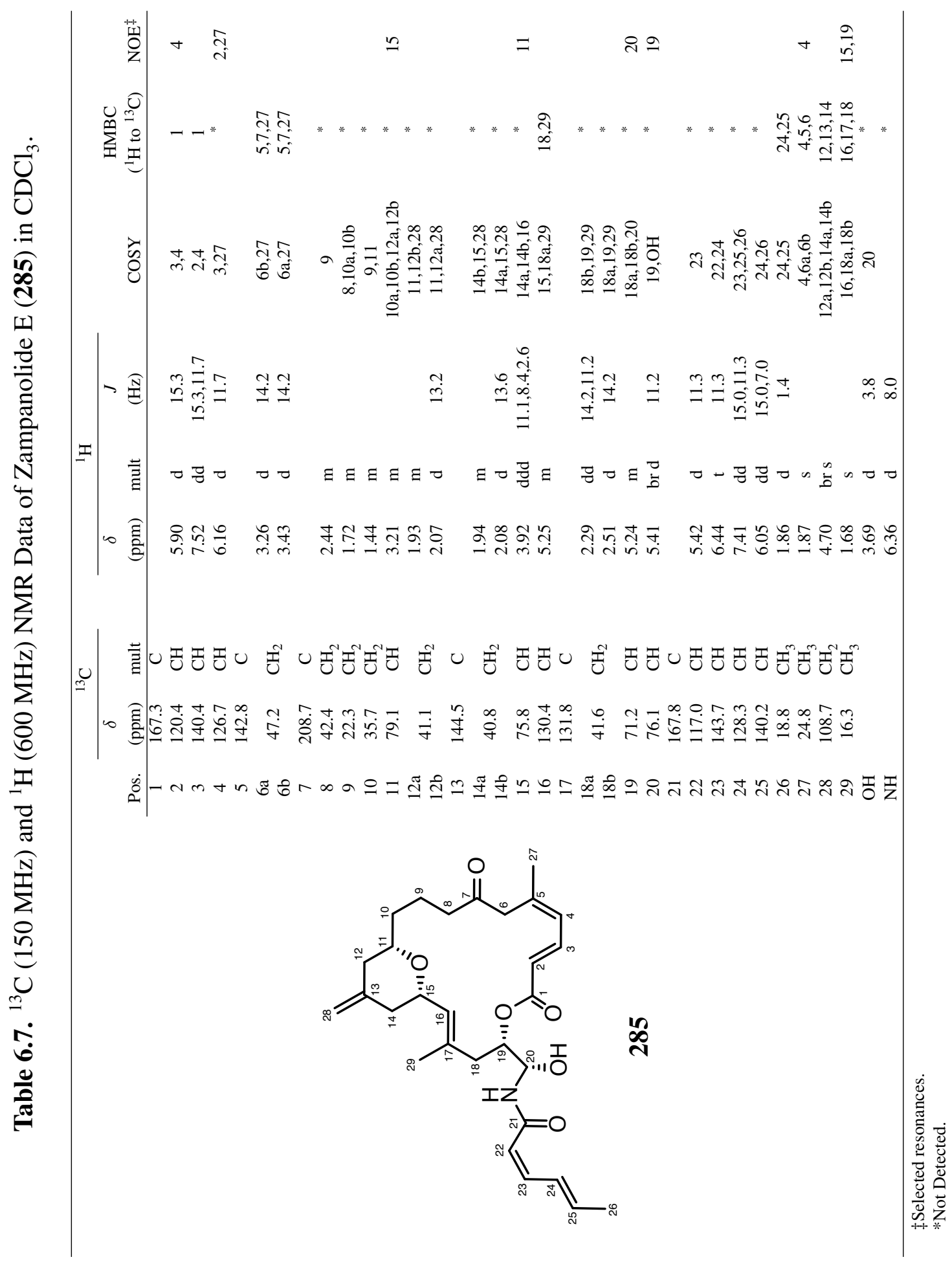




\subsection{Biological Activity}

Zampanolides B-E (282-285), along with zampanolide A (278) and (-)-dactylolide (281), were evaluated for antiproliferative activity against the human leukaemia cell line HL-60 at the School of Biological Sciences, VUW (see Table 6.8).

Table 6.8. $\mathrm{IC}_{50}$ values of zampanolides (282-285) and (-)-dactylolide (281) against HL-60 cell line.

\begin{tabular}{l|c}
\hline \hline Compound & Mean $^{\text {IC }_{\mathbf{5 0}} \pm \text { SEM }(\mathbf{n M})^{\dagger}}$ \\
\hline (-)-Zampanolide A (278) & $3.21 \pm 0.47$ \\
\hline (+)-Zampanolide B (282) & $3.29 \pm 1.41$ \\
\hline (-)-Zampanolide C (283) & $3.83 \pm 0.40$ \\
\hline (-)-Zampanolide D (284) & $5.29 \pm 1.07$ \\
\hline (+)-Zampanolide E (285) & $306 \pm 8.00$ \\
\hline (-)-Dactylolide (281) & $238 \pm 25.00$ \\
\hline \hline
\end{tabular}

$\dagger$ Values obtained from $n=3$ preparations.

As previously mentioned, zampanolide A (278) displays significant cytotoxic toward several cell lines at low nanomolar range, however its microtubule-stabilising properties was discovered at VUW in 2009. ${ }^{236}$ In 2012, a high resolution mass spectrometry (HRMS) study carried out by Field et al. provided more insight into the protein binding sites of 278. ${ }^{237}$ The study revealed that zampanolide A (278) binds to the luminal site of $\beta$-tubulin, adjacent to the paclitaxel-binding site, thus disrupting the function of the microtubule and arresting the cells in mitosis. Interestingly, the binding is covalent and irreversible, which may mean that $\mathbf{2 7 8}$ may overcome multi-drug resistance (MDR) developed from over-expression of the P-glycoprotein (P-gp) drug efflux pump. In addition, the HRMS study also revealed that the covalent binding is either between the asparagine-228 residue and C-3, or the histidine-229 residue and C-9 of the macrocyclic moiety of 278. The covalent binding involved conjugate additions of the nucleophilic side-arms of the amino acids to the $\alpha, \beta$-unsaturated carbonyl moieties of 278. In 2013, Steinmetz and co-workers reported the high resolution crystal structure of zampanolide A (278) complexed with $\alpha, \beta$-tubulin, which confirmed the covalent binding between the histidine-229 and C-9. 259

Although several total syntheses of zampanolide A (278) have been achieved, only a small amount of structure-activity work has been reported. The analogues for the 
structure-activity relationships (SAR) studies were carried out on side-products from the synthesis of (-)-zampanolide A (278) by Uenishi and co-workers. ${ }^{254}$ The C-20 epimer of (-)-zampanolide A was found to be 10-fold less active than (-)-zampanolide A (278) while the bis-amide analogue was 500-fold less active, suggesting that the configuration at $\mathrm{C}-20$ has some significance in the cytotoxicity, and a bulkier group at C-20 was not favourable.

In this study, zampanolide B-D (282-284) exhibited nanomolar antiproliferative activity towards the HL-60 cell line, all of which are comparable to zampanolide A (278). On the other hand, zampanolide $\mathrm{E}$ (285) was the least potent, with an $\mathrm{IC}_{50}$ value of $306 \mathrm{nM}$. The dramatic decrease in activity of $\mathbf{2 8 5}$ is due to the loss of the double bond $\Delta_{8,9}$, considering its involvement in the binding process to the $\beta$-tubulin, as key to the mode of action of 278. Hence the reduction of the double bond $\Delta_{8,9}$ in $\mathbf{2 8 5}$ is the reason for its 95 -fold loss in antiproliferative potency in correlation to 278. Suprisingly, zampanolide C (283) showed similar activity to zampanolide A (278) despite the alteration to the configuration of the double $\Delta_{8,9}$ ( $E$ in $\mathbf{2 7 8}$ to $Z$ in $\mathbf{2 8 3}$ ). Interestingly, (-)-dactylolide (281) was shown to be slightly more active than $\mathbf{2 8 5}$ despite the absence of the $N$-acyl hemiaminal side chain in 281, which plays a dramatic role in the activities of these compounds.

The change to the double bonds configuration around the macrocylic latone or the $N$-acyl hemiaminal side chain showed little or no effect on the potency of these new zampanolides. Since zampanolide E (285) showed comparable activity to (-)-dactylolide (281), this suggests that the double bond $\Delta_{8,9}$ and the $N$-acyl hemiaminal side chain are both essential for the high potency of these compounds. 


\subsection{Concluding Remarks}

The marine sponge Cacospongia mycofijiensis has proved to be a prolific source of structurally diverse and biologically active secondary metabolites. An NMR-guided investigation of the Tongan C. mycofijiensis sponge has led to isolation of four minor new macrolides, zampanolides B-E (282-285) and a new oxygenated sesquiterpene, isodictyodendrillin A (280).

Zampanolides B-D (282-284) shared the same gross structural features as zampanolide A (278), and differ only in the configuration of the double bonds on the macrocyclic ring or the side chain. While zampanolide E (285) also shared the same gross structural features as $\mathbf{2 7 8}$, the double bond between C-8 and C-9 in $\mathbf{2 7 8}$ is reduced in $\mathbf{2 8 5}$. Interestingly, alterations to the geometry of these double bonds did not have any effect on the potency of zampanolide B-D (282-284). However the loss of the double bond in zampanolide E (285) has led to a 95-fold reduction in antiproliferative potency.

In addition, several biologically active known compounds were also isolated including latrunculin A (248), laulimalide (259), isolaulimalide (258), neolaulimalide (277), zampanolide A (278) and dactylolide (281). The re-isolation of 278 and 281 from this sponge, established a firm conclusion regarding the controversial configuration of dactylolide, which possesses the same absolute configuration as (-)-zampanolide A (278) and has a levorotatory optical rotation.

Furthermore, the isolation of the new minor zampanolide analogues may have not been possible if conventional bioassay-guided methods were used due to the numerous biologically active compounds present in the sponge and the fact that these new congeners were present in such a minor quantities relative to the major metabolites. Therefore the utilisation of NMR-guided isolation methods has enabled the detection and isolation of these minor biologically active compounds. 


\section{Chapter 7}

\section{Conclusion}

The largely unexplored marine environment harbours a huge biodiversity, making it a rich source to discover novel structures with novel mechanisms of action that cover biologically relevant chemical space with the potential to treat many diseases.

Over the course of this study, 15 new and several known compounds were isolated from Tongan and New Zealand marine sponges using a spectroscopy-guided isolation approach. Although bioassay-guided isolation is still the most common procedure for characterising new natural products with defined biological activity, the isolation of these new compounds demonstrated the capability of using a structure-based assay. Nonetheless, bioassay and structure-based approaches both have their own benefits and drawbacks, and neither is better or worse than the other.

This research were carried out on sponges collected from two different geographical locations - the temperate and the tropical regions. The Marine Natural Products Group at VUW has used an NMR-based screening method to identify promising organisms worthy of further investigation based on sponges collected from New Zealand. This method was adapted to find a sponge ( $\approx$ one in ten sponges) that contained detectable secondary metabolites. The application of this technique to Tongan sponges found that for almost every sponge examined, the screened fractions contained predominantly secondary metabolites. Hence, the main problem encountered in this study was not finding secondary metabolites but finding novel compounds. Although some of the techniques developed in this study have helped find novel compounds, additional sophisticated analytical methods are required for rapid identification of well-known secondary metabolites and detection of novel compounds.

Several of the sponges screened in this study showed interesting NMR signals that warrant further investigation. The undetermined linear peptide obtained from the New Zealand sponge Cliona celata (MNP_7119) appeared to be a novel metabolite which makes 
it an important candidate for further investigation. The New Zealand sponge Stelletta crater (MNP_7031) needs further chemical analysis for new 4-methylenesterols, since craterols A and B are the only secondary metabolites to be reported from this sponge, indicating that further investigation into this sponge should be undertaken. In addition, the Tongan sponges PTN4_02H, PTN4_38A, PTN4_42E, PTN4_27B, PTN4_02H and PTN3_45C are worthy of further chemical investigation.

Furthermore, the isolation of the new zampanolide analogues from the Tongan sponge Cacospongia mycofijiensis provided additional SAR information since there are only a few structure-activity studies that have been reported. This study showed that the $N$-acyl hemiaminal side chain and the double bond $\Delta_{8,9}$ play an important role in the high potency of this family of compounds. However, mode of action studies of these biologically active compounds are needed to assess the potential of these compounds as drug leads or biochemical tools for future development. 


\section{Chapter 8}

\section{Experimental}

\subsection{General Experimental}

NMR spectra were obtained using a Varian DirectDrive spectrometer equipped with a triple-resonance $\mathrm{HCN}$ cryogenic probe, operating at $600 \mathrm{MHz}$ for the ${ }^{1} \mathrm{H}$ nucleus and $150 \mathrm{MHz}$ for the ${ }^{13} \mathrm{C}$ nucleus. The ${ }^{15} \mathrm{~N}$ nucleus was indirectly detected using ${ }^{1} \mathrm{H}-{ }^{15} \mathrm{~N}$ CIGAR experiment. Chemical shifts $\delta$ (ppm) were internally referenced to the residual solvent peak for ${ }^{1} \mathrm{H}$ and ${ }^{13} \mathrm{C}$. ${ }^{260}$ The ${ }^{15} \mathrm{~N}$ chemical shifts were externally referenced to nitromethane $\left(\mathrm{CH}_{3} \mathrm{NO}_{2}\right)$ as $0 \mathrm{ppm}$. For acid sensitive compounds, a catalytic amount (1-2 $\mu \mathrm{L})$ of $d_{5}$-pyridine was added to each NMR sample performed in $\mathrm{CDCl}_{3}$ to prevent compound degradation due to acidity associated with the solvent. ${ }^{1} \mathrm{H}$ NMR quantification of samples was performed with $\mathrm{CH}_{3} \mathrm{NO}_{2}$ internal standard (100 $\mu \mathrm{L}$ in $\left.5 \mathrm{~mL} \mathrm{CDCl}_{3}\right)$, using the acquisition parameters described by West. $\frac{53}{5}$

TLC analyses were performed on Machery-Nagel Alugram SIL G/UV 254 normal-phase silica plates using a mobile phase of $5 \% \mathrm{MeOH} / \mathrm{CH}_{2} \mathrm{Cl}_{2}$ unless otherwise stated. The TLC plates were visualised by either (1) fluorescence quenching under UV light ( $\lambda=254 \mathrm{~nm})$, (2) fluorescence under UV light $(\lambda=350 \mathrm{~nm})$, (3) dipping in $5 \% \mathrm{H}_{2} \mathrm{SO}_{4}$ (conc.)/MeOH solution, followed by dipping in a solution of $0.1 \%$ vanillin in $\mathrm{EtOH}(\% \mathrm{wt} / \mathrm{vol})$ then heating, or (4) a combination of the above.

HRESIMS data were obtained from an Agilent 6530 Accurate-Mass Q-TOF LC-MS equipped with a 1260 Infinity binary pump. Optical rotations were measured using a Rudolph Autopol II polarimeter. UV spectra were recorded on a Shimadzu UV-160 spectrophotometer. IR spectra were recorded using a Brüker Alpha FT-IR spectrometer. Normal-phase column chromatography was performed using 2,3-dihydroxypropoxypropylderivatised silica (DIOL), or silica $\left(\mathrm{SiO}_{2}\right)$. Reversed-phase column chromatography was carried out using Supelco Diaion HP20 or Mitsubishi Diaion HP20SS poly(styrene 
divinylbenzene) (PSDVB) resin. Size exclusion chromatography was performed using Sephadex LH20.

High-pressure liquid chromatography (HPLC) was performed using two separate HPLC systems, either a Rainin Dynamax SD-200 solvent delivery module with $25 \mathrm{~mL}$ pump heads (analytical and semi-preparative scale). UV detection for HPLC runs was obtained with a Varian Prostar 335 photodiode array detector. The second HPLC system was an Agilent Technologies 1260 Infinity HPLC equipped with a quaternary pump, a thermostatted column compartment and diode array detector (DAD), followed by an Agilent 380-evaporative light scattering detector (ELSD). Reversed-phase HPLC was performed using a Phenomenex Luna C18 column — analytical $(4.6 \times 250 \mathrm{~mm}, 5 \mu \mathrm{m})$ or semi-preparative $(10 \times 250 \mathrm{~mm}, 5 \mu \mathrm{m})$. Normal-phase HPLC was perfomed using a custom-packed Phenomenex DIOL column — analytical $(4.0 \times 250 \mathrm{~mm}, 5 \mu \mathrm{m})$ or semipreparative $(10 \times 250 \mathrm{~mm}, 5 \mu \mathrm{m})$.

All solvents used in bench-top chromatography and HPLC were HPLC grade (purchased from Fisher Scientific). Water was glass-distilled and deionised using a MilliQ system. The solvent compositions used are all reported as the \% v/v, unless otherwise stated.

Tongan marine specimens obtained during the three collection trips were immediately frozen, and transported to New Zealand. New Zealand specimens were collected by NIWA. The specimens were stored at $-18{ }^{\circ} \mathrm{C}$ in the School of Chemical and Physical Sciences, VUW until required for extraction. Once a specimen was selected, it was screened according to the protocol described in Appendix A. Purified compounds were submitted to the School of Biological Sciences, VUW for biological testing. For sponge identification, the organic matter was dissolved by immersing small samples $\left(\approx 1 \mathrm{~cm}^{3}\right)$ in concentrated $\mathrm{HNO}_{3}$ or $15 \% \mathrm{NaOCl}$ solution, after which any spicules present settled to the bottom of the tube. Spicules were separated from the mother liquor by centrifugation and decantation. After washing thoroughly with $\mathrm{H}_{2} \mathrm{O}$, the spicules were then analysed under an optical microscope and/or scanning electron microscopy (SEM). These images were compared with descriptions in the literature to classify the sponge. A voucher sample of each extracted sponge has been stored at SCPS, VUW. 


\subsection{Computational Methods}

The structural optimisations for makaluvamine W (183) were carried out with the Gaussian 09 suite of programs (Revision D.01) ${ }^{139}$ using the density functional method (DFT) with the the PBE0 hybrid functional ${ }^{140}$ and the balanced, polarised def2-TZVP basis-set ${ }^{141}$ of triple- $\zeta$ quality. The Polarisable Continuum Model (PCM) using the integral equation formalism variant (IEFPCM) ${ }^{142}$ with the SMD parameter set established by Cramer and Truhlar ${ }^{261}$ was used to model the effects of the solvent. Frequency calculations at the same level of theory were employed to ensure that the obtained structures are minima on the potential energy surface. The same methodology was used for the NMR calculations, but the basis-set was completely de-contracted to ensure a greater level of flexibility in the nuclear region. The DP4 procedure was used to unambiguously confirm the assignment of the NMR spectrum. 143

\subsection{Isolation of Aerothionin from PTN3_16F}

PTN3_16F is an unidentified sponge collected from the coastline of Houma, 'Eua, Tonga in late November 2008. A $50 \mathrm{~g}$ frozen sample was extracted twice in $200 \mathrm{~mL}$ $\mathrm{MeOH}$ overnight. The second then first extracts were cyclic-loaded onto a $40 \mathrm{~mL}$ PSDVB column, pre-equilibrated in $\mathrm{MeOH}$. The loaded column was then washed with $150 \mathrm{~mL}$ of $\mathrm{H}_{2} \mathrm{O}$ and fractionated with $150 \mathrm{~mL}$ portions of (i) $40 \% \mathrm{Me}_{2} \mathrm{CO} / \mathrm{H}_{2} \mathrm{O}$ (fraction A, $2057.6 \mathrm{mg}$ ), (ii) $60 \% \mathrm{Me}_{2} \mathrm{CO} / \mathrm{H}_{2} \mathrm{O}$ (fraction $\mathbf{B}, 502.3 \mathrm{mg}$ ), (iii) $80 \% \mathrm{Me}_{2} \mathrm{CO} / \mathrm{H}_{2} \mathrm{O}$ (fraction C, $688.2 \mathrm{mg}$ ) and (iv) $\mathrm{Me}_{2} \mathrm{CO}$ (fraction $\mathbf{D}, 146.1 \mathrm{mg}$ ).

A portion $\left(90.0 \mathrm{mg}\right.$ ) of fraction $\mathbf{C}$ was loaded onto a $15 \mathrm{~mL} \mathrm{SiO}{ }_{2}$ column and eluted sequentially with $50 \mathrm{~mL}$ portions of $\mathrm{CH}_{2} \mathrm{Cl}_{2}, 5 \%, 10 \%, 15 \%, 30 \%$ (fraction $\mathbf{E}, 14.7 \mathrm{mg}$ ), $50 \%, 75 \%, 90 \%$ EtOAc in $\mathrm{CH}_{2} \mathrm{Cl}_{2}$, and EtOAc. A total of 68 fractions were collected. Fraction E was separated on an analytical C18 reversed-phase HPLC column with a solvent gradient of $65 \%$ to $80 \% \mathrm{MeOH}$ in $\mathrm{H}_{2} \mathrm{O}$ as the mobile phase at a flow rate of $1 \mathrm{~mL} / \mathrm{min}$ to afford fraction $\mathbf{F}\left(t_{\mathrm{R}} 17.81 \mathrm{~min}, 9.8 \mathrm{mg}\right)$. Fraction $\mathbf{F}$ was separated on an analytical $\mathrm{C} 18$ reversed-phase HPLC column with $80 \% \mathrm{MeOH}$ in $\mathrm{H}_{2} \mathrm{O}$ as the mobile 
phase at a flow rate of $1 \mathrm{~mL} / \mathrm{min}$ to afford aerothionin $\left(\mathbf{5 0}, t_{\mathrm{R}} 8.00 \mathrm{~min}, 5.5 \mathrm{mg}\right)$.

Aerothionin (50). Colourless solid; HRESIMS, $[\mathrm{M}+\mathrm{H}]^{+}$, observed $\mathrm{m} / \mathrm{z}$ 814.8554, calculated 814.8557 for $\mathrm{C}_{24} \mathrm{H}_{27}{ }^{79} \mathrm{Br}_{4} \mathrm{~N}_{4} \mathrm{O}_{8}, \Delta=-0.37$ ppm; all NMR data as previously described. 66

\subsection{Isolation of Compounds from Stelletta crater}

The sponge identified as Stelletta crater (MNP_7031, 1579.0 g) was collected from the Three Kings Islands, New Zealand in 2002. A frozen $106 \mathrm{~g}$ sample was extracted twice in $400 \mathrm{~mL} \mathrm{MeOH}$ overnight. The filtered extracts were cyclic loaded onto an $80 \mathrm{~mL}$ column pre-equilibrated in $\mathrm{MeOH}$. The loaded column was then washed with $250 \mathrm{~mL}$ of $\mathrm{H}_{2} \mathrm{O}$ and fractionated with $250 \mathrm{~mL}$ portions of (i) $30 \% \mathrm{Me}_{2} \mathrm{CO} / \mathrm{H}_{2} \mathrm{O}$ (fraction $\mathbf{A}, 19.5 \mathrm{mg}$ ), (ii) $75 \% \mathrm{Me}_{2} \mathrm{CO} / \mathrm{H}_{2} \mathrm{O}$ (fraction $\mathbf{B}, 34.8 \mathrm{mg}$ ) and (iii) $\mathrm{Me}_{2} \mathrm{CO}$ (fraction C, $221.5 \mathrm{mg}$ ).

A portion $\left(17.8 \mathrm{mg}\right.$ ) of fraction $\mathbf{C}$ was loaded onto a $10 \mathrm{~mL} \mathrm{SiO}{ }_{2}$ column and eluted successively with $30 \mathrm{~mL}$ portions of $\mathrm{CH}_{2} \mathrm{Cl}_{2}, 1 \%$ (fraction $\mathbf{D}, 3.6 \mathrm{mg}$ ), 3\%, 5\%, 7\%, $10 \%, 15 \%, 30 \%$ EtOAc in $\mathrm{CH}_{2} \mathrm{Cl}_{2}$, and EtOAc. A total of 40 fractions were collected. Fraction D was separated on an analytical C18 reversed-phase HPLC column with 100\% $\mathrm{MeOH}$ as the mobile phase at a flow rate of $1 \mathrm{~mL} / \mathrm{min}$ to yield craterols $\mathrm{A}\left(\mathbf{9 4}, t_{\mathrm{R}} 13.5\right.$ $\min , 1.6 \mathrm{mg})$ and $\mathrm{B}\left(\mathbf{9 5}, t_{\mathrm{R}} 15.4 \mathrm{~min}, 1.8 \mathrm{mg}\right)$.

Craterol A (94). White amorphous solid; $[\alpha]_{\mathrm{D}}^{26}-106.7$ ( $c$ 0.075, MeOH); UV (MeOH) $\lambda_{\max } 217 \mathrm{~nm}$ ( $\epsilon$ 5309); IR (film) $\nu_{\max }$ 3355, 2959, 2929, 2851, 1567, 1446, 1372, 1346, 1304, 1075, 1027, $887 \mathrm{~cm}^{-1}$; NMR data see Table 3.2. HRESIMS, [M + Na $]^{+}$, observed $m / z$ 433.3432, calculated 433.3441 for $\mathrm{C}_{29} \mathrm{H}_{46} \mathrm{ONa}, \Delta=-2.08 \mathrm{ppm}$.

Craterol B (95). White amorphous solid; $[\alpha]_{\mathrm{D}}^{26}-100.0$ (c 0.070, MeOH); UV (MeOH) $\lambda_{\max } 216 \mathrm{~nm}\left(\epsilon\right.$ 4493); IR (film) $\nu_{\max } 3369,2929,2885,2663,1570,1467,1372,1345$, 1303, 1075, 1026, $890 \mathrm{~cm}^{-1}$; NMR data see Table 3.3. HRESIMS, $[\mathrm{M}+\mathrm{H}]^{+}$, observed $m / z$ 425.3762, calculated 425.3778 for $\mathrm{C}_{30} \mathrm{H}_{49} \mathrm{O}, \Delta=-3.76 \mathrm{ppm}$. 


\subsection{Isolation of Compounds from Zyzzya fuliginosa}

\subsubsection{Screening}

The sponge Zyzzya fuliginosa (PTN4_10A, $1459.0 \mathrm{~g}$ ) was collected using SCUBA from Fakafotulā, Vava'u, Tonga in late November 2009. A 50 g frozen sample was extracted twice in $200 \mathrm{~mL} \mathrm{MeOH}$ overnight. The second then first extracts were cyclic-loaded onto an $80 \mathrm{~mL}$ PSDVB column, pre-equilibrated in $\mathrm{MeOH}$. The loaded column was then washed with $250 \mathrm{~mL}$ of $\mathrm{H}_{2} \mathrm{O}$ and fractionated with $250 \mathrm{~mL}$ portions of (i) $20 \%$ $\mathrm{Me}_{2} \mathrm{CO} / \mathrm{H}_{2} \mathrm{O}$ (fraction A, $64.1 \mathrm{mg}$ ), (ii) $40 \% \mathrm{Me}_{2} \mathrm{CO} / \mathrm{H}_{2} \mathrm{O}$ (fraction $\mathbf{B}, 28.5 \mathrm{mg}$ ), (iii) $60 \% \mathrm{Me}_{2} \mathrm{CO} / \mathrm{H}_{2} \mathrm{O}$ (fraction C, $53.5 \mathrm{mg}$ ), (iv) $80 \% \mathrm{Me}_{2} \mathrm{CO} / \mathrm{H}_{2} \mathrm{O}$ (fraction $\mathbf{D}, 48.6 \mathrm{mg}$ ) and (v) $\mathrm{Me}_{2} \mathrm{CO}$ (fraction E, $151.1 \mathrm{mg}$ ).

Fraction A was loaded onto a $10 \mathrm{~mL}$ DIOL column and eluted sequentially with $50 \mathrm{~mL}$ portions of $\mathrm{CH}_{2} \mathrm{Cl}_{2}$ (fraction $\mathbf{F}, 23.8 \mathrm{mg}$ ), 50\% EtOAc in $\mathrm{CH}_{2} \mathrm{Cl}_{2}$, EtOAc, 50\% $\mathrm{MeOH}$ in EtOAc (fraction $\mathbf{G}, 18.5 \mathrm{mg}$ ), $\mathrm{MeOH}$ and $50 \% \mathrm{MeOH} / \mathrm{H}_{2} \mathrm{O}$ (fraction $\mathbf{H}, 2.6 \mathrm{mg}$ ). Fraction F was purified on an analytical C18 reversed-phase HPLC column with a solvent gradient of $30 \%$ to $40 \% \mathrm{MeOH}$ in $0.2 \% \mathrm{HCOOH}$ as the mobile phase at a flow rate of $1 \mathrm{~mL} / \mathrm{min}$ to afford damirone $\mathrm{B}\left(\mathbf{4 7}, t_{\mathrm{R}} 8.6 \mathrm{~min}, 5.2 \mathrm{mg}\right)$. Fraction $\mathbf{G}$ was purified on an analytical C18 reversed-phase HPLC column with a solvent gradient of $10 \%$ to $40 \% \mathrm{MeOH}$ in $0.1 \% \mathrm{HCOOH}_{(\mathrm{aq})}$ as the mobile phase at a flow rate of $1 \mathrm{~mL} / \mathrm{min}$ to afford damirone $\mathrm{B}$ $\left(47, t_{\mathrm{R}} 16.6 \mathrm{~min}, 5.2 \mathrm{mg}\right)$. Fraction $\mathbf{H}$ was purified on an analytical C18 reversed-phase HPLC column with $40 \% \mathrm{MeOH}$ in $0.2 \% \mathrm{HCOOH}_{(\mathrm{aq})}$ as the mobile phase at a flow rate of $1 \mathrm{~mL} / \mathrm{min}$, yielding makaluvamine $\mathrm{K}\left(\mathbf{1 5 7}, t_{\mathrm{R}} 8.7 \mathrm{~min}, 0.1 \mathrm{mg}\right)$.

A $20.0 \mathrm{mg}$ subsample of fraction B was loaded onto a $10 \mathrm{~mL}$ DIOL column and eluted successively with $30 \mathrm{~mL}$ portions of $\mathrm{CH}_{2} \mathrm{Cl}_{2}$ (fraction $\mathbf{I}, 0.8 \mathrm{mg}$ ), $50 \%$ EtOAc in $\mathrm{CH}_{2} \mathrm{Cl}_{2}$ (fraction $\mathbf{J}, 1.1 \mathrm{mg}$ ), EtOAc, $50 \% \mathrm{MeOH}$ in EtOAc (fraction $\mathbf{K}, 4.5 \mathrm{mg}$ ), $\mathrm{MeOH}$ (fraction $\mathbf{L}, 1.0 \mathrm{mg}$ ) and $50 \% \mathrm{MeOH} / \mathrm{H}_{2} \mathrm{O}$ (fraction $\mathbf{M}, 0.6 \mathrm{mg}$ ). Fraction $\mathbf{I}$ contained makaluvanone (151), while fractions $\mathbf{K}, \mathbf{L}$ and $\mathbf{M}$ contained makaluvamine K (157). Fraction $\mathbf{J}$ was purified on an analytical C18 reversed-phase HPLC column with a solvent gradient of $40 \%$ to $55 \% \mathrm{MeOH}$ in $0.2 \% \mathrm{HCOOH}_{(\mathrm{aq})}$ as the mobile phase at a flow rate of 
$1 \mathrm{~mL} / \mathrm{min}$ to afford 6-bromodamirone $\mathrm{B}\left(\mathbf{1 8 2}, t_{\mathrm{R}} 9.40 \mathrm{~min}, 0.1 \mathrm{mg}\right)$. The other portion $(8.0 \mathrm{mg})$ of fraction $\mathbf{B}$ was purified on a $10 \mathrm{~mL}$ DIOL column and eluted sequentially with $30 \mathrm{~mL}$ portions of $\mathrm{CH}_{2} \mathrm{Cl}_{2}, 25 \%$ (fraction $\mathbf{N}, 1.3 \mathrm{mg}$ ), $50 \%, 60 \%$ EtOAc in $\mathrm{CH}_{2} \mathrm{Cl}_{2}$ (fraction $\mathbf{O}, 1.1 \mathrm{mg}$ ), EtOAc (fraction $\mathbf{P}, 0.4 \mathrm{mg}$ ) and $\mathrm{MeOH}$. Fractions $\mathbf{O}$ and $\mathbf{P}$ contained damirone B (47). Fraction $\mathbf{N}$ was fractionated on an analytical C18 reversed-phase HPLC column with a solvent gradient of $40 \%$ to $55 \% \mathrm{MeOH}$ in $0.2 \% \mathrm{HCOOH}_{(\mathrm{aq})}$ as the mobile phase at a flow rate of $1 \mathrm{~mL} / \mathrm{min}$ to afford 6-bromodamirone $\mathrm{B}\left(\mathbf{1 8 2}, t_{\mathrm{R}} 9.40 \mathrm{~min}, 0.1 \mathrm{mg}\right)$.

Fraction C (53.5 mg) was loaded onto an LH20* column $(25 \mathrm{~mm} \times 1.5 \mathrm{~m})$ and eluted with $50 \% \mathrm{CH}_{2} \mathrm{Cl}_{2} / \mathrm{MeOH}$. A total of 200 fractions were collected. The fractions were combined based on TLC and ${ }^{1} \mathrm{H}$ NMR evidence. Five fractions, $\mathbf{Q}-\mathbf{U}$, were independently purified using the same solvent system $\left(40 \%-50 \% \mathrm{MeOH}\right.$ in $\left.0.2 \% \mathrm{HCOOH}_{(\mathrm{aq})}\right)$ over an analytical C18 reversed-phase HPLC column at a flow rate of $1 \mathrm{~mL} / \mathrm{min}$. The samples were collected and combined to provide makaluvamines A (145, 0.1 mg), E (149, $1.2 \mathrm{mg})$, $\mathrm{F}(\mathbf{1 5 0}, 0.5 \mathrm{mg})$ and $\mathrm{K}(\mathbf{1 5 7}, 3.3 \mathrm{mg})$

\subsubsection{Bulk Isolation}

Zyzzya fuliginosa (PTN4_10A, $1042.7 \mathrm{~g}$ ) collected at Vava'u, Tonga, was extracted twice in $3 \mathrm{~L}$ of $\mathrm{MeOH}$ overnight. The filtered extracts were cyclic-loaded onto a $200 \mathrm{~mL}$ PSDVB column, pre-equilibrated in $\mathrm{MeOH}$. The loaded column was then washed with $1.0 \mathrm{~L}$ of $\mathrm{H}_{2} \mathrm{O}$ and fractionated with $1.0 \mathrm{~L}$ portions of (i) $20 \% \mathrm{Me}_{2} \mathrm{CO} / \mathrm{H}_{2} \mathrm{O}$ (fraction A, $585.2 \mathrm{mg}$ ), (ii) $40 \% \mathrm{Me}_{2} \mathrm{CO} / \mathrm{H}_{2} \mathrm{O}$ (fraction $\mathbf{B}, 2072.2 \mathrm{mg}$ ), (iii) $60 \% \mathrm{Me}_{2} \mathrm{CO} / \mathrm{H}_{2} \mathrm{O}$ (fraction $\mathbf{C}, 1611.4 \mathrm{mg}$ ), (iv) $80 \% \mathrm{Me}_{2} \mathrm{CO} / \mathrm{H}_{2} \mathrm{O}$ (fraction $\mathbf{D}, 970.0 \mathrm{mg}$ ), (v) $\mathrm{Me}_{2} \mathrm{CO}$ (fraction $\mathbf{E}, 422.4 \mathrm{mg}$ ) and (vi) $25 \% \mathrm{MeOH} / \mathrm{H}_{2} \mathrm{O}$ (fraction $\mathbf{F}, 322.3 \mathrm{mg}$ ).

Fraction C was cyclic-loaded onto a PSDVB column (200 mL) and eluted successively with $1.0 \mathrm{~L}$ portions of $40 \% \mathrm{MeOH} / \mathrm{H}_{2} \mathrm{O}, 60 \% \mathrm{MeOH} / \mathrm{H}_{2} \mathrm{O}, 80 \% \mathrm{MeOH} / \mathrm{H}_{2} \mathrm{O}$ (fraction G, $178.8 \mathrm{mg}), \mathrm{MeOH}$ and $\mathrm{Me}_{2} \mathrm{CO}$. A portion $(113.1 \mathrm{mg}$ ) of fraction $\mathbf{G}$ was separated on an analytical C18 reversed-phase HPLC column with a solvent gradient of $20 \%$ to $50 \% \mathrm{MeCN}$ in $0.2 \% \mathrm{HCOOH}_{(\mathrm{aq})}$ as the mobile phase at a flow rate of $1 \mathrm{~mL} / \mathrm{min}$ to afford

\footnotetext{
${ }^{*}$ Size-exclusion chromatography was utilised to remove the fatty acid residue.
} 
makaluvamines A (145, $\left.t_{\mathrm{R}} 4.20 \mathrm{~min}, 1.9 \mathrm{mg}\right), \mathrm{K}\left(\mathbf{1 5 7}, t_{\mathrm{R}} 8.80 \mathrm{~min}, 6.4 \mathrm{mg}\right), \mathrm{E}(\mathbf{1 4 9}$, $\left.t_{\mathrm{R}} 14.70 \mathrm{~min}, 4.0 \mathrm{mg}\right)$, and $\mathrm{W}\left(\mathbf{1 8 3}, t_{\mathrm{R}} 20.0 \mathrm{~min}, 6.1 \mathrm{mg}\right)$. Fraction $\mathbf{H}\left(t_{\mathrm{R}} 7.75 \mathrm{~min}\right.$, $6.3 \mathrm{mg}$ ) collected from the HPLC was further purified on an analytical C18 reversedphase HPLC column with a solvent gradient of $15 \%$ to $40 \% \mathrm{MeCN}$ in $0.2 \% \mathrm{HCOOH}_{(\mathrm{aq})}$ as the mobile phase at a flow rate of $1 \mathrm{~mL} / \mathrm{min}$ to afford tsitsikammanine $\mathrm{B}\left(\mathbf{1 8 4}, t_{\mathrm{R}}\right.$ $10.80 \mathrm{~min}, 0.5 \mathrm{mg}$ ). A $10.0 \mathrm{mg}$ subsample of fraction $\mathbf{F}$ was purified on an analytical C18 reversed-phase HPLC column with a solvent gradient of $20 \%$ to $50 \% \mathrm{MeCN}$ in $0.2 \%$ $\mathrm{HCOOH}_{(\mathrm{aq})}$ as the mobile phase at a flow rate of $1 \mathrm{~mL} / \mathrm{min}$ to afford makaluvic acid A $\left(\mathbf{1 6 5}, t_{\mathrm{R}} 18.60 \mathrm{~min}, 0.6 \mathrm{mg}\right)$. A $10.0 \mathrm{mg}$ subsample of fraction $\mathbf{F}$ was fractionated on an analytical C18 reversed-phase HPLC column with a solvent gradient of $20 \%$ to $50 \%$ $\mathrm{MeCN}$ in $0.2 \% \mathrm{HCOOH}_{(\mathrm{aq})}$ as the mobile phase at a flow rate of $1 \mathrm{~mL} / \mathrm{min}$ to afford makaluvamine $\mathrm{C}\left(\mathbf{1 4 7}, t_{\mathrm{R}} 6.30 \mathrm{~min}, 0.7 \mathrm{mg}\right)$.

Damirone B (47). Purple solid; HRESIMS, [M+Na $]^{+}$, observed $\mathrm{m} / \mathrm{z}$ 225.0640, calculated 225.0634 for $\mathrm{C}_{11} \mathrm{H}_{10} \mathrm{~N}_{2} \mathrm{O}_{2} \mathrm{Na}, \Delta=2.66 \mathrm{ppm}$; all NMR data as previously described. 63

Makaluvamine A (145). Green solid; HRESIMS, $[\mathrm{M}+\mathrm{H}]^{+}$, observed $\mathrm{m} / z$ 202.0978, calculated 202.0975 for $\mathrm{C}_{11} \mathrm{H}_{12} \mathrm{~N}_{3} \mathrm{O}, \Delta=1.48$ ppm; all NMR data as previously described. 119

Makaluvamine C (147). Green solid; HRESIMS, $[\mathrm{M}+\mathrm{H}]^{+}$, observed $\mathrm{m} / z$ 202.0975, calculated 202.0975 for $\mathrm{C}_{11} \mathrm{H}_{12} \mathrm{~N}_{3} \mathrm{O}, \Delta=0.00 \mathrm{ppm}$; all NMR data as previously described. 119

Makaluvamine E (149). Green solid; HRESIMS, $[\mathrm{M}+\mathrm{H}]^{+}$, observed $m / z$ 321.1487, calculated 321.1472 for $\mathrm{C}_{19} \mathrm{H}_{19} \mathrm{~N}_{3} \mathrm{O}_{2}, \Delta=4.67 \mathrm{ppm}$; all NMR data as previously described. 119

Makaluvamine F (150). Purple solid; HRESIMS, $[\mathrm{M}+2+\mathrm{H}]^{+}$, observed $m / z$ 418.0057, calculated 418.0043 for $\mathrm{C}_{18} \mathrm{H}_{15}{ }^{81} \mathrm{BrN}_{3} \mathrm{O}_{2} \mathrm{~S}, \Delta=3.35 \mathrm{ppm}$; all NMR data as previously described. 119

Makaluvanone (151). Dark brown solid; HRESIMS, $[\mathrm{M}+\mathrm{H}]^{+}$, observed $m / z$ 280.9918, 
calculated 280.9920 for $\mathrm{C}_{11} \mathrm{H}_{10}{ }^{79} \mathrm{BrN}_{2} \mathrm{O}_{2}, \Delta=-0.71 \mathrm{ppm}$; all NMR data as previously described. 119

Makaluvamine K (157). Green solid; HRESIMS, $[\mathrm{M}+\mathrm{H}]^{+}$, observed $m / z$ 322.1556, calculated 322.1550 for $\mathrm{C}_{19} \mathrm{H}_{20} \mathrm{~N}_{3} \mathrm{O}_{2}, \Delta=1.86 \mathrm{ppm}$; all NMR data as previously described. 115

Makaluvic acid A (165). Brown solid; HRESIMS, $[\mathrm{M}+\mathrm{H}]^{+}$, observed $\mathrm{m} / z$ 195.0765, calculated 195.0764 for $\mathrm{C}_{9} \mathrm{H}_{11} \mathrm{~N}_{2} \mathrm{O}_{3}, \Delta=0.51 \mathrm{ppm}$; all NMR data as previously described. 129

6-Bromodamirone B (182). Dark purple solid; UV (MeOH) $\lambda_{\max } 202 \mathrm{~nm}(\epsilon$ 9316), $212 \mathrm{~nm}\left(\epsilon\right.$ 7822), $251 \mathrm{~nm}\left(\epsilon\right.$ 7139); IR (film) $\nu_{\max }$ 3197, 2953, 2923, 2870, 1713, 1665, $1377 \mathrm{~cm}^{-1}$; NMR data see Table 4.2; HRESIMS, $[\mathrm{M}+\mathrm{H}]^{+}$, observed $\mathrm{m} / \mathrm{z} 280.9918$, calculated 280.9920 for $\mathrm{C}_{11} \mathrm{H}_{10}{ }^{79} \mathrm{BrN}_{2} \mathrm{O}_{2}, \Delta=-0.71 \mathrm{ppm}$.

Makaluvamine W (183). Brown-purple solid; UV (MeOH) $\lambda_{\max } 201 \mathrm{~nm}(\epsilon$ 41961), $219 \mathrm{~nm}\left(\epsilon\right.$ 35287), $285 \mathrm{~nm}$ ( $\epsilon$ 19276); IR (film) $\nu_{\max } 3330,2924,2853,1592,1352$, $1055 \mathrm{~cm}^{-1}$; NMR data see Table 4.4; HRESIMS, $[\mathrm{M}+\mathrm{H}]^{+}$, observed $\mathrm{m} / z$ 214.0977, calculated 214.0975 for $\mathrm{C}_{12} \mathrm{H}_{12} \mathrm{~N}_{3} \mathrm{O}, \Delta=0.93$ ppm.

Tsitsikammanine B (184). Dark red solid; HRESIMS, $[\mathrm{M}+\mathrm{H}]^{+}$, observed $\mathrm{m} / \mathrm{z}$ 318.1237, calculated 318.1237 for $\mathrm{C}_{19} \mathrm{H}_{16} \mathrm{~N}_{3} \mathrm{O}_{2}, \Delta=0.00 \mathrm{ppm}$; all NMR data as previously described. 134

\subsection{Isolation of Compounds from Leucetta sp.}

\subsubsection{Screening}

The sponge Leucetta sp. (PTN3_45H, 825.0 g) was collected using SCUBA from Tu'ungasika, Vava 'u, Tonga in late November 2009. A $50.0 \mathrm{~g}$ frozen sample was extracted twice in $250 \mathrm{~mL}$ MeOH overnight. The filtered extracts were cyclic-loaded onto a $120 \mathrm{~mL}$ 
PSDVB column, pre-equilibrated in $\mathrm{MeOH}$. The loaded column was then washed with $400 \mathrm{~mL}$ of $\mathrm{H}_{2} \mathrm{O}$ and fractionated with $250 \mathrm{~mL}$ portions of (i) $30 \% \mathrm{Me}_{2} \mathrm{CO} / \mathrm{H}_{2} \mathrm{O}$ (fraction A, $51.6 \mathrm{mg}$ ), (ii) $75 \% \mathrm{Me}_{2} \mathrm{CO} / \mathrm{H}_{2} \mathrm{O}$ (fraction $\mathbf{B}, 114.4 \mathrm{mg}$ ) and (iii) $\mathrm{Me}_{2} \mathrm{CO} / \mathrm{H}_{2} \mathrm{O}$ (fraction C, $41.1 \mathrm{mg})$.

A portion (31.9 mg) of fraction $\mathbf{C}$ was loaded onto a $10 \mathrm{~mL}$ PSDVB column and eluted successively with $30 \mathrm{~mL}$ portions of $30 \%, 40 \%, 50 \%, 60 \%, 70 \%$ (fraction D, $6.9 \mathrm{mg}$ ), $80 \% \mathrm{Me}_{2} \mathrm{CO}$ in $\mathrm{H}_{2} \mathrm{O}$, and $\mathrm{Me}_{2} \mathrm{CO}$. Fraction $\mathbf{D}$ was loaded onto a $15 \mathrm{~mL} \mathrm{SiO}{ }_{2}$ column and eluted sequentially with $40 \mathrm{~mL}$ portions of $\mathrm{CH}_{2} \mathrm{Cl}_{2}, 10 \%, 15 \%$ (fraction $\mathbf{E}, 0.4 \mathrm{mg}$ ), $30 \%$ (fraction $\mathbf{F}, 0.5 \mathrm{mg}$ ), $50 \% \mathrm{EtOAc}$ in $\mathrm{CH}_{2} \mathrm{Cl}_{2}$, and EtOAc. Fraction $\mathbf{E}$ was further purified on an analytical C18 reversed-phase HPLC column with 95\% $\mathrm{MeCN}$ in $\mathrm{H}_{2} \mathrm{O}$ as the mobile phase at a flow rate of $1 \mathrm{~mL} / \mathrm{min}$ to afford cyclolinteinone $\left(\mathbf{2 2 4}, t_{\mathrm{R}} 5.00 \mathrm{~min}\right.$, $0.2 \mathrm{mg}$ ). Fraction $\mathbf{F}$ was purified on an analytical C18 reversed-phase HPLC column with $95 \% \mathrm{MeCN}$ in $\mathrm{H}_{2} \mathrm{O}$ as the mobile phase at a flow rate of $1 \mathrm{~mL} / \mathrm{min}$ to afford naamidine $\mathrm{A}$ $\left(\mathbf{2 1 3}, t_{\mathrm{R}} 3.00 \mathrm{~min}, 0.3 \mathrm{mg}\right)$

\subsubsection{Bulk Isolation}

Leucetta sp. (PTN3_45H, $300.0 \mathrm{~g}$ ) collected from an Tu'ungasika, Vava'u, Tonga, was extracted twice with $\mathrm{MeOH}(1.5 \mathrm{~L})$ overnight. The extracts were cyclic-loaded onto a $600 \mathrm{~mL}$ PSDVB column, pre-equilibrated in $\mathrm{MeOH}$. The loaded column was then washed with 2.0 $\mathrm{L}$ of $\mathrm{H}_{2} \mathrm{O}$ and partitioned with $2.0 \mathrm{~L}$ portions of (i) $40 \% \mathrm{Me}_{2} \mathrm{CO} / \mathrm{H}_{2} \mathrm{O}$ (fraction $\mathrm{A}$, $215.0 \mathrm{mg}$ ), (ii) $60 \% \mathrm{Me}_{2} \mathrm{CO} / \mathrm{H}_{2} \mathrm{O}$ (fraction $\mathrm{B}, 236.2 \mathrm{mg}$ ), (iii) $80 \% \mathrm{Me}_{2} \mathrm{CO} / \mathrm{H}_{2} \mathrm{O}$ (fraction C, $277.2 \mathrm{mg}$ ) and (iv) $\mathrm{Me}_{2} \mathrm{CO}$ (fraction D, $296.3 \mathrm{mg}$ ).

Fraction $\mathbf{B}$ was loaded onto a $15 \mathrm{~mL} \mathrm{SiO}_{2}$ column and eluted sequentially with $50 \mathrm{~mL}$ portions of $\mathrm{CH}_{2} \mathrm{Cl}_{2}$ (fraction $\mathbf{E}, 101.6 \mathrm{mg}$ ), 5\%, $15 \%, 20 \%, 30 \%, 50 \%$ EtOAc in $\mathrm{CH}_{2} \mathrm{Cl}_{2}$, and EtOAc. The less polar fraction (fraction E) from the $\mathrm{SiO}_{2}$ column was loaded onto a $15 \mathrm{~mL} \mathrm{SiO}_{2}$ column and eluted successively with $50 \mathrm{~mL}$ portions of $n$-hexane, $\mathrm{CH}_{2} \mathrm{Cl}_{2}$ (fractions $\mathbf{F}, 80.0 \mathrm{mg}$ ), EtOAc, and $\mathrm{MeOH}$. A portion $(6.0 \mathrm{mg}$ ) of fraction $\mathbf{F}$ was fractionated on an analytical C18 reversed-phase HPLC column with 55\% MeCN in $\mathrm{H}_{2} \mathrm{O}$ as the mobile phase at a flow rate of $1 \mathrm{~mL} / \mathrm{min}$ to provide fraction $\mathbf{G}\left(t_{\mathrm{R}} 8.10 \mathrm{~min}\right.$, 
$3.2 \mathrm{mg}$ ). Fraction $\mathbf{G}$ was purified on an analytical $\mathrm{C} 18$ reversed-phase HPLC column with $55 \% \mathrm{MeCN}$ in $\mathrm{H}_{2} \mathrm{O}$ as the mobile phase at a flow rate of $1 \mathrm{~mL} / \mathrm{min}$ yielded naamidine $\mathrm{A}$ $\left(\mathbf{2 1 3}, t_{\mathrm{R}} 3.00 \mathrm{~min}, 0.6 \mathrm{mg}\right)$ and naamidine $\mathrm{K}\left(\mathbf{2 4 3}, t_{\mathrm{R}} 10.00 \mathrm{~min}, 0.9 \mathrm{mg}\right)$.

Fraction $\mathbf{C}$ was loaded onto a $15 \mathrm{~mL} \mathrm{SiO}_{2}$ column and eluted sequentially with $50 \mathrm{~mL}$ portions of $\mathrm{CH}_{2} \mathrm{Cl}_{2}$ (fraction $\mathbf{H}, 16.5 \mathrm{mg}$ ), $2 \%$ (fraction $\mathbf{I}, 22.5 \mathrm{mg}$ ), 3\% (fraction $\mathbf{J}$, $5.8 \mathrm{mg}$ ), 5\%, 7\%, 8\%, 10\%, 12\%, 15\%, 30\% (fraction $\mathbf{K}, 10.2 \mathrm{mg}$ ), 50\% EtOAc in $\mathrm{CH}_{2} \mathrm{Cl}_{2}$, and EtOAc. In all, 105 fractions were collected. The less polar fraction $\mathbf{H}$ was fractionated on an analytical C18 reversed-phase HPLC column with $90 \% \mathrm{MeOH}$ in $\mathrm{H}_{2} \mathrm{O}$ as the mobile phase at a flow rate of $1 \mathrm{~mL} / \mathrm{min}$ to afford 2,4,6-triphenyl-1-hexene $\left(\mathbf{2 4 0}, t_{\mathrm{R}} 17.30 \mathrm{~min}, 2.1 \mathrm{mg}\right)$ and $2 E, 6 Z, 9 Z$-2-methyl-2,6,9-icosatrienal (223, $t_{\mathrm{R}} 43.15 \mathrm{~min}$, $0.3 \mathrm{mg}$ ). Fraction I was purified on an analytical C18 reversed-phase HPLC column with $90 \% \mathrm{MeOH}$ in $\mathrm{H}_{2} \mathrm{O}$ as the mobile phase at a flow rate of $1 \mathrm{~mL} / \mathrm{min}$ to provide fraction $\mathbf{L}$ $\left(t_{\mathrm{R}} 9.10 \mathrm{~min}, 0.3 \mathrm{mg}\right.$ ). Fraction $\mathbf{L}$ was fractionated on an analytical C18 reversed-phase HPLC column with $85 \% \mathrm{MeOH}$ in $\mathrm{H}_{2} \mathrm{O}$ as the mobile phase at a flow rate of $1 \mathrm{~mL} / \mathrm{min}$ yielded oculatolide $\left(\mathbf{2 4 2}, t_{\mathrm{R}} 8.55 \mathrm{~min}, 0.1 \mathrm{mg}\right)$. Fraction $\mathbf{J}$ was separated on an analytical C18 reversed-phase HPLC column with $85 \% \mathrm{MeOH}$ in $\mathrm{H}_{2} \mathrm{O}$ as the mobile phase at a flow rate of $1 \mathrm{~mL} / \mathrm{min}$ to give dytesinin $\mathrm{A}\left(\mathbf{2 4 1}, t_{\mathrm{R}} 15.30 \mathrm{~min}, 1.0 \mathrm{mg}\right)$. Fraction $\mathbf{K}$ was purified on an analytical C18 reversed-phase HPLC column with $90 \% \mathrm{MeOH}$ in $\mathrm{H}_{2} \mathrm{O}$ as the mobile phase at a flow rate of $1 \mathrm{~mL} / \mathrm{min}$ to provide glycerol ethers $\mathrm{A}\left(\mathbf{2 4 4}, t_{\mathrm{R}} 25.00 \mathrm{~min}, 2.0 \mathrm{mg}\right)$, B (245, $\left.t_{\mathrm{R}} 33.17 \mathrm{~min}, 0.3 \mathrm{mg}\right)$ and C (246, $\left.t_{\mathrm{R}} 44.85 \mathrm{~min}, 0.4 \mathrm{mg}\right)$.

Fraction $\mathbf{D}$ was loaded onto a $15 \mathrm{~mL} \mathrm{SiO}_{2}$ column and eluted sequentially with $50 \mathrm{~mL}$ portions of $\mathrm{CH}_{2} \mathrm{Cl}_{2}, 1 \%, 2 \%, 3 \%, 5 \%, 7 \%, 8 \%, 10 \%, 12 \%, 15 \%, 20 \%, 30 \%, 40 \%, 50 \%$ EtOAc in $\mathrm{CH}_{2} \mathrm{Cl}_{2}$, and EtOAc. In all, 96 fractions were collected. The $1 \%$ to $3 \% \mathrm{CH}_{2} \mathrm{Cl}_{2}$ in EtOAc fractions were combined to give fraction $\mathbf{M}(72.3 \mathrm{mg})$, while the $7 \%$ to $15 \%$ $\mathrm{CH}_{2} \mathrm{Cl}_{2}$ in EtOAc fractions provided fraction $\mathbf{N}(43.9 \mathrm{mg})$. Fraction $\mathbf{M}$ was loaded onto a $15 \mathrm{~mL} \mathrm{SiO}{ }_{2}$ column and eluted sequentially with $50 \mathrm{~mL}$ portions of $\mathrm{CH}_{2} \mathrm{Cl}_{2}, 1 \%, 2 \%$, $3 \%$ (fraction $\mathbf{O}, 10.0 \mathrm{mg}$ ), 4\%, 5\%, 10\% EtOAc in $\mathrm{CH}_{2} \mathrm{Cl}_{2}$, and EtOAc. Fraction $\mathbf{O}$ was fractionated on an analytical C18 reversed-phase HPLC column with $100 \% \mathrm{MeOH}$ as the mobile phase at a flow rate of $1 \mathrm{~mL} / \mathrm{min}$ to afford glycerol lipids A $\left(\mathbf{2 3 8}, t_{\mathrm{R}} 8.24 \mathrm{~min}\right.$, $5.1 \mathrm{mg})$ and $\mathrm{B}\left(\mathbf{2 3 9}, t_{\mathrm{R}} 9.58 \mathrm{~min}, 0.2 \mathrm{mg}\right)$. Fraction $\mathbf{N}$ was subjected to a semi-preparative 
C18 reversed-phase HPLC column using $100 \% \mathrm{MeOH}$ as the mobile phase at a flow rate of $4 \mathrm{~mL} / \mathrm{min}$ to give fraction $\mathbf{P}\left(t_{\mathrm{R}} 10.12 \mathrm{~min}, 0.8 \mathrm{mg}\right)$, fraction $\mathbf{Q}\left(t_{\mathrm{R}} 11.24 \mathrm{~min}, 2.1 \mathrm{mg}\right)$, fraction $\mathbf{R}\left(t_{\mathrm{R}} 12.40 \mathrm{~min}, 1.4 \mathrm{mg}\right)$, fraction $\mathbf{S}\left(t_{\mathrm{R}} 13.65 \mathrm{~min}, 8.0 \mathrm{mg}\right)$, fraction $\mathbf{T}\left(t_{\mathrm{R}}\right.$ $14.20 \mathrm{~min}, 9.9 \mathrm{mg}$ ), fraction $\mathbf{U}\left(t_{\mathrm{R}} 16.08 \mathrm{~min}, 3.9 \mathrm{mg}\right), 5 \alpha, 8 \alpha$-epidioxy-24-ethylcholesta6,22-dien-3 $\beta$-ol $\left(\mathbf{2 3 6}, t_{\mathrm{R}} 17.34 \mathrm{~min}, 3.7 \mathrm{mg}\right)$ and $5 \alpha, 8 \alpha$-epidioxy-24-ethylcholesta-6-en$3 \beta$-ol $\left(\mathbf{2 3 4}, t_{\mathrm{R}} 19.50 \mathrm{~min}, 1.5 \mathrm{mg}\right)$.

Fraction $\mathbf{P}$ was purified on an analytical C18 reversed-phase HPLC column with $90 \%$ $\mathrm{MeOH}$ in $\mathrm{H}_{2} \mathrm{O}$ as the mobile phase at a flow rate of $1 \mathrm{~mL} / \mathrm{min}$ to afford $5 \alpha, 8 \alpha$ epidioxycholesta-6,9(11),22-trien-3 $\beta$-ol $\left(\mathbf{2 2 7}, t_{\mathrm{R}} 8.24 \mathrm{~min}, 17.00 \mathrm{mg}\right)$. Fraction $\mathbf{Q}$ was purified on an analytical C18 reversed-phase HPLC column with $85 \% \mathrm{MeOH}$ in $\mathrm{H}_{2} \mathrm{O}$ as the mobile phase at a flow rate of $1 \mathrm{~mL} / \mathrm{min}$ to yield $5 \alpha, 8 \alpha$-epidioxy-24norcholesta-6,22-dien-3 $\beta$-ol (228, $\left.t_{\mathrm{R}} 31.14 \mathrm{~min}, 0.5 \mathrm{mg}\right)$, additional $227\left(t_{\mathrm{R}} 33.25 \mathrm{~min}\right.$, $0.7 \mathrm{mg}$ ), $5 \alpha, 8 \alpha$-epidioxy-cholesta-6,22,24(28)-trien-3 $\beta$-ol (231, $\left.t_{\mathrm{R}} 36.60 \mathrm{~min}, 0.4 \mathrm{mg}\right)$ and 5 $\alpha, 8 \alpha$-epidioxy-24-methylcholesta-6,9(11),24(28)-trien-3 $\beta$-ol (232, $t_{\mathrm{R}} 38.79$ min, $0.3 \mathrm{mg}$ ). Fraction $\mathbf{R}$ was separated on an analytical C18 reversed-phase HPLC column with $90 \% \mathrm{MeOH}$ in $\mathrm{H}_{2} \mathrm{O}$ as the mobile phase at a flow rate of $1 \mathrm{~mL} / \mathrm{min}$ to give $5 \alpha, 8 \alpha$-epidioxy-24-methylcholesta-6,9(11),22-trien-3 $\beta$-ol (233, $\left.t_{\mathrm{R}} 20.32 \mathrm{~min}, 1.1 \mathrm{mg}\right)$. Fraction $\mathbf{S}$ was purified on an analytical C18 reversed-phase HPLC column with $85 \%$ $\mathrm{MeOH}$ in $\mathrm{H}_{2} \mathrm{O}$ as the mobile phase at a flow rate of $1 \mathrm{~mL} / \mathrm{min}$ to yield $5 \alpha, 8 \alpha$ epidioxy-24-cholesta-6,22-dien-3 $\beta$-ol (226, $\left.t_{\mathrm{R}} 21.75 \mathrm{~min}, 3.8 \mathrm{mg}\right)$ and $5 \alpha, 8 \alpha$-epidioxy24-methylcholesta-6,24(28)-dien-3 $\beta$-ol (229, $\left.t_{\mathrm{R}} 24.54 \mathrm{~min}, 0.5 \mathrm{mg}\right)$. Fraction $\mathbf{T}$ was fractionated on an analytical C18 reversed-phase HPLC column with 90\% $\mathrm{MeOH}$ in $\mathrm{H}_{2} \mathrm{O}$ as the mobile phase at a flow rate of $1 \mathrm{~mL} / \mathrm{min}$ to provide additional $229\left(t_{\mathrm{R}} 22.60\right.$ $\min , 0.3 \mathrm{mg})$ and $5 \alpha, 8 \alpha$-epidioxy-24-methylcholesta-6,22-dien-3 $\beta$-ol (230, $t_{\mathrm{R}} 26.20 \mathrm{~min}$, $5.7 \mathrm{mg}$ ). Fraction $\mathbf{U}$ was purified on an analytical C18 reversed-phase HPLC column with $90 \% \mathrm{MeOH}$ in $\mathrm{H}_{2} \mathrm{O}$ as the mobile phase at a flow rate of $1 \mathrm{~mL} / \mathrm{min}$ to yield $5 \alpha, 8 \alpha$-epidioxy-24-hydroperoxycholesta-6,28(29)-dien-3 $\beta$-ol (237, $\left.t_{\mathrm{R}} 7.00 \mathrm{~min}, 0.7 \mathrm{mg}\right)$, $5 \alpha, 8 \alpha$-epidioxycholesta-6-en-3 $\beta$-ol $\left(\mathbf{2 2 5}, t_{\mathrm{R}} 24.90 \mathrm{~min}, 0.4 \mathrm{mg}\right)$ and $5 \alpha, 8 \alpha$-epidioxy-24ethylcholesta-6,24(28)-dien-3 $\beta$-ol (235, $\left.t_{\mathrm{R}} 27.85 \mathrm{~min}, 0.3 \mathrm{mg}\right)$.

Naamidine A (213). Yellow solid; HRESIMS, $[\mathrm{M}+\mathrm{Na}]^{+}$, observed $\mathrm{m} / \mathrm{z} 456.1644$, 
calculated 456.1642 for $\mathrm{C}_{23} \mathrm{H}_{23} \mathrm{~N}_{5} \mathrm{O}_{4} \mathrm{Na}, \Delta=0.44 \mathrm{ppm}$; all $\mathrm{NMR}$ data as previously described. 189

2E,6Z,9Z-2-Methyl-2,6,9-icosatrienal (223). Colourless oil; HRESIMS, $\left[\mathrm{M}+\mathrm{Na}-\mathrm{H}_{2} \mathrm{O}\right]^{+}$, observed $m / z$ 309.2563, calculated 309.2553 for $\mathrm{C}_{21} \mathrm{H}_{34} \mathrm{Na}, \Delta=3.23 \mathrm{ppm}$; all NMR data as previously described. 208

Cyclolinteinone (224). Yellow solid; HRESIMS, $[\mathrm{M}+\mathrm{Na}]^{+}$, observed $m / z$ 407.2570, calculated 407.2557 for $\mathrm{C}_{25} \mathrm{H}_{36} \mathrm{O}_{3} \mathrm{Na}, \Delta=3.19 \mathrm{ppm}$; all NMR data as previously described. 209

$\mathbf{5} \alpha, \mathbf{8} \alpha$-Epidioxycholesta-6-en-3 $\beta$-ol (225). White solid; HRESIMS, $[\mathrm{M}+\mathrm{Na}]^{+}$, observed $m / z$ 439.3184, calculated 439.3183 for $\mathrm{C}_{27} \mathrm{H}_{44} \mathrm{O}_{3} \mathrm{Na}, \Delta=0.23 \mathrm{ppm}$; all NMR data as previously described. $210 \mid 262$

5 $\alpha, 8 \alpha$-Epidioxy-24-cholesta-6,22-dien-3 $\beta$-ol (226). White solid; HRESIMS, $[\mathrm{M}+\mathrm{H}]^{+}$, observed $m / z, 415.3209$, calculated 415.3207 for $\mathrm{C}_{27} \mathrm{H}_{43} \mathrm{O}_{3}, \Delta=0.48 \mathrm{ppm}$; all NMR data as previously described. 210

5 $\alpha, 8 \alpha$-Epidioxycholesta-6,9(11),22-trien-3 $\beta$-ol (227). White solid; HRESIMS, [M + Na $]^{+}$, observed $m / z$ 435.2856, calculated 435.2870 for $\mathrm{C}_{27} \mathrm{H}_{40} \mathrm{O}_{3} \mathrm{Na}, \Delta=-3.22 \mathrm{ppm}$; all NMR data as previously described. 210

5 $\alpha, 8 \alpha$-Epidioxy-24-norcholesta-6,22-dien-3 $\beta$-ol (228). White solid; HRESIMS, $[\mathrm{M}+\mathrm{Na}]^{+}$, observed $m / z$ 423.2869, calculated 423.2870 for $\mathrm{C}_{26} \mathrm{H}_{40} \mathrm{O}_{3} \mathrm{Na}, \Delta=-0.24 \mathrm{ppm}$; all NMR data as previously described. $210[262$

5 $\alpha, 8 \alpha$-Epidioxy-24-methylcholesta-6,24(28)-dien-3 $\beta$-ol (229). White solid; HRESIMS, $[\mathrm{M}+\mathrm{H}]^{+}$, observed $m / z$ 429.3362, calculated 429.3363 for $\mathrm{C}_{28} \mathrm{H}_{45} \mathrm{O}_{3}, \Delta=-0.23 \mathrm{ppm}$; all NMR data as previously described. 210

5 $\alpha, \mathbf{8} \alpha$-Epidioxy-24-methylcholesta-6,22-dien-3 $\beta$-ol (230). White solid; HRESIMS, $[\mathrm{M}+\mathrm{H}]^{+}$, observed $\mathrm{m} / \mathrm{z}$ 429.3362, calculated 429.3363 for $\mathrm{C}_{28} \mathrm{H}_{45} \mathrm{O}_{3}, \Delta=-0.23$ ppm; all NMR data as previously described. 210 
$\mathbf{5} \alpha, \mathbf{8} \alpha$-Epidioxy-cholesta-6,22,24(28)-trien-3 $\beta$-ol (231). White solid; HRESIMS, $[\mathrm{M}+\mathrm{Na}]^{+}$, observed $m / z$ 449.3023, calculated 449.3026 for $\mathrm{C}_{28} \mathrm{H}_{42} \mathrm{O}_{3} \mathrm{Na}, \Delta=-0.67 \mathrm{ppm}$; all NMR data as previously described. $\stackrel{263}{2}$

5 $\alpha, 8 \alpha$-Epidioxy-24-methylcholesta-6,9(11),24(28)-trien-3 $\beta$-ol (232). White solid; HRESIMS, $[\mathrm{M}+\mathrm{Na}]^{+}$, observed $m / z$ 449.3023, calculated 449.3026 for $\mathrm{C}_{28} \mathrm{H}_{42} \mathrm{O}_{3} \mathrm{Na}, \Delta=-0.67 \mathrm{ppm}$; all NMR data as previously described. 210

5 $\alpha, 8 \alpha$-Epidioxy-24-methylcholesta-6,9(11),22-trien-3 $\beta$-ol (233). White solid; HRESIMS, $[\mathrm{M}+\mathrm{Na}]^{+}$, observed $m / z 449.3018$, calculated 449.3026 for $\mathrm{C}_{28} \mathrm{H}_{42} \mathrm{O}_{3} \mathrm{Na}, \Delta=-1.78 \mathrm{ppm}$; all NMR data as previously described. $\stackrel{210[262}{2}$

5 $\alpha, 8 \alpha$-Epidioxy-24-ethylcholesta-6-en-3 $\beta$-ol (234). White solid; HRESIMS, $[\mathrm{M}+\mathrm{Na}]^{+}$, observed $m / z$ 467.3497, calculated 467.3496 for $\mathrm{C}_{29} \mathrm{H}_{48} \mathrm{O}_{3} \mathrm{Na}, \Delta=0.21 \mathrm{ppm}$; all NMR data as previously described. 210

5 $\alpha, 8 \alpha$-Epidioxy-24-ethylcholesta-6,24(28)-dien-3 $\beta$-ol (235). White solid; HRESIMS, $[\mathrm{M}+\mathrm{H}]^{+}$, observed $\mathrm{m} / \mathrm{z} 442.3524$, calculated 442.3520 for $\mathrm{C}_{29} \mathrm{H}_{47} \mathrm{O}_{3}, \Delta=0.90$ ppm; all NMR data as previously described. 210

5 $\alpha, 8 \alpha$-Epidioxy-24-ethylcholesta-6,22-dien-3 $\beta$-ol (236). White solid; HRESIMS, $[\mathrm{M}+\mathrm{H}]^{+}$, observed $m / z$ 443.3521, calculated 443.3520 for $\mathrm{C}_{29} \mathrm{H}_{47} \mathrm{O}_{3}, \Delta=0.22 \mathrm{ppm}$; all NMR data as previously described. $210|262| 263$

5 $\alpha, 8 \alpha$-Epidioxy-24-hydroperoxycholesta-6,28(29)-dien-3 $\beta$-ol (237). White solid; HRESIMS, $[\mathrm{M}+\mathrm{Na}]^{+}$, observed $m / z$ 497.3235, calculated 497.3237 for $\mathrm{C}_{29} \mathrm{H}_{46} \mathrm{O}_{5} \mathrm{Na}, \Delta=-0.40 \mathrm{ppm}$; all NMR data as previously described. 264

Glycerol Lipid A (238). Colourless oil; NMR data see Table 5.5; HRESIMS, [M+ Na $]^{+}$, observed $m / z$ 403.3183, calculated 403.3183 for $\mathrm{C}_{24} \mathrm{H}_{44} \mathrm{O}_{3} \mathrm{Na}, \Delta=0.00 \mathrm{ppm}$.

Glycerol Lipid B (239). Colourless oil; NMR data see Table 5.6, HRESIMS, [M - $\left.\mathrm{H}_{2} \mathrm{O}\right]^{+}$, observed $m / z$ 364.3337, calculated 364.3336 for $\mathrm{C}_{24} \mathrm{H}_{44} \mathrm{O}_{2}, \Delta=0.27 \mathrm{ppm}$.

2,4,6-Triphenyl-1-hexene (240). Colourless oil; HRESIMS, $[\mathrm{M}+\mathrm{K}]^{+}$, observed $\mathrm{m} / \mathrm{z}$ 
351.1522, calculated 351.1510 for $\mathrm{C}_{24} \mathrm{H}_{24} \mathrm{~K}, \Delta=3.41$ ppm; all NMR data as previously described. 211212

Dytesinin A (241). Colourless oil; HRESIMS, [M - H $]^{-}$, observed $\mathrm{m} / \mathrm{z}$ 317.2131, calculated 317.2122 for $\mathrm{C}_{20} \mathrm{H}_{29} \mathrm{O}_{3}, \Delta=-2.84 \mathrm{ppm}$; all NMR data as previously described. 214

Oculatolide (242). Yellow oil; HRESIMS, $[\mathrm{M}+\mathrm{H}]^{+}$, observed $m / z$ 319.2189, calculated 319.2185 for $\mathrm{C}_{20} \mathrm{H}_{31} \mathrm{O}_{3}, \Delta=1.25 \mathrm{ppm}$; all NMR data as previously described. ${ }^{214}$

Naamidine K (243). Yellow amorphous solid; UV (MeOH) $\lambda_{\max } 208 \mathrm{~nm}$ ( $\epsilon$ 31032), $226 \mathrm{~nm}$ ( $\epsilon$ 24960), $384 \mathrm{~nm}$ ( $\epsilon$ 12829); IR (film) $\nu_{\max }$ 3348, 2927, 2854, 1790, 1733, 1611, 1510, 1446, $1247 \mathrm{~cm}^{-1}$; NMR data see Table 5.7; HRESIMS, $[\mathrm{M}+\mathrm{H}]^{+}$, observed $\mathrm{m} / \mathrm{z}$ 450.1777, calculated 450.1772 for $\mathrm{C}_{23} \mathrm{H}_{24} \mathrm{~N}_{5} \mathrm{O}_{5}, \Delta=1.11 \mathrm{ppm}$.

Glycerol Ether A (244). Colourless oil; NMR data see Table 5.2; HRESIMS, [M+ H] ${ }^{+}$, observed $m / z$ 343.3210, calculated 343.3207 for $\mathrm{C}_{21} \mathrm{H}_{43} \mathrm{O}_{3}, \Delta=-0.87 \mathrm{ppm}$.

Glycerol Ether B (245). Colourless oil; NMR data see Table 5.3, HRESIMS, $[\mathrm{M}+\mathrm{H}]^{+}$, observed $m / z$ 357.3361, calculated 357.3363 for $\mathrm{C}_{22} \mathrm{H}_{45} \mathrm{O}_{3}, \Delta=0.56 \mathrm{ppm}$.

Glycerol Ether C (246). Colourless oil; NMR data see Table 5.3; HRESIMS, [M+ H] $]^{+}$, observed $m / z$ 371.3523, calculated 371.3520 for $\mathrm{C}_{23} \mathrm{H}_{47} \mathrm{O}_{3}, \Delta=-0.81 \mathrm{ppm}$.

\subsubsection{Oxidation of the Glycerol Ethers}

A $100 \mu \mathrm{g}$ subsample each of $\mathbf{2 4 4 - 2 4 6}$ was dissolved in a biphasic solution of $\mathrm{CHCl}_{3}$ $(2 \mathrm{~mL}), \mathrm{MeCN}(2 \mathrm{~mL})$ and $\mathrm{H}_{2} \mathrm{O}(3 \mathrm{~mL})$. To this, $1 \mathrm{mg}$ of $\mathrm{RuCl}_{3}$ and $5 \mathrm{mg}$ of $\mathrm{NaIO}_{4}$ was added. After the solution was stirred for 2 hours at room temperature, the solution was filtered and washed with $\mathrm{CHCl}_{3}$ and $\mathrm{MeCN}$. The $\mathrm{CHCl}_{3}$ and $\mathrm{MeCN} / \mathrm{H}_{2} \mathrm{O}$ layers were separated and the solvent removed in vacuo. The samples were analysed by MS.

Glycerol Ether A Oxidation Product. Colourless oil; HRESIMS, [M+ Na $]^{+}$, observed $m / z$ 195.1349, calculated 195.1356 for $\mathrm{C}_{10} \mathrm{H}_{20} \mathrm{O}_{2} \mathrm{Na}, \Delta=-3.59 \mathrm{ppm}$. 
Glycerol Ether B Oxidation Product. Colourless oil; HRESIMS, $\left[\mathrm{M}+\mathrm{NH}_{4}-\mathrm{H}_{2} \mathrm{O}\right]^{+}$, observed $m / z$ 158.1538, calculated 158.1539 for $\mathrm{C}_{9} \mathrm{H}_{20} \mathrm{NO}, \Delta=-0.63 \mathrm{ppm}$.

Glycerol Ether C Oxidation Product. Colourless oil; HRESIMS, $[\mathrm{M}+\mathrm{Na}]^{+}$, observed $m / z$ 181.1200, calculated 181.1199 for $\mathrm{C}_{9} \mathrm{H}_{18} \mathrm{O}_{2} \mathrm{Na}, \Delta=0.55 \mathrm{ppm}$.

\subsection{Isolation of Compounds from Cacospongia mycofi- jiensis}

\subsubsection{Screening}

The sponge identified as Cacospongia mycofijiensis (PTN4_26A, 2760.0 g) was collected from an underwater cave, 'Eua, Tonga, June 2016. A $105 \mathrm{~g}$ sample of the sponge was cut into small pieces and extracted twice with $\mathrm{MeOH}(400 \mathrm{~mL})$ overnight. The second and first extracts were cyclic loaded onto a column packed with $80 \mathrm{~mL}$ PSDVB, pre-equilibrated in $\mathrm{MeOH}$. The loaded column was washed with $250 \mathrm{~mL}$ of $\mathrm{H}_{2} \mathrm{O}$ and partitioned with $250 \mathrm{~mL}$ portions of (i) $40 \% \mathrm{Me}_{2} \mathrm{CO} / \mathrm{H}_{2} \mathrm{O}$ (fraction $\mathbf{A}, 17.5 \mathrm{mg}$ ), (ii) $60 \%$ $\mathrm{Me}_{2} \mathrm{CO} / \mathrm{H}_{2} \mathrm{O}$ (fraction $\mathbf{B}, 69.7 \mathrm{mg}$ ), (iii) $80 \% \mathrm{Me}_{2} \mathrm{CO} / \mathrm{H}_{2} \mathrm{O}$ (fraction $\mathbf{C}, 619.9 \mathrm{mg}$ ) and (iv) $\mathrm{Me}_{2} \mathrm{CO}$ (fraction $\mathbf{D}, 278.9 \mathrm{mg}$ ).

Fraction $\mathbf{C}$ was loaded onto a $50 \mathrm{~mL} \mathrm{SiO}_{2}$ column and eluted successively with $150 \mathrm{~mL}$ portions of $\mathrm{CH}_{2} \mathrm{Cl}_{2}$ [fractions $\mathbf{E}(14.6 \mathrm{mg}$ ) and $\mathbf{F}(10.9 \mathrm{mg})$ ], 5\%, 10\% (fraction $\mathbf{G}$, $155.4 \mathrm{mg}$ ), $20 \%$ (fraction $\mathbf{H}, 216.7 \mathrm{mg}$ ), 30\% (fraction $\mathbf{I}, 16.3 \mathrm{mg}$ ), 50\% EtOAc in $\mathrm{CH}_{2} \mathrm{Cl}_{2}$ (fraction $\mathbf{J}, 34.6 \mathrm{mg}$ ) and EtOAc [fractions $\mathbf{K}(4.6 \mathrm{mg}$ ) and $\mathbf{L}(14.0 \mathrm{mg})$ ]. A total of 160 fractions were collected. Fraction E contained dendrolasin (249), while fraction $\mathbf{G}$ contained mycothiazole (256). Fraction $\mathbf{H}$ was predominately latrunculin A (248), while laulimalide (259) was a major component of fraction J. Fraction K contained neolaulimalide (277), while isolaulimalide (258) was present in fraction $\mathbf{L}$.

Fraction $\mathbf{F}$ was loaded onto a $15 \mathrm{~mL} \mathrm{SiO}_{2}$ column and eluted successively with $50 \mathrm{~mL}$ portions of $n$-hexane, $1 \%, 3 \%, 5 \%, 7 \%, 10 \%, 15 \%, 30 \%, 50 \%$ EtOAc in $n$-hexane and 
EtOAc. A total of 76 fractions were collected. Fractions 25-28 (5\% n-hexane in EtOAc) were combined to afford isodictyodendrillin A (280, $1.0 \mathrm{mg})$, while fractions 29-32 (5\% to $7 \% n$-hexane in EtOAc) provided dictyodendrillin A $(\mathbf{2 7 9}, 2.0 \mathrm{mg})$. Fraction I was separated on an analytical C18 reversed-phase HPLC column with 70\% $\mathrm{MeOH}$ in $\mathrm{H}_{2} \mathrm{O}$ as the mobile phase at a flow rate of $1 \mathrm{~mL} / \mathrm{min}$ to yield 6,7-epoxylatrunculin $\mathrm{A}$ $\left(\mathbf{2 7 6}, t_{\mathrm{R}} 10.9 \mathrm{~min}, 5.5 \mathrm{mg}\right)$, dactylolide $\left(\mathbf{2 8 1}, t_{\mathrm{R}} 14.7 \mathrm{~min}, 0.2 \mathrm{mg}\right)$ and zampanolide A $\left(\mathbf{2 7 8}, t_{\mathrm{R}} 21.5 \mathrm{~min}, 2.0 \mathrm{mg}\right.$ ). In addition, two zampanolide-like compounds (fraction $\mathbf{M}$, $t_{\mathrm{R}} 20.4 \mathrm{~min}, 0.7 \mathrm{mg}$ and fraction $\mathbf{N}, t_{\mathrm{R}} 0.9 \mathrm{~min}, 0.9 \mathrm{mg}$ ) were isolated, which will be discussed in the bulk extraction section.

\title{
8.7.2 First Bulk Isolation
}

\author{
Performed by C. R. Harland
}

Cacospongia mycofijiensis (PTN4_26A, 527.0 g) collected from an underwater cave, 'Eua, Tonga, was cut into small pieces and extracted twice with $\mathrm{MeOH}$ (2.0 L) overnight. The second then first extracts were cyclic-loaded onto a $400 \mathrm{~mL}$ PSDVB column, preequilibrated in $\mathrm{MeOH}$. The loaded column was then washed with $1.2 \mathrm{~L}$ of $\mathrm{H}_{2} \mathrm{O}$ and fractionated with 1.2 L portions of (i) $40 \% \mathrm{Me}_{2} \mathrm{CO} / \mathrm{H}_{2} \mathrm{O}$ (fraction $\mathrm{A}, 795.0 \mathrm{mg}$ ), (ii) $60 \%$ $\mathrm{Me}_{2} \mathrm{CO} / \mathrm{H}_{2} \mathrm{O}$ (fraction $\mathbf{B}, 1202.2 \mathrm{mg}$ ), (iii) $80 \% \mathrm{Me}_{2} \mathrm{CO} / \mathrm{H}_{2} \mathrm{O}$ (fraction $\mathbf{C}, 2871.3 \mathrm{mg}$ ), and (iv) $\mathrm{Me}_{2} \mathrm{CO}$ (fraction $\mathbf{D}, 725.4 \mathrm{mg}$ ).

A portion (1000.0 mg) of fraction $\mathbf{B}$ was loaded onto a $175 \mathrm{~mL} \mathrm{SiO}{ }_{2}$ column and eluted sequentially with $525 \mathrm{~mL}$ portions of $\mathrm{CH}_{2} \mathrm{Cl}_{2}, 5 \%, 10 \%$ (fraction $\mathbf{E}, 110.0 \mathrm{mg}$ ), $20 \%$ (fraction $\mathbf{F}, 324.5 \mathrm{mg}$ ), 30\%, 50\% EtOAc in $\mathrm{CH}_{2} \mathrm{Cl}_{2}$ (fraction $\mathbf{G}, 76.8 \mathrm{mg}$ ), and EtOAc (fraction $\mathbf{H}, 46.4 \mathrm{mg}$ ). Fraction $\mathbf{E}$ contained mycothiazole (256), while fraction $\mathbf{F}$ was predominately latrunculin A (248). Fraction $\mathbf{G}$ was loaded onto a $20 \mathrm{~mL} \mathrm{SiO}_{2}$ column and eluted successively with $60 \mathrm{~mL}$ portions of $\mathrm{CH}_{2} \mathrm{Cl}_{2}, 5 \%, 10 \%$ (fraction I, $3.2 \mathrm{mg}$ ), $20 \%$ (fraction $\mathbf{J}, 24.5 \mathrm{mg}$ ), 30\% (fraction $\mathbf{K}, 8.5 \mathrm{mg}$ ), 40\% (fraction $\mathbf{L}, 6.0 \mathrm{mg}$ ), 50\% EtOAc in $\mathrm{CH}_{2} \mathrm{Cl}_{2}$ (fraction $\mathbf{M}, 6.5 \mathrm{mg}$ ), and EtOAc. Fractions $\mathbf{J}$ and $\mathbf{K}$ contained latrunculin A (248), while the fractions $\mathbf{L}$ and $\mathbf{M}$ contained impure zampanolide and a zampanolidelike compound, respectively. Fraction $\mathbf{H}$ was loaded onto a $15 \mathrm{~mL} \mathrm{SiO}_{2}$ column and 
eluted successively with $45 \mathrm{~mL}$ portions of $\mathrm{CH}_{2} \mathrm{Cl}_{2}, 5 \%, 10 \%$ (fraction $\mathbf{N}, 0.3 \mathrm{mg}$ ), $20 \%$ (fraction $\mathbf{O}, 1.1 \mathrm{mg}$ ), 30\% (fraction $\mathbf{P}, 5.8 \mathrm{mg}$ ), 40\%, 50\% EtOAc in $\mathrm{CH}_{2} \mathrm{Cl}_{2}$, and EtOAc. Fractions $\mathbf{N}$ and $\mathbf{O}$ contained latrunculin A (248), while fraction $\mathbf{P}$ was predominately zampanolide.

The remainder $\left(200.0 \mathrm{mg}\right.$ ) of fraction $\mathbf{B}$ was loaded onto a $30 \mathrm{~mL} \mathrm{SiO}{ }_{2}$ column and eluted sequentially with $90 \mathrm{~mL}$ portions of $\mathrm{CH}_{2} \mathrm{Cl}_{2}$ (fraction $\mathbf{Q}, 3.5 \mathrm{mg}$ ), $5 \%$ (fraction $\mathbf{R}, 19.9 \mathrm{mg}$ ), $10 \%$ (fraction $\mathbf{S}, 22.8 \mathrm{mg}$ ), $20 \%$ (fraction $\mathbf{T}, 19.1 \mathrm{mg}$ ), 30\% (fraction $\mathbf{U}$, $15.8 \mathrm{mg}$ ), 50\% EtOAc in $\mathrm{CH}_{2} \mathrm{Cl}_{2}$ (fraction $\mathbf{V}, 4.2 \mathrm{mg}$ ) and EtOAc (fraction $\mathbf{W}, 14.1 \mathrm{mg}$ ). Fraction $\mathbf{Q}$ contained dendrolasin (249), while fraction $\mathbf{R}$ contained mycothiazole (256). Fractions $\mathbf{S}, \mathbf{T}$ and $\mathbf{U}$ contained latrunculin A (248). Zampanolide A (278) was the major component of fraction $\mathbf{V}$, while fraction $\mathbf{W}$ contained laulimalide (259).

Fraction D (2871.3 mg) was loaded onto a $200 \mathrm{~mL} \mathrm{SiO}{ }_{2}$ column and eluted successively with $600 \mathrm{~mL}$ portions of $n$-hexane (fraction $\mathbf{X}, 248.6 \mathrm{mg}$ ), 10\% (fraction $\mathbf{Y}, 573.7 \mathrm{mg}$ ), $25 \%$ (fraction $\mathbf{Z}, 417.0 \mathrm{mg}$ ), $50 \% \mathrm{CH}_{2} \mathrm{Cl}_{2}$ in $n$-hexane (fraction $\mathbf{A A}, 700.0 \mathrm{mg}$ ), $\mathrm{CH}_{2} \mathrm{Cl}_{2}$ (fraction AB, $58.8 \mathrm{mg}$ ), 25\% (fraction AC, $122.4 \mathrm{mg}$ ), 25\% (fraction AD, $61.4 \mathrm{mg}$ ) and EtOAc (fraction AE, $111.6 \mathrm{mg}$ ). Fraction $\mathbf{X}$ contained dendrolasin (249), while mycothiazole (256) was the major component in fractions $\mathbf{Y}$ and $\mathbf{Z}$. Fraction $\mathbf{A A}$ was predominately latrunculin A (248), while laulimalide (259) was present in fraction AC. Fraction AD contained neolaulimalide (277), while isolaulimalide (258) was present in fraction AE. Fraction AB was separated on a semi-preparative C18 reversed-phase HPLC column with $70 \% \mathrm{MeCN}$ in $\mathrm{H}_{2} \mathrm{O}$ as the mobile phase at a flow rate of $4 \mathrm{~mL} / \mathrm{min}$ to yield 6,7-epoxylatrunculin A $\left(\mathbf{2 7 6}, t_{\mathrm{R}} 5.7 \mathrm{~min}, 5.4 \mathrm{mg}\right)$ and latrunculin A $\left(\mathbf{2 4 8}, t_{\mathrm{R}} 10.60 \mathrm{~min}\right.$, $6.6 \mathrm{mg}$ ). In addition, impure dactylolide (fraction $\mathbf{A F}, t_{\mathrm{R}} 7.18 \mathrm{~min}, 0.2 \mathrm{mg}$ ), impure zampanolide A (fraction AG, $t_{\mathrm{R}} 8.40 \mathrm{~min}, 9.4 \mathrm{mg}$ ), and zampanolide-like compound (fraction $\mathbf{A H}, t_{\mathrm{R}} 11.80 \mathrm{~min}, 0.9 \mathrm{mg}$ ) were also collected.

\section{Performed by T. Taufa}

Fraction I was purified on an analytical C18 reversed-phase HPLC column with 50\% $\mathrm{MeCN}$ in $\mathrm{H}_{2} \mathrm{O}$ as the mobile phase at a flow rate of $1 \mathrm{~mL} / \mathrm{min}$ to yield two samples of dactylolide (281) ( $t_{\mathrm{R}} 42.0 \mathrm{~min}, 0.4 \mathrm{mg} ; t_{\mathrm{R}} 52.0 \mathrm{~min}, 0.4 \mathrm{mg}$ ). 
Samples that contained impure dactylolide, impure zampanolide A and zampanolide-like compounds from fraction $\mathbf{B}$ (fractions $\mathbf{L}, \mathbf{M}, \mathbf{P}$ and $\mathbf{V}$ ) of the bulk extraction were combined for a final purification. The combined sample $(16.4 \mathrm{mg})$ was purified on an analytical C18 reversed-phase HPLC column with a solvent gradient of $50 \%$ to $60 \% \mathrm{MeCN}$ in $\mathrm{H}_{2} \mathrm{O}$ as the mobile phase at a flow rate of $1 \mathrm{~mL} / \mathrm{min}$ to afford $6,7-$ epoxylatrunculin A $\left(\mathbf{2 7 6}, t_{\mathrm{R}} 13.90 \mathrm{~min}, 5.7 \mathrm{mg}\right)$, zampanolide B (282, $t_{\mathrm{R}} 22.40 \mathrm{~min}$, $1.1 \mathrm{mg})$, zampanolide D $\left(\mathbf{2 8 4}, t_{\mathrm{R}} 23.80 \mathrm{~min}, 0.3 \mathrm{mg}\right)$, zampanolide A $\left(\mathbf{2 7 8}, t_{\mathrm{R}} 27.40 \mathrm{~min}\right.$, $1.6 \mathrm{mg})$, zampanolide C (283, $\left.t_{\mathrm{R}} 28.90 \mathrm{~min}, 0.2 \mathrm{mg}\right)$, zampanolide $\mathrm{E}\left(\mathbf{2 8 5}, t_{\mathrm{R}} 30.20 \mathrm{~min}\right.$, $0.1 \mathrm{mg})$ and latrunculin $\mathrm{A}\left(\mathbf{2 4 8}, t_{\mathrm{R}} 31.90 \mathrm{~min}, 0.1 \mathrm{mg}\right)$

Samples that contained impure dactylolide, impure zampanolide A and zampanolide-like compounds from fraction $\mathbf{C}$ (fractions $\mathbf{A F}, \mathbf{A G}, \mathbf{A H}$ ) of the bulk extraction and the screened (fractions $\mathbf{M}$ and $\mathbf{N}$ ), were combined for a final purification. The combined sample $(14.3 \mathrm{mg})$ was purified on an analytical C18 reversed-phase HPLC column with a solvent gradient of $50 \%$ to $55 \% \mathrm{MeCN}$ in $\mathrm{H}_{2} \mathrm{O}$ as the mobile phase at a flow rate of $1 \mathrm{~mL} / \mathrm{min}$ to afford 6,7-epoxylatrunculin A $\left(\mathbf{2 7 6}, t_{\mathrm{R}} 14.50 \mathrm{~min}, 2.0 \mathrm{mg}\right)$, zampanolide B $\left(\mathbf{2 8 2}, t_{\mathrm{R}} 23.20 \mathrm{~min}, 1.3 \mathrm{mg}\right)$, zampanolide $\mathrm{D}\left(\mathbf{2 8 4}, t_{\mathrm{R}} 25.70 \mathrm{~min}, 1.0 \mathrm{mg}\right)$, zampanolide A $\left(\mathbf{2 7 8}, t_{\mathrm{R}} 29.88 \mathrm{~min}, 4.2 \mathrm{mg}\right)$, zampanolide C (283, $\left.t_{\mathrm{R}} 31.55 \mathrm{~min}, 0.1 \mathrm{mg}\right)$, zampanolide E $\left(\mathbf{2 8 5}, t_{\mathrm{R}} 32.95 \mathrm{~min}, 0.1 \mathrm{mg}\right)$ and dactylolide $\left(\mathbf{2 8 6}, t_{\mathrm{R}} 39.90 \mathrm{~min}, 0.1 \mathrm{mg} ; t_{\mathrm{R}} 43.80 \mathrm{~min}\right.$, $0.6 \mathrm{mg})$.

\subsubsection{Second Bulk Isolation}

Performed by C. R. Harland

Cacospongia mycofijiensis (PTN4_26A, 503.0 g) collected from an underwater cave, 'Eua, Tonga, was extracted twice with $\mathrm{MeOH}(2.0 \mathrm{~L})$ overnight. The extracts were cyclicloaded onto a $400 \mathrm{~mL}$ PSDVB column, pre-equilibrated in $\mathrm{MeOH}$. The loaded column was then washed with $1.2 \mathrm{~L}$ of $\mathrm{H}_{2} \mathrm{O}$ and fractionated with $1.2 \mathrm{~L}$ portions of (i) $40 \%$ $\mathrm{Me}_{2} \mathrm{CO} / \mathrm{H}_{2} \mathrm{O}$ (fraction $\mathrm{A}, 107.9 \mathrm{mg}$ ), (ii) $60 \% \mathrm{Me}_{2} \mathrm{CO} / \mathrm{H}_{2} \mathrm{O}$ (fraction $\mathbf{B}, 2699.4 \mathrm{mg}$ ), (iii) $80 \% \mathrm{Me}_{2} \mathrm{CO} / \mathrm{H}_{2} \mathrm{O}$ (fraction C, $1666.6 \mathrm{mg}$ ) and (iv) $\mathrm{Me}_{2} \mathrm{CO}$ (fraction D, $698.3 \mathrm{mg}$ ). 
Fraction $\mathbf{B}$ was loaded onto a $150 \mathrm{~mL} \mathrm{SiO}_{2}$ column and eluted sequentially with $500 \mathrm{~mL}$ portions of $\mathrm{CH}_{2} \mathrm{Cl}_{2}$ (fraction $\mathbf{E}, 89.2 \mathrm{mg}$ ), $5 \%$ (fraction $\mathbf{F}, 292.6 \mathrm{mg}$ ), $10 \%$ (fraction G, $582.1 \mathrm{mg}$ ), $20 \%$ (fraction H, $850.1 \mathrm{mg}$ ), 30\% (fraction I, 133,5 mg), 50\% EtOAc in $\mathrm{CH}_{2} \mathrm{Cl}_{2}$ (fraction $\mathbf{J}, 170.9 \mathrm{mg}$ ), EtOAc (fraction $\mathbf{K}, 280.1 \mathrm{mg}$ ) and $\mathrm{Me}_{2} \mathrm{CO}$ (fraction L, $98.5 \mathrm{mg}$ ). Fraction $\mathbf{E}$ contained dendrolasin (249), while mycothiazole (256) was the major component in fractions $\mathbf{F}$ and $\mathbf{G}$. Fraction $\mathbf{H}$ was predominately latrunculin A (248), while laulimalide (259) was present in fraction J. Fraction $\mathbf{K}$ contained neolaulimalide (277), while isolaulimalide (258) was present in fraction L. Fraction I was loaded onto a $30 \mathrm{~mL} \mathrm{SiO}{ }_{2}$ column and eluted sequentially with $90 \mathrm{~mL}$ portions of $\mathrm{CH}_{2} \mathrm{Cl}_{2}, 5 \%, 10 \%$ (fraction $\mathbf{M}, 2.1 \mathrm{mg}$ ), 20\%, 30\% (fraction $\mathbf{N}, 80.9 \mathrm{mg}$ ), 50\% EtOAc in $\mathrm{CH}_{2} \mathrm{Cl}_{2}$, EtOAc and $\mathrm{Me}_{2} \mathrm{CO}$.

Fraction $\mathbf{C}$ was loaded onto a $150 \mathrm{~mL} \mathrm{SiO}_{2}$ column and eluted sequentially with $500 \mathrm{~mL}$ portions of $\mathrm{CH}_{2} \mathrm{Cl}_{2}$ (fraction $\mathbf{T}, 130.3 \mathrm{mg}$ ), 5\% (fraction $\mathbf{U}, 127.2 \mathrm{mg}$ ), 10\% (fraction $\mathbf{V}, 296.6 \mathrm{mg}$ ), 20\% (fraction W, $49.9 \mathrm{mg}$ ), 30\% (fraction $\mathbf{X}, 57.5 \mathrm{mg}$ ), 50\% EtOAc in $\mathrm{CH}_{2} \mathrm{Cl}_{2}$, EtOAc (fraction $\mathbf{Y}, 108.9 \mathrm{mg}$ ) and $\mathrm{Me}_{2} \mathrm{CO}$ (fraction $\mathbf{Z}, 240.0 \mathrm{mg}$ ). Fraction T contained dendrolasin (249), while mycothiazole (256) was the major component in fractions $\mathbf{U}$ and $\mathbf{V}$. Fraction $\mathbf{W}$ was predominately latrunculin A (248). Fraction Y contained neolaulimalide (277) and isolaulimalide (258) was present in fraction $\mathbf{Z}$. Fraction $\mathbf{X}$ was loaded onto a $15 \mathrm{~mL} \mathrm{SiO}_{2}$ column and eluted sequentially with $50 \mathrm{~mL}$ portions of $\mathrm{CH}_{2} \mathrm{Cl}_{2}, 5 \%, 10 \%, 15 \%, 20 \%, 30 \%$ (fraction $\mathbf{A A}, 12.1 \mathrm{mg}$ ), 50\% EtOAc in $\mathrm{CH}_{2} \mathrm{Cl}_{2}$ (fraction $\mathbf{A B}, 3.1 \mathrm{mg}$ ) and EtOAc.

\section{Performed by T. Taufa}

Fraction $\mathbf{M}$ was purified on an analytical C18 reversed-phase HPLC column with 50\% $\mathrm{MeCN}$ in $\mathrm{H}_{2} \mathrm{O}$ as the mobile phase at a flow rate of $1 \mathrm{~mL} / \mathrm{min}$ to yield two samples of dactylolide (281) $\left(t_{\mathrm{R}} 42.24 \mathrm{~min}, 0.7 \mathrm{mg} ; t_{\mathrm{R}} 51.68 \mathrm{~min}, 0.8 \mathrm{mg}\right)$.

Fraction $\mathbf{N}$ was purified on an analytical C18 reversed-phase HPLC column with $55 \% \mathrm{MeCN}$ in $\mathrm{H}_{2} \mathrm{O}$ as the mobile phase at a flow rate of $1 \mathrm{~mL} / \mathrm{min}$ to afford $6,7-$ epoxylatrunculin A (276, $\left.t_{\mathrm{R}} 14.50 \mathrm{~min}, 2.0 \mathrm{mg}\right)$, fraction $\mathbf{O}\left(t_{\mathrm{R}} 14.92 \mathrm{~min}, 1.6 \mathrm{mg}\right)$, fraction $\mathbf{P}\left(t_{\mathrm{R}} 15.10 \mathrm{~min}, 3.3 \mathrm{mg}\right)$, zampanolide A $\left(\mathbf{2 7 8}, t_{\mathrm{R}} 18.12 \mathrm{~min}, 10.8 \mathrm{mg}\right)$, fraction 
$\mathbf{Q}\left(t_{\mathrm{R}} 19.85 \mathrm{~min}, 5.9 \mathrm{mg}\right)$, fraction $\mathbf{R}\left(t_{\mathrm{R}} 22.71 \mathrm{~min}, 1.2 \mathrm{mg}\right)$ and fraction $\mathbf{S}\left(t_{\mathrm{R}} 23.90 \mathrm{~min}\right.$, $1.0 \mathrm{mg}$ ). Fraction $\mathbf{O}$ was separated on an analytical C18 reversed-phase HPLC column with $40 \% \mathrm{MeCN}$ in $\mathrm{H}_{2} \mathrm{O}$ as the mobile phase at a flow rate of $1 \mathrm{~mL} / \mathrm{min}$ to afford zampanolide B $\left(\mathbf{2 8 2}, t_{\mathrm{R}} 88.23 \mathrm{~min}, 0.2 \mathrm{mg}\right)$. Fraction $\mathbf{P}$ was separated on an analytical C18 reversed-phase HPLC column with $50 \% \mathrm{MeCN}$ in $\mathrm{H}_{2} \mathrm{O}$ as the mobile phase at a flow rate of $1 \mathrm{~mL} / \mathrm{min}$ to afford zampanolide $\mathrm{D}\left(\mathbf{2 8 4}, t_{\mathrm{R}} 28.75 \mathrm{~min}, 0.6 \mathrm{mg}\right)$. Fraction Q was fractionated on an analytical C18 reversed-phase HPLC column with 50\% MeCN in $\mathrm{H}_{2} \mathrm{O}$ as the mobile phase at a flow rate of $1 \mathrm{~mL} / \mathrm{min}$ to afford zampanolide $\mathrm{C}\left(\mathbf{2 8 3}, t_{\mathrm{R}}\right.$ $36.29 \mathrm{~min}, 0.9 \mathrm{mg}$ ). Fraction $\mathbf{R}$ was separated on an analytical C18 reversed-phase HPLC column with $50 \% \mathrm{MeCN}$ in $\mathrm{H}_{2} \mathrm{O}$ as the mobile phase at a flow rate of $1 \mathrm{~mL} / \mathrm{min}$ to afford zampanolide $\mathrm{E}\left(\mathbf{2 8 5}, t_{\mathrm{R}} 36.40 \mathrm{~min}, 0.2 \mathrm{mg}\right)$.

Fractions $\mathbf{A A}$ and $\mathbf{A B}$ were combined and purified on an analytical C18 reversed-phase HPLC column using a solvent gradient of $50 \%$ to $60 \% \mathrm{MeCN}$ in $\mathrm{H}_{2} \mathrm{O}$ as the mobile phase at a flow rate of $1 \mathrm{~mL} / \mathrm{min}$ to afford 6,7-epoxylatrunculin $\mathrm{A}\left(\mathbf{2 7 6}, t_{\mathrm{R}} 14.57 \mathrm{~min}, 5.2 \mathrm{mg}\right)$, zampanolide B $\left(\mathbf{2 8 2}, t_{\mathrm{R}} 23.12 \mathrm{~min}, 0.3 \mathrm{mg}\right)$, zampanolide D $\left(\mathbf{2 8 4}, t_{\mathrm{R}} 24.88 \mathrm{~min}, 0.2 \mathrm{mg}\right)$, zampanolide A $\left(\mathbf{2 7 8}, t_{\mathrm{R}} 28.37 \mathrm{~min}, 5.0 \mathrm{mg}\right)$, zampanolide C (283, $\left.t_{\mathrm{R}} 29.66 \mathrm{~min}, 0.1 \mathrm{mg}\right)$ and zampanolide $\mathrm{E}\left(\mathbf{2 8 5}, t_{\mathrm{R}} 33.12 \mathrm{~min}, 0.1 \mathrm{mg}\right)$.

Latrunculin A (248). White amorphous solid; HRESIMS, $[\mathrm{M}+\mathrm{Na}]^{+}$, observed $\mathrm{m} / \mathrm{z}$ 444.1819, calculated 444.1815 for $\mathrm{C}_{22} \mathrm{H}_{31} \mathrm{NO}_{5} \mathrm{SNa}, \Delta=0.90 \mathrm{ppm}$; all NMR data as previously described. $\stackrel{217}{21}$

Dendrolasin (249). Colourless oil; HRESIMS, $[\mathrm{M}+\mathrm{H}]^{+}$, observed $m / z$ 219.1739, calculated 219.1743 for $\mathrm{C}_{15} \mathrm{H}_{23} \mathrm{O}, \Delta=-1.82 \mathrm{ppm}$; all NMR data as previously described. ${ }^{217}$

Mycothiazole (256). Colourless glass-like solid; HRESIMS, $[\mathrm{M}+\mathrm{H}]^{+}$, observed $\mathrm{m} / \mathrm{z}$ 405.2195, calculated 405.2206 for $\mathrm{C}_{22} \mathrm{H}_{33} \mathrm{~N}_{2} \mathrm{O}_{3} \mathrm{~S}, \Delta=-2.71 \mathrm{ppm}$; all NMR data as previously described. $\frac{2251226}{.26}$

Isolaulimalide (258). Colourless oil; HRESIMS, $[\mathrm{M}+\mathrm{H}]^{+}$, observed $m / z$ 515.2994, calculated 515.3003 for $\mathrm{C}_{30} \mathrm{H}_{43} \mathrm{O}_{7}, \Delta=-1.75 \mathrm{ppm}$; all NMR data as previously described. 227,228 
Laulimalide (259). Colourless oil; HRESIMS, $[\mathrm{M}+\mathrm{H}]^{+}$, observed $\mathrm{m} / z$ 515.2980, calculated 515.3003 for $\mathrm{C}_{30} \mathrm{H}_{43} \mathrm{O}_{7}, \Delta=-4.46 \mathrm{ppm}$; all NMR data as previously described. 2271228

6,7-Epoxylatrunculin A (276). White amorphous solid; HRESIMS, $[\mathrm{M}+\mathrm{Na}]^{+}$, observed $m / z$ 460.1757, calculated 460.1764 for $\mathrm{C}_{22} \mathrm{H}_{31} \mathrm{NO}_{6} \mathrm{SNa}, \Delta=-1.52 \mathrm{ppm}$; all NMR data as previously described. 265

Neolaulimalide (277). Colourless oil; HRESIMS, $[\mathrm{M}+\mathrm{H}]^{+}$, observed $m / z$ 515.2993, calculated 515.3003 for $\mathrm{C}_{30} \mathrm{H}_{43} \mathrm{O}_{7}, \Delta=-1.94 \mathrm{ppm}$; all NMR data as previously described. 266

Zampanolide A (278). White amorphous solid; $[\alpha]_{\mathrm{D}}^{26}-113.4\left(c 0.11, \mathrm{CH}_{2} \mathrm{Cl}_{2}\right)$; $[\alpha]_{\mathrm{D}}^{26}-154.6$ (c 0.11, MeOH); UV (MeOH) $\lambda_{\max } 201 \mathrm{~nm}(\epsilon$ 2535), $226 \mathrm{~nm}(\epsilon$ 2066), $266 \mathrm{~nm}(\epsilon$ 1876); IR (film) $\nu_{\max } 2924,2887,2851,1710,1668,1631,1611,1521,1353,1042 \mathrm{~cm}^{-1}$; HRESIMS, $[\mathrm{M}+\mathrm{Na}]^{+}$, observed $m / z$ 518.2516, calculated 518.2513 for $\mathrm{C}_{29} \mathrm{H}_{37} \mathrm{NO}_{6} \mathrm{Na}$, $\Delta=0.58$ ppm; all NMR data as previously described. 235

Dictyodendrillin A (279). Colourless oil; HRESIMS, [M + H $]^{+}$, observed $\mathrm{m} / \mathrm{z}$ 251.1640, calculated 251.1642 for $\mathrm{C}_{15} \mathrm{H}_{23} \mathrm{O}_{3}, \Delta=0.80 \mathrm{ppm}$; all NMR data as previously described. 243

Isodictyodendrillin A (280). Colourless oil; $[\alpha]_{\mathrm{D}}^{27}-66.7\left(c 0.035, \mathrm{CH}_{2} \mathrm{Cl}_{2}\right) ; \mathrm{UV}(\mathrm{MeOH})$ $\lambda_{\max } 215 \mathrm{~nm}$ ( $\epsilon$ 1936); IR (film) $\nu_{\max }$ 2919, 2854, 2233, 2220, 2170, 1737, 1577, 1109, $944 \mathrm{~cm}^{-1}$; NMR data see Table 6.2. HRESIMS, $[\mathrm{M}+\mathrm{Na}]^{+}$, observed $\mathrm{m} / z$ 273.1466, calculated 273.1461 for $\mathrm{C}_{15} \mathrm{H}_{22} \mathrm{O}_{3} \mathrm{Na}, \Delta=1.83 \mathrm{ppm}$;

Dactylolide (281). Colourless oil; $[\alpha]_{\mathrm{D}}^{26}-80.0\left(c 0.025, \mathrm{CH}_{2} \mathrm{Cl}_{2}\right) ;[\alpha]_{\mathrm{D}}^{26}-40.0(c 0.025$, $\mathrm{MeOH}) ; \mathrm{UV}(\mathrm{MeOH}) \lambda_{\max } 203 \mathrm{~nm}(\epsilon$ 10380), $226 \mathrm{~nm}(\epsilon$ 7460), $277 \mathrm{~nm}(\epsilon$ 5514); IR (film) $\nu_{\max } 3329,3285,2906,2876,2031,1720,1687,1657,1596 \mathrm{~cm}^{-1}$; HRESIMS, $[\mathrm{M}+\mathrm{Na}]^{+}$, observed $\mathrm{m} / \mathrm{z}$ 407.1834, calculated 407.1829 for $\mathrm{C}_{23} \mathrm{H}_{28} \mathrm{O}_{5} \mathrm{Na}, \Delta=1.22 \mathrm{ppm}$; all NMR data as previously described. $[238$

Zampanolide B (282). White amorphous solid; $[\alpha]_{\mathrm{D}}^{24}+27.3\left(\right.$ c $\left.0.11, \mathrm{CH}_{2} \mathrm{Cl}_{2}\right)$; UV 
(MeOH) $\lambda_{\max } 227 \mathrm{~nm}$ ( $\epsilon$ 8333), $263 \mathrm{~nm}$ ( $\epsilon$ 8843); IR (film) $\nu_{\max }$ 3239, 2908, 2864, 1670, 1685, 1647, 1579, 1422, $1016 \mathrm{~cm}^{-1}$; NMR data see Table 6.4, HRESIMS, $[\mathrm{M}+\mathrm{Na}]^{+}$, observed $m / z 518.2514$, calculated 518.2513 for $\mathrm{C}_{29} \mathrm{H}_{37} \mathrm{NO}_{6} \mathrm{Na}, \Delta=0.19 \mathrm{ppm}$;

Zampanolide C (283). White amorphous solid; $[\alpha]_{\mathrm{D}}^{25}-266.7\left(c 0.015, \mathrm{CH}_{2} \mathrm{Cl}_{2}\right)$; UV $(\mathrm{MeOH}) \lambda_{\max } 201 \mathrm{~nm}(\epsilon 12707), 264 \mathrm{~nm}(\epsilon 11206)$; IR (film) $\nu_{\max } 3316,2929,2854,1657$, 1635, 1521, 1432, 1152, $1051 \mathrm{~cm}^{-1}$; NMR data see Table 6.5. HRESIMS, $[\mathrm{M}+\mathrm{Na}]^{+}$, observed $m / z$ 518.2513, calculated 518.2513 for $\mathrm{C}_{29} \mathrm{H}_{37} \mathrm{NO}_{6} \mathrm{Na}, \Delta=0.00 \mathrm{ppm}$.

Zampanolide D (284). White amorphous solid; $[\alpha]_{\mathrm{D}}^{26}-114.3\left(c 0.035, \mathrm{CH}_{2} \mathrm{Cl}_{2}\right)$; $\mathrm{NMR}$ data see Table 6.6. HRESIMS, $[\mathrm{M}+\mathrm{Na}]^{+}$, observed $m / z$ 518.2509, calculated 518.2513 for $\mathrm{C}_{29} \mathrm{H}_{37} \mathrm{NO}_{6} \mathrm{Na}, \Delta=-0.77 \mathrm{ppm}$.

Zampanolide E (285). White amorphous solid; $[\alpha]_{\mathrm{D}}^{26}+240.0\left(c 0.05, \mathrm{CH}_{2} \mathrm{Cl}_{2}\right)$; NMR data see Table 6.7, HRESIMS, $[\mathrm{M}+\mathrm{Na}]^{+}$, observed $m / z$ 520.2674, calculated 520.2670 for $\mathrm{C}_{29} \mathrm{H}_{39} \mathrm{NO}_{6} \mathrm{Na}, \Delta=0.77 \mathrm{ppm}$. 


\section{Appendix A}

\section{Current Screening Protocol}

1. Voucher Sample Preparation

- Take a voucher specimen of $\approx 10 \mathrm{~g}$ of sponge material, ensuring that both the ectoderm and endoderm are represented.

- Label and store the voucher sample in $75 \% \mathrm{IPA} / \mathrm{H}_{2} \mathrm{O}$.

2. Extraction

- Extract $\approx 100 \mathrm{~g}$ of crude sponge material in $400 \mathrm{~mL}$ of $\mathrm{MeOH}$ overnight.

- Filter the first extract and set aside. Re-extract the sponge material (and filter paper/celite) in $400 \mathrm{~mL}$ of $\mathrm{MeOH}$ overnight.

- Filter the second extract.

- Keep all sponge material (and filter paper/celite) until the screen is complete at which time it may be discarded.

\section{Cyclic Loading}

- Pass the second extract through the screen column with a flow rate of $\approx 10 \mathrm{~mL} / \mathrm{min}$

- Pass the first extract through the screen column with a flow rate of $\approx 10 \mathrm{~mL} / \mathrm{min}$. Combine the eluent with that of the second extract.

- Dilute the combined eluents with $800 \mathrm{~mL}$ of distilled $\mathrm{H}_{2} \mathrm{O}$. Pass the diluted eluents back through the screen column at a flow rate of $\approx 10 \mathrm{~mL} / \mathrm{min}$.

- Dilute the eluent with $1.6 \mathrm{~L}$ of distilled $\mathrm{H}_{2} \mathrm{O}$. Pass the diluted eluent back through the screen column at a flow rate of $\approx 10 \mathrm{~mL} / \mathrm{min}$.

- The eluent should be kept until the screen is complete at which time it may be discarded.

4. Elution 
- Elute the screen column with $250 \mathrm{~mL}$ of distilled $\mathrm{H}_{2} \mathrm{O}$ at a flow rate of $\approx 10 \mathrm{~mL} / \mathrm{min}$. The $\mathrm{H}_{2} \mathrm{O}$ eluent can be discarded immediately.

- Elute the screen column with $250 \mathrm{~mL}$ of $30 \%$ distilled $\mathrm{Me}_{2} \mathrm{CO}$ in distilled $\mathrm{H}_{2} \mathrm{O}\left(75 \mathrm{~mL} \mathrm{Me}_{2} \mathrm{CO}\right.$ to $\left.175 \mathrm{~mL} \mathrm{H}_{2} \mathrm{O}\right)$ at a flow rate of $\approx 10 \mathrm{~mL} / \mathrm{min}$.

- Elute the screen column with $250 \mathrm{~mL}$ of $75 \%$ distilled $\mathrm{Me}_{2} \mathrm{CO}$ in distilled $\mathrm{H}_{2} \mathrm{O}\left(187.5 \mathrm{~mL} \mathrm{Me}_{2} \mathrm{CO}\right.$ to $\left.62.5 \mathrm{~mL} \mathrm{H}_{2} \mathrm{O}\right)$ at a flow rate of $\approx 10 \mathrm{~mL} / \mathrm{min}$.

- Elute the screen column with $250 \mathrm{~mL}$ of distilled $\mathrm{Me}_{2} \mathrm{CO}$ at a flow rate of $\approx 10 \mathrm{~mL} / \mathrm{min}$.

5. Backloading the $75 \% \mathrm{Me}_{2} \mathrm{CO} / \mathrm{H}_{2} \mathrm{O}$ Fraction

- Dilute the $75 \% \mathrm{Me}_{2} \mathrm{CO} / \mathrm{H}_{2} \mathrm{O}$ fraction with $250 \mathrm{~mL}$ of distilled $\mathrm{H}_{2} \mathrm{O}$. Pass the diluted eluent through the backloading column at a flow rate of $\approx 8 \mathrm{~mL} / \mathrm{min}$.

- Dilute the eluent with $500 \mathrm{~mL}$ of distilled $\mathrm{H}_{2} \mathrm{O}$. Pass the diluted eluent back through the backloading column at a flow rate of $\approx 8 \mathrm{~mL} / \mathrm{min}$.

- The eluent should be kept until the screen is complete at which time it may be discarded.

- Elute the backloading column with $150 \mathrm{~mL}$ of distilled $\mathrm{Me}_{2} \mathrm{CO}$.

6. Processing the $75 \% \mathrm{Me}_{2} \mathrm{CO} / \mathrm{H}_{2} \mathrm{O}$ Fraction

- Concentrate the $\mathrm{Me}_{2} \mathrm{CO}$ eluent of the backloading column to dryness and transfer to a pre-weighed sample vial. Concentrate to dryness and record the mass.

- Sub-sample $\approx 30 \mathrm{mg}$ of material for NMR analysis if necessary.

- Prepare an NMR sample in $\approx 700 \mu \mathrm{L}$ of $\mathrm{CD}_{3} \mathrm{OD}$ in a $5 \mathrm{~mm}$ NMR tube.

7. Backloading the $30 \% \mathrm{Me}_{2} \mathrm{CO} / \mathrm{H}_{2} \mathrm{O}$ Fraction

- Dilute the $30 \% \mathrm{Me}_{2} \mathrm{CO} / \mathrm{H}_{2}$ Ofraction with $250 \mathrm{~mL}$ of distilled $\mathrm{H}_{2} \mathrm{O}$. Pass the diluted eluent through the backloading column at a flow rate of $\approx 8 \mathrm{~mL} / \mathrm{min}$.

- Dilute the eluent with $500 \mathrm{~mL}$ of distilled $\mathrm{H}_{2} \mathrm{O}$. Pass the diluted eluent back through the backloading column at a flow rate of $\approx 8 \mathrm{~mL} / \mathrm{min}$. 
- The eluent should be kept until the screen is complete at which time it may be discarded.

- Elute the backloading column with $150 \mathrm{~mL}$ of distilled $\mathrm{MeOH}$.

8. Processing the $30 \% \mathrm{Me}_{2} \mathrm{CO} / \mathrm{H}_{2} \mathrm{O}$ Fraction

- Concentrate the $\mathrm{Me}_{2} \mathrm{CO}$ eluent of the backloading column to dryness and transfer to a pre-weighed sample vial. Concentrate to dryness and record the mass.

- Sub-sample $\approx 30 \mathrm{mg}$ of material for NMR analysis if necessary.

- Prepare an NMR sample in $\approx 700 \mu \mathrm{L}$ of $\mathrm{CD}_{3} \mathrm{OD}$ in a $5 \mathrm{~mm}$ NMR tube.

9. NMR Analysis of the $30 \% \mathrm{Me}_{2} \mathrm{CO} / \mathrm{H}_{2} \mathrm{O}$ Fraction

- Run a ${ }^{1} \mathrm{H}$ NMR spectrum of the sample on the $600 \mathrm{MHz}$ instrument using the standard Screen ${ }^{1} \mathrm{H}$ parameter set (experiment time: $\approx 4 \mathrm{~min}$ ).

10. Processing the $100 \% \mathrm{Me}_{2} \mathrm{CO}$ Fraction

- Concentrate the $\mathrm{Me}_{2} \mathrm{CO}$ eluent of the backloading column to dryness and transfer to a pre-weighed sample vial. Concentrate to dryness and record the mass.

- Sub-sample $\approx 30 \mathrm{mg}$ of material for NMR analysis if necessary.

- Prepare an NMR sample in $\approx 700 \mu \mathrm{L}$ of $\mathrm{CDCl}_{3}$ in a $5 \mathrm{~mm}$ NMR tube.

11. NMR Analysis of the $100 \% \mathrm{Me}_{2} \mathrm{CO}$ Fraction

- Run a ${ }^{1} \mathrm{H}$ NMR spectrum of the sample on the $600 \mathrm{MHz}$ instrument using the standard Screen ${ }^{1} \mathrm{H}$ parameter set (experiment time: $\approx 4 \mathrm{~min}$ ). 


\section{Appendix B}

\section{NMR Spectra of Known Compounds from Zyzzya}

\section{fuliginosa}

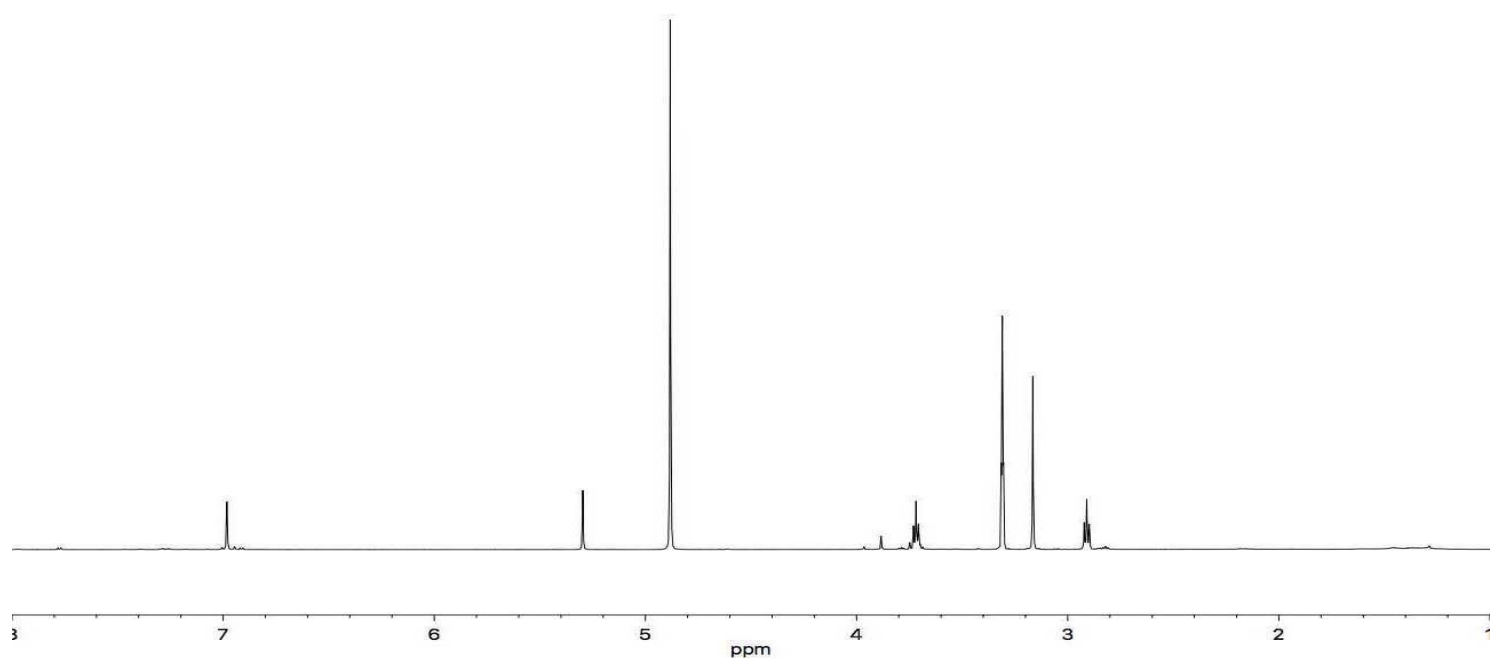

${ }^{1} \mathrm{H}$ NMR spectrum of damirone B (47) $\left(600 \mathrm{MHz}, \mathrm{CD}_{3} \mathrm{OD}\right)$

$\stackrel{1}{\frac{1}{0}} \stackrel{\frac{1}{5}}{\frac{1}{5}}$

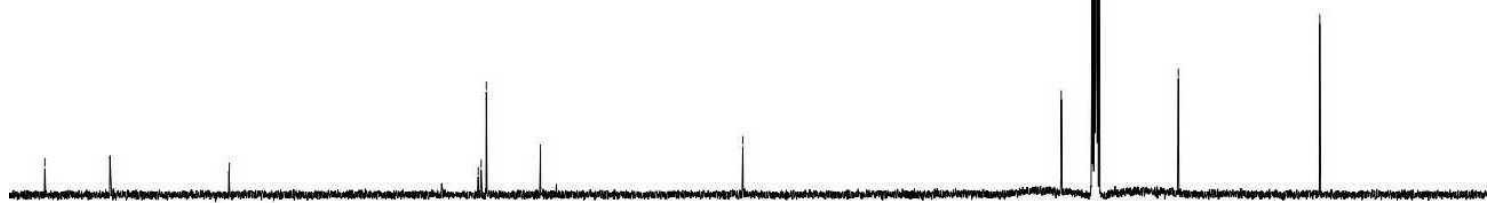

${ }^{13} \mathrm{C}$ NMR spectrum of damirone $\mathrm{B}(47)\left(150 \mathrm{MHz}, \mathrm{CD}_{3} \mathrm{OD}\right)$ 

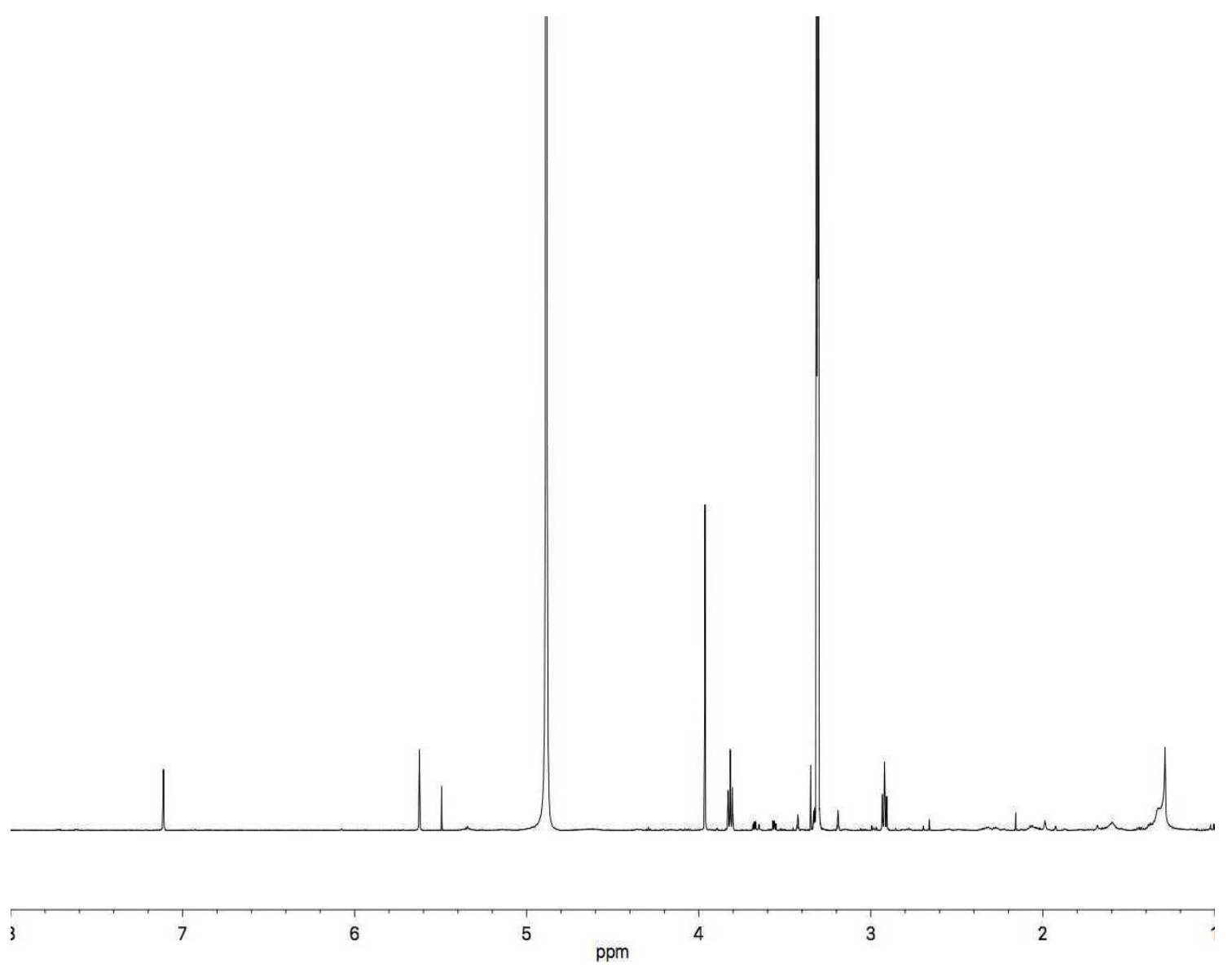

${ }^{1} \mathrm{H}$ NMR spectrum of makaluvamine A (145) $\left(600 \mathrm{MHz}, \mathrm{CD}_{3} \mathrm{OD}\right)$

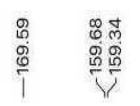

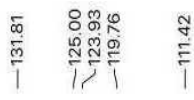

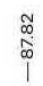

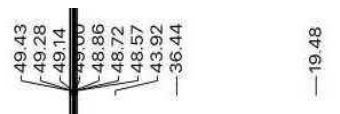

30

160

140

120

100

${ }^{13} \mathrm{C}$ NMR spectrum of makaluvamine $\mathrm{A}(\mathbf{1 4 5})\left(150 \mathrm{MHz}, \mathrm{CD}_{3} \mathrm{OD}\right)$. 


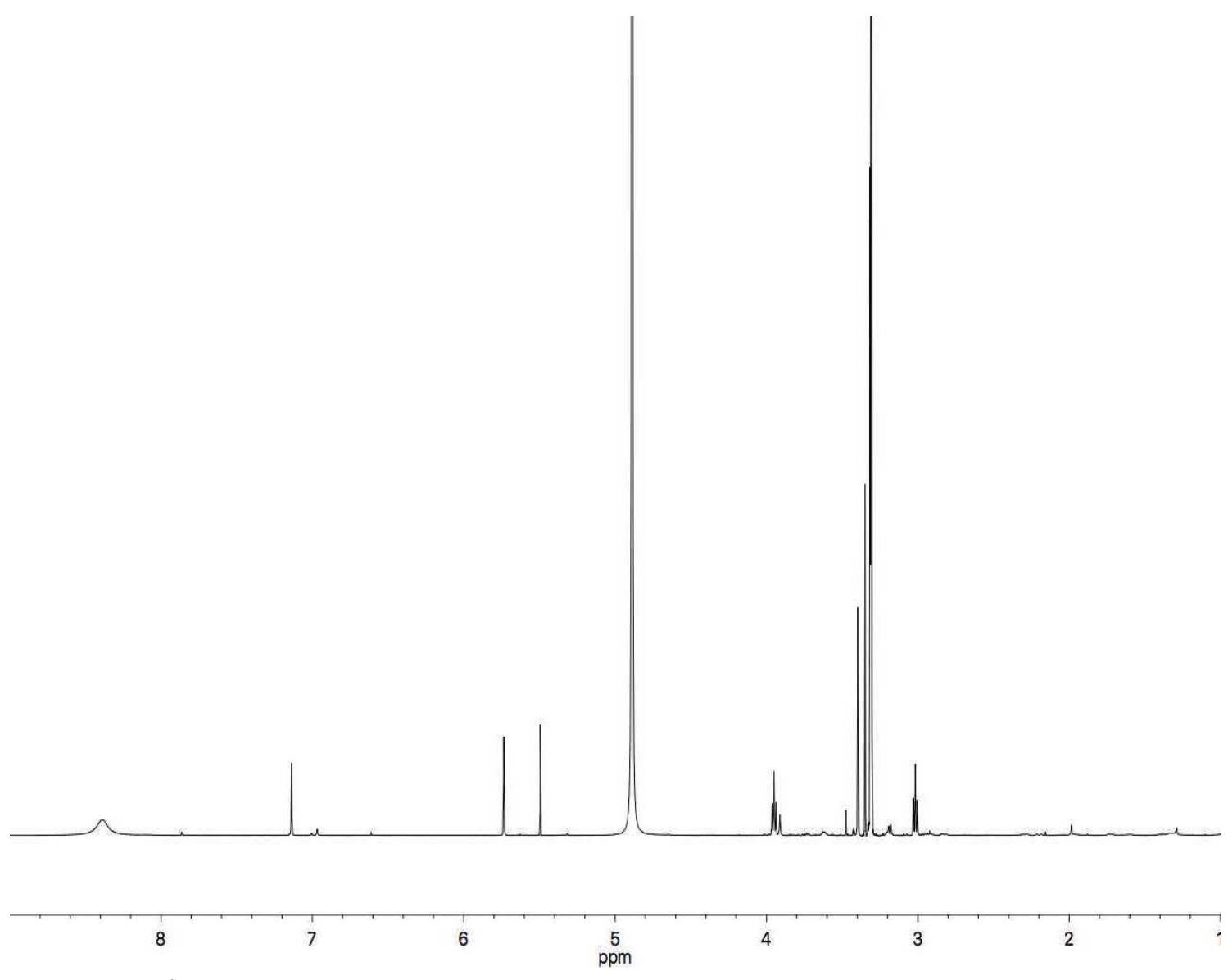

${ }^{1} \mathrm{H}$ NMR spectrum of makaluvamine $\mathrm{C}$ (147) (600 MHz, $\mathrm{CD}_{3} \mathrm{OD}$ )

${ }^{13} \mathrm{C}$ NMR spectrum of makaluvamine $\mathrm{C}(\mathbf{1 4 7})\left(150 \mathrm{MHz}, \mathrm{CD}_{3} \mathrm{OD}\right)$. 

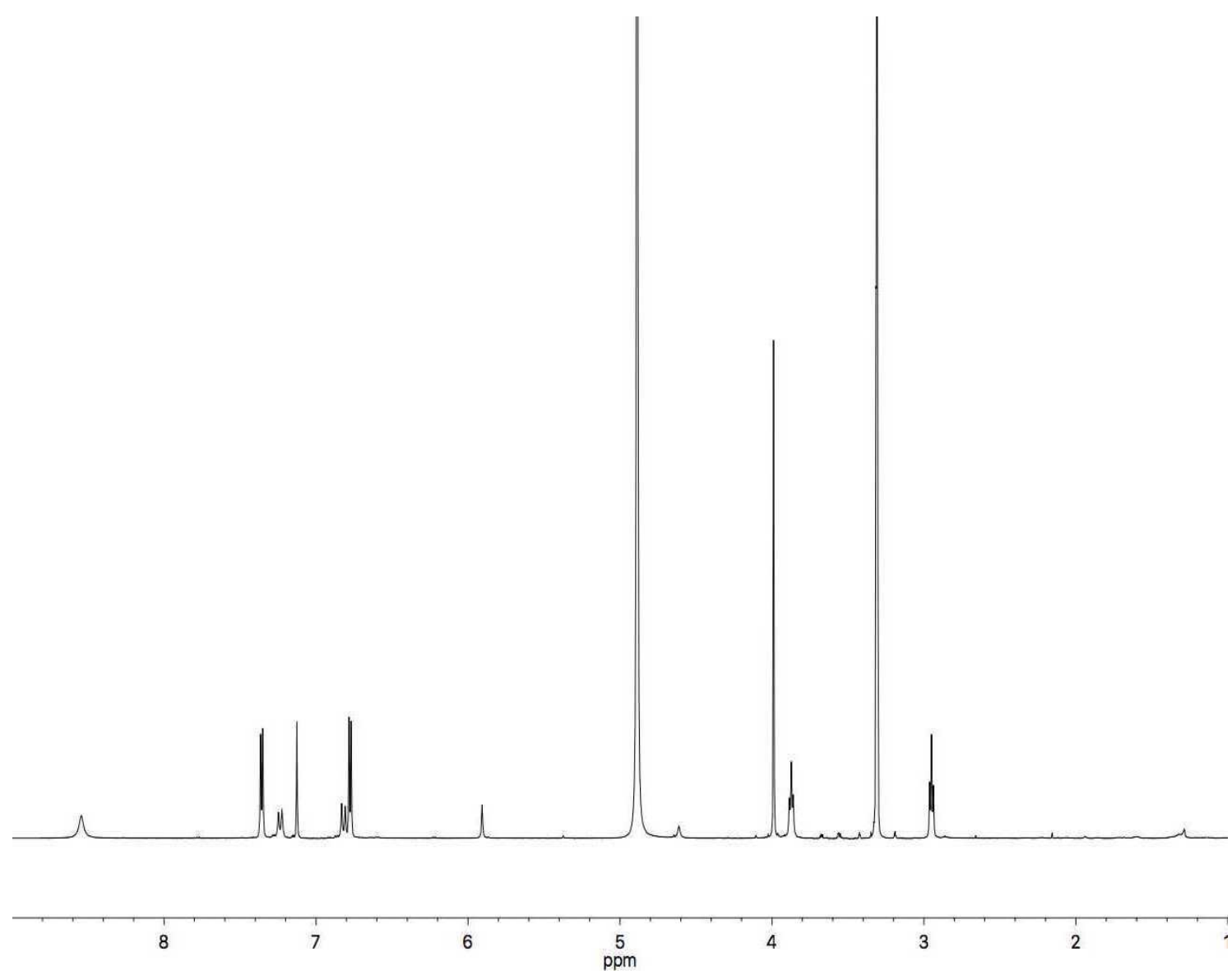

${ }^{1} \mathrm{H}$ NMR spectrum of makaluvamine $\mathrm{E}(149)$ (600 MHz, $\mathrm{CD}_{3} \mathrm{OD}$ )

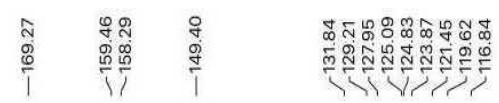

$\underset{\substack{5 \\ 1}}{\infty}$
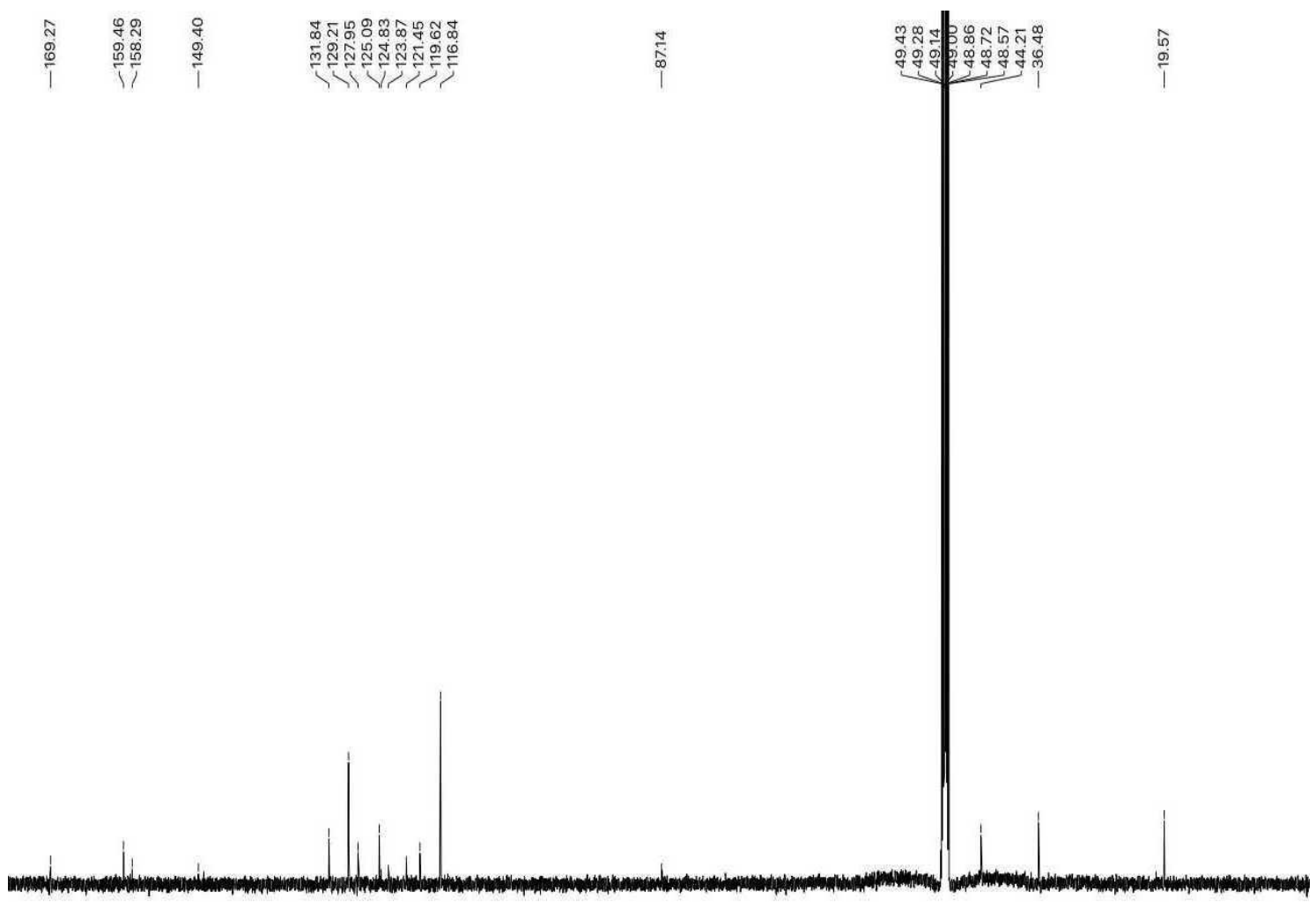

160

$140 \quad 120$

100

ppm

80

60

40

20

${ }^{13} \mathrm{C}$ NMR spectrum of makaluvamine $\mathrm{E}(149)$ (150 MHz, $\left.\mathrm{CD}_{3} \mathrm{OD}\right)$. 

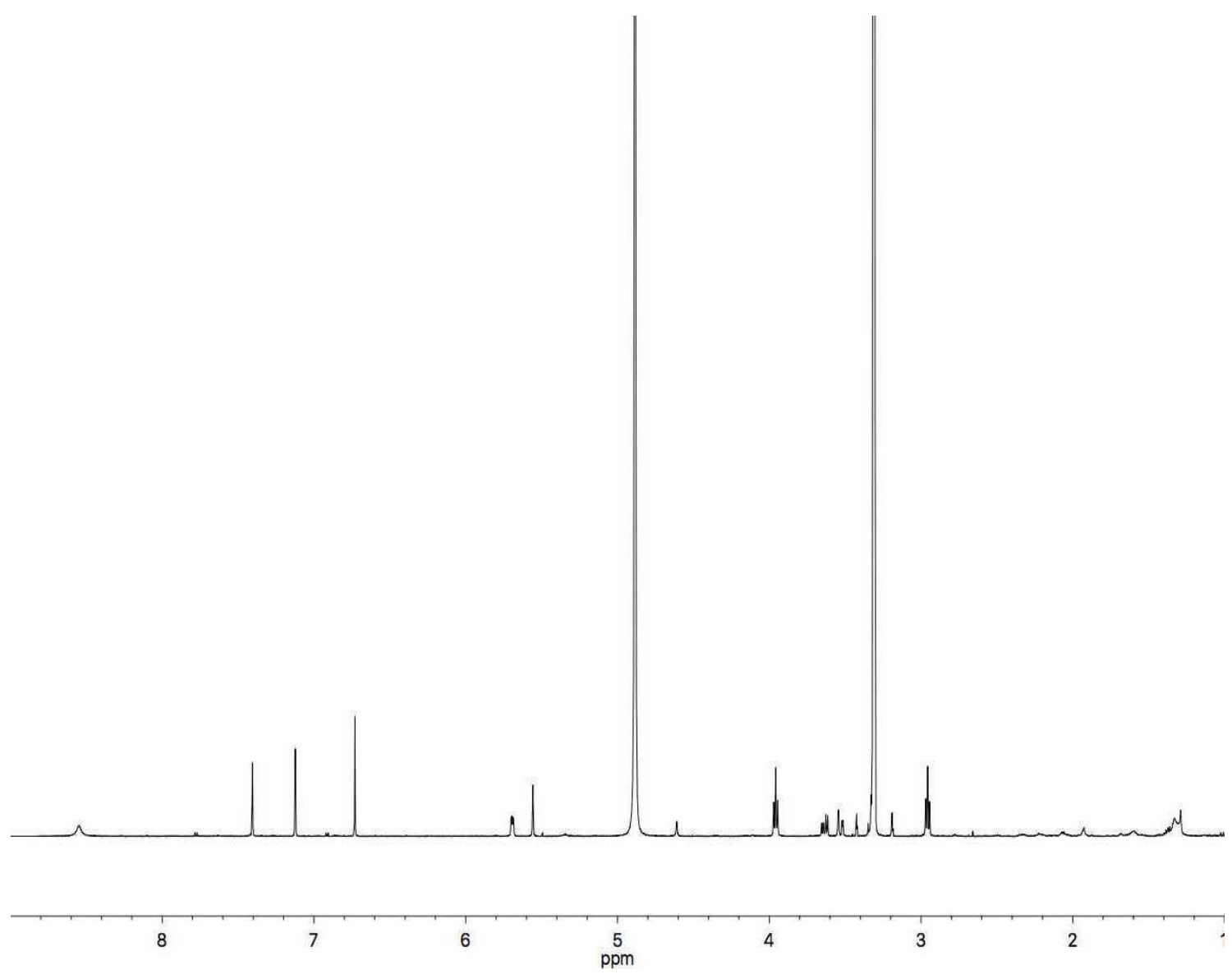

${ }^{1} \mathrm{H}$ NMR spectrum of makaluvamine $\mathrm{F}(\mathbf{1 5 0})$ (600 MHz, $\mathrm{CD}_{3} \mathrm{OD}$ )
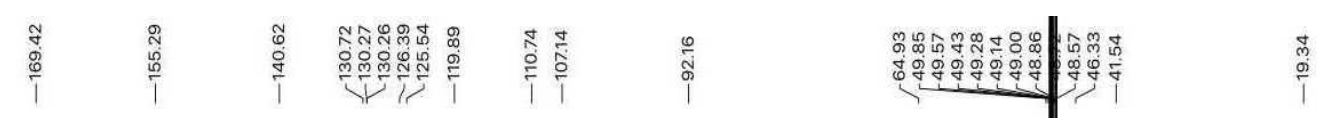

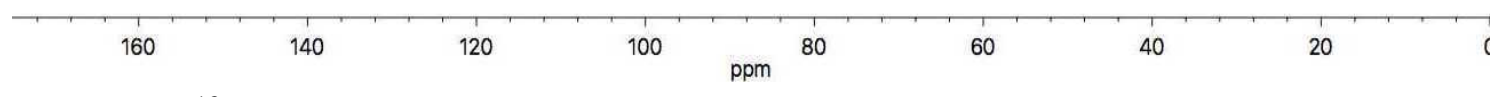

${ }^{13} \mathrm{C}$ NMR spectrum of makaluvamine $\mathrm{F}(\mathbf{1 5 0})$ (150 MHz, $\left.\mathrm{CD}_{3} \mathrm{OD}\right)$. 

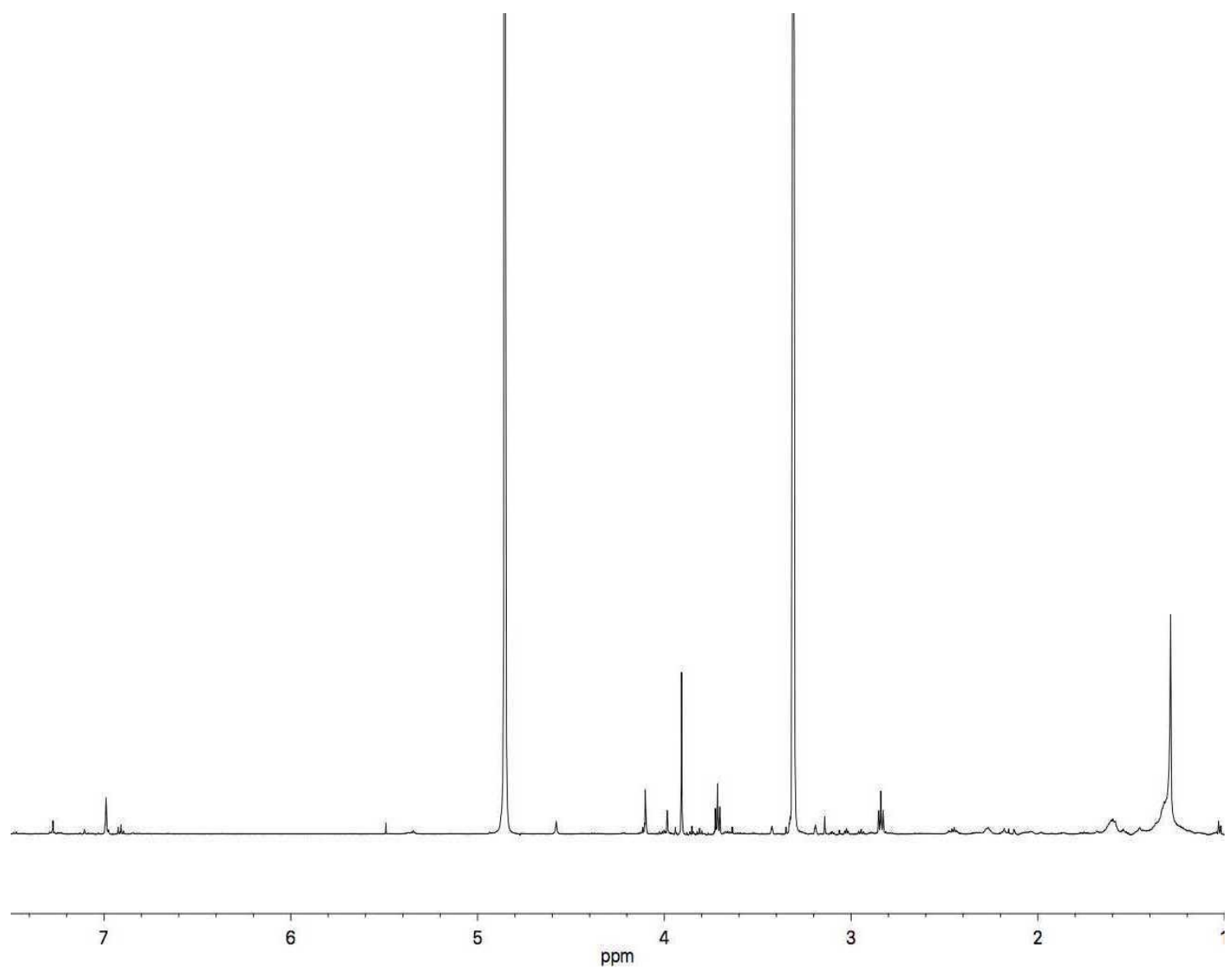

${ }^{1} \mathrm{H}$ NMR spectrum of makaluvanone (151) $\left(600 \mathrm{MHz}, \mathrm{CD}_{3} \mathrm{OD}\right)$

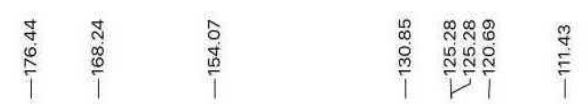

${ }^{13} \mathrm{C}$ NMR spectrum of makaluvanone (151) $\left(150 \mathrm{MHz}, \mathrm{CD}_{3} \mathrm{OD}\right)$. 

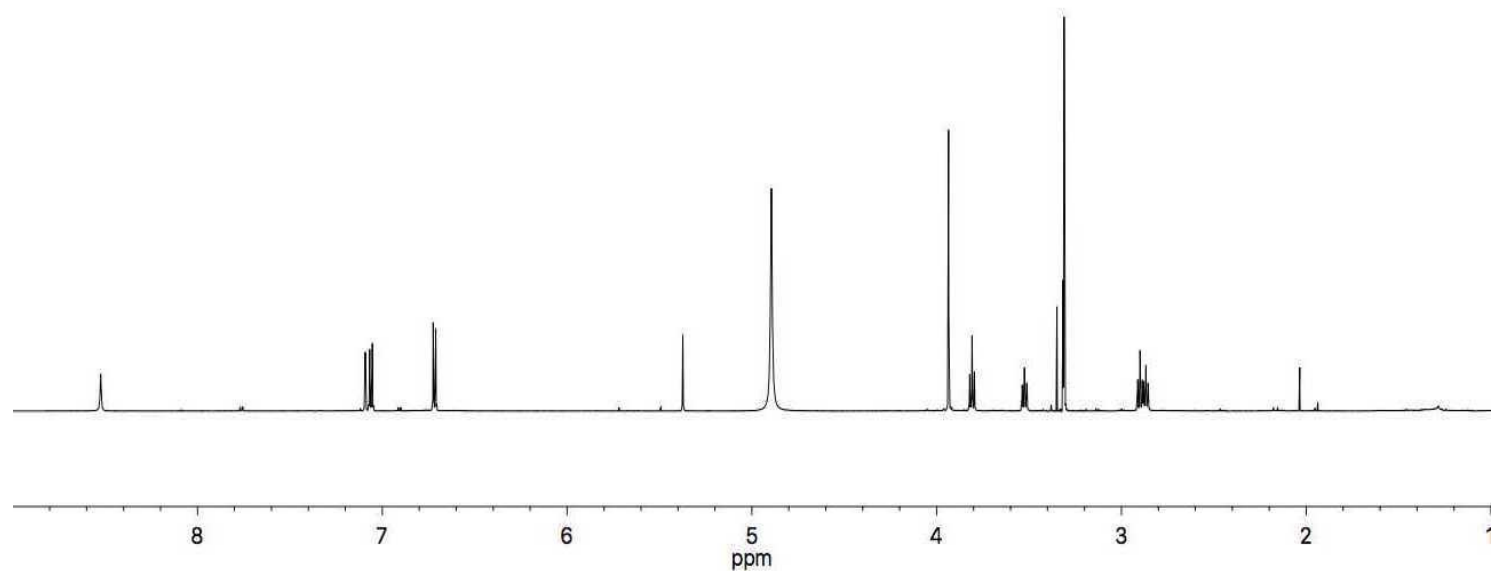

${ }^{1} \mathrm{H}$ NMR spectrum of makaluvamine K (157) (600 MHz, $\mathrm{CD}_{3} \mathrm{OD}$ )

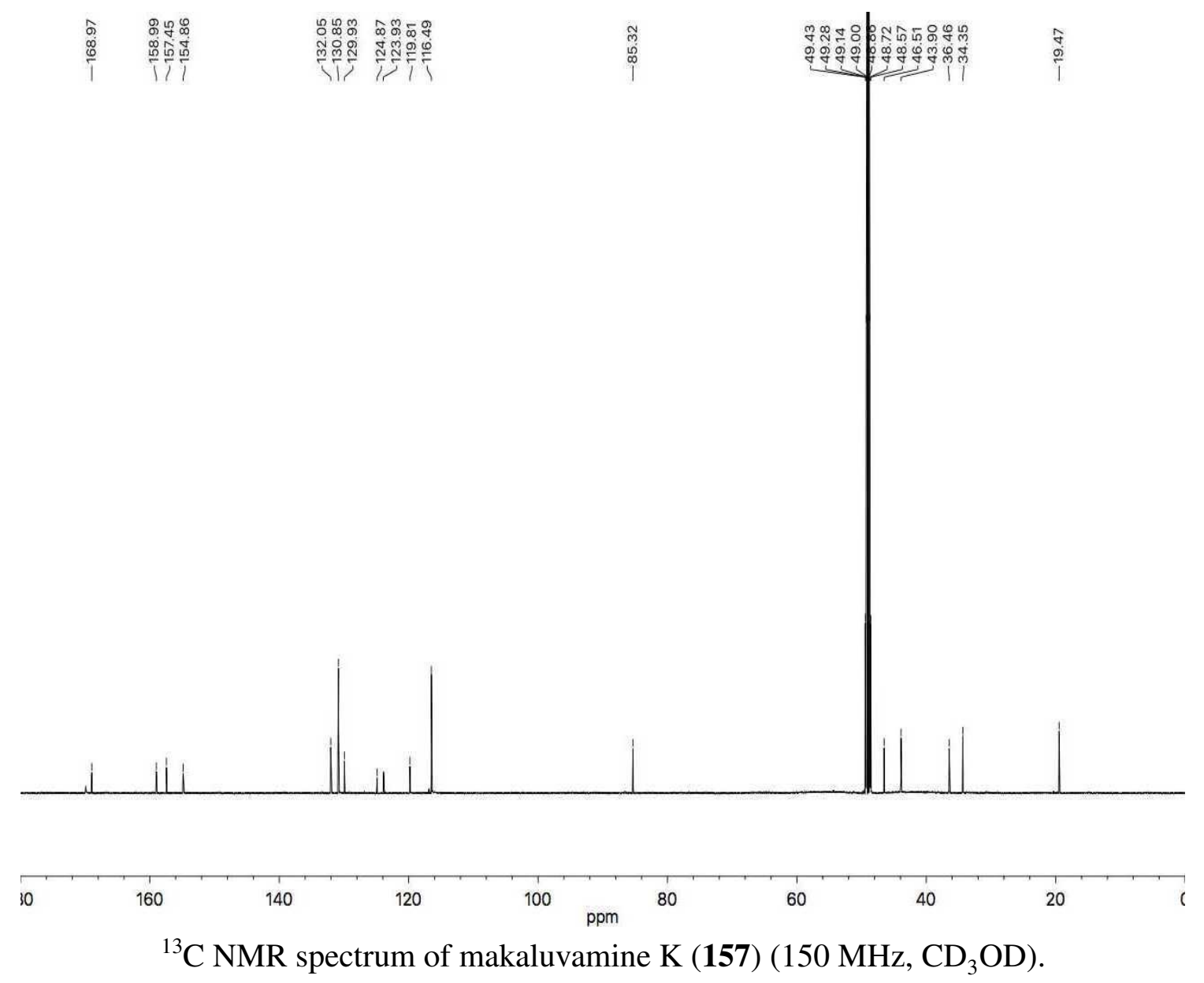



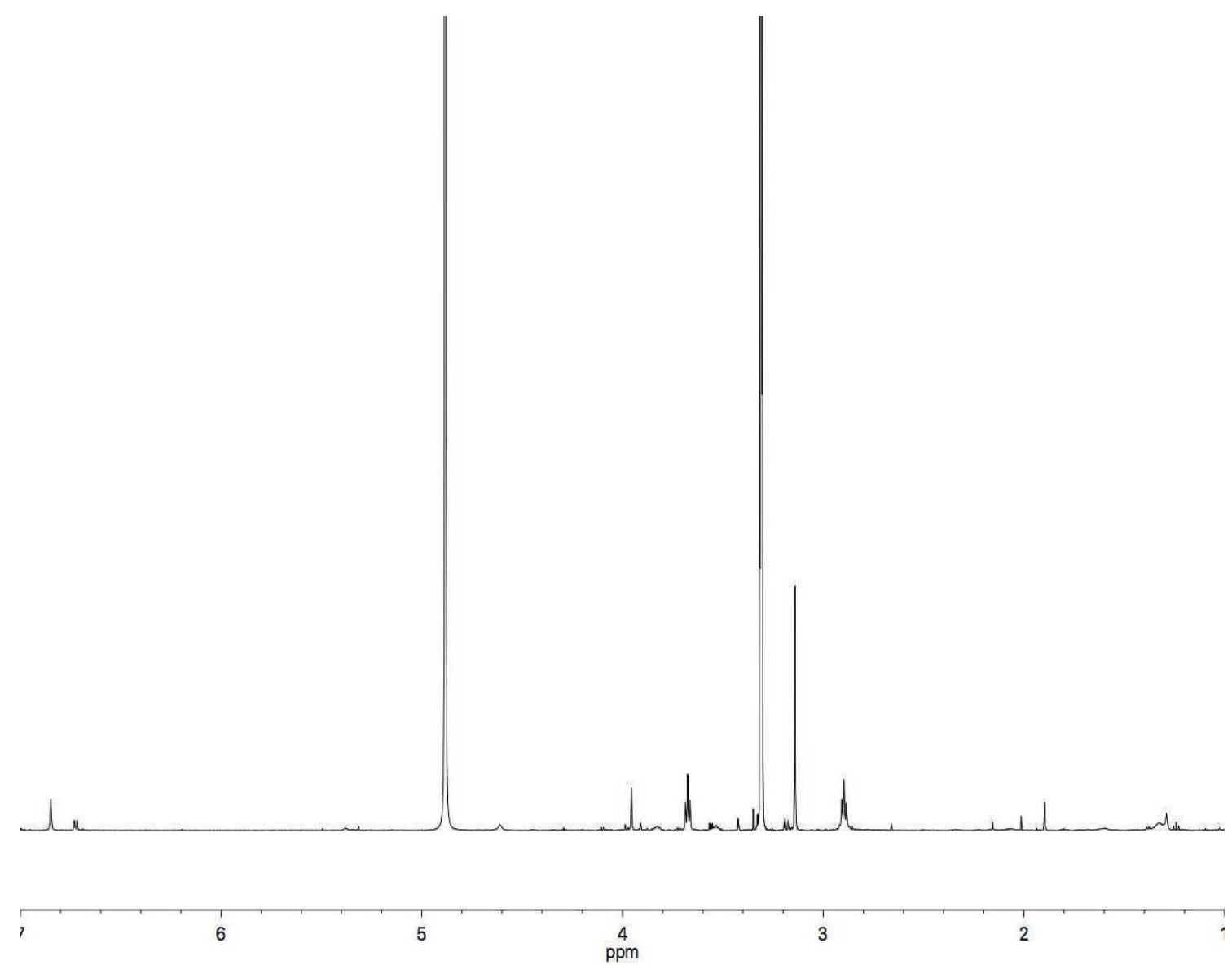

${ }^{1} \mathrm{H}$ NMR spectrum of makaluvic acid A (165) (600 MHz, $\left.\mathrm{CD}_{3} \mathrm{OD}\right)$

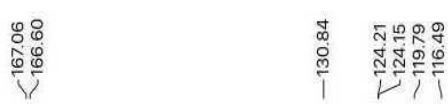

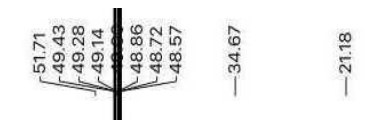

$30 \quad 160+140$

${ }^{13} \mathrm{C}$ NMR spectrum of makaluvic acid A (165) (150 MHz, $\left.\mathrm{CD}_{3} \mathrm{OD}\right)$. 

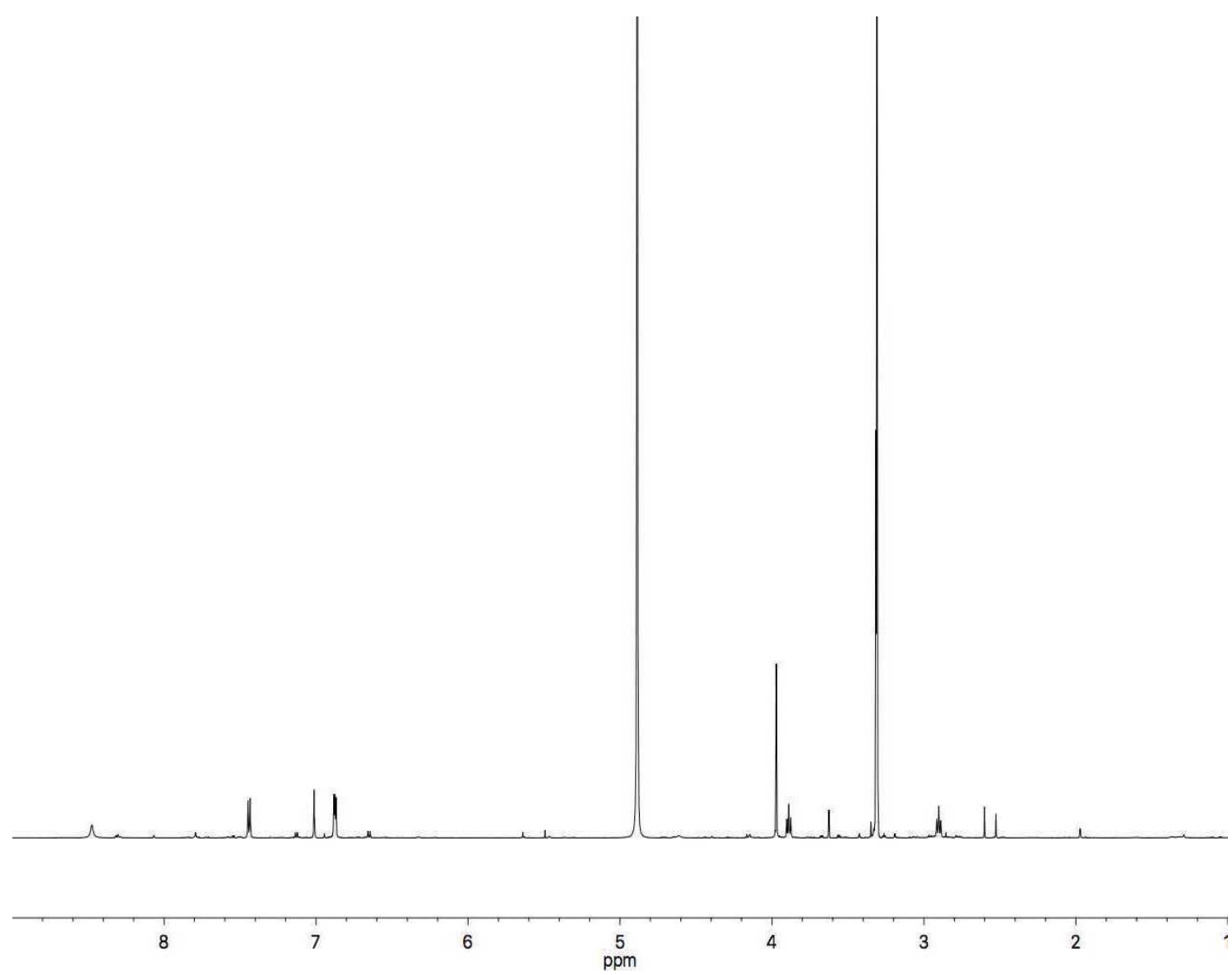

${ }^{1} \mathrm{H}$ NMR spectrum of tsitsikammanine B (184) (600 MHz, $\left.\mathrm{CD}_{3} \mathrm{OD}\right)$
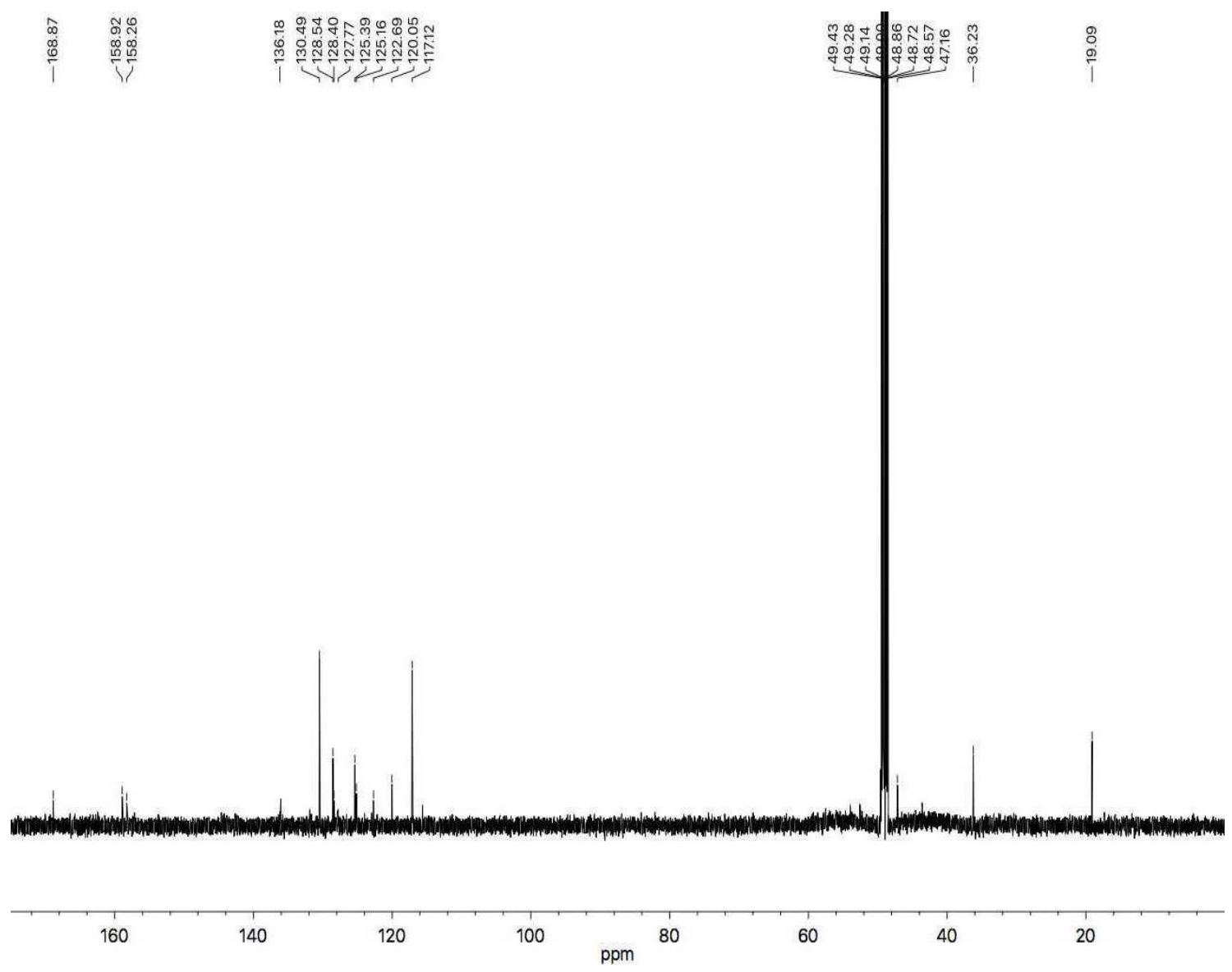

${ }^{13} \mathrm{C}$ NMR spectrum of tsitsikammanine B (184) $\left(150 \mathrm{MHz}, \mathrm{CD}_{3} \mathrm{OD}\right)$. 


\section{Appendix C}

\section{NMR Spectra of Known Compounds from Leucetta sp.}

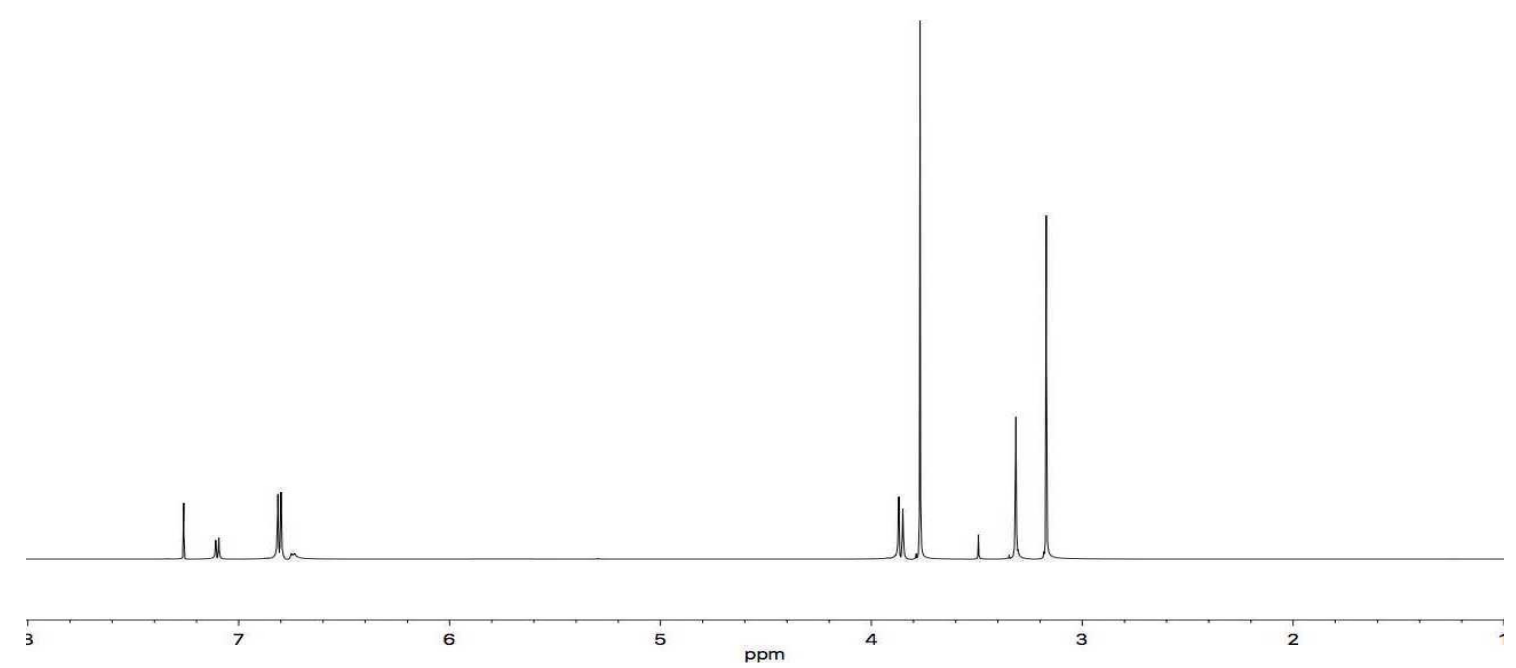

${ }^{1} \mathrm{H}$ NMR spectrum of naamidine A (213) $\left(600 \mathrm{MHz}, \mathrm{CDCl}_{3}\right)$.

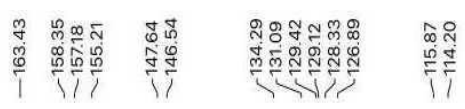
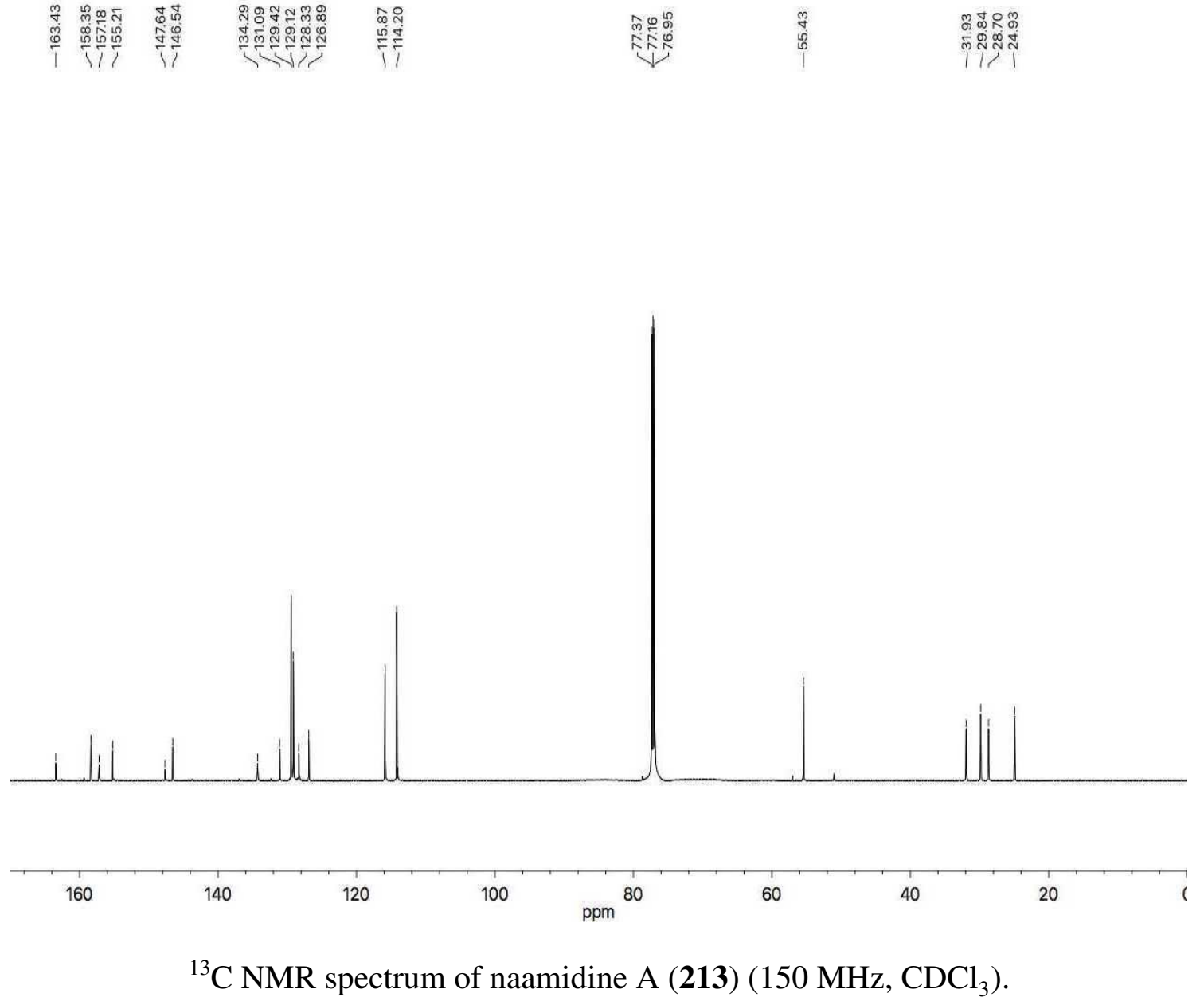


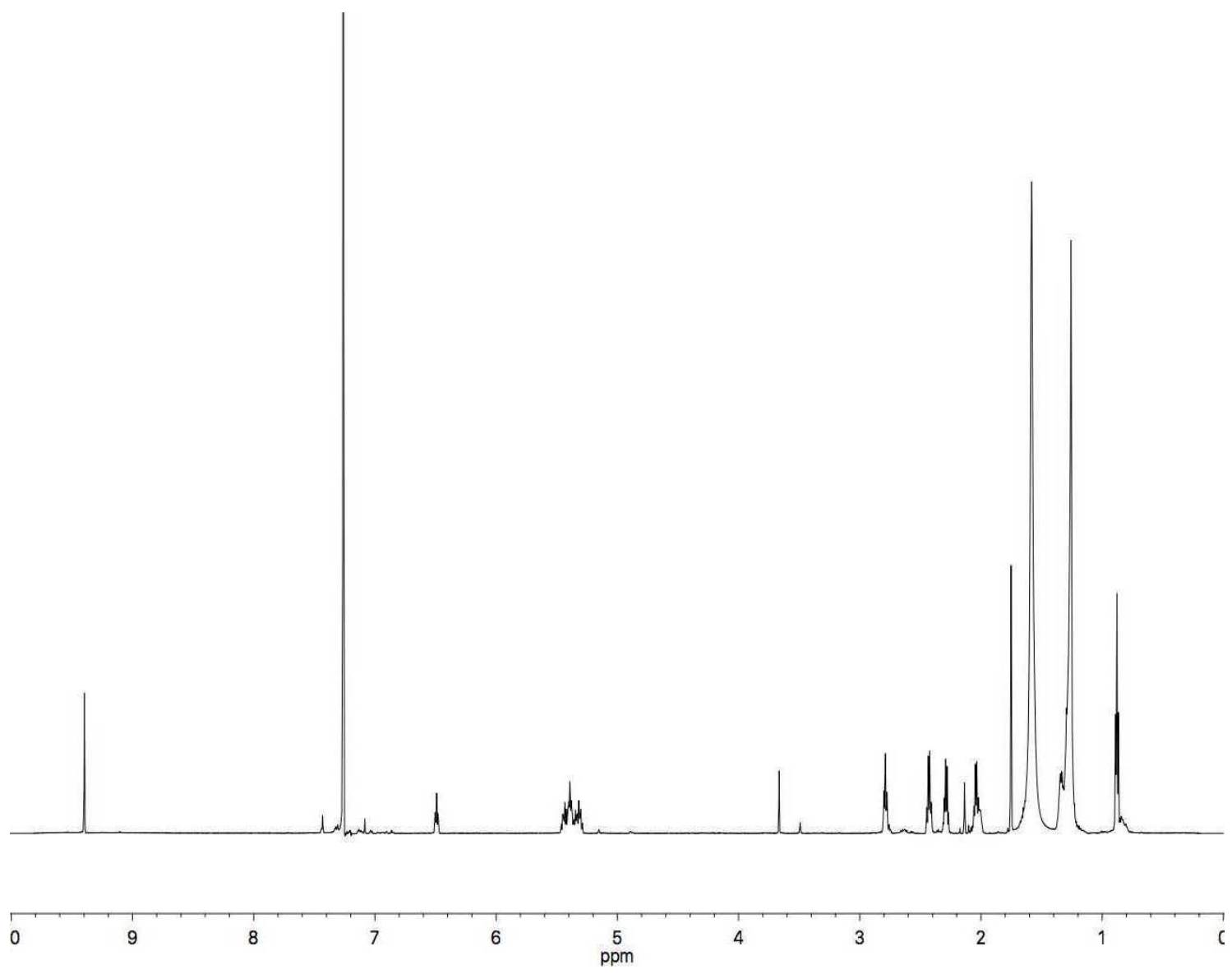

${ }^{1} \mathrm{H}$ NMR spectrum of 2E,6Z,9Z-2-Methyl-2,6,9-icosatrienal (223) (600 MHz, $\mathrm{CDCl}_{3}$ ).

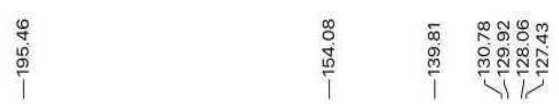

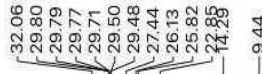

${ }^{13} \mathrm{C}$ NMR spectrum of 2E,6Z,9Z-2-Methyl-2,6,9-icosatrienal (223) (150 MHz, $\mathrm{CDCl}_{3}$ ). 

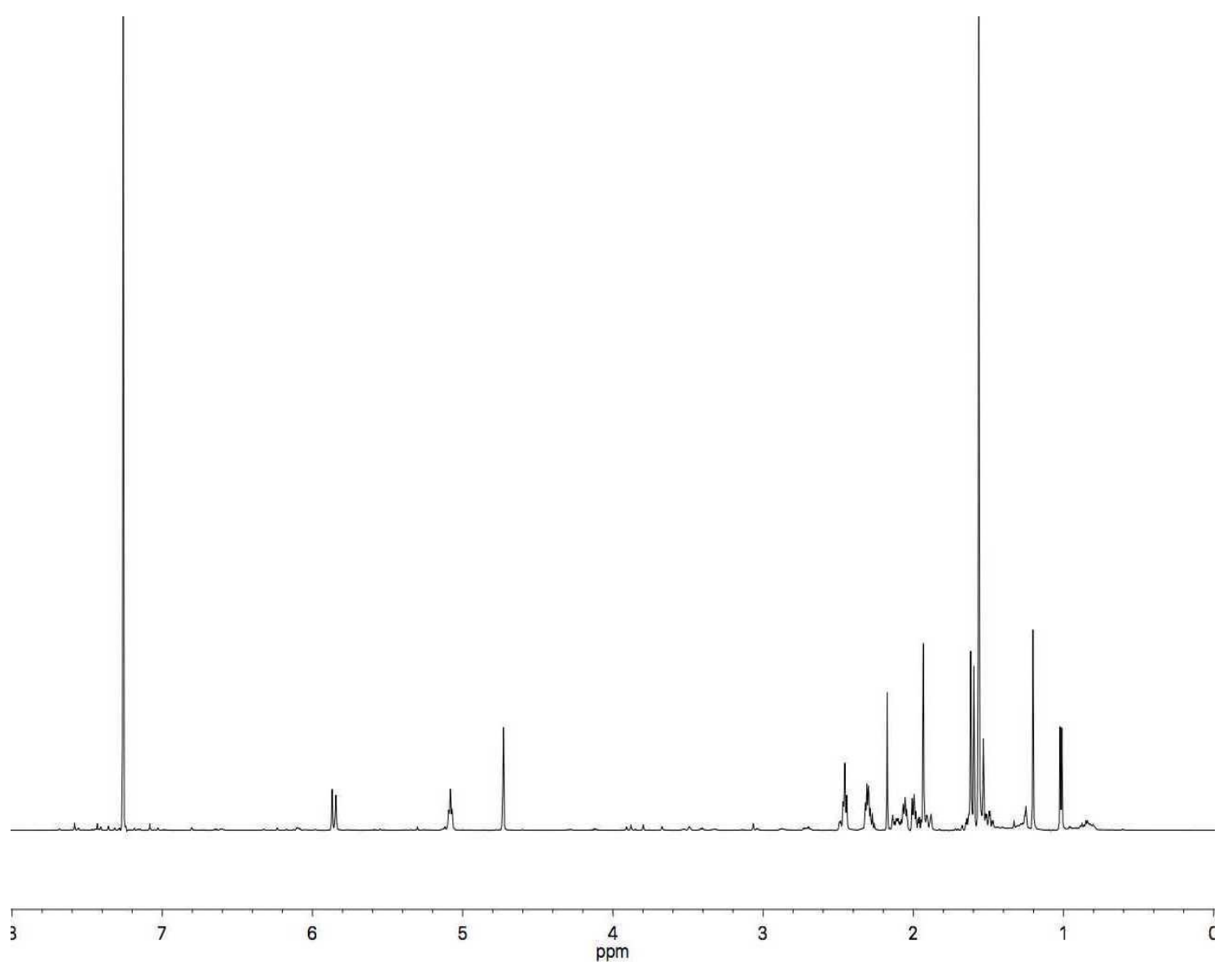

${ }^{1} \mathrm{H}$ NMR spectrum of cyclolinteinone (224) (600 MHz, $\left.\mathrm{CDCl}_{3}\right)$.

\begin{tabular}{|c|c|c|}
\hline $\begin{array}{l}\stackrel{\circ}{0} \\
\stackrel{0}{\circ} \\
\stackrel{\rho}{1}\end{array}$ & $\begin{array}{l}\text { No } \\
0 \% \\
0 \% \\
i=0\end{array}$ & 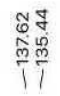 \\
\hline
\end{tabular}

${ }^{13} \mathrm{C}$ NMR spectrum of cyclolinteinone (224) $\left(150 \mathrm{MHz}, \mathrm{CDCl}_{3}\right)$. 


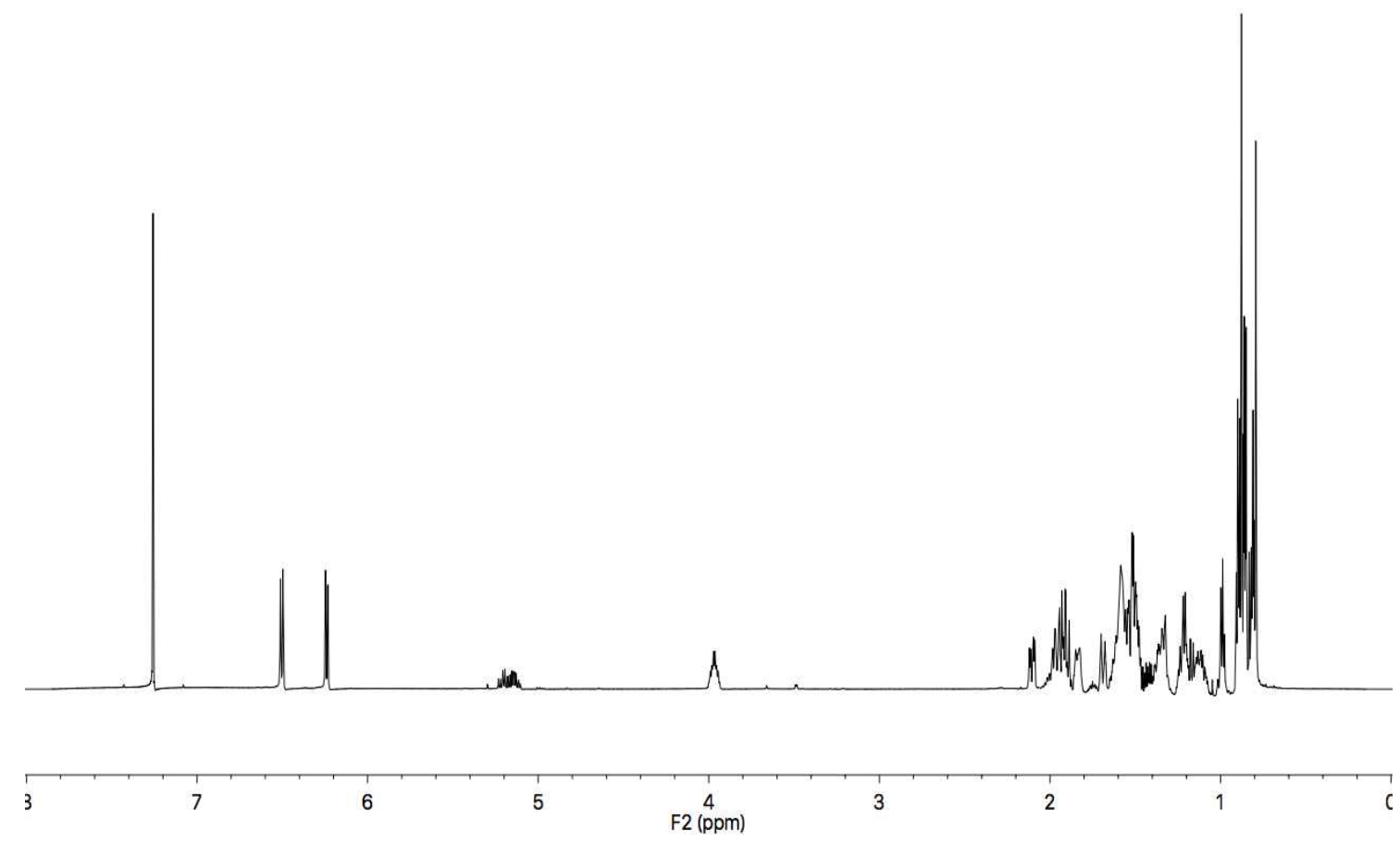

${ }^{1} \mathrm{H}$ NMR spectrum of $5 \alpha, 8 \alpha$-Epidioxycholesta-6-en-3 $\beta$-ol (225) (600 MHz, $\mathrm{CDCl}_{3}$ ).

$$
\text { H }
$$

.

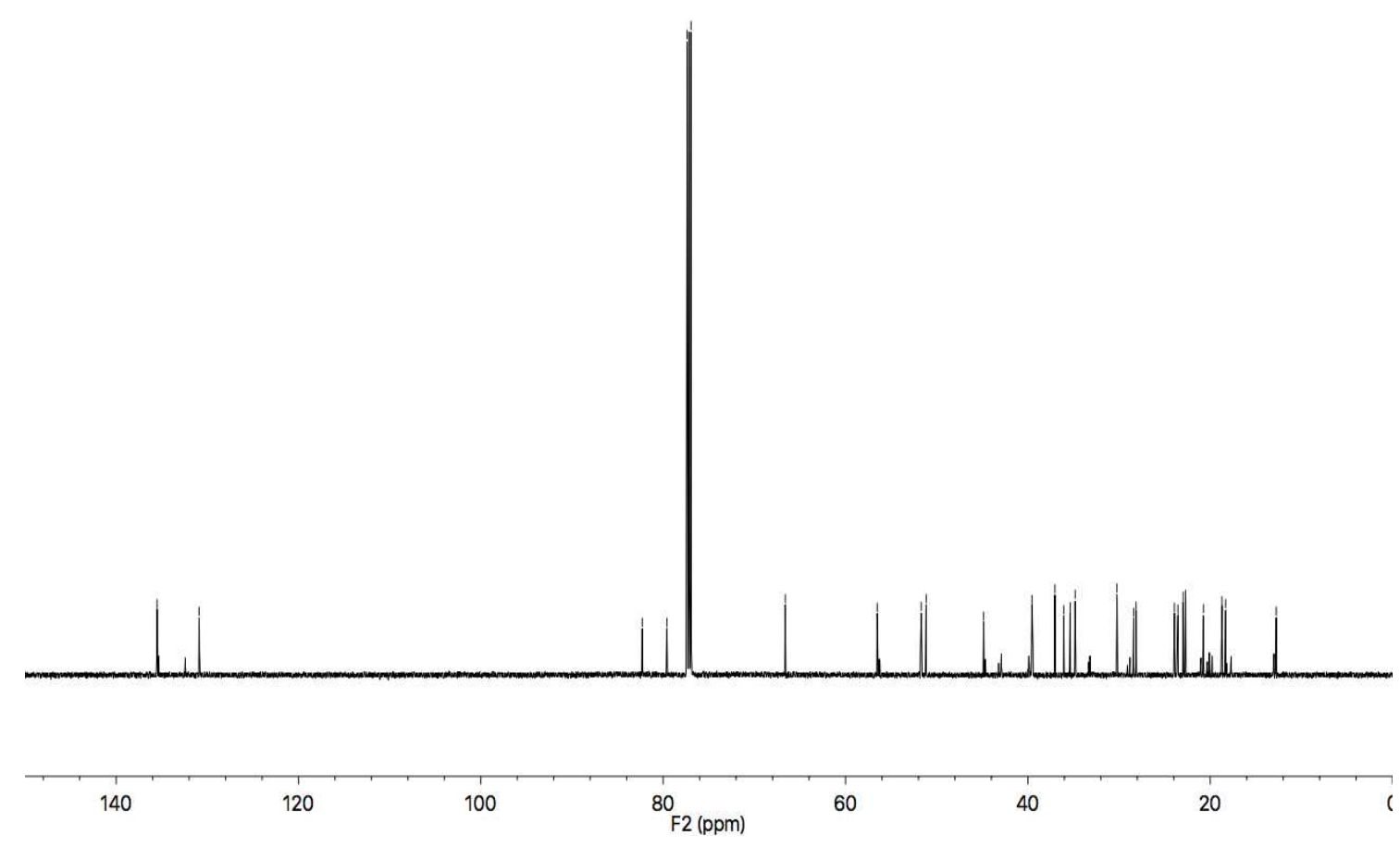

${ }^{13} \mathrm{C}$ NMR spectrum of $5 \alpha, 8 \alpha$-Epidioxycholesta-6-en-3 $\beta$-ol (225) $\left(150 \mathrm{MHz}, \mathrm{CDCl}_{3}\right)$. 


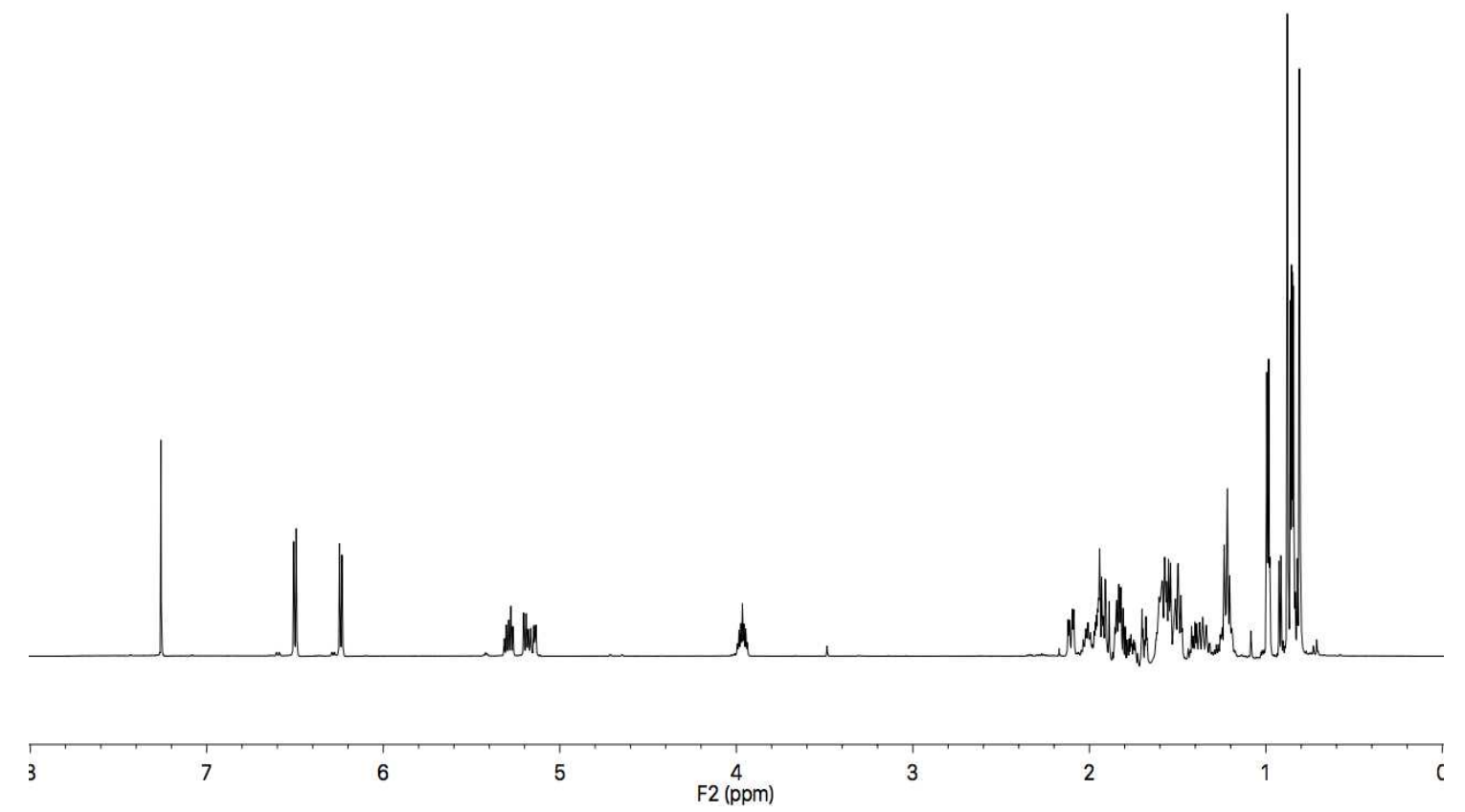

${ }^{1} \mathrm{H}$ NMR spectrum of $5 \alpha, 8 \alpha$-Epidioxy-24-cholesta-6,22-dien-3 $\beta$-ol (226) (600 MHz, $\left.\mathrm{CDCl}_{3}\right)$.

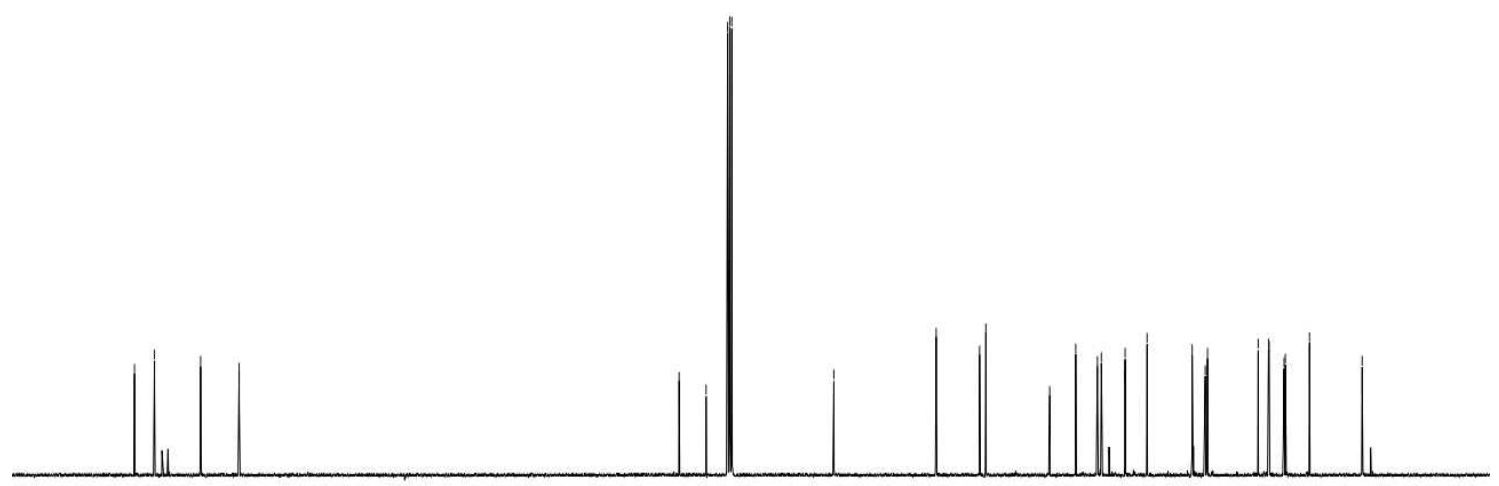

140

120

100

80 F2 (ppm)

60

20

${ }^{13} \mathrm{C}$ NMR spectrum of $5 \alpha, 8 \alpha$-Epidioxy-24-cholesta-6,22-dien-3 $\beta$-ol (226) (150 MHz, $\left.\mathrm{CDCl}_{3}\right)$. 


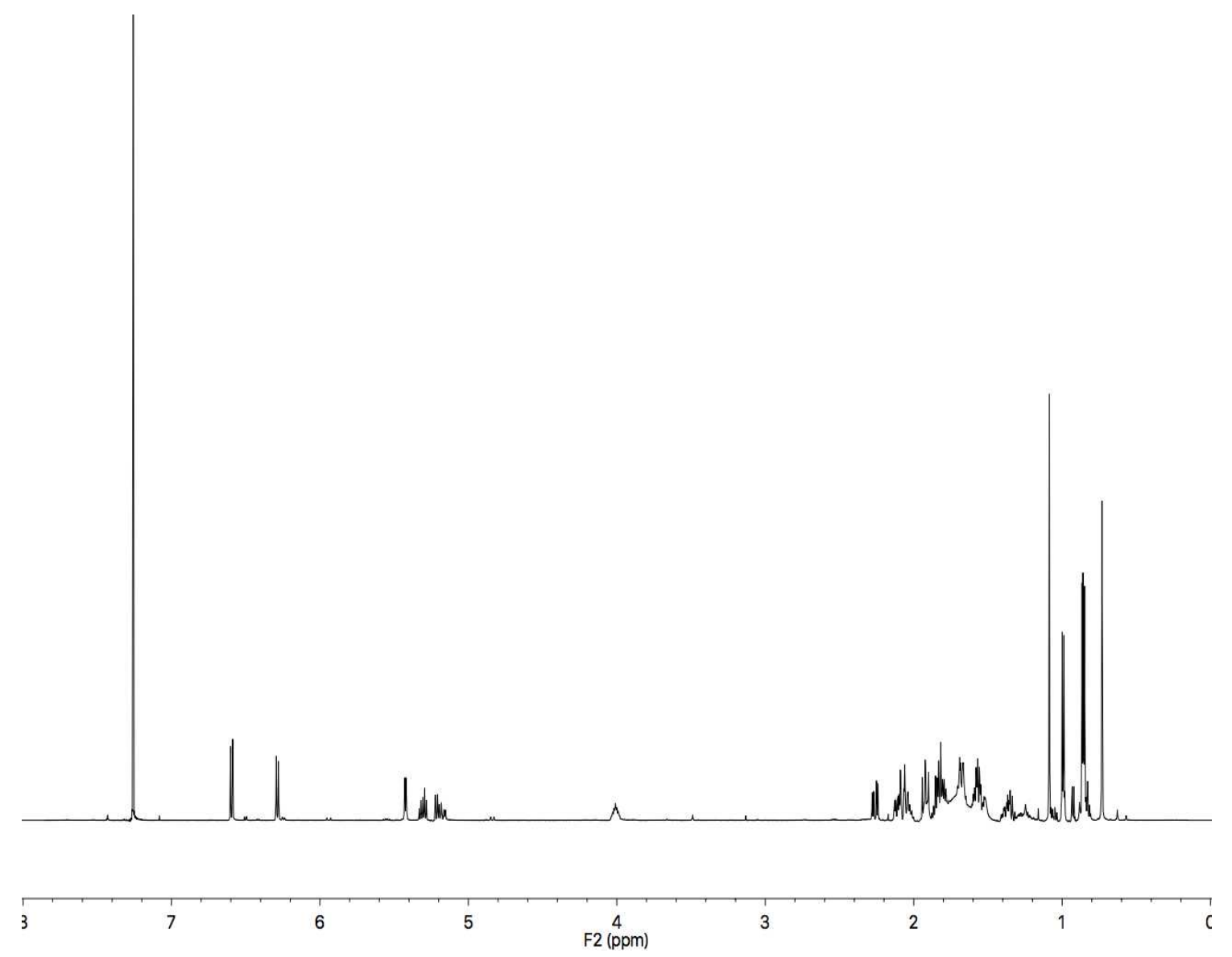

${ }^{1} \mathrm{H}$ NMR spectrum of $5 \alpha, 8 \alpha$-Epidioxycholesta-6,9(11),22-trien-3 $\beta$-ol (227) (600 MHz, $\left.\mathrm{CDCl}_{3}\right)$.
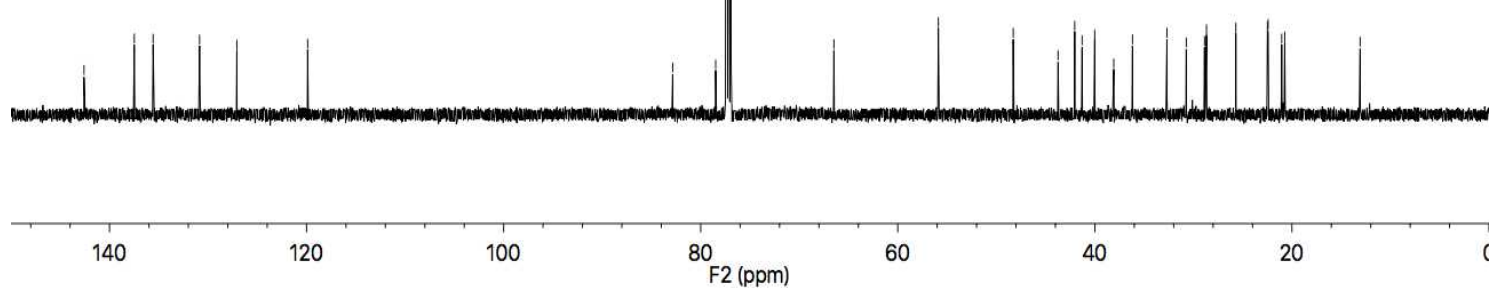

${ }^{13} \mathrm{C}$ NMR spectrum of $5 \alpha, 8 \alpha$-Epidioxycholesta-6,9(11),22-trien-3 $\beta$-ol (227) (150 MHz, $\left.\mathrm{CDCl}_{3}\right)$. 


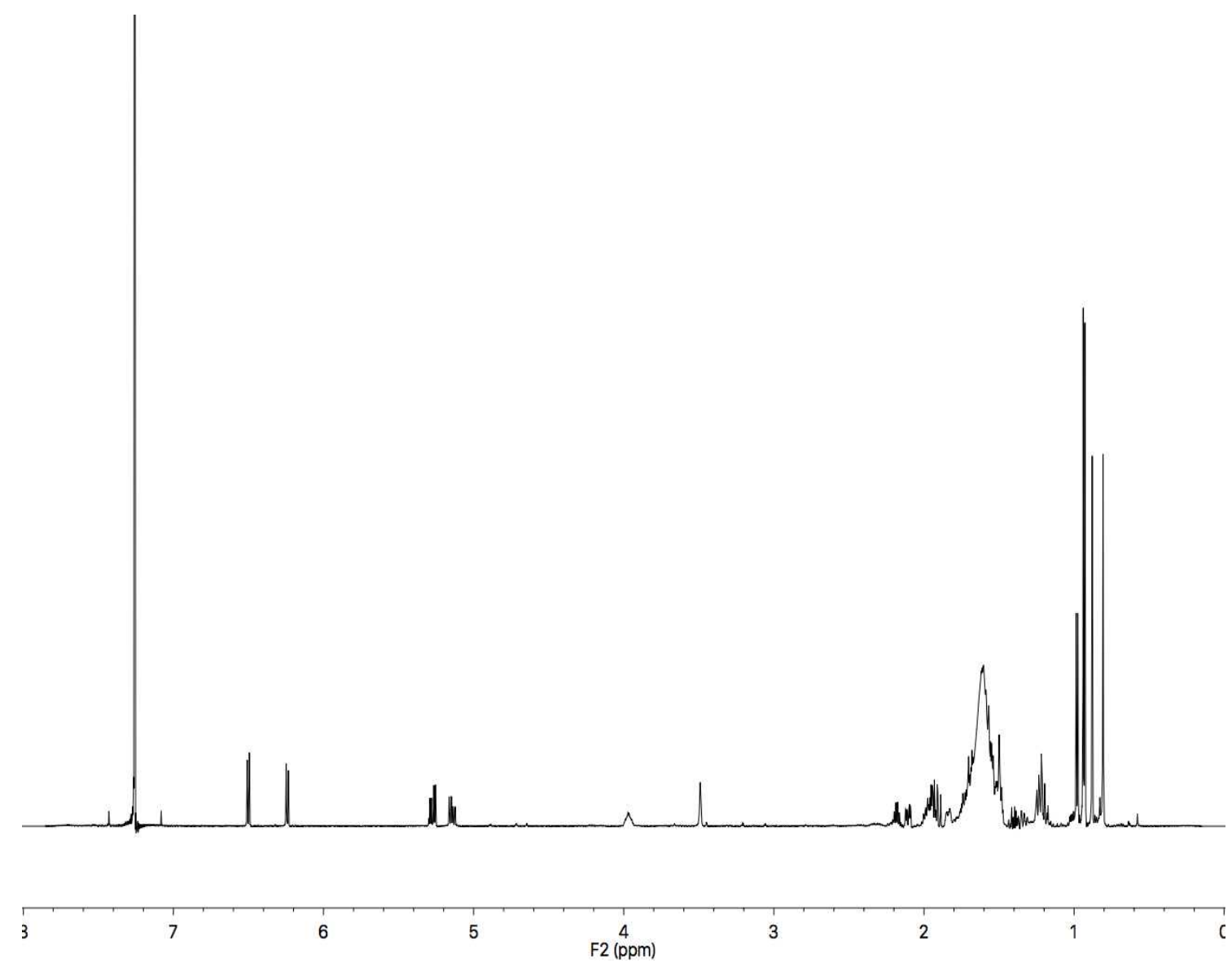

${ }^{1} \mathrm{H}$ NMR spectrum of $5 \alpha, 8 \alpha$-Epidioxy-24-norcholesta-6,22-dien-3 $\beta$-ol (228) (600 MHz, $\left.\mathrm{CDCl}_{3}\right)$.

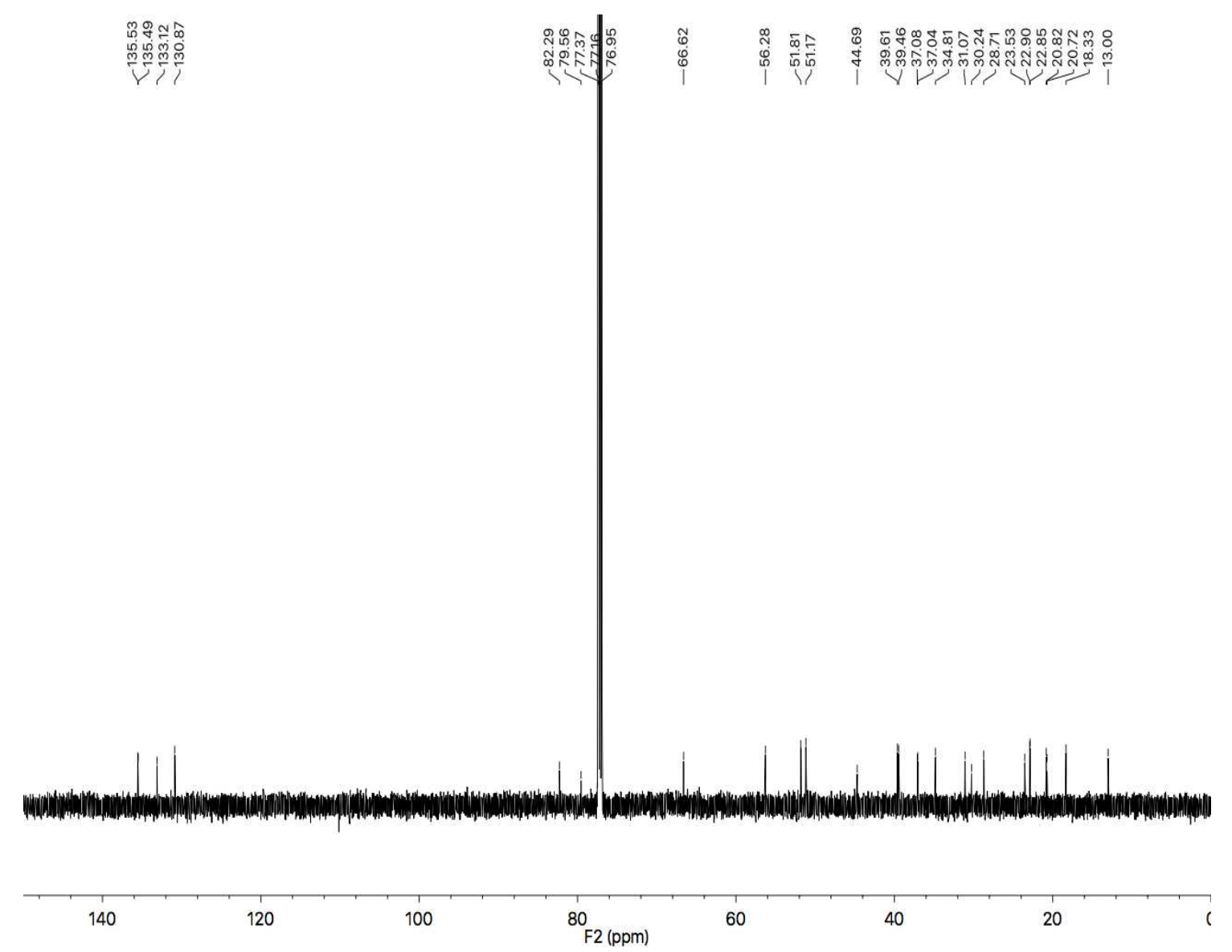

${ }^{13} \mathrm{C}$ NMR spectrum of $5 \alpha, 8 \alpha$-Epidioxy-24-norcholesta-6,22-dien-3 $\beta$-ol (228) $\left(150 \mathrm{MHz}, \mathrm{CDCl}_{3}\right)$. 


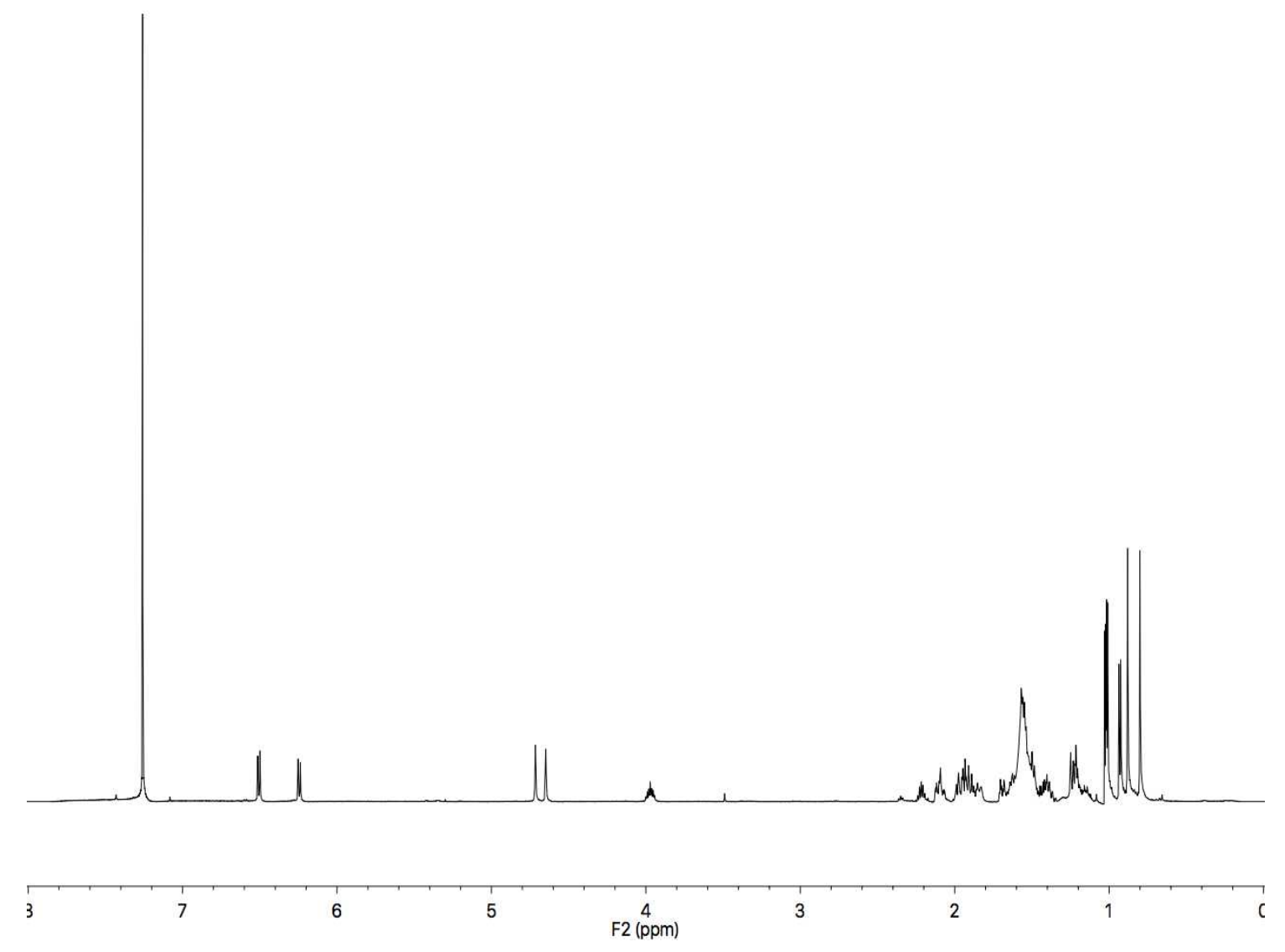

${ }^{1} \mathrm{H}$ NMR spectrum of 5 $\alpha, 8 \alpha$-Epidioxy-24-methylcholesta-6,24(28)-dien-3 $\beta$-ol (229) (600 MHz, $\mathrm{CDCl}_{3}$ ).
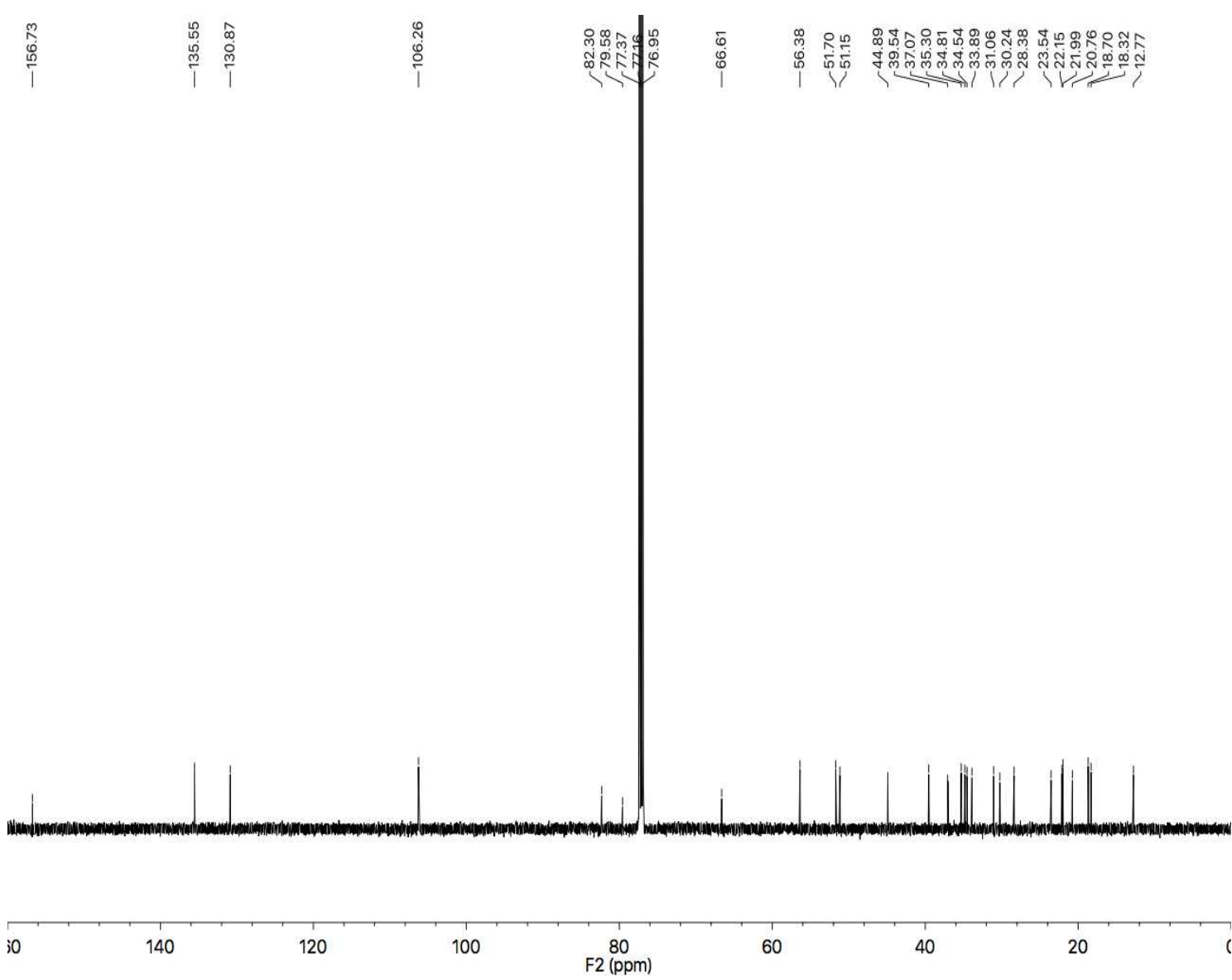

${ }^{13} \mathrm{C}$ NMR spectrum of $5 \alpha, 8 \alpha$-Epidioxy-24-methylcholesta-6,24(28)-dien-3 $\beta$-ol (229) (150 MHz, $\mathrm{CDCl}_{3}$ ). 


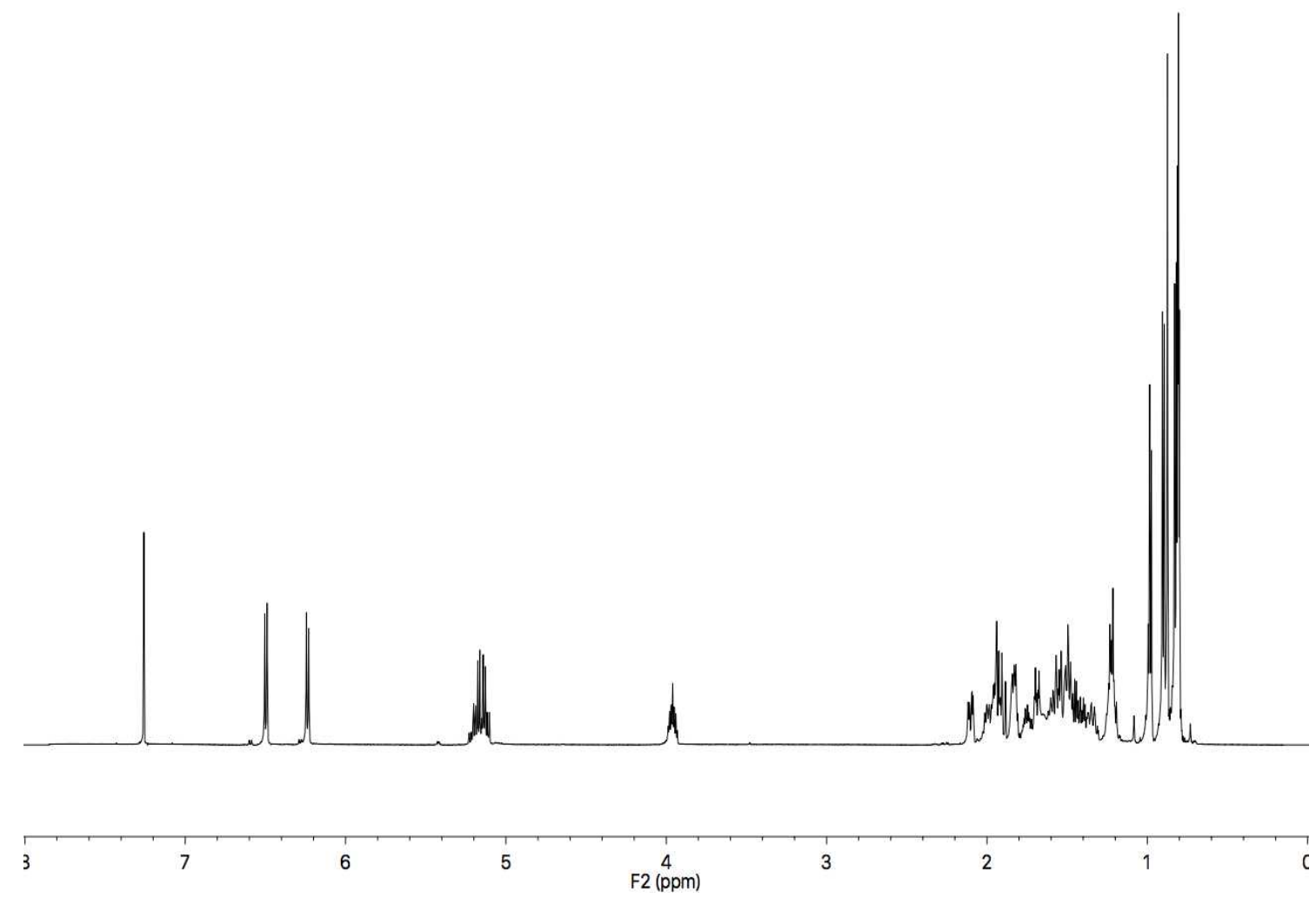

${ }^{1} \mathrm{H}$ NMR spectrum of $5 \alpha, 8 \alpha$-Epidioxy-24-methylcholesta-6,22-dien-3 $\beta$-ol (230) (600 MHz, $\mathrm{CDCl}_{3}$ ).

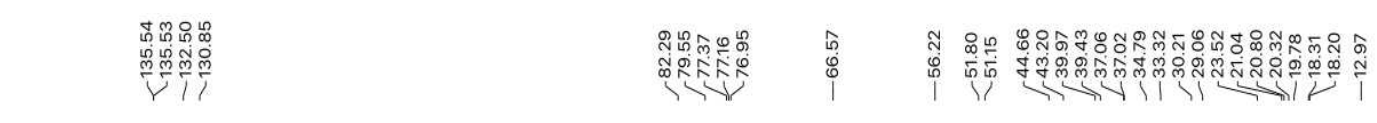

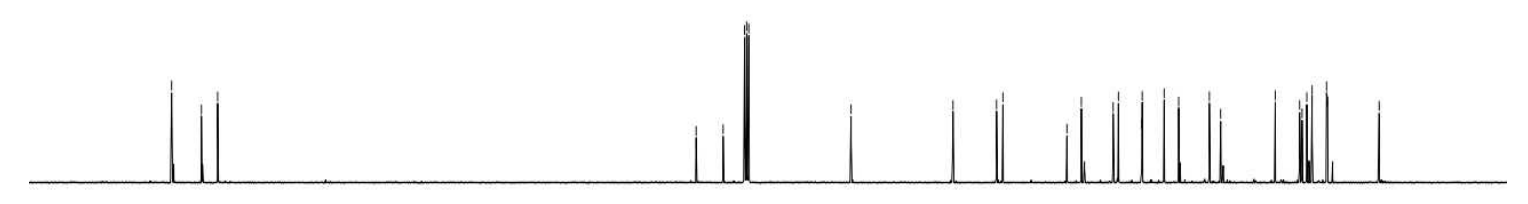

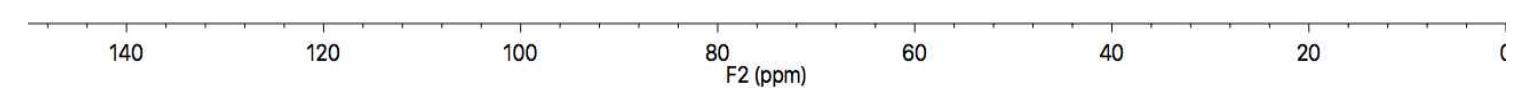

${ }^{13} \mathrm{C}$ NMR spectrum of $5 \alpha, 8 \alpha$-Epidioxy-24-methylcholesta-6,22-dien-3 $\beta$-ol (230) $\left(150 \mathrm{MHz}, \mathrm{CDCl}_{3}\right)$. 

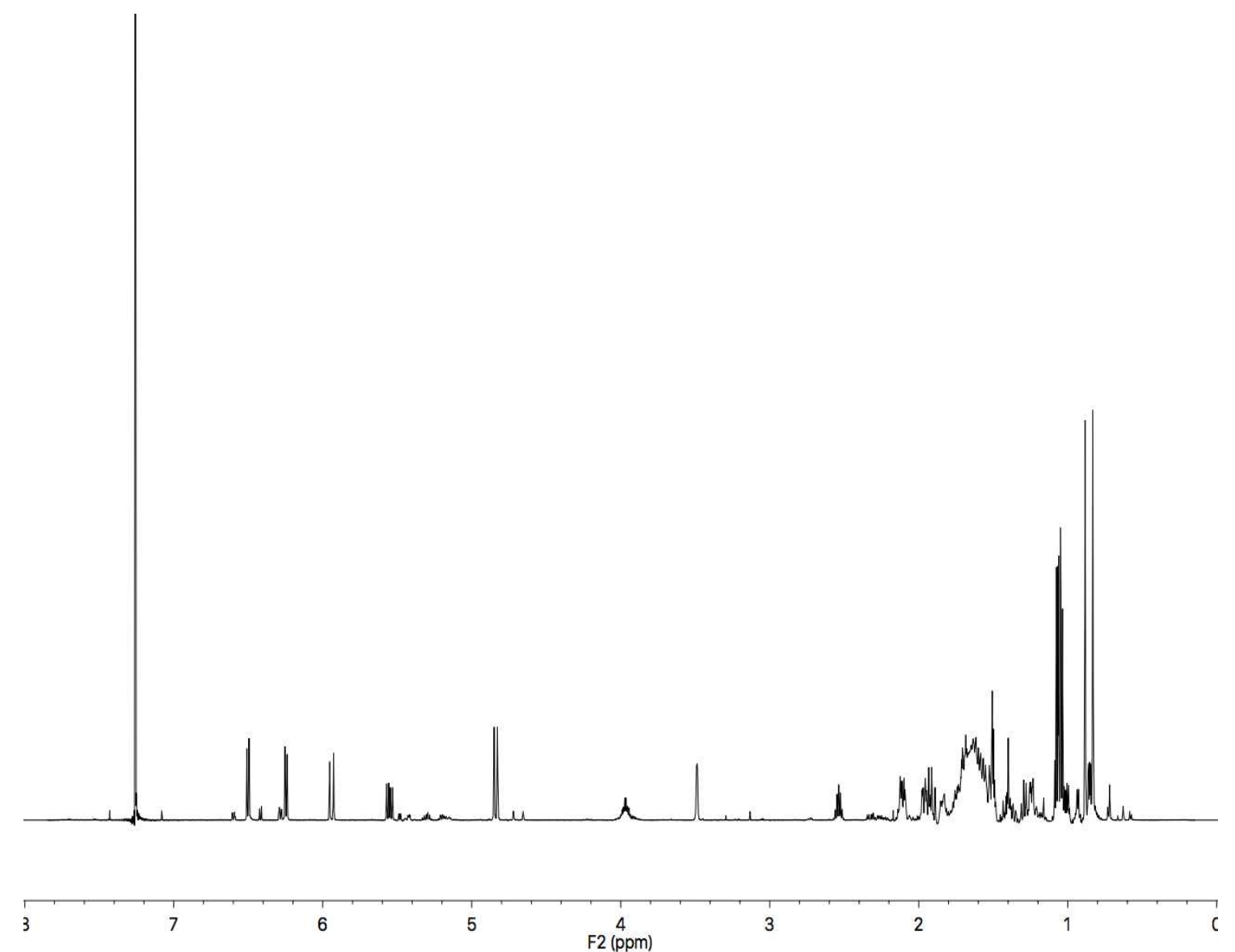

${ }^{1} \mathrm{H}$ NMR spectrum of $5 \alpha, 8 \alpha$-Epidioxy-cholesta-6,22,24(28)-trien-3 $\beta$-ol (231) (600 MHz, $\mathrm{CDCl}_{3}$ ).

\begin{tabular}{|c|c|c|c|c|c|c|}
\hline $\begin{array}{c}\text { के } \\
\text { N } \\
\stackrel{0}{1}\end{array}$ & 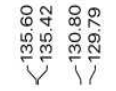 & $\frac{1}{\frac{\pi}{\sigma}}$ & 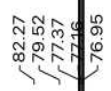 & $\begin{array}{l}\bar{\emptyset} \\
\dot{0} \\
i\end{array}$ & 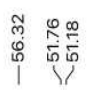 & 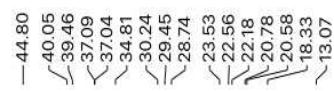 \\
\hline
\end{tabular}
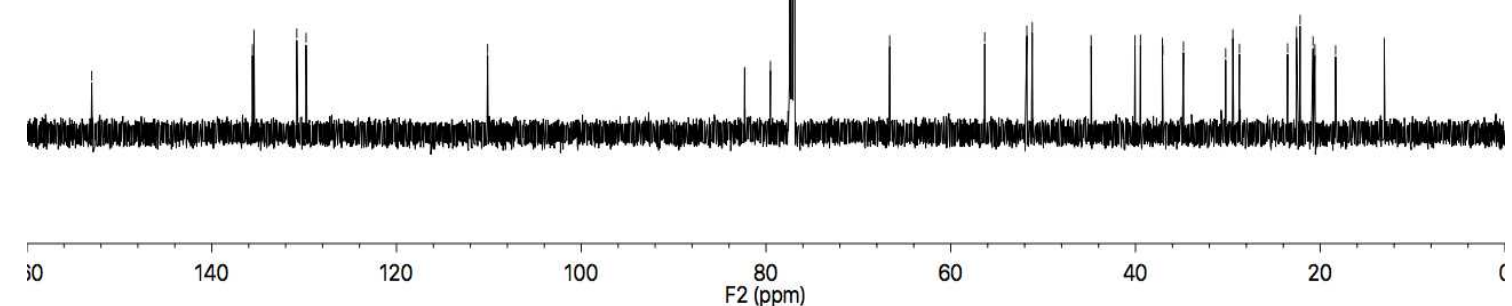

${ }^{13} \mathrm{C}$ NMR spectrum of $5 \alpha, 8 \alpha$-Epidioxy-cholesta-6,22,24(28)-trien-3 $\beta$-ol (231) (150 MHz, $\left.\mathrm{CDCl}_{3}\right)$. 


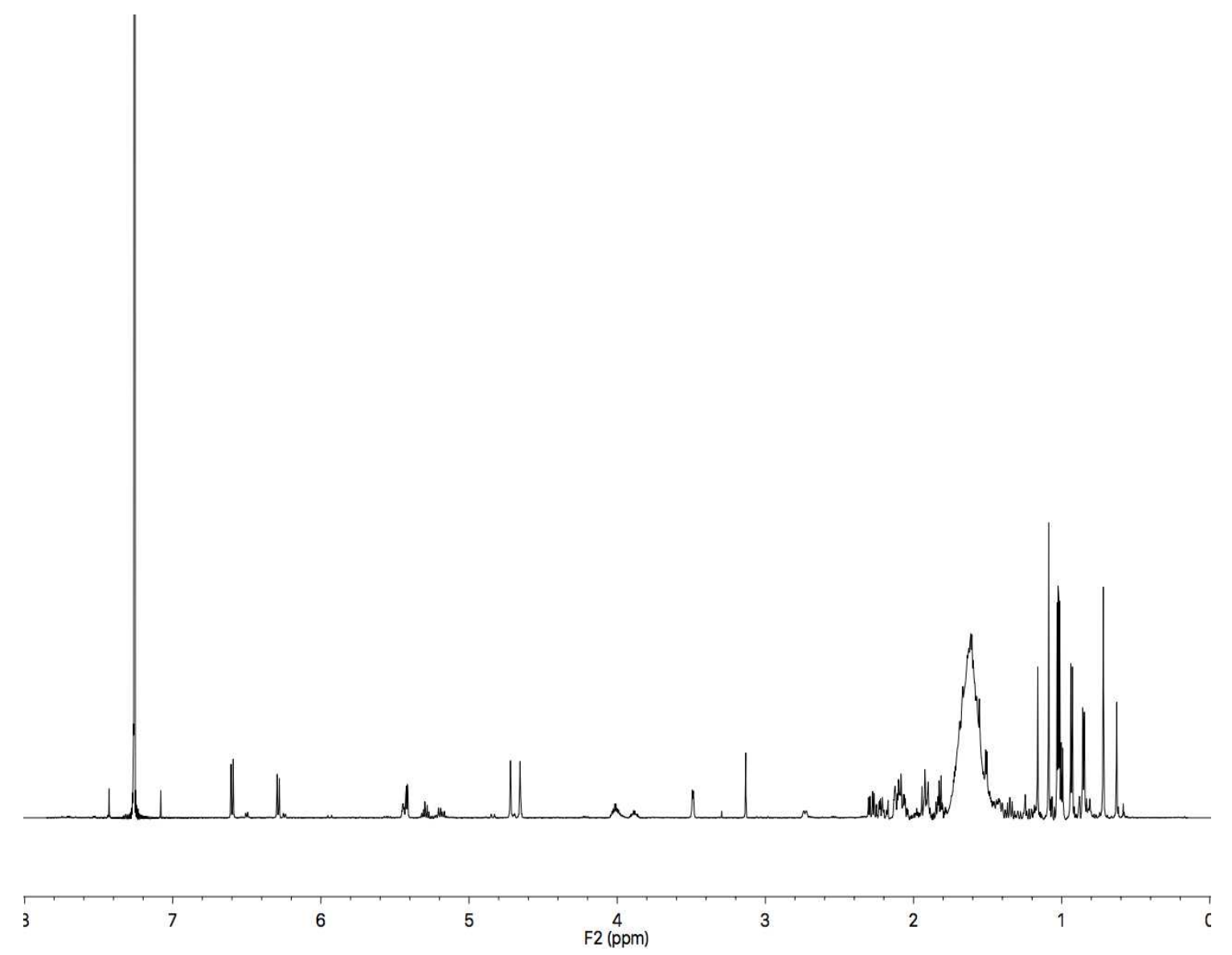

${ }^{1} \mathrm{H}$ NMR spectrum of $5 \alpha, 8 \alpha$-Epidioxy-24-methylcholesta-6,9(11),24(28)-trien-3 $\beta$-ol (232) $\left(600 \mathrm{MHz}, \mathrm{CDCl}_{3}\right)$.

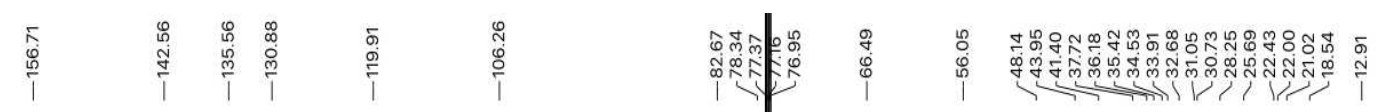

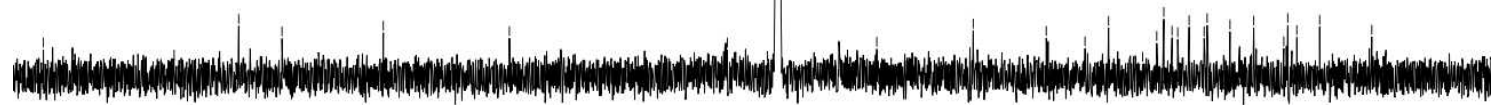

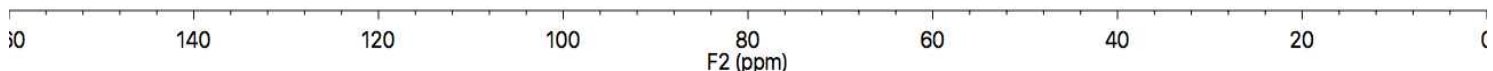

${ }^{13} \mathrm{C}$ NMR spectrum of $5 \alpha, 8 \alpha$-Epidioxy-24-methylcholesta-6,9(11),24(28)-trien-3 $\beta$-ol (232) (150 MHz, $\left.\mathrm{CDCl}_{3}\right)$. 


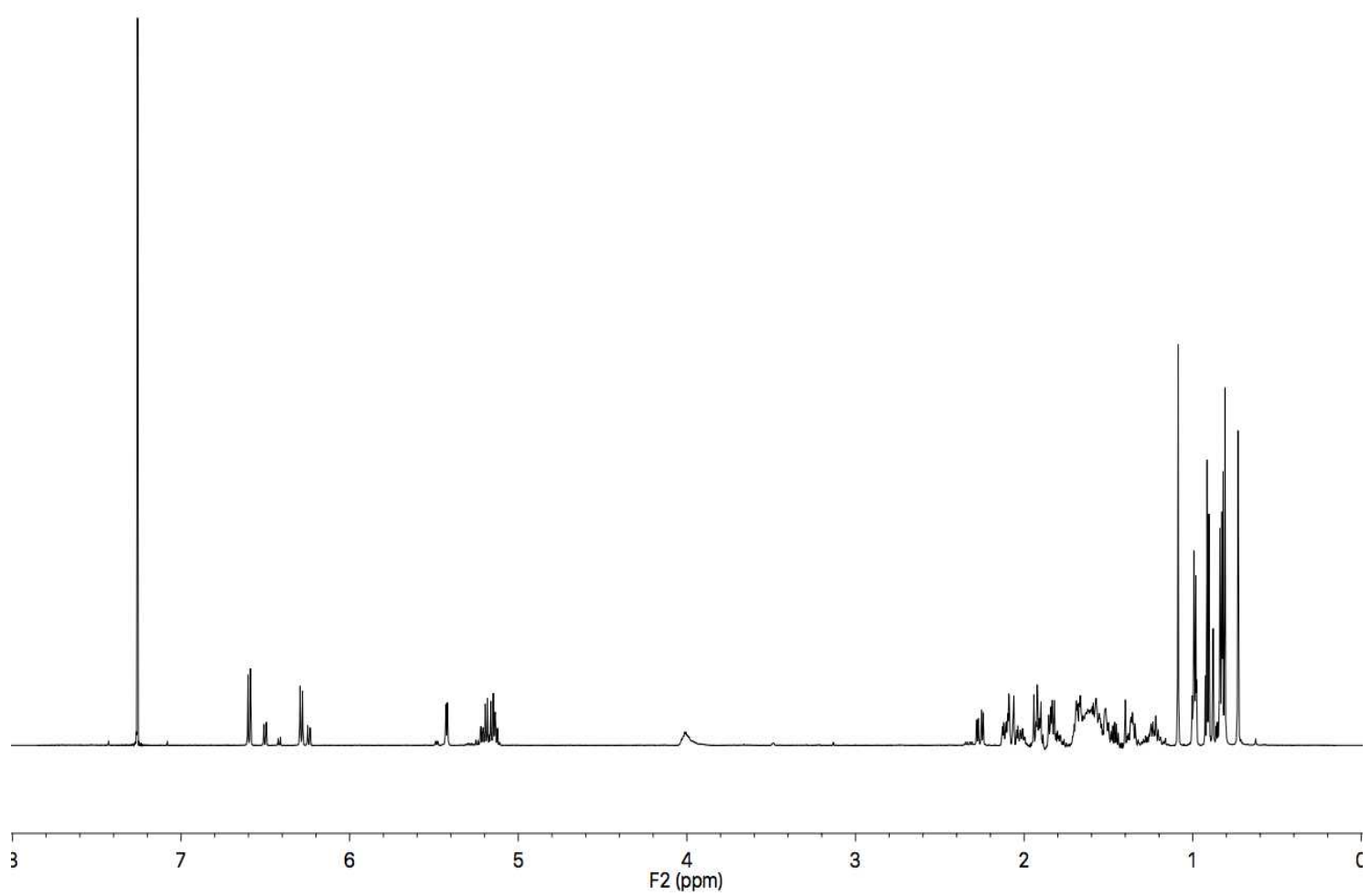

${ }^{1} \mathrm{H}$ NMR spectrum of 5 $\alpha, 8 \alpha$-Epidioxy-24-methylcholesta-6,9(11),22-trien-3 $\beta$-ol (233) (600 MHz, $\mathrm{CDCl}_{3}$ ).
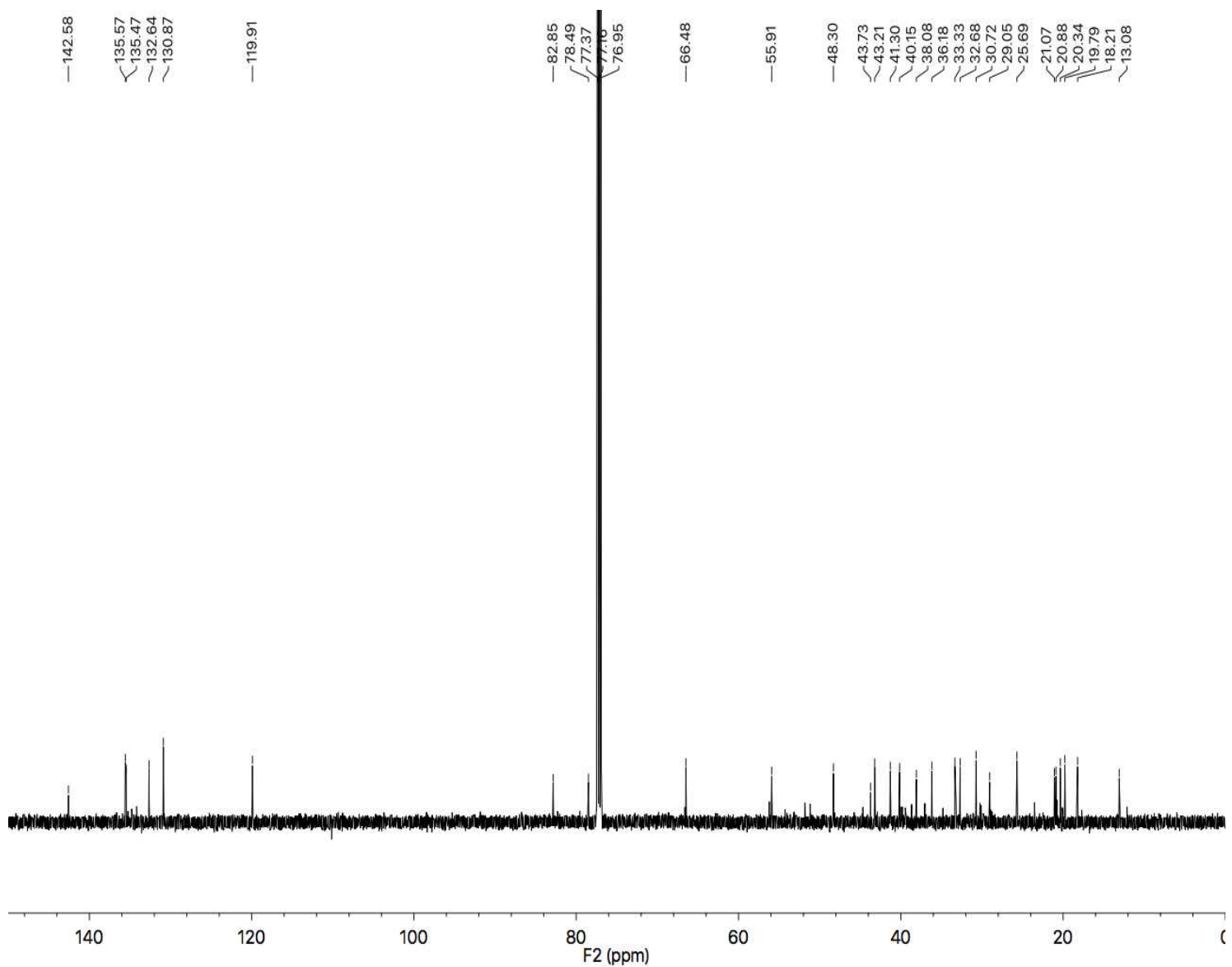

60

20

${ }^{13} \mathrm{C}$ NMR spectrum of $5 \alpha, 8 \alpha$-Epidioxy-24-methylcholesta-6,9(11),22-trien-3 $\beta$-ol (233) $\left(150 \mathrm{MHz}, \mathrm{CDCl}_{3}\right)$. 


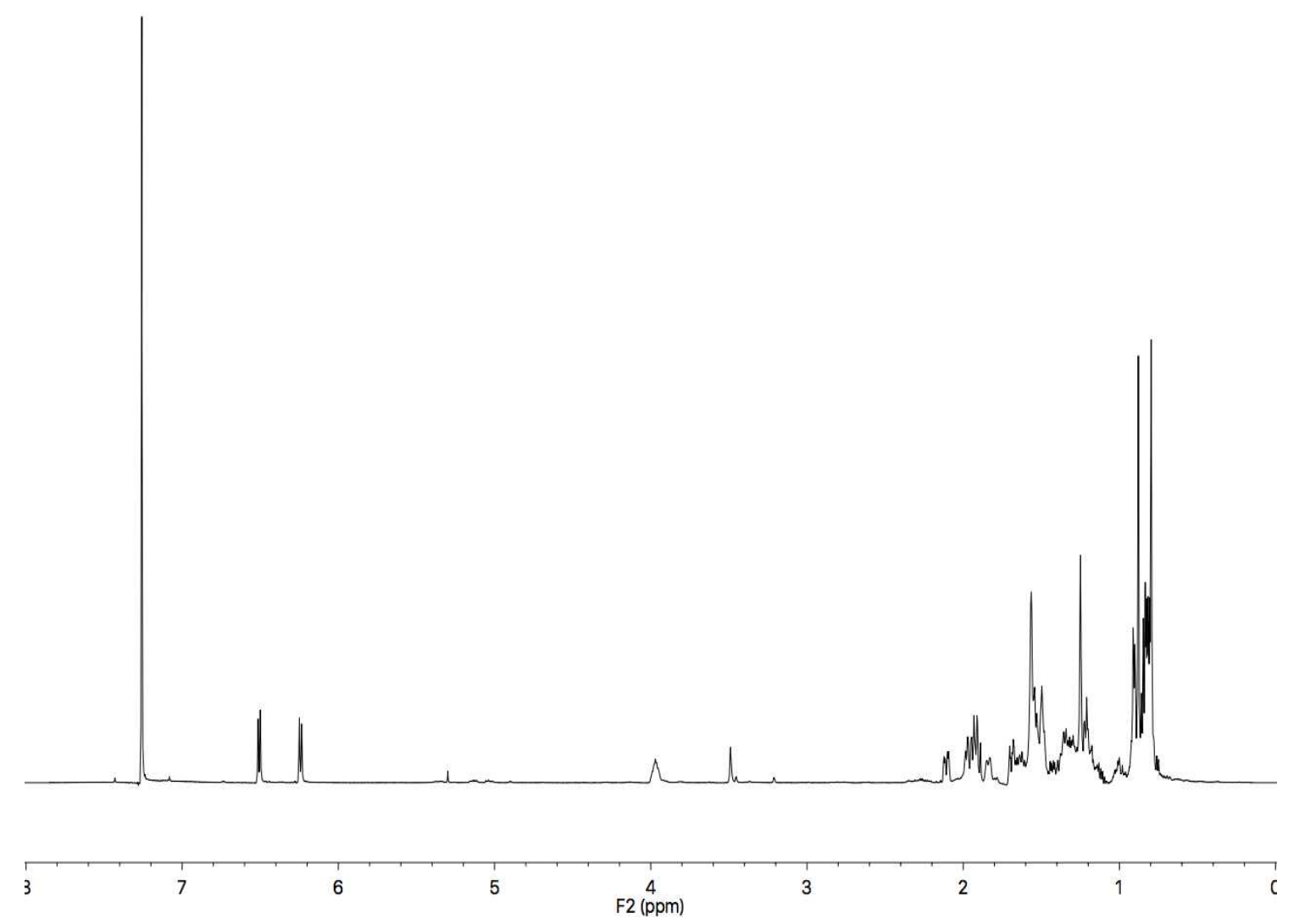

${ }^{1} \mathrm{H}$ NMR spectrum of $5 \alpha, 8 \alpha$-Epidioxy-24-ethylcholesta-6-en-3 $\beta$-ol (234) (600 MHz, $\left.\mathrm{CDCl}_{3}\right)$.

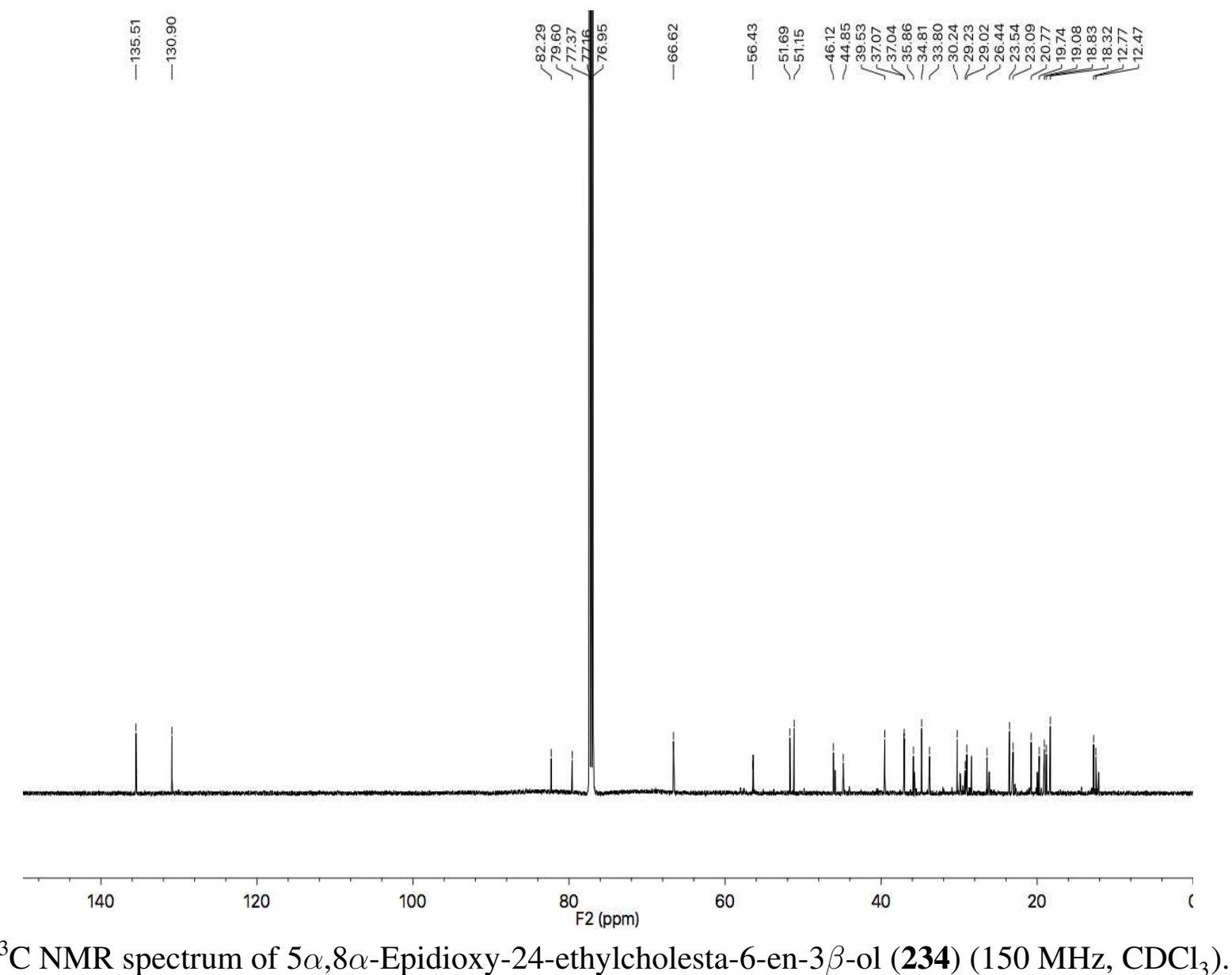

${ }^{13} \mathrm{C}$ NMR spectrum of $5 \alpha, 8 \alpha$-Epidioxy-24-ethylcholesta-6-en-3 $\beta$-ol (234) (150 MHz, $\left.\mathrm{CDCl}_{3}\right)$. 


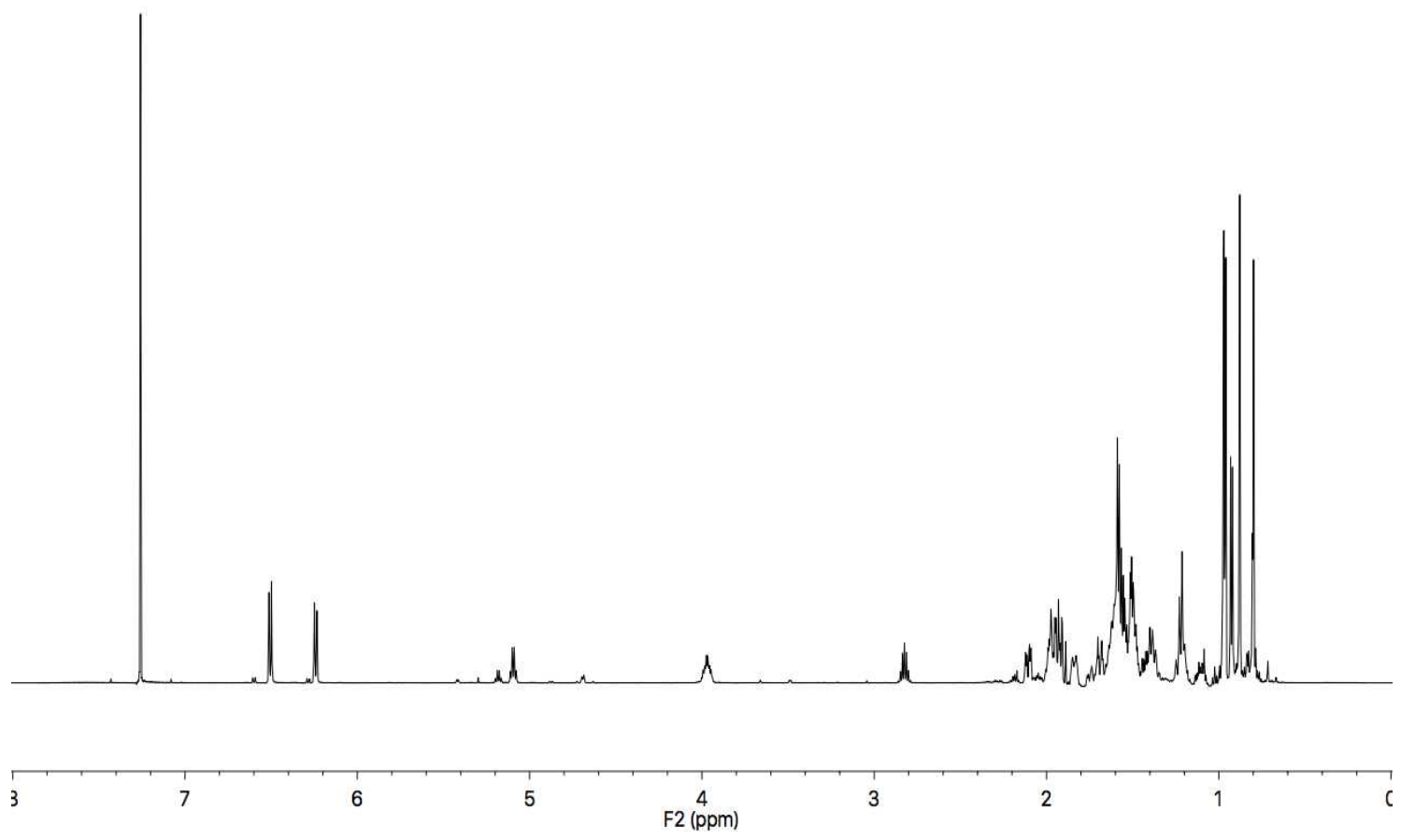

${ }^{1} \mathrm{H}$ NMR spectrum of 5 $\alpha, 8 \alpha$-Epidioxy-24-ethylcholesta-6,24(28)-dien-3 $\beta$-ol (235) $\left(600 \mathrm{MHz}, \mathrm{CDCl}_{3}\right)$.
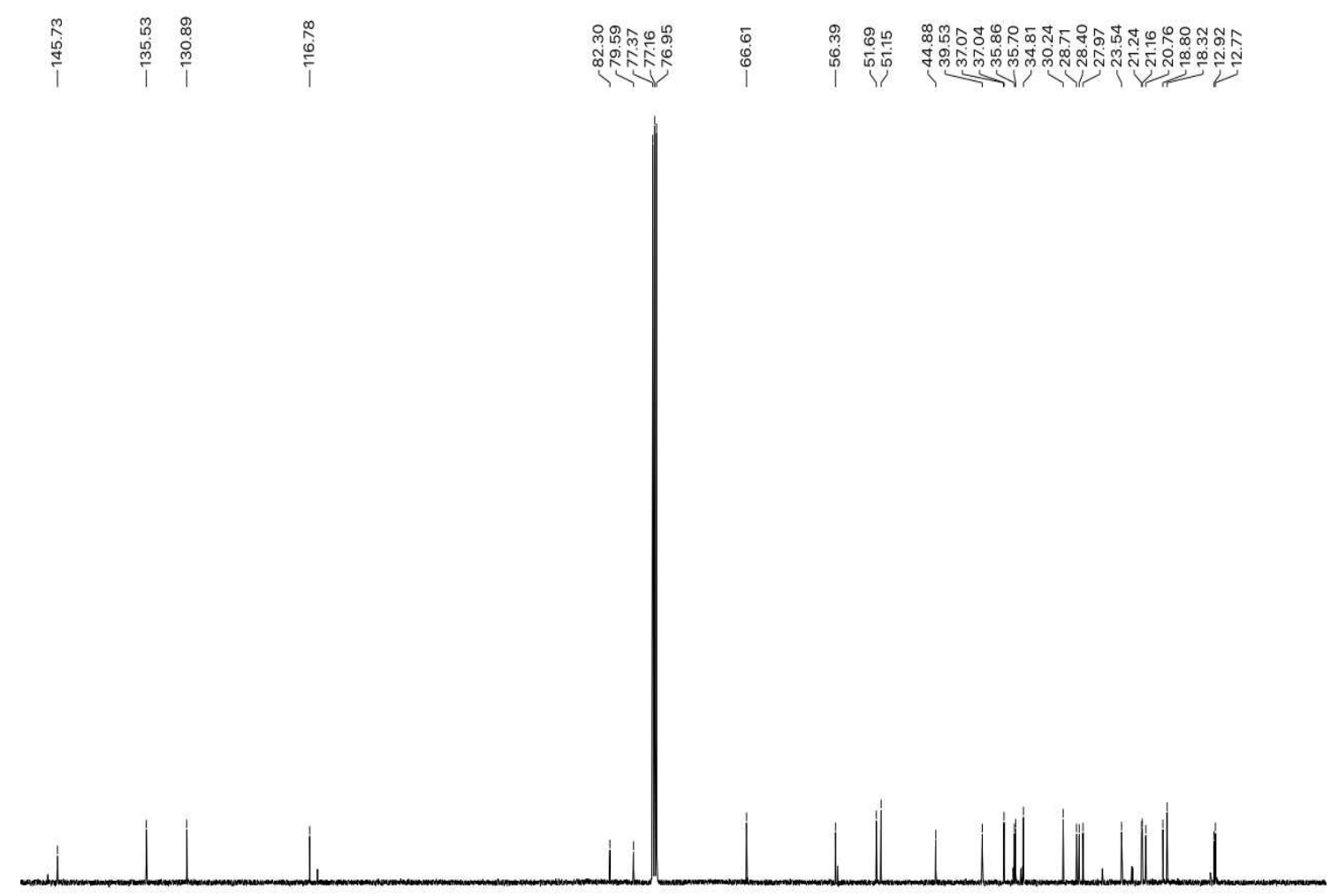

$140 \quad 120$

80 F2 (ppm)

60

20

${ }^{13} \mathrm{C}$ NMR spectrum of $5 \alpha, 8 \alpha$-Epidioxy-24-ethylcholesta-6,24(28)-dien-3 $\beta$-ol (235) $\left(150 \mathrm{MHz}, \mathrm{CDCl}_{3}\right)$. 


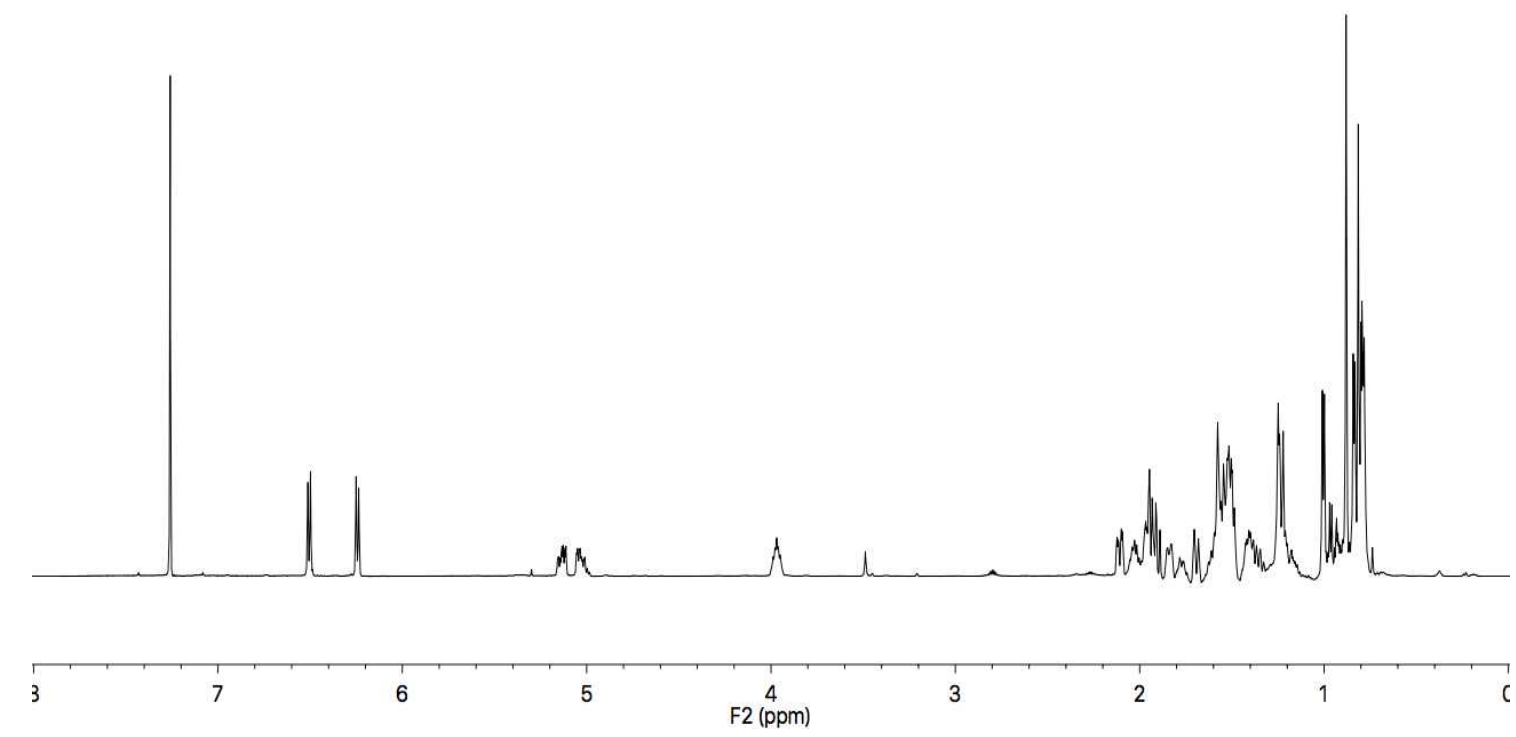

${ }^{1} \mathrm{H}$ NMR spectrum of $5 \alpha, 8 \alpha$-Epidioxy-24-ethylcholesta-6,22-dien-3 $\beta$-ol (236) $\left(600 \mathrm{MHz}, \mathrm{CDCl}_{3}\right)$.

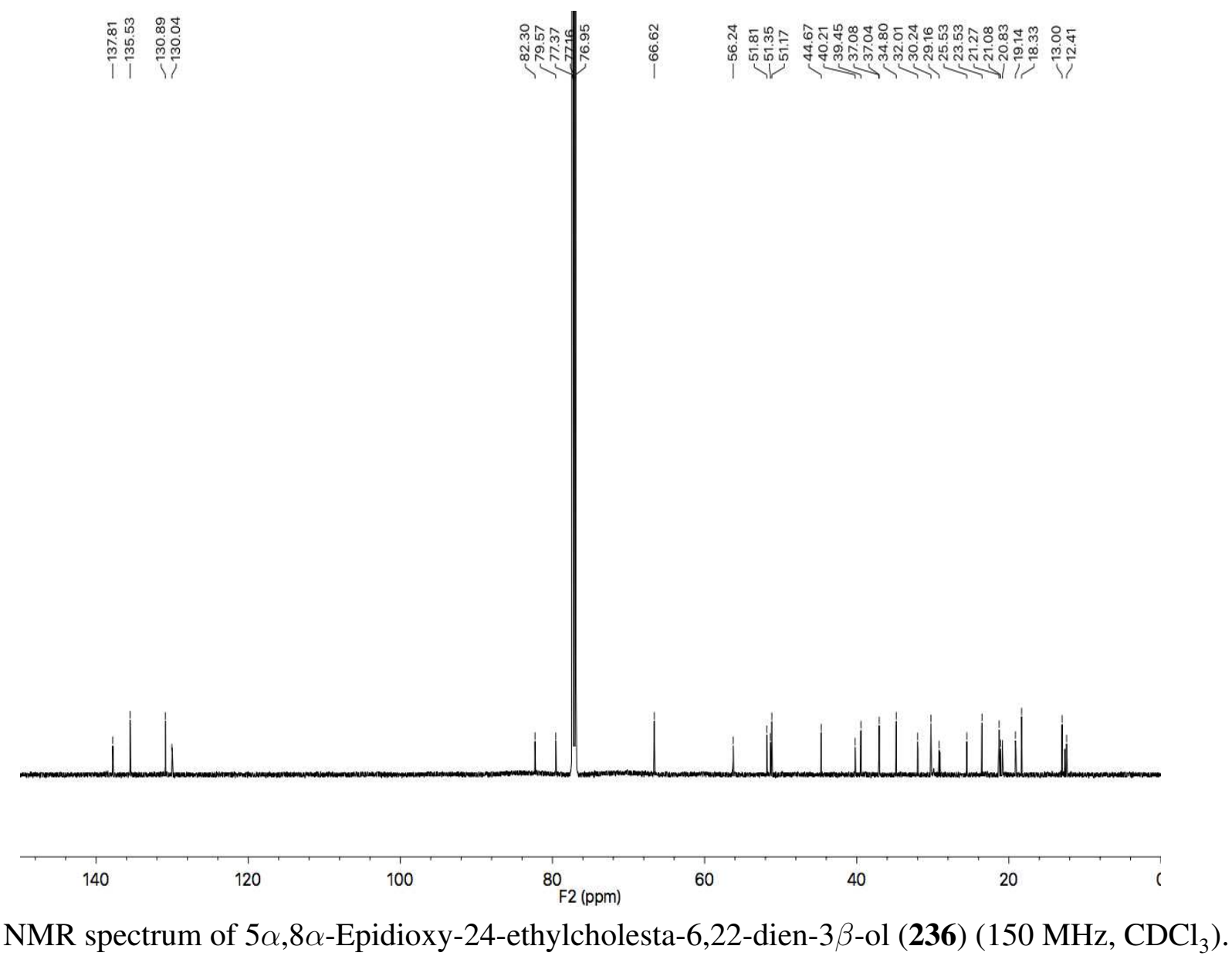




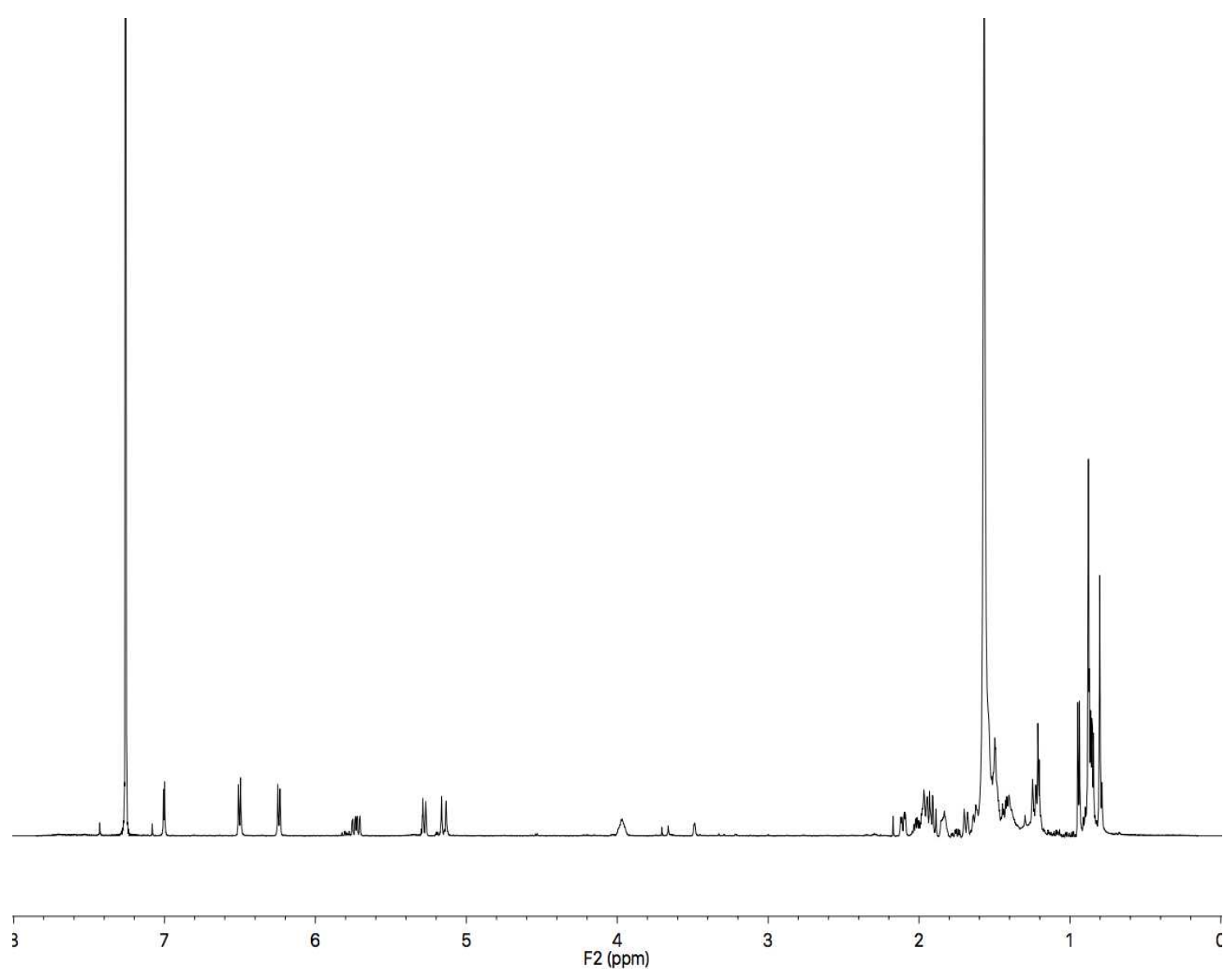

${ }^{1} \mathrm{H}$ NMR spectrum of $5 \alpha, 8 \alpha$-Epidioxy-24-hydroperoxycholesta-6,28(29)-dien-3 $\beta$-ol (237) (600 MHz, $\left.\mathrm{CDCl}_{3}\right)$.

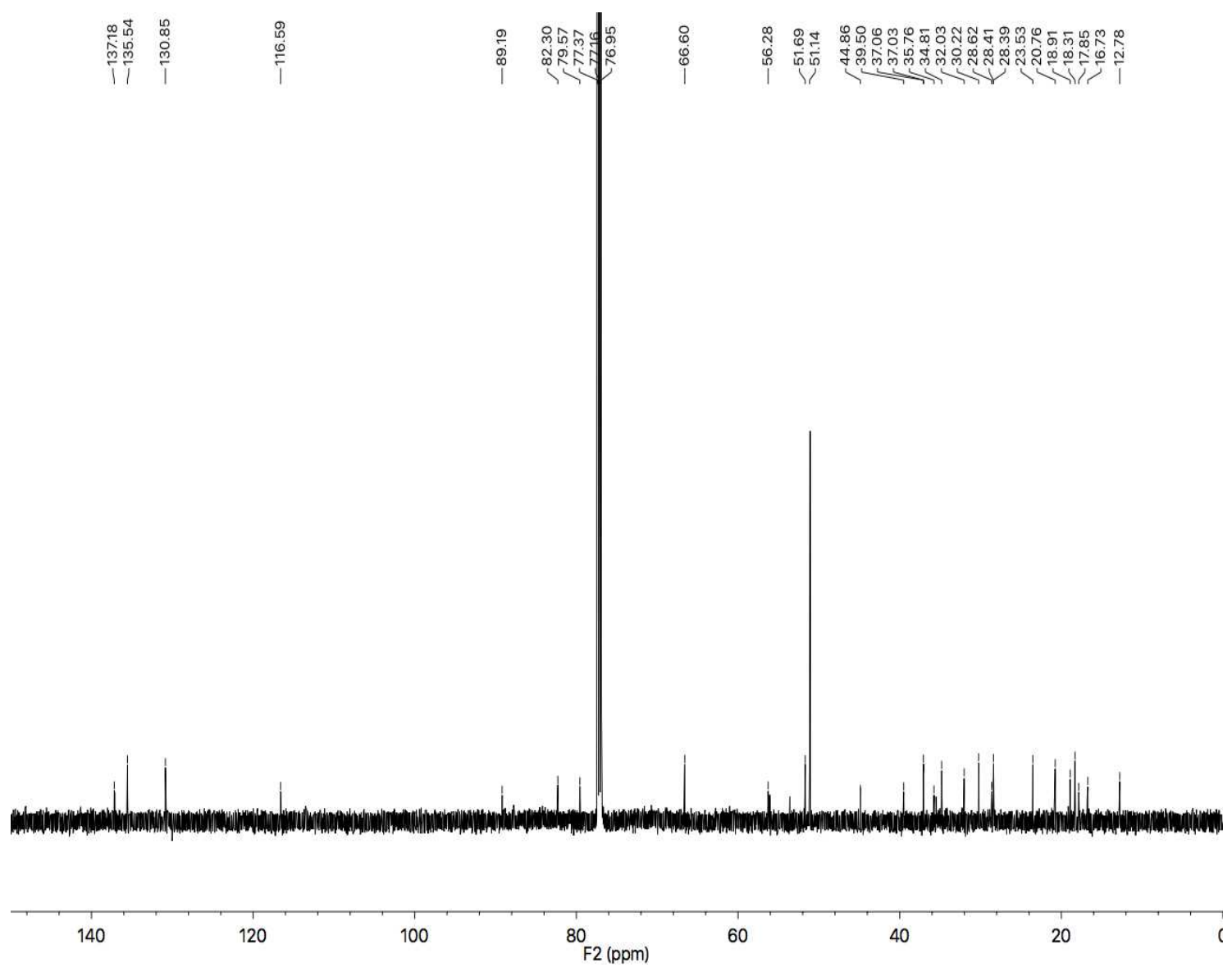

${ }^{13} \mathrm{C}$ NMR spectrum of $5 \alpha, 8 \alpha$-Epidioxy-24-hydroperoxycholesta-6,28(29)-dien-3 $\beta$-ol (237) (150 MHz, $\mathrm{CDCl}_{3}$ ). 

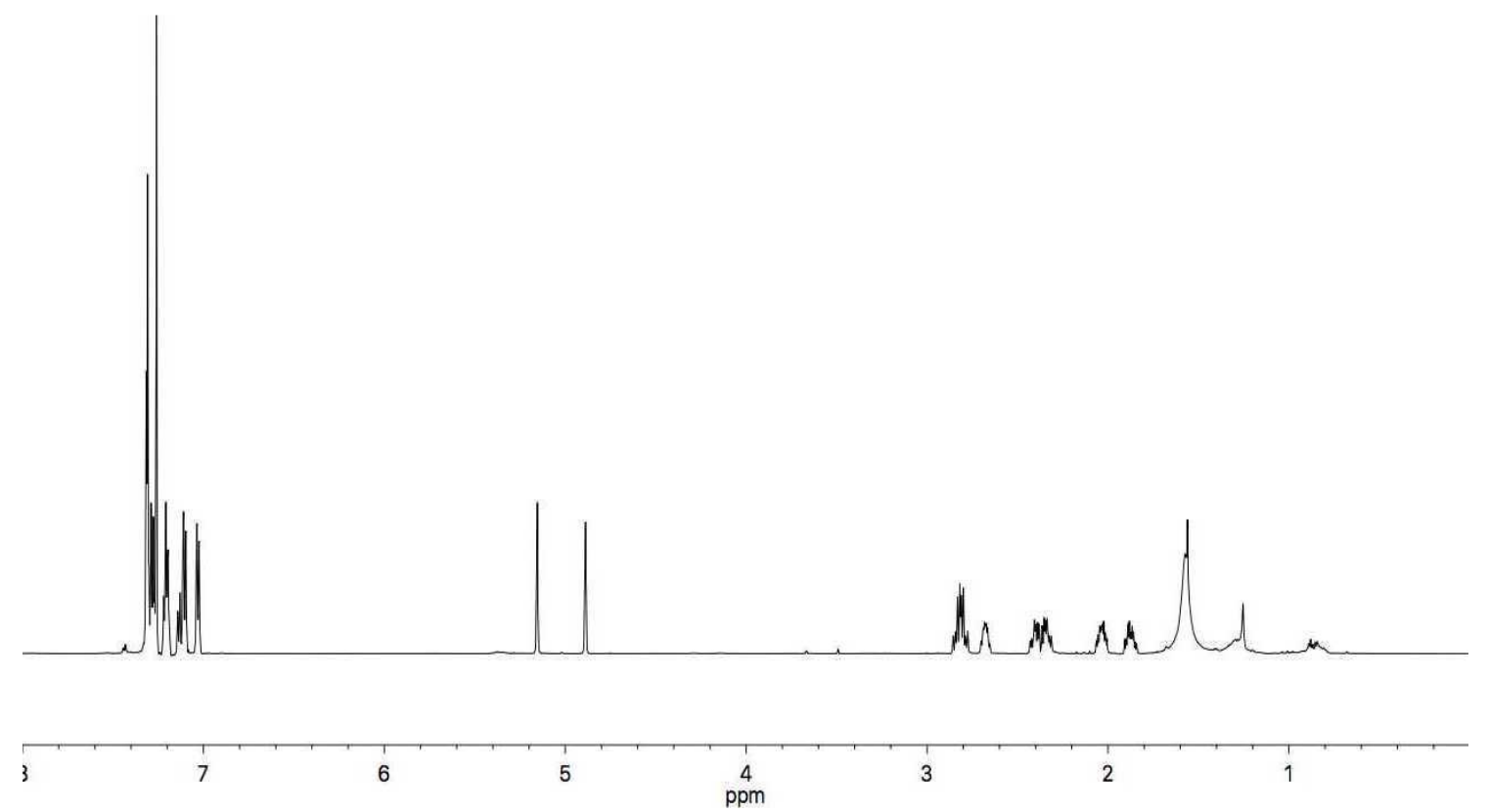

${ }^{1} \mathrm{H}$ NMR spectrum of 2,4,6-triphenyl-1-hexene (240) (600 MHz, $\mathrm{CDCl}_{3}$ ).

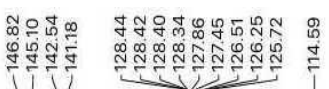

广广门

in

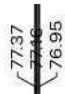

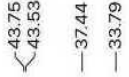

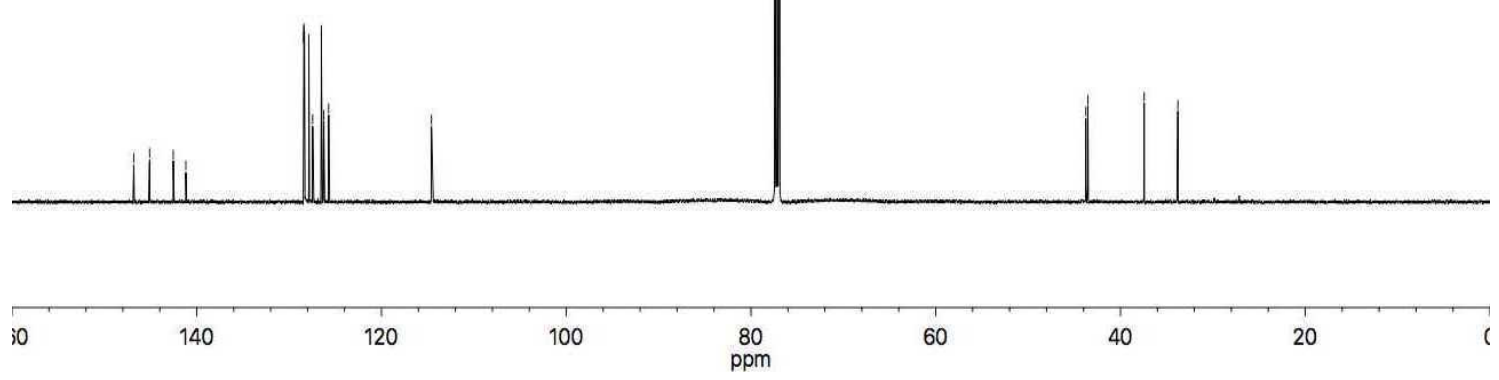

${ }^{13} \mathrm{C}$ NMR spectrum of compound 2,4,6-triphenyl-1-hexene (240) $\left(150 \mathrm{MHz}, \mathrm{CDCl}_{3}\right)$. 
NMR Spectra of Known Compounds from Cacospongia

\section{mycofijiensis}

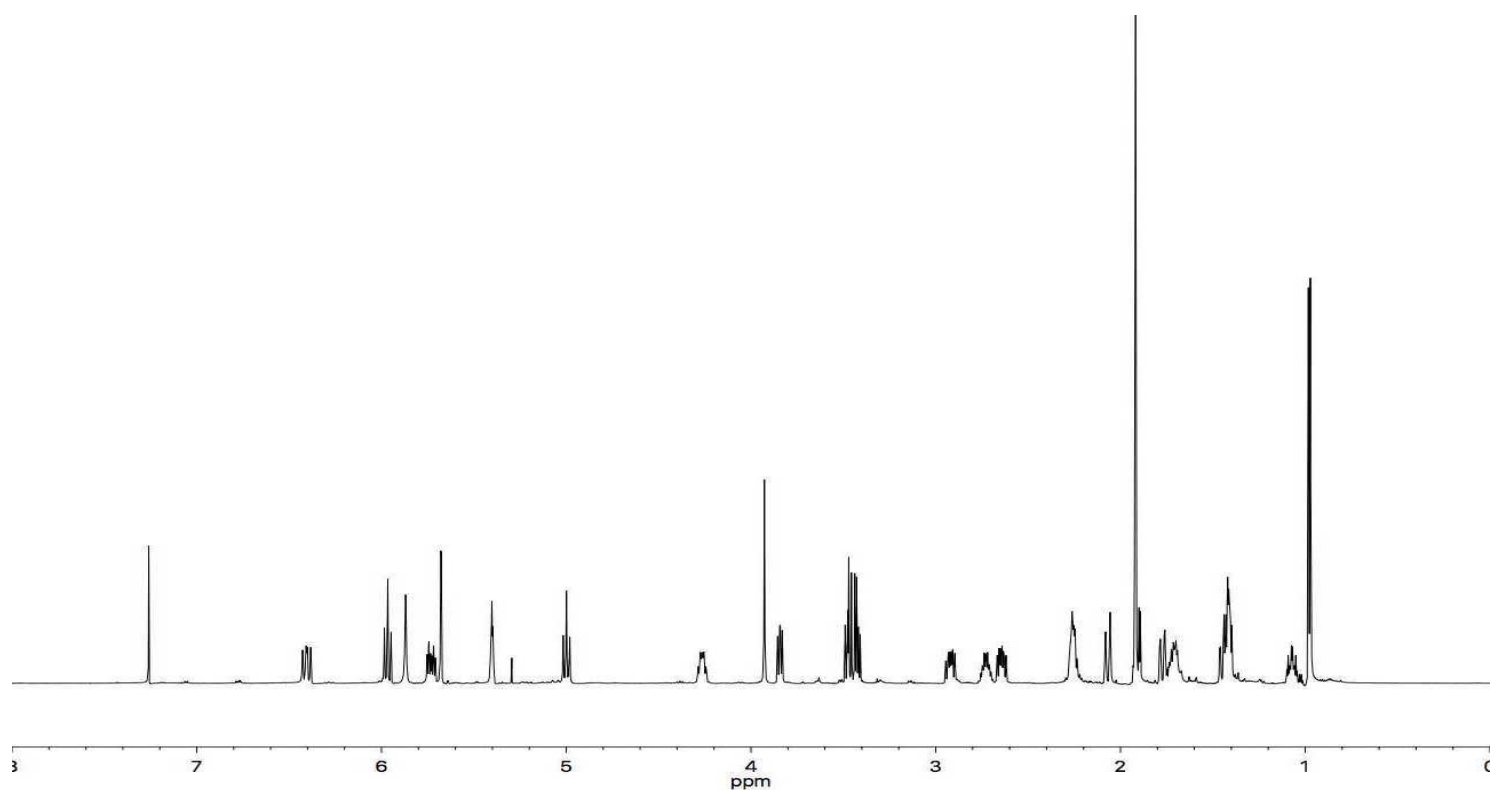

${ }^{1} \mathrm{H}$ NMR spectrum of latrunculin A (248) $\left(600 \mathrm{MHz}, \mathrm{CDCl}_{3}\right)$.

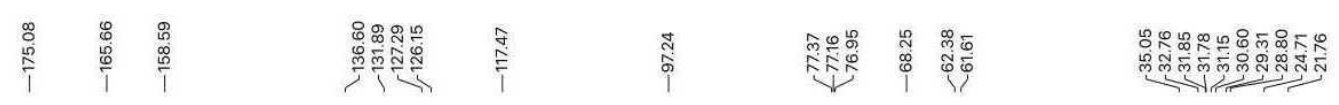

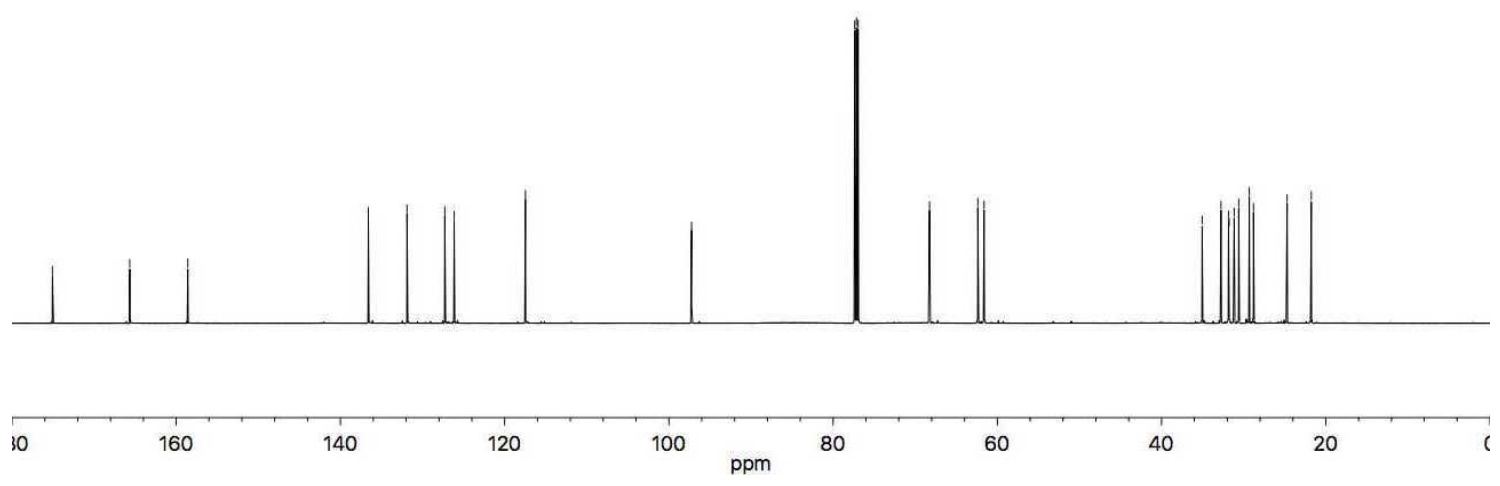

${ }^{13} \mathrm{C}$ NMR spectrum of latrunculin A (248) $\left(150 \mathrm{MHz}, \mathrm{CDCl}_{3}\right)$. 

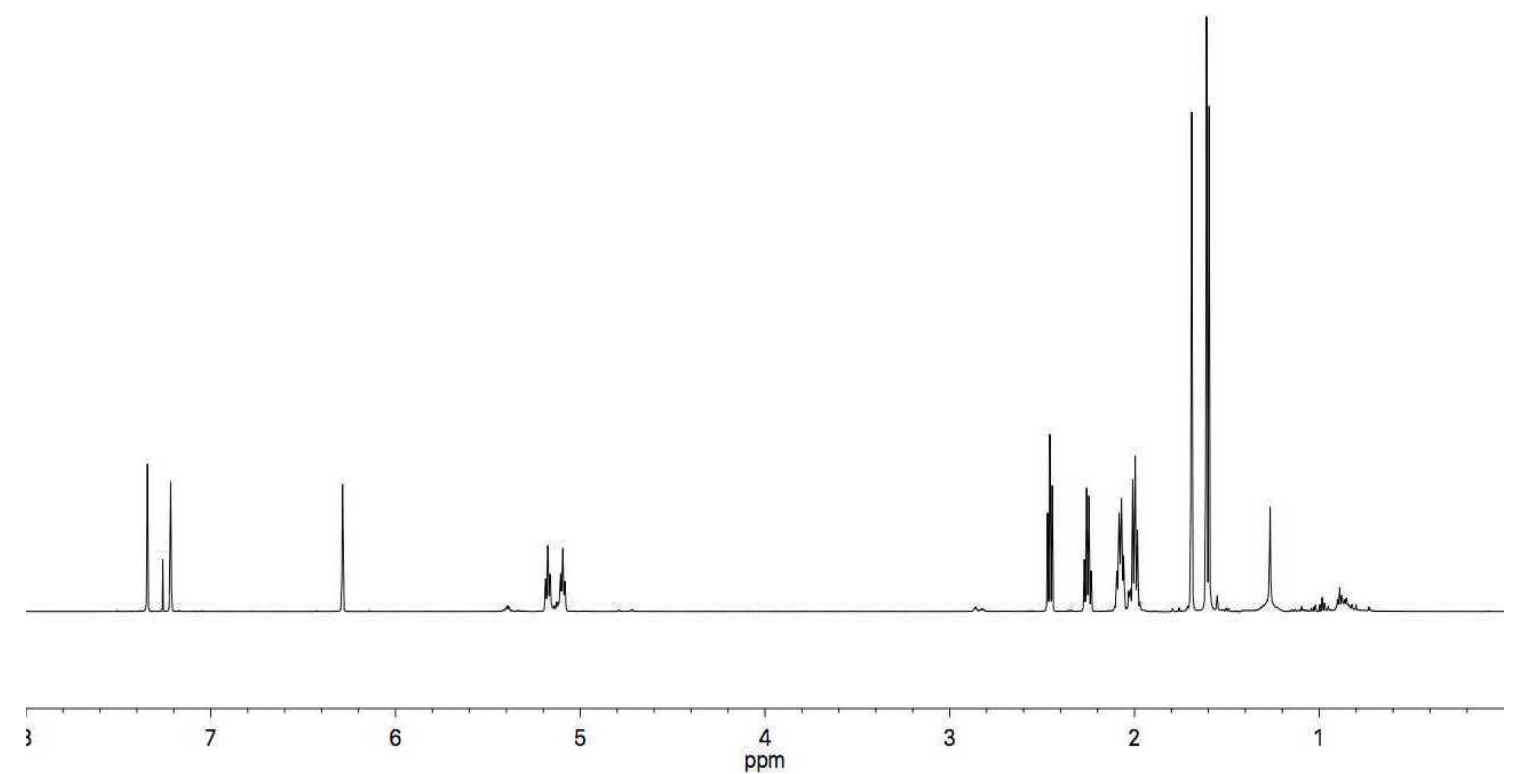

${ }^{1} \mathrm{H}$ NMR spectrum of dendrolasin (249) $\left(600 \mathrm{MHz}, \mathrm{CDCl}_{3}\right)$.

\begin{tabular}{|c|c|c|c|c|c|}
\hline 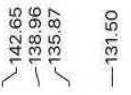 & 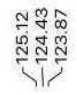 & 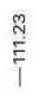 & 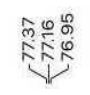 & $\begin{array}{l}0 \\
\infty \\
0 \\
0 \\
0 \\
1\end{array}$ & 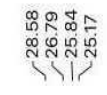 \\
\hline
\end{tabular}
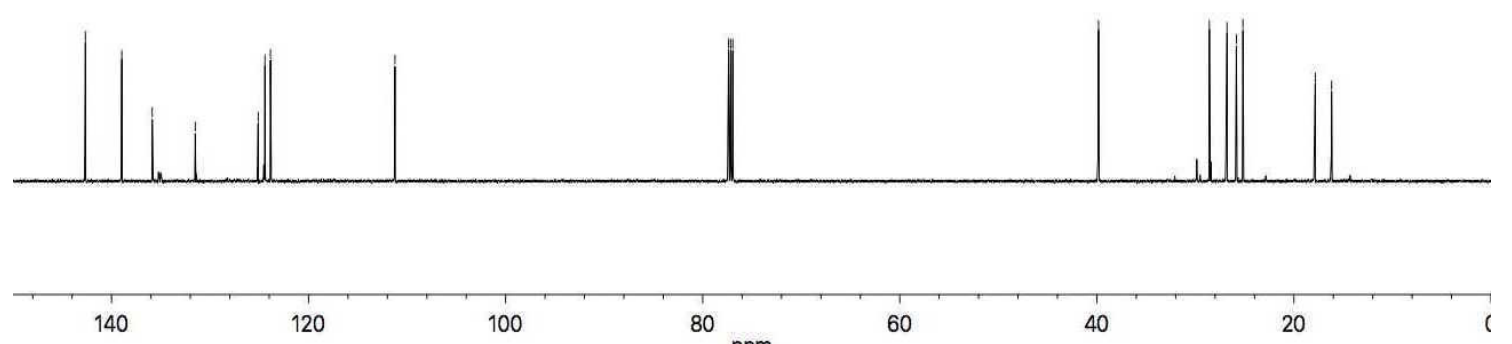

100

$80 \mathrm{ppm}$

60

40

20

${ }^{13} \mathrm{C}$ NMR spectrum of dendrolasin (249) $\left(150 \mathrm{MHz}, \mathrm{CDCl}_{3}\right)$. 

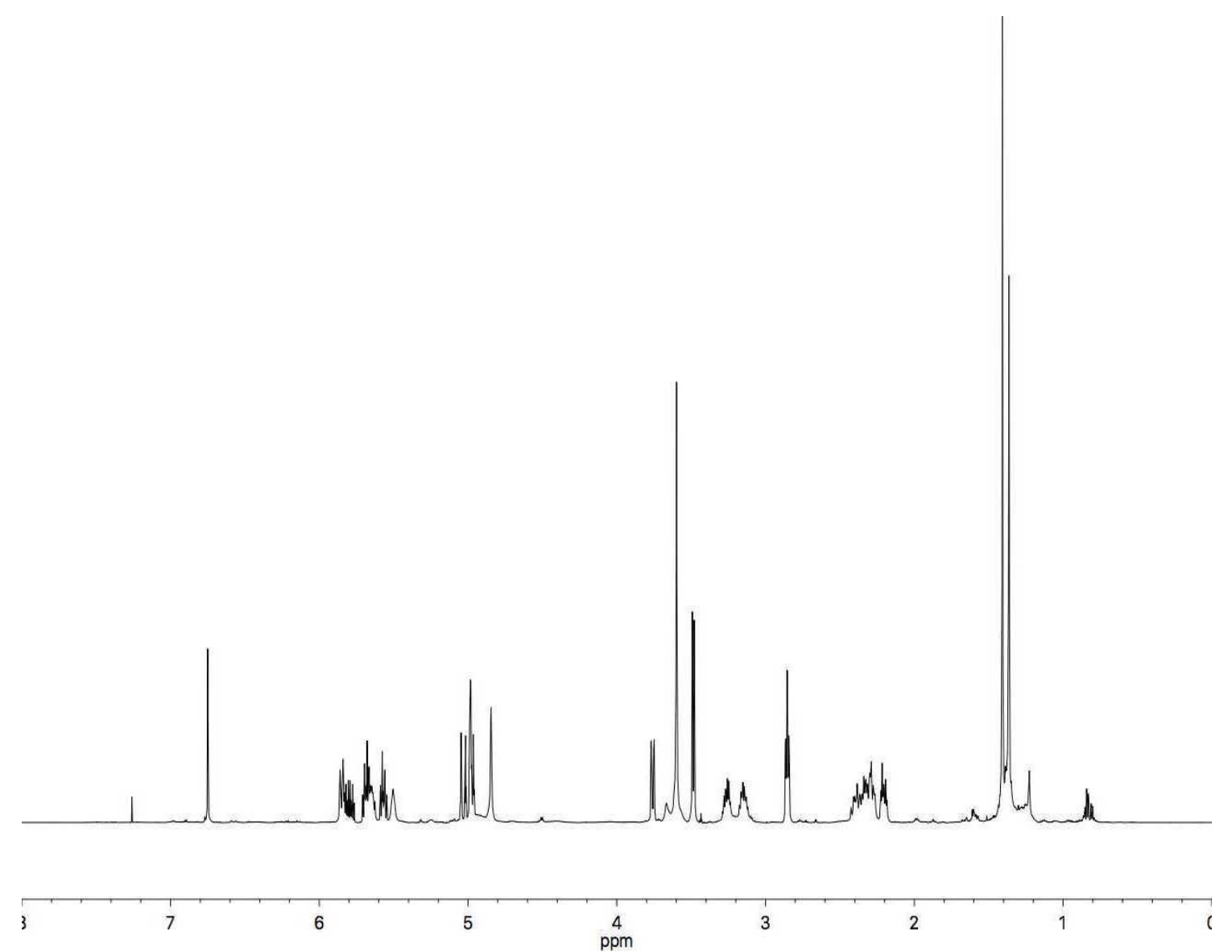

${ }^{1} \mathrm{H}$ NMR spectrum of mycothiazole (256) $\left(600 \mathrm{MHz}, \mathrm{CDCl}_{3}\right)$.

\begin{tabular}{|c|c|c|c|c|c|c|c|c|}
\hline $\begin{array}{l}\infty \\
\stackrel{0}{0} \\
\stackrel{2}{z}\end{array}$ & 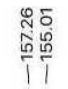 & i & 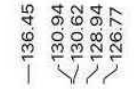 & 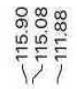 & 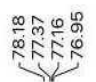 & ஜू & 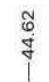 & 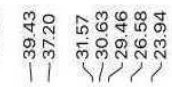 \\
\hline
\end{tabular}

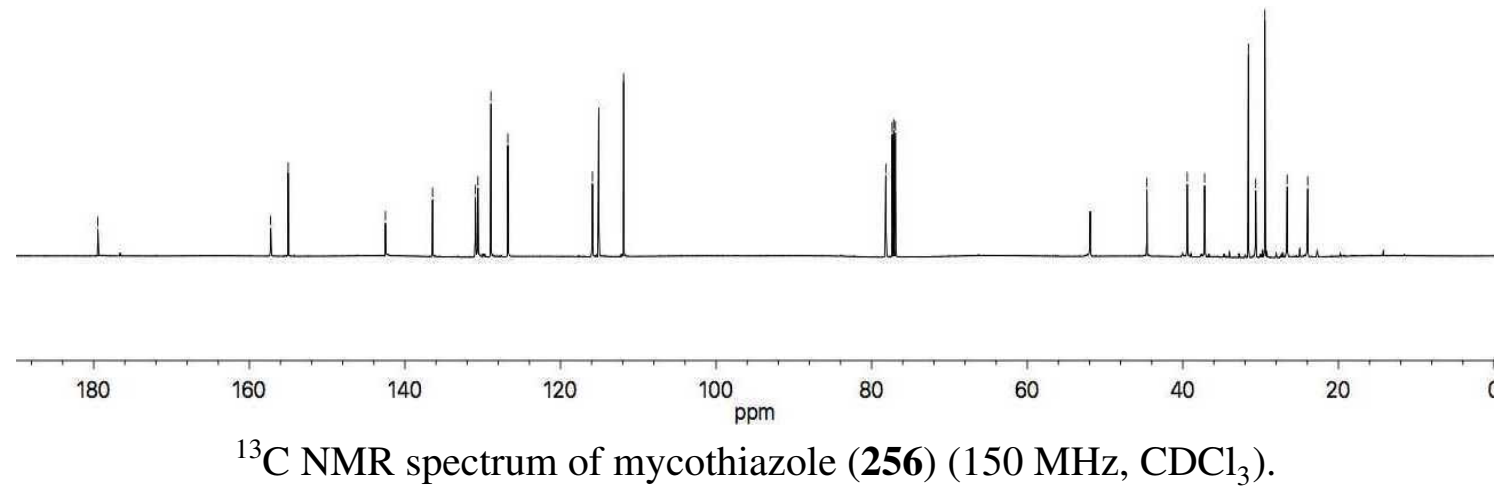




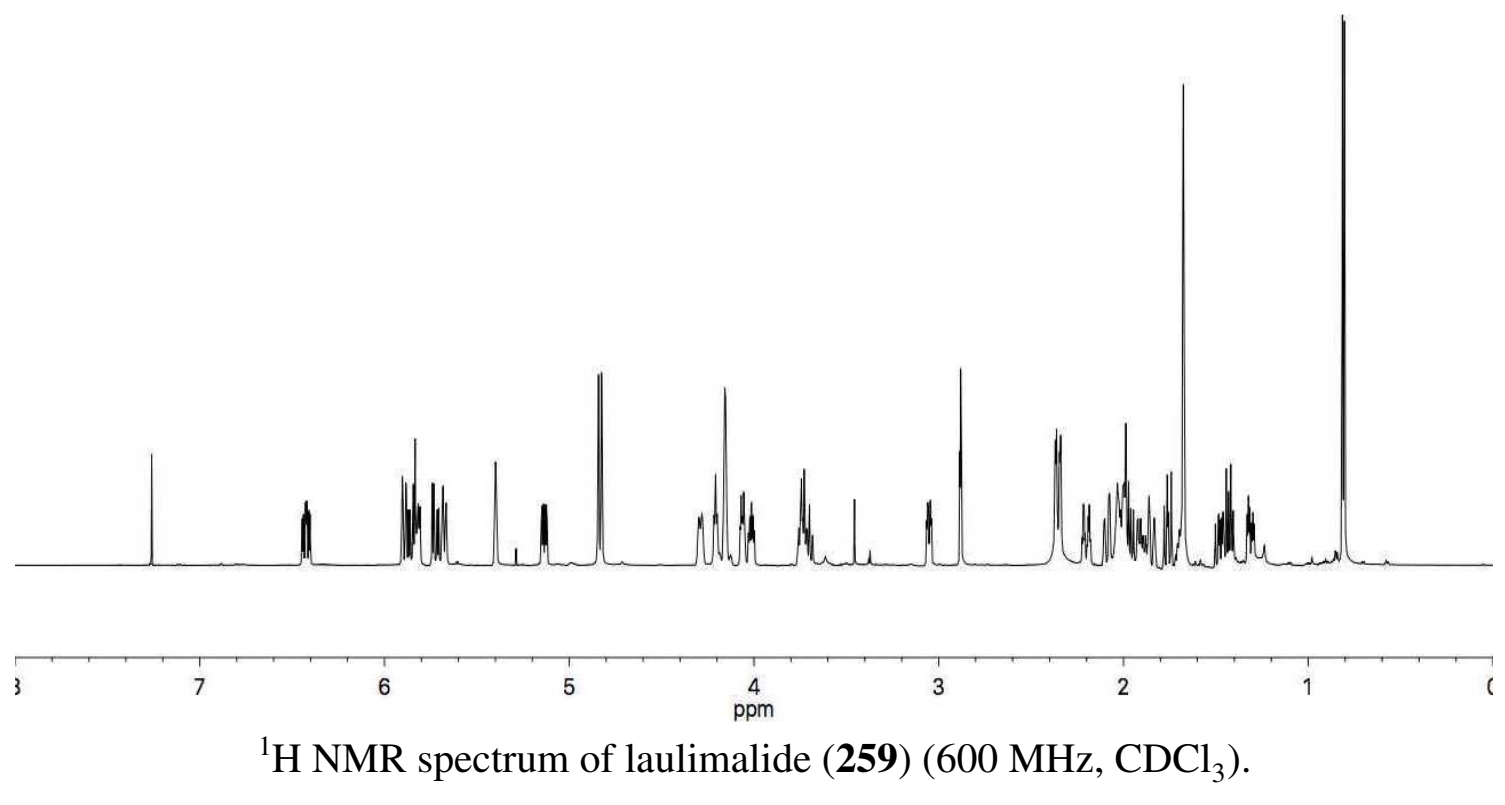

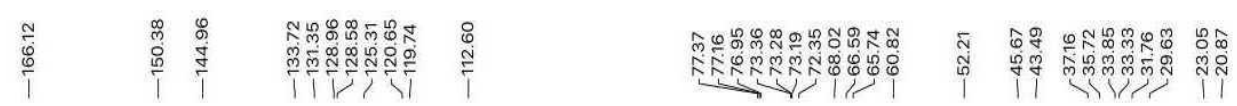
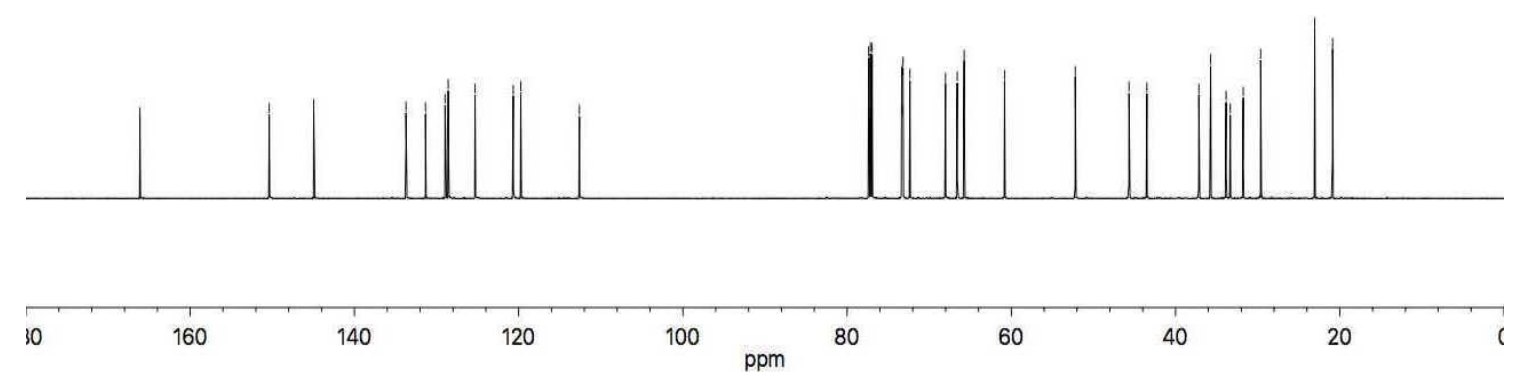

${ }^{13} \mathrm{C}$ NMR spectrum of laulimalide (259) $\left(150 \mathrm{MHz}, \mathrm{CDCl}_{3}\right)$. 


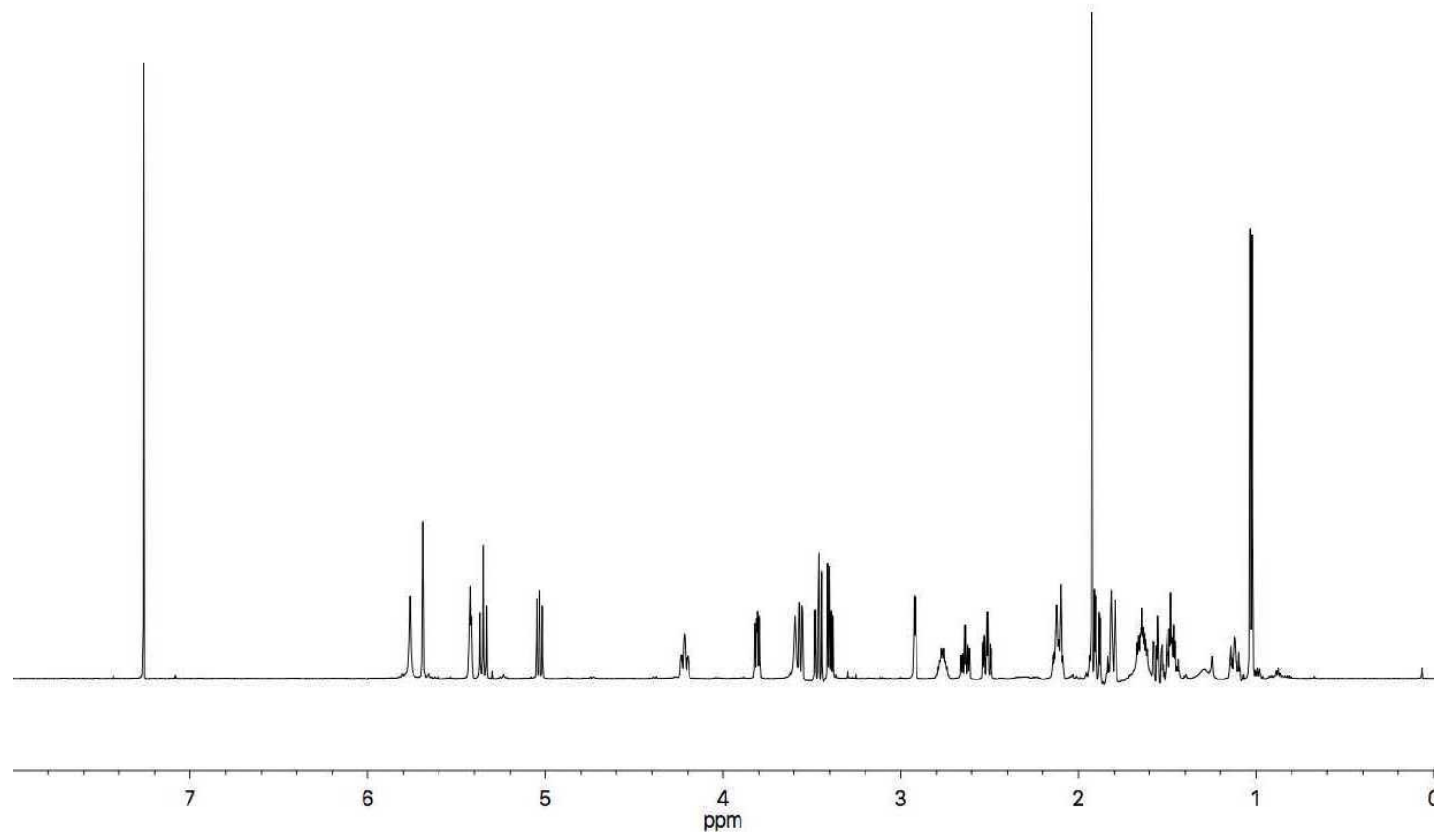

${ }^{1} \mathrm{H}$ NMR spectrum of 6,7-epoxylatrunculin A (276) $\left(600 \mathrm{MHz}, \mathrm{CDCl}_{3}\right)$.
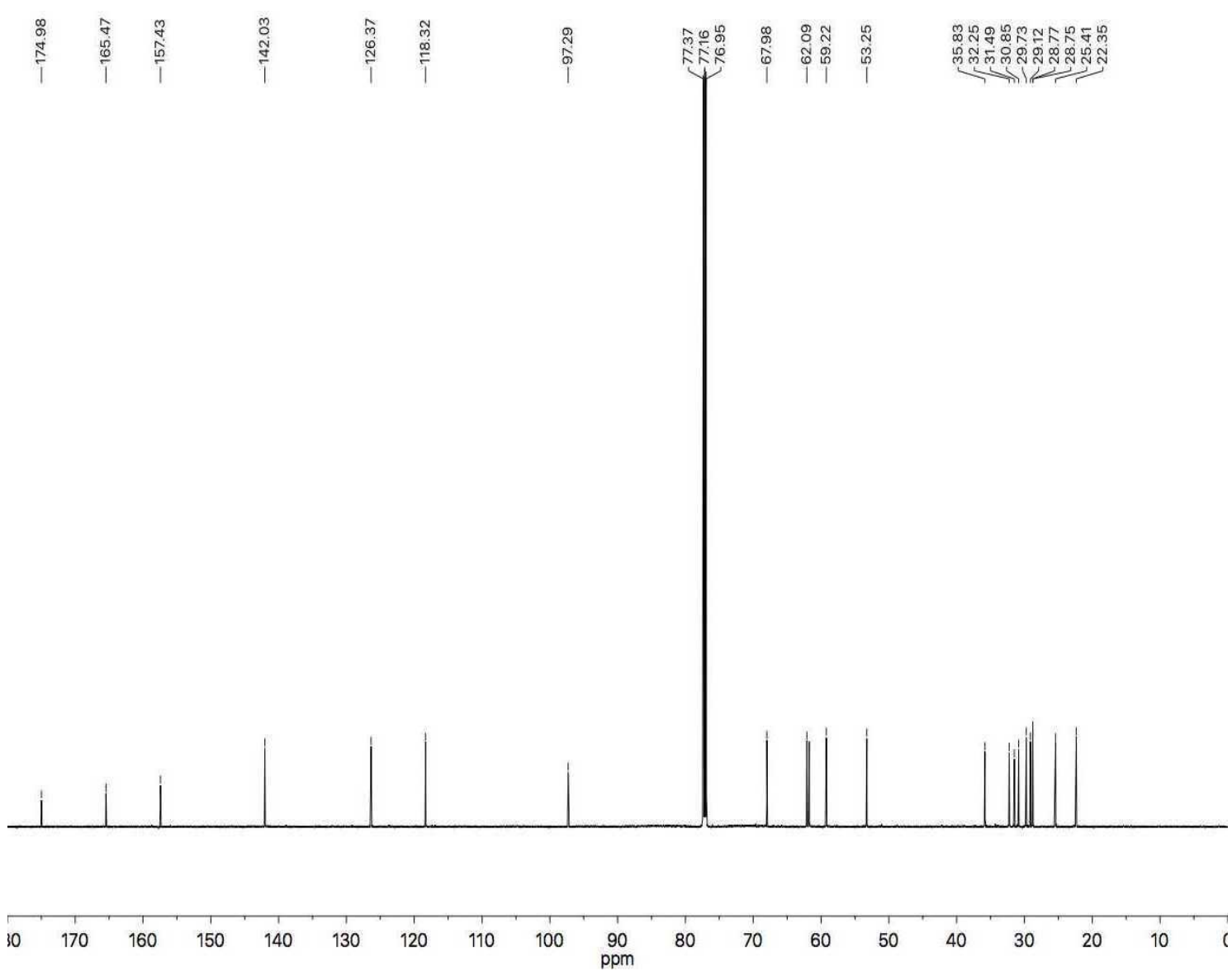

${ }^{13} \mathrm{C}$ NMR spectrum of 6,7-epoxylatrunculin $\mathrm{A}(\mathbf{2 7 6})\left(150 \mathrm{MHz}, \mathrm{CDCl}_{3}\right)$. 

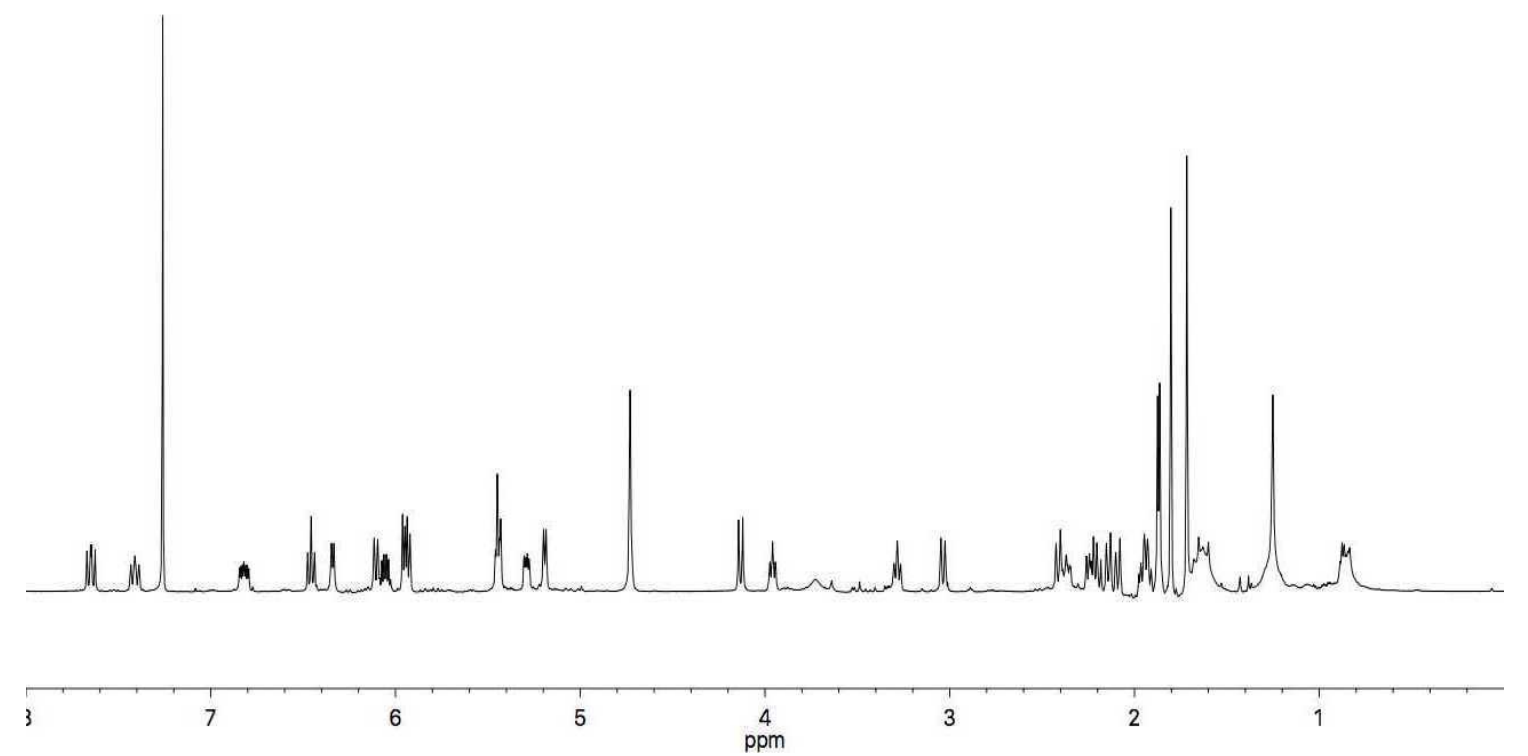

${ }^{1} \mathrm{H}$ NMR spectrum of zampanolide A (278) $\left(600 \mathrm{MHz}, \mathrm{CDCl}_{3}\right)$.
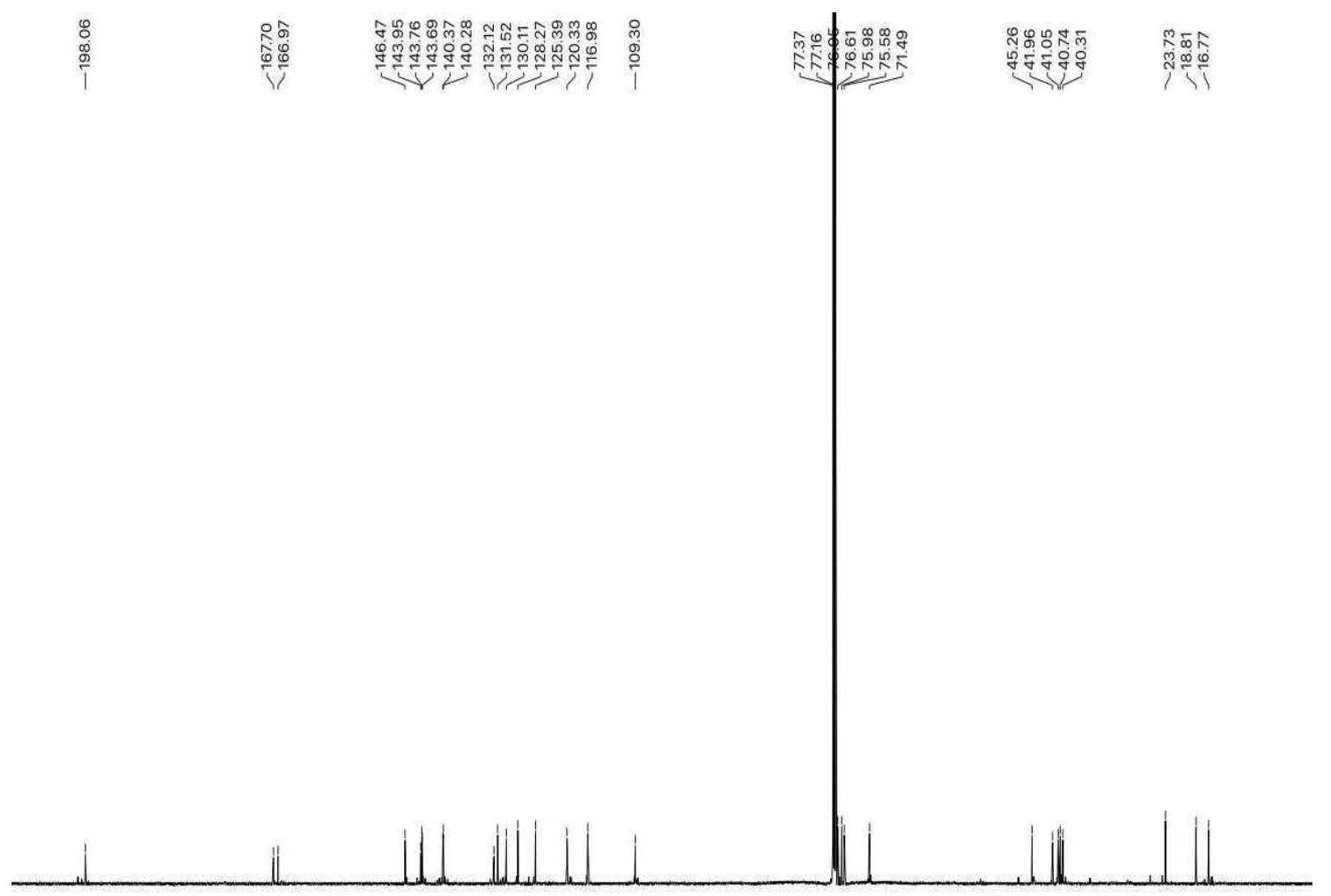

200

$180 \quad 160$ 140 120 ppm $^{100}$ 80 60 40 20 ${ }^{13} \mathrm{C}$ NMR spectrum of zampanolide A (278) $\left(150 \mathrm{MHz}, \mathrm{CDCl}_{3}\right)$. 

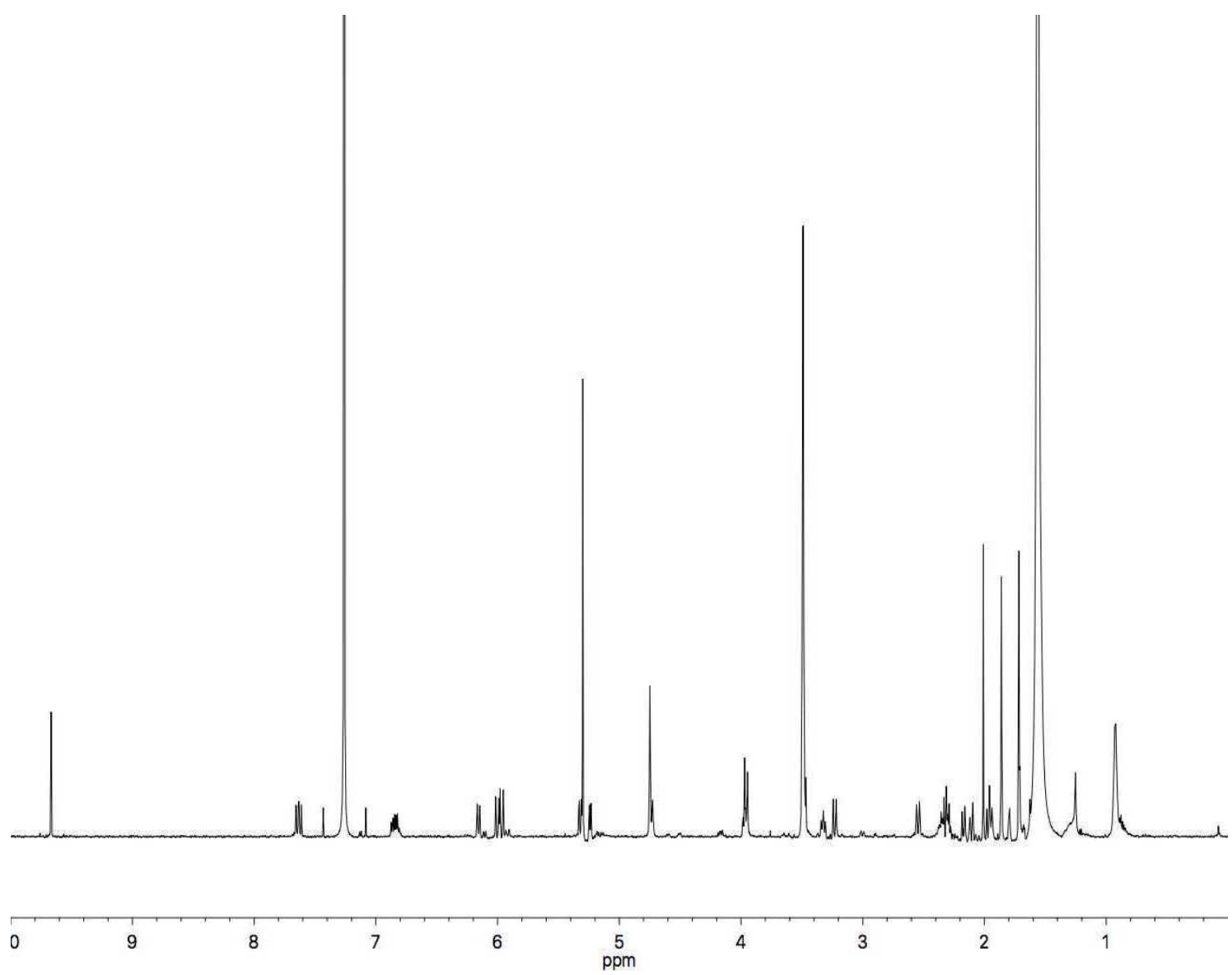

${ }^{1} \mathrm{H}$ NMR spectrum of (-)-dactylolide (281) (600 MHz, $\left.\mathrm{CDCl}_{3}\right)$.

\begin{tabular}{|c|c|c|c|c|c|c|c|}
\hline 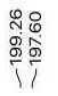 & \begin{tabular}{l}
\multirow{1}{*}{} \\
$\vdots$ \\
$\vdots$
\end{tabular} & 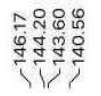 & 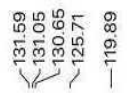 & 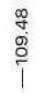 & 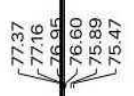 & 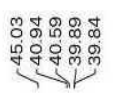 & ind \\
\hline
\end{tabular}

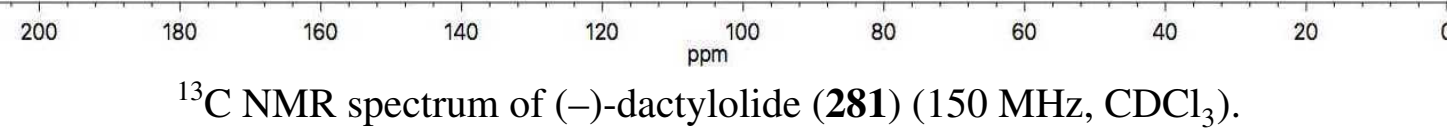



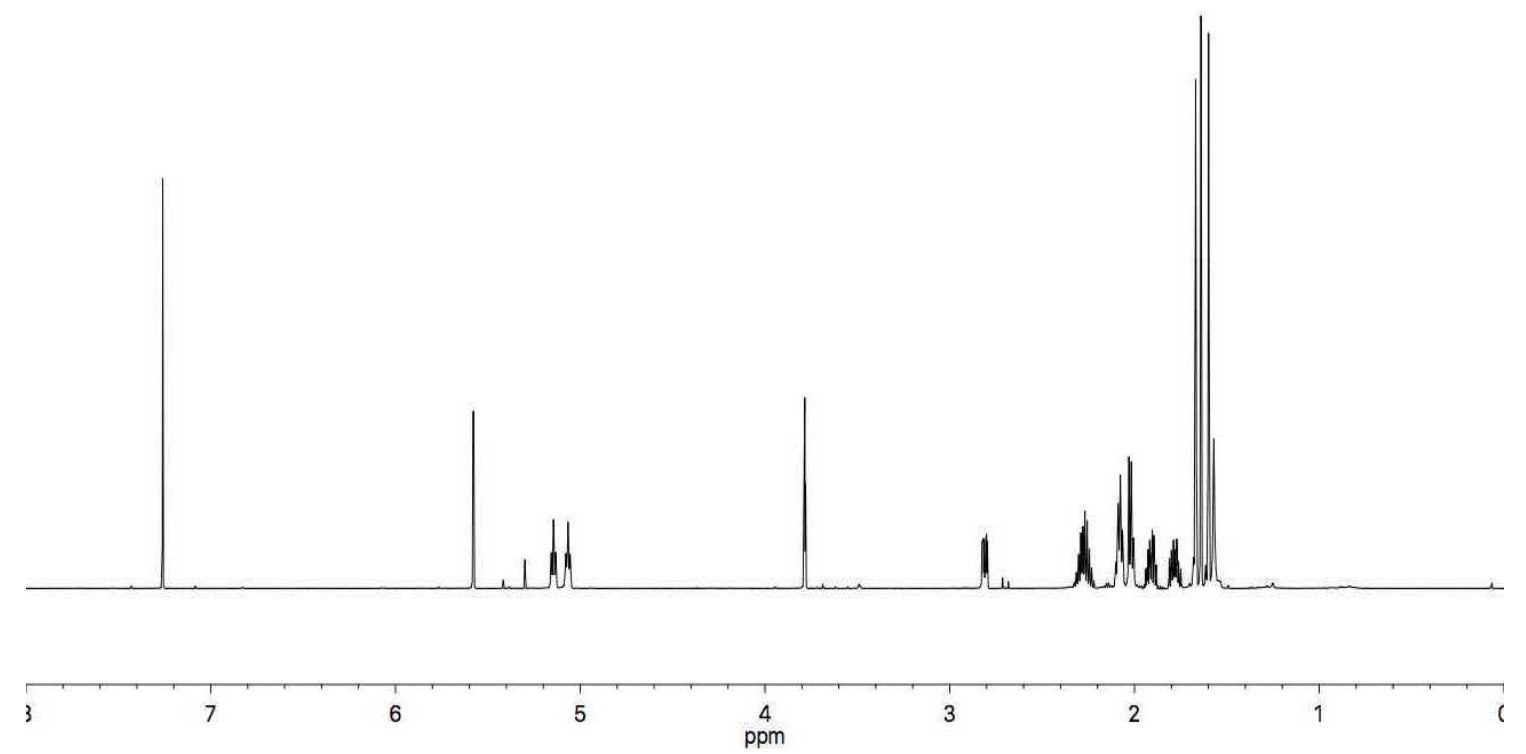

${ }^{1} \mathrm{H}$ NMR spectrum of dictyodendrillin A (279) $\left(600 \mathrm{MHz}, \mathrm{CDCl}_{3}\right)$.
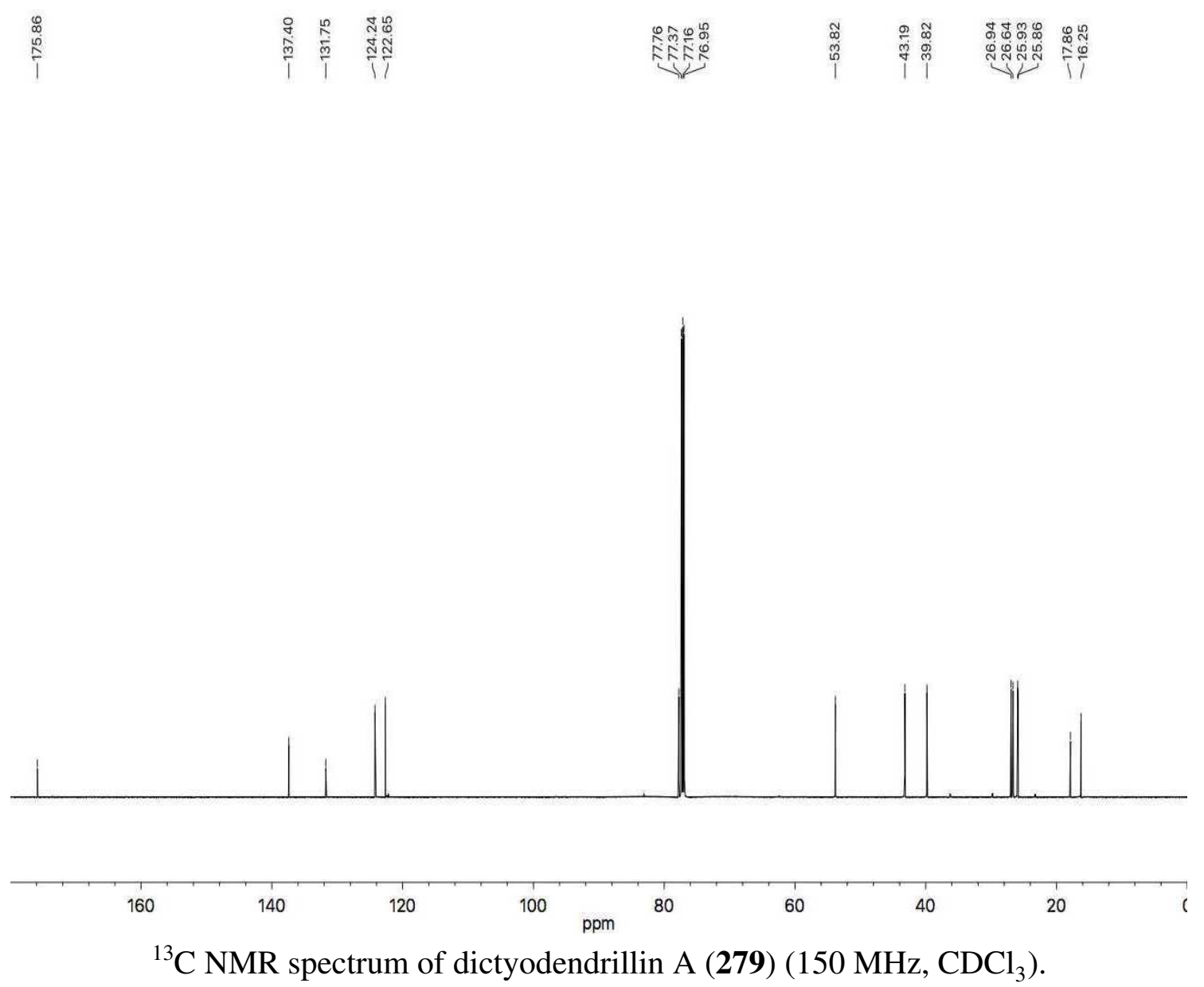
Appendix E

\section{Craterol A Spectra}

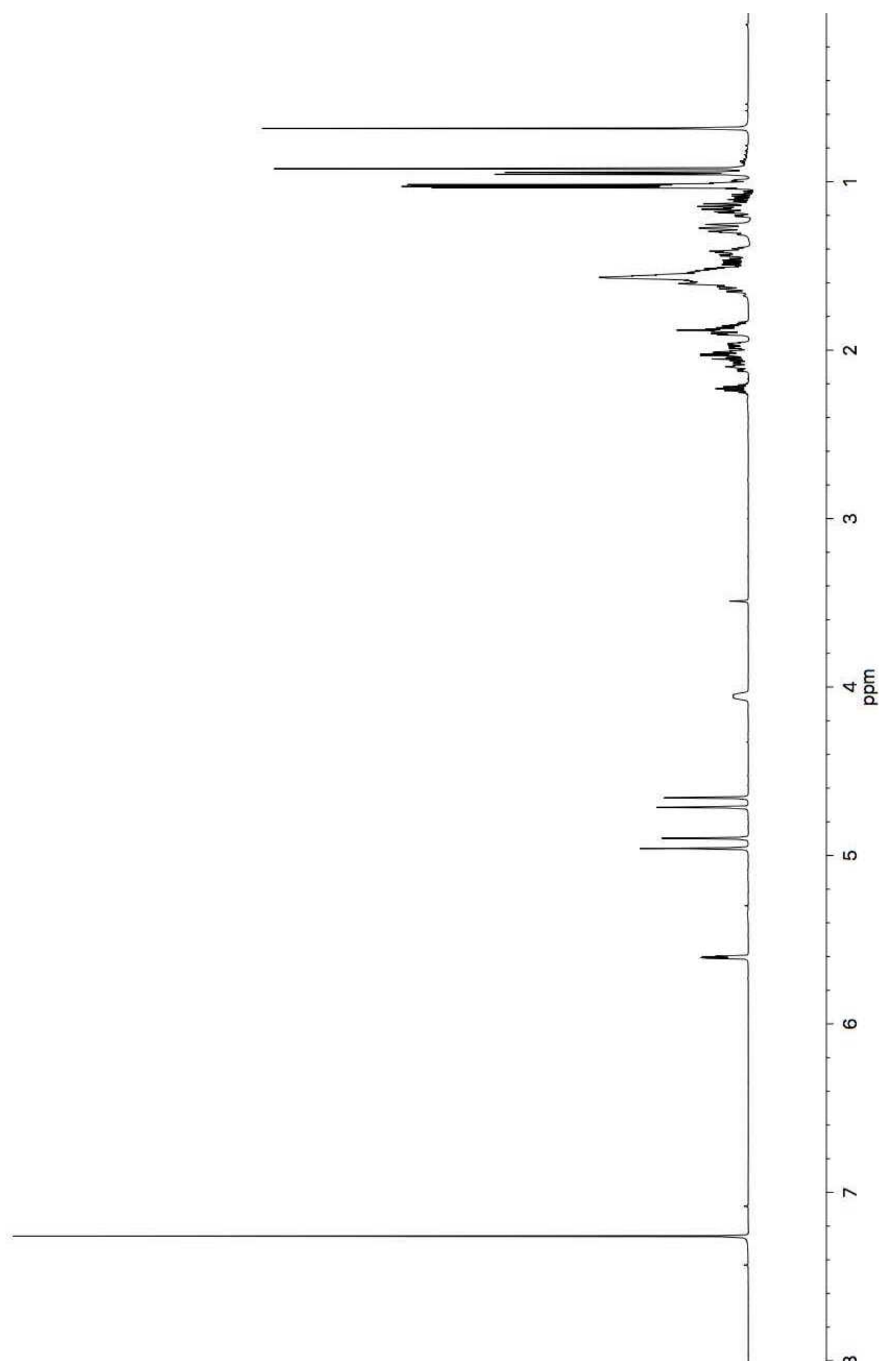

${ }^{1} \mathrm{H}$ NMR spectrum of craterol A (94) $\left(600 \mathrm{MHz}, \mathrm{CDCl}_{3}\right)$. 
(udd) $\downarrow \unlhd$

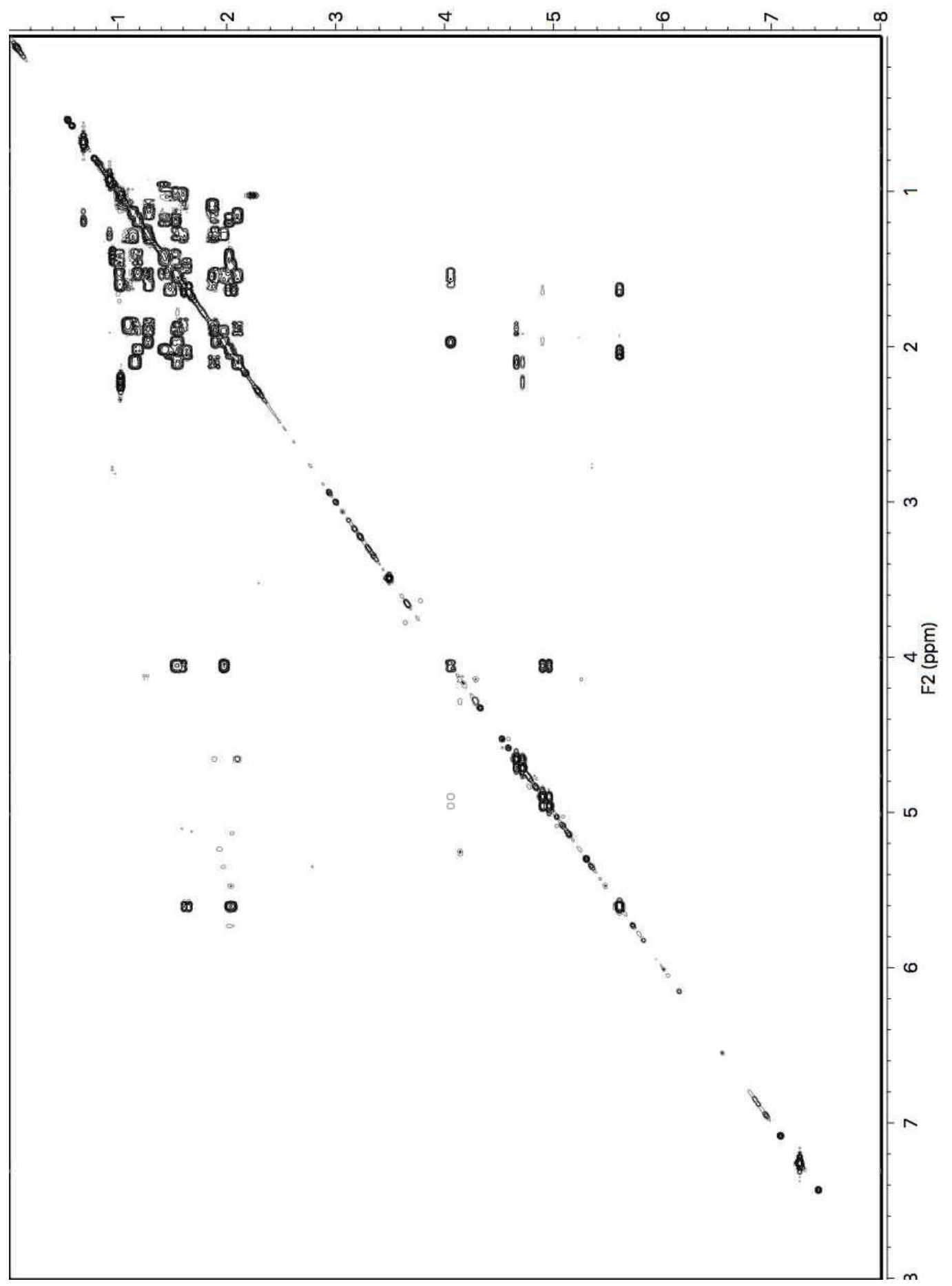

COSY spectrum of craterol A (94) (600 MHz, $\left.\mathrm{CDCl}_{3}\right)$. 


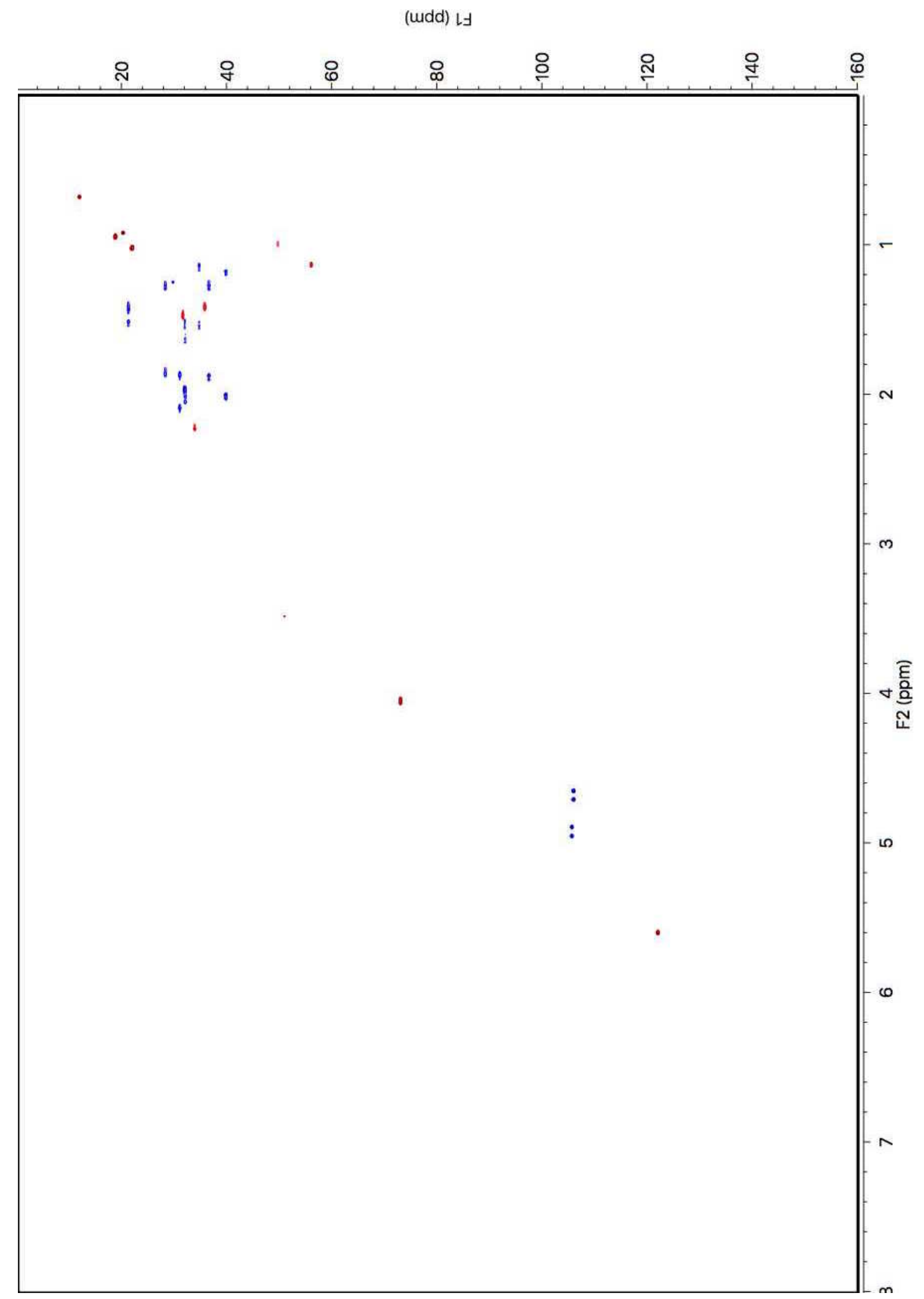

HSQC spectrum of craterol A (94) $\left(600 \mathrm{MHz}, \mathrm{CDCl}_{3}\right)$. 


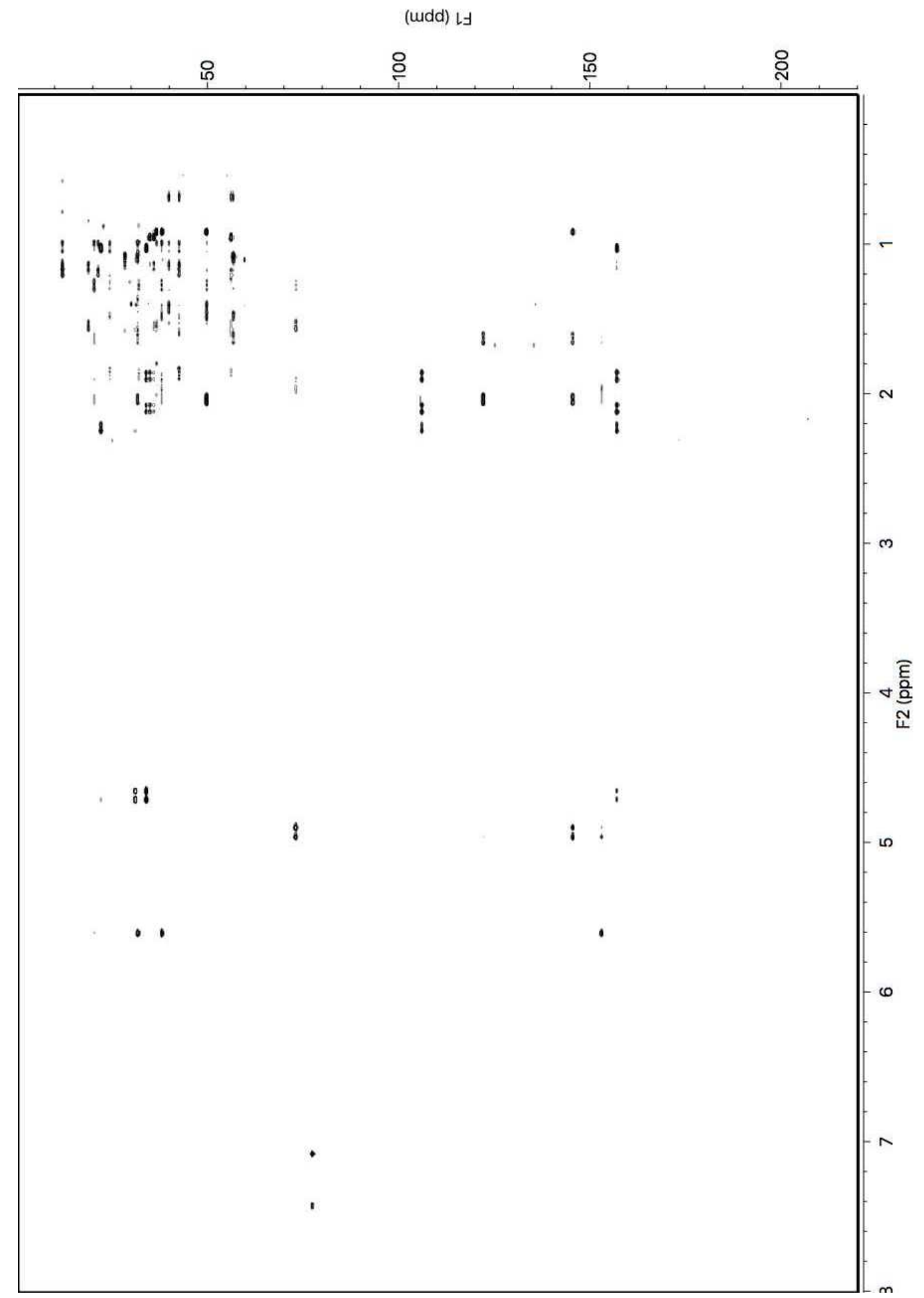

HMBC spectrum of craterol A (94) (600 MHz, $\left.\mathrm{CDCl}_{3}\right)$. 


$$
\begin{aligned}
& \text { †0ZL- } \\
& \angle 8.81 \\
& \neg \varepsilon \circ Z \\
& \text { ZOZz } \\
& \text { 9เzZ } \\
& \text { Zt } \forall Z^{S} \\
& \angle 8.82- \\
& \text { El'L } \\
& \text { ZLLE } \\
& \text { 9o Zह } \\
& \text { ('ze } \\
& \text { ( } 8 \varepsilon \\
& \varepsilon 8 \nabla \varepsilon \\
& \text { เ6. } 98 \\
& \downarrow 99 \varepsilon \\
& 20,8 \varepsilon \\
& 16.68 \\
& \angle 9 \cdot 2 t]
\end{aligned}
$$

${ }^{13} \mathrm{C}$ NMR spectrum of craterol A $(\mathbf{9 4})\left(150 \mathrm{MHz}, \mathrm{CDCl}_{3}\right)$. 
Appendix F

\section{Craterol B Spectra}

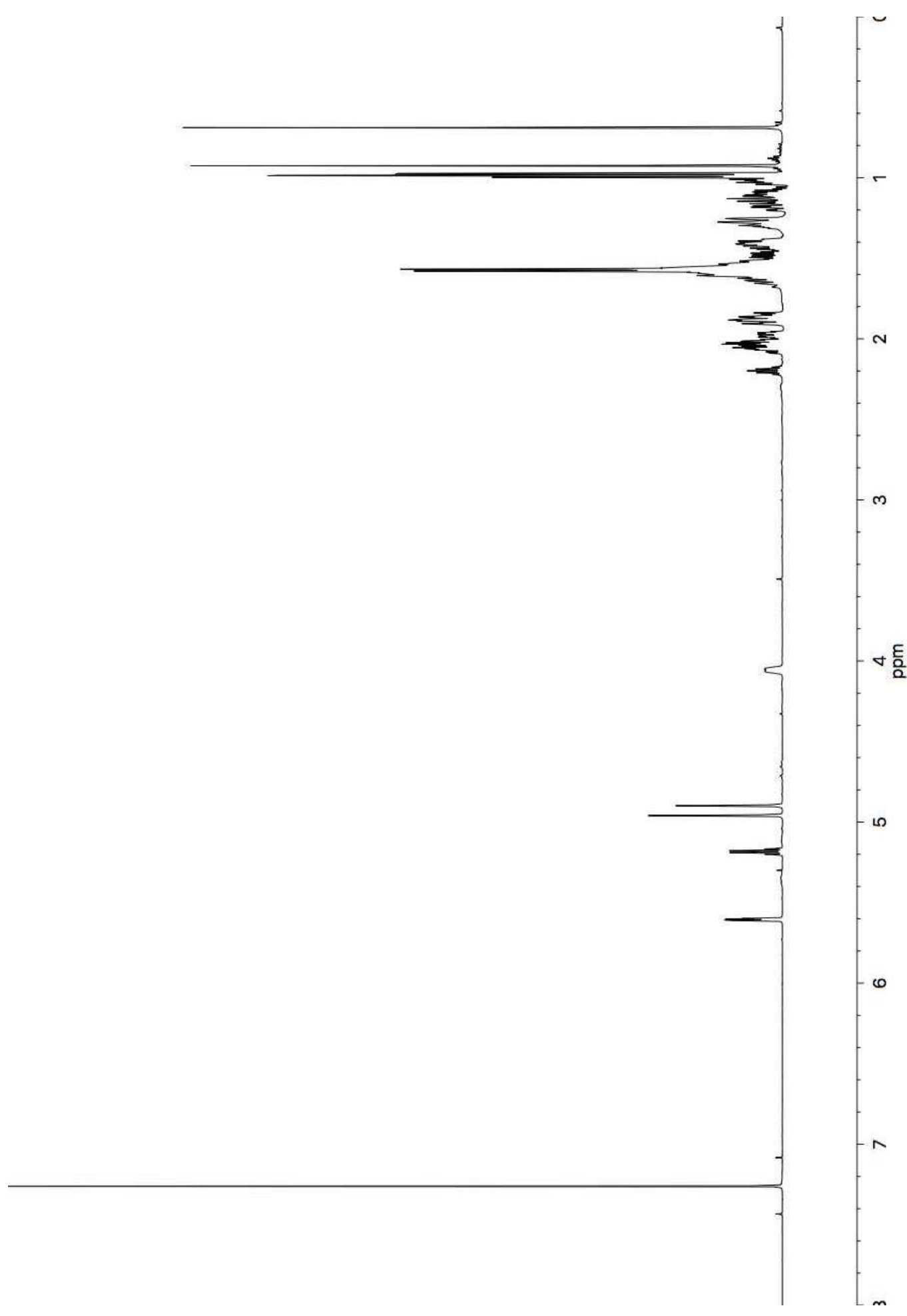

${ }^{1} \mathrm{H}$ NMR spectrum of craterol B (95) $\left(600 \mathrm{MHz}, \mathrm{CDCl}_{3}\right)$. 
(udd) $L J$

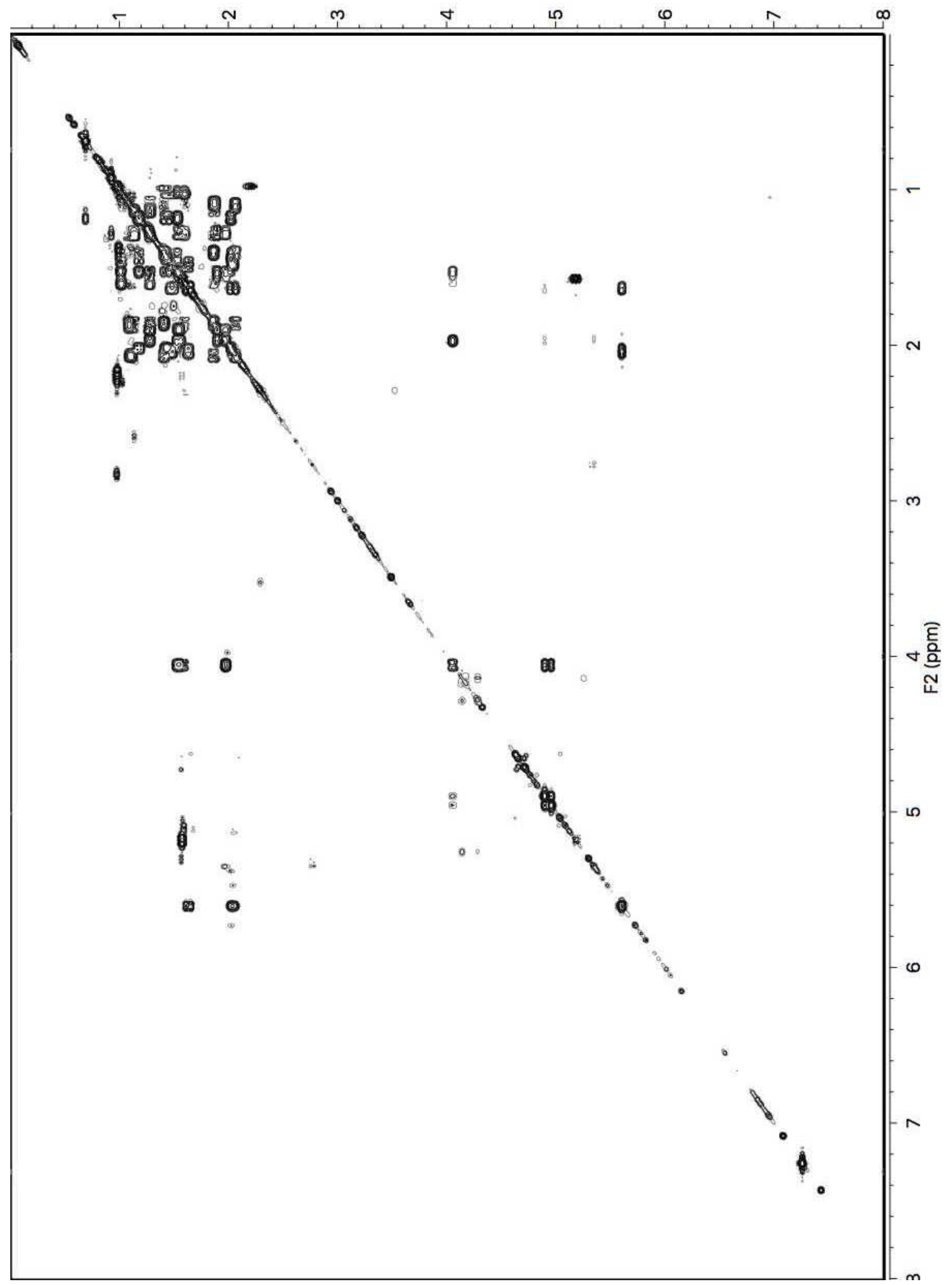

COSY spectrum of craterol B (95) $\left(600 \mathrm{MHz}, \mathrm{CDCl}_{3}\right)$. 


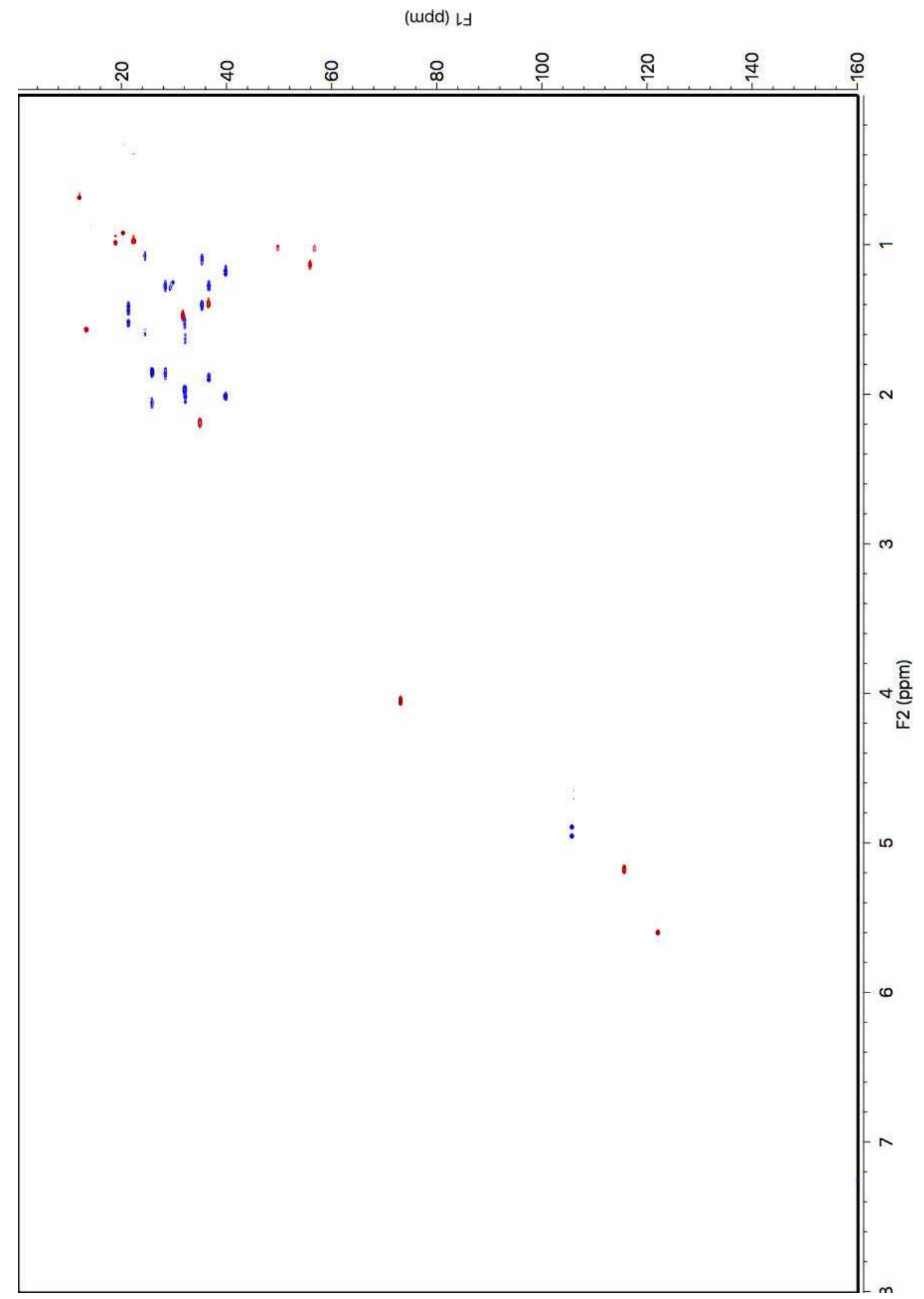

HSQC spectrum of craterol B (95) $\left(600 \mathrm{MHz}, \mathrm{CDCl}_{3}\right)$. 


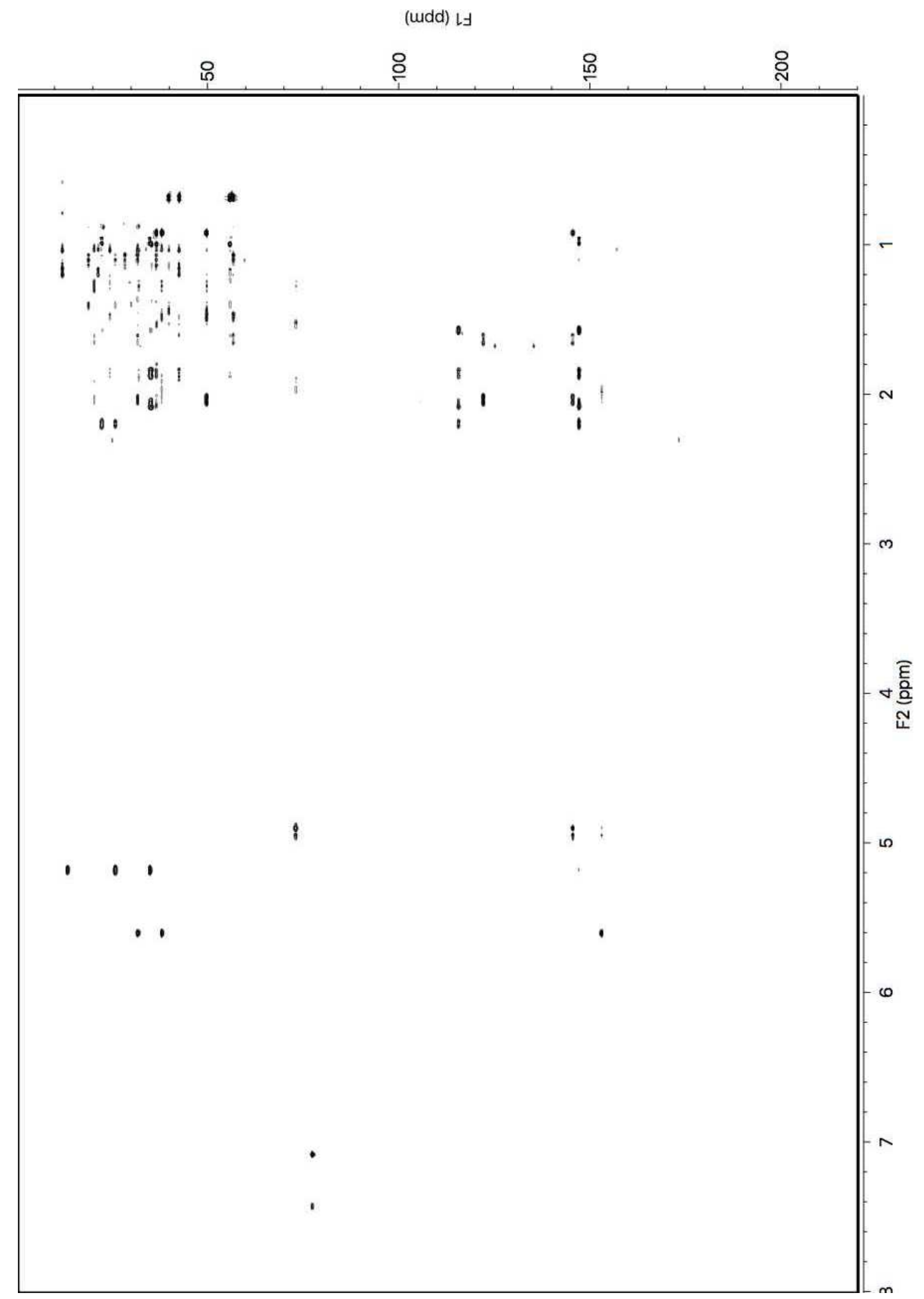

HMBC spectrum of craterol B (95) (600 MHz, $\left.\mathrm{CDCl}_{3}\right)$. 


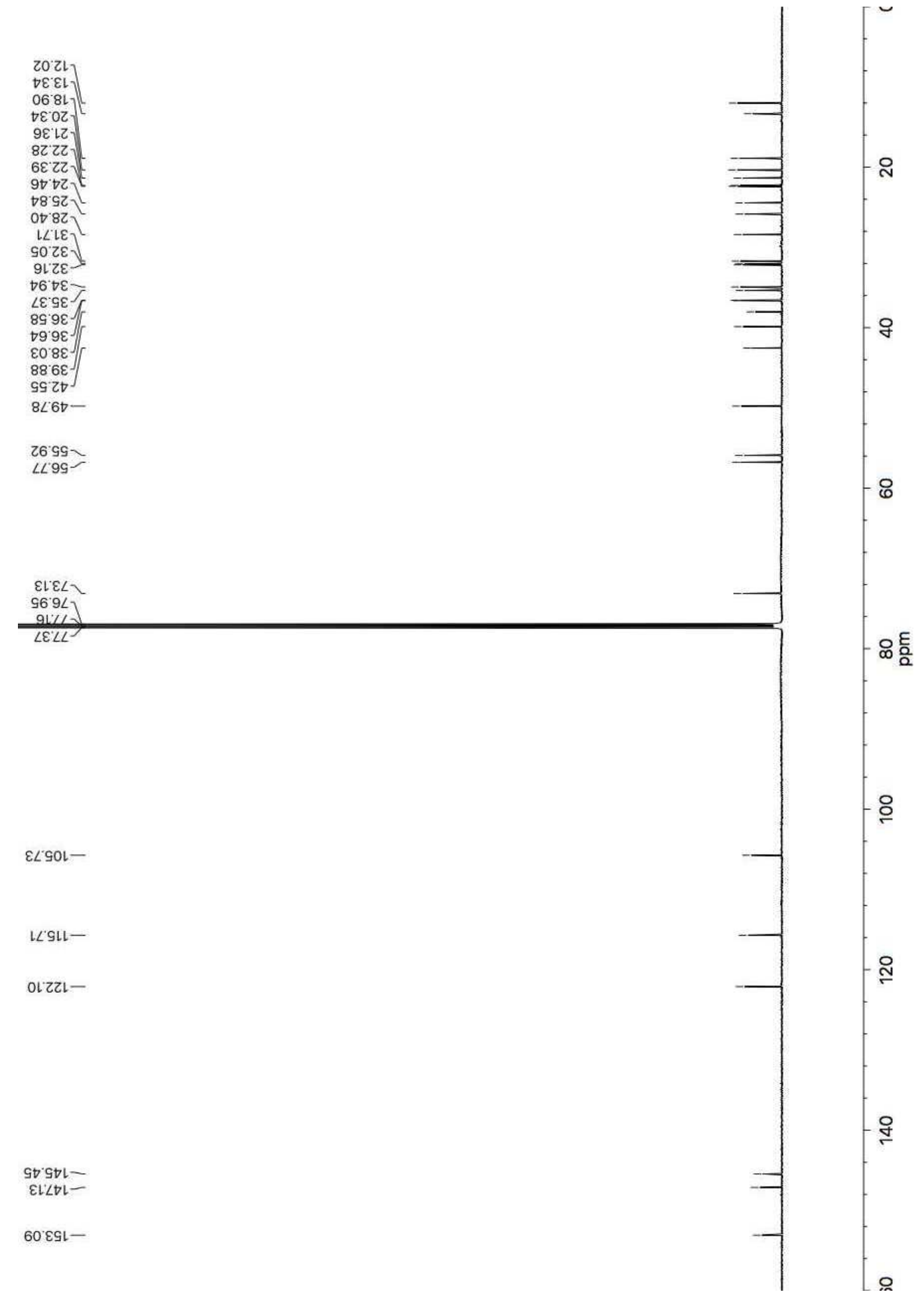

${ }^{13} \mathrm{C}$ NMR spectrum of craterol B $(\mathbf{9 5})\left(150 \mathrm{MHz}, \mathrm{CDCl}_{3}\right)$. 
Appendix $G$

\section{6-Bromodamirone B Spectra}

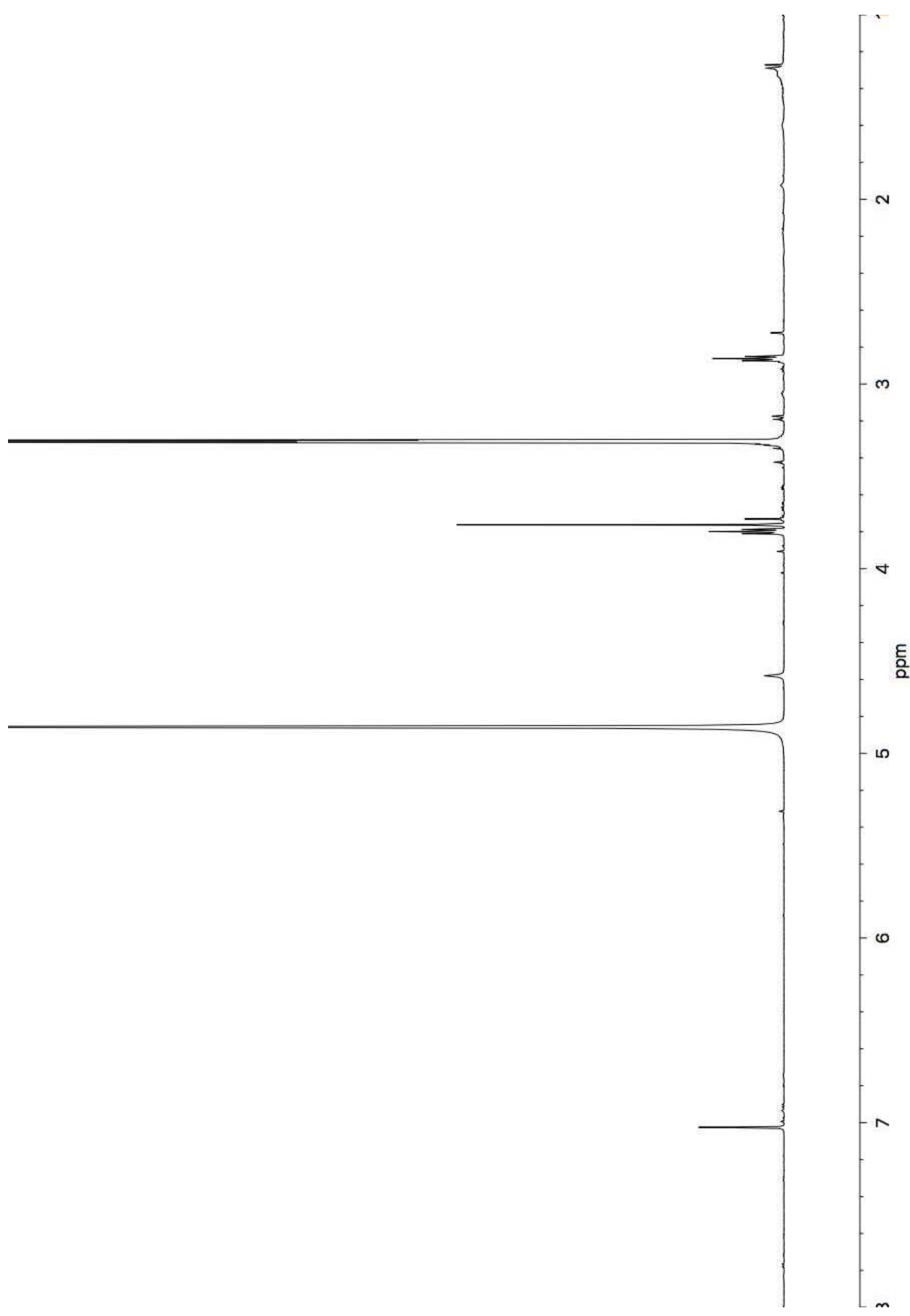

${ }^{1} \mathrm{H}$ NMR spectrum of 6-bromodamirone B (182) (600 MHz, $\left.\mathrm{CD}_{3} \mathrm{OD}\right)$. 
(udd) IJ

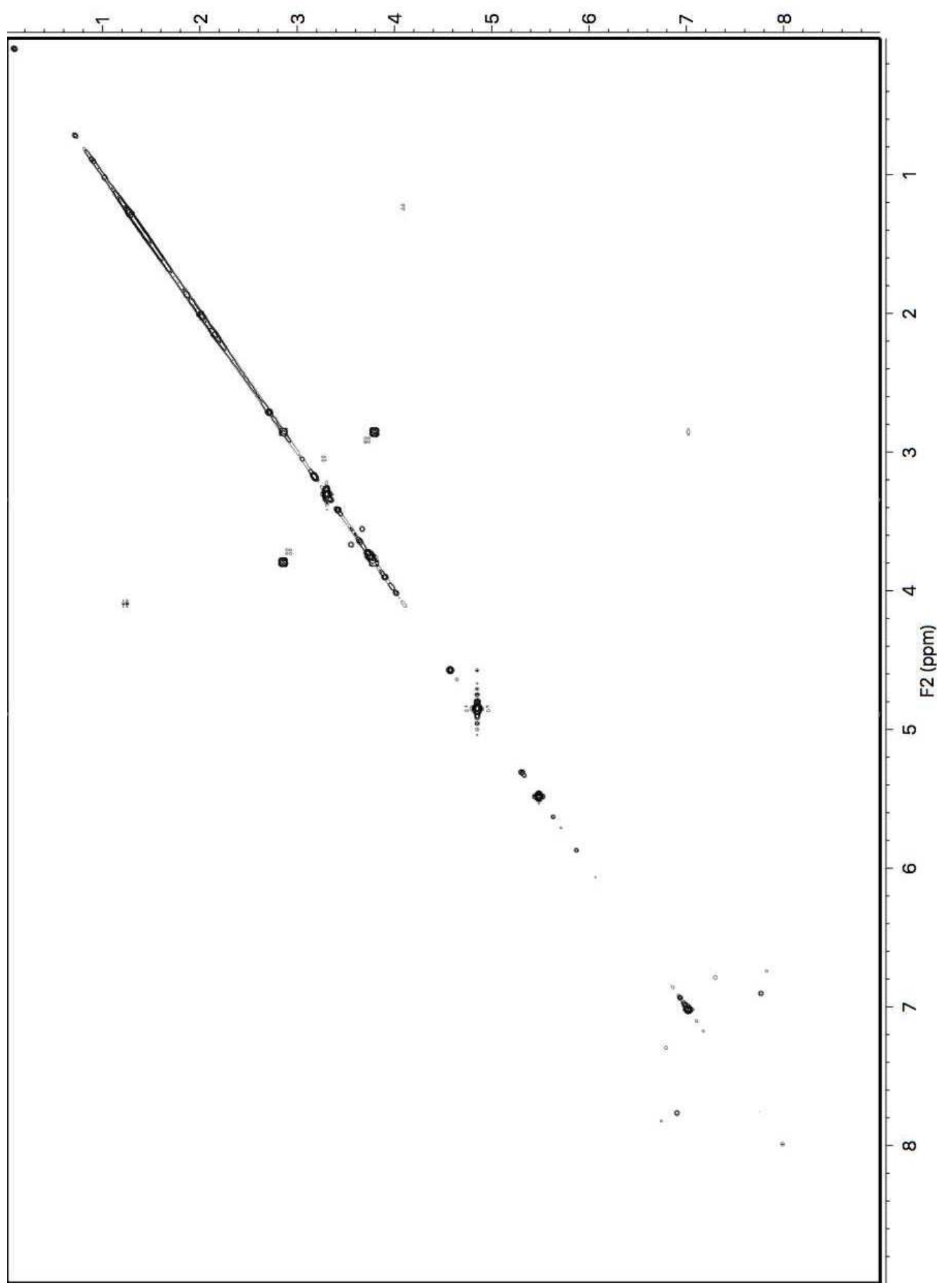

COSY spectrum of 6-bromodamirone B (182) (600 MHz, $\left.\mathrm{CD}_{3} \mathrm{OD}\right)$. 
(udd) IJ

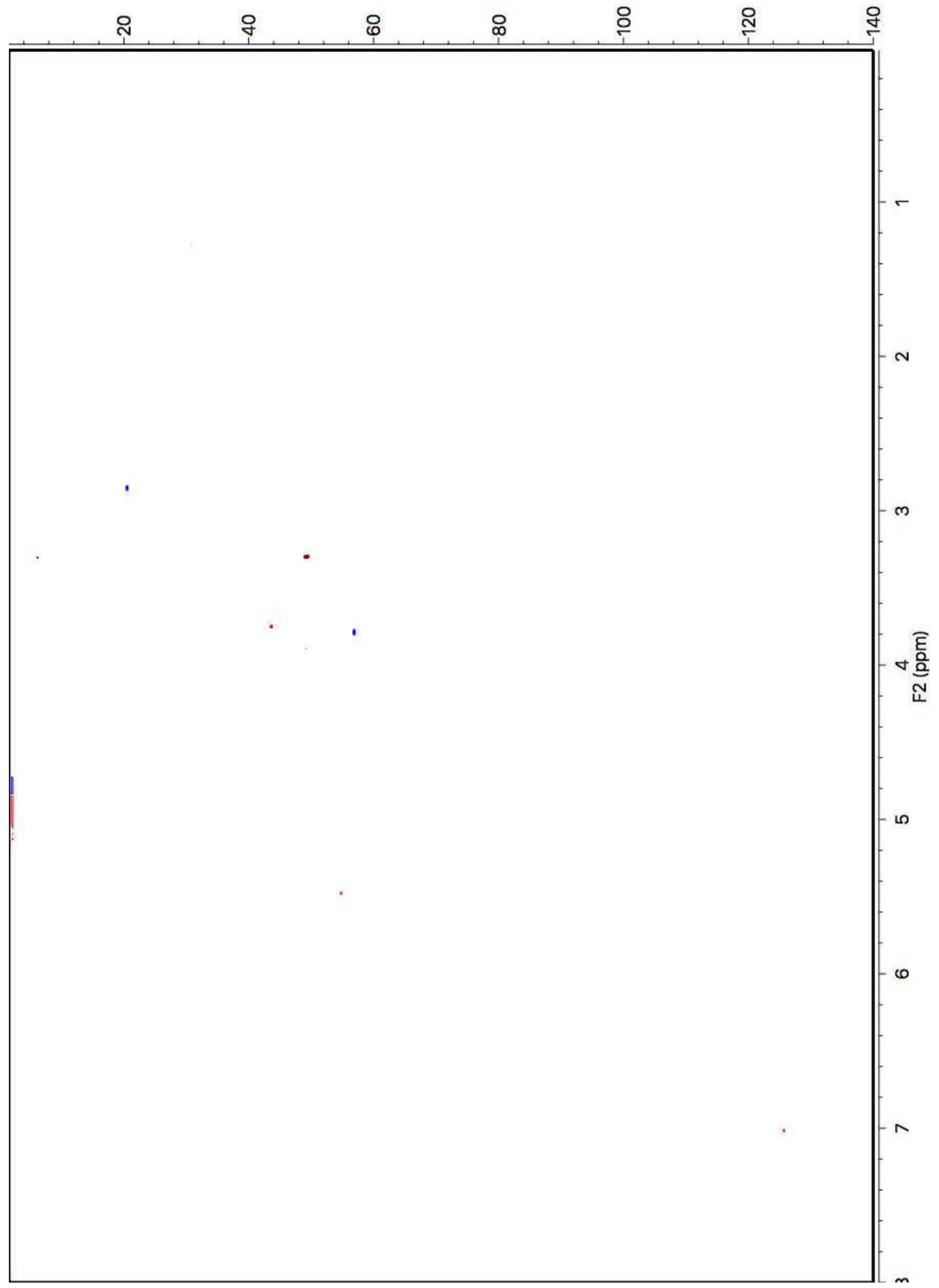

HSQC spectrum of 6-bromodamirone B (182) (600 MHz, $\left.\mathrm{CD}_{3} \mathrm{OD}\right)$. 


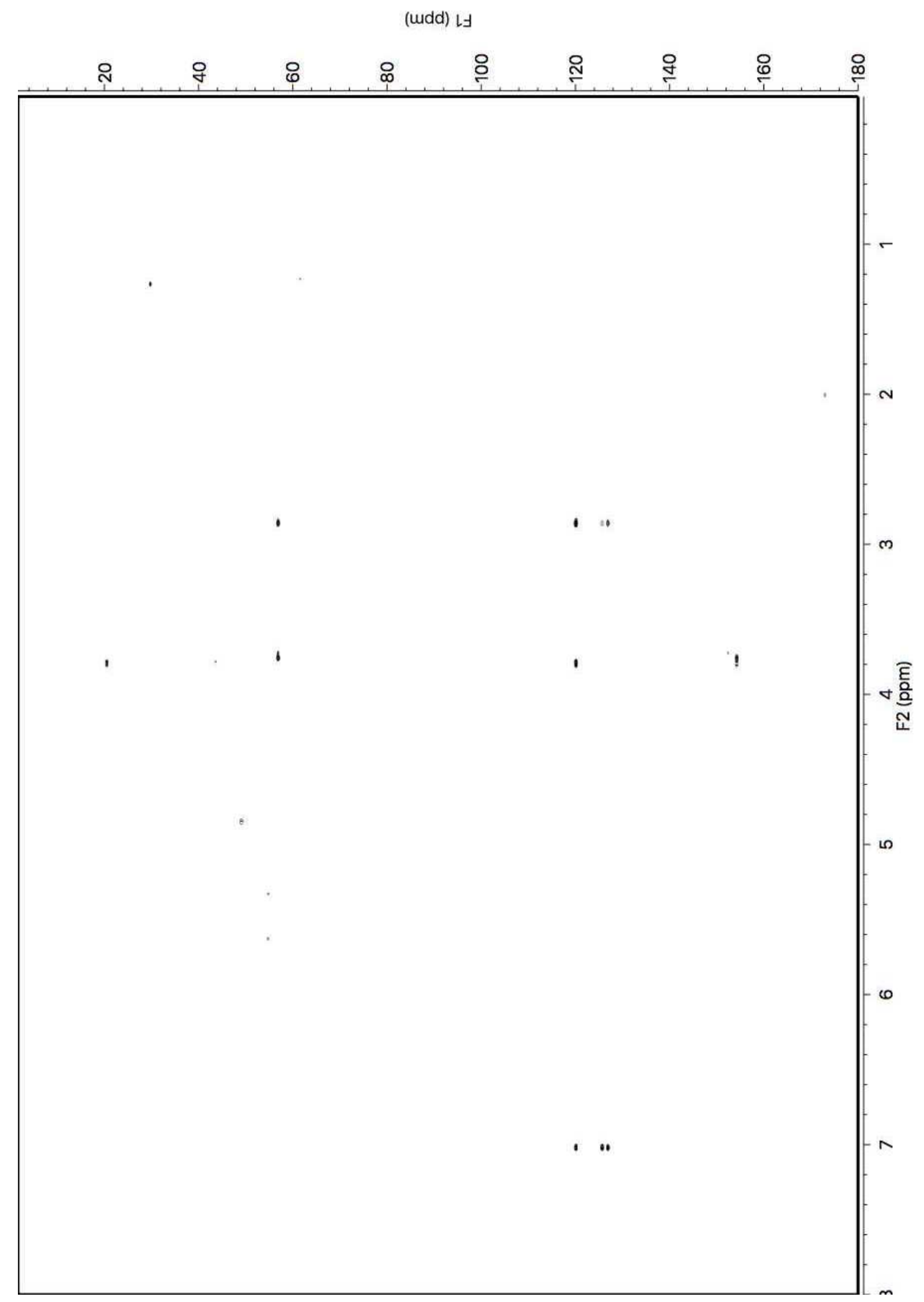

HMBC spectrum of 6-bromodamirone B (182) (600 MHz, $\left.\mathrm{CD}_{3} \mathrm{OD}\right)$. 


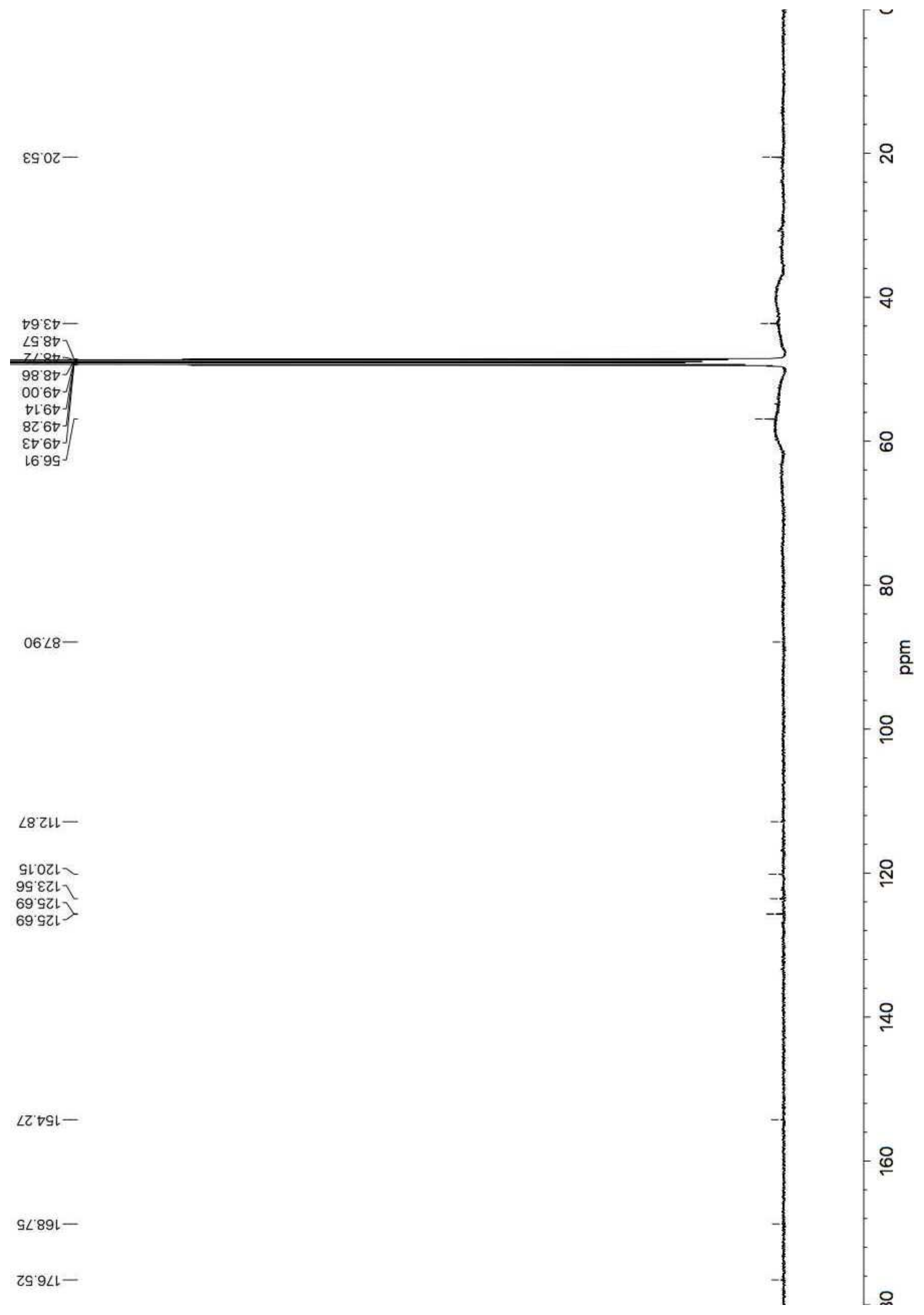

${ }^{13} \mathrm{C}$ NMR spectrum of 6-bromodamirone B (182) (150 MHz, $\left.\mathrm{CD}_{3} \mathrm{OD}\right)$. 


\section{Makaluvamine W Spectra}

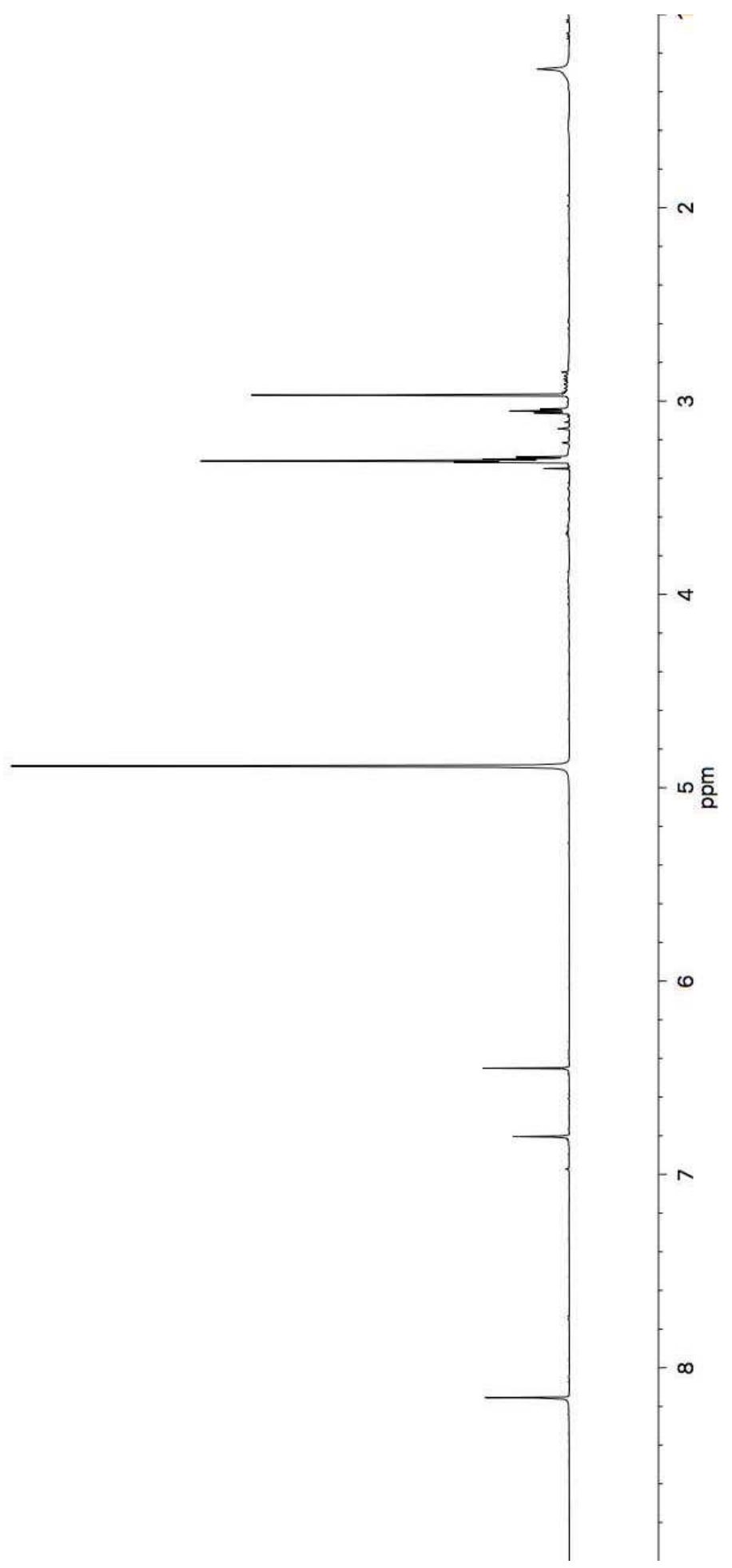

${ }^{1} \mathrm{H}$ NMR spectrum of makaluvamine W (183) (600 MHz, $\left.\mathrm{CD}_{3} \mathrm{OD}\right)$. 


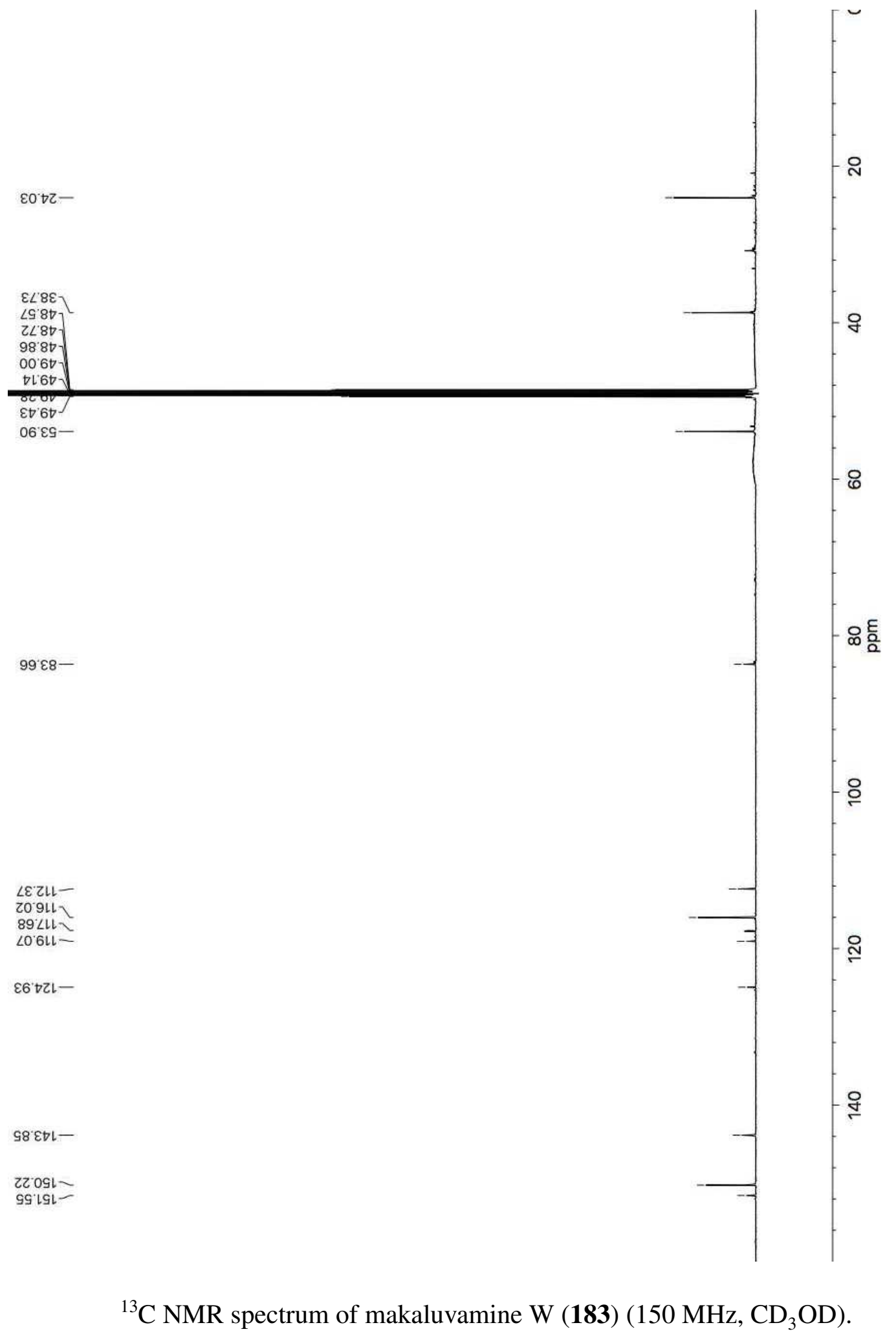




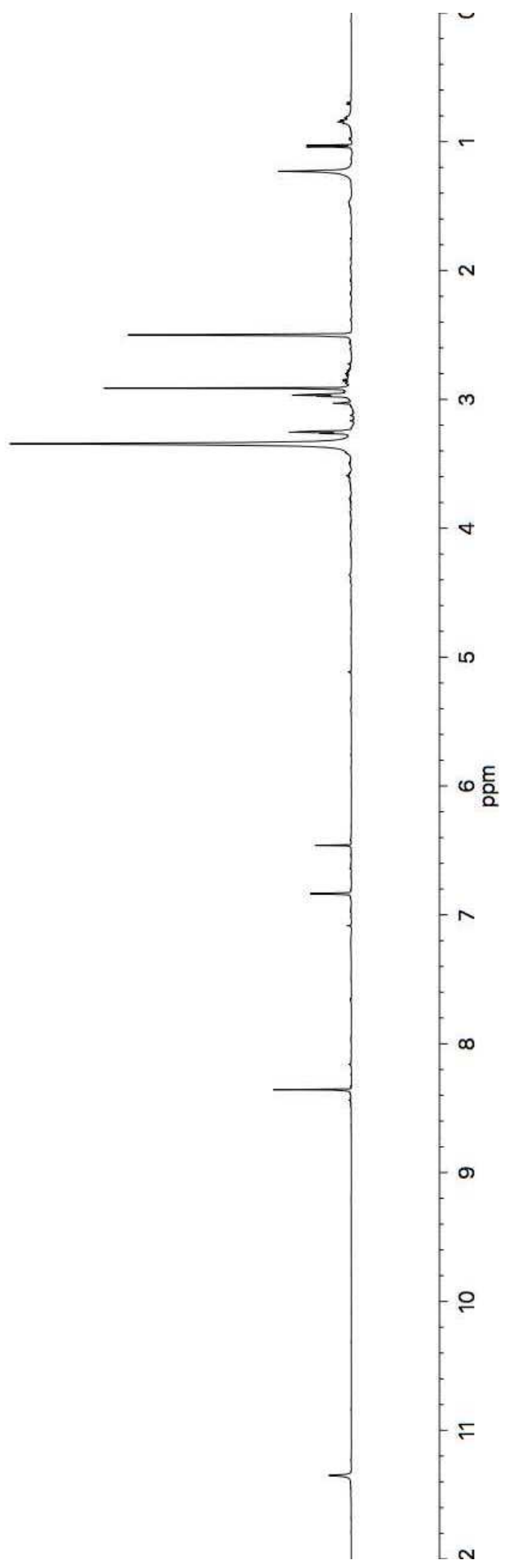

${ }^{1} \mathrm{H}$ NMR spectrum of makaluvamine W (183) (600 MHz, DMSO- $\left.d_{6}\right)$. 
(udd) $L J$

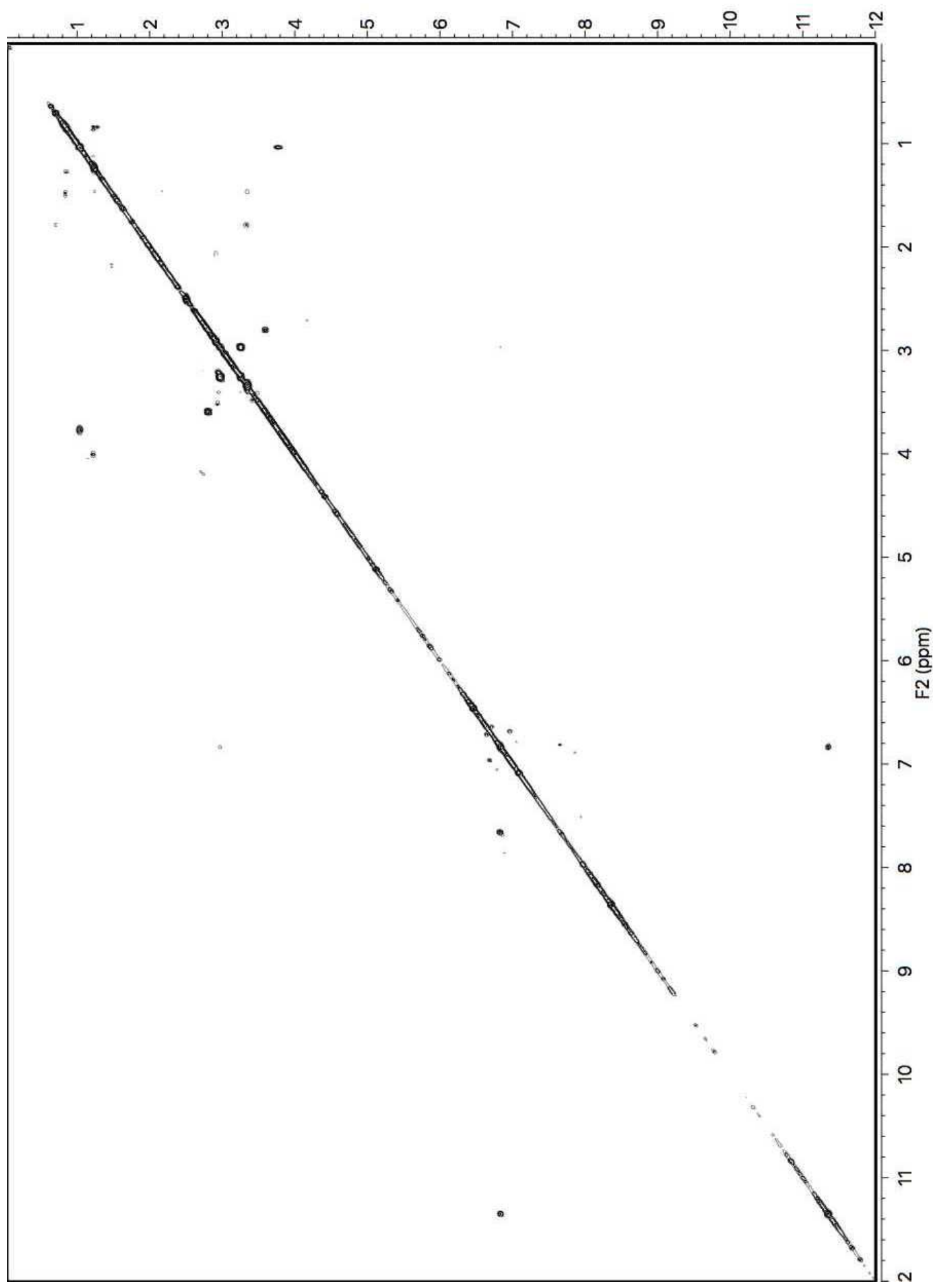

COSY spectrum of makaluvamine W (183) $\left(600 \mathrm{MHz}, \mathrm{DMSO}-d_{6}\right)$. 


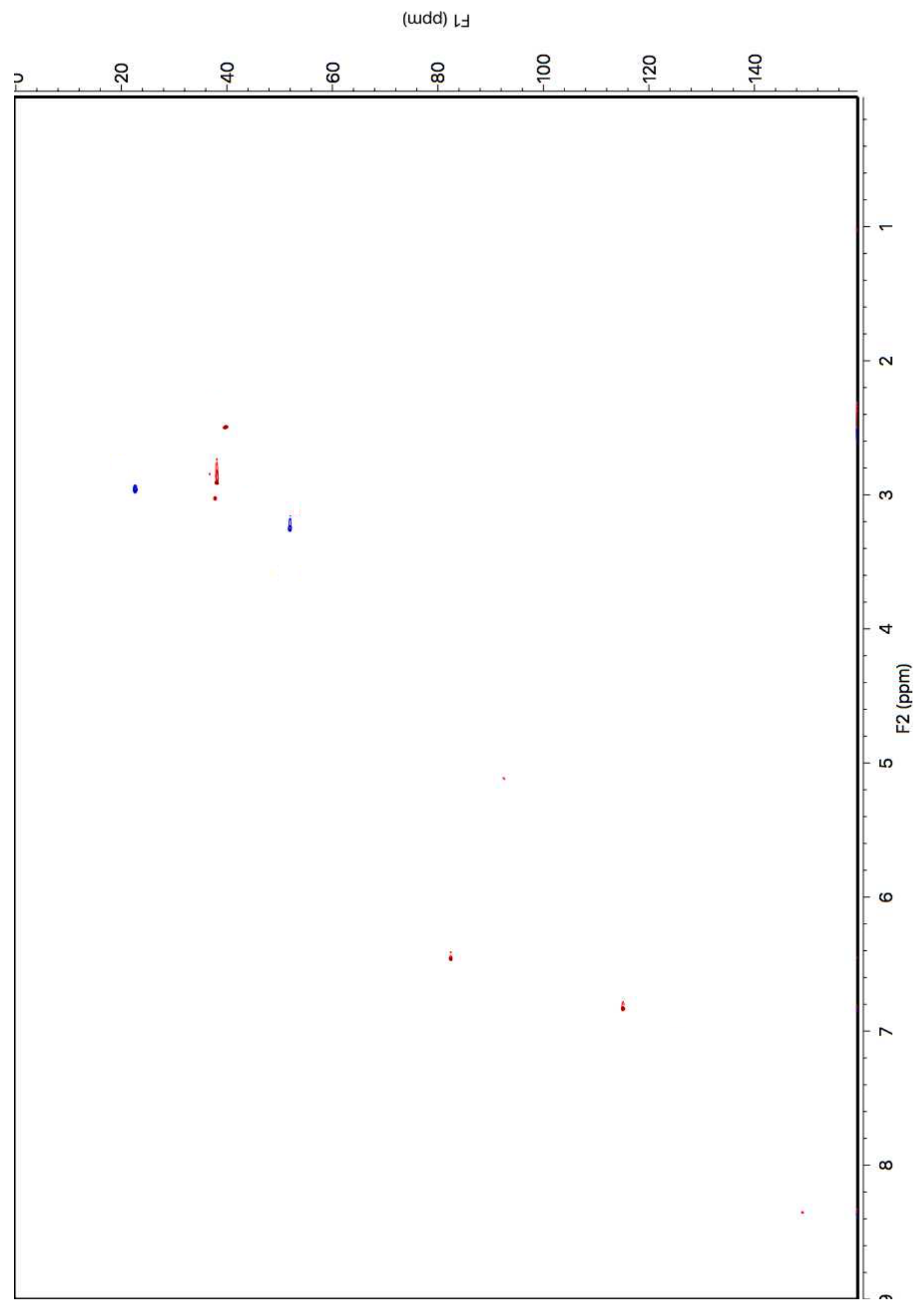

HSQC spectrum of makaluvamine W (183) $\left(600 \mathrm{MHz}, \mathrm{DMSO}-d_{6}\right)$. 


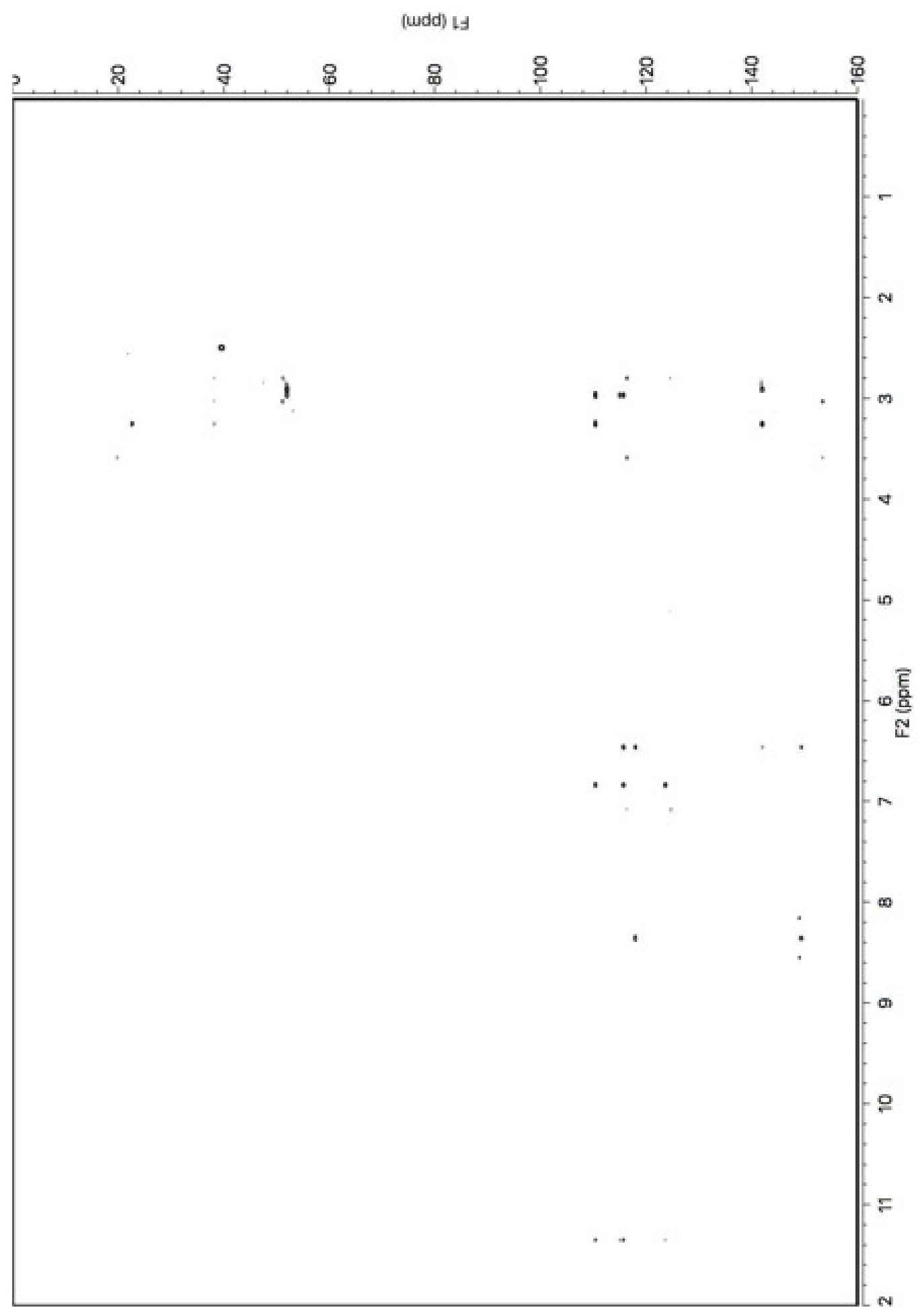

HMBC spectrum of makaluvamine W (183) $\left(600 \mathrm{MHz}, \mathrm{DMSO}-d_{6}\right)$. 


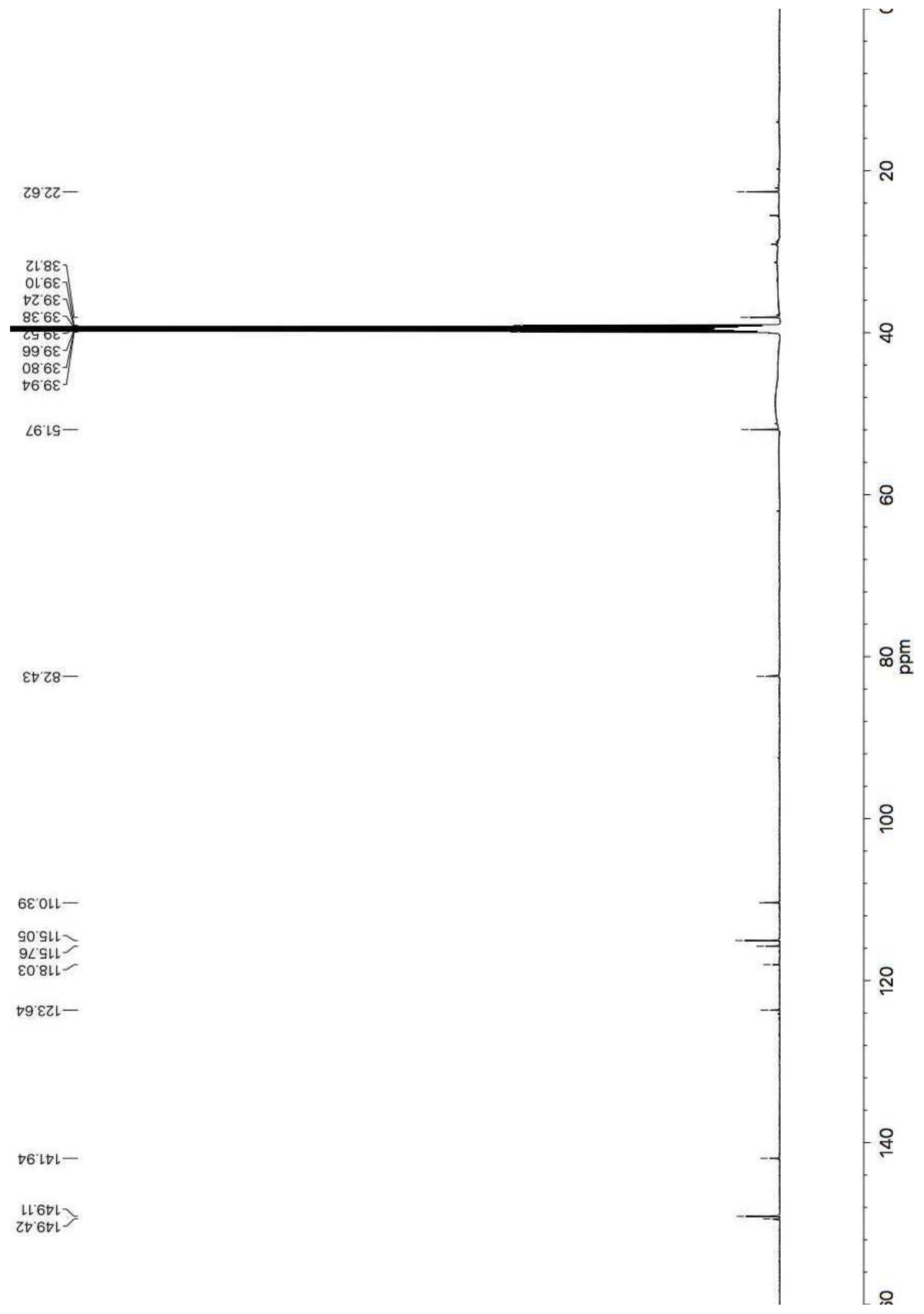

${ }^{13} \mathrm{C}$ NMR spectrum of makaluvamine W (183) $\left(150 \mathrm{MHz}\right.$, DMSO- $\left.d_{6}\right)$. 


\section{Appendix I}

\section{Glycerol Lipid A Spectra}

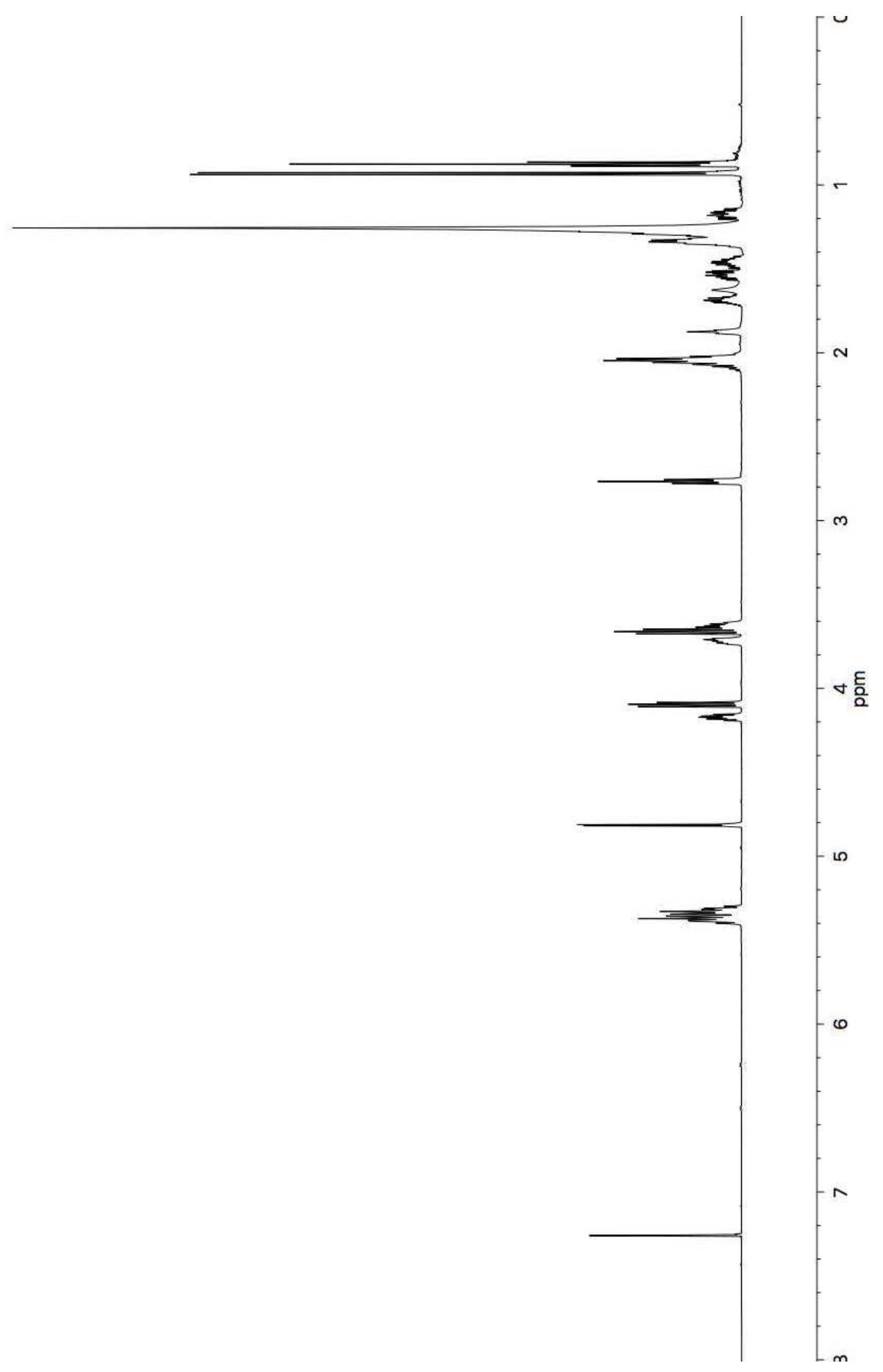

${ }^{1} \mathrm{H}$ NMR spectrum of glycerol lipid A (238) $\left(600 \mathrm{MHz}, \mathrm{CDCl}_{3}\right)$. 
(udd) $L \exists$

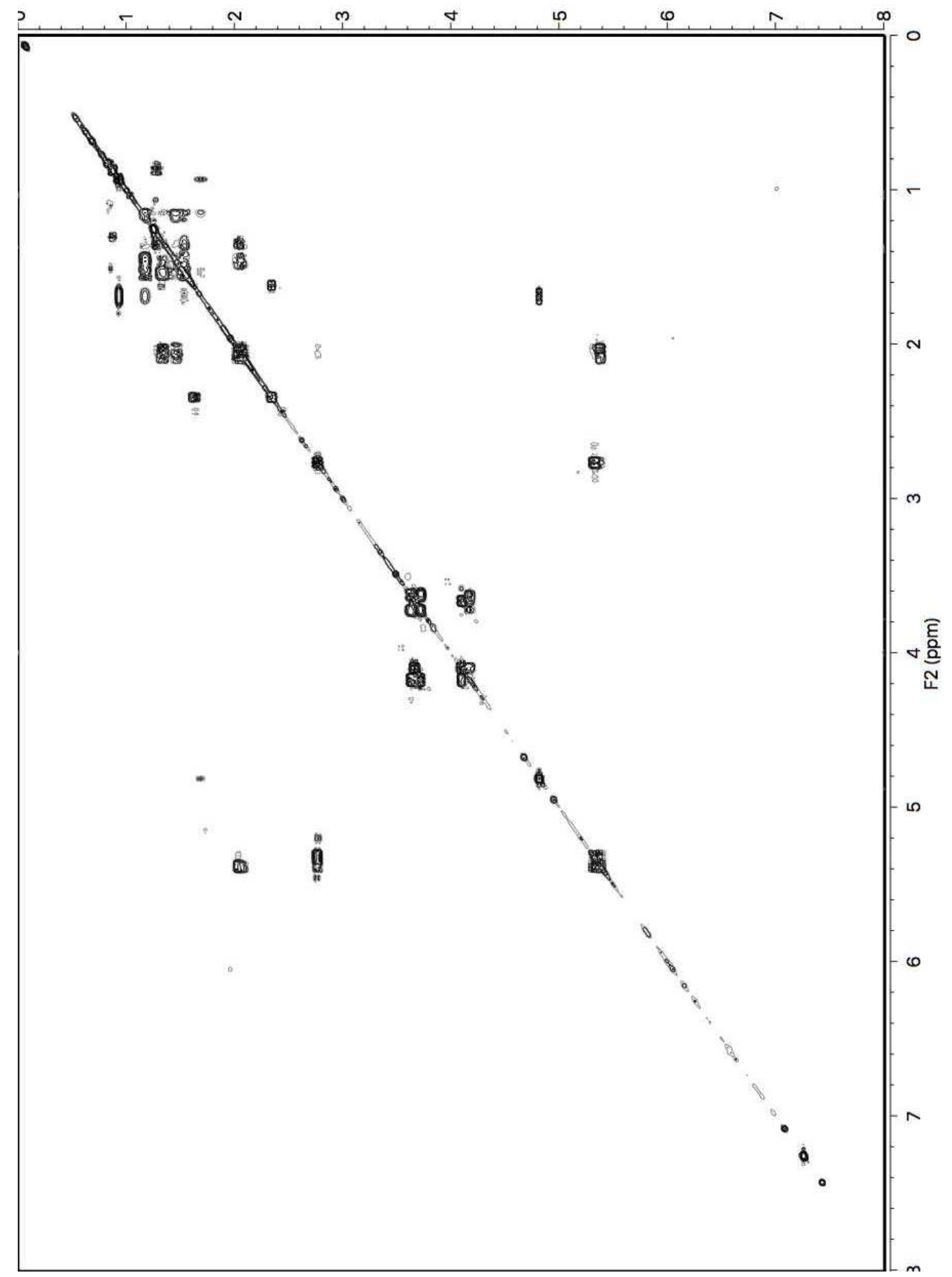

COSY spectrum of glycerol lipid A (238) $\left(600 \mathrm{MHz}, \mathrm{CDCl}_{3}\right)$. 


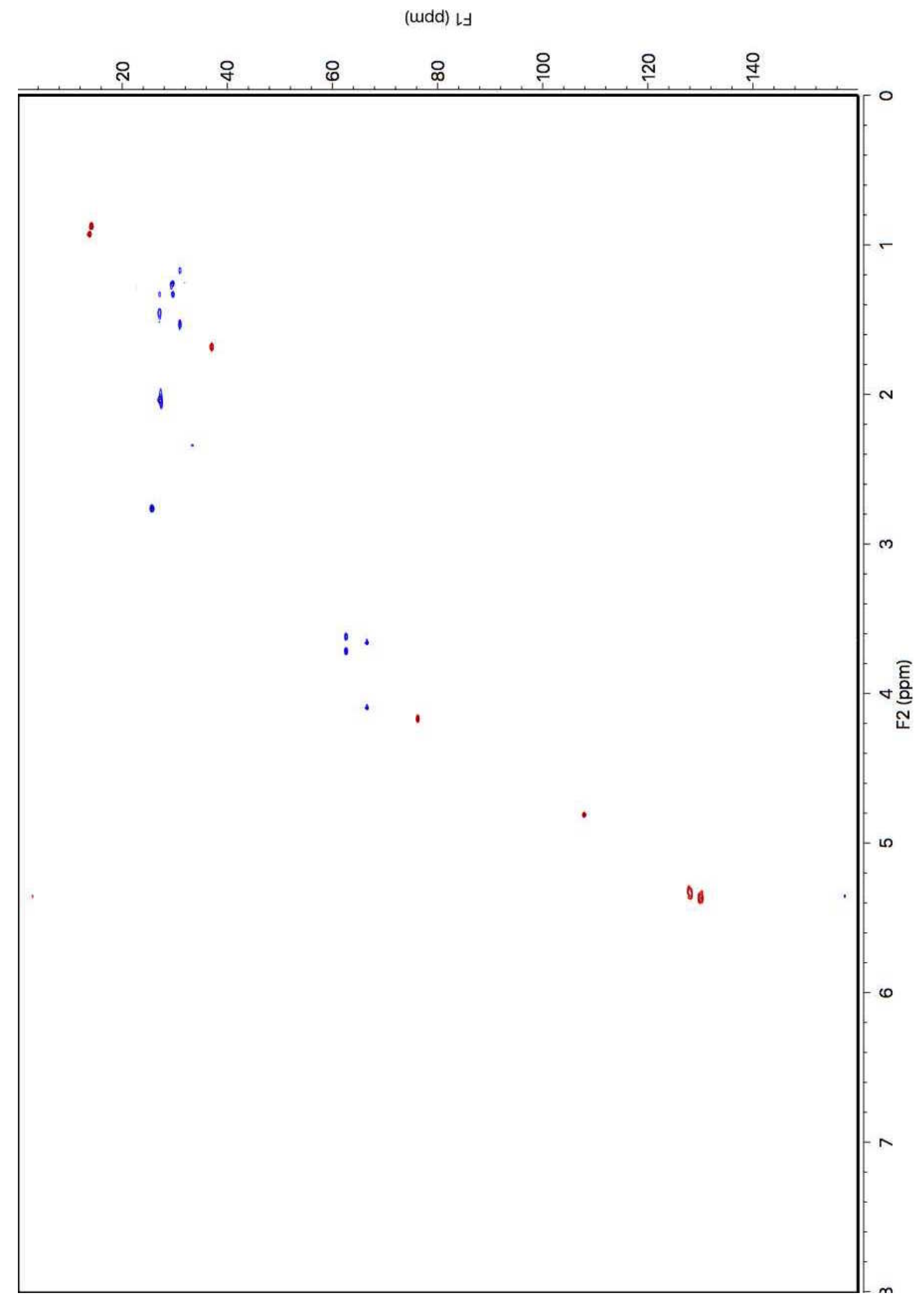

HSQC spectrum of glycerol lipid A (238) $\left(600 \mathrm{MHz}, \mathrm{CDCl}_{3}\right)$. 


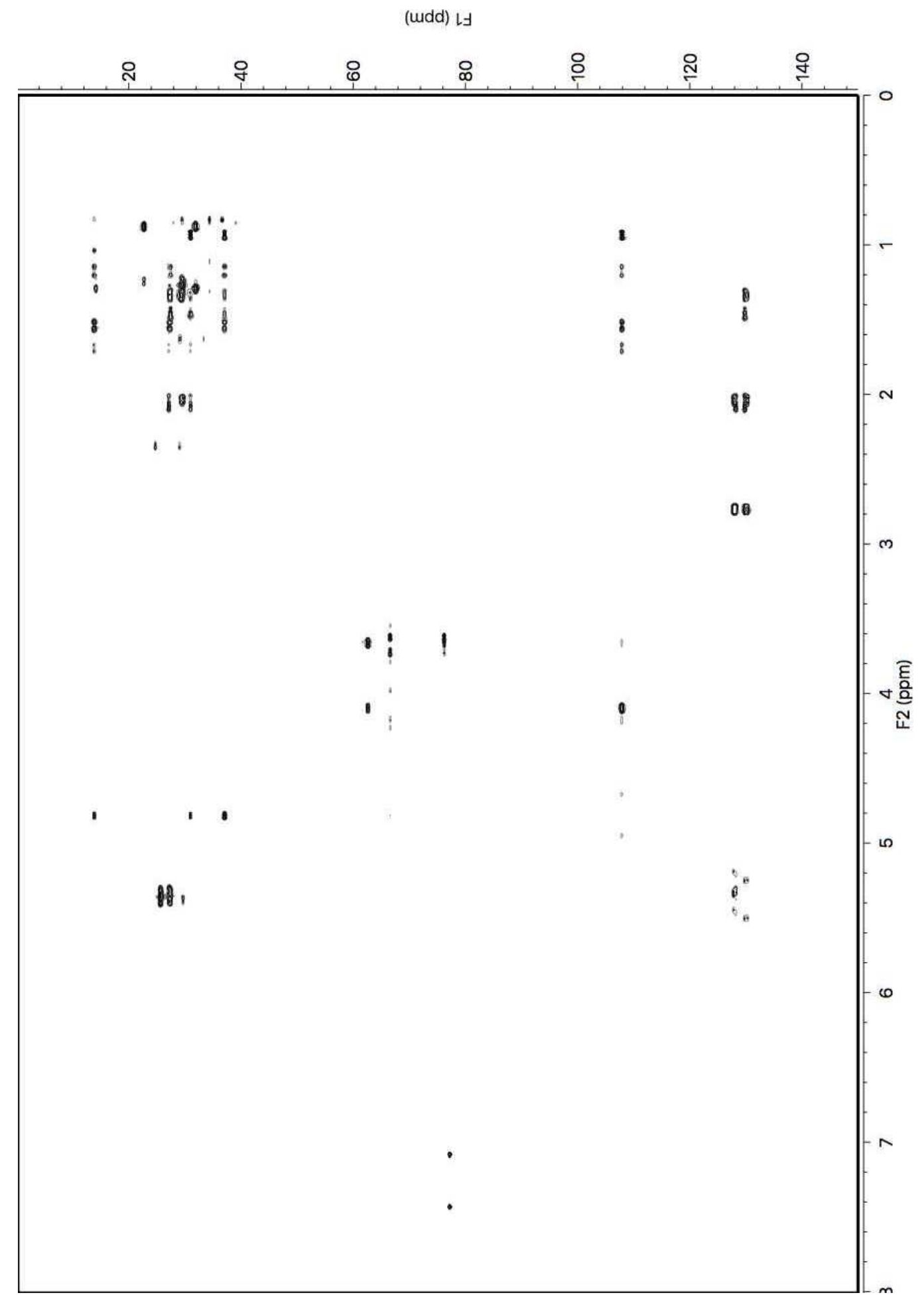

HMBC spectrum of glycerol lipid A (238) (600 MHz, $\mathrm{CDCl}_{3}$ ). 


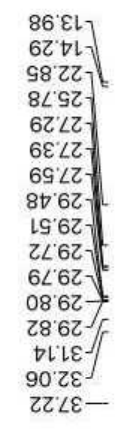

LL29-

SL99-

$6 \varepsilon 94]$

$91 \angle L J$

$70801-$

$\angle 6: 2 Z 1$

$968 \mathrm{gll-}$

Z† $96 \mathrm{EL}$ 厂

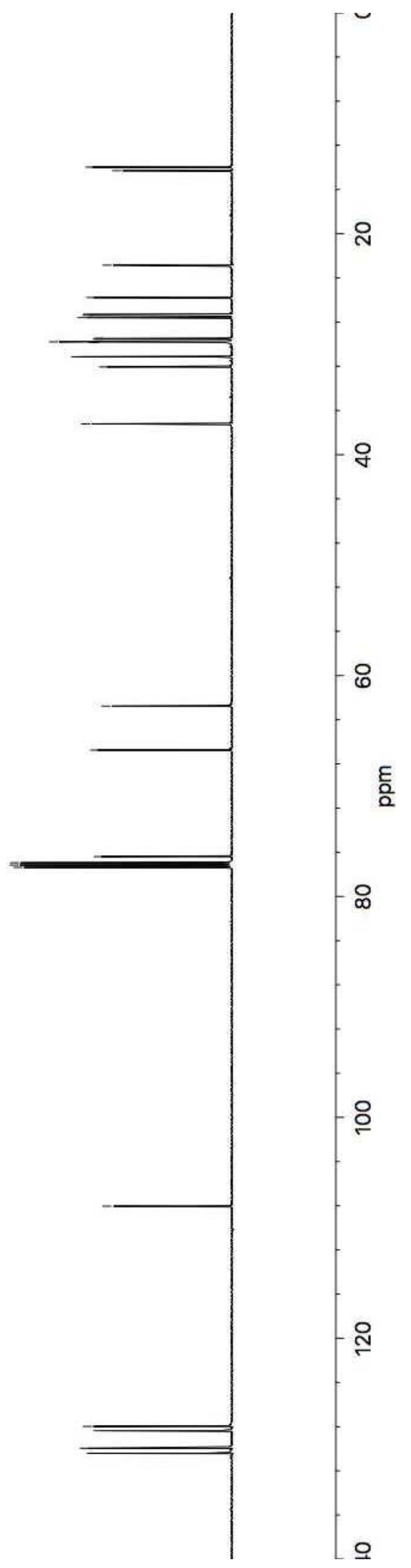

${ }^{13} \mathrm{C}$ NMR spectrum of glycerol lipid A (238) $\left(150 \mathrm{MHz}, \mathrm{CDCl}_{3}\right)$. 


\section{Glycerol Lipid B Spectra}

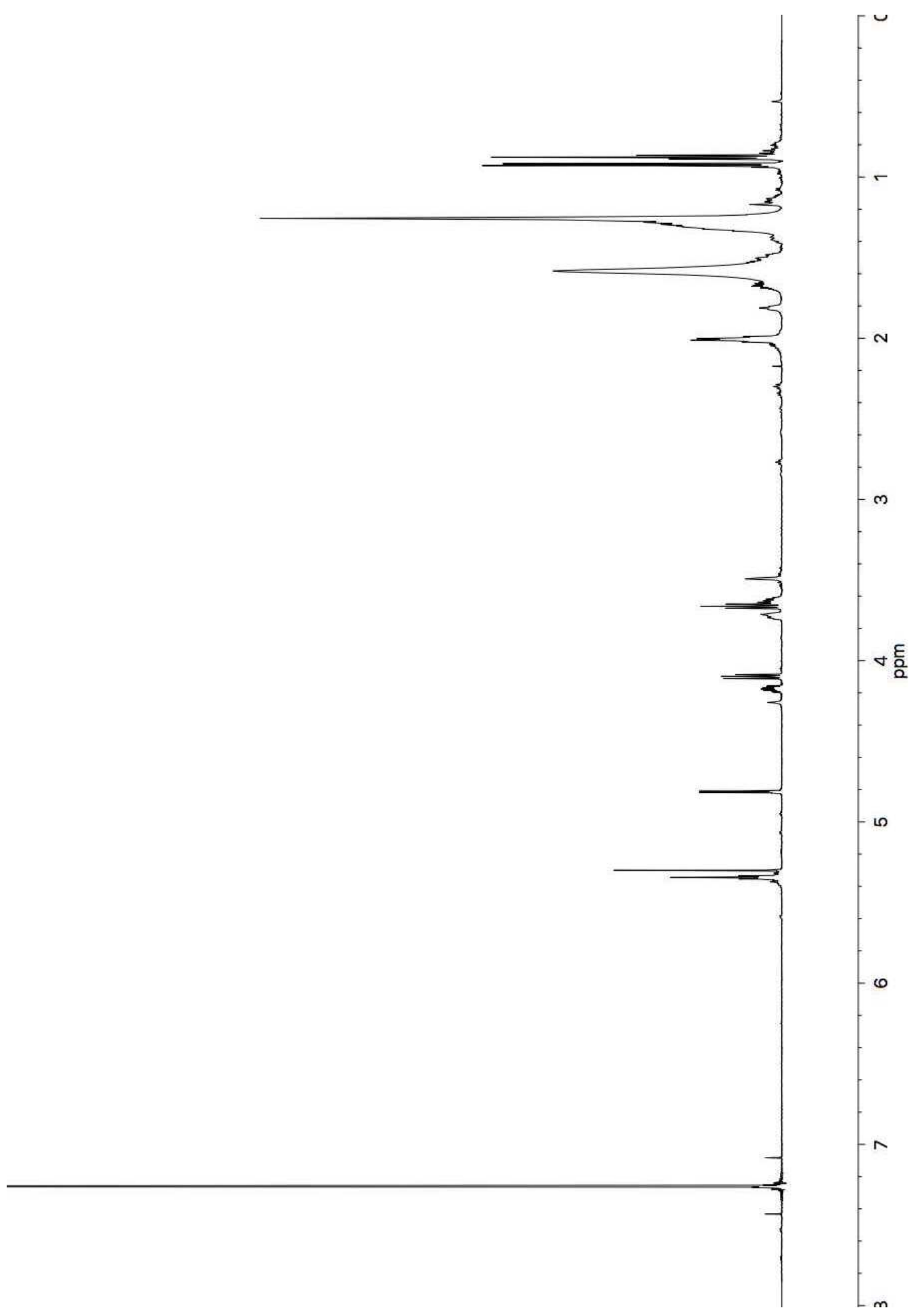

${ }^{1} \mathrm{H}$ NMR spectrum of glycerol lipid B (239) (600 MHz, $\mathrm{CDCl}_{3}$ ). 
(udd) $\downarrow \unlhd$

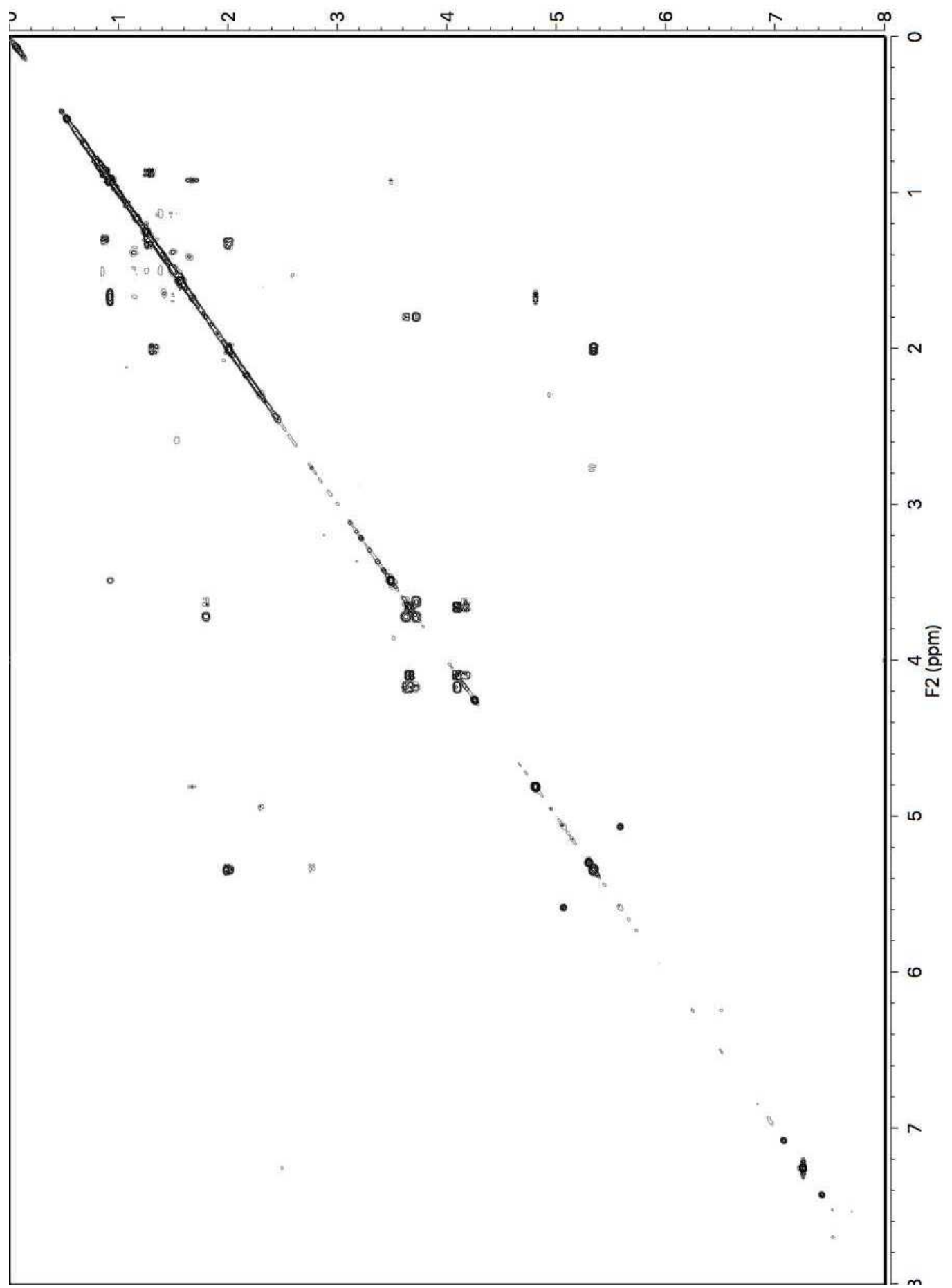

COSY spectrum of glycerol lipid B (239) (600 MHz, $\left.\mathrm{CDCl}_{3}\right)$. 
(udd) ᄂ

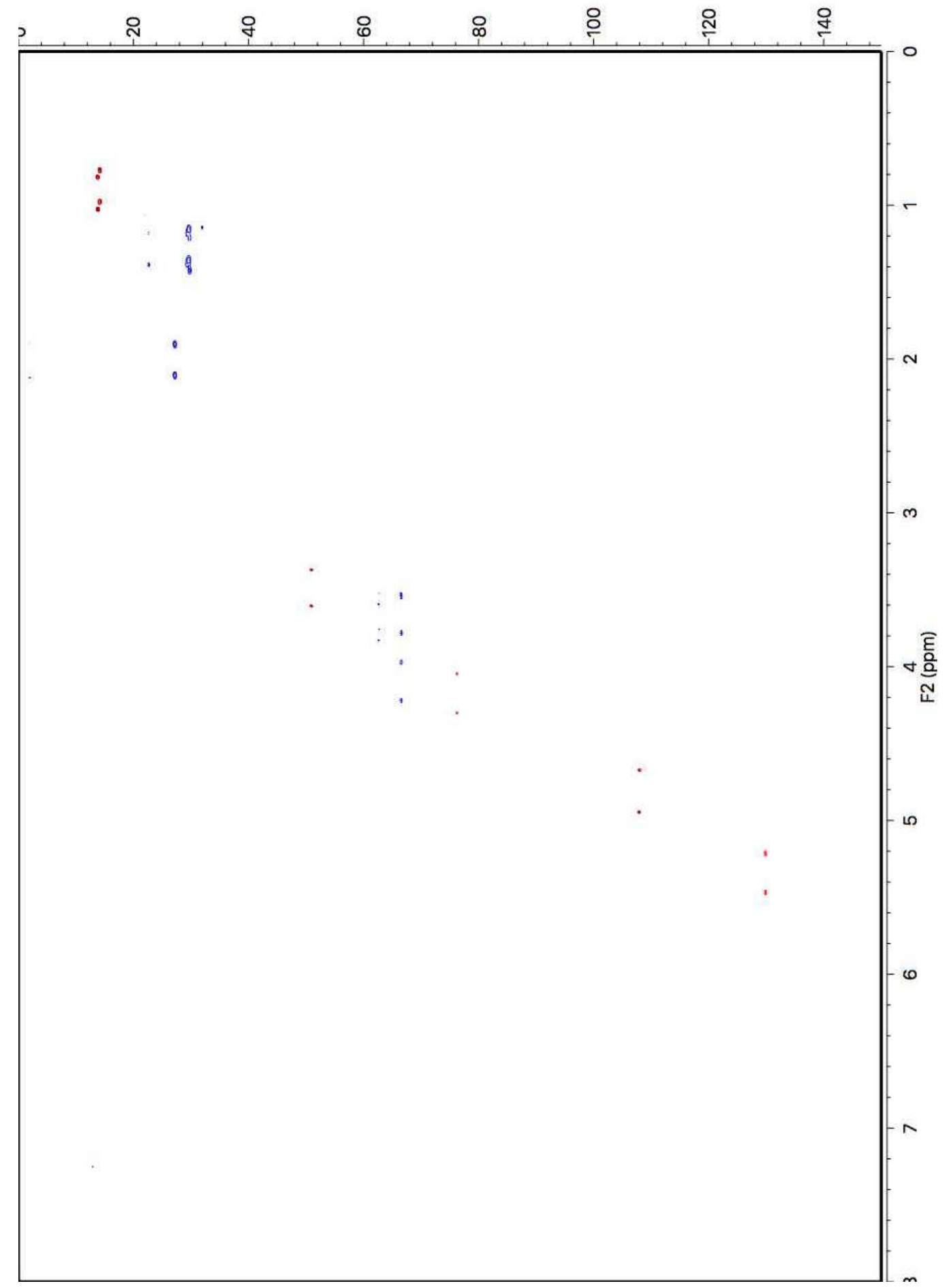

Fully-coupled HSQC spectrum of glycerol lipid B (239) $\left(600 \mathrm{MHz}, \mathrm{CDCl}_{3}\right)$. 


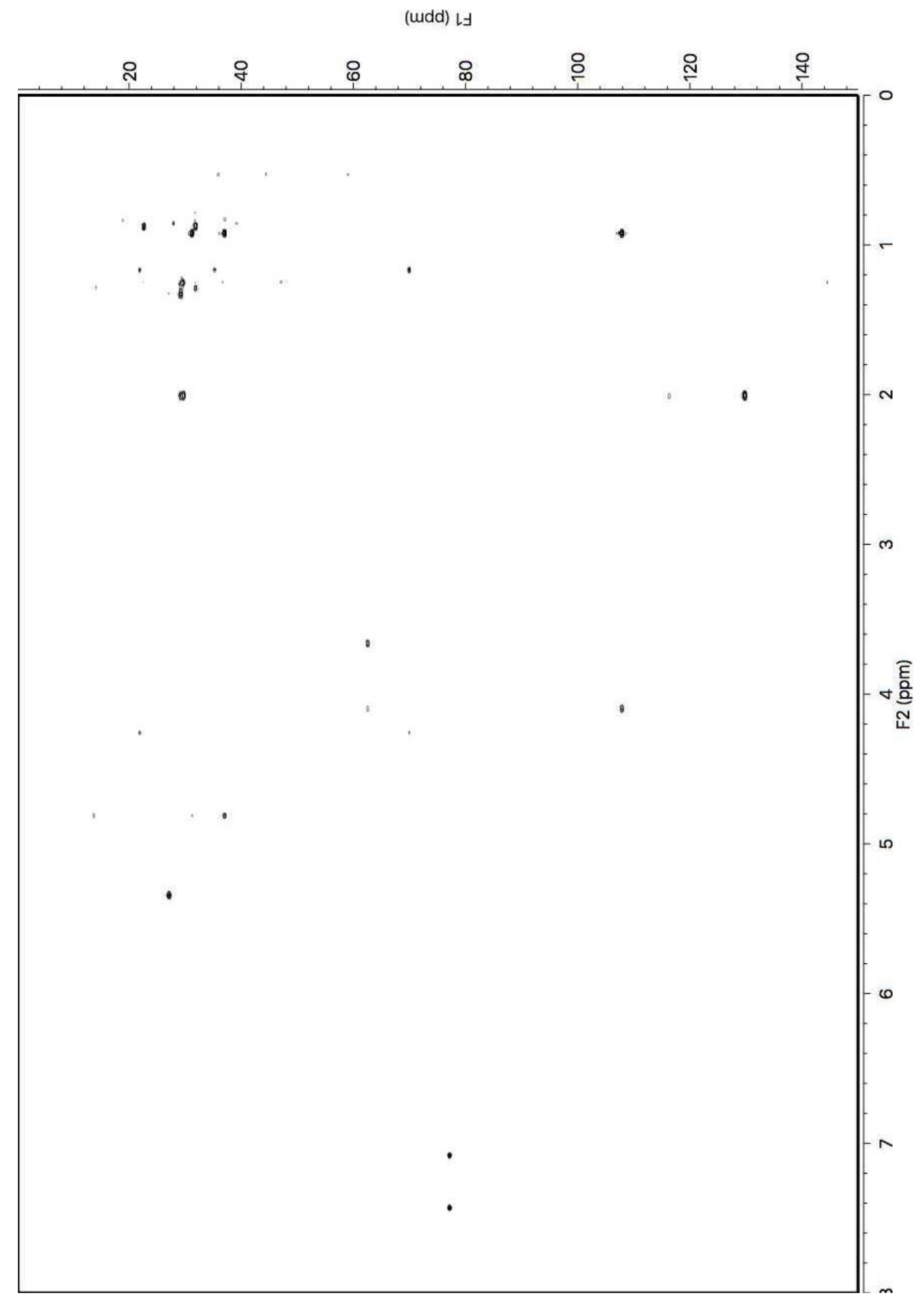

HMBC spectrum of glycerol lipid B (239) $\left(600 \mathrm{MHz}, \mathrm{CDCl}_{3}\right)$. 
$\varepsilon 6^{\circ} \varepsilon \downarrow$
$0 \varepsilon^{\circ} \nabla \downarrow$

$9822-$

$\quad 1 \angle Z$
$9 \varepsilon \angle Z$

$\angle E L Z$

¿† $62-$

$8+62$

2962

$Z \angle 62$
0862

28.62

16.62
$\varepsilon 6.6 z$

96.62

9662

$\angle \nabla t \varepsilon$

$\angle 0 Z \varepsilon]$
$9 Z \angle \varepsilon$

6L29-

$\forall \angle 99-$

$\angle \varepsilon 9 \angle>$

$91 \angle L)$

$\angle E L L$

$21801-$

$\angle 662 l>$

60081

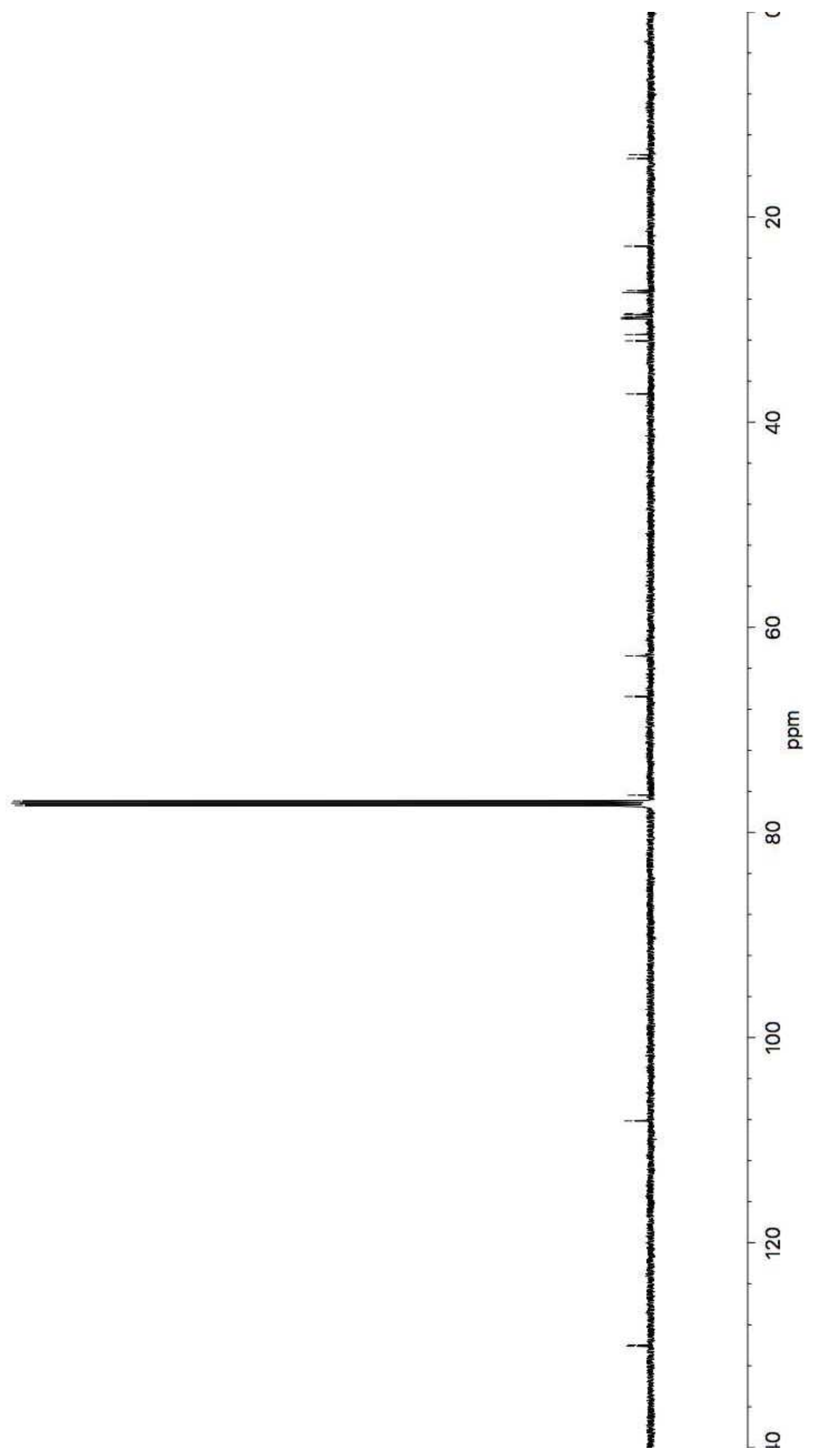

${ }^{13} \mathrm{C}$ NMR spectrum of glycerol lipid B (239) $\left(150 \mathrm{MHz}, \mathrm{CDCl}_{3}\right)$. 


\section{Naamidine K Spectra}

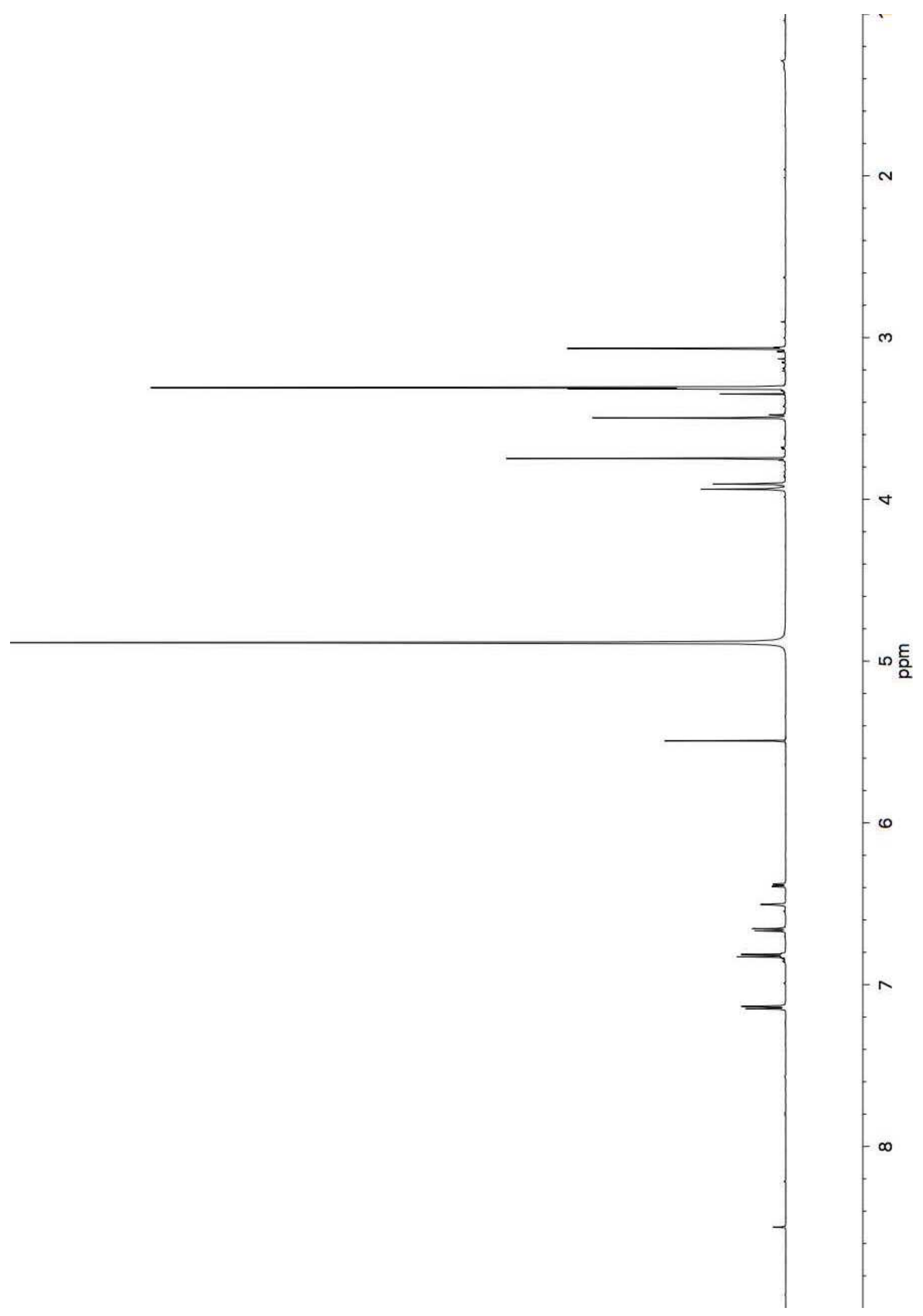

${ }^{1} \mathrm{H}$ NMR spectrum of naamidine $\mathrm{K}(\mathbf{2 4 3})\left(600 \mathrm{MHz}, \mathrm{CD}_{3} \mathrm{OD}\right)$. 
(udd) $\downarrow J$

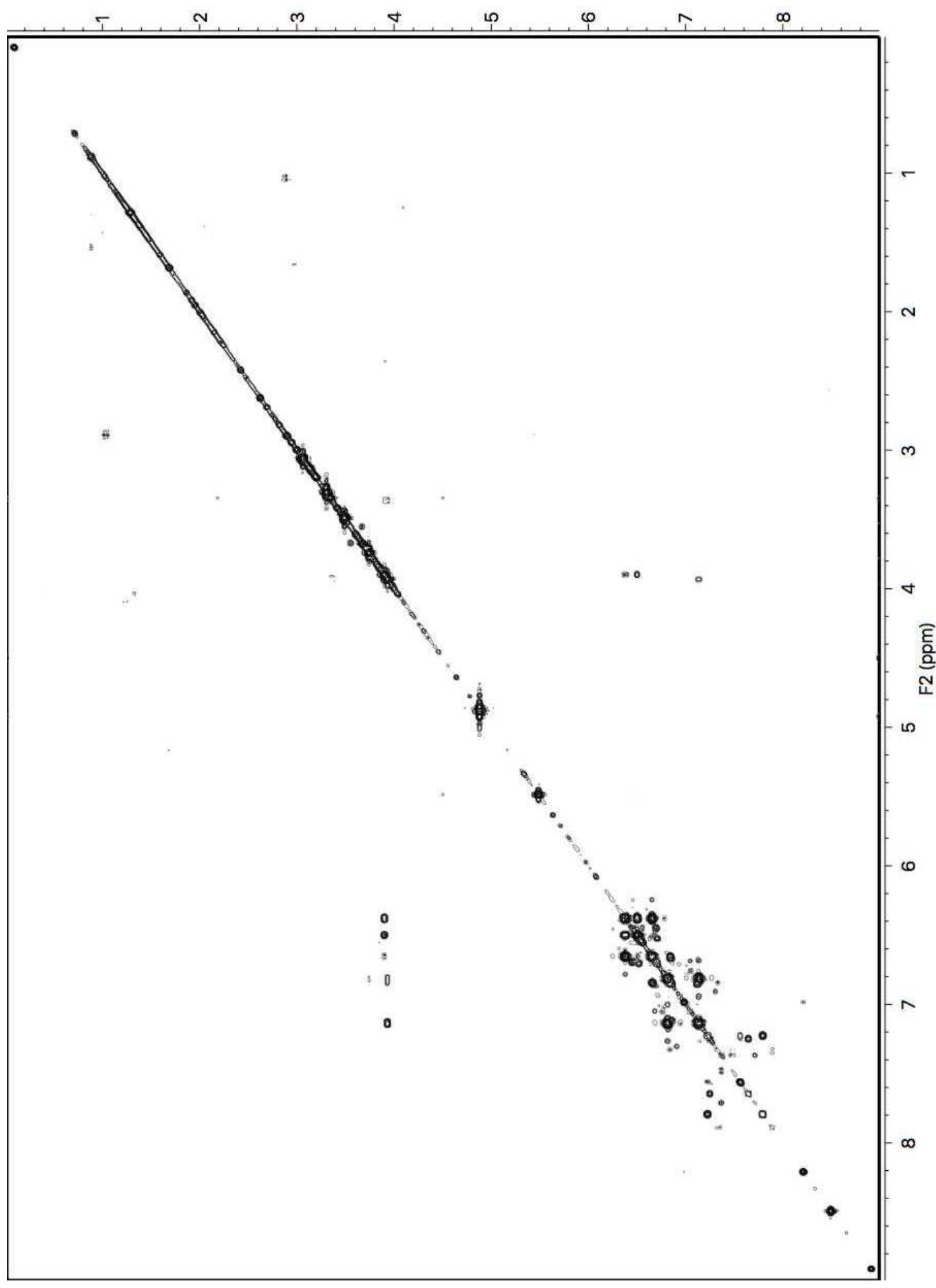

COSY spectrum of naamidine $\mathrm{K}(\mathbf{2 4 3})\left(600 \mathrm{MHz}, \mathrm{CD}_{3} \mathrm{OD}\right)$. 
(udd) I

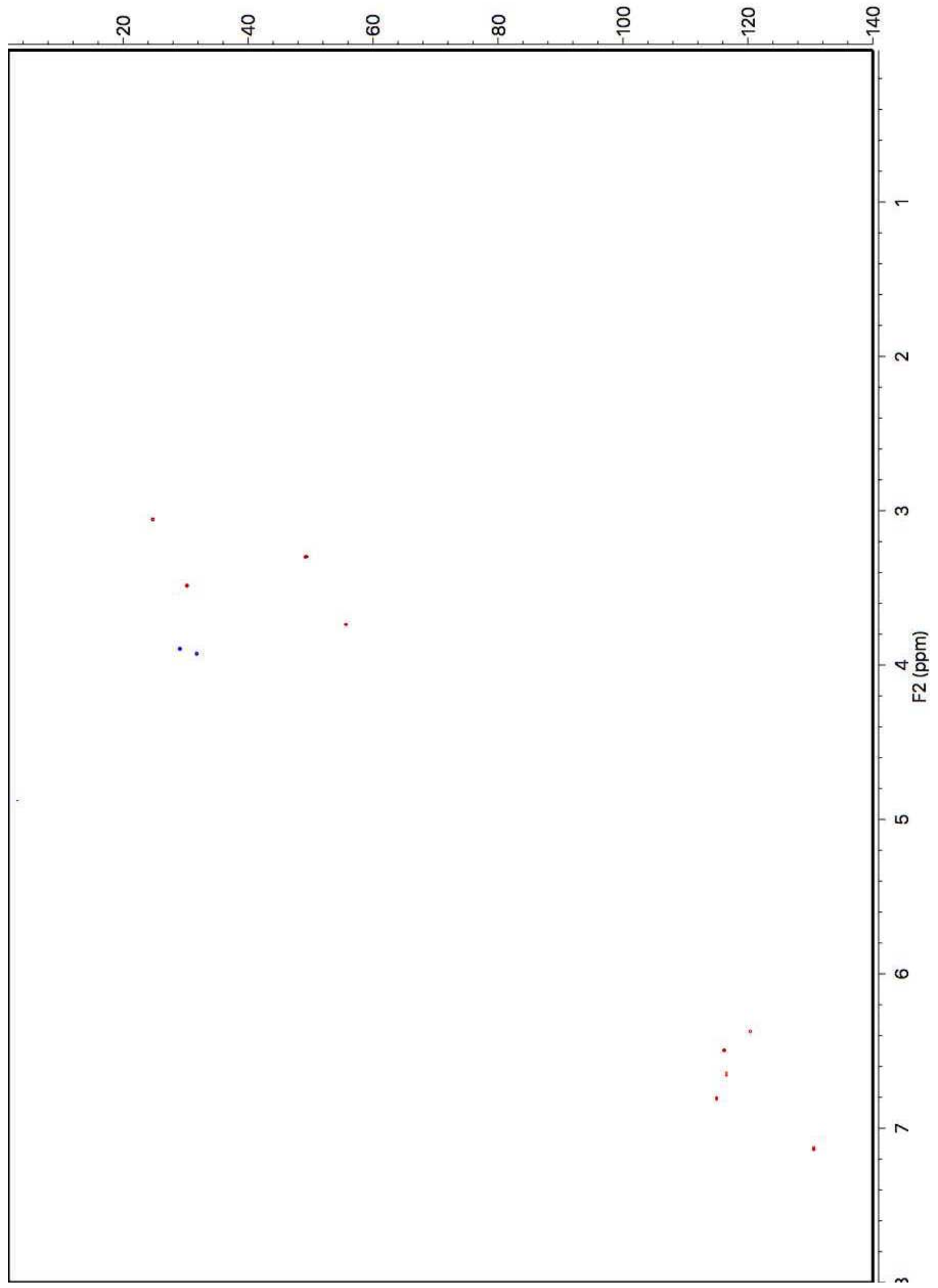

HSQC spectrum of naamidine $\mathrm{K}(\mathbf{2 4 3})\left(600 \mathrm{MHz}, \mathrm{CD}_{3} \mathrm{OD}\right)$. 


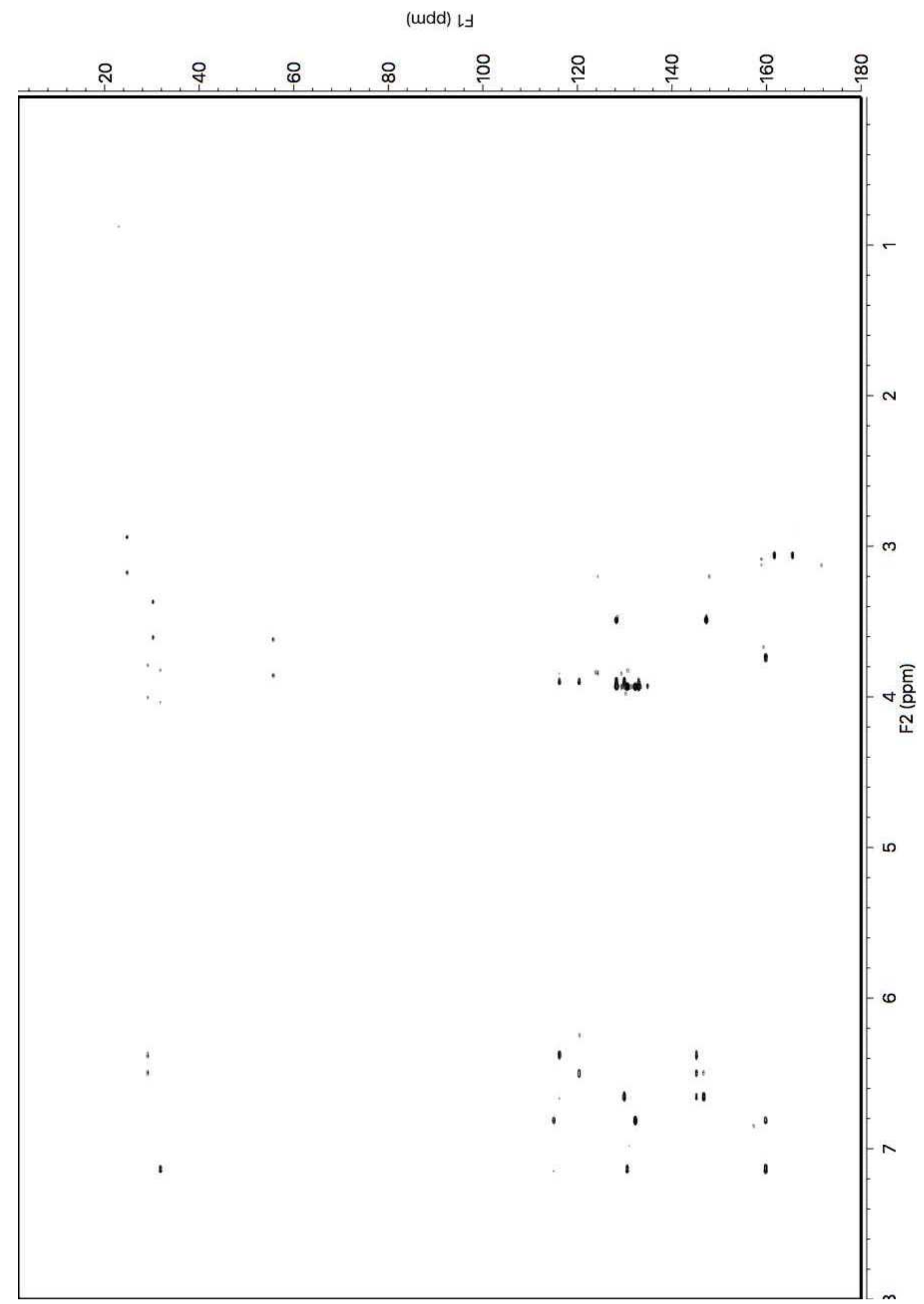

HMBC spectrum of naamidine $\mathrm{K}(\mathbf{2 4 3})\left(600 \mathrm{MHz}, \mathrm{CD}_{3} \mathrm{OD}\right)$.

266 


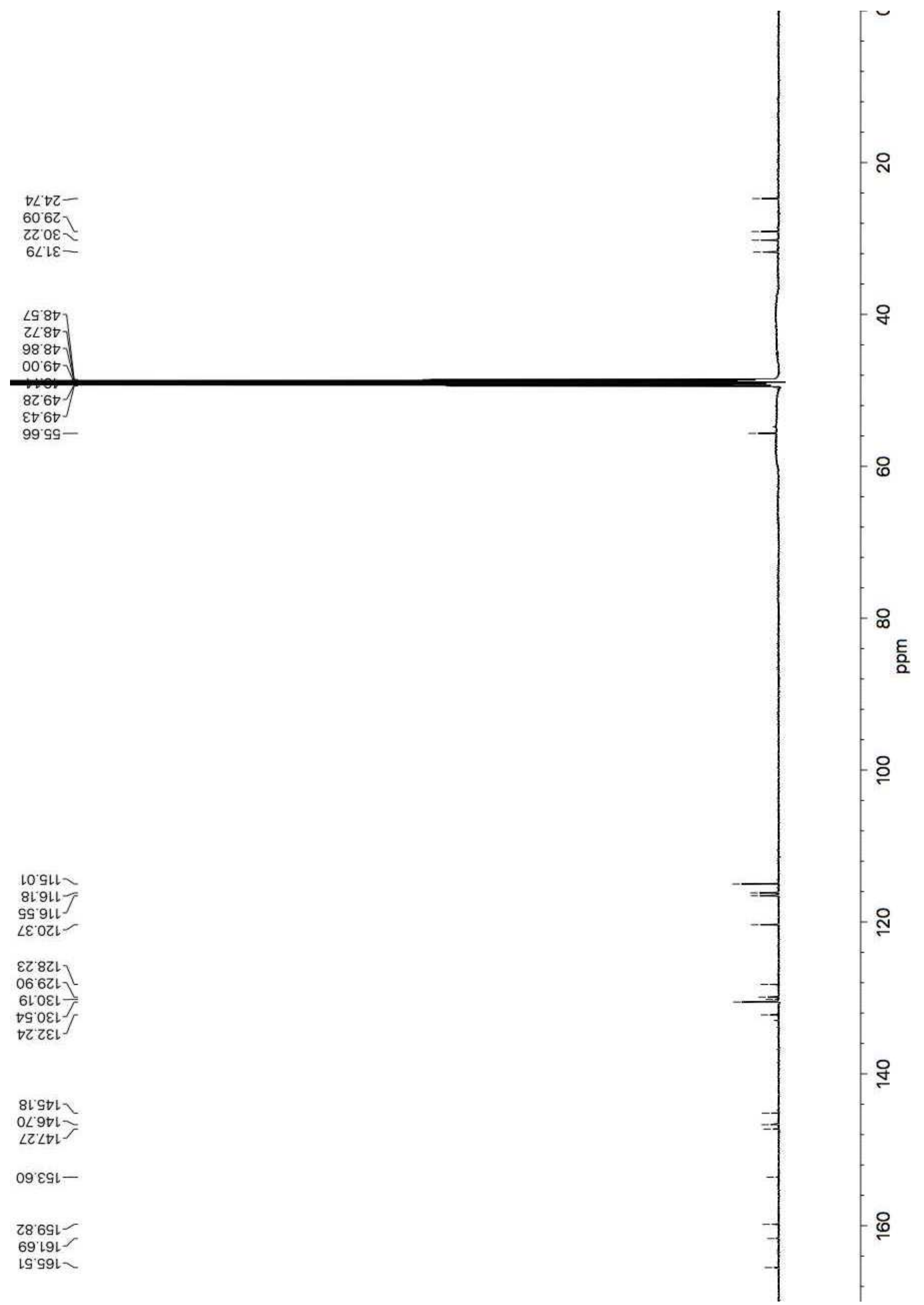

${ }^{13} \mathrm{C}$ NMR spectrum of naamidine $\mathrm{K}(\mathbf{2 4 3})\left(150 \mathrm{MHz}, \mathrm{CD}_{3} \mathrm{OD}\right)$. 


\section{Glycerol Ether A Spectra}

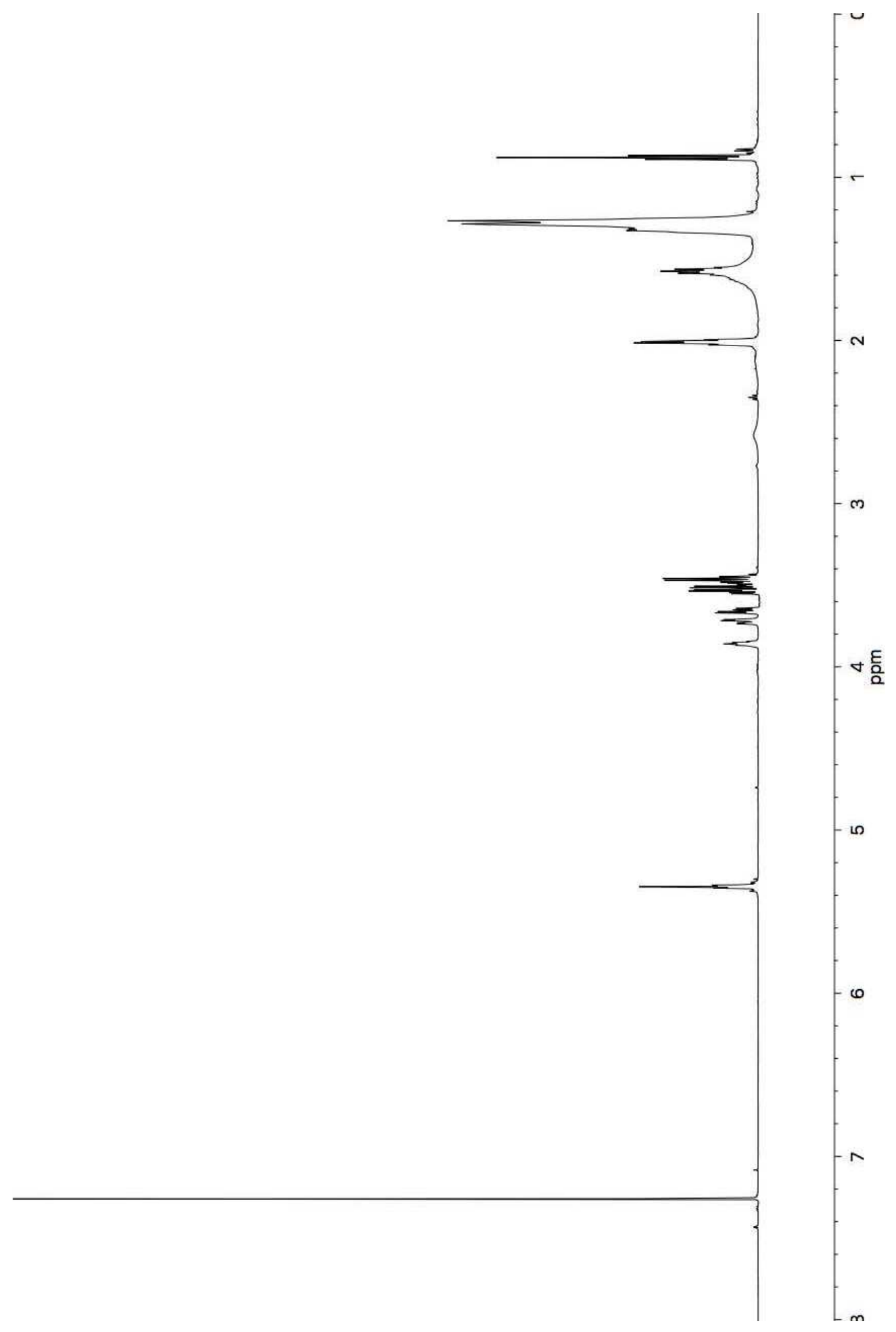

${ }^{1} \mathrm{H}$ NMR spectrum of glycerol ether A (244) $\left(600 \mathrm{MHz}, \mathrm{CDCl}_{3}\right)$. 


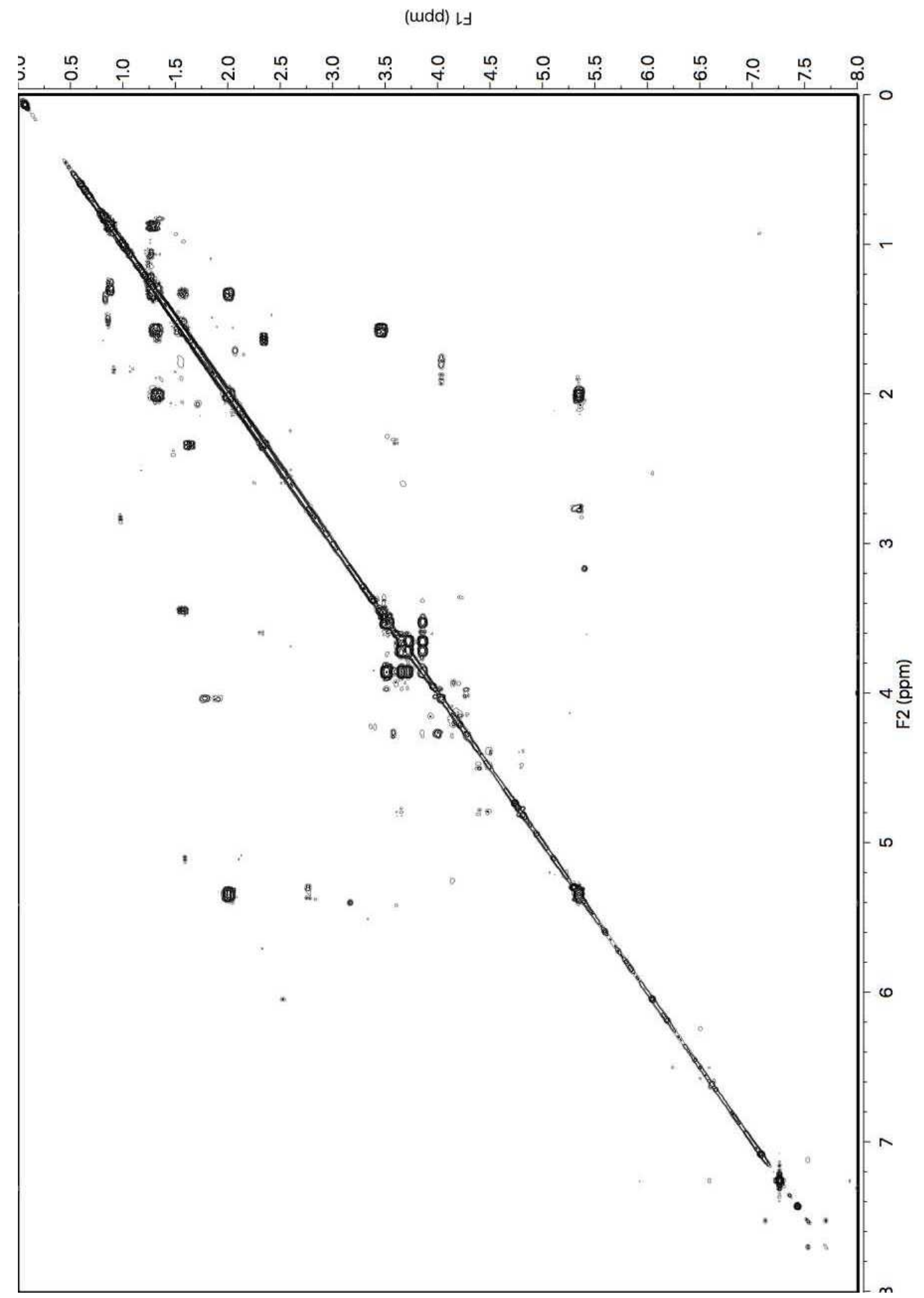

COSY spectrum of glycerol ether A (244) $\left(600 \mathrm{MHz}, \mathrm{CDCl}_{3}\right)$. 
(udd) IJ

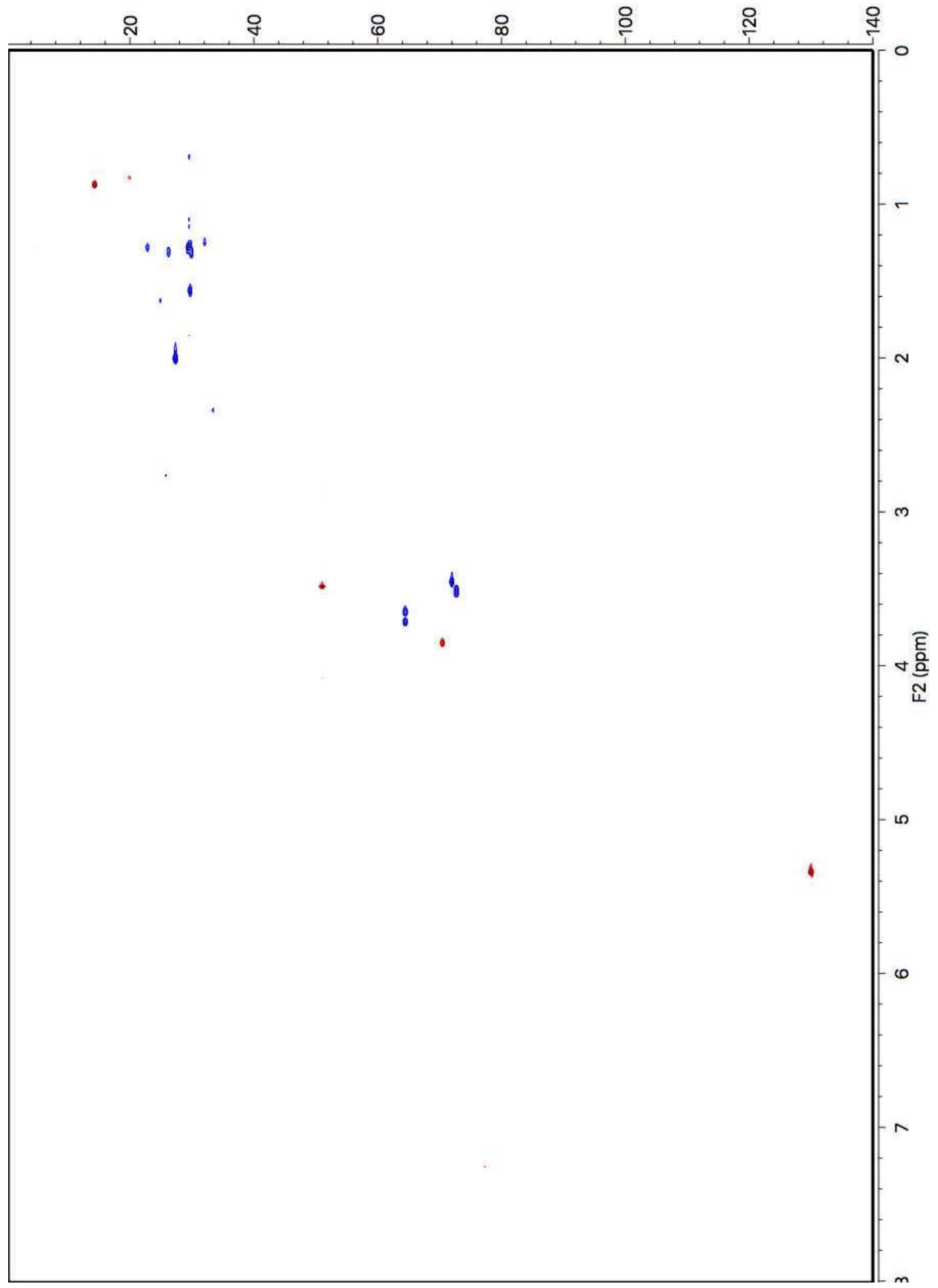

HSQC spectrum of glycerol ether A (244) $\left(600 \mathrm{MHz}, \mathrm{CDCl}_{3}\right)$. 


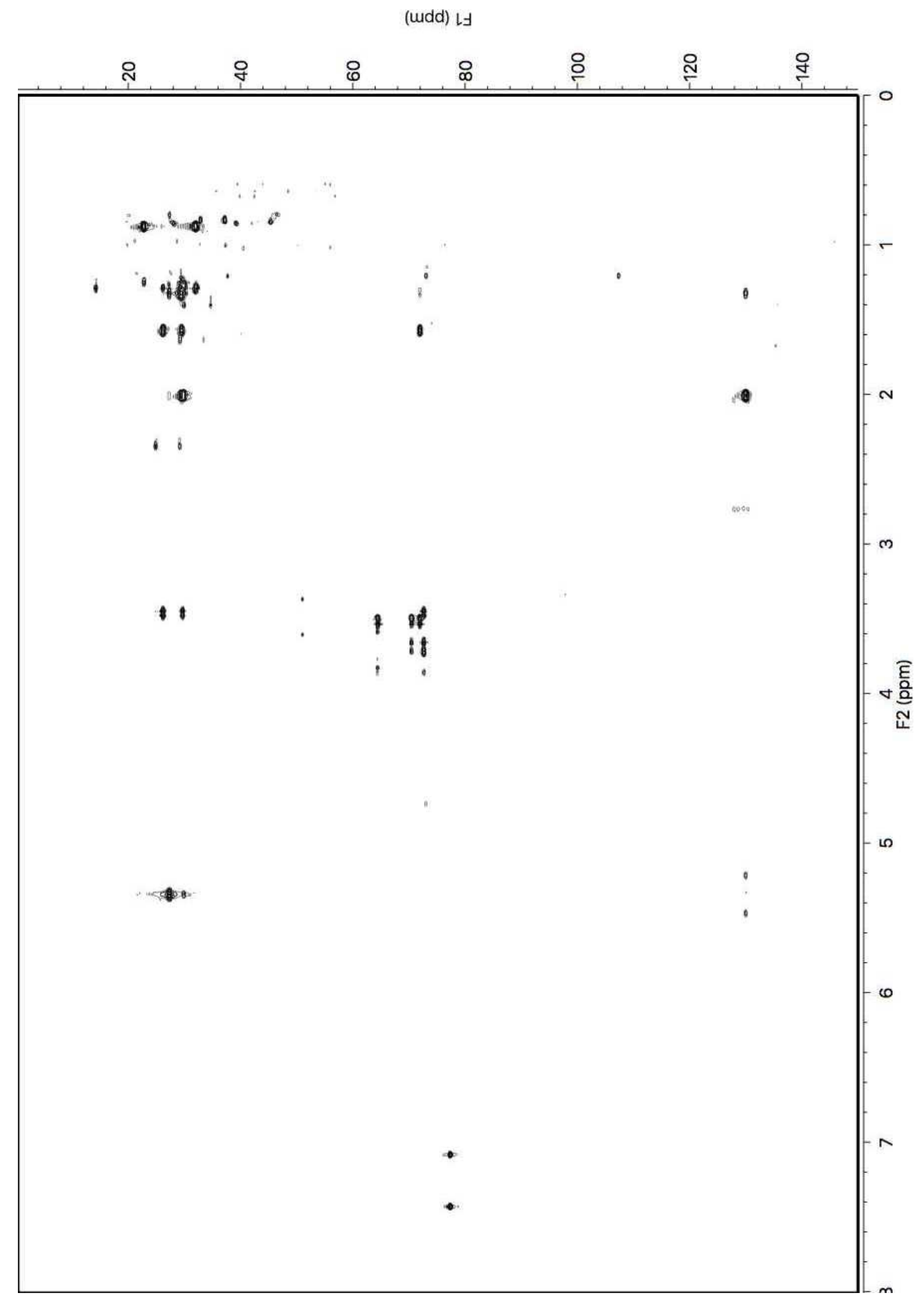

HMBC spectrum of glycerol ether A (244) $\left(600 \mathrm{MHz}, \mathrm{CDCl}_{3}\right)$. 
$896 z-$

8962

\&L6Z

0662

$266 \mathrm{Z}$

$90 \mathrm{Z} \varepsilon$

$60^{\circ} \mathrm{OLC}$

OLZL

$969<$

$91: L$
$\angle E L L$

${ }^{13} \mathrm{C}$ NMR spectrum of glycerol ether A (244) $\left(150 \mathrm{MHz}, \mathrm{CDCl}_{3}\right)$. 


\section{Glycerol Ether B Spectra}

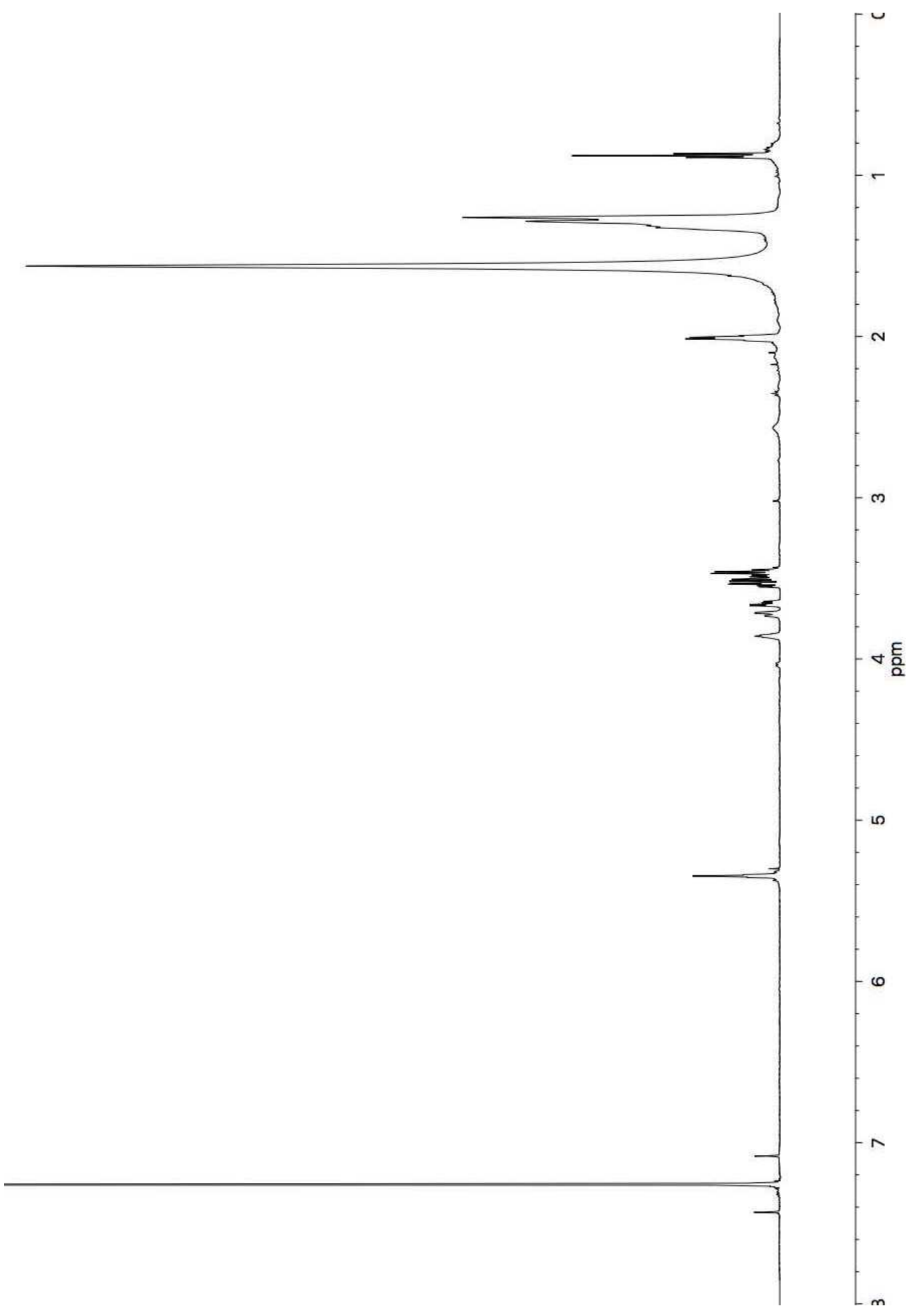

${ }^{1} \mathrm{H}$ NMR spectrum of glycerol ether B (245) $\left(600 \mathrm{MHz}, \mathrm{CDCl}_{3}\right)$. 
(udd) $L \exists$

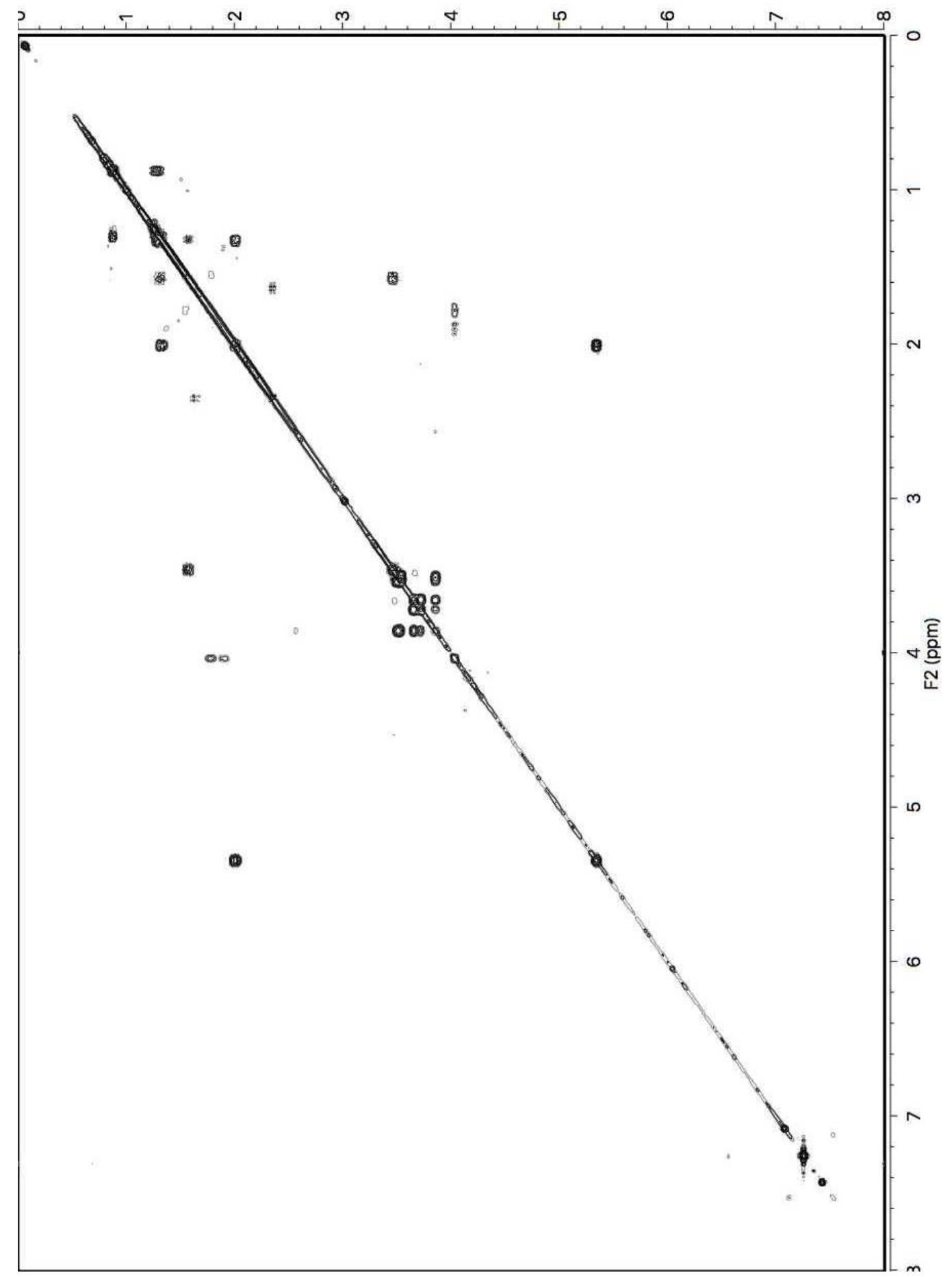

COSY spectrum of glycerol ether B (245) (600 MHz, $\left.\mathrm{CDCl}_{3}\right)$. 


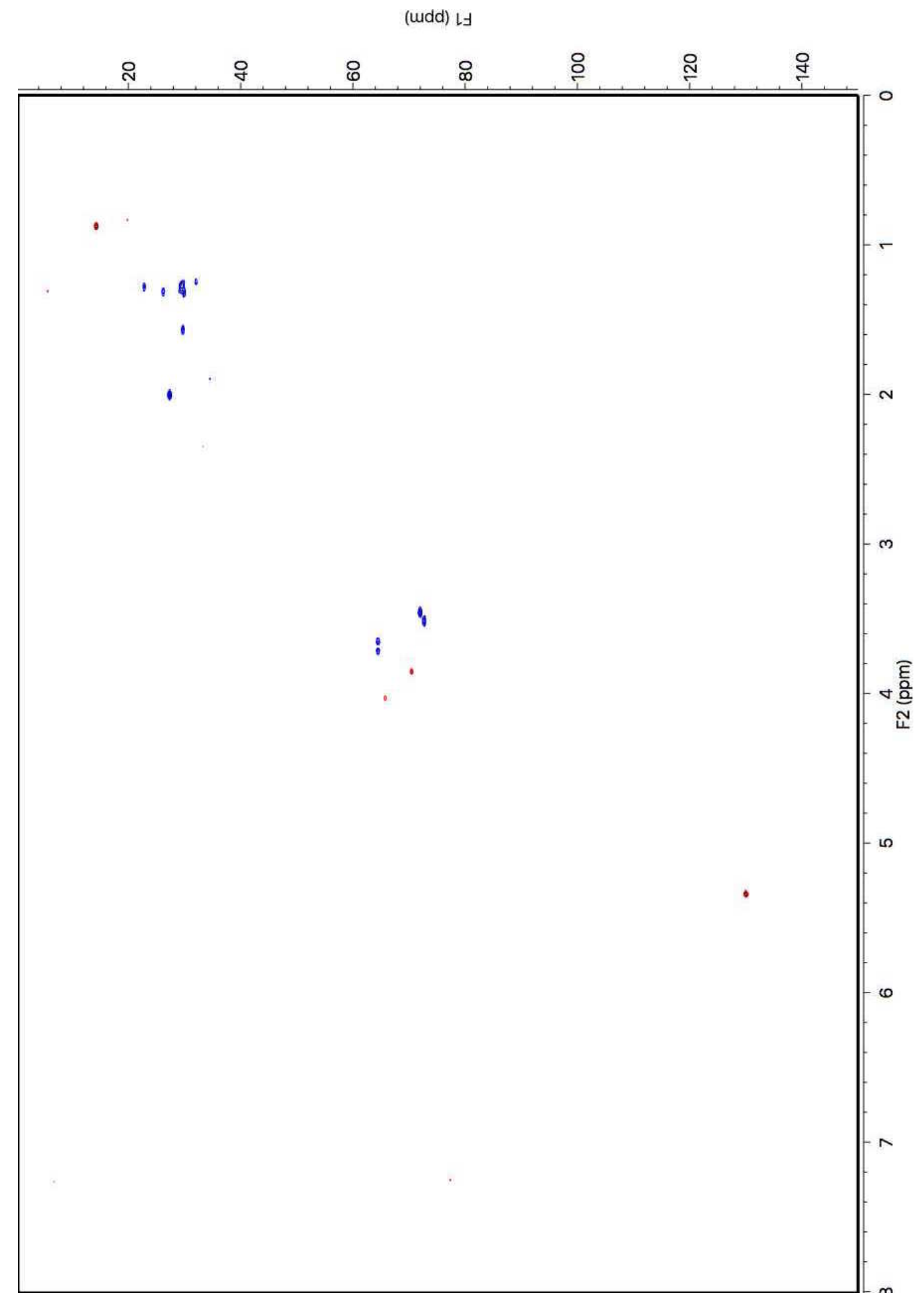

HSQC spectrum of glycerol ether B (245) (600 MHz, $\left.\mathrm{CDCl}_{3}\right)$. 


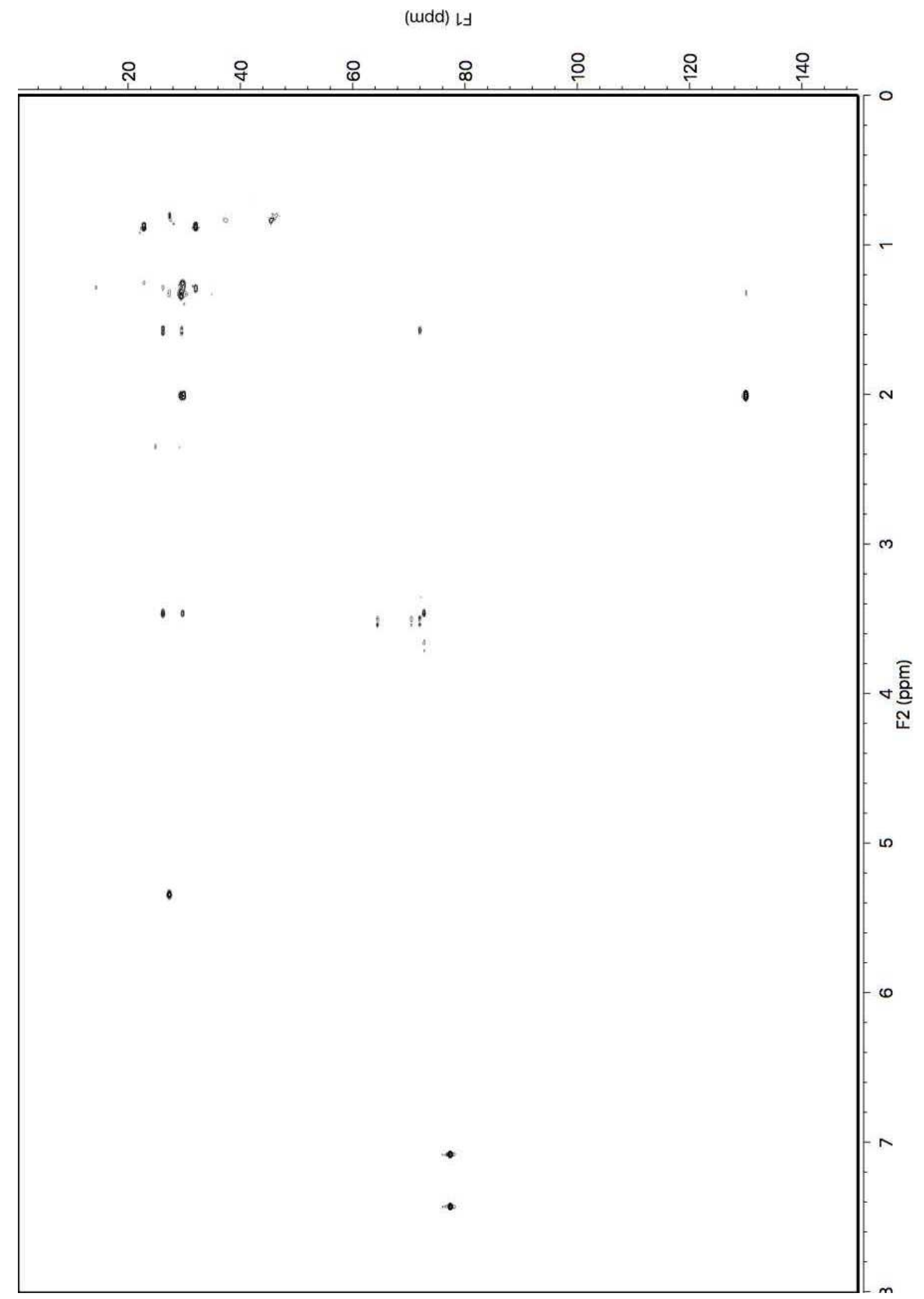

HMBC spectrum of glycerol ether B (245) (600 MHz, $\left.\mathrm{CDCl}_{3}\right)$. 


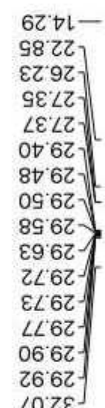

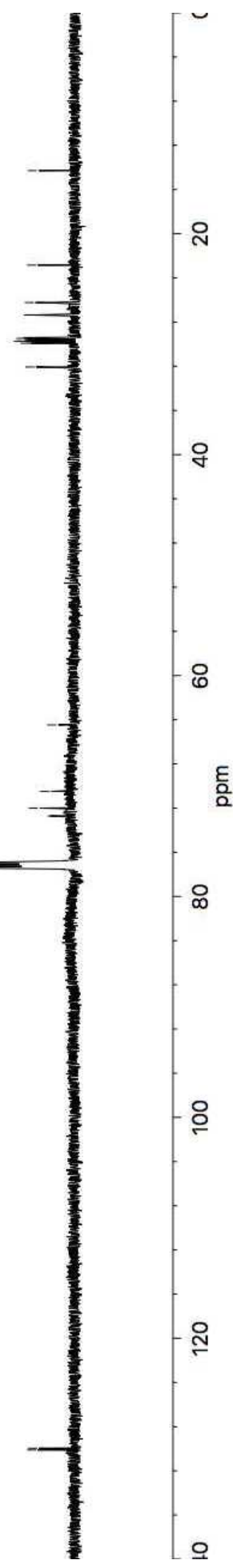

${ }^{13} \mathrm{C}$ NMR spectrum of glycerol ether B (245) $\left(150 \mathrm{MHz}, \mathrm{CDCl}_{3}\right)$. 


\section{Glycerol Ether C Spectra}

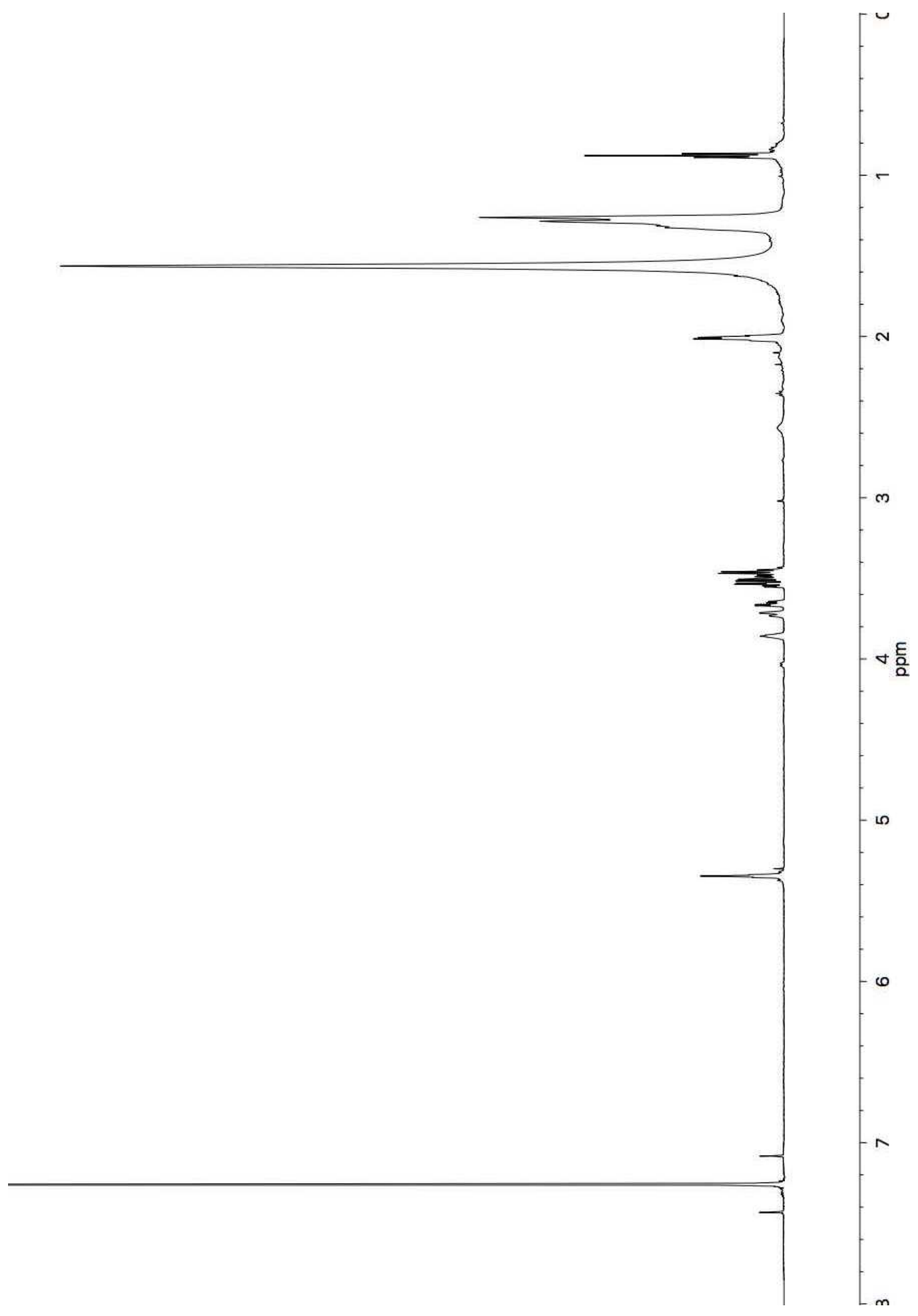

${ }^{1} \mathrm{H}$ NMR spectrum of glycerol ether C (246) (600 MHz, $\mathrm{CDCl}_{3}$ ). 
(udd) $\downarrow \exists$

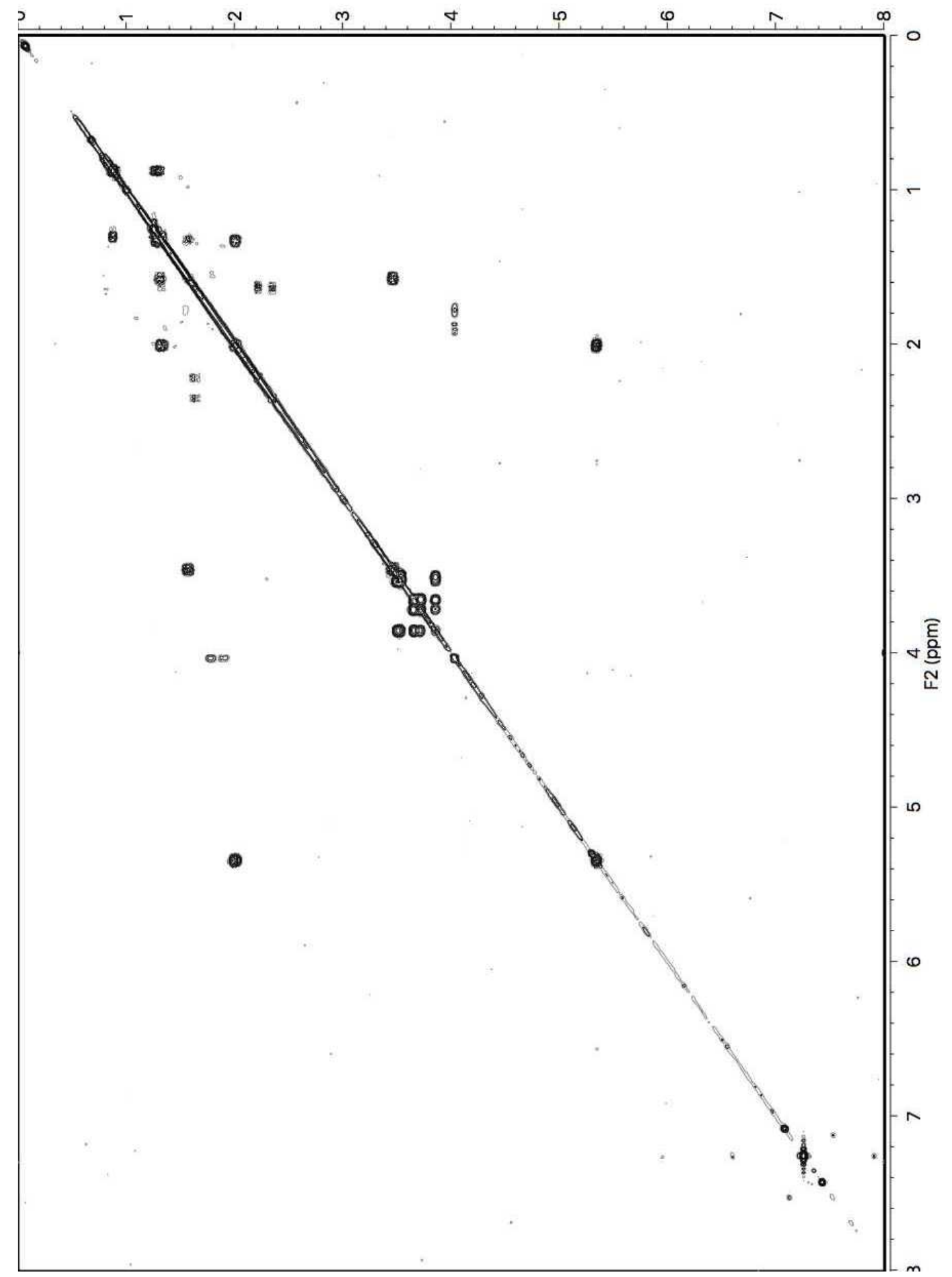

COSY spectrum of glycerol ether C (246) (600 MHz, $\left.\mathrm{CDCl}_{3}\right)$. 


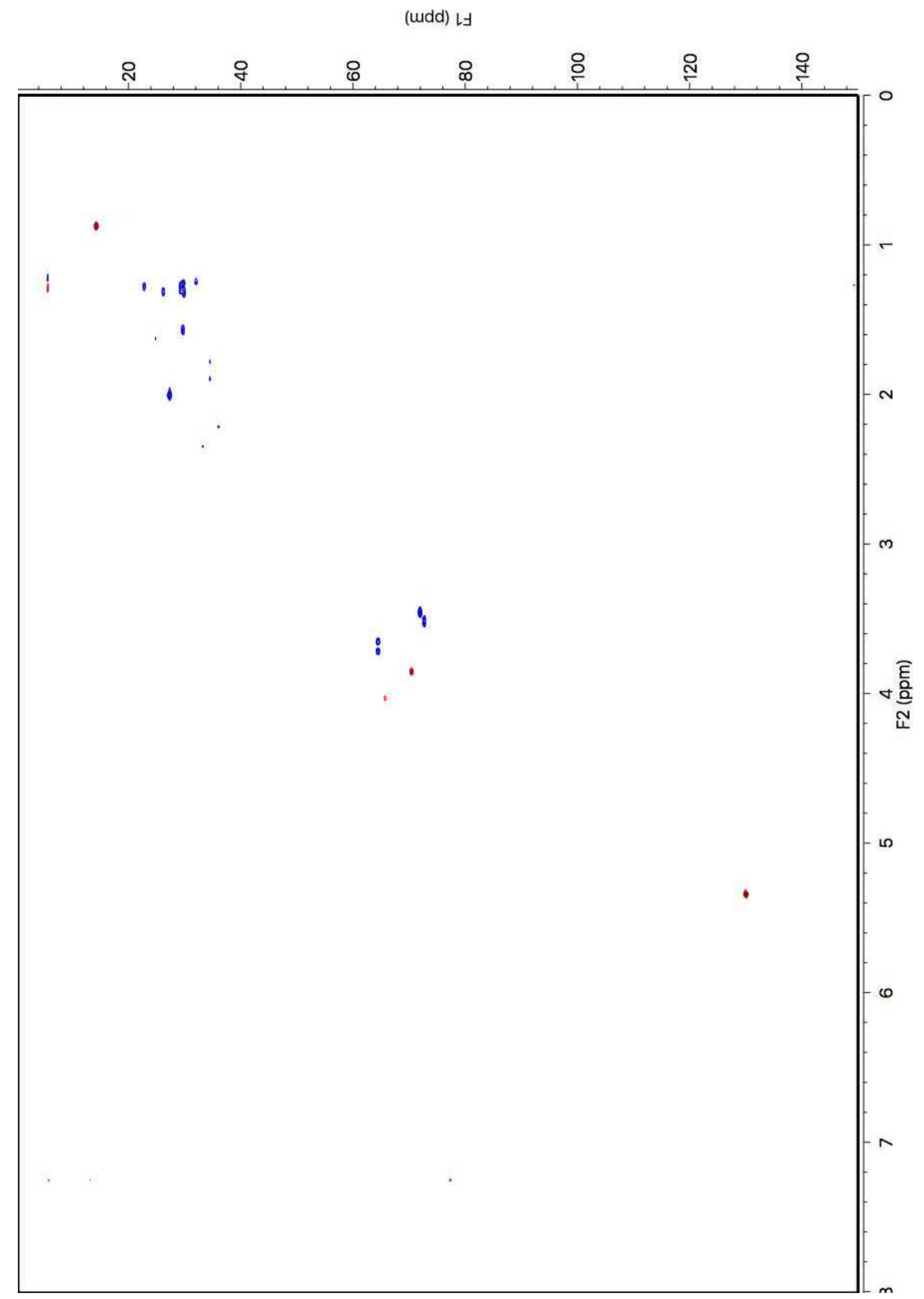

HSQC spectrum of glycerol ether C (246) (600 MHz, $\mathrm{CDCl}_{3}$ ). 


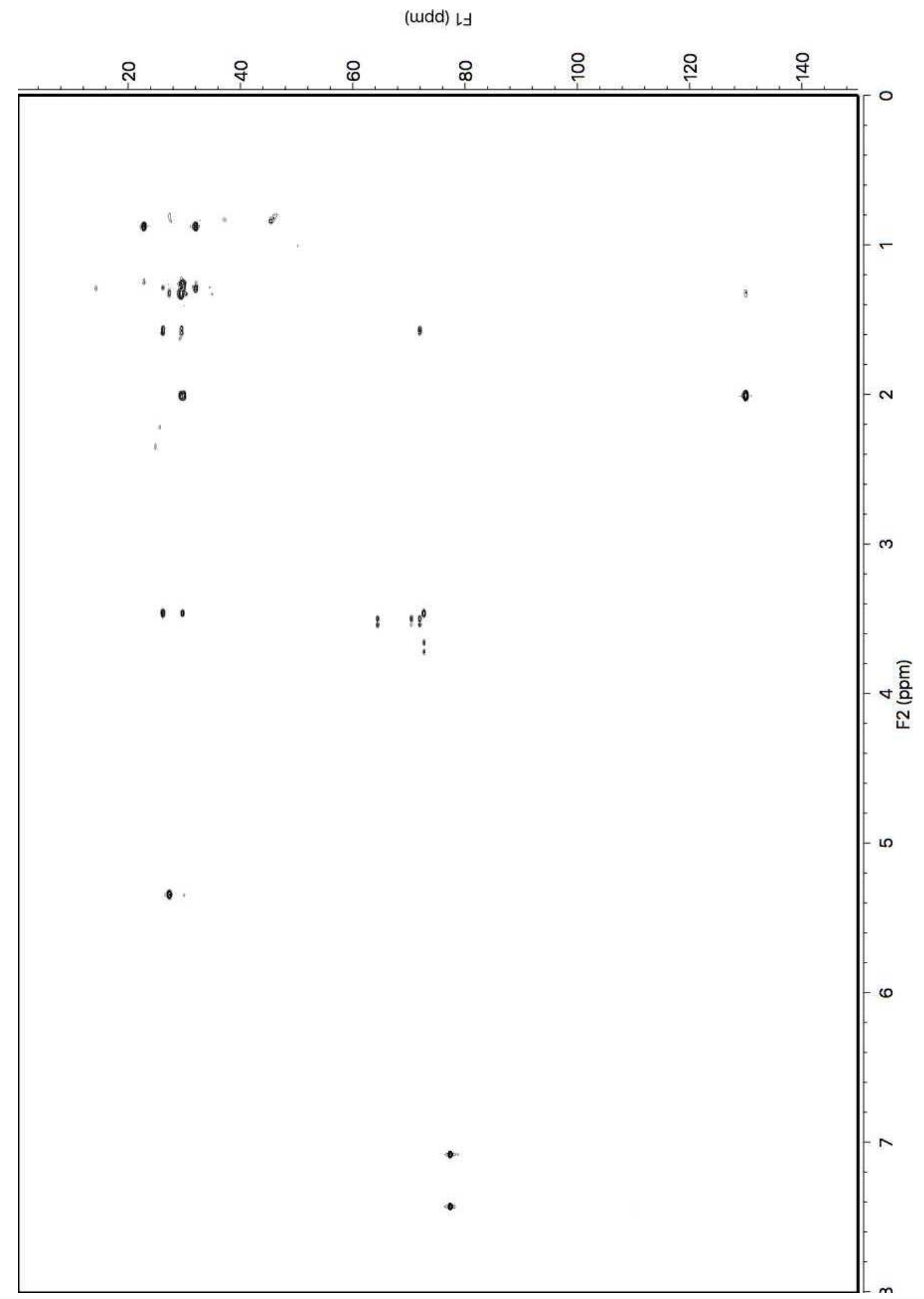

HMBC spectrum of glycerol ether C (246) (600 MHz, $\mathrm{CDCl}_{3}$ ). 


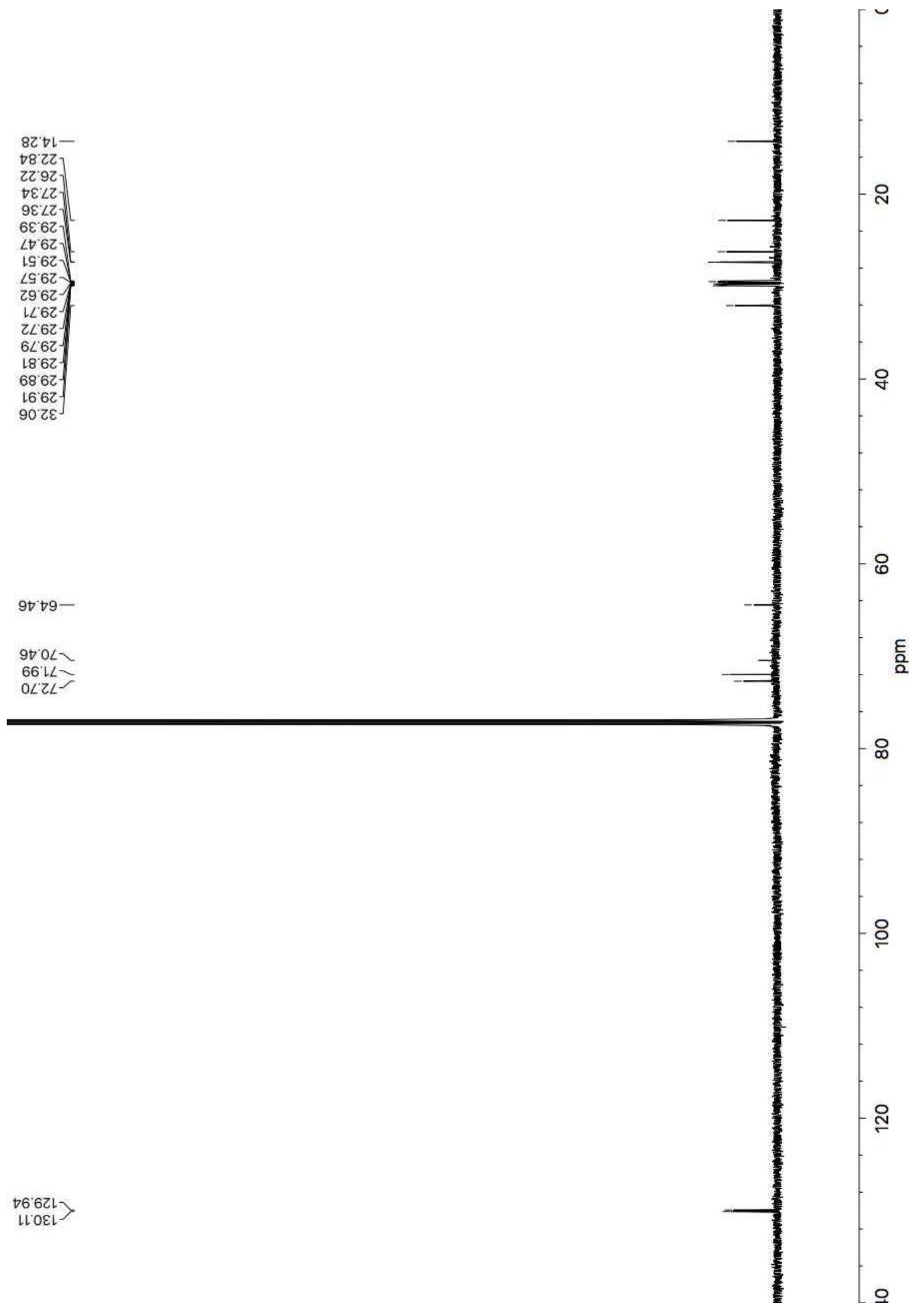

${ }^{13} \mathrm{C}$ NMR spectrum of glycerol ether C (246) $\left(150 \mathrm{MHz}, \mathrm{CDCl}_{3}\right)$. 
Appendix $O$

\section{Isodictyodendrillin A}

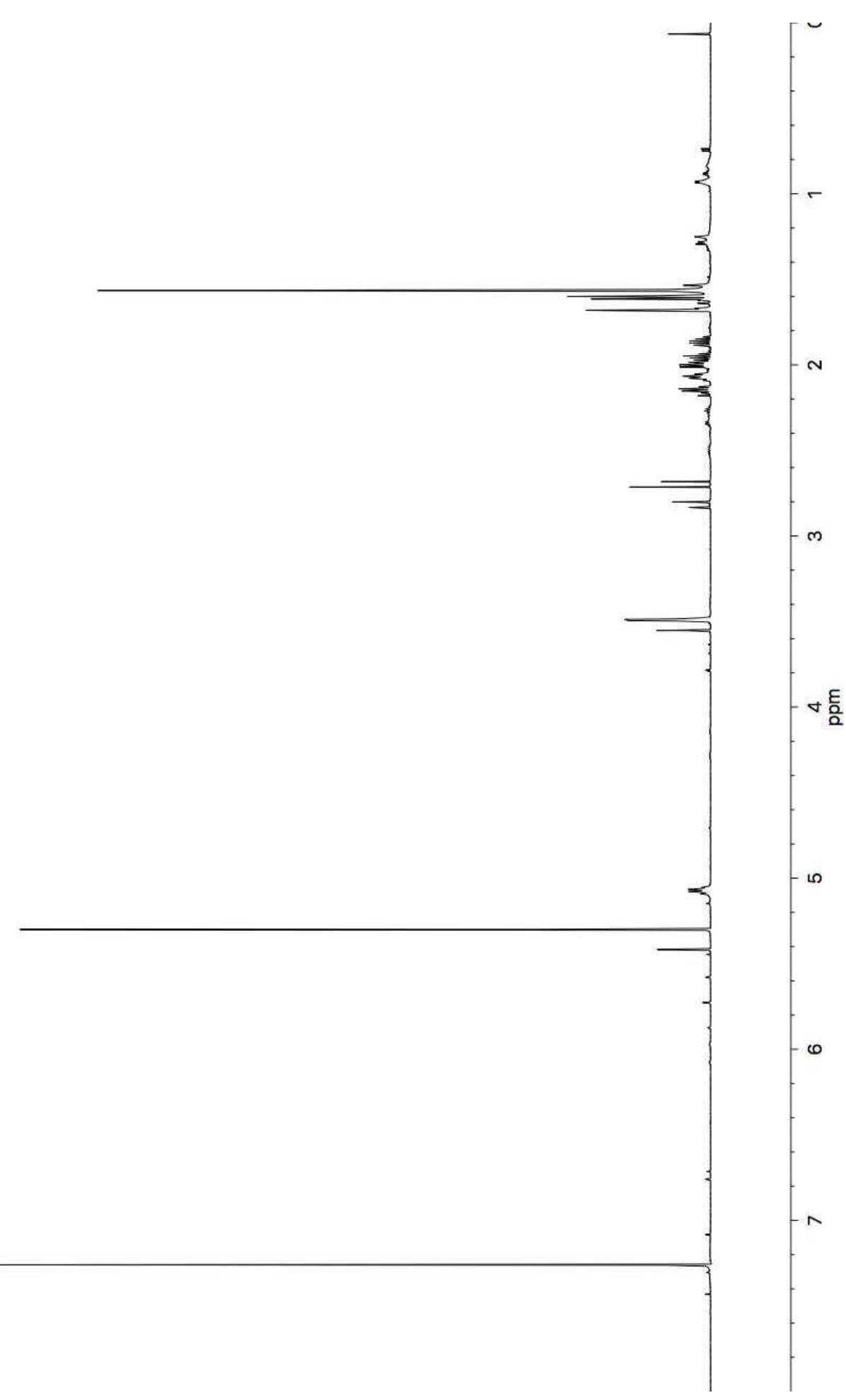

${ }^{1} \mathrm{H}$ NMR spectrum of isodictyodendrillin A (280) $\left(600 \mathrm{MHz}, \mathrm{CDCl}_{3}\right)$. 
(udd) $\downarrow \unlhd$

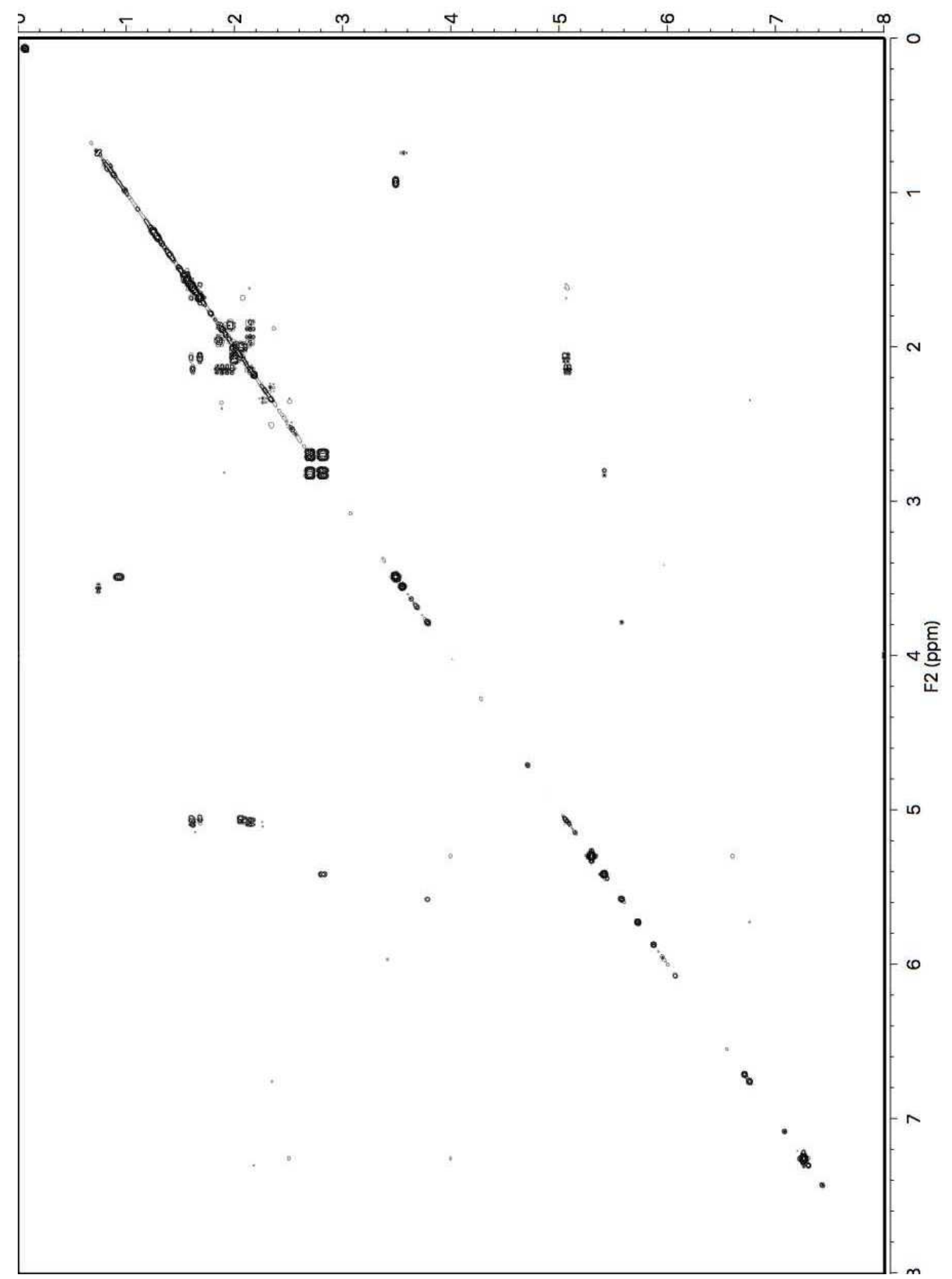

COSY spectrum of isodictyodendrillin A (280) (600 MHz, $\left.\mathrm{CDCl}_{3}\right)$. 


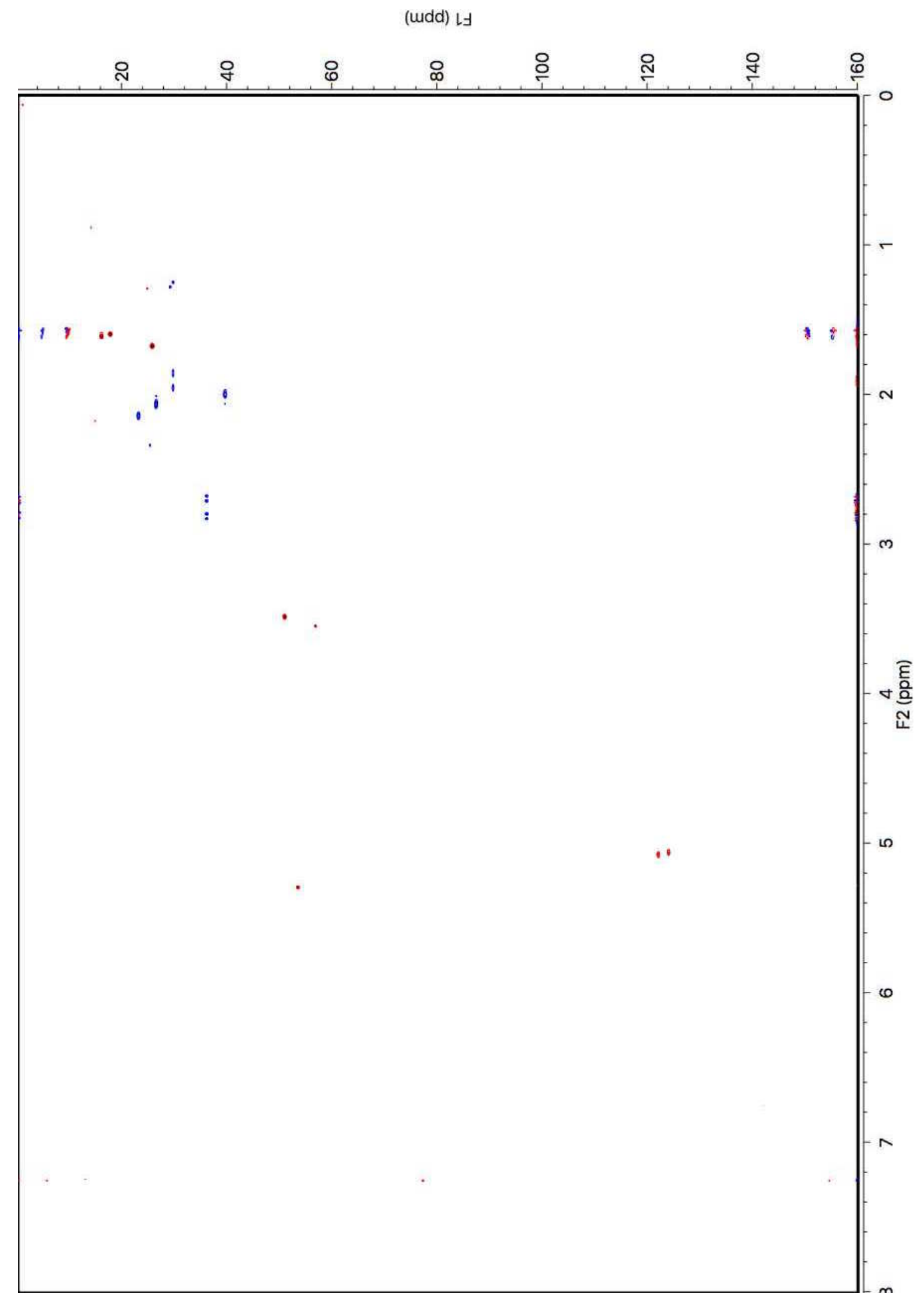

HSQC spectrum of isodictyodendrillin A (280) (600 MHz, $\left.\mathrm{CDCl}_{3}\right)$. 


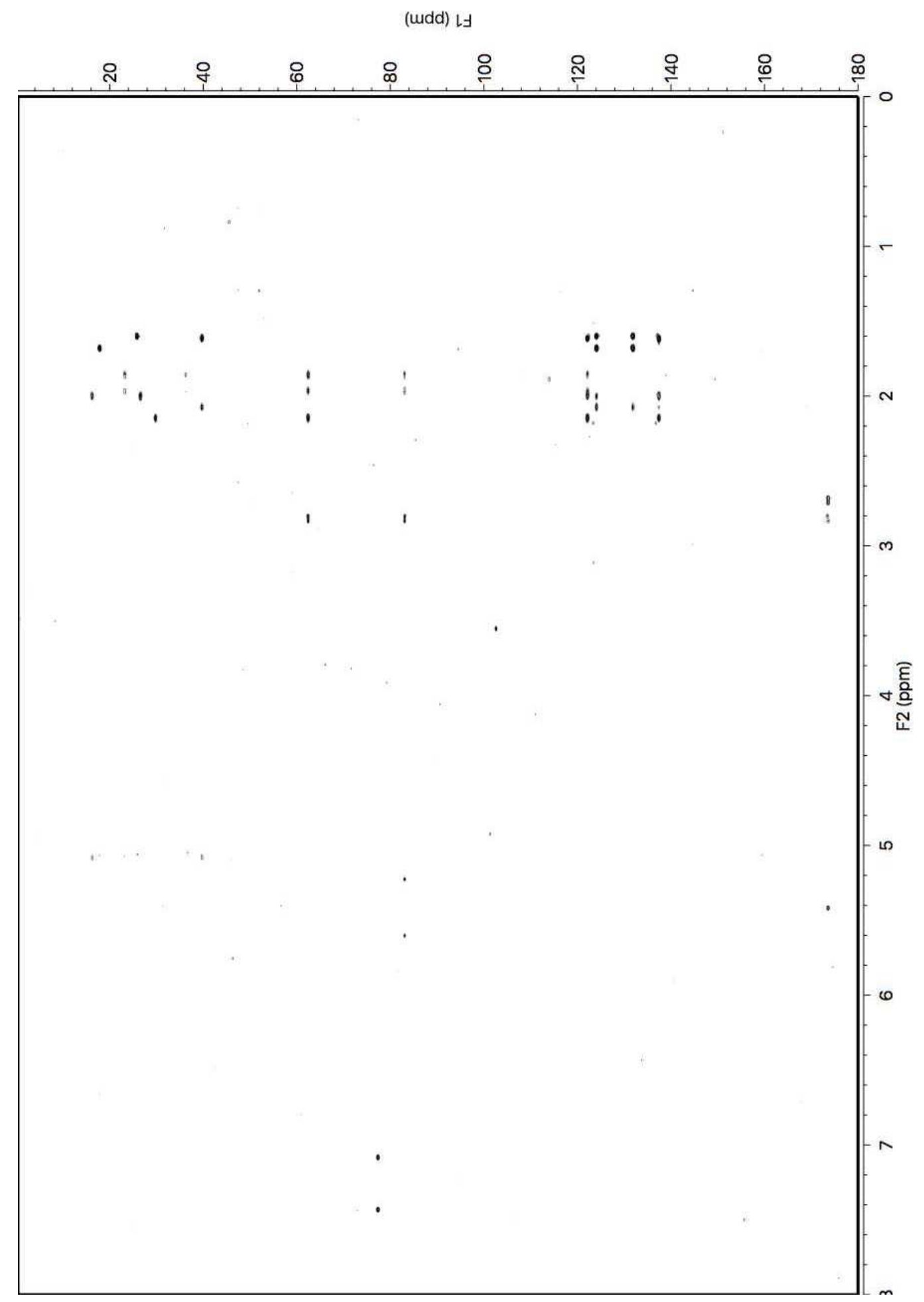

HMBC spectrum of isodictyodendrillin A (280) (600 MHz, $\left.\mathrm{CDCl}_{3}\right)$. 


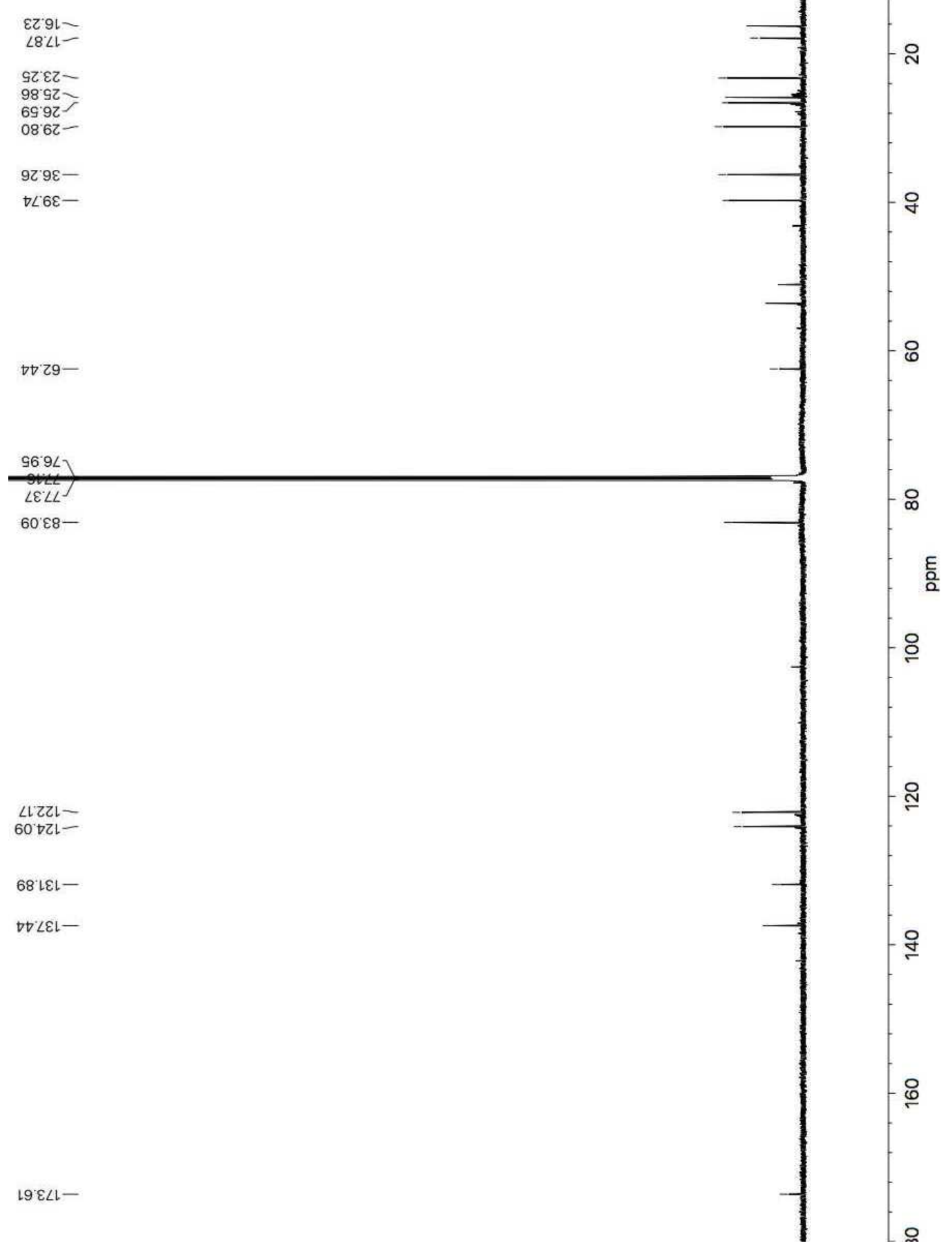

${ }^{13} \mathrm{C} \mathrm{NMR}$ spectrum of isodictyodendrillin $\mathrm{A}(\mathbf{2 8 0})\left(150 \mathrm{MHz}, \mathrm{CDCl}_{3}\right)$. 


\section{Zampanolide B}

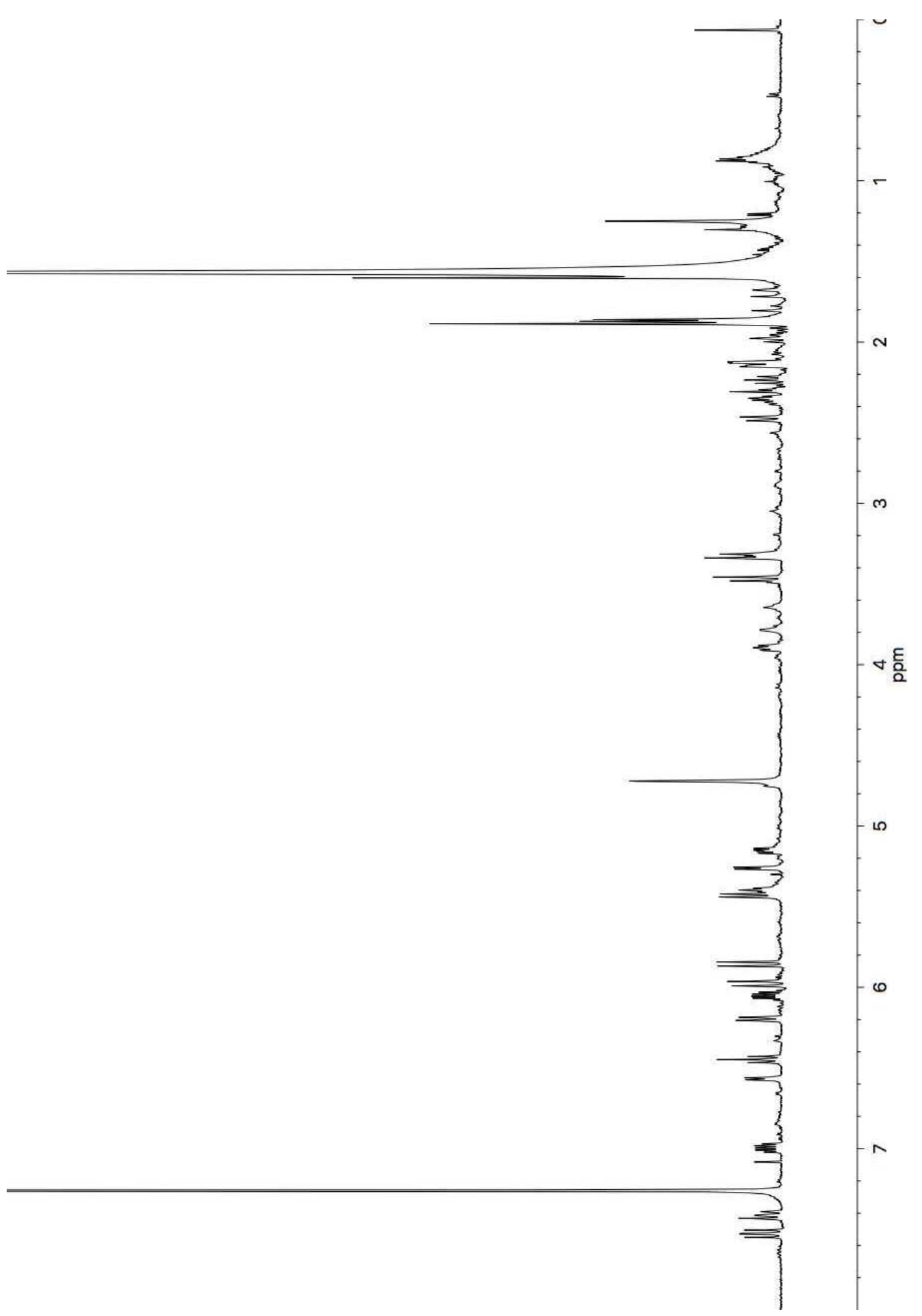

${ }^{1} \mathrm{H}$ NMR spectrum of zampanolide B (282) (600 MHz, $\left.\mathrm{CDCl}_{3}\right)$. 
(udd) $\downarrow \unlhd$

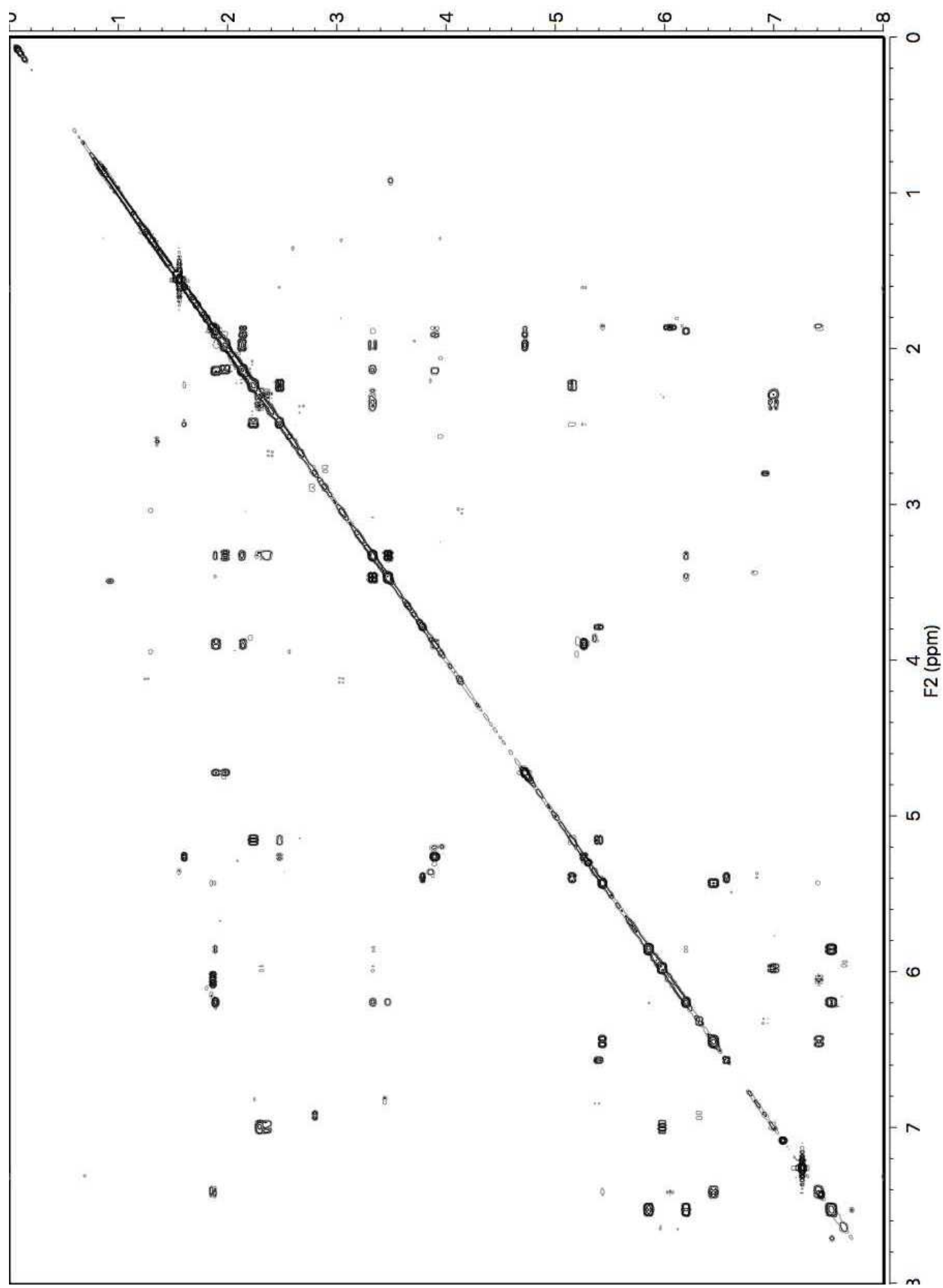

COSY spectrum of zampanolide B (282) $\left(600 \mathrm{MHz}, \mathrm{CDCl}_{3}\right)$. 


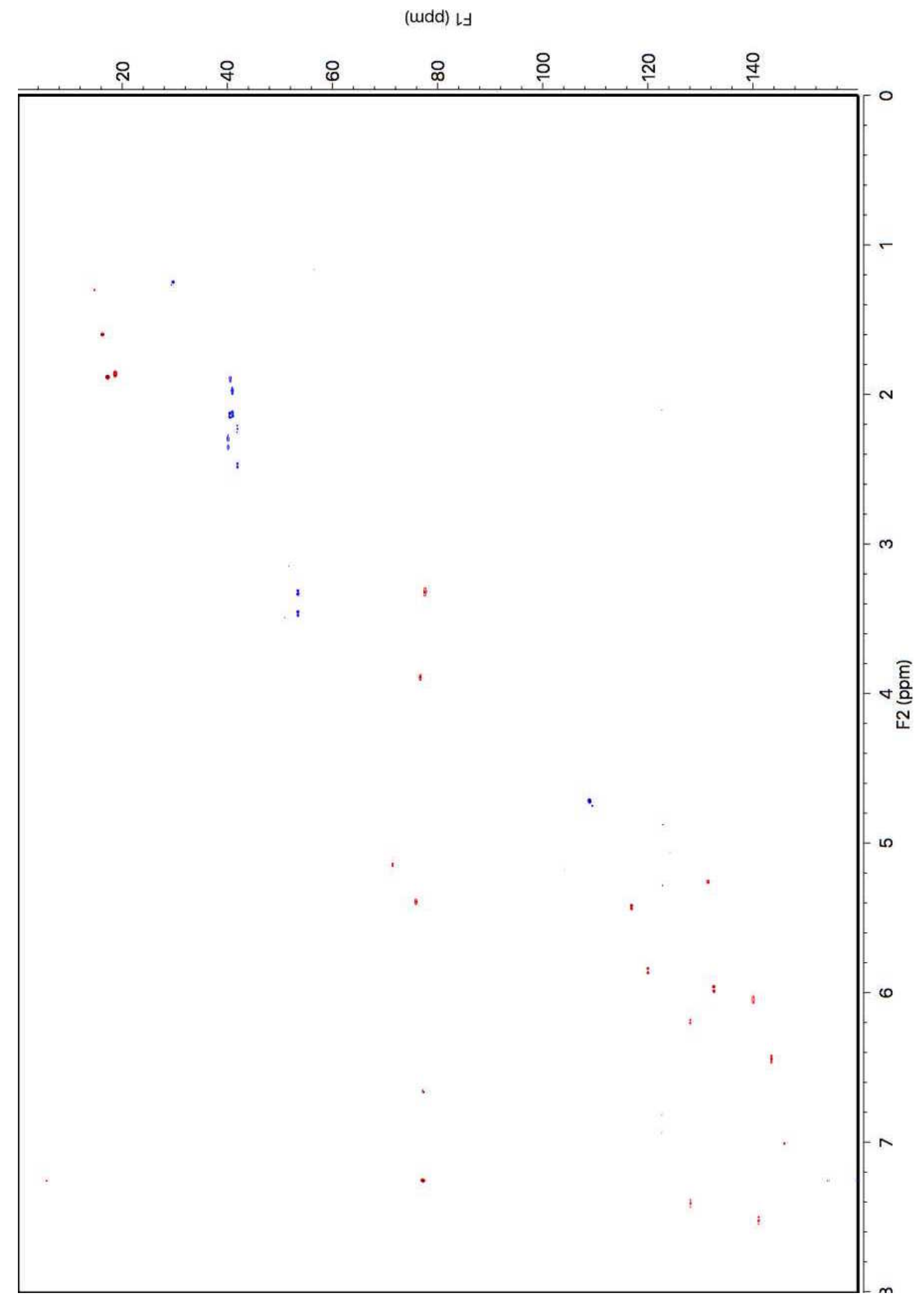

HSQC spectrum of zampanolide B (282) (600 MHz, $\left.\mathrm{CDCl}_{3}\right)$. 


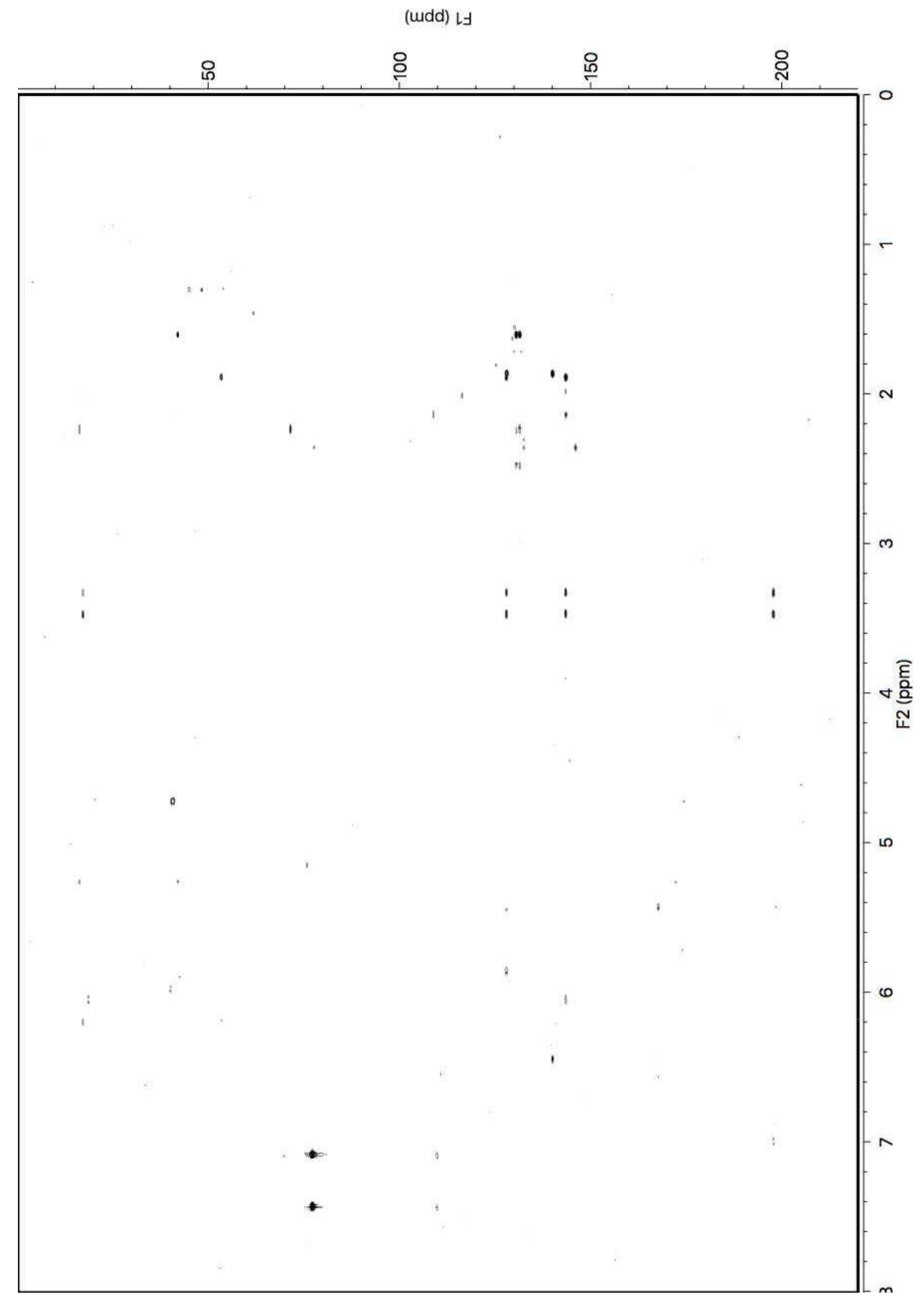

HMBC spectrum of zampanolide B (282) (600 MHz, $\mathrm{CDCl}_{3}$ ). 


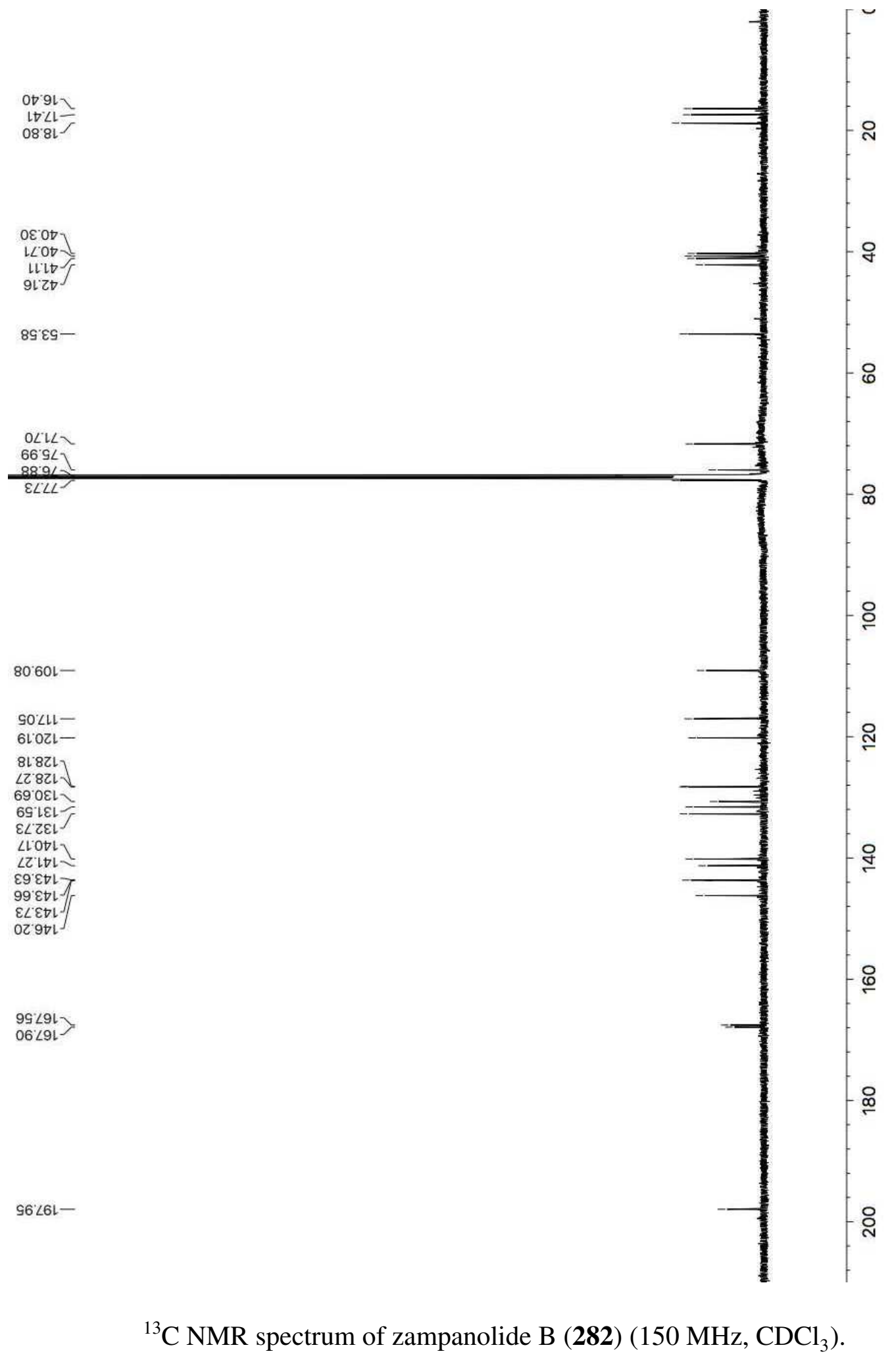


Appendix $Q$

\section{Zampanolide C}

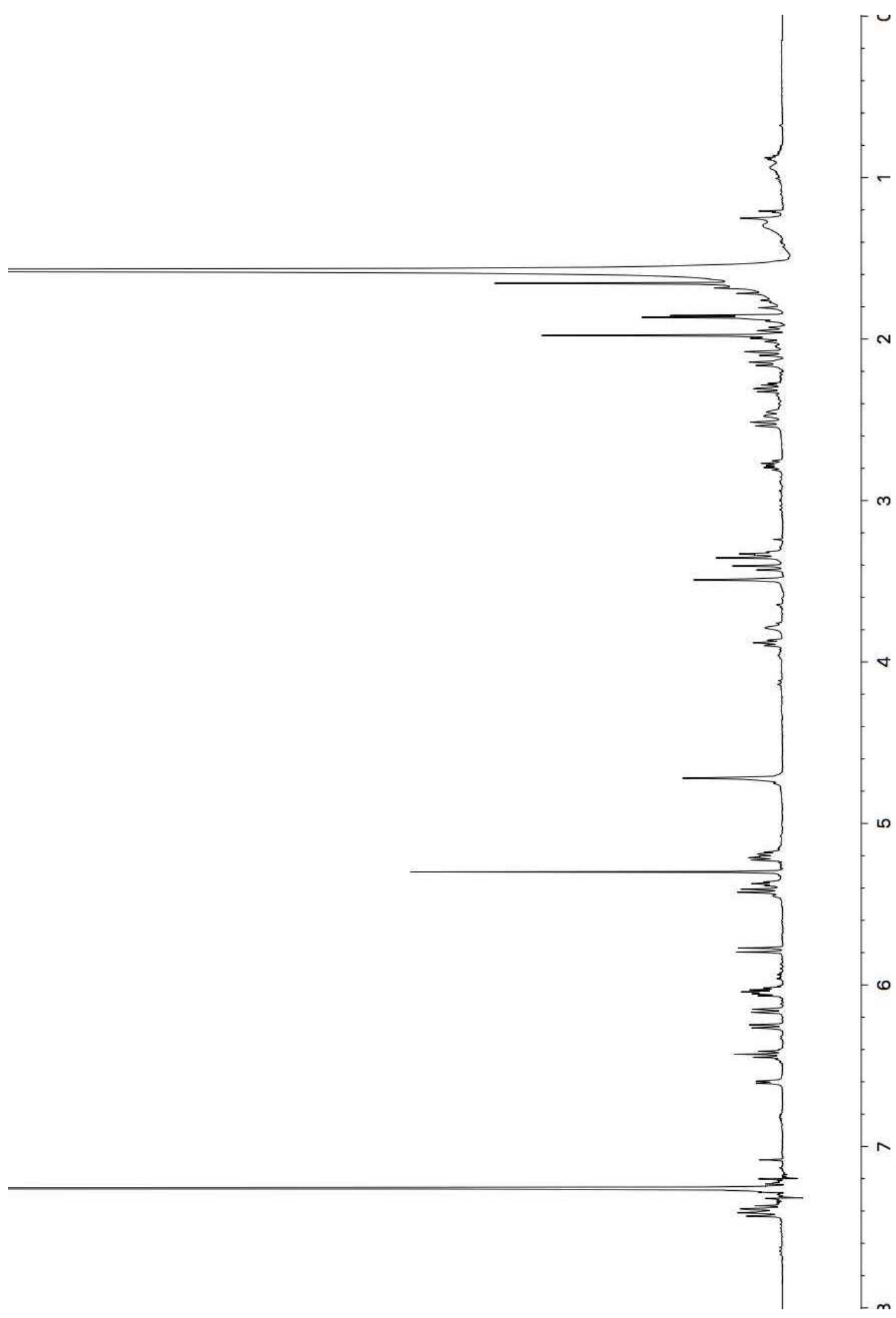

${ }^{1} \mathrm{H}$ NMR spectrum of zampanolide C (283) (600 MHz, $\left.\mathrm{CDCl}_{3}\right)$. 
(udd) $\downarrow\rfloor$

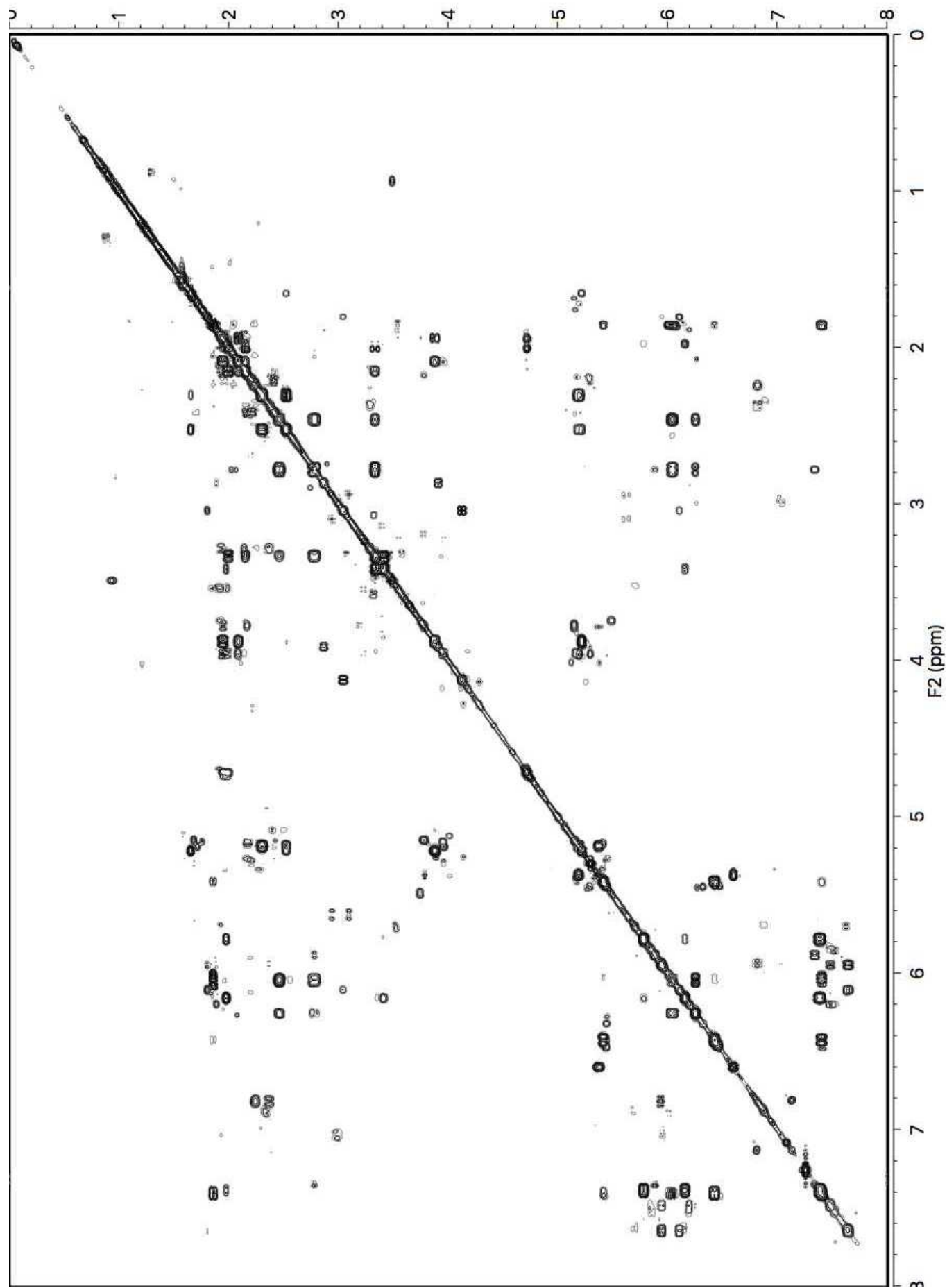

COSY spectrum of zampanolide C (283) $\left(600 \mathrm{MHz}, \mathrm{CDCl}_{3}\right)$. 


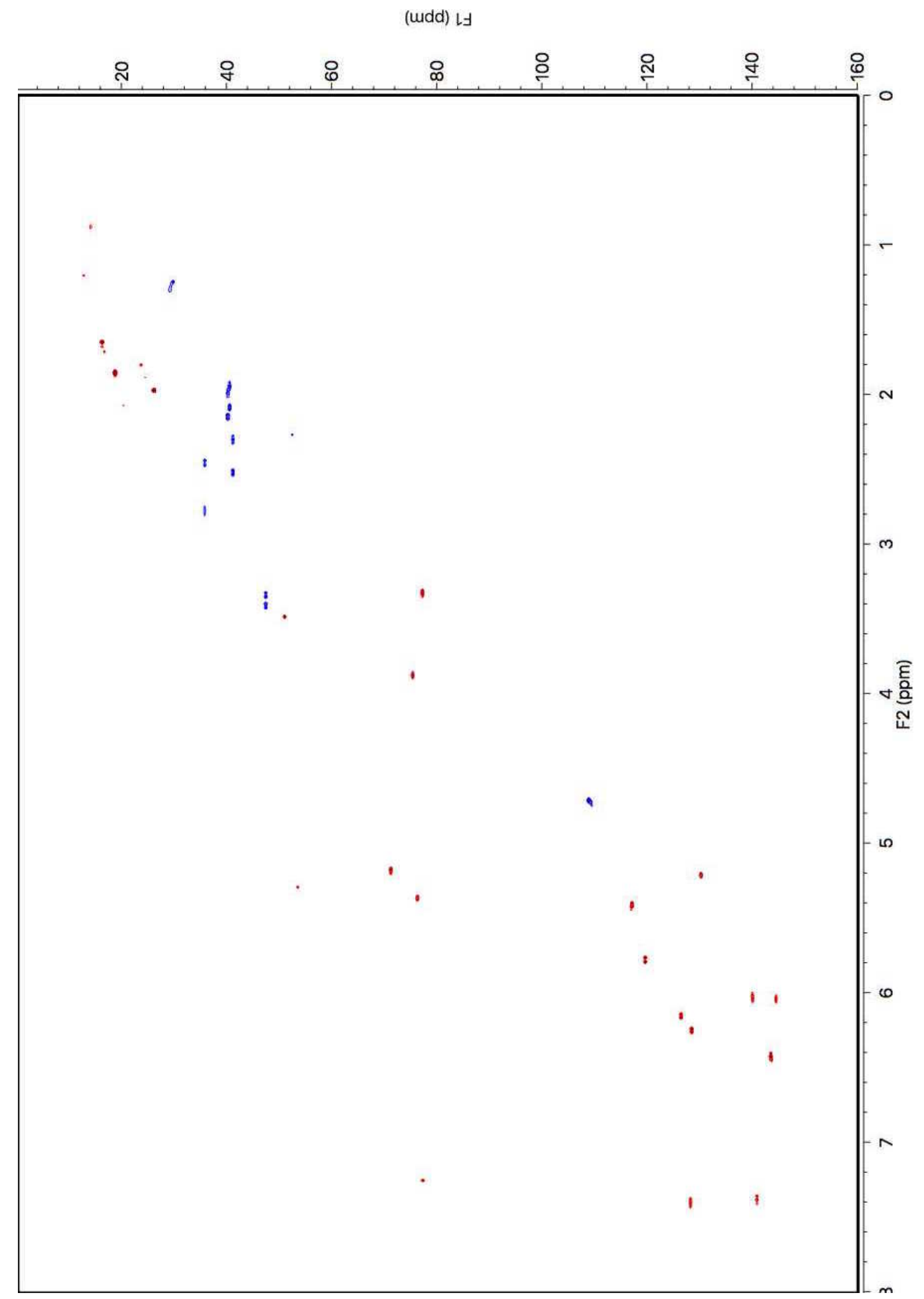

HSQC spectrum of zampanolide C (283) (600 MHz, $\left.\mathrm{CDCl}_{3}\right)$. 


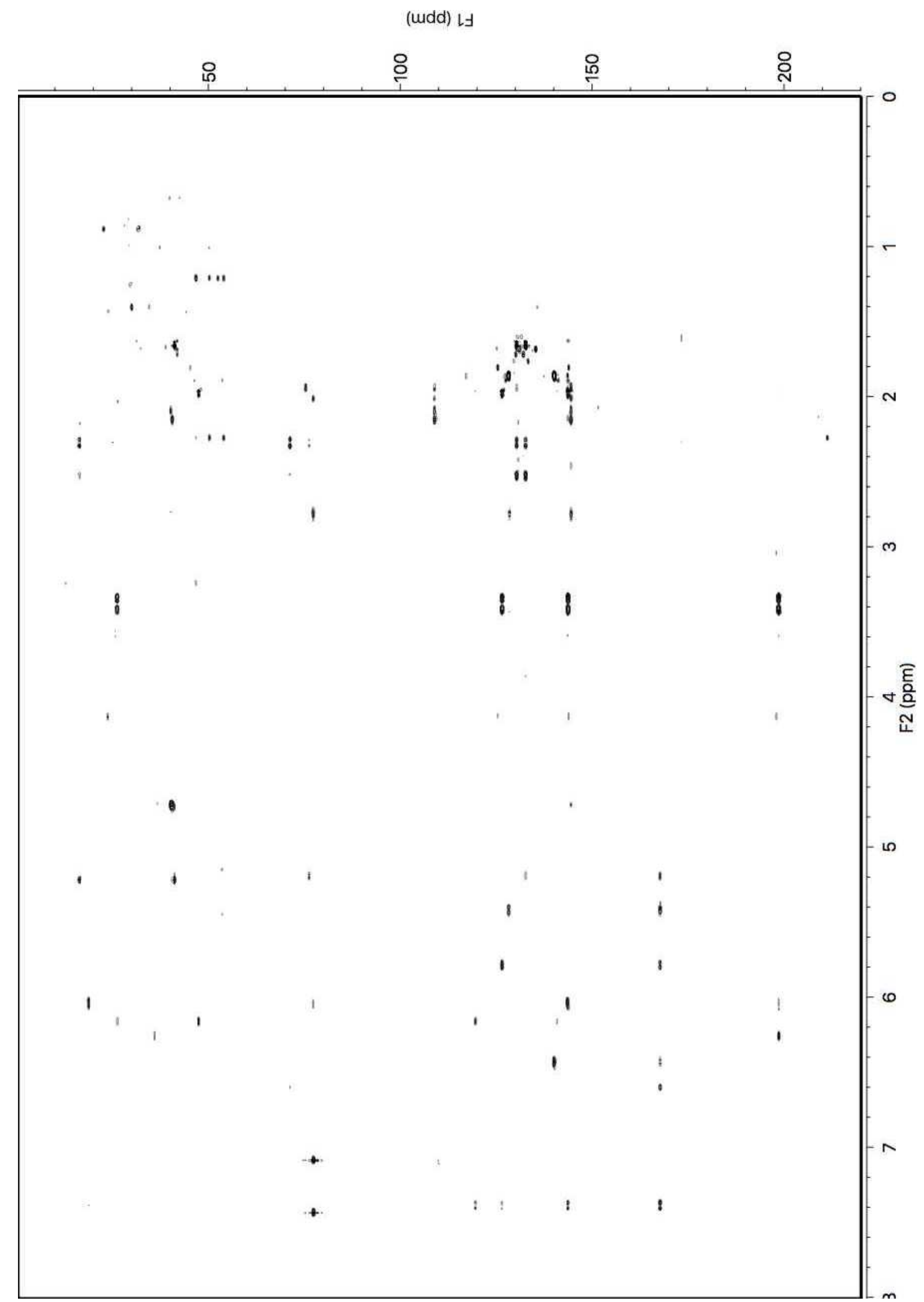

HMBC spectrum of zampanolide C (283) (600 MHz, $\mathrm{CDCl}_{3}$ ).

296 


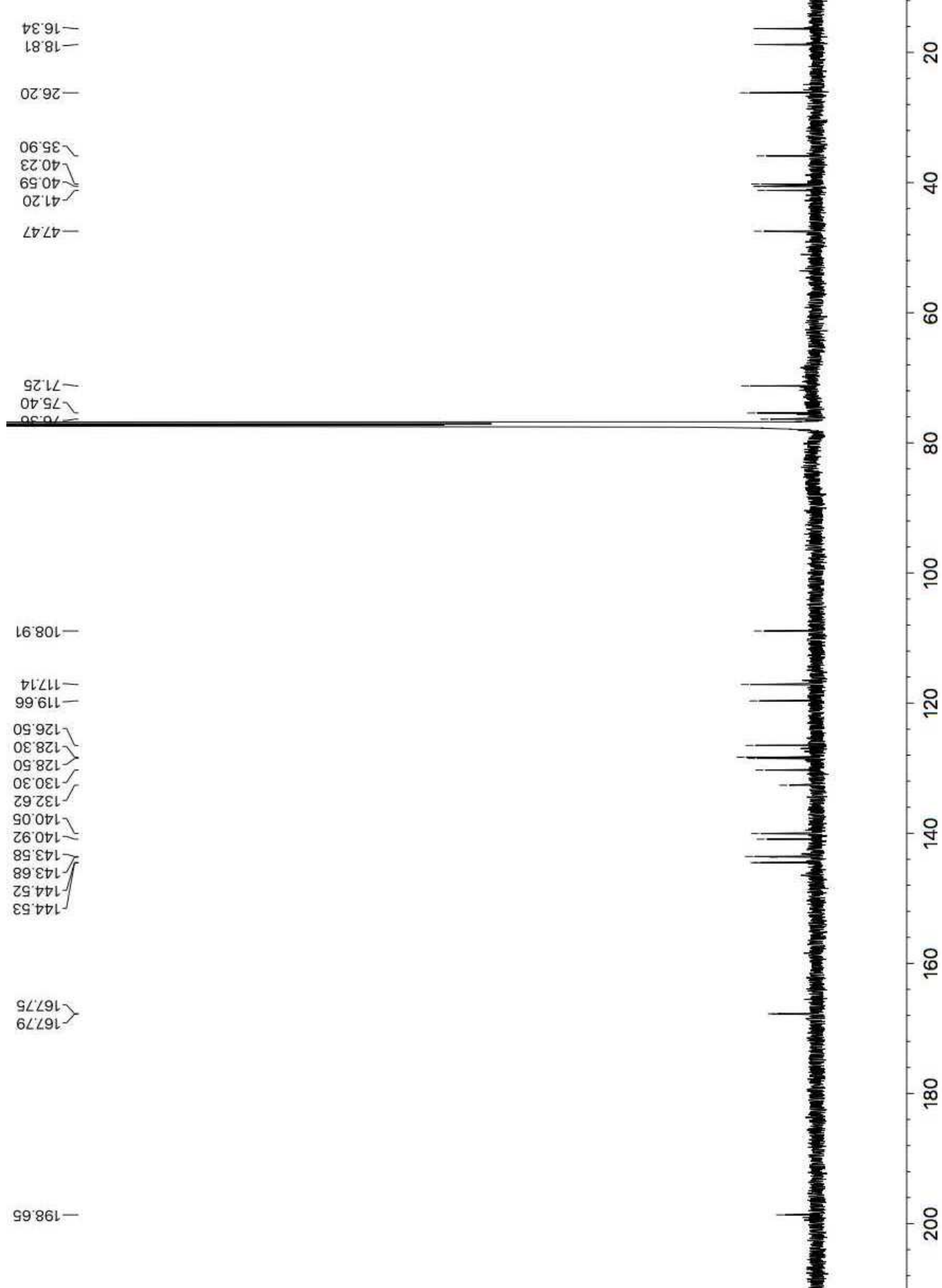

${ }^{13} \mathrm{C}$ NMR spectrum of zampanolide C (283) $\left(150 \mathrm{MHz}, \mathrm{CDCl}_{3}\right)$. 


\section{Zampanolide D}

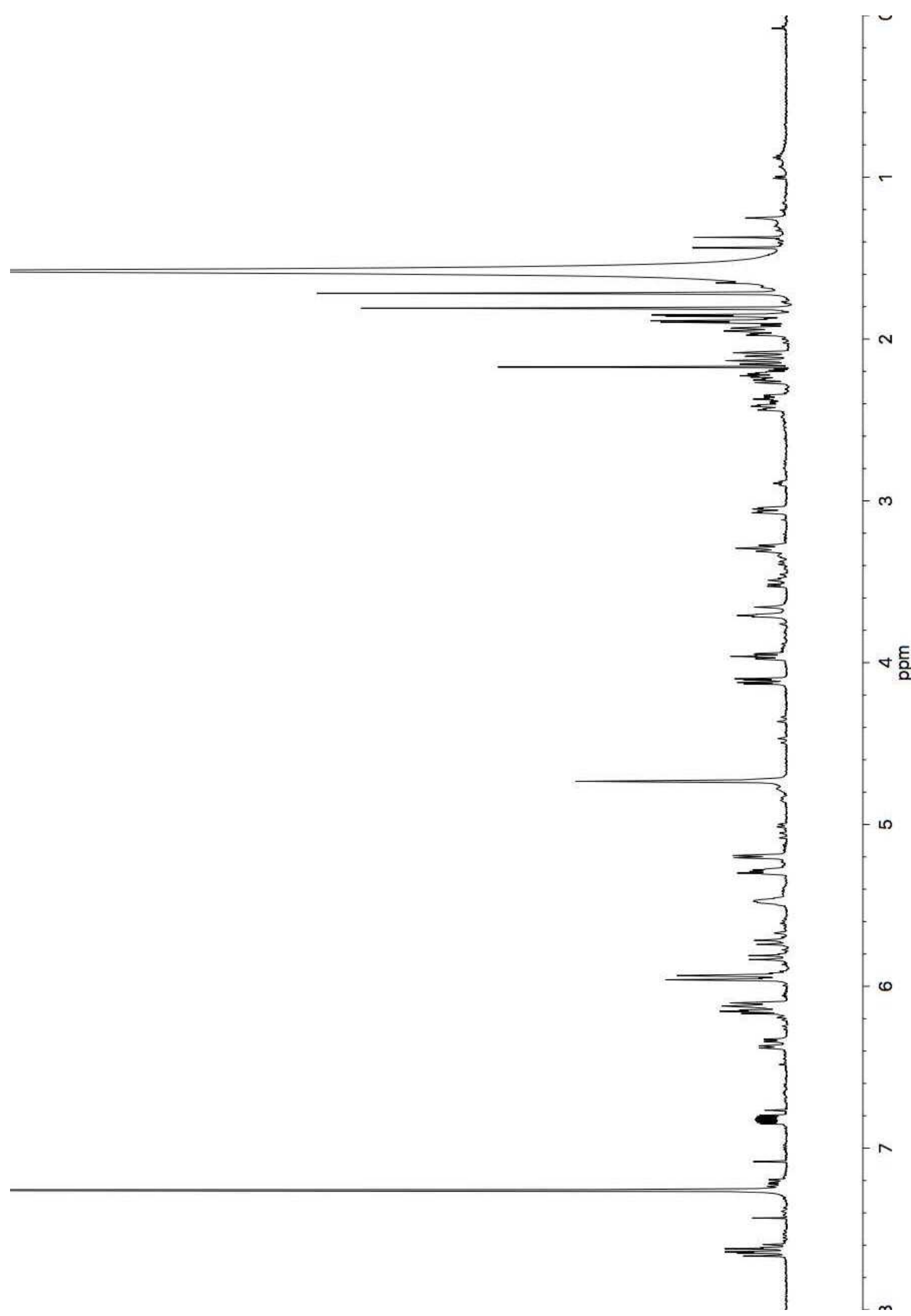

${ }^{1} \mathrm{H}$ NMR spectrum of zampanolide D (284) $\left(600 \mathrm{MHz}, \mathrm{CDCl}_{3}\right)$. 
(udd) $\downarrow \exists$

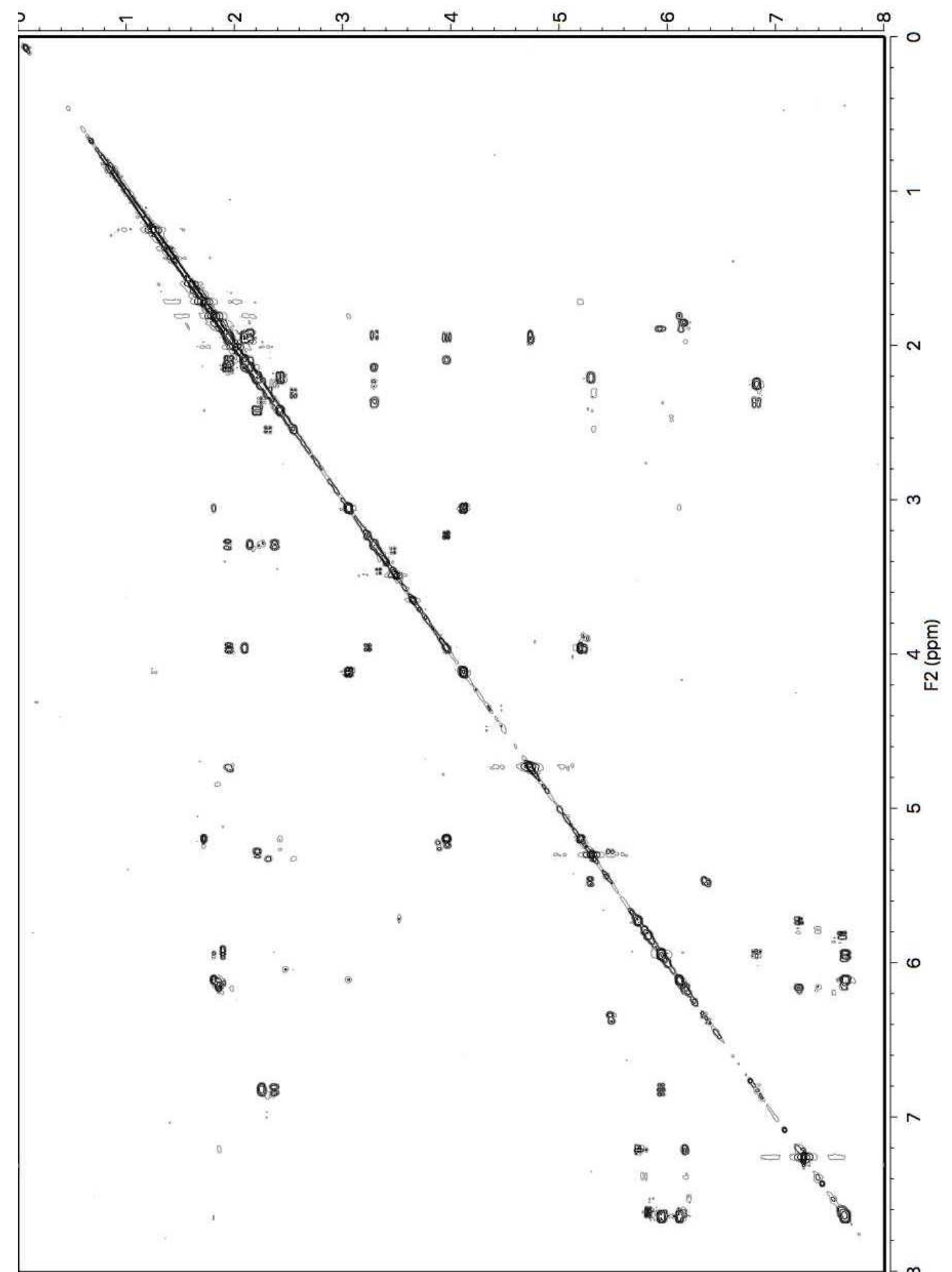

COSY spectrum of zampanolide D (284) (600 MHz, $\left.\mathrm{CDCl}_{3}\right)$. 


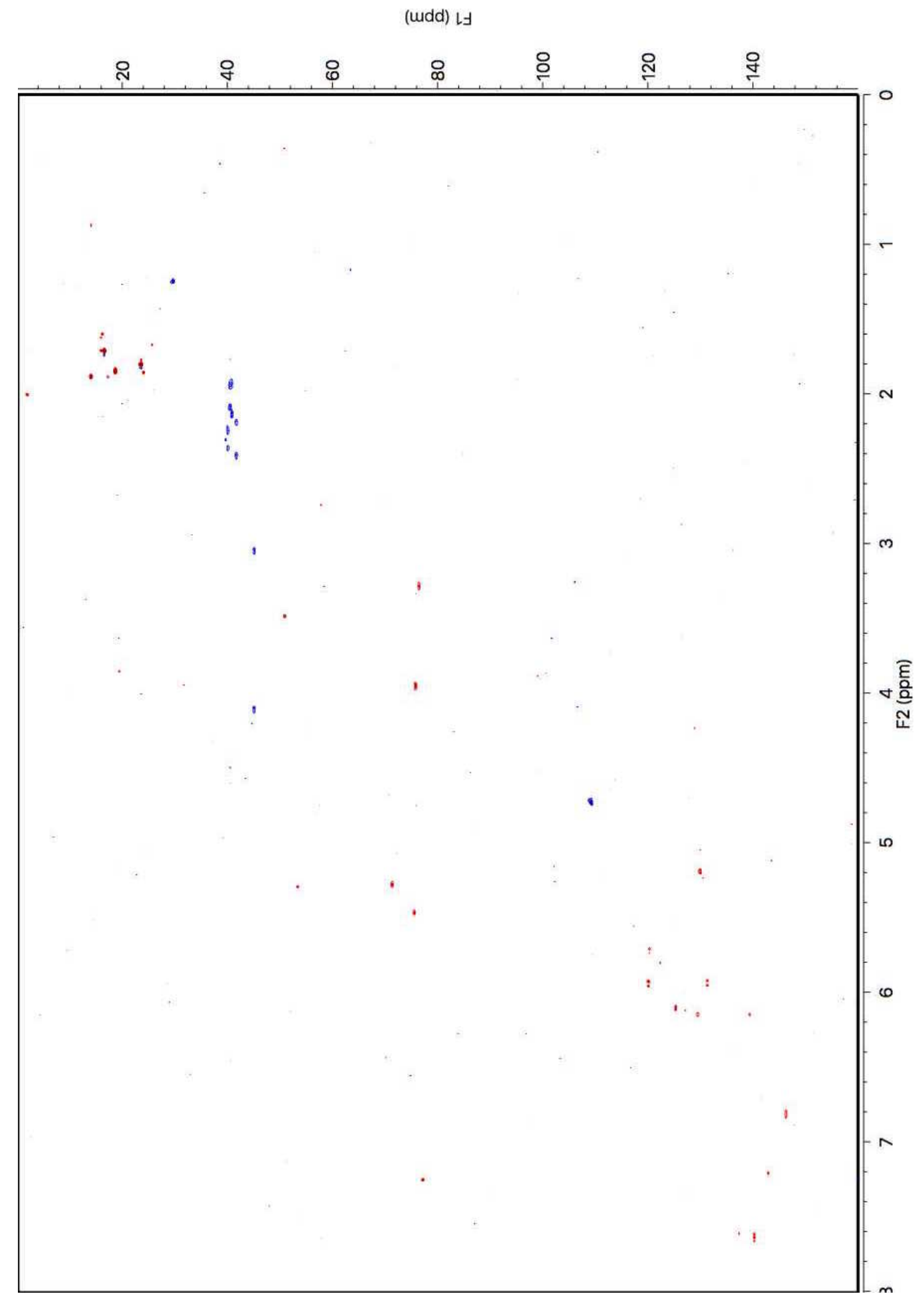

HSQC spectrum of zampanolide D (284) (600 MHz, $\mathrm{CDCl}_{3}$ ). 


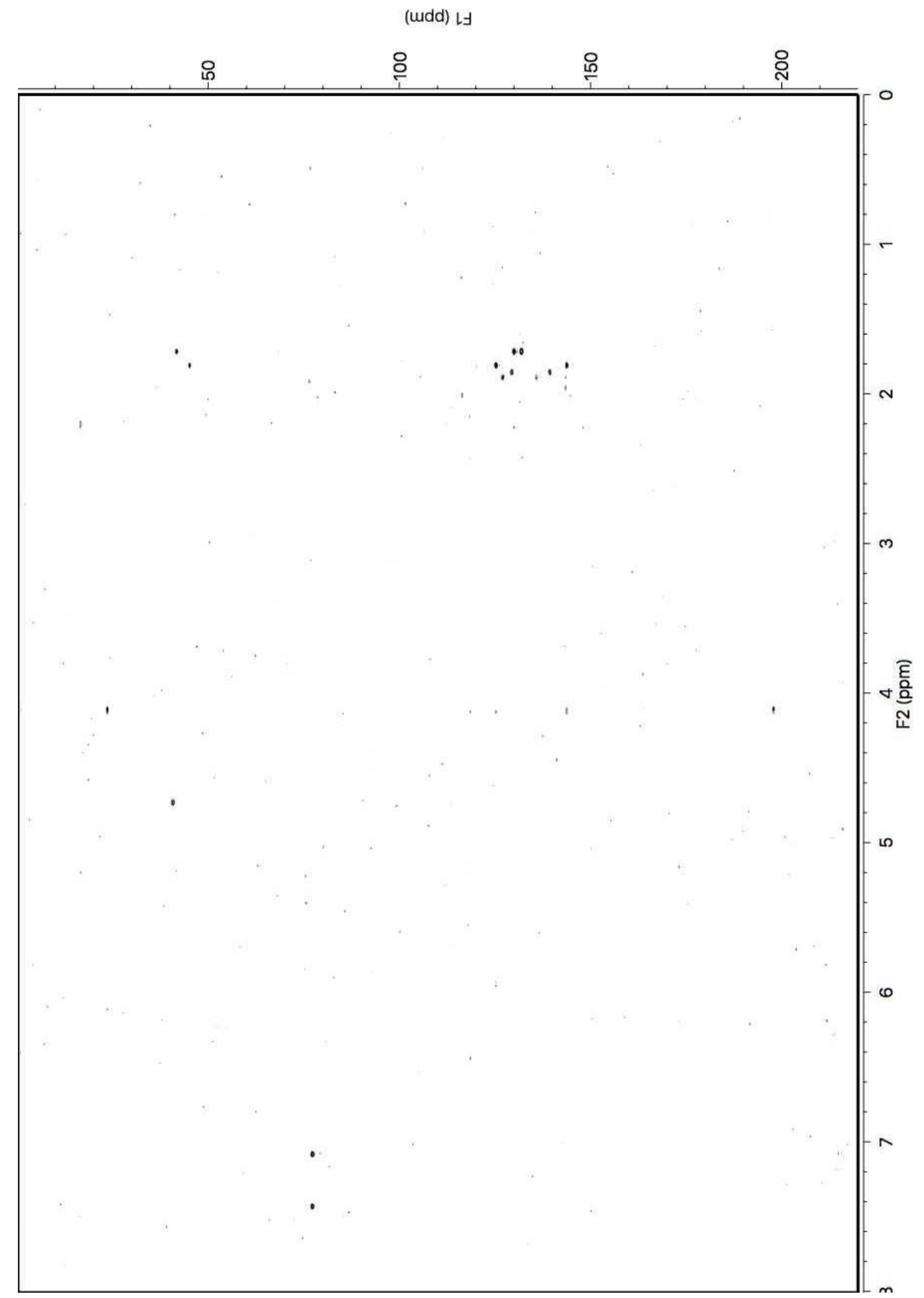

HMBC spectrum of zampanolide D (284) (600 MHz, $\mathrm{CDCl}_{3}$ ). 


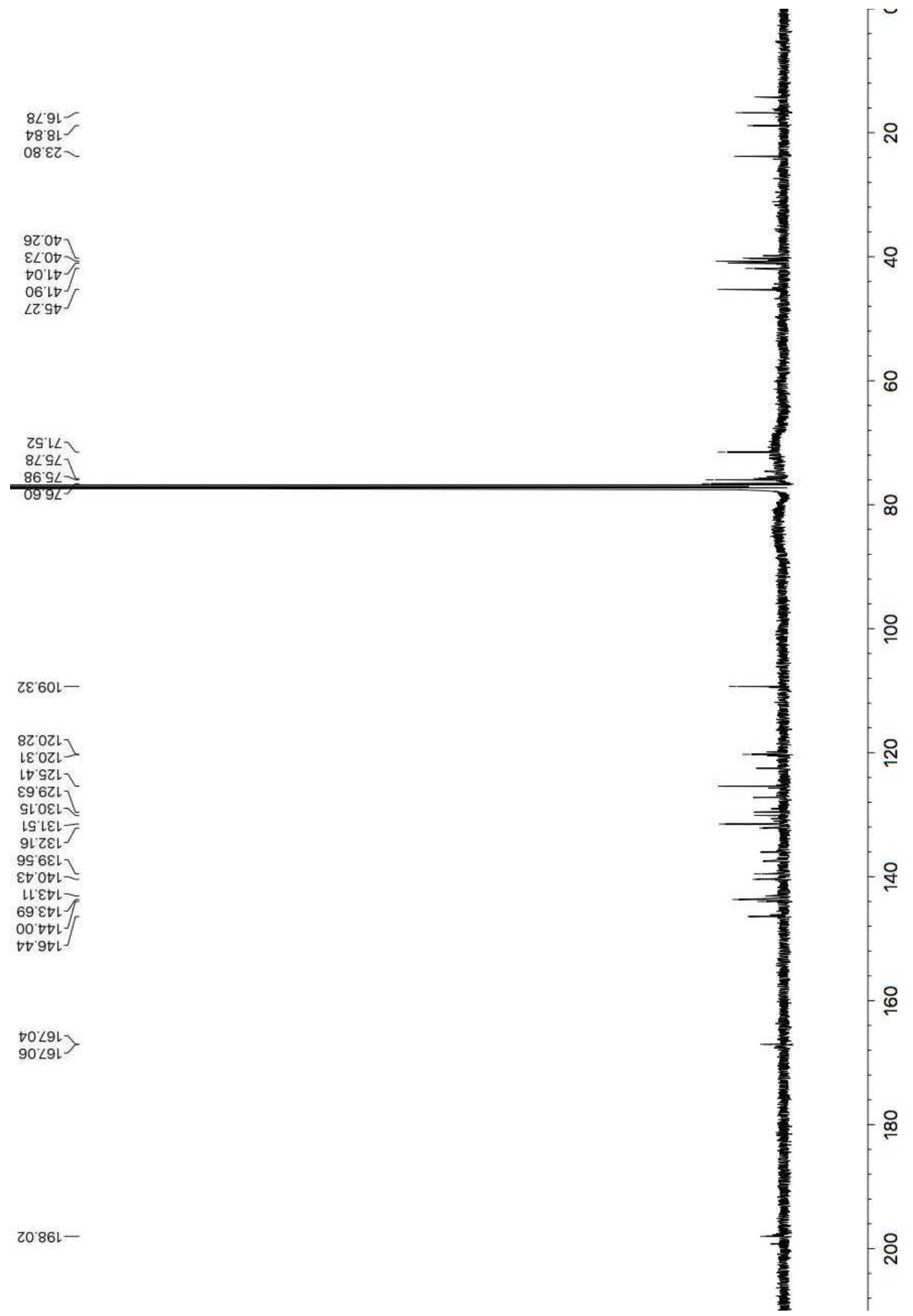

${ }^{13} \mathrm{C}$ NMR spectrum of zampanolide D (284) $\left(150 \mathrm{MHz}, \mathrm{CDCl}_{3}\right)$. 
Appendix S

\section{Zampanolide E}

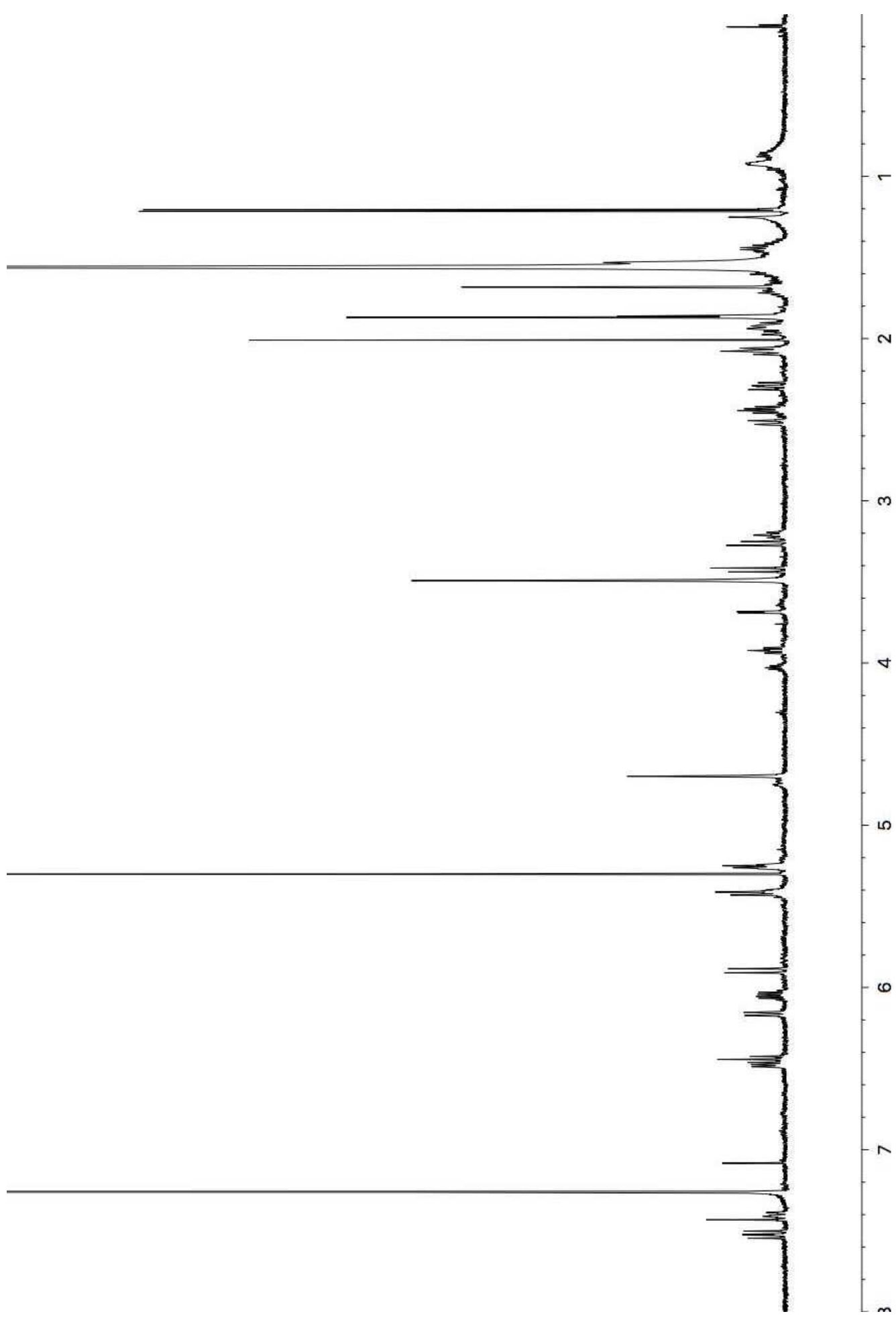

${ }^{1} \mathrm{H}$ NMR spectrum of zampanolide E (285) (600 MHz, $\left.\mathrm{CDCl}_{3}\right)$. 
(udd) $\downarrow \exists$

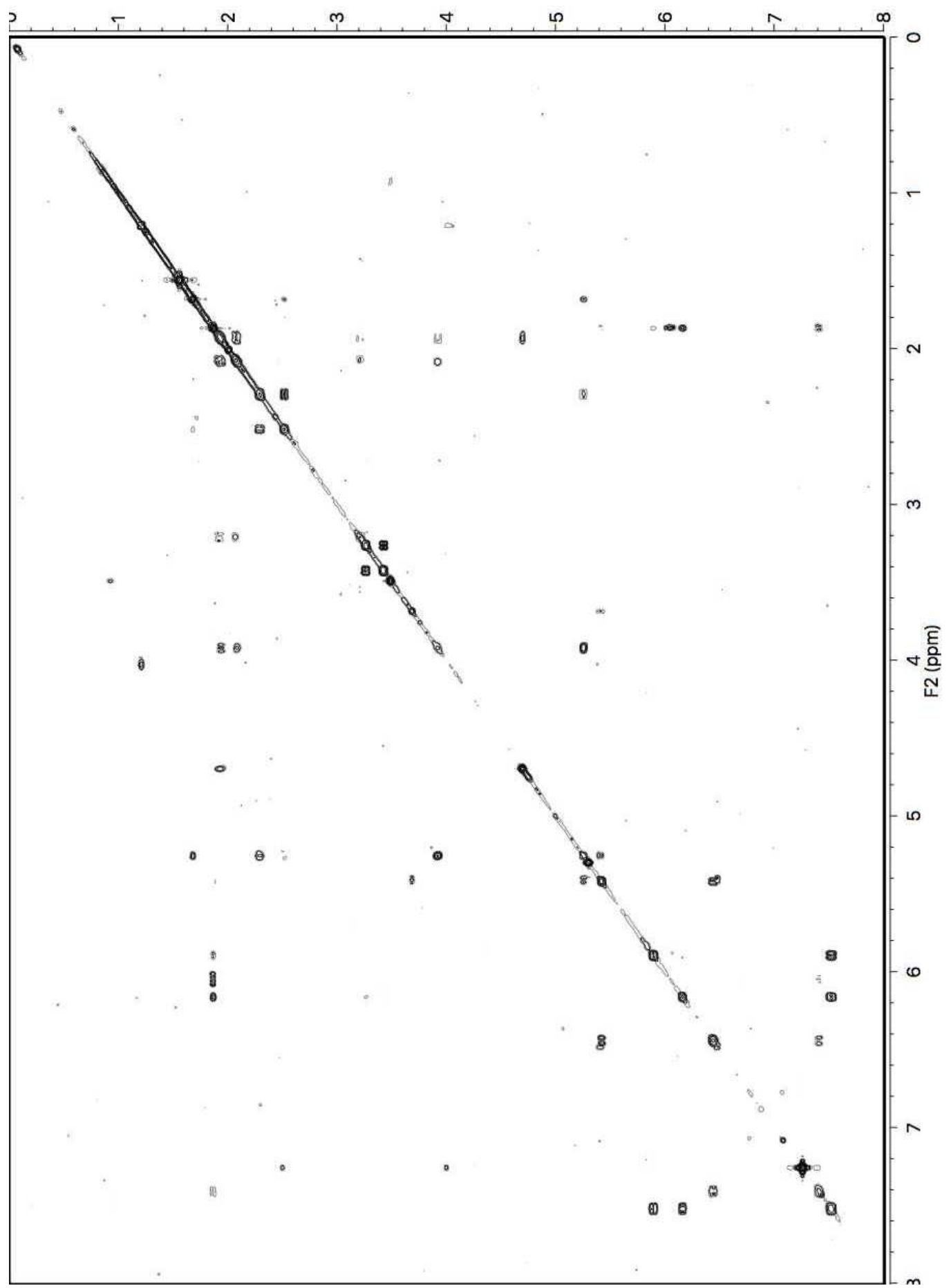

COSY spectrum of zampanolide E (285) $\left(600 \mathrm{MHz}, \mathrm{CDCl}_{3}\right)$. 


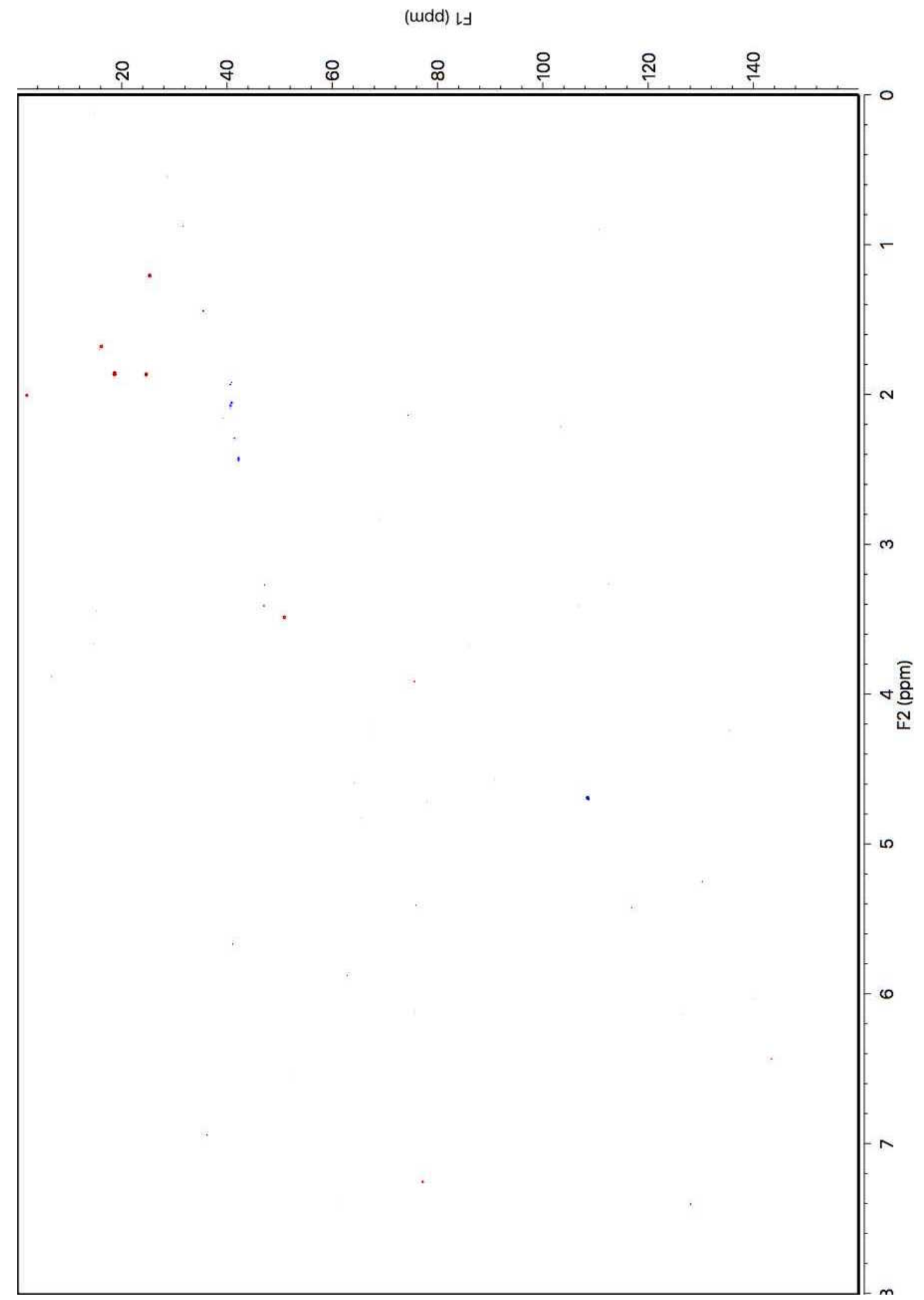

HSQC spectrum of zampanolide E (285) (600 MHz, $\mathrm{CDCl}_{3}$ ). 


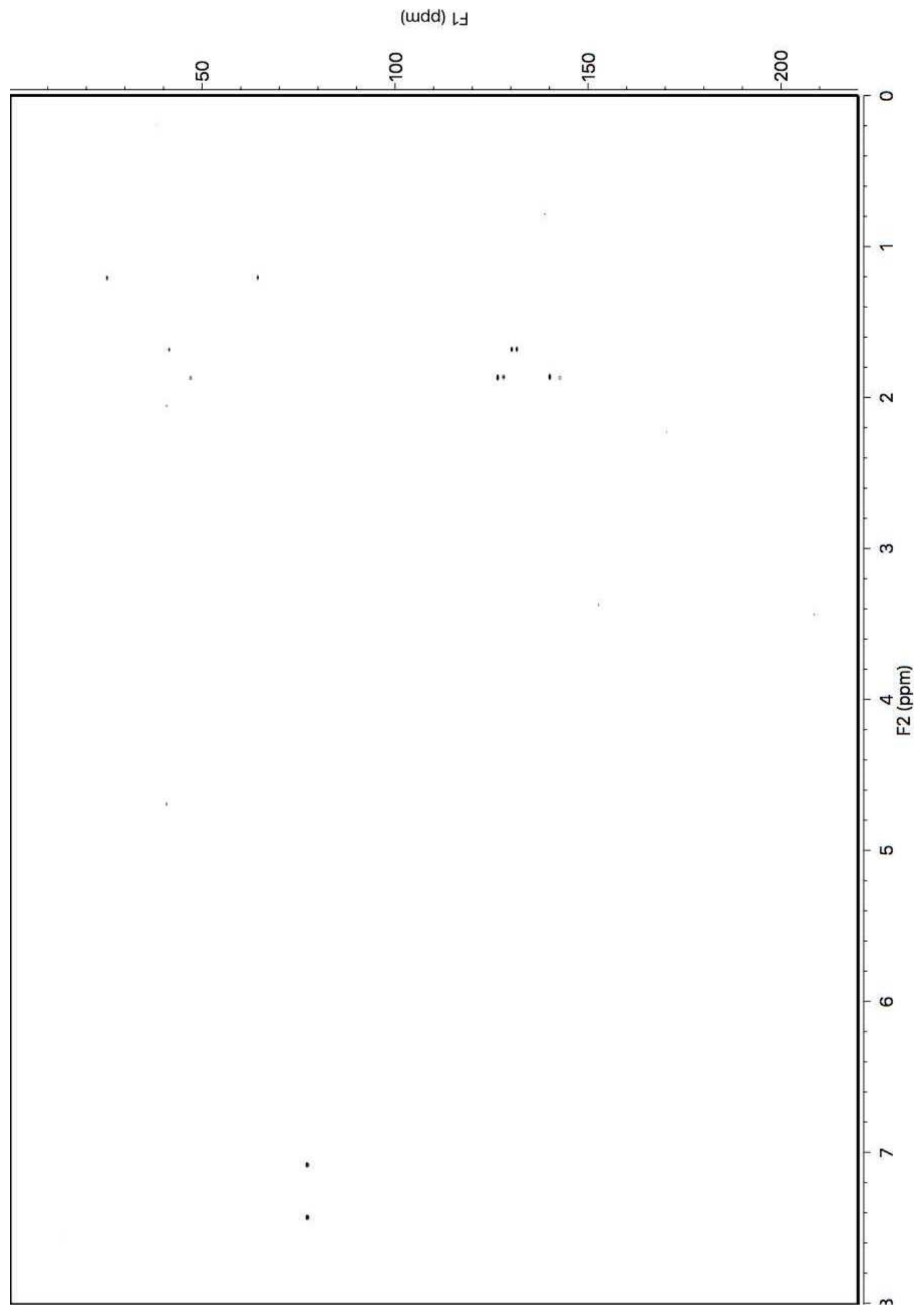

HMBC spectrum of zampanolide E (285) $\left(600 \mathrm{MHz}, \mathrm{CDCl}_{3}\right)$. 


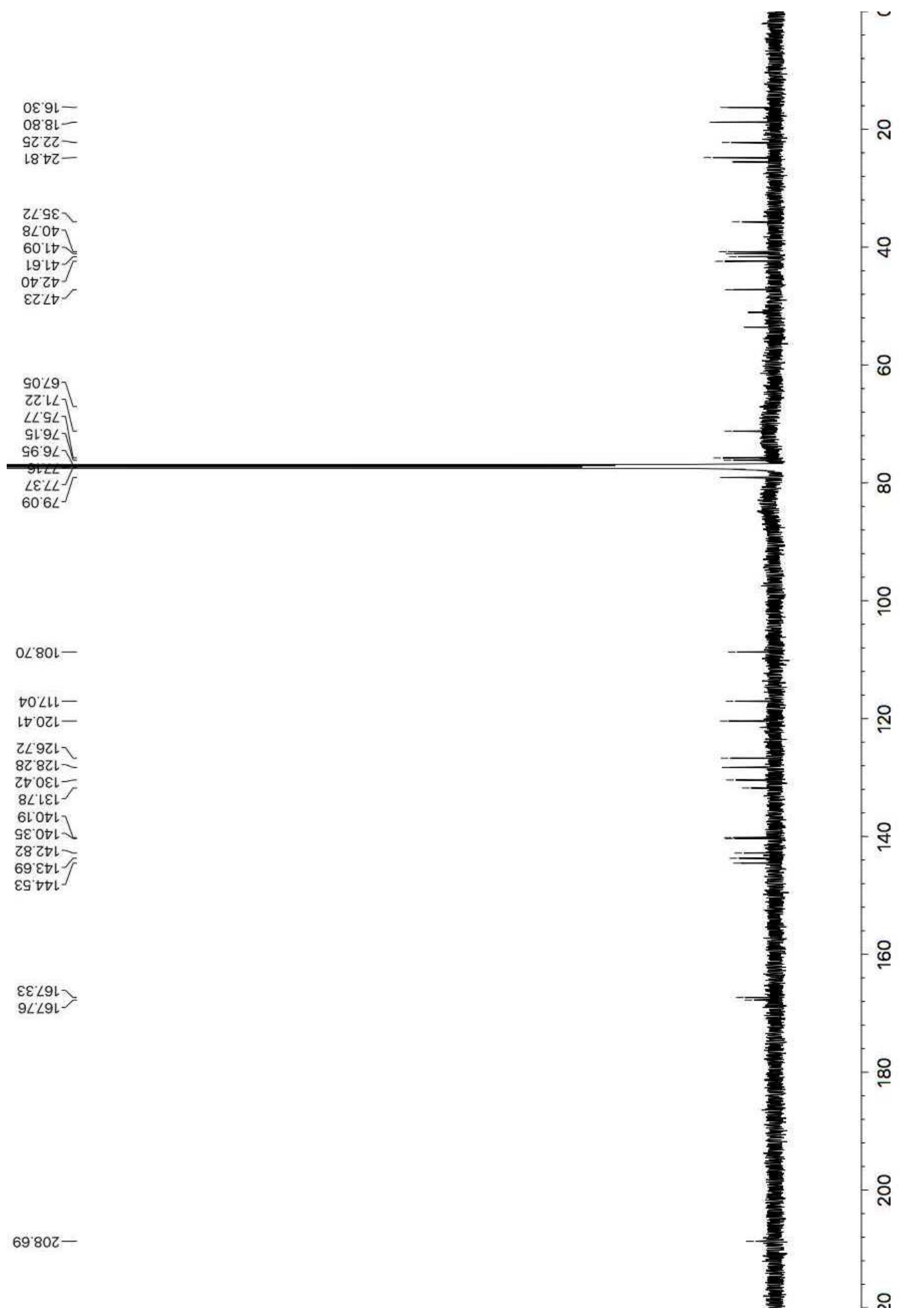

${ }^{13} \mathrm{C}$ NMR spectrum of zampanolide E (285) $\left(150 \mathrm{MHz}, \mathrm{CDCl}_{3}\right)$. 


\section{References}

1. Ji, H.; Li, X.; Zhang, H. EMPO Rep. 2009, 10, 194-200.

2. Newman, D. J.; Cragg, G. M.; Snader, K. M. Nat. Prod. Rep. 2000, 17, 215-234.

3. Cragg, G. M.; Newman, D. J. Expert Opin. Investig. Drugs 2000, 9, 2783-2797.

4. Haefner, B. Drug Discov. Today 2003, 8, 536-544.

5. Donia, M.; Hamann, M. T. Lancet. Infect. Dis. 2003, 3, 338-348.

6. Carté, B. K. Bioscience 1996, 46, 271-286.

7. Mayer, A. M. S.; Lehmann, V. K. B. The Pharmacologist 2000, 42, 62-69.

8. Proksch, P.; Edrada, R. A.; Ebel, R. Appl. Microbiol. Biotechnol. 2002, 59, 125-134.

9. Dias, D. A.; Urban, S.; Roessner, U. Metabolites 2012, 2, 303-336.

10. Bergmann, W.; Feeney, R. J. J. Am. Chem. Soc. 1950, 72, 2809-2810.

11. Bergmann, W.; Feeney, R. J. J. Org. Chem. 1951, 16, 981-987.

12. Bergmann, W.; Burke, D. C. J. Org. Chem. 1955, 20, 1501-1507.

13. Nussbaum, F. V.; Brands, M.; Hinzen, B.; Weigand, S.; Habich, D. Angew. Chem. Int. Ed. 2006, 45, 5072-5129.

14. Luzhetskyy, A.; Pelzer, S.; Bechthold, A. Curr. Opin. Investig. Drugs. 2007, 8, 608613.

15. Newman, D. J.; Cragg, G. M. J. Nat. Prod. 2007, 70, 461-477.

16. Newman, D. J. J. Med. Chem. 2008, 51, 2589-2599.

17. Martins, A.; Vieira, H.; Gaspar, H.; Santos, S. Mar. Drugs 2014, 12, 1066-1101.

18. Blunt, J. W.; Munro, M. H. G. MarinLit - A Database of the Marine Natural Products Literature, 2017. http://pubs.rsc.org/marinlit/.

19. McIntosh, M.; Cruz, L. J.; Hunkapiller, M. W.; Gray, W. R.; Olivera, B. M. Arch. Biochem. Biophys. 1982, 218, 329-233.

20. Olivera, B. M.; Cruz, L. J.; de Santos, V.; LeCheminant, G.; Griffin, D.; Zeikus, R.; McIntosh, M.; Galyean, R.; Varga, J.; Gray, W. R.; Rivier, J. Biochemistry 1987, 26, 2086-2090.

21. Miljanich, G. P. Curr. Med. Chem. 2004, 11, 3029-3040.

22. Mayer, A. M.; Glaser, K. B.; Cuevas, C.; Jacobs, R. S.; Kem, W.; Little, R. D.; McIntosh, J. M.; Newman, D. J.; Potts, B. C.; Shuster, D. E. Trends Pharmacol. Sci. 2010, 31, 255-265.

23. Wright, A. E.; Forleo, D. A.; Gunawardana, G. P.; Gunasekera, S. P.; Koehn, F. E.; McConnell, O. J. J. Org. Chem. 1990, 55, 4508-4512. 
24. Rinehart, K. L.; Holt, T. G.; Fregeau, N. L.; Stroh, J. G.; Keifer, P. A.; Sun, F.; Li, L. H.; Martin, D. G. J. Org. Chem. 1990, 55, 4512-4515.

25. Molinski, T. F.; Dalisay, D. S.; Lievens, S. L.; Saludes, J. P. Nat. Rev. Drug Discov. 2009, 8, 69-85.

26. Imhoff, J. F.; Labes, A.; Wiese, J. Biotechnol. Adv. 2011, 29, 468-482.

27. Cortes, J.; Montero, A. J.; Glück, S. Cancer Treat. Rev. 2012, 38, 143-151.

28. Pettit, G. R.; Kamano, Y.; Herald, C. L.; Tuinman, A. A.; Boettner, F. E.; Kizu, H.; Schmidt, J. M.; Baczynskyj, L.; Tomer, K. B.; Bontems, R. J. J. Am. Chem. Soc. 1987, 109, 6883-6885.

29. Senter, P. D.; Sievers, E. L. Nat. Biotechnol. 2012, 30, 631-637.

30. Hooper, J. N. A.; Van Soest, R. W. M. Systema Porifera: a guide to the classification of sponges, 1st ed.; Kluwer Academic/Plenum: New York, 2002.

31. van Soest, R. W. M. et al. World Porifera Database, 2017. http://www. marinespecies.org/porifera.

32. van Soest, R. W. M.; Boury-Esnault, N.; Vacelet, J.; Dohrmann, M.; Erpenbeck, D.; de Voogd, N. J.; Santodomingo, N.; Vanhoorne, B.; Kelly, M.; Hooper, J. N. A. PLOS ONE 2012, 7, e35105.

33. Gazave, E.; Lapébie, P.; Ereskovsky, A. V.; Vacelet, J.; Renard, E.; Cárdenas, P.; Borchiellini, C. Hydrobiologia 2012, 687, 3-10.

34. Blunt, J. W.; Copp, B. R.; Keyzers, R. A.; Munro, H. G., M; Prinsep, M. R. Nat Prod. Rep. 2016, 33, 382-431.

35. Perdicaris, S.; Vlachogianni, T.; Valavanidis, A. Nat Prod. Chem. Res. 2013, 1, 1-8.

36. Lee, Y. K.; Lee, J.-H.; Lee, H. K. J. Microbiol. 2001, 39, 254-264.

37. Faulkner, D. J.; Unson, M. D.; Bewley, C. A. Pure Appl. Chem. 1994, 66, 19831990.

38. Bewley, C. A.; Faulkner, D. J. Angew. Chem., Int. Ed. 1998, 37, 2167-2178.

39. Bakus, G. J.; Green, G. Science 1974, 185, 951-953.

40. Manes, L. V.; Bakus, G. J.; Crews, P. Tetrahedron Lett. 1984, 25, 931-934.

41. Kelly-Borges, M.; Vacelet, J. Mem. Queensl. Mus. 1995, 38, 477-503.

42. Sperry, S.; Valeriote, F. A.; Corbett, T. H.; Crews, P. J. Nat. Prod. 1998, 61, 241247.

43. Crews, P.; Bescansa, P.; Bakus, G. J. Experientia 1985, 41, 690-691.

44. Crews, P.; Bescansa, P. J. Nat. Prod. 1986, 49, 1041-1052.

45. Quinõá, E.; Crews, P. Tetrahedron Lett. 1987, 28, 3229-3232.

46. Meragelman, K. M.; McKee, T. C.; Boyd, M. R. J. Nat. Prod. 2001, 64, 389-392. 
47. Barber, J. M. E. K. Chemical and Biological Aspects of Secondary Metabolites from Tongan Marine Sponges, PhD Thesis, Victoria University of Wellington, 2012.

48. Barber, J. M.; Quek, N. C. H.; Leahy, D. C.; Miller, J. H.; Bellows, D. S.; Northcote, P. T. J. Nat. Prod. 2011, 74, 809-815.

49. Woolner, V. H. The Isolation and Structure Elucidation of Secondary Metabolites from Tongan Marine Invertebrates, MSc Thesis, Victoria University of Wellington, 2012.

50. Hoffmeister, J. E.; Alling, H. L.; Whipple, L. Geology of Eua, Tonga; The Museum: Honolulu, Hawaii, 1932.

51. Singh, A. J. The Structure-Directed Isolation of New Secondary Metabolites from South Pacific Sponges, PhD Thesis, Victoria University of Wellington, 2012.

52. Lipinski, C. A.; Lombardo, F.; Dominy, B. W.; Feeney, P. J. Adv. Drug Deliv. Rev. 1997, 23, 3-25.

53. West, L. M. The isolation of secondary metabolites from New Zealand marine sponges, PhD Thesis, Victoria University of Wellington, 2001.

54. Liedekerke, B. M. V.; Nelis, J. H.; Lambert, W. E.; Leenheer, A. P. D. Anal. Chem. 1989, 61, 728-732.

55. Halabalaki, M.; Vougogiannopoulou, K.; Mikros, E.; Skaltsounis, A. L. Curr. Opin. Biotechnol. 2014, 25, 1-7.

56. Stockman, B. J.; Dalvit, C. Prog. Nucl. Magn. Reson. Spectrosc. 2002, 41, 187-231.

57. Stockman, B. J. Prog. Nucl. Magn. Reson. Spectrosc. 1998, 33, 109-151.

58. Ryan, J. M. Novel Secondary Metabolites from New Zealand Marine Sponges, $\mathrm{PhD}$ Thesis, Victoria University of Wellington, 2007.

59. Keyzers, R. A. The Isolation of Biologically Active Secondary Metabolites from New Zealand Marine Organisms, $\mathrm{PhD}$, Victoria University of Wellington, 2003.

60. Popplewell, W. L. Isolation and Structure Elucidation of New Secondary Metabolites from New Zealand Marine Red Algae, PhD Thesis, Victoria University of Wellington, 2008.

61. Dowle, K. O. New Nitrogenous Spongian Diterpenes from the New Zealand Marine Sponge Darwinella oxeata, MSc Thesis, Victoria University of Wellington, 2008.

62. Silverstein, R. M.; Webster, F. X. Spectrometric Identification of Organic Compounds, 6th ed.; John Wiley \& Sons, Inc.: New York, 1998.

63. Stierle, D. B.; Faulkner, D. J. J. Nat. Prod. 1991, 54, 1131-1133.

64. Capon, R. J.; Ghisalberti, E. L.; Jefferies, P. R. Aust. J. Chem. 1982, 35, 2583-2587.

65. Wright, A. E.; Pomponi, S. A.; McConnell, O. J.; Kohmoto, S.; McCarthy, P. J. Nat. Prod. 1987, 50, 976-978.

66. Fattorusso, E.; Minale, L.; Sodano, G.; Moody, K.; Thomson, R. H. Chem. Comm. 1970, 752-753. 
67. Jiménez, C.; Quinõá, E.; Adamczeski, M.; Hunter, L. M.; Crews, P. J. Org. Chem. 1991, 56, 3403-3410.

68. Taufa, T. New Sesterterpenes from Marine Sponges from the Tropical Waters of the Kingdom of Tonga, MSc Thesis, Victoria University of Wellington, 2010.

69. Raverty, W.; Thomson, R.; King, T. J. Chem. Soc. 1977, 10, 1204-1211.

70. Kobayashi, M.; Shimizu, N.; Kitagawa, I.; Kyogoku, Y.; Harada, N.; Uda, H. Tetrahedron Lett. 1985, 26, 3833-3836.

71. Tsukamoto, S.; Yamashita, T.; Matsunage, S.; Fusetani, N. J. Org. Chem. 1999, 64, 3794-3795.

72. Matsunaga, S.; Yamashita, T.; Tsukamoto, S.; Fusetani, N. J. Nat. Prod. 1999, 62, 1202-1204.

73. Nazawa, D.; Takikawa, H.; Mori, K. Bioorg. Med. Chem. 2001, 11, 1481-1483.

74. Lu, Z.; van Wagoner, R. M.; Harper, M. K.; Baker, H. L.; Hooper, J. N. A.; Bewley, C. A.; Ireland, C. M. J. Nat. Prod. 2011, 74, 185-193.

75. Shin, H. J.; Rashid, M. A.; Cartner, L. K.; Bokesch, H. R.; Wilson, J. A.; McMahon, J. B.; Gustafson, K. R. Tetrahedron Lett. 2015, 56, 4215-4219.

76. Bergquist, P.; Lawson, M. P.; Lavis, A.; Cambie, R. C. Biochem. Sys. Ecol. 1984, $12,63-84$.

77. Ravi, B. N.; Wells, R. J.; Croft, K. D. J. Org. Chem. 1981, 46, 1998-2001.

78. MaCabe, T.; Clardy, J.; Minale, L.; Pizza, C.; Zollo, F.; Riccio, R. Tetrahedron Lett. 1982, 23, 3307-3310.

79. Su, J. Y.; Meng, Y. H.; Zeng, L. M.; Fu, X.; Schmitz, F. J. J. Nat. Prod. 1994, 57, $1450-1451$.

80. McCormick, J. L.; McKee, T. C.; Cardellina, J. H.; Leid, M.; Boyd, M. R. J. Nat. Prod. 1996, 59, 1047-1050.

81. Oku, N.; Matsunaga, S.; Wada, S. I.; Watabe, S.; Fusetani, N. J. Nat. Prod. 2000, 63, 205-209.

82. Lan, W. J.; Lin, C. W.; Su, J. Y.; Zeng, L. M. Chem. J. Chin. Univ. 2005, 26, 22702272.

83. Xue, D. Q.; Mao, S. C.; Yu, X. Q.; Guo, Y. W. Biochem. Sys. Ecol. 2013, 49, 101106.

84. Li, Y.; Tang, H.; Tian, X.; Lin, H.; Wang, M.; Yao, M. Fitoterapia 2015, 106, 226230.

85. Guerriero, A.; Debitus, C.; Pietra, F. Helv. Chim. Acta 1991, 1991, 487-494.

86. Li, H.; Matsunaga, S.; Fusetani, N. Experientia 1994, 50, 771-773.

87. Miyamoto, T.; Kodama, K.; Aramaki, Y.; Higuchi, R.; van Soest, R. W. M. Tetrahedron Lett. 2001, 42, 6349-6351. 
88. Lin, H. W.; Wang, Z. L.; Wu, J. H.; Shi, N.; Zhang, H. J.; Chen, W. S.; MorrisNatschke, S. L.; Lin, A. S. J. Nat. Prod. 2007, 70, 1114-1117.

89. Ryu, G.; Matsunaga, S.; Fusetani, N. J. Nat. Prod. 1996, 59, 512-514.

90. Sheikh, Y. M.; Djerassi, C. Tetrahedron 1974, 30, 4095-4103.

91. Pritchard, K.; Ward, V.; Battershill, C.; Bergquist, P. R. Marine Sponges: Forty-Six Sponges of Northern New Zealand; 1984.

92. Kelly, M.; Herr, B. Splendid sponges - a guide to the sponges of New Zealand; Report, 2015.

93. Kelly, M.; Herr, B. Splendid sponges - a guide to the sponges of New Zealand; Report, 2017.

94. Heftmann, E.; Ko, S. T.; Bennett, R. D. J. Chromatogr. 1966, 21, 490-494.

95. Hiai, S.; Oura, H.; Nakajima, T. Planta Med. 1976, 29, 116-122.

96. Kho, E.; Imagawa, D. K.; Rohmer, M.; Kashman, Y.; Djerassi, C. J. Org. Chem. 1981, 46, 1836-1839.

97. Kobayashi, M.; Kawazoe, K.; Katori, T.; Kitagawa, I. Chem. Pharm. Bull. 1992, 40, 1773-1778.

98. Sugo, Y.; Inouye, Y.; Nakayama, N. Steroids 1995, 60, 738-742.

99. Qureshi, A.; Faulkner, D. J. J. Nat. Prod. 2000, 63, 841-842.

100. Angawi, R. F.; Calcinai, B.; Cerrano, C.; Dien, H. A.; Fattorusso, E.; Scala, F.; Taglialatela-Scafati, O. J. Nat. Prod. 2009, 72, 2195-2198.

101. Zhang, H. J.; Yi, Y. H.; Lin, H. W. Helv. Chim. Acta 2010, 93, 1120-1126.

102. de Marino, S.; Sepe, V.; DÁuria, M. V.; Bifulco, G.; Renga, B.; Petek, S.; Fiorucci, S.; Zampella, A. Org. Biomol. Chem. 2011, 9, 4856-4862.

103. de Marino, S.; Ummarino, R.; DÁuria, M. V.; Chini, M. G.; Bifulco, G.; Renga, B.; D’Amore, C.; Fiorucci, S.; Debitus, C.; Zampella, A. J. Med. Chem. 2011, 54, 3065-3075.

104. Sepe, V.; Ummarino, R.; DÁuria, M. V.; Chini, M. G.; Bifulco, G.; Renga, B.; D’Amore, C.; Debitus, C.; Fiorucci, S.; Zampella, A. J. Med. Chem. 2012, 55, 8493.

105. Chini, M. G.; Jones, C. R.; Zampella, A.; DÁuria, M. V.; Renga, B.; Fiorucci, S.; Butts, C. P.; Bifulco, G. J. Org. Chem. 2012, 77, 1489-1496.

106. de Marino, S.; Ummarino, R.; DÁuria, M.; Chini, M. G.; Bifulco, G.; DÁmore, C.; Renga, B.; Mencarelli, A.; Petek, S.; Fiorucci, S.; Zampella, A. Steroids 2012, 77, 484-495.

107. Guo, J.; Chiang, C.; Lu, M.; Chang, W.; Su, J. Mar. Drugs 2012, 10, 1536-1544.

108. Sepe, V.; DÁmore, C.; Ummarino, R.; Renga, B.; D’Auria, M. V.; Novellino, E.; Sinisi, A.; Taglialatela-Scafati, O.; Nakao, Y.; Limongelli, V.; Zampella, A.; Fiorucci, S. Eur. J. Med. Chem. 2014, 73, 126-134. 
109. Gong, J.; Sun, P.; Jiang, N.; Riccio, R.; Lauro, G.; Bifulco, G.; Li, T.; Gerwick, W. H.; Zhang, H. Org. Lett. 2014, 16, 2224-2227.

110. Renga, B.; Mencarelli, A.; DÁmore, C.; Cipriani, S.; DÁuria, M. V.; Sepe, V.; Chini, M. G.; Monti, M. C.; Bifulco, G.; Zampella, A.; Fiorucci, S. PLoS ONE 2012, 7, e30443.

111. Umeyama, A.; Shoji, N.; Enoki, M.; Arihara, S. J. Nat. Prod. 1997, 60, 296-298.

112. Zahid, S.; Udenigwe, C. C.; Ata, A.; Eze, M. O.; Segstro, E. P.; Holloway, P. Nat. Prod. Res. 2006, 20, 1283-1289.

113. Antunes, E. M.; Copp, B. R.; Davies-Coleman, M. T.; Samaai, T. Nat. Prod. Rep. $\mathbf{2 0 0 5}, 22,62-72$.

114. Dijoux, M. G.; Gamble, W. R.; Hallock, Y. F.; Cardellina, J. H.; van Soest, R.; Boyd, M. R. J. Nat. Prod. 1999, 62, 636-637.

115. Schmidt, E. W.; Harper, M. K.; Faulkner, D. J. J. Nat. Prod. 1995, 58, 1861-1867.

116. Chang, L. C.; Otero-Quintero, S.; Hooper, J. N. A.; Bewley, C. A. J. Nat. Prod. 2002, 65, 776-778.

117. Sakemi, S.; Sun, H. H.; Jefford, C. W.; Bernardinelli, G. Tetrahedron Lett. 1989, 30, 2517-2520.

118. Venables, D. A.; Barrows, L. R.; Lassota, P.; Ireland, C. M. Tetrahedron Lett. 1997, $38,721-722$.

119. Radisky, D. C.; Radisky, E. S.; Barrows, L. R.; Copp, B. R.; Kramer, R. A.; Ireland, C. M. J. Am. Chem. Soc. 1993, 115, 1632-1638.

120. Venables, D. A.; Concepción, G. P.; Matsumota, S. S.; Barrows, L. R.; Ireland, C. M. J. Nat. Prod. 1997, 60, 408-410.

121. Casapullo, A.; Cutignano, A.; Bruno, I.; Bifulco, G.; Debitus, C.; GomezPaloma, L.; Riccio, R. J. Nat. Prod. 2001, 64, 1354-1356.

122. Carney, J. R.; Scheuer, P. J.; Kelly-Borges, M. Tetrahedron 1993, 49, 8483-8486.

123. Hu, J. F.; Schetz, J. A.; Kelly, M.; Peng, J. N.; Ang, K. K. H.; Flotow, H.; Leong, C. Y.; Ng, S. B.; Buss, A. D.; Wilkins, S. P.; Hamann, M. T. J. Nat. Prod. 2002, 65, 476-480.

124. Crews, P.; Gerwick, W.; Schmitz, F.; France, D.; Bair, K.; Wright, A.; Hallock, Y. Pharm. Biol. 2003, 41, 39-52.

125. Perry, N. B.; Blunt, J. W.; Munro, M. H. G. Tetrahedron 1988, 44, 1727-1734.

126. Utkina, N. K.; Gerasimenko, A. V.; Popov, D. Y. Russ. Chem. Bull. Int. Ed. 2003, $52,258-260$.

127. Ireland, C. M.; Radisky, D. C.; Barrows, L. R.; Kramer, R. US5414001, 1995.

128. Dijoux, M. G.; Schnabel, P. C.; Hallock, Y. F.; Boswell, J. L.; Johnson, T. R.; Wilson, J. A.; Ireland, C. M.; van Soest, R.; Boyd, M. R.; Barrows, L. R.; Cardellina, J. H. Bioorg. Med. Chem. 2005, 13, 6035-6044. 
129. Fu, X.; Ng, P. L.; Schmitz, F. J.; Hossain, M. B.; van der Helm, D.; Kelly-Borges, M. J. Nat. Prod. 1996, 59, 1104-1106.

130. Utkina, N. K.; Makarchenko, A. E.; Denisenko, V. A.; Dmitrenok, P. S. Tetrahedron Lett. 2004, 45, 7491-7494.

131. Utkina, N. K.; Makarchenko, A. E.; Denisenko, V. A. J. Nat. Prod. 2005, 68, 14241427.

132. Tasdemir, D.; Mangalindan, G. C.; Concepción, G. P.; Harper, M. K.; Ireland, C. M. Chem. Pharm. Bull. 2001, 49, 1628-1630.

133. Mancini, I.; Guella, G.; Debitus, C.; Duhet, D.; Pietra, F. Helv. Chim. Acta 1994, 77, 1886-1894.

134. Hooper, G. J.; Davies-Coleman, M. T.; Kelly-Borges, M.; Coetzee, P. S. Tetrahedron Lett. 1996, 37, 7135-7138.

135. White, K. N.; Amagata, T.; Oliver, A. G.; Tenney, K.; Wenzel, P. J.; Crews, P. J. Org. Chem. 2008, 73, 8719-8722.

136. Molinski, T. F. Curr. Opin. Biotechnol. 2010, 21, 819-826.

137. Genta-Jouve, G.; Francezon, N.; Puissant, A.; Auberger, P.; Vacelet, J.; Pérez, T.; Fontana, A.; Mourabit, A., A; Thomas, P., O Magn. Reson. Chem. 2011, 49, 533536.

138. Dattelbaum, J. D.; Singh, A. J.; Field, J. J.; Miller, J. H.; Northcote, P. T. J. Org. Chem. 2015, 80, 304-312.

139. Frisch, M. J. et al. Gaussian 09, Revision D.01, 2009.

140. Adamo, C.; Barone, V. J. Chem. Phys. 1999, 110, 6158-6169.

141. Weigend, F.; Ahlrichs, R. Phys. Chem. Chem. Phys. 2005, 7, 3297-3305.

142. Barone, V.; Cossi, M.; Tomasi, J. J. Chem. Phys. 1997, 107, 3210-3221.

143. Smith, S. G.; Goodman, J. M. J. Am. Chem. Soc. 2010, 132, 12946-12959.

144. Lill, R. E.; Major, D. A.; Blunt, J. W.; Munro, M. H. G.; Battershill, C. N.; McLean, M. G.; Baxter, R. L. J. Nat. Prod. 1995, 58, 306-311.

145. Perry, N. B.; Blunt, J. W.; McCombs, J. D.; Munro, M. H. G. J. Org. Chem. 1986, $51,5476-5478$.

146. Urban, S.; Hickford, S. J. H.; Blunt, J. W.; Munro, M. H. G. Curr. Org. Chem. 2000 , 4, 766-805.

147. Gunasekera, S. P.; Zuleta, I. A.; Longley, R. E.; Wright, A. E.; Pomponi, S. A. J. Nat. Prod. 2003, 66, 1615-1617.

148. Reyes, F.; Martin, R.; Rueda, A.; Fernandez, R.; Montalvo, D.; Gomez, C.; SanchezPuelles, J. M. J. Nat. Prod. 2004, 67, 463-465.

149. Antunes, E. M.; Beukes, D. R.; Kelly, M.; Samaai, T.; Barrows, L. R.; Marshall, K. M.; Sincich, C.; Davies-Coleman, M. T. J. Nat. Prod. 2004, 67, 12681276. 
150. Harayama, Y.; Kita, Y. Curr. Med. Chem. 2005, 9, 1567-1588.

151. Kobayashi, J.; Cheng, J. F.; Ishibashi, M.; Nakamura, H.; Ohizumi, Y.; Hirata, Y.; Sasaki, T.; Lu, H.; Clardy, J. Tetrahedron Lett. 1987, 28, 4939-4942.

152. Cheng, J.; Ohizumi, Y.; Wälchli, M. R.; Nakamura, H.; Hirata, Y.; Sasaki, T.; Kobayashi, J. J. Org. Chem. 1988, 53, 4621-4624.

153. DÁmbrosio, M.; Chiasera, G.; Pietra, F.; Tató, M. Tetrahedron 1996, 52, 88998906.

154. Sun, H. H.; Sakemi, S.; Burres, N.; McCarthy, P. J. Org. Chem. 1990, 55, 49644966.

155. Gunasekera, S. P.; McCarthy, P. J.; Longley, R. E.; Pomponi, S. A.; Wright, A. E. J. Nat. Prod. 1999, 62, 1208-1211.

156. Keyzers, R. A.; Samaai, T.; Davies-Coleman, M. T. Tetrahedron Lett. 2004, 45, 9415-9418.

157. Keyzers, R. A.; Arendse, C. E.; Hendricks, D. T.; Samaai, T.; DaviesColeman, M. T. J. Nat. Prod. 2005, 68, 506-510.

158. Na, M. K.; Ding, Y. Q.; Wang, B.; Tekwani, B. L.; Schinazi, R. F.; Franzblau, S.; Kelly, M.; Stone, R.; Li, X. C.; Ferreira, D.; Hamann, M. T. J. Nat. Prod. 2010, 73, 383-387.

159. Gunasekera, S. P.; McCarthy, P. J.; Longley, R. E.; Pomponi, S. A.; Wright, A. E.; Lobkovsky, E.; Clardy, J. J. Nat. Prod. 1999, 62, 173-175.

160. Botić, T.; Defant, A.; Zanini, P.; Žužek, M. C.; Frangež, R.; Janussen, D.; Kersken, D.; Knez, Z.; Mancini, I.; Sepčić, Eur. J. Med. Chem. 2017, 136, 294 304.

161. Möarki, F.; Robertson, A. V.; Witkop, B. J. Am. Chem. Soc. 1961, 83, 3341-3342.

162. Ishibashi, M.; Iwasaki, T.; Imai, S.; Sakamoto, S.; Yamaguchi, K.; Ito, A. J. Nat. Prod. 2001, 64, 108-110.

163. Peters, S.; Spiteller, P. J. Nat. Prod. 2007, 70, 1274-1277.

164. Baumann, C.; Bröckelmann, M.; Fugmann, B.; Steffan, B.; Steglich, W.; Sheldrick, W. S. Angew. Chem. Int. Ed. Engl. 1993, 32, 1087-1089.

165. Peters, S.; Jaeger, R. J. R.; Spiteller, P. Eur. J. Org. Chem. 2008, 319-323.

166. Peters, S.; Spiteller, P. Eur. J. Org. Chem. 2007, 1571-1576.

167. Hu, J.; Fan, H.; Xiong, J.; Wu, S. Chem. Rev. 2011, 111, 5465-5491.

168. Davis, R. A.; Buchanan, M. S.; Duffy, S.; Avery, V. M.; Charman, S. A.; Charman, W. N.; White, K. L.; Shackleford, D. M.; Edstein, M. D.; Andrews, K. T.; Camp, D.; Quinn, R. J. J. Med. Chem. 2012, 55, 5851-5858.

169. Davis, R. A.; Duffy, S.; Fletcher, S.; Avery, V. M.; Quinn, R. J. J. Org. Chem. 2013, 78, 9608-9613.

170. Zou, Y.; Hamann, M. T. Org. Lett. 2013, 15, 1516-1519. 
171. Zlotkowski, K.; Hewitt, W. M.; Yan, P.; Bokesch, H. R.; Peach, M. L.; Nicklaus, M. C.; O’Keefe, B. R.; McMahon, J. B.; Gustafson, K. R.; Schneekloth, J. S. Org. Lett. 2017, 19, 1726-1729.

172. Kobayashi, J.; Madono, T.; Shigemori, H. Tetrahedron Lett. 1995, 36, 5589-5590.

173. Ovenden, S. P. B.; Nielson, J. L.; Liptrot, C. H.; Willis, R. H.; Tapiolas, D. M.; Wright, A. D.; Motti, C. A. J. Nat. Prod. 2011, 74, 65-68.

174. Daletos, G.; de Voogd, N. J.; Müller, W. E. G.; Wray, V.; Lin, W.; Feger, D.; Kubbutat, M.; Aly, A. H.; Proksch, P. J. Nat. Prod. 2014, 77, 218-226.

175. Stewart, M.; Fell, P. M.; Blunt, J. W.; Munro, M. H. G. Aust. J. Chem. 1997, 50, 341-348.

176. Rodríguez, A. D.; Ramírez, C.; Rodríguez, I. I.; González, E. Org. Lett. 1999, 1, 527-530.

177. Davidson, J. P.; Corey, E. J. J. Am. Chem. Soc. 2003, 125, 13486-13489.

178. Rodríguez, I. I.; Rodríguez, A. D. J. Nat. Prod. 2003, 66, 855-857.

179. Rodríguez, I. I.; Rodríguez, A. D.; Wang, Y.; Franzblau, S. G. Tetrahedron Lett. 2006, 47, 3229-3232.

180. Hohmann, C.; Schneider, K.; Bruntner, C.; Irran, E.; Nicholson, G.; Bull, A. T.; Jones, A. L.; Brown, R.; Stach, J. E. M.; Goodfellow, M.; Beil, W.; Krämer, M.; Imhoff, J. F.; Süssmuth, R. D.; Fiedler, H. J. Antibiot. 2009, 62, 99-104.

181. Sommer, P. S. M.; Almeida, R. C.; Schneider, K.; Beil, W.; Süssmuth, R. D.; Fiedler, H. J. Antibiot. 2008, 61, 683-686.

182. Ueki, M.; Taniguchi, M. J. Antibiot. 1993, 46, 1089-1094.

183. Sato, S.; Kajiura, T.; Noguchi, M.; Takehana, K.; Kobayashi, J.; Tsuji, T. J. Antibiot. 2001, 54, 102-104.

184. Michel, K. H.; Boeck, L. D.; Hoehn, M. M.; Jones, N. D.; Chaney, M. O. J. Antibiot. 1984, 441-445, year.

185. Takahashi, Y.; Kubota, T.; Shibazaki, A.; Gonoi, T.; Fromont, J.; Kobayashi, J. Org. Lett. 2011, 13, 3016-3019.

186. Georgantea, P.; Ioannou, E.; Evain-Bana, E.; Bagrel, D.; Martinet, N.; Vagias, C.; Roussis, V. Tetrahedron 2016, 72, 3262-3269.

187. Roué, M.; Quévrain, E.; Domart-Coulon, I.; Bourguet-Kondracki, M. L. Nat. Prod. Rep. 2012, 29, 739-751.

188. Edrada, R. A.; Stessman, C. C.; Crews, P. J. Nat. Prod. 2003, 66, 939-942.

189. Carmely, S.; Kashman, Y. Tetrahedron Lett. 1987, 28, 3003-3006.

190. Carmely, S.; Ilan, M.; Kashman, Y. Tetrahedron 1989, 45, 2193-2200.

191. Fu, S.; Barnes, J.; Do, T.; Schmitz, F. J. Nat. Prod. 1997, 60, 497-498. 
192. Dunbar, C.; Rimoldi, J.; Clark, A.; Kelly, M.; Hamann, M. T. Tetrahedron 2000, 56, 8795-8798.

193. Gross, H.; Kehraus, S.; König, G. M.; Woerheide, G.; Wright, A. D. J. Nat. Prod. 2002, 65, 1190-1193.

194. Crews, P.; Clark, D. P.; Tenney, K. J. Nat. Prod. 2003, 66, 177-182.

195. Hassan, W.; Edrada, R.; Ebel, R.; Wray, V.; Berg, A.; van Soest, R.; Wiryowidagdo, S.; Proksch, P. J. Nat. Prod. 2004, 67, 817-822.

196. Fu, X.; Schmitz, F. J.; Tanner, R. S.; Kelly-Borges, M. J. Nat. Prod. 1998, 61, 384386.

197. Carroll, A. R.; Bowden, B. F.; Coll, J. C. Aust. J. Chem. 1993, 46, 1229-1234.

198. Mancini, I.; Guella, G.; Debitus, C.; Pietra, F. Helv. Chim. Acta 1995, 78, 1178 1184.

199. Tsukamoto, S.; Kawabata, T.; Kato, H.; Ohta, T.; Rotinsulu, H.; Mangindaan, R. E. P. J. Nat. Prod. 2007, 70, 1658-1660.

200. Gong, K. K.; Tang, X. L.; Liu, Y. S.; Li, P. L.; Li, G. Q. Molecules 2016, 21, 1-8.

201. Alvi, K. A.; Peters, B. M.; Hunter, L. M.; Crews, P. Tetrahedron 1993, 49, 329-336.

202. Chan, G. W.; Mong, S.; Hemling, M. E.; Freyer, A. J.; Offen, P. H.; DeBrosse, C. W.; Sarau, H. M.; Westley, J. W. J. Nat. Prod. 1993, 56, 116-121.

203. Akee, R. K.; Carroll, T. R.; Yoshida, W. Y.; Scheuer, P. J.; Stout, T. J.; Clardy, J. J. Org. Chem. 1990, 55, 1944-1946.

204. Copp, B. R.; Fairchild, C. R.; Cornell, L.; Casazza, A. M.; Robinson, S.; Ireland, C. M. J. Med. Chem. 1998, 41, 3909-3911.

205. Kong, F.; Faulkner, D. J. J. Org. Chem. 1993, 58, 970-971.

206. Jayatilake, G. S.; Baker, B. J.; McClintock, B. Tetrahedron Lett. 1997, 38, 75077510.

207. Kehraus, S.; König, G. M.; Wright, A. D. J. Org. Chem. 2002, 67, 4989-4992.

208. Watanabe, K.; Tsuda, Y.; Iwashima, M.; Iguchi, K. J. Nat. Prod. 2000, 63, 258-260.

209. Conte, M. R.; Fattorusso, E.; Lanzotti, V.; Magno, S.; Mayol, L. Tetrahedron 1994, 50, 13469-13476.

210. Gunatilaka, A. A. L.; Gopichand, Y.; Schmitz, F. J.; Djerassi, C. J. Org. Chem. 1981, 46, 3860-3866.

211. Mayo, F. R. J. Am. Chem. Soc. 1968, 90, 1289-1295.

212. Ayer, W. A.; Muir, D. J.; Chakravarty, P. Phytochemistry 1996, 42, 1321-1324.

213. Hansen, P. E. Prog. Nucl. Magn. Reson. Spectrosc. 1981, 175-296.

214. Shimbo, K.; Tsuda, M.; Fukushi, E.; Kawabatab, J.; Kobayashi, J. Tetrahedron 2000, 56, 7923-7926. 
215. Yu, S.; Deng, Z.; Proksch, P.; Lin, W. J. Nat. Prod. 2006, 69, 1330-1334.

216. Williams, D. E.; Keyzers, R. A.; Warabi, K.; Desjardine, K.; Riffell, J. L.; Roberge, M.; Andersen, R. J. J. Org. Chem. 2007, 72, 9842-9845.

217. Kakou, Y.; Crews, P.; Bakus, G. J. J. Nat. Prod. 1987, 50, 482-484.

218. Johnson, T. A.; Tenney, K.; Cichewicz, R. H.; Morinaka, B. I.; White, K. N.; Amagata, T.; Subramanian, B.; Media, J.; Mooberry, S. L.; Valeriote, F. A.; Crews, P. J. Med. Chem. 2007, 50, 3795-3803.

219. Wegerski, C. J.; Hammond, J.; Tenney, K.; Matainaho, T.; Crews, P. J. Nat. Prod. 2007, 70, 89-94.

220. Johnson, T. A.; Amagata, T.; Oliver, A. G.; Tenney, K.; Valeriote, F. A.; Crews, P. J. Org. Chem. 2008, 73, 7255-7259.

221. Kashman, Y.; Groweiss, A.; Shmueli, U. Tetrahedron Lett. 1980, 21, 3629-3632.

222. Spector, I.; Shochet, N. R.; Kashman, Y.; Groweiss, A. Science 1983, 219, 493-495.

223. Hoye, T. R.; Ayyad, S. E. N.; Eklov, B. M.; Hashish, N. E.; Shier, W. T.; El Sayed, K. A.; Hamann, M. T. J. Am. Chem. Soc. 2002, 124, 7405-7410.

224. Amagata, T.; Johnson, T. A.; Cichewicz, R. H.; Tenney, K.; Mooberry, S. L.; Media, J.; Edelstein, M.; Valeriote, F. A.; Crews, P. J. Med. Chem. 2008, 72347242.

225. Crews, P.; Kakou, Y.; Quinõá, E. J. Am. Chem. Soc. 1988, 110, 4365-4368.

226. Sonnenschein, R. N.; Johnson, T. A.; Tenney, K.; Valeriote, F. A.; Crews, P. J. Nat. Prod. 2006, 69, 145-147.

227. Quinõá, E.; Kakou, Y.; Crews, P. J. Org. Chem. 1988, 53, 3642-3644.

228. Corley, D. G.; Herb, R.; Moore, R. E.; Scheuer, P. J.; Paul, V. J. J. Org. Chem. 1988, $53,3644-3646$.

229. Mooberry, S. L.; Tien, G.; Hernandez, A. H.; Plubrukarn, A.; Davidson, B. S. Cancer Res. 1999, 59, 653-660.

230. Pryor, D. E.; OB́rate, A.; Bilcer, G.; DS̃az, J. F.; Wang, Y.; Wang, Y.; Kabaki, M.; Jung, M. K.; Andreu, J. M.; Ghosh, A. K.; Giannakakou, P.; Hamel, E. Biochemistry 2002, 41, 9109-9115.

231. Johnson, T. A.; Tenney, K.; Cichewicz, R. H.; Morinaka, B. I.; White, K. N.; Amagata, T.; Subramanian, B.; Media, J.; Mooberry, S. L.; Valeriote, F. A.; Crews, P. J. Med. Chem. 2007, 50, 3795-3803.

232. Johnson, T. A.; Amagata, T.; Oliver, A. G.; Tenney, K.; Valeriote, F. A.; Crews, P. J. Org. Chem. 2008, 73, 7255-7259.

233. Johnson, T. A.; Amagata, T.; Sashidhara, K. V.; Oliver, A. G.; Tenney, K.; Matainaho, T.; Ang, K. K. H.; McKerrow, J. H.; Crews, P. Org. Lett. 2009, 11, 1975-1978.

234. Johnson, T. A. et al. J. Nat. Prod. 2011, 74, 2545-2555. 
235. Tanaka, J.; Higa, T. Tetrahedron Lett. 1996, 37, 5535-5538.

236. Field, J. J.; Singh, A. J.; Kanakkanthara, A.; Halafihi, T.; Northcote, P. T.; Miller, J. H. J. Med. Chem. 2009, 52, 7328-7332.

237. Field, J. F. et al. Chem. Biol. 2012, 19, 686-698.

238. Cutignano, A.; Bruno, I.; Bifulco, G.; Casapullo, A.; Debitus, C.; GomezPaloma, L.; Riccio, R. Eur. J. Org. Chem. 2001, 775-778.

239. Northcote, P. T. Personal Communication, 2016.

240. Höller, U.; König, G. M.; Wright, A. D. J. Nat. Prod. 1997, 60, 832-835.

241. Bonny, M. L.; Capon, R. J. J. Nat. Prod. 1994, 57, 539-540.

242. Butler, M. S.; Capon, R. J. Aust. J. Chem. 1992, 45, 1705-1743.

243. Tran, N. H.; Hooper, J. N. A.; Capon, R. J. Aust. J. Chem. 1995, 48, 1757-1760.

244. Culioli, G.; Daoudi, M.; Mesguiche, V.; Valls, R.; Piovetti, L. Phytochemistry 1999, $52,1447-1454$.

245. Altena, I. A.; Miller, D. A. Aust. J. Chem. 1989, 42, 2181-2190.

246. Cimino, G.; Stefano, S. D.; Minale, L. Experientia 1974, 30, 18-20.

247. Seto, H.; Furihata, K.; Otake, N.; Itoh, Y.; Takahashi, S.; Haneishi, T.; Ohuchi, M. Tetrahedron Lett. 1984, 25, 337-340.

248. Uhrin, D.; Batta, G.; Hruby, V. J.; Barlow, P. N.; Kövér, K. E. J. Magn. Reson. 1998, $130,155-161$.

249. Barrow, C. J.; Blunt, J. W.; Munro, H. G., M J. Nat. Prod. 1989, 52, 346-359.

250. Chen, Q. H.; Kingston, D. G. Nat. Prod. Rep. 2014, 31, 1202-1226.

251. Smith, A. B.; Safonov, I. G.; Corbett, R. M. J. Am. Chem. Soc. 2001, 123, 1242612427.

252. Smith, A. B.; Safonov, I. G.; Corbett, R. M. J. Am. Chem. Soc. 2002, 124, 1110211113.

253. Ding, F.; Jennings, M. P. J. Org. Chem. 2008, 73, 5965-5976.

254. Uenishi, J.; Iwamoto, T.; Tanaka, J. Org. Lett. 2009, 11, 3262-3265.

255. Mukhopadhyay, P.; Zuber, G.; Wipf, P.; Beratan, D. N. Angew. Chem. Int. Ed. 2007, $46,6450-6452$.

256. Sanchez, C. C.; Keck, G. E. Org. Lett. 2005, 7, 3053-3056.

257. Hoye, T. R.; Hu, M. J. Am. Chem. Soc. 2003, 125, 9576-9577.

258. Morgan, J. B.; Mahdi, F.; Liu, Y.; Coothankandaswamy, V.; Jekabsons, M. B.; Johnson, T. A.; Sashidhara, K. V.; Crews, P.; Nagle, D. G.; Zhou, Y. D. Bioorg. Med. Chem. 2010, 18, 5988-5994. 
259. Prota, A. E.; Bargsten, K.; Zurwerra, D.; Field, J. J.; Diaz, J. F.; Altmann, K. H.; Steinmetz, M. O. Science 2013, 339, 587-590.

260. Gottlieb, H. E.; Kotlyar, V.; Nudelman, A. J. Org. Chem. 1997, 62, 7512-7515.

261. Marenich, A. V.; Cramer, C. J.; Truhlar, D. G. J. Phys. Chem. 2009, 113, 6378-6396.

262. Im, K. S.; Nam, K. I.; Sim, C. J.; Jung, J. H. Kor. J. Pharmacogn. 2000, 31, 401-406.

263. Mishra, P. D.; Wahidulla, S.; D’Souza, L.; Kamat, S. Y. Ind. J. Chem. 1996, 35B, 806-809.

264. Yutaka, S.; Adachi, K.; Shizuri, Y. J. Nat. Prod. 1999, 62, 152-154.

265. Blasberger, D.; Carmely, S.; Cojocaru, M.; Spector, I.; Shochet, N. R.; Kashman, Y. Liebigs Ann. Chem. 1989, 1171-1188.

266. Tanaka, J.; Higa, T.; Bernardinelli, G.; Jefford, C. W. Chem. Lett. 1996, 25, 255256. 